\title{
Public Opinion About Energy: A Literature Review
}

\author{
Barbara C. Farhar \\ Partricia Weis \\ Charles T. Unseld \\ Barbara A. Burns
}
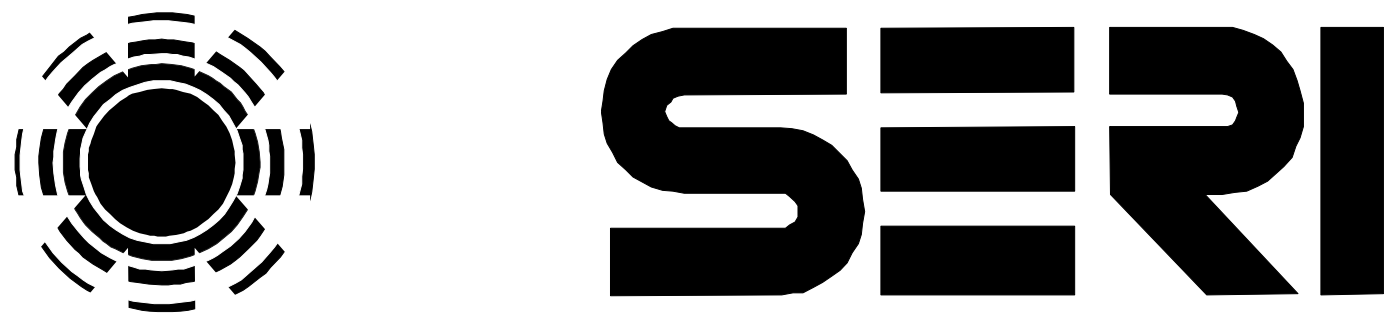

Solar Energy Research Institute

A Division of Midwest Research Institute

1536 Cole Boulevard

Golden, Colorado 80401

Operated for the

U.S. Department of Energy Under Contract No. EG-77-C-01-4042

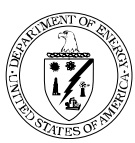




\section{NOTICE}

This report was prepared as an account of work sponsored by the United States Government. Neither the United States nor the United States Department of Energy, nor any of their employees, nor any of their contractors, subcontractors, or their employees, makes any warranty, express or implied, or assumes any legal liability or responsibility for the accuracy, completeness or usefulness of any information, apparatus, product or process disclosed, or represents that its use would not infringe privately owned rights. 


\title{
PUBLIC OPINION ABOUT ENERGY: A LITERATURE REVIEW
}

\author{
BARBARA C. FARHAR \\ PATRICIA WEIS \\ CHARLES T. UNSELD \\ BARBARA A. BURNS
}

JUNE 1979

PREPARED UNDER TASKS 5124 AND 5328.30

\section{Solar Energy Research Institute}

1536 Cole Boulevard

Golden, Colorado 80401

A Division of Midwest Research Institute

Prepared for the

U.S. Department of Energy

Contract No. EG-77-C-01-4042 


\section{FOREWORD}

This report was prepared by staff in the Institutional and Environmental Assessment and the Policy Analysis branches of the Analysis Division, Solar Energy Research Institute, Golden, Colorado. The project was designed by and carried out under the direction of Barbara C. Farhar and Patricia Weis. They also were the principal authors. Charles Unseld and Barbara Burns authored significant portions of the report.

The data contained in this report were collected between 1973 and 1978 before the dramatic events of 1979 , including the Three Mile Island accident, sudden gasoline price increases, and spot gasoline shortages. Dramatic energy events in the years 1973 to 1978 have altered public opinion about energy. We should expect the events of 1979 to have major impacts on public opinion, impacts not represented in this report. The magnitude of these impacts will become known only through continued research.

A project as broad and complex as this one inevitably relied on the assistance and support of a large group of specialists. The authors wish to acknowledge other SERI staff for assistance with literature searches, preparation of materials, and reviews. They are Robin Saltonstall, A. L. Berger, J. Chervenak, Larry Preston, Barbara Quintana, Bill Belew, Barbara Wood, Floyd Shoemaker, Dennis Schiffel, David Roessner, and Rebecca Vories. Others outside of SERI also contributed research assistance to the project. They are Julie Wondollek, Heidi Burgess, Tom Wilson, John Seidel, and Susan Persson.

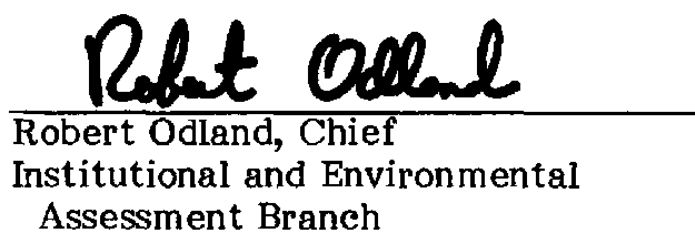

Approved for:

SOLAR ENERGY RESEARCH INSTITUTE

Melvin K. Simmons, Assistant Director Analysis Division 


\section{CONTENTS}

Page

Summary $\ldots \ldots \ldots \ldots \ldots \ldots \ldots \ldots \ldots \ldots \ldots \ldots \ldots \ldots \ldots \ldots \ldots \ldots \ldots \ldots \ldots$

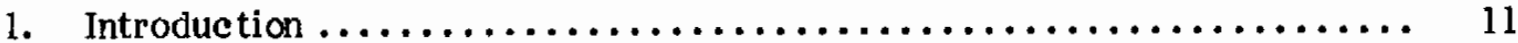

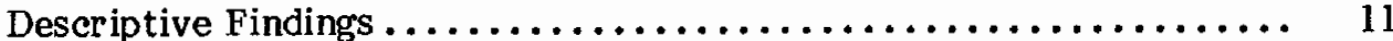

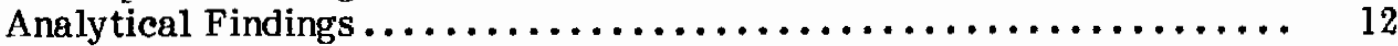

The Literature Review: A Perspective.................... 12

Attitudes and Their Relationship to Action ................. 13

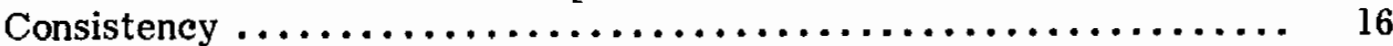

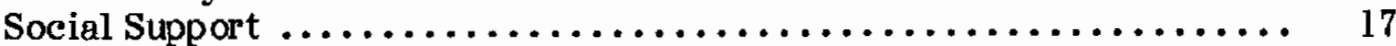

Individual Vs. Collective Action $\ldots \ldots \ldots \ldots \ldots \ldots \ldots \ldots \ldots \ldots \ldots \ldots \ldots$

What Surveys Can Tell Us ........................... 18

What Surveys Cannot Tell Us $\ldots \ldots \ldots \ldots \ldots \ldots \ldots \ldots \ldots \ldots \ldots \ldots \ldots \ldots$

Policy Relevance................................. 20

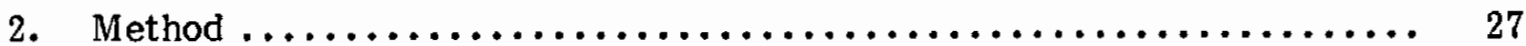

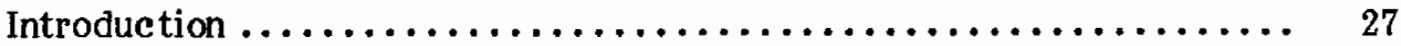

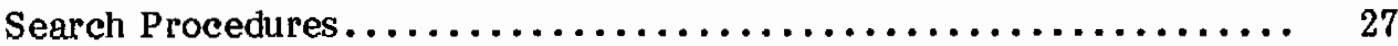

Surveys Included in This Review ...................... 28

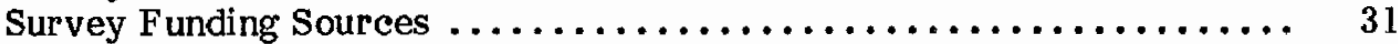

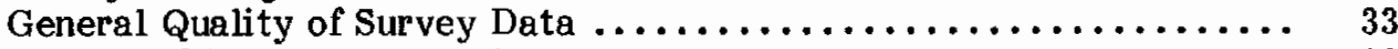

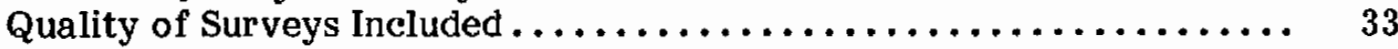

Multivariate Categories .............................. 35

Coding Procedures .............................. 41

3. The Energy Problem $\ldots \ldots \ldots \ldots \ldots \ldots \ldots \ldots \ldots \ldots \ldots \ldots \ldots \ldots \ldots \ldots \ldots$

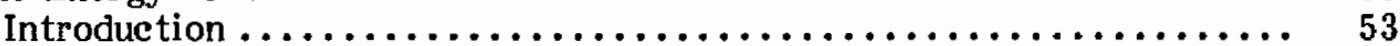

Context: The Energy Debate ......................... 53

Perceived Seriousness of the Energy Situation .............. 57

Energy Crisis: "Real" or "Contrived"? ................... 62

A ttribution of Cause and Responsibility $\ldots \ldots \ldots \ldots \ldots \ldots \ldots \ldots \ldots, 67$

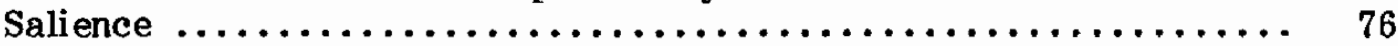

Perceived Impacts of the Energy Problem ................. 87

Perceived Future Energy Situation ..................... 89

Perceived Solutions to the Energy Problem $\ldots \ldots \ldots \ldots \ldots \ldots \ldots \ldots \ldots . . \ldots 0$

Summary: Is There an Energy Crisis? .................... 112

4. Energy Demand Reduction: Conservation $\ldots \ldots \ldots \ldots \ldots \ldots \ldots \ldots \ldots \ldots$

Perspectives on Energy Conservation ................... 115

Transportation Conservation .......................... 119

Residential Conservation $\ldots \ldots \ldots \ldots \ldots \ldots \ldots \ldots \ldots \ldots \ldots \ldots \ldots \ldots \ldots \ldots$

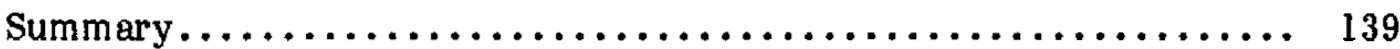

5. Solar Energy $\ldots \ldots \ldots \ldots \ldots \ldots \ldots \ldots \ldots \ldots \ldots \ldots \ldots \ldots \ldots \ldots \ldots \ldots \ldots \ldots$ 141

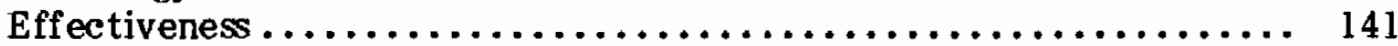

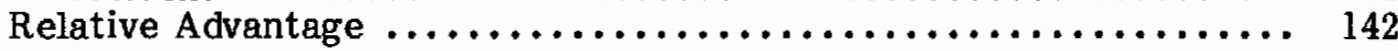

Knowledge and Information Sources..................... 154

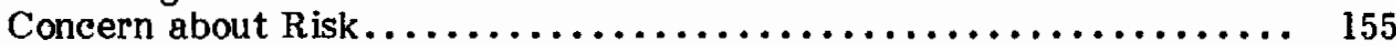

Behavioral Intention and Action ....................... 155

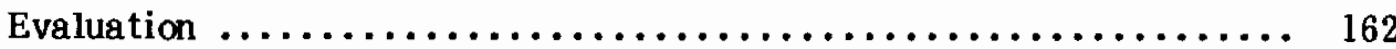

Regional Differences $\ldots \ldots \ldots \ldots \ldots \ldots \ldots \ldots \ldots \ldots \ldots \ldots \ldots \ldots \ldots \ldots, 164$ 
6. Conventional Energy Supply Sources $\ldots \ldots \ldots \ldots \ldots \ldots \ldots \ldots \ldots \ldots \ldots \ldots, 167$

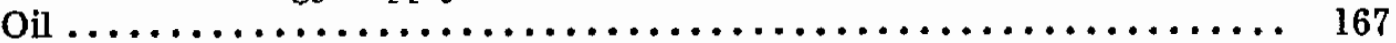

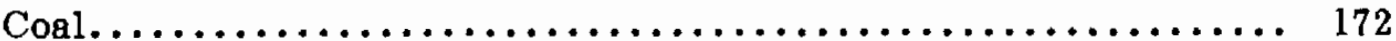

Nuclear Energy ................................ 175

Regional Differences ............................ 197

Energy/Environment Trade-Offs....................... 197

Comparative Findings on Supply Sources.................. 198

7. Analytical Findings: Summary of Sociodemographic Analyses ....... 207

Perception of the Energy Situation $\ldots \ldots \ldots \ldots \ldots \ldots \ldots \ldots \ldots \ldots \ldots, 207$

Energy and the Environment ......................... 210

Knowledgeability and Information Sources about Energy .......... 212

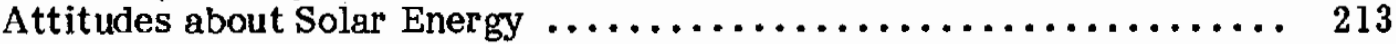

Attitudes toward Nuclear Energy $\ldots \ldots \ldots \ldots \ldots \ldots \ldots \ldots \ldots \ldots \ldots \ldots . \ldots \ldots \ldots$

Attitudes about Energy Conservation $\ldots \ldots \ldots \ldots \ldots \ldots \ldots \ldots \ldots \ldots . . \ldots 215$

8. Analytical Findings: Social-Psychological Variables ............. 219

Accounting for Belief in the Energy Crisis .................. 219

Belief in the Energy Crisis as an Explanatory Variable.......... 226

Knowledge .................................... 236

Perceived Impacts of the Energy Crisis................... 239

Belief in the Efficacy of Energy Conservation .............. 241

Concern about Risk.............................. 241

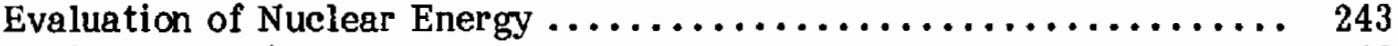

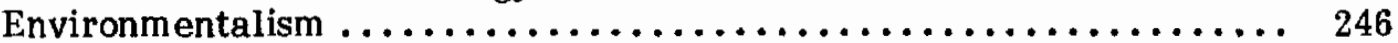

Other Analyses $\ldots \ldots \ldots \ldots \ldots \ldots \ldots \ldots \ldots \ldots \ldots \ldots \ldots \ldots \ldots \ldots \ldots \ldots . \ldots \ldots$

Summary................................ 247

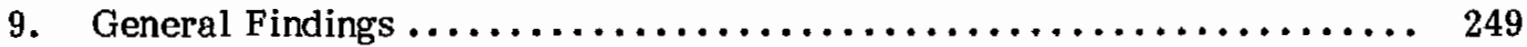

Relevance of Attitude Surveys to Policy.................. 249

Public Definitions of the Situation ...................... 249

Energy Conservation............................... 250

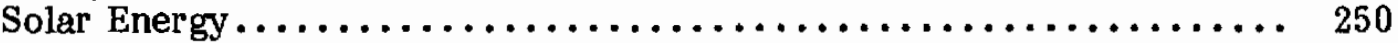

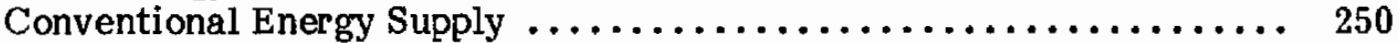

Analysis of Trends................................ 252

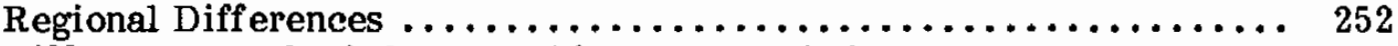

Differences by Sociodemographic Characteristics............. 252

Social-Psychological Variables . ...................... 256

Bibliogrøphy $\ldots \ldots \ldots \ldots \ldots \ldots \ldots \ldots \ldots \ldots \ldots \ldots \ldots \ldots \ldots \ldots \ldots \ldots \ldots \ldots \ldots, 259$

Appendix A. Funding Sources for Public Opinion

Polls on Energy Topies ............................. 283

Appendix B. Sociodemographic Variables ..................... 285

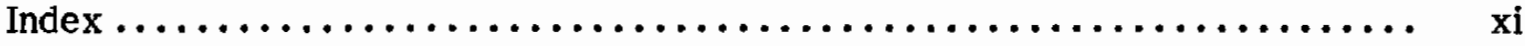




\section{LIST OF TABLES}

1-1 Level of Adoption Decision Making by Type of Energy Source ....... 22

2-1 Funding Sources for Public Opinion Polls on Energy Topics .......... 32

2-2 Quality Rating of Public Opinion Surveys .................. 36

2-3 Preli minary Universe of Public Opinion Surveys on Energy $\ldots \ldots \ldots \ldots \ldots 43$

3-1 Perceived Seriousness of Energy Situation in the United States .............................. 58

3-2 Perception of Reality of the Energy Crisis $\ldots \ldots \ldots \ldots \ldots \ldots \ldots \ldots \ldots$

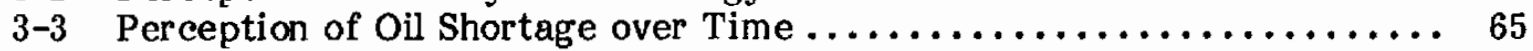

3-4 Who the Public Blamed for the Energy Situation $\ldots \ldots \ldots \ldots \ldots \ldots \ldots \ldots$

3-5 Perceived Salience of the Energy Problem $\ldots \ldots \ldots \ldots \ldots \ldots \ldots \ldots \ldots \ldots . \ldots 78$

3-6 National Problems Perceived as Very Serious . . . . . . . . . . . . . 79

3-7 National Issues Eliciting Most Personal Concern ............... 80

3-8 Perceived Relative Importance of Energy as a

Government Concern ............................. 83

3-9 Perceived Relative Importance of Energy Policy for Congress . . . . . . . 8 84

3-10 Perceived Seriousness of Energy Shortages................... 86

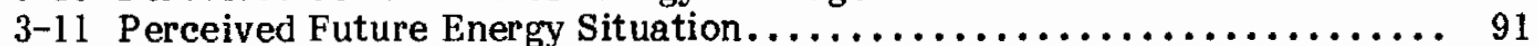

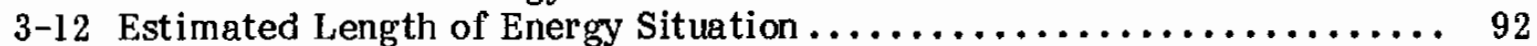

3-13 Anticipated Costs of Gas and Electricity (Michigan Sample) . . . . . . . . 94

$3-14$ Perceived Future Oil Supply $\ldots \ldots \ldots \ldots \ldots \ldots \ldots \ldots \ldots \ldots \ldots \ldots \ldots \ldots . . \ldots 6$

3-15 Perceived Future Supply of Natural Gas ................... 99

3-16 Most Used Infor mation Sources (Local Surveys) . . . . . . . . . . . . . 102

3-17 Most Trusted Information Sources ...................... 103

3-18 Credibility of Infor mation Sources on the Energy Crisis ............ 104

3-19 Credibility of Information Sources on the Energy Shortage . . . . . . 106

3-20 President Carter's Handling of the Energy Situation .............. 108

3-21 Adequacy of Measures in Carter's Plan .................... 109

4-1 Reported Transportation Conservation Measures Taken ............ 121

$4-2$ Reasons Given for Saving Gasoline....................... 122

4-3 Reported Household Energy Conservation: Appliances ............ 134

4-4 Reported Household Energy Conservation: Heating and Cooling ....... 136

5-1 Purchase Decision Factors............................ 143

5-2 Volunteered Disadvantages of Solar Energy . . . . . . . . . . . . . . 144

5-3 Volunteered Explanations of Negative Solar Purchase Decisions........ 146

5-4 Volunteered Advantages of Solar . ....................... 150

5-5 Homeseeker's Desired Infor mation about Solar Energy ............. 156

5-6 Plans to Invest in Solar Systems in the Next Two to

Three Years by Demographic Characteristics ............... 159

5-7 Reaction to Solar Energy Systems if the Cost Is the Same.......... 161 
Page

6-1 Volunteered Advantages of Nuclear Power ................. 178

6-2 Likelihood and Desirability of Potential Effects of

a Nuclear Plant: Desirable Effects ...................... 180

6-3 Volunteered Disadvantages of Nuclear Power-National Samples ....... 182

6-4 Likelihood and Desirability of Potential Effects of a

Nuclear Plant: Undesirable Effects-Local Sample ............. 184

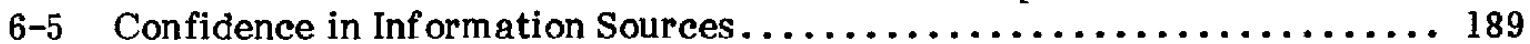

6-6 Attitudes Toward Protest Groups ......................... 190

6-7 Favorability Toward Nuclear Power for the

Nation and Community............................ 192

6-8 Serious Environmental Problems if the United States

Is to be Energy Self - Sufficient . . . . . . . . . . . . . . . . . . 199

6-9 Preferences for Adequate Energy Versus the Environment . . . . . . . 200

6-10 Perceived Relative Advantage and Risk of Alternative

Energy Sources for Elec tric Power Generation ............... 203

6-11 Summary of Energy Supply Comparisons $\ldots \ldots \ldots \ldots \ldots \ldots \ldots \ldots \ldots \ldots$

8-1 Summary of Relationships Between Variables Analyzed .......... 220

8-2 Knowledge of Oil Imports by Belief in Energy Crisis.............. 224

8-3 Objective Data on Oil Imports .......................... 225

8-4 Belief in Energy Crisis by Acceptance of

Energy Conservation Policies ....................... 230

8-5 Perceived Salience by Reported Conservation Behavior ............ 233

8-6 Concern about Risk by Favorability to Nuclear Power Plants ......... 242 


\section{LIST OF FIGURES}

Page

2-A Locations of the Surveys $\ldots \ldots \ldots \ldots \ldots \ldots \ldots \ldots \ldots \ldots \ldots \ldots 29$

2-B Timing of Surveys ......................... 30

2-C Matrix of Perceived Costs and Benefits

of Alternatives ......................... 38

3-A Perceived Seriousness of the Energy Crisis............60

3-B Proportion Responding the Oil Shortage

Is Real Vs. Contrived ......................... 66

3-C Attribution of Major Blame for the Energy Crisis ........ 71

6-A Attitudes Toward More Offshore Drilling

by Oil Companies ......................... 170

6-B Favorability Toward Increased Strip Mining ........... 176

6-C Perceived Safety of Nuclear Power Plants ............... 185

6-D Attitudes Toward Speed-up in Construction and

Building of More Nuclear Plants .................. 193

6-E Perception of Nuclear Power Plants as

Worthwhile at Different Cost Levels .............. 195

6-F Preferences for Adequate Energy Versus

the Environment 


\section{SUMMARY}

This study reviewed and analyzed 115 surveys of the general population, 82 of national samples and 33 of local or regional samples, taken between 1973 and 1978. Also examined were studies of special groups, such as homeowners and oil company executives. Studies on most energy supply alternatives are included: energy conservation, solar energy, fossil fuels, and nuclear energy. Findings presented in this summary are supported by evidence thoroughly documented in the body of this report. Conclusions are based on the location of a pattern of findings across several surveys; therefore, conclusions presented in this summary are those for which consistent evidence was found in several surveys of the general public.

In understanding public opinion about energy in the United States, several points should be kept in mind. A survey is an attempt to measure and aggregate the variegated and segmented opinions of the polity. Opinion is segmented by a variety of factors: group affiliations, geographical region, social class, occupation, and so on. Each individual is situated in a particular social milieu and thus experiences the environment differently. Experiences affecting an individual's opinion of whether an energy crisis actually exists can include, for example, if one's own schools and factories are closed due to fuel shortages, if gasoline is available, if utility bills increase, and what information is available to the individual.

Further, individuals vary in their personal responses to these experiential differences. Two individuals living in approximately the same life circumstances can respond in completely different ways-one might view an energy crisis as an exciting challenge to creative ability and altruistic motives; another might perceive it to be a serious threat and seek to deny its existence.

Survey findings can be used more accurately when one is aware of these complexities. Maintaining common sense and avoiding truisms about "the public" also enhance an accurate perception of public sentiment about the nation's energy situation.

Survey data have certain limitations, such as problems of theory and measurement. These limitations are discussed in detail in the report. In spite of these limitations, attitudes are held to be causally related to action, although they do not fully explain behavior. The methodological quality of the surveys included in this review was judged to be sufficient to warrant drawing conclusions from the body of data.

The salience of public opinion for policy varies by the kind and level of policy decision making. For some energy alternatives, public opinion is more immediately and directly relevant than for others. The development and use of nuclear energy is a collective decision, very different in character from an individual decision to purchase solar heating or engage in energy conservation. Organizations such as utilities and industries decide about the use of nuclear energy or large solar energy facilities. As a result, the link between public opinion and individual purchase decisions is closer than the link between public opinion and using the political process to influence energy policy. If energy conservation and small-scale solar energy technologies are to have an impact on the nation's energy supplies, decisions and action will be needed by millions of individual persons. 


\section{Is There an Energy Crisis?}

Does the public perceive an energy crisis in the United States? The survey data indicate that most people do not believe there is an energy crisis but perceive instead a serious national energy problem. About three-quarters have defined the energy situation as serious for the past five years. About 40 percent have defined the situation as "very serious."

Inflation, unemployment, and crime clearly emerge from the survey data as matters of grave concern to the American public. Energy is not viewed as a problem of most, nor of least, importance but falls somewhere between. A majority feels that the nation faces energy shortages and rising energy costs in the foreseeable future, whether for political or natural reasons. About half of the public appears to think that the nation's supply of oil and natural gas is beginning to dwindle, and smaller proportions perceive this trend on a worldwide scale.

Early in the "energy crisis" (1973), a majority tended to view the situation as contrived by institutions and persons for their own benefit, but by 1977 the public was almost polarized on this issue. Currently, a majority perceives energy shortages as real, but a large minority still believes the situation has been contrived by various institutions.

Much of the public is willing to admit that the nation engages in wasteful and unnecessary energy consumption. Oil companies and the federal government are perceived by many as the institutions most responsible for the nation's energy problems. Smaller proportions of the public blame the OPEC countries, industry and business, and environmentalists for contributing to energy problems. Other causative factors perceived by the public are growing populations and the finite nature of fossil fuel resources.

Some studies examined the relationship between belief in an energy crisis and other energy attitudes and behaviors, such as willingness to engage in energy conservation. No clear empirical support is located that establishes a relationship between belief in an energy crisis, or perception of its seriousness and reality, and any other attitudes or behaviors. Based on available evidence, belief in an energy crisis does not lead to conservation behavior or to the use of solar energy.

The following are hypotheses about why people believe in an energy crisis that are suggested, but not conclusively demonstrated, by survey data.

- Those attributing energy shortages to political and economic contrivance are less likely to believe in an energy crisis than those attributing shortages to declining availability of fossil fuels.

- Those experiencing negative lif estyle consequences from energy-related problems are more likely to believe in an energy crisis than those who do not experience such consequences.

- Those more informed about energy facts and issues are more likely to believe in an energy crisis than the uninformed.

- Those with greater environmental concern are more likely to believe in an energy crisis than those with less concern. 
Differences in belief in an energy crisis were found by some demographic characteristics. Higher educational and occupational levels are found to correlate with perceived seriousness and reality of the energy situation. Higher income groups generally express a greater belief in the energy crisis than do lower income groups. No difference in belief in the energy crisis is indicated by gender, race, political orientation, lifestyle characteristics, or urban/rural residence.

Impacts of the energy problem, varying in severity from inconvenience to job losses, have been experienced by most of the public. Evidence indicates that impacts are borne disproportionately by those in lower income groups. Older people report more adverse effects of the energy situation than do younger people. Nonwhites experience more negative financial impacts due to energy shortages than do whites.

\section{Public Perceptions of Fossil Fuels}

Not nearly as many survey data exist for oil, natural gas, and coal as energy supplies as for other energy alternatives. Several studies indicate that a sizable minority of the public does not realize that the United States must import oil. None ask why the nation should strive to be energy independent, although several studies show that opinion is divided about the feasibility of self-sufficiency. So few data exist on favorability toward reducing oil imports that conclusions about public opinion are not possible.

Price increases or incentives to oil companies are generally opposed; oil companies are widely perceived as taking excess profits. Options such as a profit tax or controls on profits are favored, while government ownership is opposed by study majorities. Deregulation of natural gas prices as an incentive to increase supply is favored, except when resultant price increases were mentioned in one study whereupon a majority opposed deregulation.

The public views coal, especially strip-mined coal, as a way to expand energy supplies; however, potentially impacted local communities are somewhat less favorable. Coal is perceived as an effective source owing to domestic availability; a perceived benefit of coal use is decreased dependency on foreign oil. Data suggest some environmental concern about the production and use of coal, with those in the West being most concerned.

Using fossil fuels as a supply alternative is favored least in the West, which contains offshore oil, strip-minable coal, and oil shale. Westerners are more concerned about air pollution and less enthusiastic than others about oil shale exploration. People in the Northeast and West are more pessimistic about coal as a long-term source than in the South and Midwest. Although national majorities favor strip mining, most Westerners oppose it.

\section{Energy Conservation Issues}

About 85 percent of the public reports that it has engaged in at least "a fair amount" of energy-conserving activity. Nevertheless, the data indicate that energy conservation has not been practiced assiduously; for example, the most frequently mentioned conservation action is turning off lights when not in use. Residential conservation is consistently preferred over reduced driving. 
For transportation conservation, about 80 percent of the public is opposed to raising gasoline prices to reduce consumption. Most people believe that gasoline rationing would be effective in decreasing energy consumption; nevertheless, the public opposes gasoline rationing. However, rationing is preferred to gasoline price increases. A major reason for opposing rationing is that no real shortage is perceived to exist. Another reason for oppasition is that rationing would create a "black market" for gasoline. The currently proposed policy feature of the rationing scheme, a "white market," would help offset this particular objection to rationing.*

Driving less through reducing the number of trips, carpooling, and using mass transit is perceived as infeasible and disadvantageous by most people. Most report that they are driving slower because of the 55-mph speed limit.

Most people oppose special taxation of "gas guzzler" cars. Slight majorities favor relaxing emission controls on automobiles to increase gas mileage, although the public is polarized on this issue.

The survey data do not strongly support the following findings, but limited empirical evidence suggests that:

- As gasoline prices increase, more people would use less gasoline. However, price increases are perceived as unfair and hard on consumers.

- Willingness to drive more slowly and to buy smaller cars may be partially dependent on what others are doing.

- There is much public support for government regulation of automobile manufacture to increase gas mileage of new cars.

The practices most frequently used for residential conservation are those that are least inconvenient and least effective. As a conservation measure increases in inconvenience and/or cost, it is practiced by fewer people. Measures that are practiced most frequently are turning off lights and appliances when not in use and lowering thermostats. Practiced by about a third of the public are use of lower wattage bulbs, running full washer and dishwasher loads, shutting off rooms, and decreasing air conditioning. About one in 10 people uses cold water laundry, uses a fireplace for heat, weatherizes, or insulates his home.

Policy options preferred by most of the public are daylight savings time and tax credits or deductions for home insulation. Opposed by much of the public is peak-load pricing for utilities.

Survey data do not strongly support the following findings, but limited evidence suggests that:

- Levels of technical knowledge concerning how to conserve energy effectively are low in the general public.

*Present rationing plans call for issuance of gasoline coupons on the basis of registered automobile ownership. Those not using all their coupons could sell them for top dollar to those wanting to buy more than their allotment. 
- Perceived decreases in utility bills may be a more important motivation for engaging in energy conservation than concern about an energy crisis.

- There may be greater willingness to engage in domestic energy conservation if others do so as well.

Some differences on energy conservation policies are identified by demographic characteristics. On a number of policy options, older groups tend to support policies which hold costs down, while younger groups are less supportive particularly if rationing is proposed as a means of controlling costs. More highly educated groups appear to be less supportive of gasoline price maintenance with rationing, but more supportive of policies of somewhat higher prices with some limitations on supply, than are less educated groups. The more highly educated are more in favor of transportation-related conservation, such as mass transit (although they are not more inclined than other groups to use it). Urban residents are more favorable than others toward mass transit. Lower income groups tend to favor policies that would keep consumer prices low.

In addition, differences by demographic characteristics are found in conservation knowledge, attitudes, and practices. Survey data indicate that women may be slightly more favorable toward energy conservation than men. Men and women who engage in conservation tend to do so in activities consonant with their sex roles. Younger groups tend to doubt more than older groups that government and industry are effectively conserving energy. The more highly educated report turning down thermostats more frequently than other groups. Lower income groups tend to report engaging in less conservation behavior than higher income groups; evidence suggests that this may be due to their already minimal use of energy.

\section{Solar Energy As an Alternative}

Very few data concerning citizen attitudes, knowledge, and practices relative to solar energy exist on the national level. The data included in this report are derived largely from marketing studies of special, localized samples.

Public attitudes toward solar energy can only be deseribed as positive. Data on regional differences suggest that those in the West may be more favorable to solar energy than the rest of nation and that those in the South are less favorable.

One relevant question is the extent of residential solar systems currently used in the nation. The most recent data (collected in January 1979) are from one survey item asking about ownership of solar-powered heating units for heat and/or hot water. The findings show that, nationally, fewer than 0.5 percent own such systems. There are, however, interesting demographic differences in solar ownership. Two percent of opinion leaders already own solar heating systems. One percent of the following demographic categories presently own solar systems: those aged 18-29 and 30-44; those earning $\$ 7,000$ to $\$ 15,000 /$ year; those in the Northeast and in the West; those in rural counties; those with at least some college education; executive-professional and blue collar workers; Republicans; political liberals; families with teen-age children; and employed females. Fewer than one percent of those in other categories own solar systems. 
The same survey asked whether people thought they might buy solar systems in the next two or three years. One-quarter of opinion leaders and of those earning over $\$ 25,000 /$ year indicated they are considering such a purchase, the highest proportions of all demographic categories.

In marketing studies, cost and reliability of systems are frequently mentioned concerns of potential solar buyers, but about 40 percent in a few studies indicate they would consider solar energy even if it costs more per month in the long run than alternatives. Nonmonetary benefits attributed to solar energy in several studies are fuel resource savings and lack of environmental pollution.

Findings show strong citizen support for tax incentives to promote solar energy use. In two studies, immediate tax credits are preferred over tax deductions over time or lowinterest loans. In one study, about 40 percent prefer to have a solar loan as part of their mortgage while an equal proportion pref er a separate loan for solar equipment. Owning a solar system is widely preferred to leasing one.

A few differences in attitudes toward solar energy are identified by demographic characteristics. Greater support for solar energy is found among younger age groups, higher income levels, professional/managerial workers, and whites. No differences are evidenced by other demographic characteristics.

\section{The Nuclear Energy Alternative}

Majorities of national samples view nuclear energy as technically feasible and expect it to assume a major role in electric power generation in the future, although sizable minorities of the population (up to one-third) are unsure. The major problems perceived as associated with nuclear power development are safety and environmental damage from radioactivity and waste disposal. Increasingly large majorities consider these problems serious. The public appears to be increasingly polarized over nuclear safety; the disposal of nuclear wastes has emerged as a major reason for opposing nuclear power. Yet, majorities consistently favor continued construction of nuclear power plants, though less consistently when nearby construction is proposed. Varying results from local samples make judgments about public response to nuclear siting risky without surveying each locality. The generally increased favorability of nuclear plant neighbors found in some studies is not necessarily an indicator of response to new proposals in other communities.

Favorable opinion toward nuclear power showed no variation by region. Those in the West and the Northeast are more likely to oppose a plant in their area than those elsewhere. Easterners are more concerned about nuclear safety than others.

Evidence indicates greater general favorability toward nuclear energy among men than women, while women exhibit greater general opposition than men. Women are more concerned than men about nuclear safety. Younger persons are more likely to oppose nuclear power and to display concern about risk than are older ones. Displaying the least concern about nuclear safety are those in the middle age ranges. Income was found to be positively related to general favorability toward nuclear energy and to the desirability of having more nuclear power plants in one's vicinity. Higher levels of income are also associated with higher levels of perceived safety of nuclear power plants. Professional/ managerial workers are more likely to favor nuclear energy and less likely to perceive it as risky. Whites are more favorable than nonwhites. 


\section{Preferred Energy Supply Sources}

It is difficult to compare public assessments of energy supply options: each energy supply technology is perceived as having both positive and negative aspects. For example, coal is perceived as plentiful but environmentally undesirable; nuclear energy as effective but having undesired side effects such as waste disposal problems; solar energy as environmentally and economically desirable over the long term but with high initial costs. No data exist on which of these factors are more important to the public in evaluating energy supply sources.

The data show that strip mining is favored least of all the options-offshore oil drilling and building more nuclear plants are favored by 60 to 70 percent majorities and development of solar energy by 80 to 90 percent. One recent poll in New York State ranks energy conservation and solar energy as the best future sources of energy. The public seems to place the most faith in solar energy, coal, and nuclear energy as long-term future energy sources.

\section{Energy and the Environment}

Environmental degradation resulting from energy development is perceived to be related to conventional supply sources-especially coal and nuclear energy. Few data exist on how the public would choose in a tradeoff between energy and the environment.

The existing data appear to indicate that public opinion about energy-environment tradeoffs is polarized, with sizable minorities favoring each side of the issue. Public concern seems to lean toward adequate energy supplies (rather than environment) when shortagerelated events occur.

Women are found to be more strongly in favor of environmental protection and conservation than men. On virtually every item where concern for environmental quality was gauged, younger people show more consistent support for the environment than older people. Support for the environmental side of the energy-environment issue tends to increase as educational level increases. The findings suggest a pattern of greater environmental support among lower than higher income groups, except where environmental quality is posed as entailing higher consumer costs at which point higher income groups are more likely to favor the environment. White collar workers are found to be more favorable to environmental protection than are blue collar workers in cases where energy costs would increase. In general, rural groups are more likely than urban groups to favor adequate energy over environmental protection.

Since education, occupation and income tend to intercorrelate, these findings on their relationship to environmental concern are somewhat curious. The explanation may lie in the positive association between higher social status and environmental concern when price is at issue.

The existing data on regional differences show that Westerners exhibit more environmental concern over strip mining than those in the East. 


\section{An Aware Public?}

Surprisingly few data exist on how knowledgeable the public is about energy in general. The limited data available indicate low public awareness of government efforts to solve the energy crisis. For example, one study shows that, by 1975, half of the people did not know there is a federal energy agency. In a few studies, majorities say they follow presidential speeches about energy and inflation. The limited data available suggest that a sizable minority (possibly about one-third) are unaware of fundamental energy facts, such as the national importation of oil. For example, in May 1977 and April 1978 surveys, one-third incorrectly believed that the United States does not import oil from other countries. The majority, however, answered correctly.

Part of the reason for misinf ormation about energy facts might lie in the inconsistency of information available to the public. This inconsistency, in terms of public statements by authorities and published energy information, is documented in this report. In part, the public may also not have been attentive enough to energy information to form an accurate assessment of the nation's energy situation.

Findings on awareness of gasoline mileage figures are too few to permit drawing conclusions about the extent of this awareness in the population. No data exist on knowledge concerning the effects of driving more slowly or of the relaxation of auto emissions control in increasing gasoline mileage.

Most of the public has heard about using solar energy for heating and generating electricity. A frequently mentioned explanation for not considering a solar system purchase is that people have insufficient information about solar energy on which to base a decision.

Evidence on nuclear energy suggests that awareness of the location of nuclear plants is not widespread, but awareness is higher in areas where new plants are proposed. From local studies, it is found that heightened knowledge leads to increased community polarization over the nuclear issue.

The hypothesis that the more informed an individual is about energy issues, the more likely that person is to believe in an energy crisis received support in two analyses. This evidence is insufficient to permit more than a tentative conclusion, pending further research.

Men are found to be exposed to more information sources about energy than women and are som ewhat more knowledgeable. Higher educational levels are found to be positively associated with higher levels of knowledge on a variety of energy items. Clear patterns of difference by income and occupational level are revealed with regard to knowledge about energy issues, a difference probably confounded by educational level. There is a consistent pattern in the data of greater reported knowledge among whites than among nonwhites on energy-related issues. Rural and urban people have accurate information on different specific issues, but are about equally knowledgeable.

Mass media appear to be the major source of information about energy. Insufficient data and mixed findings on eredibility of information sources prevent drawing conclusions about the public's trust in information received. Credibility of energy information sources (government, consumer groups, industry) is explored in a few studies, with each source enjoying some credibility; however, no pattern of findings is located. The few findings that exist are mixed and probably noncomparable. For nuclear energy, evidence suggests that scientists, federal agencies, and environmentalists are perceived as credible sources of information. 
The survey data on awareness and information sources suggest two conclusions. One is that so little is known about public awareness concerning energy that more research is required to define knowledge levels and information requirements. The second is that government programs to extend public awareness of energy facts and issues and technical knowledge, particularly in energy conservation and solar energy, require much greater emphasis. 


\section{SझPI}




\section{CHAPTER 1}

\section{INTRODUCTION}

The primary purpose of any literature review is to draw together a fragmented body of knowledge and interpret it in such a way that it will be more useful and meaningful than if it remained dispersed. For the Solar Energy Research Institute (SERI), a literature review on citizen attitudes about energy issues served two goals. The first was to provide a comprehensive body of information to undergird and inform policy analyses performed at SERI and at the U.S. Department of Energy (as well as elsewhere), and the second was to provide a platform for future research on the sociopolitical aspects of the domestic energy situation in general and of solar energy in particular.*

The approach used in this review organized survey findings in an analytical framework to determine whether enough data exist to draw conclusions about the state of knowledge on citizen attitudes, knowledge, and practices relevant to energy issues and alternatives. Using this approach, gaps in empirical research findings also can be identified. The methods and analytical framework employed are described in Chapter 2.

The universe of surveys included in this review must be viewed as preliminary because a vast number of public opinion studies of one kind or another have focused on energy issues. This review focuses on surveys of the public-at-large rather than on qualitative studies or surveys of special interest groups. The survey data are organized and analyzed according to a set of categories described in Chapter 2. These categories are elements of a preliminary model of what influences citizen favorability toward and, where relevant, adoption of different energy alternatives.

A comprehensive review of existing survey data on citizen attitudes toward energy follows in this report.

\section{DESCRIPTIVE FINDINGS}

Descriptive findings from the surveys are presented in Chapters $3,4,5$, and 6 . The public's definition of the energy situation is the focus of Chapter 3. Reported survey findings concern issues such as the public's belief in the existence of an energy crisis, whether they perceive the crisis to be real or contrived, to whom or what they attribute responsibility for the energy situation, what importance they attach to the energy problem, what impacts of the energy problem they have experienced, what solutions they perceive, and their expectations about the nation's future energy situation.

Chapters 4, 5, and 6 are concerned with the two overall alternatives facing the United States in its attempt to achieve greater energy self-sufficiency: reducing the demand for energy and increasing energy supplies. Chapter 4 describes public opinion concerning energy conservation pertaining to transportation and domestic energy use-whether it is efficacious, how knowledgeable people are about conservation, whether they favor it, and

*Sociopolitical aspects include, but are not limited to, citizen attitude studies. They include, as well, social impact assessment, analyses of stakeholder group preferences, social cost/benefit analyses, exploration of institutional roles, and investigations of community dynamics. 
whether they engage in it. Findings on the solar energy alternative are described in Chapter 5. Public opinion concerning more conventional sources of energy-oil and natural gas, coal, and nuclear energy-are discussed in Chapter 6.* Where data have been located that compare public preferences for different energy supply sources, these data are discussed in a section of Chapter 6 on comparative findings.

\section{ANALYTICAL FINDINGS}

Analytical findings from the surveys are presented in Chapters 7 and 8 . In Chapter 7, a summary of analytical findings by 10 major sociodemographic characteristics is presented. Used as independent variables in analyses, these characteristics are gender, age, education, income, occupation, race, political orientation, religious affiliation, lifestyle characteristics (including marital status, housing characteristics and stage in the family life cycle, home ownership, and transportation characteristics), and urban/rural place of residence. Detailed sections on each of these variables are presented in Appendix B. Chapter 8 describes analytical findings using various social-psychological variables. Used as explanatory variables in survey analyses, these variables include perceived causes of the energy crisis, belief in the energy crisis, knowledgeability, perceived impact of the energy crisis, belief in the efficacy of energy conservation, concern about risk, evaluation of nuclear energy, environmentalism, and other variables. Chapter 9 briefly summarizes the report's survey findings.

For the reader interested in a discussion intended for the layperson on the problems of theory and measurement in surveys and how survey data are useful to the policymaker, the balance of this chapter will be pertinent. The study's methods are deseribed in Chapter 2, including a discussion of the categories used to organize data and a list of the surveys included. Other readers, less interested in theory and method, may wish to begin their reading with Chapter 3 on the public's perception of the energy problem.

\section{THE LITERATURE REVIEW: A PERSPECTIVE}

In the remainder of this chapter, the context for understanding the usefulness of the review will be set by discussing the nature of survey data. The concept "attitude" is defined and its relationship to action described. Public opinion is distinguished from private opinion, and the importance of this distinction is discussed. Individual and collective action is distinguished, and the relevance of survey data to each is discussed. Finally, what policymakers would (or possibly should) like to know from public opinion surveys, why they would (should) like to know it, and what they are likely to get will be described.

In short, surveys of public opinion tell us only part of what we need to know about people and energy. That part is significant when it is the product of sound methods, but it does not yield the complete story about the human dimensions of energy.

Survey research has shortcomings and limitations, but it also has strengths. As Deutscher (1973) has observed, "We do not discard reports because of biases or flaws of one sort or another. If we did, there would be no history" (p. 5).

\footnotetext{
*Hydropower as an energy supply source is not discussed owing to lack of data in the surveys included in this review.
} 


\section{SURVEYS}

A survey is a snapshot. It momentarily "stops the action" of the ongoing life of thought and sentiment.

The quality of the information contained in a survey, as in a photograph-its focus, accuracy, clarity, and lucidity-depends in part on the skill of the survey researcher (or photographer) and in part on his methods and tools (cameras, film, instruments).

The survey snapshot gives us a description of public opinion at one point in time. Even longitudinal data (collected at specific time intervals) provide only a succession of snapshots, not enough to make a moving picture.

When carefully collected, survey data can be descriptive of an entire population, providing systematic and comparable empirical data that can be quantified and analyzed. But what is the nature of the empirical data that can be collected through a survey? Generally, surveys of public opinion purport to measure attitudes, beliefs, knowledge and information sources, behavioral intention, and, sometimes, behavior.

\section{ATTITUDES AND THEIR RELATIONSHIP TO ACTION}

An attitude is a predisposition to action. It has cognitive, affective, and behavioral elements. Cognitive implies some descriptive and analytical knowledge about the object (person, place, thing, behavior, idea, process) with respect to which the attitude is held. Affective refers to the feeling content of the attitude, how intense (or salient) the attitude is and whether the emotion is positive or antipathetic. Behavioral elements are the verbal expressions of the attitude, and, sometimes, the motive link between attitude and action.

Attitudes have been described as beliefs, sentiments, sets, evaluations, and intentions. Linn (1965) argued that

One of the most diversely defined concepts in social psychology is attitude. Not only are there vast differences concerning what properly constitutes an attitude, but there has been developing a large literature debating how attitudes should be measured (p. 353).

Instead of engaging in the controversy on the definition of attitude, the definition used at the outset-an attitude is a predisposition to action-is used. A verbal response to a questionnaire or interview item is behavior (verbal behavior) which is thought to be an observable index of attitude.

A controversy has been raging in sociology, psychology, and political science for at least 40 years about the relationship between what people say and what they do. Public opinion surveys and techniques of attitude scaling which use statistics and computing capabilities were developed, and this in turn permitted speedy processing of vastly greater amounts of data than previously possible (Babbie, 1973; Guttman, 1944; Lazarsfeld, 1948; Likert, 1932; Osgood, 1969; Thurstone and Chave, 1929). An extensive 
literature emerged on known problems in attitude measurement and scaling* particularly related to the issue of predicting behavior from these measurements. In fact, Deutscher (1973) stated flatly, "Responses to formal interviews inform us about behavior in a formal interviewing situation and little else" (p. 149).

The second source of concern was that much of the literature attempting to relate attitudes to behavior dealt with the relationship between racial prejudice and overt discrimination (e.g., LaPiere, 1935; DeFleur and Westie, 1958; Linn, 1965; Merton, 1940). Clearly, the problem of racial discrimination was perceived as a problem of the attitudes and behavior of individuals rather than as a social problem. The discrepancy observed between attitude and behavior in race relations was termed "hyprocrisy."

The social scientist has no obligation to attempt to shape the social world in accordance with personal feelings about how that world should be. In fact, to describe the social world accurately (as a physical scientist seeks to describe the physical world and a biologist the biological world), a social researcher is well advised to minimize personal impact on the natural processes being observed. The relationship between attitude and action is an empirically observable phenomenon. Society needs to know more about what is before it can intelligently assess how to go about changing itself.

The evidence suggests that a correlation between attitude and action is defensible on the basis of social science findings, but that correlation most definitely is not 1.0; many factors other than attitudes influence what people ultimately do. Some of the reasons for differences between attitudes and action are described below. These explanations of the observed discrepancy fall into two related categories: (1) problems in theoretical constructs and (2) problems in the measurement of attitudes and behavior.

\section{Theoretical Constructs}

Attitude and action have different characteristics, such that measuring and comparing them contain elements of the classic apples/oranges problem.

Action has been differentiated into verbal responses and overt actions. Deutscher (1966) stressed the nonverbal aspects of behavior when attempting to compare words with deeds. However, a very large proportion of significant social behavior is symbolic, and this verbal behavior represents a gray area in the attitude-behavior dichotomy. As Jones and Harris (1967) have noted, "When a person verbalizes an opinion he may or may not hold an underlying attitude that 'corresponds' to that opinion" (p. 1). Jones and Harris demonstrated in a laboratory experiment that people perceived someone as expressing a "true" underlying attitude when they saw that the social situation was not coercing any particular point of view.** Schuman and Johnson (1976) distinguished "elicited verbal attitudes" from "spontaneous verbal attitudes." Elicited attitudes are responses to questionnaires, interviews, or other direct measurement methods. Spontaneous attitudes are expressions of opinion that emerge in everyday conversations with friends and others. Schuman and Johnson considered spontaneous attitudes as a form of behavior. "Attitude" as discussed in the literature and as used in this report refers to elicited attitudes.

*See, for example, Babbie, 1973 ; Merton, 1940.

**This lack of constraint in the social setting in which an opinion is being expressed is the hallmark of the survey interview. 


\section{Problems in Measurement}

Deutscher (1973) reviewed three studies on the attitude-behavior relationship conducted at three points in time over a 30-year period.* He argued that the three studies, all of which had been methodologically criticized, demonstrated the lack of correlation between attitude and action. Rebutting this position, Ajzen et al. (1970) argued that none of the three studies actually measured the attitude-behavior relationship. Ajzen et al. showed that the three studies compared attitude toward an object with behavioral intention and behavioral intention with behavior, but none compared attitude toward an object with behavior toward that object.

Several other reasons for the apparent discrepancy between attitude and action in the empirical literature have been offered. These include: (1) "cutting corners" by interviewers and coders (Roth, 1965); (2) "social desirability," which is the observed inclination of respondents to strive for the "right answer" (Taylor, 1961); (3) "acquiescence response sets," which is the tendency exhibited by some respondents to go along with anything presented (Taylor, 1961); and (4) the existence of different kinds of attitudes and acts (noted earlier). Further, Deutscher (1973) argued that the very notion of simple linear cause-and-effect relationships has "by and large been discarded in the philosophy of science" (p. 91).

Liska (1974) also pointed out several reasons for the discrepant findings. When the social object of the attitude is unfamiliar, attitudes may be poorly formed, thus reducing their impact on behavior. Another problem is that, when attitudes are measured at the same level of generality as behavior, they are more predictive of behavior but this "generality equivalence" is difficult to achieve. Liska also cited as a methodological difficulty the "play-like atmosphere" of attitude measurement situations. He concluded that the issue of the attitude-behavior relationship remained unresolved.

\section{Public and Private Opinions}

One of the more important distinctions in helping to understand the mixed empirical evidence was that drawn by Deutscher (1973) between public and private opinions. This distinction can readily be observed in everyday life in the difference between private opinions shared among intimates and opinions stated openly and publicly. The survey interview or questionnaire situation was succinctly summarized in the following passage:

The respondent is urged to reveal his most private opinions on an object without relating it to any other objects, or placing it in any context, with the assurance that the interviewer doesn't care what he says and no one else will ever know he said it (Deutscher, 1973, p. 149).

Private opinions become public when people can express themselves collectively with anonymity, as in purchasing decisions and voting. In most of social life, utterances are treated as public and consequences follow from them. Feelings are frequently masked

\footnotetext{
*The studies reviewed were LaPiere (1935), DeFleur and Westie (1958), and Linn (1965).
} 
for purposes of reputation, politics, economic gain, prestige, and maintenance of norms. All manner of common impulses to action are suppressed and even repressed.* Clearly, the survey, with its promises of confidentiality and anonymity, is designed to elicit private opinion.** The question is, what relationship do these private opinions have to public opinion and to action?

A marked congruence has been noted in the social science literature between attitude (as measured in surveys) and specific behaviors such as voting, buying habits, and leisure time activities, which are the collective actions of individuals, not the organized action of groups or communities. To quote Deutscher (1966):

It would be a serious selective distortion of the existing evidence to suggest that all of it indicates an incongruence between what people say and what they do. Consumers sometimes do change their buying habits in ways they say they will, people frequently vote as they tell pollsters they will, urban relocation populations may accurately predict to interviewers the type of housing they will obtain, local party politicians do in fact employ the campaign tactics which they believe to be most effective, and youngsters will provide survey researchers with reports of their own contact or lack of contact with the police which are borne out by police records (p. 247).

Even so, there still exists much of significance in social life that is constrained by factors other than attitudinal, and it is to be expected that public opinion survey data would be less useful in increasing understanding in these areas. One critical variable is social support, described below.

\section{CONSISTENCY}

A major theoretical school of thought in social psychology has centered on the relationship between actions and attitudes. Three explanatory schemes, though not identical, have the same fundamental notion in common. These are the theory of cognitive dissonance (Festinger, 1957), balance theory (Rosenberg et al., 1960), and the congruity model (Osgood, Suci, and Tannenbaum, 1957). The fundamental notion is that action inconsistent with attitudes is a force for attitude change. Action that is consistent with attitudes is held to produce a state of psychic equilibrium. Action that is inconsistent with attitudes is held to produce a state of disequilibrium, imbalance, or cognitive dissonance. Dissonance is "a state of psychological discomfort or tension which motivates efforts to achieve consonance" (Brown, 1965, p. 584). The cognitive elements affected are knowledge, opinion, and belief about the social environment, oneself, or one's behavior. The state of tension or strain resulting from cognitive dissonance is thought to result in cognitive shif ts to bring attitudes into consonance with behavior. A relatively low tolerance for ambiguity is implied. It follows that if people change their behavior, their attitudes will eventually "fall into line." This notion has been empirically supported (see, for example, King and Janis, 1956).

*Much psychotherapy is conducted with the direct purpose of putting people "in touch" with their own feelings.

**The problem of purposeful lying does not appear to be widespread, although it is known to occur. 


\section{SOCIAL SUPPORT}

As sophistication in analysis increased, multivariate techniques permitted the statistical manipulation of more than one attitudinal variable, with weighting techniques employed. When multivariate analyses are used, the question arises as to whether attitudes and other effects on behavior, such as social support, are merely additive or interactive. Social support variables affecting behavior which have been established in the literature are as follows: group size, cohesiveness, status, frequency of interaction, group power, duration of group membership, group identification, visibility of behavior, and legitimacy of group norms (Liska, 1974).

One approach to the social support variable is to treat it as an intervening variable in a consistency model. If social support is congruent with attitudes, it should reinforce the effects of attitudes on behavior in a given situation. If it is not congruent, it will counterbalance attitudes and decrease attitude-behavior consistency (Liska, 1974).

A second approach is to treat attitudes and social support as equivalent variables in accounting for the behavioral outcome (Liska, 1974). Empirical evidence has suggested that attitudes are more important than social support in accounting for behavior in competitive situations, and social support is the more important variable in cooperative situations (Liska, 1974).

A third approach, the interaction model, has received less empirical support than the additive model. This model assumes that neither attitude nor social support has an independent effect on behavior, but that the effect of one depends on the level of the other.

While the attitude-behavior controversy is far from settled, an interaction model used with multiple attitude measures points to a direction for future investigation that takes full advantage of survey methodology and multivariate techniques to increase the power of analyses.

Schuman and Johnson (1976) concluded from a recent extensive review of the attitudebehavior controversy literature and empirical studies:

Our review has shown that most attitude-behavior studies yield positive results. The correlations that do occur are large enough to indicate that important causal forces are involved .... They are rarely large enough to suggest that attitudinal responses can serve as mechanical substitutes for behavioral measures.... This is not to deny that there are important areas where attitudinal measures are largely unrelated to behavior, but these should be seen as interesting cases that reveal something special about social life-e.g., that the behavior in question is performed with little awareness or informed anticipation or that social constraints on behavior are of exceptional power. Such findings do not mean that attitude and behavior are unrelated (p. 199).

The authors felt that, while social support can help clarify the attitude-behavior relationship, perhaps greater insight would result from "constructing variations in the situation of action" and asking for "personal definitions of the situation." They noted that the "current emphasis on attribution theory in social psychology (Jones et al., 1972) can be seen as an experimental reorientation in the direction of studying personal perspectives" (p. 202). 


\section{INDIVIDUAL VS. COLLECTIVE ACTION}

An important dichotomy relevant to what survey data can and cannot tell us relates to different levels of action in society. Although each person's opinion may carry equal weight in a public opinion poll, that person assuredly does not carry such weight in influencing policy, implementing decisions, or other ways. For decisions and actions within the purview of the individual actor, such as what home to buy, what college to attend, or what candidate to support, the results of opinion surveys are directly relevant to the action in question. However, for decisions of national policy, allocation of tax monies, location of major projects, and the like, survey data are only partially relevant because these decisions are made at the systemic rather than at the individual level.

Data other than surveys must be collected to gain a more comprehensive understanding of social processes relevant to energy issues. Employing different measurements of and independent sources of inf ormation on the same phenomenon (Webb et al., 1966) improves the accuracy of knowledge and the degree of confidence in it.

\section{WHAT SURVEYS CAN TELL US}

Assuming sound methodology (see Chapter 2), survey data can provide accurate descriptions for the sampled population within the sociopolitical context at a given moment on the following kinds of variables:

- attitudes toward the idea of an object in the abstract (person, place, thing, idea, practice, and the like), favorable or unfavorable;

- beliefs about what is real, true, moral, factual; perceptions of reality;

- levels of knowledge, subjectively assessed and objectively tested;

- $\quad$ sources of information and frequency of contact;

- $\quad$ preferences and wishes;

- fears and concerns;

- behavioral intentions, plans;

- evaluation of a specific object (favorability or opposition, yes or no, for or against); and

- certain sociodemographic information (e.g., gender).

With somewhat less accuracy, survey data can also tell us:

- salience of an object; importance, priorities;

- $\quad$ other (more sensitive) sociodemographic information (e.g., income);

- actual behavior (already taken); 
- needs; and

- reasons for opinions; rationales.

These latter variables are more subject to measurement problems and respondent/interviewer difficulties, such as forgetting, lying, selective inattention, desire to please, desire to impress, inability to distinguish needs from desires or to articulate needs clearly, and difficulty in knowing why one feels as one does.

Survey data are accurate and valid to a greater or lesser degree by the sensitivity of the topic of the survey. Surveys have been conducted on a vast array of topies, but it is to be expected that the findings from surveys on political attitudes and behavior are more accurate in describing the population than surveys on, for example, sexual attitudes and behavior. Attitudes on sensitive topies, being very emotionally laden, are much more difficult for the respondent to articulate.

Properly analyzed, survey data can be used to describe relationships among variables and the strength of these relationships, to test hypothesized relationships, and to generate multivariate analyses with which to draw causal inferences concerning predictor and dependent variables. They can describe populations. They permit limited prediction of certain classes of behavior (buying decisions, voting, religious observation, leisure time activity) for the population as a whole or for any particular individual within it. Certain classes of individuals may be predicted to be more likely to behave in specified ways than other classes of individuals. The survey provides sound empirical data descriptive of population segments. On the basis of survey data, we are permitted to say that people are more likely to do $\mathrm{X}$ rather than $\mathrm{Y}$ if we know their attitudes with respect to $\mathrm{X}$ and $\mathrm{Y}$, but we cannot say this with a probability value.

\section{WHAT SURVEYS CANNOT TELL US}

- Survey data cannot be used to tell us what the important questions are.

- They cannot tell us what a given individual will do in many situations.

- They do not permit us to predict with any degree of confidence how attitudes will change at some future time.

- They do not allow us to foretell what future fears, concerns, beliefs, and attitudes will emerge over time.

- They cannot inform us as to the effectiveness of or public response to any particular project or policy decision, since these are subject to political forces beyond public opinion.

- They cannot be used to describe or reveal processes at the social system level.

- They cannot project future policy issues or decisions.

- They cannot predict what the totality of individual actions will be in certain classes of behavior, especially in fad or fashion and in nonroutine situations. 
Further cautions are required in understanding the value of this review. The results from any one item in any given survey should be viewed very tentatively. Enough technical problems of measurement exist that only when items have been replicated can a pattern of response be said to exist. Further, several items used to measure the same attitude or opinion with comparable results is a much stronger treatment than the use of a single item (Scott, 1968).

Item results can be affected by whether items are open-ended or forced choice, by item wording, and by the placement of the item in the context of other items in the instrument. Findings can also be affected by sampling problems and interviewer effects.

In the strictest sense, the aggregation of survey items that do not replicate each other, a method employed in this report, is not considered scientifically valid. Hypotheses cannot legitimately be tested in this way. Nevertheless, in organizing a body of empirical knowledge, it is extremely useful to search out patterns of findings, which provide us with a partial test of convergent validity. When a major purpose of the exercise is to provide social science information of interest to the policymaker, as is the case in this report, such aggregation is essential and necessary. The approach provides relevant information to the social researcher by aiding the formulation of hypotheses and providing item wording to assist replication of previous work and, thus, the cumulation of knowledge.

Research and polling customs have developed in such a way that anyone embarking on a study of any topic is free to devise his or her own items (within the bounds of sound technique). While this approach results in findings not comparable in the strictest sense and, thus, not directly assisting systematic accumulation of empirical evidence, it does offer certain advantages. A policy of total replication (given the expense of survey data collection and analysis) would obliterate much of the freshness and variety provided by numerous researchers exploring problems. The existing diversity in studies is a strength on the national scale reflected in this report.

Caution is necessary in settling on a finding when only one item or survey produces the result. Just because no findings contradictory to that item exist, it is still tentative. When contradictory findings do exist, unless interpretation is possible to account for the contradiction, no conclusion is possible. When findings are not contradictory, but reveal a pattern of findings supported in several surveys, it is concluded that the empirical evidence has revealed a social fact.

In this review, conclusions are based on patterns of findings. If items are identical, three to four similar findings are evidence of a trend or pattern; if not identical, five or more items are evidence of a trend. For many findings only one item exists. These are reported but no conclusions are drawn. Mixed or contradictory findings are also discussed. Where no conclusions are possible research gaps are identified.

\section{POHCY RELEVANCE}

In their review of the literature on attitudes toward nuclear energy, Melber et al. (1977) stated that "... public poll data carefully gathered, compared, and evaluated, can perform an important function in providing public input to the [energy policy] decision process" (p. 305). However, they warn: 
As far as we know, no one has yet argued that public policy decisions are primarily determined by public opinions. In fact, this seems particularly unlikely in the case of energy policy decisions because there appear to be so many real constraints on the course that energy decisions can take (p. 303).

The salience of public opinion, and thus of survey findings, for policy varies by the kind and level of policy decision making. The development and adoption of nuclear energy is a collective adoption decision. Such decisions are very different in character from an individual decision to purchase solar heating or engage in conservation activities. As a result, data on public opinion are more directly relevant to policies pertaining to individual decisions such as energy conservation and domestic use of solar energy. Organizations such as utilities and industries decide about the use of nuclear energy or industrial process heat. Table 1-1 summarizes the structural location of adoption decision making for each energy source. It should be kept in mind, however, that national policy (e.g., tax incentives) can affect individual decision making.

Because public opinion is more directly relevant to some policy decisions than others, it is useful to distinguish two types of policy decision making: those decisions involving (1) public policy, and (2) research policy. Public policy decisions pertain to the creation and allocation of public monies for the administration of the government, social control and sanctions, defense, and public welfare. Research policy decisions, which are usually thought to be a subset of public policy, entail the allocation and expenditure of public funds to support basic and applied scientific investigations into general and specific topics of concern. The choice of research topics and the emphasis given to each in the distribution of resources constitute a major policy decision process occurring at the national level. For example, the huge federal investment in research on nuclear energy constituted a series of major national policy decisions.

The allocation of governmental support to research in solar energy is a research policy decision (not an adoption decision); the creation of tax incentives and information programs is a public policy decision. Survey research is ordinarily more oriented to questions of public policy than research policy. Survey findings reveal public preferences for policy alternatives such as price increases, rationing of energy supplies, and tax incentives. Public opinion polls on nuclear energy tend to be addressed to the general problem of whether the public will tolerate nuclear plants and how the public feels about the idea of nuclear energy in general, but not to specific plans or behavioral options.

This is not to say that survey research is irrelevant to policymakers concerned about research policy and collective alternatives. Melber et al. (1977) listed the following benefits to policymakers from survey findings: (1) broader perspective than that put forward by special interest groups, (2) forewarning of implementation problems, (3) need for improved information distribution, (4) need for more productive mechanisms for resolving disputes, and (5) stimulus for new and more socially acceptable solutions to problems that have arisen. The authors indicated that "good" energy decisions are guided by social values. Therefore, the utility of survey data for policy decisions on collective alternatives concerns social values more and individual behavior less. There is a relationship between public opinion and collective adoption (Farhar et al., 1978) but that relationship is indirect, finding expression that affects policy outcomes only through actions of citizen activists and other collectivity channels. It is precisely here that "private opinion" becomes relevant, because the anonymous, permissive expression of opinion encouraged by the interview setting, to the degree that the setting is successful 


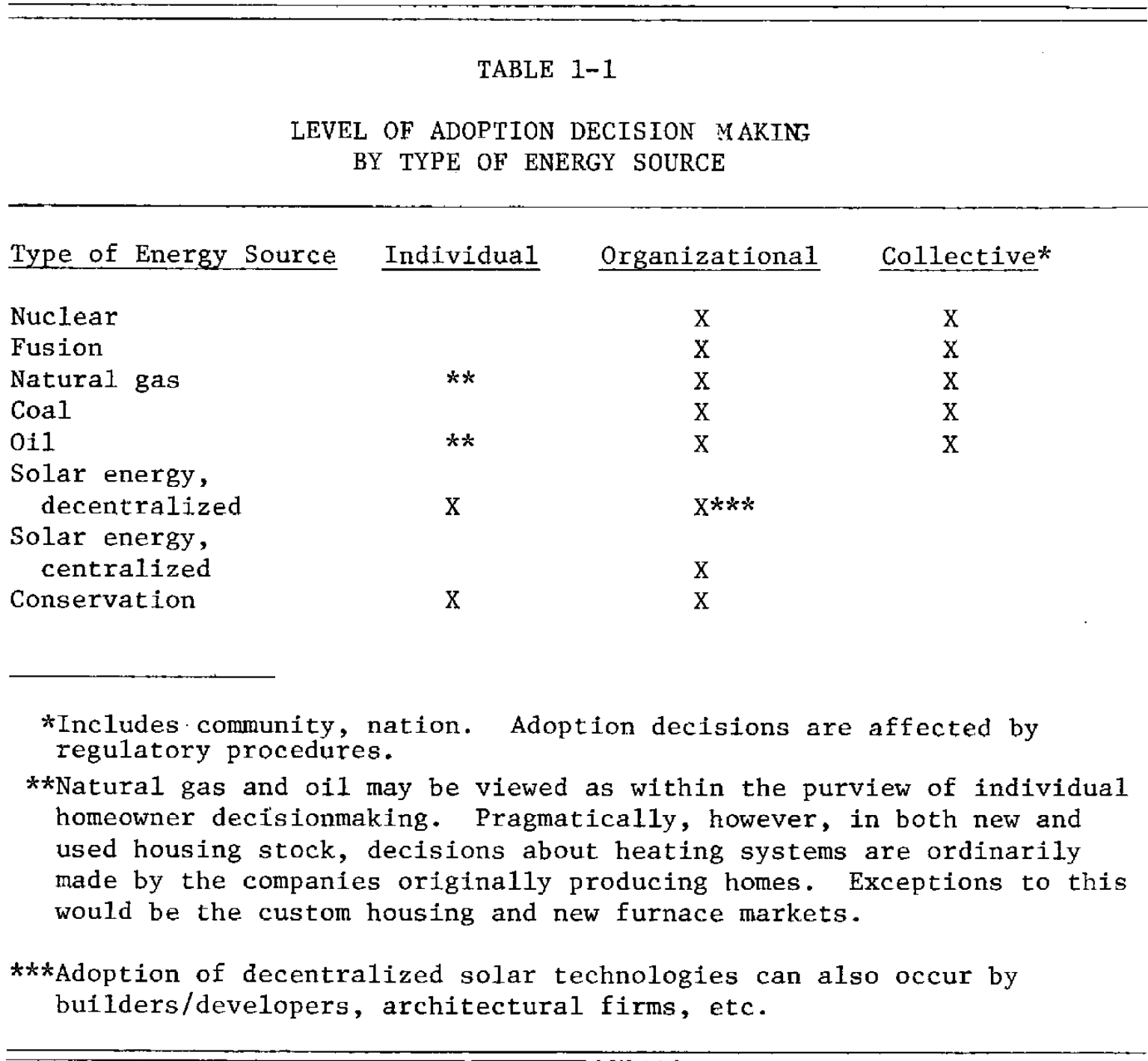


in eliciting an expression of honest attitude, without the constraint of social variables prohibiting such expression, permits description of what ultimately will affect outcomes. Constrained emotion does not disappear, but seeks an outlet for its expression. Thus, the information revealed in surveys describes the emotional milieu in which a given policy thrives or withers.

Survey data on the use of solar energy and energy conservation is more closely linked to action than for other energy sources, since the kinds of behaviors involved in adopting each are amenable to individual action. Survey data are less directly linked to organizational adoption decisions, such as utility adoption of solar energy as a centralized energy source, although they can indicate the popularity of an organizational action. They are useful in describing the social acceptability of policies to encourage or discourage solar energy and energy conservation. With any innovative topic such as solar energy, however, the usefulness of survey data on policy preferences is limited by low levels of knowledge on the part of the population at large, many of whom are unaware of the implications of various policy alternatives, and unfamiliar with the social and economic implications of new technologies. They can say whether it "sounds like a good idea," but they cannot say how they will feel about it when they know more or have experienced it.

Another important contribution to policy from survey data is the description of the perceived world as a social fact. In the physical world, an explorer may discover oil in Texas, but not in Minnesota. A policymaker may be pleased that Texas's energy supply problems are solved for the moment, and he is likely to view the Minnesota energy supply situation as a problem to be solved. He accepts the limitations of the physical world without question. It is difficult to argue with Mother Nature. But if he learns that running large power lines diagonally across the state of Minnesota is not socially acceptable, he may become very angry at the existence of a social limitation.

Whether the policymaker believes that the public is right or wrong, a fount of wisdom or misguided and short sighted, ultimately what people want will affect the outcome, and coercive measures go only a certain distance in gaining compliance with or tolerance of undesired policies. A great deal of public money has been spent on what ultimately proved to be socially unacceptable policies. What is perceived to be most desirable or least harmful should be of great interest to any policymaker, in his or her own selfinterest, and certainly from a professional point of view.

It is important to understand that attitudes about energy and energy policy options can be affected by a variety of related (but indirect) factors, such as who is promoting the policy. If President Carter is recommending a certain line of action on energy, and an individual dislikes President Carter, that person will tend to be disinclined to support the policy. Emanating from some other, more acceptable, source, the policy might be acceptable. Therefore, public opinion on policy alternatives are inseparable from the organizations and persons who stand for them. Further, as Phillips (1978) pointed out, attitudes toward other topics can affect attitudes toward energy policy. For example, pollsters had been reporting "somewhat improving" public attitudes toward major corporations during 1977 and 1978. This improvement in attitude probably affected how the public viewed major oil and energy companies and their role in the nation's energy problems. Phillips argued that President Carter's rebukes of oil companies did little to enhance the political chances of his energy package at that time.

A variety of factors beyond public attitudes can affect the social acceptability of a policy or a technology. Scott and Shore (1974) distinguished "tractable" and "intractable" 
variables.* Policy decisions can affect tractable variables; intractable variables are those which cannot be directly affected by policy decisions and their implementation. The distinction is not based on qualities inherent in variables themselves, but in their relationship to the research topic. For example, in their research on the negative income tax, "sense of internal fate control" was well established in the literature as relevant to poverty, but Scott and Shore considered it intractable through policy measures. The relationship of age and poverty presented a variable, age, that could be taken into account in program policy.

Attitudes toward energy issues are intractable variables not directly amenable to change through policy decisions. Public opinion changes over time, but for purposes of any given policy decision opinion should be viewed more as a parameter for than as a target of policy.

Lopreato and Meriwether (1976) suggested that knowledge of regional differences in energy matters, given recent pressure for regionalization, would be helpful to policymakers. These differences include energy sources, consumption behavior, prices and attitudes. Perlman and Warren (1977) conducted a comparative study of families responding to the energy crisis in Oregon, Connecticut, and Alabama. They indicated that policy alternatives are supported or opposed by various groups in American society depending largely on how they perceive their interests to be affected by the interests of the main regions of the nation and by the interests of particular industries, especially the automobile industry. Perlman and Warren found that economic production is of paramount importance to energy decision makers, environmental concerns were of less importance, and equity was an even less powerful constraint on policy. Equity was defined as "the attempt to distribute costs and benefits of public policy in appropriately fair increments across various socioeconomic segments of the population" (p. 172). Survey data permitted the researchers to discover that a disproportionate negative impact of energy shortages had been suffered by those in lowest income groups, minorities, and the aged. An increase in energy prices particularly disadvantages those with annual incomes below $\$ 15,000$. If social equity is a social value, then this information should be important to the energy policymaker in choosing among policy options.

Phillips (1978) analyzed President Carter's energy program in light of available public opinion data, and concluded:

The public did not react enthusiastically ... because major elements of that program were at odds with majority viewpoints on matters so fundamental to American politics as growth versus energy conservation, production incentives versus income redistribution, and on the relative role of federal regulation (p. 14).

Deutscher (1966) asserted that the policymaker "as a man of action . . . is interested in overt behavior," and especially in behavioral changes (p. 235);

We cannot blandly suggest to the policymaker that if he changes behavior, a change in attitude will follow. Nor can we lead him to assume that if he can alter attitudes, he need only wait patiently for the appropriate behavior to develop (p. 252).

\footnotetext{
*Tractable variables have also been termed variables "manipulable" through policy action.
} 
Public policy is a stimulus designed to evoke a behavioral response.* Since behavior is correlated to attitudes, public policies that fly in the face of public attitudes are unlikely to evoke the desired behavioral response unless coercion mandates compliance. Thus, survey data on citizen attitudes, beliefs, definitions of the situation, knowledge, fears and concerns, and preferences provides a fundamental framework against which policy options should be assessed.

Policymakers can also discover whether a policy idea is popular. A survey can be used to discern whether policies, such as gasoline rationing or tax incentives, are accepted by the public. Policymakers can discover through surveys whether a policy "worked" through self-reports of behavioral response. They can learn the public's behavioral intentions at a given point in time, their definition of the relative importance of things, and their preferences for various options, all of which are directly relevant to assessing the social desirability of any given policy option.

*It has already been argued that attitudes are not directly amenable to change by public policy. 


\section{SEP|}




\section{CHAPTER 2}

\section{METHOD}

\section{INTRODUCTION}

This review of public surveys on energy alternatives was begun with literature searches. It soon became apparent that a wealth of data existed. The same kinds of issues were being explored across surveys, but some organizing framework was needed to locate patterns of findings. The following steps were taken to organize and present the data:

- Studies of the general public were singled out from special group samples as more easily comparable. They were assigned arbitrary identification numbers which were used in coding and which serve as the reference numbers in this report.

- A set of categories was developed by which to sort findings similar in content but not necessarily identical in wording. These categories, taken together, reflect a preliminary theoretical approach to public preference and action concerning energy.

- Tabular findings of each survey of the general public (115 studies) were photocopied and physically sorted by categories. Analytical findings were sorted by independent variable.

- Within each category, findings from several studies were reviewed and reported.

- Where patterns of findings were discerned, these were identified and described.

- When categories contained no data or isolated findings, research gaps were noted.

Described in this chapter are the literature search procedures employed, the surveys included in this preliminary review, survey funding sources, general quality of survey data, an assessment of the quality of surveys included, the multivariate categories used to organize the data, and the coding procedures employed.

\section{SEARCH PROCEDURES}

The literature search emphasized, but was not limited to, studies of the general public rather than specific groups such as homeowners or the elderly. Surveys of special populations were acquired as they were encountered, but there was no attempt at a comprehensive collection of these studies.

Most surveys of public attitudes toward energy alternatives are not formally published or easily retrievable. Four computerized literature files were searched first in January 1978 for studies conducted after 1973. These were:

- The New York Times Information Bank;

- Lockheed Dialog Retrieval Service, NTIS, File 6; 
- Lockheed Dialog Retrieval Service, ENERGYLINE, Energy Index, File 69;

- DOE/RECON, Technical Information Center.

Major studies and periodical articles listed in these files provided bibliographic references to further studies. Fifty state energy offices were asked about ongoing or already completed attitude studies. Finally, a lengthy list of authors, institutions, and interested parties provided the basis for personal contacts within the research community who provided bibliographies and articles for the effort. The search resulted in a preliminary collection of 115 original surveys of the general public and many other specialized surveys and analytic pieces. Information on work sponsored by utilities and private companies continues to arrive and this bibliography will be expanded in the future. The collection of 115 original surveys permits the broadest review of the attitude literature on energy alternatives conducted to date.

\section{SURVEYS INCLUDED IN THIS REVIEW}

A survey is a systematic collection of data from a specified population using a structured data collection instrument (interview schedule or questionnaire) at a specific period of time. Thus, surveys are identified on the basis of data collection effort, not on the basis of reports. Each new data collection period represents a new survey of the population. The 115 surveys mentioned above comprise the preliminary universe of surveys included in our systematic analysis of the existing attitude data. The criterion for inclusion of a survey in the review was a sampling technique designed to provide results representative of the entire population studied, rather than of a specific group. Qualitative studies, purposive samples, and samples of special populations were omitted from the systematic analysis, although results from them are noted throughout the report where they enrich the discussion and complete the presentation of findings. The surveys included contained items relevant to energy, but may not have been limited to energy topics.

A map depicting the locations of surveys included (general population surveys) is presented in Figure 2-A. National surveys numbered 82, comprising 71 percent of the surveys included; 33 state and local surveys make up the balance. Several surveys were conducted in the East and far West, with little survey activity in the Northwest, the Plains, the Midwest, and the South.

Each survey was assigned an arbitrary "study number" as part of a coding process. A list of the surveys by study number, along with author, area sampled, sample size, and date of data collection, is presented in Table 2-3 at the end of this Chapter. Since the citation system in this report is based on the study numbers, the reader should refer to this table, and subsequently to the bibliography, to locate references.

All surveys included in the universe reviewed in this report were conducted between June 1973 and April 1978 (see Figure 2-B). A large number of surveys were conducted around the nation in 1974, 1975, and 1977, with considerably less survey activity during 1976.* As will be seen in the discussion on descriptive survey findings, where a survey was conducted sometimes affected its results. Thus, the survey findings are presented in the context of their "time and space" for interpretive purposes.

*The reason for the apparent slowdown in survey activity during the Bicentennial year is unclear. Some ongoing surveys may not have included energy-relevant items. 


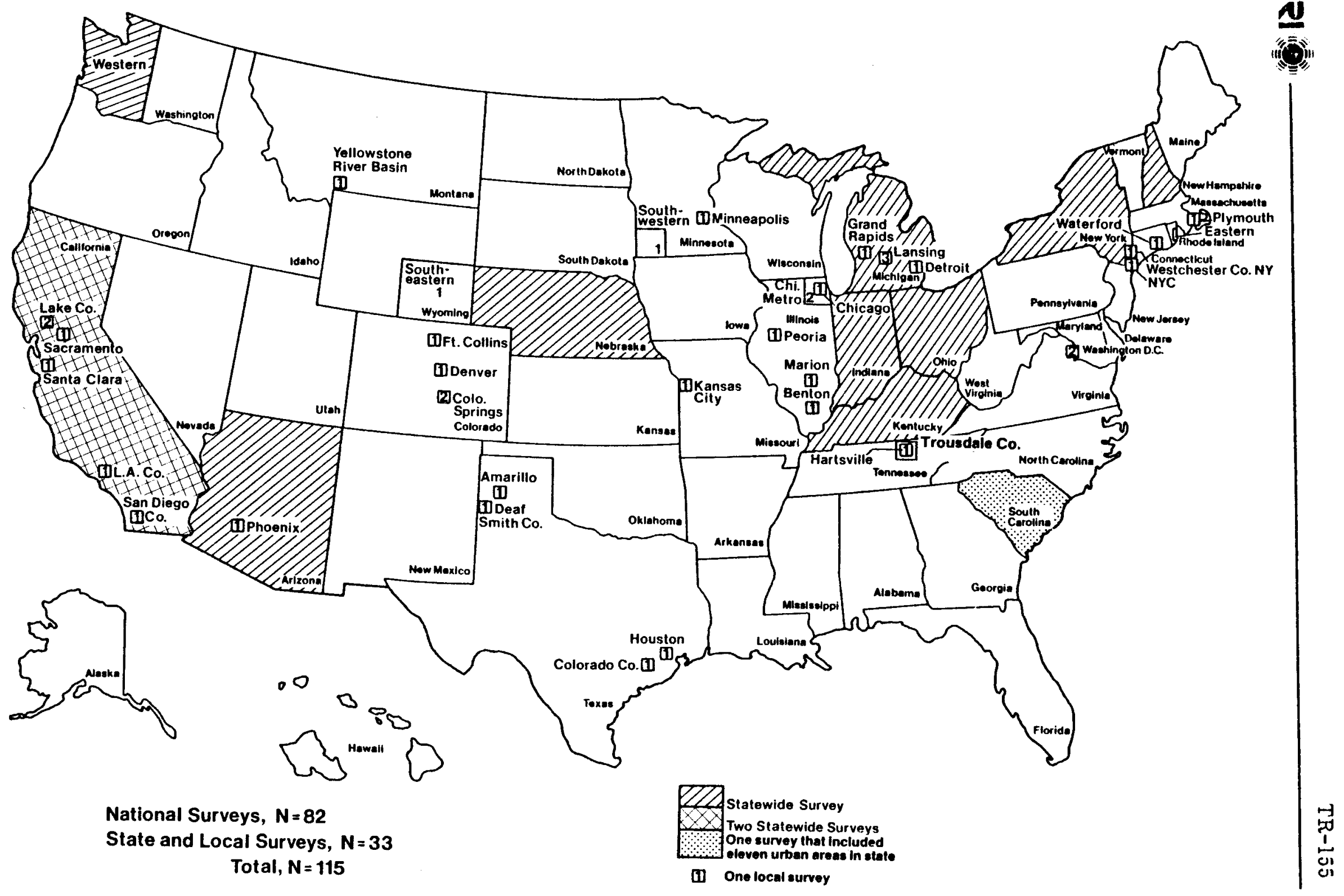

Figure 2-A. LOCATIONS OF THE SURVEYS 

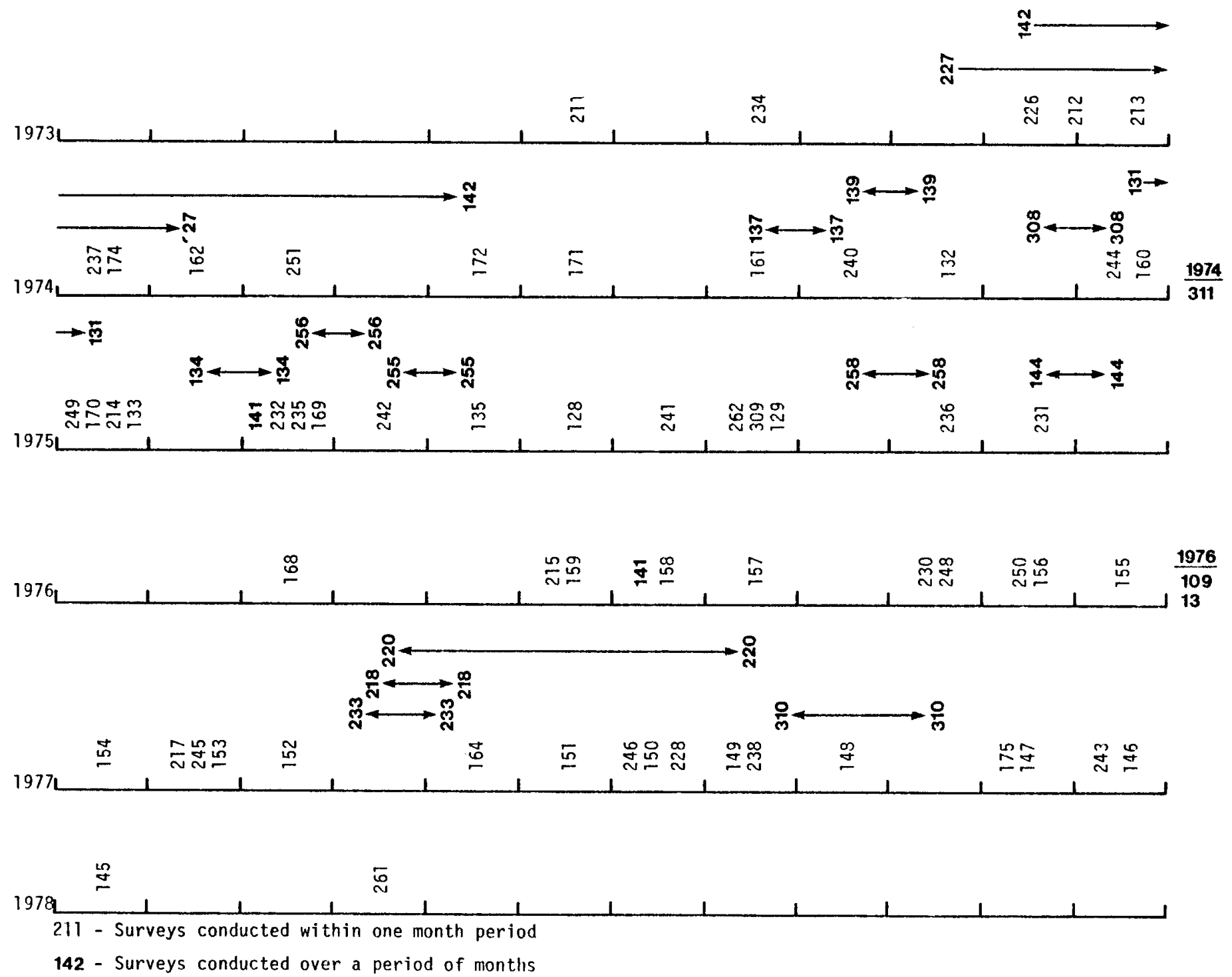

Figure 2-B. TIMING OF SURVEYS 


\section{SURVEY FUNDING SOURCES}

Public opinion surveys are expensive to conduct. Knowing who paid for surveys of public attitudes toward energy is useful in assessing whether a particular bias may have entered the body of knowledge through hidden or not-so-hidden agendas of sponsoring organizations. Such bias may sometimes be detected in the kinds of questions asked and omitted, the response categories employed in forced-choice items, the arrangement of items in the instrument, item wording itself, and so on. Ordinarily, bias is not introduced purposefully by researchers who strive to collect data in such a way that the range of possible responses is accurately measured. Rather, bias can creep in through more institutionalized routes: certain important questions may never be explored because no one is interested in paying to have them explored, or certain questions may be explored for a more narrow purpose than a broad understanding of public opinion (which this study seeks to achieve).

The funding sources for the surveys included in this review are summarized in Table 21. The majority ( 53 percent) of the surveys included were conducted by the Roper, Harris, and Gallup organizations. These organizations are maintained through user subscription and special contracts to conduct surveys by government and private industry. They are, therefore, somewhat more influenced by what government and industry want to know than by what researchers need or what the general public would like to know about itself. About a third of the surveys were financed by federal agencies, including energy, resource, and scientific agencies. No research included here was funded by environmental agencies. State and local agencies and universities paid for 10 percent of the surveys, and private sources (e.g., utilities) for six percent. Funding sources were not reported in seven surveys. A list of the funding sources appears in Appendix A.

This distribution of funding sources suggests that the majority of those paying for the public opinion surveys in energy represented here have been interested in national rather than local descriptions. This national bias may easily be the result of the search procedures used and the difficulty of locating or the paucity of local studies.

Description, rather than analysis, was the purpose of almost all of the surveys included. Some of the major national polls systematically run cross-tabulations on each questionnaire item by major sociodemographic characteristics (e.g., gender, political orientation, religious affiliation and income). However, statistical tests are most of ten not applied; therefore, significant differences in opinion among elements of the population are not statistically identified. Moreover, virtually no scaling or factor analyses* have been used. Researchers are largely absent from the ranks of those conducting surveys addressing energy topics, which helps explain the dearth of analytical information on survey findings. In general, one receives the impression that interpretations of survey findings are written for media rather than scholarly consumption. Much of the relevance of the survey findings for policy has thus been neglected.

\footnotetext{
*Using several items rather than one to measure a specific attitudinal factor, such as belief in the energy crisis.
} 


\section{TABLE 2-1}

FUNDING SOURCES FOR PUBLIC OPINION POLLS ON ENERGY TOPICS

\begin{tabular}{|c|c|c|}
\hline Funding Organization* & $\begin{array}{l}\text { Percentage } \\
\text { f Surveys }\end{array}$ & $\begin{array}{ll} & \text { Number } \\
\text { of } & \text { Surveys } \\
\end{array}$ \\
\hline Major pollsters (Roper, Harris, Gallup) & $53 \%$ & $(61)$ \\
\hline $\begin{array}{l}\text { Federal agencies (FEA, ERDA, NSF, NRC, } \\
\text { NIMH, DOI) }\end{array}$ & 25 & $(29)$ \\
\hline $\begin{array}{l}\text { State and local agencies and universities } \\
\quad \text { (I11., S.C., N.H., Ky., Mich., Nebr., Co1 }\end{array}$ & Lo.) ${ }^{9}$ & $(10)$ \\
\hline $\begin{array}{l}\text { Private sources (utilities, manufacturers, } \\
\text { consulting firms) }\end{array}$ & 5 & $(6)$ \\
\hline $\begin{array}{l}\text { Combination of federal agencies and private } \\
\text { sources }\end{array}$ & 2 & $(2)$ \\
\hline Not reported & 6 & 7) \\
\hline Total & 100 & $(115)$ \\
\hline \multicolumn{3}{|c|}{$\begin{array}{l}\text { *See Appendix A for list of funding sources. } \\
\text { NOTE: These surveys contained items relevant to energy, but may not } \\
\text { have been limited to energy topics. }\end{array}$} \\
\hline
\end{tabular}




\section{GENERAL QUALTY OF SURVEY DATA}

Public opinion assessment depends upon valid and reliable measurement. Validity refers to the accurate measurement of what is purported to be measured. In questions about public policy preferences, for example, are actual preferences in fact measured, or are preferences only within a list of forced-choice responses measured? Do respondents articulate their thoughts and feelings about a given topic accurately and completely (including their confusion)? Do they respond only to the stimulus of a set of questions that elicits partial response or subtly guides their response? Sound field work and pretesting of instruments aid in increasing the validity of survey instruments. For most of the surveys reported here, field work and pretesting were not conducted; some assumptions must theref ore be made about their validity. These assumptions include that the instruments asked the right questions (in the sense of validity measuring the respondents' feelings about the topies at hand) and that they asked questions to elicit a complete response about that topic.

Reliability refers to the capability of the instrument to elicit the same response from the same respondent over time (unless the respondent has changed his or her mind). More generally, reliability refers to the capability of an instrument to measure the same attitude in different times and places. As Deutscher (1973) defines it, ". . reliability ... focuses on the degree of consistency in observations obtained from the devices we employ ..." (p. 106). Reliability and validity are separate constructs: measurement can be consistently in error as well as consistently correct, but when reliability is low, validity must be low.

Validity in measurement of attitudes does not imply that actual behavior will follow expressed sentiment. Validity in surveys refers to the accurate measurement of attitudes, beliefs, opinions, awareness, and intention. Certain items may attempt to measure action, as subjectively reported; these have special problems in validity based on difficulties in recall, desire to impress the researchers, selective inattention, and so on. The important point here is that surveys may be valid and not predictive of either future sentiment or behavior.

\section{QUAIITY OF SURVEYS INCLUDED}

The general methodological quality of the surveys included for the systematic review was assessed. If the body of empirical findings on public attitudes toward energy alternatives was compiled using sound methods of sampling, data collection and analysis, findings can be reported with more confidence. On the other hand, serious questions have been raised recently about the quality of survey research in the United States (Bailar and Lanphier, 1978). Assessing the overall quality of the surveys provides a parameter for reporting and assimilating survey findings.

No data on the training or background of those who conducted the surveys included in this study were available. Their quality was assessed on the basis of a number of parameters described below. These parameters are among those mentioned by Bailer and Lanphier as indicators of high quality survey methodology, but they do not include all possible indicators of methodological quality. Rather, they represent a moderate but adequate level of competence and quality in descriptive survey work.

Most of the surveys included in this review did not employ sophisticated statistical treatment in their analyses. Cross-tabulation, usually without statistical tests of 
significance, was the most frequently used analytical technique. The surveys were thus not ranked on the appropriateness of statistical tests used. Clear, concise, and complete presentations of both the methodology employed in the surveys and of the findings were relatively rare. Survey reports and articles were thus not rated on the adequacy of their presentations. Surveys were ranked on the following variables, assigning scores as noted:

- Sample type:

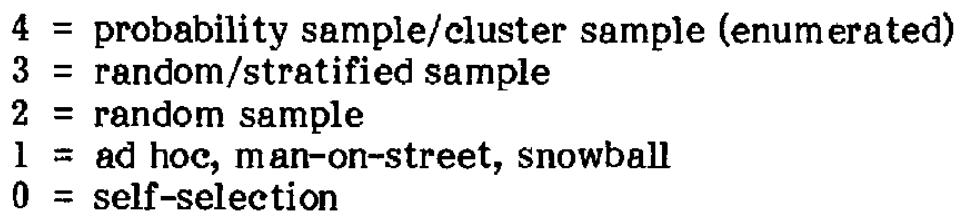

Purposive or random samples of special populations (e.g., homebuyers) were omitted from the universe of surveys, as previously noted.

- Sample size (to be considered in conjunction with sample type):

$2=$ size apparently adequate to represent population studied (return rate $\geq 70$ percent)*

$l$ = sample size adequate for some statistical manipulations $(\mathrm{N} \geq 50$; return rate 30 to 70 percent)

$0=$ all other sample sizes.

- Data collection technique:

3 = face-to-face interviews

$2=$ telephone interviews

$l$ = mail questionnaire

- Obvious item bias:**

$3=$ nonbias of items or good distribution of "biased" items

$2=$ relative nonbias of items, distribution unclear

1 = some bias detectable

$0=$ obvious distortions affecting findings.

The range of possible total scores was 0 to 12 .

*The return or response rates presented by authors and used in the quality rating may not be strictly comparable. The response rate is the number of respondents in the study divided by the number of potential respondents in the sample. Studies reported insufficient data to calculate comparable response rates among them.

**"Loaded" items of a Likert type were not considered biased; these items are purposely "loaded" to lead the respondent to reveal his "loaded" feelings, rather than to respond with cliches (Deutscher 1973, p. 153). The following are some examples of biased items: "Would you prefer nuclear energy to having not enough electricity?" and "How serious is not having enough fuel oil?" 
The quality rating did not involve the subjective judgment of coders, with the exception of the fourth parameter. Item bias was detected in a few of the surveys for a few items, but by and large it did not appear to be widespread enough to affect findings seriously.

Table 2-2 provides a summary of findings for the quality rating exercise performed on the universe of surveys included in this review $(\mathrm{N}=115)$. On the quality scale ranging from 0 to 12 possible points, the mean score of the distribution was 9.72 , with a standard deviation of 1.78. The results of the quality rating were overwhelmed by the high number of surveys conducted by Harris, Gallup, Roper, and Opinion Research Corporation which received relatively high values. The modal score was 11 . We concluded that the surveys were moderately competent, but not outstandingly so, since our scale was designed to measure moderate but adequate quality. Thus, the summary of findings to be presented in this report should be viewed by the reader with a degree of caution. Some unquantifiable margin of error exists in the body of data assembled. What should be given the most weight is the consistency of findings in survey after survey in sample proportions expressing various sentiments, and in patterns of analytical results.

\section{MULTIVARIATE CATEGORIES}

A set of categories was employed to organize the vast array of diverse survey findings. These categories are multivariate in the sense that items similar in content, but not necessarily identical in wording, are clustered together under the categorical rubric. Such a coding process enabled locating and describing patterns of findings across many different surveys employing various item wording. Actual item replication is necessary for statistical analyses of cross-sectional and longitudinal data. The procedure employed here allowed grouping of otherwise disparate data to draw together a somewhat fragmented body of knowledge. The methodological rationale for the procedure has been outlined by Lucas (1974), although the quantitative coding procedure he described has not been employed in this preliminary review. The categories employed are the following:

- Perceived eff ectiveness of the alternative

- Perceived relative advantage of the alternative

- Concern about risk

- Knowledgeability

- Information sources

- Behavioral intention and action

- Evaluation (favorability or opposition)

- $\quad$ Perceived and preferred decision making (including policy preference)

The general theoretical notions underlying the multivariate categories are as follows. An incentive to action may come into being through environmental change (such as an energy crisis) or from other sources. Once a problem is perceived to exist, alternative solutions will be preferred or adopted (or not), depending on the following kinds of variables. 
TABLE 2- 2

QUALITY RATING OF PUBLIC OPINION SURVEYS

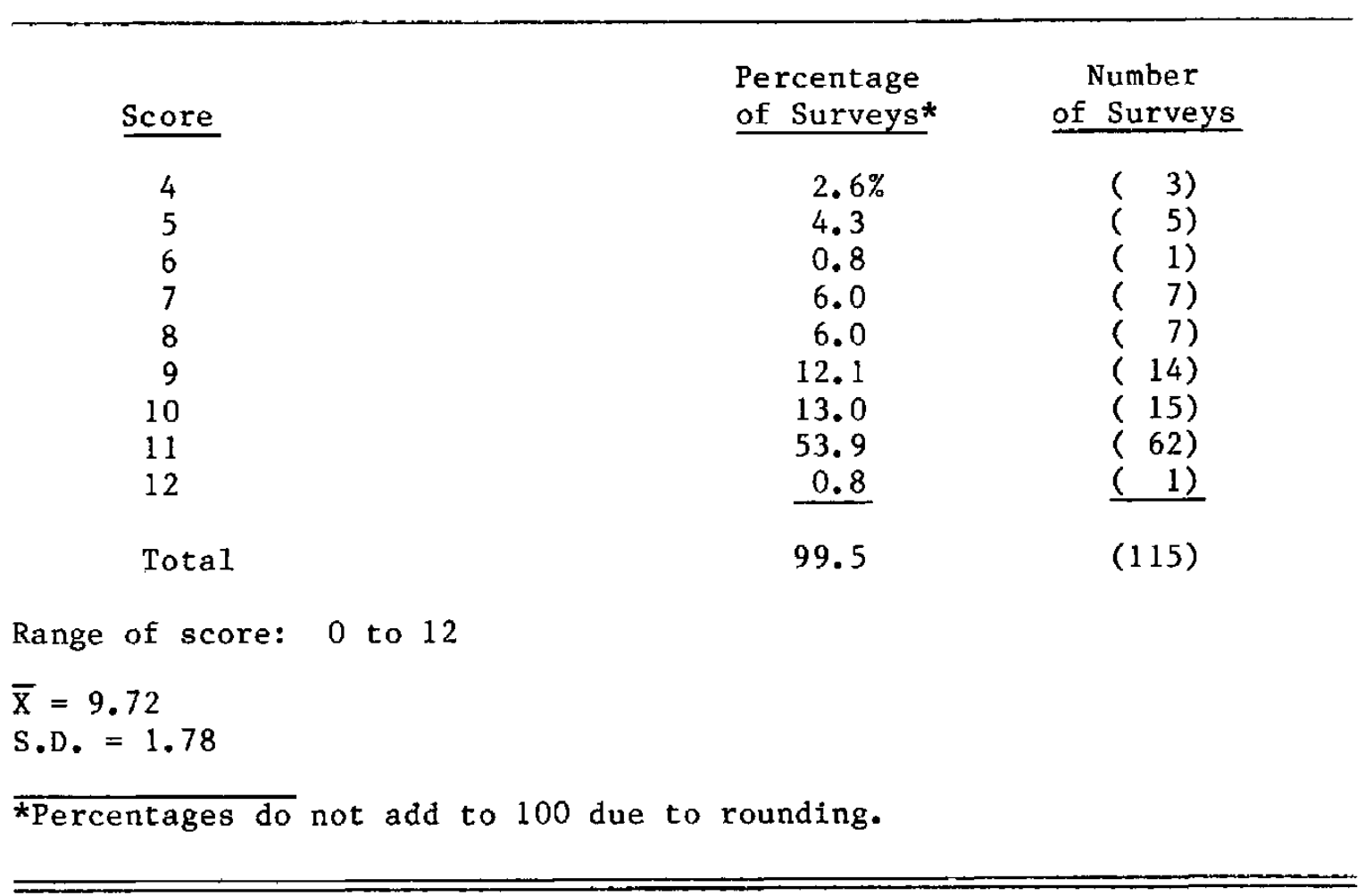




\section{Perceived Effectiveness of the Alternative}

Will it actually work? Will it produce the effect it is purportedly capable of producing? For example, will conservation measures be effective in reducing demand for energy? Can solar energy actually heat water and homes?

\section{Perceived Relative Advantage of the Alternative}

If the alternative has already been employed, as is the case with nuclear energy, what are the experiential advantages and disadvantages of its use? If it has not been employed, what are the public's expectations about its advantages or disadvantages? Put another way, what benefits will accrue from the use of that alternative, and what harm might result if it were used? What benefits and harm could be anticipated if it were not used?

Benefit and harm could result for both the individual member of the society (egoistic view) and for the community, region, or society as a whole (altruistic view). Further, perceived benefits and costs extend beyond economic ones to include environmental, health and saf ety, and sociopolitical impacts. The idea of relative advantage implies (1) identification of perceived benefits and costs, (2) weighing of these, (3) comparison of this alternative to other options, and (4) a decision as to the advantage of choosing this alternative relative to other options.

The matrix of perceived advantages and disadvantages of alternative solutions presented in Figure 2-C illustrates the complexity of this variable.

The same matrix can be used to organize per ceived eff ects of solutions already in use.

Opinions may change over time as to the perceived relative advantage of any given solution. This is particularly the case with technological innovation after adoption occurs. Experience with the actual effects of an innovation, once adopted, may result in a later discontinuance decision if the experience is not salutory. A major unanticipated impact is social polarization over the issue, as has occurred, for example, in nuclear energy and in weather modification. Thus, in this category, both anticipated benefits and costs (affecting the adoption decision), and actual benefits and costs (affecting the continuance decision) are considered.

\section{Concern about Risk}

Since Carson's The Silent Spring (1962), our society has become increasingly concerned with the unintended and unanticipated consequences of action, particularly action affecting "the commons" (e.g., Hardin, 1968) for which no particular institution is responsible. As a result, a number of statutes and adminstrative procedures have come into being (notably NEPA-The National Environmental Policy Act of 1969) requiring consideration of unintended secondary and tertiary effects of proposed actions. The environmental impact statement, technology assessment, and social impact assessment are incipient formal methods for dealing with the problem of forecasting future consequences of decisions.

Public opinion about an energy alternative may be affected by perceived harmful secondary and tertiary impacts (or "side effects"); data on these opinions are categorized 


\begin{tabular}{|c|c|c|c|c|}
\hline & Individual & Community & Region & Nation \\
\hline $\begin{array}{l}\text { COSTS } \\
\text { Economic } \\
\text { Sociopolitical } \\
\text { Environmental } \\
\text { Health/safety }\end{array}$ & & & & \\
\hline $\begin{array}{l}\text { BENEFITS } \\
\text { EconoInic } \\
\text { Sociopolitical } \\
\text { Environmental } \\
\text { Health/safety }\end{array}$ & & & & \\
\hline
\end{tabular}

Figure 2-C. MATRIX OF PERCEIVED COSTS AND BENEFITS OF ALTERNATTVES 
here. The basic idea is that where side effects defined as harmful or "risky" are perceived, the alternative will be viewed less favorably.

\section{Knowledgeability}

One common notion in diffusion theory is that the more people know about an innovative practice, the more willing they are to adopt it. Yet little evidence exists that knowledge, per se, can account for either favorability or adoption decisions. Knowledge about an innovation is a necessary but not a sufficient condition for its adoption. In fact, some studies have shown that knowledgeability may correlate negatively with favorability toward an innovation (e.g., Farhar and Mewes, 1976). People may come to know more about an alternative and like it less.

Knowledgeability about alternative solutions is measured in two ways, subjectively and objectively. Subjective measurements usually rely on items such as, "How well informed would you say you are about nuclear energy? Very well informed, somewhat informed, or not at all informed?" Objective measurements depend on items designed to test respondent ability to answer factual items correctly; e.g., "What percentage of the oil we use in the United States is imported?" Usually, a fairly good correlation exists between subjective assessment of knowledge levels and response to objective items on that alternative.

\section{Information Sources}

One of the most consistent findings from the diffusion literature is that communications about innovations must come from credible sources (Rogers and Shoemaker, 1971). Policymakers are interested in sources of energy information that are effective in reaching the general public and specific groups. Use of effective information channels insures that people are at least aware of energy alternatives. The theoretical notion is that communication of information through credible channels will increase knowledgeability and favorability, and eventually heighten the chances of acceptance or adoption.

A common sense idea of how communication works is the "hypodermic needle" concept. The mass media are viewed as "injecting" information directly into the minds of a relatively passive polity whose opinions are then thought to be influenced. Empirical evidence has not borne out this model of communication; instead, complex social processes at the community and reference group levels, involving opinion leadership and status similarity, are found to affect information flows (Rogers and Shoemaker, 1971 ).

Information about a topic is communicated most effectively through interpersonal networks when attitude and opinion formation about the topic are the issue. That is, media are eff ective in communicating some information, but interpersonal networks are effective in both communicating information and in shaping opinion about information received.

Information about energy is more likely to be believed when it comes from credible sources. Included in the findings about information sources, then, are data on the perceived credibility of various communicators about energy problems and policies. 


\section{Behavioral Intention and Action}

Action or plans for action express attitudes. If one conserves energy at home, this implies favorability toward conservation as an action alternative. Actual behavior as subjectively reported through survey data is particularly susceptible to problems of lying, recall, and the social pressure of an interview. On the other hand, the respondent is expert on his behavior, if he reports this information accurately. Certain actions, such as the decision to adopt solar energy, are not easily forgotten or lied about; it is easy for the interviewer to observe the system. Other actions, such as lowering the temperature of thermostats, are less readily observable.

Reports of intended action are even more probable to result in erroneous interpretation if they are viewed as data on what people are likely to do. The subjective intent may be accurately reported at the time of the interview but other factors can intervene before action is implemented.

Action may be viewed as contributing to the formation and maintenance of attitudes consonant with actual behavior. Thus, the category of behavioral intention and action is partially a dependent variable (to the extent we are attempting to explain behavior) and partially an independent variable (in accounting for attitudes). Findings on what people say they have done and on what they report they intend to do about energy are reported in this general category.

\section{Evaluation}

This variable refers to whether people are favorable or opposed overall to a given energy alternative. Evaluation is the dependent variable to be explained-whether people are for or against nuclear energy, solar energy, conservation, or specific policy options. It is the dependent variable in attitude studies, and an independent variable when we seek to explain actual behavior. Findings reflecting general attitudes toward the idea of a particular energy alternative, and favorability or opposition to its actual implementation, are included here.

\section{Perceived and Preferred Decision Making}

Perceived decision making refers to the public's perception of who is deciding and what is being decided. Preferred decision making refers to the public's preferences about who should be deciding, about the content of the policy decision; i.e., about what should be done, and about the process by which decisions are made. The willingness to accept or reject a particular policy option can be affected as much by normative and political values as by the variables described previously. For example, some have argued that solar policy making should not reside within the Department of Energy because it is seen as pro-nuclear ( see Farhar et al., 1979). Others, who are content with existing decision mechanisms, may be disturbed about policy content: certain policies, such as gasoline rationing, may be almost totally unacceptable. It is in this category that findings on various policy options and opinions about who should be making policy choices are presented. 
In summary, favorable response to energy alternatives (e.g., favorable evaluation; behavioral intention to adopt or support; actual support or adoption) is likely to be fashioned by:

- General attitudes toward the idea.

- Belief in its effectiveness.

- Perceived anticipated relative advantage.

- Perceived actual relative advantage (when experience or trial runs have occurred).

- Lack of concern about side effects (risk).

- Exposure to credible sources of positive information.

- Knowledge.

- Existence of preferred institutional mechanisms and policies.

\section{CODING PROCEDURES}

Most survey results were presented item by item with an interpretive text describing the method and findings of the study. Coders filled out a form for each survey specifying location, population sampled, sample size, sampling procedure, dates of data collection, data collection technique, funding source, and whether the survey was cross-sectional or longitudinal.

By and large, interpretive texts were ignored unless they contained study data not available in tabular form. Coders photocopied all pages of tabular survey data and sorted them using a coding framework based on the multivariate categories to be used in the analysis. This sorting process was a way of organizing and categorizing the data. Coders* were trained in the use of the coding framework. Each coding decision was made by one coder and checked by another coder who had final judgment. Many, but not all, of the coding decisions were checked by two other coders as well.

The end result of this coding process, which took several months, was the body of empirical survey data sorted into multivariate categories and ready for analysis.

Coding was carried out using a system based on whether the data table was (1) descriptive (frequency distributions), or (2) analytical (cross-tabulations and results of other data manipulations). Descriptive data were organized into two major categories: (1) those pertaining to the energy situation in general, and (2) those pertaining to alternative responses (energy sources), including conservation, solar energy, nuclear energy, coal, and oil and gas. Within each of these general categories, data were further sorted into multivariate categories.

*Coders were doctoral candidates in the Department of Sociology, University of Colorado, Boulder. 
For example, if a survey item pertained to solar energy, it was fit into one of the following categories:

- belief in the technological effectiveness of solar energy (reliability, performance, obsolescence, etc.);

- concern about the effects of solar energy (environmental, safety, economic, international, equity, etc.);

- knowledge about solar energy (subjective and objective);

- $\quad$ perceived and preferred decision making about solar energy;

- anticipated harm or benefit from using solar energy (including advantages and disadvantages);

- behavioral intention regarding solar energy;

- actual action taken with reference to solar energy;

- favorability or opposition to solar energy; and

- assessment of other's attitudes toward solar energy.

Analytical findings were classified as to whether they pertained to sociodemographic or social-psychological variables. All data on sociodemographics were then sorted by independent variable, resulting in data files for each major demographic variable. These were as follows: gender, age, education, income, occupation, race, political orientation, religious affiliation, lifestyle characteristics (including marital status, housing characteristics and stage in the family life cycle, home ownership, and transportation characteristics), and urban/rural place of residence.

Social-psychological findings were those relating one variable to another; for example, relating belief in the energy crisis to energy conservation behavior. These were sorted by the independent (explanatory) variable involved in the analysis.

The following four chapters present descriptive survey findings on the energy problem as perceived by the public and public perspectives on energy conservation, solar energy, and conventional energy sources. In the subsequent two chapters, analytical findings (sociodemographic and social-psychological) are described. 
Table 2-3

PRELIMINARY UNIVERSE OF PUBLIC OPINION SURVEYS ON ENERGY

\begin{tabular}{|c|c|c|c|c|}
\hline $\begin{array}{l}\text { Study } \\
\text { Number }\end{array}$ & Author & Area Sampled & $\begin{array}{c}\text { Date } \\
\text { of Data } \\
\text { Collection } \\
\end{array}$ & $\begin{array}{l}\text { Sample } \\
\text { Size }\end{array}$ \\
\hline 104 & $\begin{array}{l}\text { City of Colorado } \\
\text { Springs }\end{array}$ & $\begin{array}{l}\text { Colorado Springs, } \\
\text { Colo. SMSA }\end{array}$ & 1976 & 400 \\
\hline $105 *$ & $\begin{array}{l}\text { City of Colorado } \\
\text { Springs }\end{array}$ & $\begin{array}{l}\text { Colorado Springs, } \\
\text { Colo. SMSA }\end{array}$ & 1974 & 2,500 \\
\hline 106 & Morrison & Lansing, Mich. & $\begin{array}{l}1974 \\
1976\end{array}$ & $\begin{array}{l}216 \\
264\end{array}$ \\
\hline 108 & Cheskin & $\begin{array}{l}\text { Chicago, Peoria, Marion } \\
\text { \& Benton, I11. }\end{array}$ & $1977 * *$ & 602 \\
\hline 109 & Abt Associates & $\begin{array}{l}\text { Calif. vs, rest of } \\
\text { states, national }\end{array}$ & 1976 & 796 \\
\hline 115 & Davis & Lansing, Mich. & $1977 * * *$ & 133 \\
\hline 116 & Gott1ieb & $\begin{array}{l}\text { Houston \& Amarillo; } \\
\text { portions of Colorado } \\
\& \text { Deaf Smith Cos., } \\
\text { Tex. }\end{array}$ & 1974 & 782 \\
\hline 117 & Willenborg & $\begin{array}{l}\text { S.Carolina. } 11 \text { urban } \\
\text { areas }\end{array}$ & 1977 & 605 \\
\hline 119 & Thomp son & Grand Rapids, Mich. & 1976 & 515 \\
\hline 120 & $\begin{array}{l}\text { Nationa1 } \\
\text { Demographics }\end{array}$ & Denver, Colo. & 1977 & 365 \\
\hline 121 & Hitlin & Washington, D.C. & 1974 & 1,115 \\
\hline 122 & Ruttenberg & Ohio & 1975 & 2,300 \\
\hline $\begin{array}{l}\text { *Conven } \\
* * \text { Date } \\
\text { publi }\end{array}$ & $\begin{array}{l}\text { ience sample. } \\
\text { of data collectio } \\
\text { cation date. }\end{array}$ & ot reported by authors; & ate supplied & is \\
\hline
\end{tabular}


Table 2-3 (continued)

\begin{tabular}{|c|c|c|c|c|}
\hline $\begin{array}{l}\text { Study } \\
\text { Number } \\
\end{array}$ & Author & Area Sa mpled & $\begin{array}{c}\text { Date } \\
\text { of Data } \\
\text { Collection } \\
\end{array}$ & $\begin{array}{l}\text { Samp le } \\
\text { Size } \\
\end{array}$ \\
\hline 123 & $\begin{array}{l}\text { Tech Analysis } \\
\text { \& Communications, } \\
\text { Inc. }\end{array}$ & Calif., N.Y., Mich. & 1977 & 1,060 \\
\hline 124 & Vollintine & Lake County, Calif. & 1975 & 786 \\
\hline 125 & Welch & Nebr. & 1977 & 1,877 \\
\hline 127 & Gi11 & Chicago Metro & 1977 & 931 \\
\hline 128 & $\begin{array}{l}\text { Opinion Research } \\
\text { Corp. } \\
\quad 1975 \mathrm{~h}\end{array}$ & Nationa1, Vol, 13 & 1975 & 1,222 \\
\hline 129 & $\begin{array}{l}\text { Opinion Research } \\
\text { Corp. } \\
\quad 1975 i\end{array}$ & Nationa1, Vol. 15 & 1975 & 1,536 \\
\hline 130 & $\begin{array}{l}\text { Opinion Research } \\
\text { Corp. } \\
\quad 1976 \mathrm{~b}\end{array}$ & Nationa1, Vo1. 23 & 1976 & 1,002 \\
\hline 131 & $\begin{array}{l}\text { Opinion Research } \\
\text { Corp. } \\
\quad 1975 \mathrm{~b}\end{array}$ & Nationa1, Vol. 7 & $\begin{array}{l}\text { Dec. } 1974 / \\
\text { Jan. } 1975\end{array}$ & 1,206 \\
\hline 132 & $\begin{array}{l}\text { Opinion Research } \\
\text { Corp. } \\
\quad 1974 \mathrm{e}\end{array}$ & National, Vol. 5 & Oct. 1974 & \\
\hline 133 & $\begin{array}{l}\text { Opinion Research } \\
\text { Corp. } \\
\quad 1975 c\end{array}$ & National, Vol. 8 & Jan. 1975 & 1,211 \\
\hline 134 & $\begin{array}{l}\text { Opinion Research } \\
\text { Corp. } \\
\quad 1975 \mathrm{~d}\end{array}$ & National, Vol. 9 & $\begin{array}{l}\text { Feb. \& Mar. } \\
1975\end{array}$ & 1,209 \\
\hline 135 & $\begin{array}{l}\text { Opinion Research } \\
\text { Corp. } \\
\quad 1975 \mathrm{~g}\end{array}$ & National, Vol. 12 & May 1975 & 905 \\
\hline
\end{tabular}

* Information not provided in report. 
Table 2-3 (continued)

\begin{tabular}{|c|c|c|c|c|}
\hline $\begin{array}{l}\text { Study } \\
\text { Number } \\
\end{array}$ & Author & Area Sampled & $\begin{array}{c}\text { Date } \\
\text { of Data } \\
\text { Collection } \\
\end{array}$ & $\begin{array}{l}\text { Sample } \\
\text { S1ze }\end{array}$ \\
\hline 136 & $\begin{array}{l}\text { Opinion Research } \\
\text { Corp. } \\
\quad 1974 \mathrm{~b}\end{array}$ & $\begin{array}{l}\text { Westchester, Jeffer- } \\
\text { son City \& Skymeadow, } \\
\text { N.Y. }\end{array}$ & Nov. 1974 & 100 \\
\hline 137 & $\begin{array}{l}\text { Opinion Research } \\
\text { Corp. } \\
\quad 1974 \mathrm{a}\end{array}$ & National, Vol. 1 & $\begin{array}{l}\text { Aug. \& Sep. } \\
1974\end{array}$ & 1,213 \\
\hline 139 & $\begin{array}{l}\text { Opinion Research } \\
\text { Corp. } \\
1974 \mathrm{c}\end{array}$ & National, Vol. 2 & $\begin{array}{l}\text { Sep. \& Oct. } \\
1974\end{array}$ & 1,210 \\
\hline 141 & $\begin{array}{l}\text { Harris and } \\
\text { Associates, Inc. }\end{array}$ & National & $\begin{array}{l}1975 \\
1976\end{array}$ & $\begin{array}{l}1,537 \\
1,497\end{array}$ \\
\hline 142 & Murray & Nationa1 & $1973-1974$ & 7,954 \\
\hline 143 & Sunstrom & $\begin{array}{l}\text { Hartsville \& Trousdale } \\
\text { Co, Tenn. }\end{array}$ & 1975 & 350 \\
\hline 144 & $\begin{array}{l}\text { Opinion Research } \\
\text { Corp. } \\
\quad 1976 c\end{array}$ & National, Vol. 21 & $\begin{array}{l}\text { Nov, \& Dec. } \\
1975\end{array}$ & 1,207 \\
\hline 145 & $\begin{array}{l}\text { Roper } \\
\quad 1978 \mathrm{a}\end{array}$ & National & Jan. 1978 & 2,000 \\
\hline 146 & $\begin{array}{l}\text { Roper } \\
\quad 1977 i\end{array}$ & National & Dec. 1977 & 2,000 \\
\hline 147 & $\begin{array}{l}\text { Roper } \\
\quad 1977 \mathrm{~h}\end{array}$ & National & Nov. 1977 & 2,000 \\
\hline 148 & $\begin{array}{l}\text { Roper } \\
\quad 1977 \mathrm{~g}\end{array}$ & National & Sep. 1977 & 2,000 \\
\hline 149 & $\begin{array}{l}\text { Roper } \\
\quad 1977 \mathrm{f}\end{array}$ & National & Aug. 1977 & 2,000 \\
\hline 150 & $\begin{array}{l}\text { Roper } \\
\quad 1977 \mathrm{e}\end{array}$ & National & July 1977 & 2,000 \\
\hline 151 & $\begin{array}{l}\text { Roper } \\
\quad 1977 \mathrm{~d}\end{array}$ & Nationa1 & June 1977 & 2,000 \\
\hline
\end{tabular}


Table 2-3 (continued)

\begin{tabular}{|c|c|c|c|c|}
\hline $\begin{array}{l}\text { Study } \\
\text { Number }\end{array}$ & Author & Area Sampled & $\begin{array}{c}\text { Date } \\
\text { of Data } \\
\text { Collection } \\
\end{array}$ & $\begin{array}{c}\text { Sample } \\
\text { Size } \\
\end{array}$ \\
\hline 152 & $\begin{array}{l}\text { Roper } \\
\quad 1977 \mathrm{c}\end{array}$ & National & Mar. 1977 & 2,000 \\
\hline 153 & $\begin{array}{l}\text { Roper } \\
\quad 1977 \mathrm{~b}\end{array}$ & National & Feb. 1977 & 2,000 \\
\hline 154 & $\begin{array}{l}\text { Roper } \\
\quad 1977 a\end{array}$ & Nationa 1 & Jan. 1977 & 2,000 \\
\hline 155 & $\begin{array}{l}\text { Roper } \\
1976 \mathrm{f}\end{array}$ & Nationa1 & Dec. 1976 & 2,000 \\
\hline 156 & $\begin{array}{l}\text { Roper } \\
1976 \mathrm{e}\end{array}$ & Nationa1 & Nov. 1976 & 2,000 \\
\hline 157 & $\begin{array}{l}\text { Roper } \\
\quad 1976 \mathrm{~d}\end{array}$ & National & Aug. 1976 & 2,000 \\
\hline 158 & $\begin{array}{l}\text { Roper } \\
1976 c\end{array}$ & National & July 1976 & 2,000 \\
\hline 159 & $\begin{array}{l}\text { Roper } \\
\quad 1976 \mathrm{~b}\end{array}$ & National & June 1976 & 2,000 \\
\hline 160 & $\begin{array}{l}\text { Roper } \\
\quad 1974 \mathrm{f}\end{array}$ & Nationa 1 & Dec. 1974 & 2,000 \\
\hline 161 & $\begin{array}{l}\text { Roper } \\
\quad 1974 \mathrm{e}\end{array}$ & Nationa 1 & Aug. 1974 & 2,000 \\
\hline 162 & $\begin{array}{l}\text { Roper } \\
1974 \mathrm{~b}\end{array}$ & National & Feb. 1974 & 2,000 \\
\hline 163 & $\begin{array}{l}\text { Roper } \\
\quad 1977 j\end{array}$ & Nationa 1 & May 1977 & 2,000 \\
\hline 164 & $\begin{array}{l}\text { Roper } \\
\quad 1976 a\end{array}$ & National & Mar. 1976 & 2,000 \\
\hline 168 & $\begin{array}{l}\text { Roper } \\
\quad 1977 \mathrm{k}\end{array}$ & National & May 1977 & 2,000 \\
\hline 169 & $\begin{array}{l}\text { Roper } \\
\quad 1975 b\end{array}$ & National & Mar. 1975 & 2,000 \\
\hline
\end{tabular}


Table 2-3 (continued)

\begin{tabular}{|c|c|c|c|c|}
\hline $\begin{array}{l}\text { Study } \\
\text { Number }\end{array}$ & Author & Area Sampled & $\begin{array}{c}\text { Date } \\
\text { of Data } \\
\text { Collection } \\
\end{array}$ & $\begin{array}{l}\text { Sample } \\
\text { Size }\end{array}$ \\
\hline 170 & $\begin{array}{l}\text { Roper } \\
\quad 1975 a\end{array}$ & Nationa 1 & Jan. 1975 & 2,000 \\
\hline 171 & $\begin{array}{l}\text { Roper } \\
\quad 1974 d\end{array}$ & National & June 1974 & 2,000 \\
\hline 172 & $\begin{array}{l}\text { Roper } \\
\quad 1974 \mathrm{c}\end{array}$ & National & May 1974 & 2,000 \\
\hline 174 & $\begin{array}{l}\text { Roper } \\
\quad 1974 a\end{array}$ & National & Jan. 1974 & 2,000 \\
\hline 175 & Gallup & Nationa 1 & Nov. 1977 & 1,500 \\
\hline 180 & $\begin{array}{l}\text { Roper } \\
\quad 1978 \mathrm{~b}\end{array}$ & National & Mar. 1978 & 2,000 \\
\hline 181 & $\begin{array}{l}\text { Cunningham \& } \\
\text { Lopreato }\end{array}$ & $\begin{array}{l}\text { Austin \& El Paso, Tex.; } \\
\text { Flagstaff \& Prescott, } \\
\text { Ariz. }\end{array}$ & Oct. 1975 & 2,403 \\
\hline 201 & $0^{\prime}$ Brien & Ariz. & Apr. 1976 & 149 \\
\hline 202 & Blakely & $\begin{array}{l}\text { Sacramento, Capay } \\
\text { Valley \& Winters, } \\
\text { Calif. }\end{array}$ & Sep. 1975 & 1,600 \\
\hline 205 & Faulkner & $\begin{array}{l}\text { Yellowstone River } \\
\text { Basin }\end{array}$ & May 1975 & 2,058 \\
\hline 207 & Bartell & Los Angeles Co., Calif. & $\begin{array}{l}\text { Feb./Mar. } \\
1974\end{array}$ & 1,069 \\
\hline 208 & Gladhart & Lansing, Mich. & May 1976 & 264 \\
\hline 209 & Camp bel1 & $\begin{array}{l}\text { New York City; South- } \\
\text { west Minn.; Santa } \\
\text { Clara Co., Calif.; } \\
\text { Washington, D.C. }\end{array}$ & Sep. 1977* & 379 \\
\hline 210 & Humme11, et al. & Ft. Collins, Colo. & 1973 & 238 \\
\hline
\end{tabular}

Study
Number
170
172
174
200
200
201
181

Date of data collection not reported by authors; date supplied is publication date. 
Table 2-3 (continued)

\begin{tabular}{|c|c|c|c|c|}
\hline $\begin{array}{l}\text { Study } \\
\text { Number }\end{array}$ & Author & Area Sampled & $\begin{array}{c}\text { Date } \\
\text { of Data } \\
\text { Collection } \\
\end{array}$ & $\begin{array}{l}\text { Sample } \\
\text { Size }\end{array}$ \\
\hline 211 & $\begin{array}{r}\text { Gallup } \\
1973\end{array}$ & Nationa 1 & June 1973 & 1,500 \\
\hline 212 & $\begin{array}{l}\text { Ga11up } \\
\quad 1974 \mathrm{a}\end{array}$ & Nationa 1 & $\begin{array}{l}\text { Nov. 30/ } \\
\text { Dec. 1, } \\
1973\end{array}$ & 1,500 \\
\hline 213 & $\begin{array}{l}\text { Ga11up } \\
\text { 1974b }\end{array}$ & National & $\begin{array}{l}\text { Dec. } 7-10, \\
1973\end{array}$ & 1,500 \\
\hline 214 & $\begin{array}{r}\text { Gallup } \\
1975\end{array}$ & Nationa1 & $\begin{array}{l}\text { Jan. } 10-15, \\
1975\end{array}$ & 1,500 \\
\hline 217 & $\begin{array}{l}\text { Gallup } \\
\quad 1977 \mathrm{~b}\end{array}$ & National & $\begin{array}{l}\text { Feb. 18-21, } \\
1977\end{array}$ & 1,500 \\
\hline 218 & $\begin{array}{l}\text { Ga11up } \\
1977 \mathrm{c}\end{array}$ & National & $\begin{array}{l}\text { Apr. 29/ } \\
\text { May 2, } 1977\end{array}$ & 1,500 \\
\hline 220 & $\begin{array}{l}\text { Ga1lup } \\
\text { 1977b }\end{array}$ & National & $\begin{array}{l}\text { Apr./Aug. } \\
1977\end{array}$ & 1,500 \\
\hline 221 & Burdge & Kentucky & $\begin{array}{l}\text { Aug. / Oct. } \\
1975\end{array}$ & 3,428 \\
\hline 222 & Purdy & $\begin{array}{l}\text { Plymouth, Mass.; } \\
\text { Waterford, Conn. }\end{array}$ & $\begin{array}{l}\text { Feb./Aug. } \\
1975\end{array}$ & 308 \\
\hline 226 & $\begin{array}{l}\text { Harris } \\
\qquad 1973 b\end{array}$ & National & $\begin{array}{l}\text { Nov. 12-15, } \\
1973\end{array}$ & 1,459 \\
\hline 227 & $\begin{array}{l}\text { Harris } \\
\quad 1974 b\end{array}$ & Nationa 1 & $\begin{array}{l}\text { Oct. } 1973 / \\
\text { Feb. } 1974\end{array}$ & 1,496 \\
\hline 228 & $\begin{array}{l}\text { Harris } \\
\quad 1977 \mathrm{c}\end{array}$ & Nationa1 & $\begin{array}{l}\text { Aug. 1, } \\
1977 *\end{array}$ & 1,540 \\
\hline 230 & $\begin{array}{l}\text { Harris } \\
\quad 1976 a\end{array}$ & Nationa 1 & $\begin{array}{l}\text { Oct. 23-26, } \\
1976\end{array}$ & 1,728 \\
\hline 231 & $\begin{array}{l}\text { Harris } \\
\qquad 19751\end{array}$ & National & Nov. $1975^{\star}$ & 1,519 \\
\hline
\end{tabular}

* Date of data collection not reported by authors; date supplied is publication date. 
Table 2-3 (continued)

\begin{tabular}{|c|c|c|c|c|}
\hline $\begin{array}{l}\text { Study } \\
\text { Number }\end{array}$ & Author & Area Sampled & $\begin{array}{c}\text { Date } \\
\text { of Data } \\
\text { Collection } \\
\end{array}$ & $\begin{array}{c}\text { Sample } \\
\text { Size } \\
\end{array}$ \\
\hline 232 & $\begin{array}{l}\text { Harris } \\
\quad 1975 c\end{array}$ & National & $\begin{array}{l}\text { Mar. } \\
1975^{*}\end{array}$ & 1,543 \\
\hline 233 & $\begin{array}{l}\text { Harris } \\
1977 d\end{array}$ & National & $\begin{array}{l}\text { Apr. 29- } \\
\text { May 6, } 1977\end{array}$ & 1,540 \\
\hline 234 & $\begin{array}{l}\text { Harris } \\
\quad 1973 a\end{array}$ & National & July 1973* & 1,537 \\
\hline 235 & $\begin{array}{l}\text { Harris } \\
\quad 1975 \mathrm{~d}\end{array}$ & National & $\begin{array}{l}\text { Mar. 13, } \\
1975^{*}\end{array}$ & 1,513 \\
\hline 236 & $\begin{array}{l}\text { Harris } \\
\quad 1975 \mathrm{~h}\end{array}$ & Nationa 1 & $\begin{array}{l}\text { Oct. } 6 \& \\
13,1975\end{array}$ & 1,519 \\
\hline 237 & $\begin{array}{l}\text { Harris } \\
1974 \mathrm{c}\end{array}$ & Nationa 1 & $\begin{array}{l}\text { Jan. } 18-22, \\
1974\end{array}$ & 1,594 \\
\hline 238 & $\begin{array}{l}\text { Harris } \\
\quad 1977 \mathrm{f}\end{array}$ & Nationa 1 & $\begin{array}{l}\text { Aug. 10-13, } \\
1977\end{array}$ & 1,491 \\
\hline 240 & $\begin{array}{l}\text { Harris } \\
\quad 1974 \mathrm{e}\end{array}$ & National & $\begin{array}{l}\text { Sep. } 2, \\
1974^{*}\end{array}$ & 1,447 \\
\hline 241 & $\begin{array}{l}\text { Harris } \\
\quad 1975 \mathrm{f}\end{array}$ & National & July 1975 & 1,497 \\
\hline 242 & $\begin{array}{l}\text { Harris } \\
1975 \mathrm{e}\end{array}$ & National & $\begin{array}{l}\text { Mid-Apr. } \\
1975\end{array}$ & 1,568 \\
\hline 243 & $\begin{array}{l}\text { Harris } \\
\quad 1977 \mathrm{~g}\end{array}$ & National & $\begin{array}{l}\text { Dec. } 2 \& 3, \\
1977\end{array}$ & 1,200 \\
\hline 244 & $\begin{array}{l}\text { Harris } \\
\quad 1974 \mathrm{f}\end{array}$ & Nationa1 & $\begin{array}{l}\text { Dec. 19, } \\
\text { 1974* }\end{array}$ & 1,525 \\
\hline 245 & $\begin{array}{l}\text { Harris } \\
\quad 1977 b\end{array}$ & National & Feb. 1977* & 1,459 \\
\hline 246 & $\begin{array}{l}\text { Haxris } \\
1977 \mathrm{e}\end{array}$ & National & $\begin{array}{l}\text { July 23-30, } \\
1977\end{array}$ & 1,515 \\
\hline
\end{tabular}

* Date of data collection not reported by authors; date supplied is publication date. 
Table 2-3 (continued)

\begin{tabular}{|c|c|c|c|c|}
\hline $\begin{array}{l}\text { Study } \\
\text { Number }\end{array}$ & Author & Area Sampled & $\begin{array}{l}\text { Date } \\
\text { of Data } \\
\text { Collection } \\
\end{array}$ & $\begin{array}{c}\text { Sample } \\
\text { Size } \\
\end{array}$ \\
\hline 248 & $\begin{array}{l}\text { Harris } \\
\quad 1976 b\end{array}$ & Nationa1 & oct. 7-11, 1976 & 1,539 \\
\hline 249 & $\begin{array}{l}\text { Harris } \\
\quad 1975 a\end{array}$ & National & Jan. 16-20, 1975 & 1,532 \\
\hline 250 & $\begin{array}{l}\text { Harris } \\
\quad 1976 \mathrm{c}\end{array}$ & National & Nov. $18,1976^{*}$ & 1,532 \\
\hline 251 & $\begin{array}{l}\text { Harris } \\
\quad 1974 \mathrm{~d}\end{array}$ & National & Mar. 1974 & 1,495 \\
\hline 252 & $\begin{array}{l}\text { San Diego Gas \& } \\
\text { Electric }\end{array}$ & $\begin{array}{l}\text { San Diego Co., } \\
\text { Calif. }\end{array}$ & Aug. 1976 & 400 \\
\hline 253 & Ga11in & New Hampshire & $\begin{array}{l}\text { Apr. 30- } \\
\text { May 2, } 1976\end{array}$ & 256 \\
\hline 255 & $\begin{array}{l}\text { Opinion Research } \\
\text { Corp. } \\
\quad 1975 \mathrm{f}\end{array}$ & Nationa1, Vol. 11 & $\begin{array}{l}\text { Apr./May } \\
1975\end{array}$ & 1,208 \\
\hline 256 & $\begin{array}{l}\text { Opinion Research } \\
\text { Corp. } \\
\quad 1975 \mathrm{e}\end{array}$ & National, Vol. 10 & $\begin{array}{l}\text { Mar. 10-21, } 1979 \\
\text { Mar. 24/Apr. } 6 \\
1975\end{array}$ & 1,208 \\
\hline 258 & $\begin{array}{l}\text { Opinion Research } \\
\text { Corp. } \\
\text { 1976a }\end{array}$ & National, Vol. 19 & $\begin{array}{l}\text { Sept. 9/Oct. } 8 \\
1975 \\
\text { Oct. 14-22, } 1975\end{array}$ & $\begin{array}{l}503 \\
505\end{array}$ \\
\hline 260 & Warren & Detroit, Mich. & Apr./June 1974 & 766 \\
\hline 261 & $\begin{array}{l}\text { Gallup } \\
\quad 1978 \mathrm{~b}\end{array}$ & National & Apr. $14-17,1978$ & 1,319 \\
\hline 262 & $\begin{array}{l}\text { Opinion Research } \\
\text { Corp. } \\
\quad 1975 \mathrm{~b}\end{array}$ & $\begin{array}{l}\text { National (no volume } \\
\text { given) }\end{array}$ & Aug. 4, 1975 & 1,007 \\
\hline 302 & TRW & $\begin{array}{l}\text { Phoenix, Kansas City } \\
\text { \& Minneapolis }\end{array}$ & Feb. 1974 & 270 \\
\hline
\end{tabular}

*Date of data collection not reported by authors; date supplied is publication date. 
Table 2-3 (continued)

\begin{tabular}{|c|c|c|c|c|}
\hline $\begin{array}{l}\text { Study } \\
\text { Number }\end{array}$ & Author & Area Sampled & $\begin{array}{c}\text { Date } \\
\text { of Data } \\
\text { Collection } \\
\end{array}$ & $\begin{array}{l}\text { Sample } \\
\text { Size } \\
\end{array}$ \\
\hline 303 & $\begin{array}{l}\text { Survey Research } \\
\text { Laboratory }\end{array}$ & $\begin{array}{l}\text { Mason, Oceana, Newaygo } \\
\text { Cos., Mich.; Natrona, } \\
\text { Converse, Carbon, A1- } \\
\text { bany, Platte, Goshen, } \\
\text { Laramie Cos., Wyo.; } \\
\text { Clallan, Jefferson, } \\
\text { Grays Harbor, Mason, } \\
\text { Pacific Cos., Wash.; } \\
\text { Bristol, Newport Cos., } \\
\text { R.I.; McHenry, Lake, } \\
\text { Kane, DuPage, Cook, } \\
\text { Will Cos., Ill. }\end{array}$ & $\begin{array}{l}\text { Spring \& } \\
\text { Summer, } \\
1976\end{array}$ & 1,431 \\
\hline 304 & Doering & Indiana & Apr. 1974 & 670 \\
\hline 307 & Vollintine & $\begin{array}{l}\text { Cobb Valley, Lake Co., } \\
\text { Calif. }\end{array}$ & July 1975 & 142 \\
\hline 308 & $\begin{array}{l}\text { Opinion Research } \\
\text { Corp. } \\
\quad 1975 a\end{array}$ & National, Vol. 6 & $\begin{array}{l}\text { Nov. 11/ } \\
\text { Dec. } 8, \\
1974\end{array}$ & 1,207 \\
\hline 309 & $\begin{array}{l}\text { Ga1lup } \\
\quad 1978 a\end{array}$ & National & $\begin{array}{l}\text { Aug, 5-8, } \\
1977\end{array}$ & 1,500 \\
\hline 310 & $\begin{array}{l}\text { Ga1lup } \\
\quad 1977 \mathrm{~d}\end{array}$ & Nationa 1 & $\begin{array}{l}\text { Nov, 18-21, } \\
1977\end{array}$ & 1,500 \\
\hline 311 & $\begin{array}{l}\text { Becker Research } \\
\text { Corp. }\end{array}$ & National & 1974 & 1,252 \\
\hline $\mathrm{N}=115$ & & & & \\
\hline
\end{tabular}




\section{SEPI}




\section{CHAPTER 3}

\section{THE ENERGY PROBLEM}

\section{INTRODUCTION}

For five years, the American public has confronted "the energy crisis." After experiencing unconstrained growth in the 1960s, the United States in 1973 suddenly faced increased gas and oil prices, long lines at gas stations, decreased speed limits, and demands for energy conservation. These events, compounded by severe winters causing job losses and other social disruptions and by droughts decreasing the supply of hydropower, made Americans more aware of their dependence on energy.

Much contradictory information has been made available to the public concerning the nation's energy situation. The first section of this chapter briefly reviews such information as a context for understanding the environment in which public opinion about energy has formed.

Given the history of energy development in the nation, during which the public was encouraged to consume cheap and plentiful supplies of gasoline and electricity, it seems that energy supply has not traditionally been viewed as a problem. Subsequent sections of this chapter present survey information on how the public is coming to view the energy situation: Do they believe there is a genuine energy crisis? To what or whom do they attribute the problem? How important do they perceive the problem to be? What impacts of the energy situation have they experienced? What are their expectations concerning the future energy situation? What solutions do they perceive?

\section{CONTEXT: THE ENERGY DEBATE}

Americans have been exposed to a confusion of information and opinions on the energy crisis and its causes. Citizen attitudes concerning energy have developed in the context of a spectrum of contradictory ideas. A brief overview of the debate surrounding the energy crisis illustrates the contrasting viewpoints received by the public which could directly affect their opinions about the energy crisis, its severity, and its causes.

Since 1973, each President has commented on the seriousness of the energy problem, emphasizing a need for immediate action:

NIXON: Unless we act swiftly and effectively, we could face a genuine energy crisis in the foreseeable future. (1974 Edition-World Almanac and Book of Facts, p. 1002)

FORD: This nation, and, in fact, the world must face the prospect of energy difficulties between now and 1985 .... (New York Times; Jan. 16, 1975; p. 24)

Two weeks after taking office, President Carter delivered an appeal for energy conservation by the American public.

CARTER: The energy crisis has not yet overwhelmed us, but it will if we do not act quickly... the alternative may be a national catastrophe... this difficult eff ort will be the "moral equivalent of war." (New York Times; April 19, 1977; p. 24) 
Midway through his second speech on energy Mr. Carter commented:

I know some of you may doubt that we face real energy shortages. (New York Times; April 19, 1977; p. 24)

What information does the public have to shape its opinion on this question?

In early 1973, at the onset of the energy shortage, the news media reported such comments as:

There is no physical shortage of energy resources in either the United States or the world for the foreseeable future and yet Americans may spend the rest of this decade coping with brownouts and blackouts and perhaps even rationing of gasoline, heating oil, and natural gas. (New York Times; April 17, 1973; p. 1)

The United States has basic energy materials to meet our needs for at least 200 years at the present levels of consumption. -John G. McLean, Chairman, Continental Oil Co. (New York Times; April 17, 1973; p. 17)

The world energy crisis or energy shortage is a fiction ..... But belief in this fiction is a fact. It makes people accept higher oil prices as imposed by nature, when they are really fixed by collusion. -Dr. Maury Adelman, Professor, M.I.T. (New York Times; April 17, 1973; p. 24)

Bluntly, there is no need for us to do anything to mitigate the long-run energy problem in this recession year of 1975. Most of what could be done now would endanger the solutions of both our recession problem and our inflation problem. Why rock the boat? -Paul A. Samuelson, Professor, M.I.T. (Newsweek; March 24, 1975; p. 76)

which were then contradicted:

In talking about energy, we are talking about the survival of the United States. -Governor Vanderhoof, Colorado (Newsweek; August 26, 1974; p. 68)

The most difficult problem facing the nation today, either internationally or domestically, is the energy crisis. -Senator Henry M. Jackson (New York Times; April 17, 1973; p. 17)

If Americans think that we've already seen the worst of the energy shortages, they're in for a shock. If we are not able to break our reliance on high-priced foreign oil our whole economic way of life will be in jeopardy. -Rogers C. B. Morton, Energy Czar (Newsweek; November 4, 1974 ; p. 76)

Faced continually with such contradictory information from reputable figures, it is easy to understand public skepticism that a crisis exists.

Not only has the public been confronted with inconsistent reports as to the validity or severity of the energy crisis, but controversy has also engendered accusations of who is to blame. 
While three U.S. Presidents stressed the importance of energy conservation by the public, none directly blamed the crisis on American consumers. Mr. Carter noted that 50 percent of the energy used for home heating could be conserved through stringent measures by homeowners. The New York Times presented a more accusing portrayal of individual consumer use. It suggested editorially that proposed legislation should:

force the American people to examine searchingly some of their values. (April 19, 1977; p. 24)

and depicted the "average American" as:

a profligate user of natural resources. He floods his home with light, even when no one is in it; he heats rooms until they are hot as ovens. He drives a gas-devouring car for a pack of cigarettes rather than walk a block. There are electric toothbrushes, combs, tie racks, and hair dryers. (Emphasis added) (April 17, 1973; p. 26)

In January 1974, U.S. oil companies reported a substantial increase in earnings during the fourth quarter of 1973. Profit increased 59 percent at Exxon, 68 percent at Mobil, 50 percent at Texaco, and 52 percent at Ashland Oil.* Several well-known public figures made the following judgments.

The energy crisis is a device the industry is using to get higher prices. -Martin Lobel, Washington, D.C., Lawyer and Energy Advisor to Sen. George McGovern (New York Times; April 17, 1973; p. 24)

Industry must become more concerned about its responsibilities to the American public. There is a difference between self-interest and national interest. -John C. Sawhill, FEA Chief (Newsweek; August 26, 1974; p. 68)

There is not an energy supply crisis (but rather) an energy monopoly crisis. -Ralph Nader (New York Times; April 18, 1977; p. 15)

In his energy speech of October 1977, Carter accused the oil industry of "the biggest ripoff in history" and "potential war profiteering." He commented:

the oil companies apparently want it all. That difference will not encourage increased production of oil, but that difference will come out of the pockets of the American consumers and go into the pockets of the oil companies themselves. (New York Times; October 14, 1977; p. 1)

In support of their profit earnings, Thornton F. Bradshaw, president of the Atlantic Richfield Company, stated:

profits are well within the average for United States industry at a time when the costs of finding new oil and gas are higher than ever. (New York Times; October 14,1977 ; p. 17)

The oil companies then leveled their own accusations. Environmentalists especially were singled out:

* See a later section on public perception of who is to blame for the energy crisis (1974 Edition-The World Almanac and Book of Facts, p. 921). 
Environmentalists are unreasonably delaying the delivery of oil from the north slope (in Alaska) and blocking refinery drilling and nuclear plant construction. -Oil industry official" (New York Times; April 17, 1973; p. 17)

Environmental straitjackets will make inevitable electric energy blackouts-not brownouts-with an accompanying economic collapse. "Utility official" (Newsweek; August 26, 1974; p. 65)

Oil companies heaped blame for energy problems upon government. John E. Swearingen, Chairman of Standard Oil of Indiana, called officials of the U.S. Department of Energy "naive" and "suggested they were incompetent as well" (New York Times; November 16, 1977 ; p. 1).

The oil companies were not alone in blaming government. Louise Dunlap of the Environmental Policy Center responded to President Nixon's proposals to ease pollution standards (to save energy) by claiming that they:

reflected the chaos and incompetence of the Nixon Administration's overall energy policy .... . The Administration and the energy industry partly created this crisis. (New York Times; November 9, 1973; p. 27)

The American public also was exposed to government and elected officials blaming each other:

In my opinion, it is apparent that either of two things happened. Either the federal officials responsible for oil policy in this country displayed an unbelievable level of incompetency, or the petroleum industry itself misrepresents the facts. I personally believe that a combination of both factors was at work. -Senator Thomas J. McIntyre (D.-N.H.) (New York Times; April 17, 1973; p. 17)

This Administration has had a bias against conservation. The bias is strengthening. -"U.S. energy official" (Newsweek; November 4, 1974; p. 77)

The Congress has not passed one piece of energy legislation this year that is of any substance. -Frank Zarb, FEA Chief (Science, Vol. 189; August 15, 1975 ; p. 533)

The U.S. energy problem is a national disgrace. The major beneficiary of inflation is govemment. History will judge the people who have been leading this country as pygmies. -William E. Simon, Secretary of the Treasury (The Saturday Evening Post, Vol. 251, No. 7; October 1976; p. 37)

Former President Nixon commented that "the problem of shortages results less from inadequate resources than from ill-conceived regulation" (New York Times; April 19, 1977; p. 53).

The American public has probably learned by now to take this sort of finger-pointing and buck-passing among its political, business, and scientific leaders more or less in stride. They must be forgiven if they tend to view public pronouncements on energy with a grain of salt. A degree of skepticism and caution about energy-related matters on the public's part seems not only understandable, but reasonable. 


\section{PERCEIVED SERIOUSNESS OF THE ENERGY SITUATION}

Over a quarter (30 studies) of the 115 surveys in our review included items on respondent assessment of the seriousness of the energy situation. Implicit in this issue of how seriously the public perceives the situation is the notion that if the nation's energy supply is defined as being problematic, the public will be more willing to take action on its own and/or to support actions by government (and possibly business) to solve the problem.

Of the 30 studies which examined public perception of the seriousness of the "energy crisis," a large proportion employed virtually the same question. A difference in bias exists between the two ways the question was asked most frequently:

- From what you have seen and heard, how serious would you say the energy shortage is-would you say it is very serious, somewhat serious, or not serious at all? (emphasis added)

- How serious would you say the energy situation in the United States is-very serious, fairly serious, or not serious at all? (emphasis added)

Although the items are not strictly comparable, their phraseology was close enough to warrant aggregating the survey data from them. The aggregation shows no notable differences in response that could be attributed to differences in item wording.

Results from the data aggregation from surveys taken between 1973 and 1978 are summarized in Table $3-1$, and change in opinion over time is graphically depicted in Figure 3-A. Table 3-1 shows that the item on seriousness was asked most frequently during 1974 and 1977. Up until about the end of 1975, about a third of the public defined the energy situation as "very serious," with considerable variability in the data.* Subsequently, the proportion with that definition has risen to about 40 percent, has displayed less variability, and has remained at that level to the present.**

Through 1975, a plurality of respondents indicated that they viewed the energy situation as "somewhat" or "fairly serious," with proportions ranging from 30 to 48 percent. The modal proportion was 45 percent. After 1975 , the proportion in this category dropped somewhat, ranging from 39 to 43 percent of the samples. Almost an equal proportion of respondents from 1976 and on defined the situation as fairly or somewhat serious and very serious. Throughout the entire period, the proportion defining the situation as "not serious at all" remained a minority ranging from a low of 12 percent to a high of 31 percent.

The majority of the public, about 75 to 80 percent, have consistently viewed the energy situation as at least somewhat serious since 1973. As shown in Figure 3-A, after an

\footnotetext{
*Results ranged from a low of 20 percent to a high of 47 percent.

**After 1975, results ranged from a low of 38 percent to a high of 44 percent.

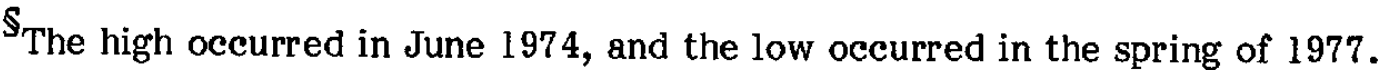


TABLE 3-1

PERCEIVED SERIOUSNESS OF ENERGY SITUATION IN THE UNITED STATESA

\begin{tabular}{|c|c|c|c|c|c|}
\hline \multirow[b]{2}{*}{$\begin{array}{l}\text { Year and } \\
\text { Studyb }\end{array}$} & \multicolumn{5}{|c|}{ Proportion Indicating } \\
\hline & $\begin{array}{c}\text { Very } \\
\text { Serius }\end{array}$ & Seriousc & $\begin{array}{l}\text { Somewhat/ } \\
\text { Fairly } \\
\text { Serious }\end{array}$ & $\begin{array}{c}\text { Not At } \\
\text { Al1 } \\
\text { Seritus }\end{array}$ & $\begin{array}{c}\text { Don't } \\
\text { Know/No } \\
\text { Opinion }\end{array}$ \\
\hline \multicolumn{6}{|l|}{1973} \\
\hline$\overline{\text { Apr. }}[141,234]$ & $47 \%$ & $(77)$ & 30 & 16 & 7 \\
\hline Sep. $[141]$ & 28 & (73) & 45 & 21 & 6 \\
\hline Nov. $[141,240]$ & 50 & $(87)$ & 37 & 9 & 4 \\
\hline \multicolumn{6}{|l|}{1974} \\
\hline$\overline{\operatorname{Jan}}[141,240]$ & 34 & $(79)$ & 45 & 17 & 4 \\
\hline Feb. $[141,240]$ & 31 & $(72)$ & 41 & 22 & 6 \\
\hline Feb.-Mar. $[207]^{d}$ & 20 & $(68)$ & 48 & 26 & 6 \\
\hline $\operatorname{Mar} .[132,134]$ & 23 & $(68)$ & 45 & 29 & 3 \\
\hline Mar. $[141,240]$ & 22 & $(66)$ & 44 & 28 & 6 \\
\hline Apr. $[141,240]$ & 23 & $(68)$ & 45 & 28 & 4 \\
\hline Apr.-June [260]e & -- & $(58)$ & - & $-\infty$ & $\ldots$ \\
\hline June $[141]$ & 22 & $(66)$ & 44 & 31 & 3 \\
\hline \multicolumn{6}{|l|}{ July or Aug. } \\
\hline$[141,240,249] \mathrm{f}$ & 26 & $(67)$ & 41 & 30 & 3 \\
\hline Aug.-Sep. [137] & 31 & $(--)$ & -- & -- & -- \\
\hline Oct. [132] & 33 & $(79)$ & 46 & 16 & 5 \\
\hline \multicolumn{6}{|l|}{1975} \\
\hline$\overline{\text { Dec.-Jan. [ }} 131]$ & 36 & (83) & 47 & 13 & 4 \\
\hline Jan. [249] & 44 & $(--)$ & -- & -- & - \\
\hline Jan.-Feb. [ 133$]$ & 36 & $(82)$ & 46 & 14 & 4 \\
\hline
\end{tabular}

aprototypical item phrasing: "From what you have heard or read, how serious would you say the energy shortage is--would you say it is very serious, somewhat serious, or not serious at al1?" and "How serious would you say the energy situation is--very serious, fairly serious or not serious at all?"

bSample national unless otherwise noted.

cusually sum of "very serious" and "somewhat serious" responses.

$\mathrm{d}_{\text {Los }}$ Angeles County, California sample.

edetroit, Michigan sample.

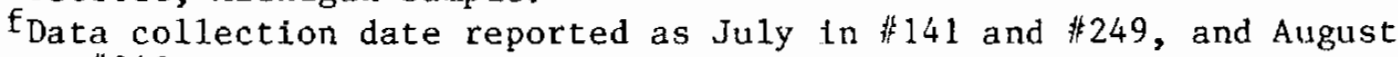
in $\|^{240 .}$ 
TABLE 3-1 (continued)

\begin{tabular}{|c|c|c|c|c|c|}
\hline $\begin{array}{l}\text { Year and } \\
\text { Study }\end{array}$ & $\begin{array}{c}\text { Very } \\
\text { Serious }\end{array}$ & Seriousc & $\begin{array}{l}\text { tion Indic } \\
\text { Somewhat/ } \\
\text { Fairly } \\
\text { Serious } \\
\end{array}$ & $\begin{array}{c}\frac{\text { ating }}{\text { Not At }} \\
\text { A11 } \\
\text { Serious }\end{array}$ & $\begin{array}{c}\text { Don't } \\
\text { Know/No } \\
\text { Opinion } \\
\end{array}$ \\
\hline $\begin{array}{l}\text { Feb. -Mar. [134] } \\
\text { Apr. }[141] \mathrm{g} \\
\text { Apr. }[242]\end{array}$ & $\begin{array}{l}37 \\
38 \\
24\end{array}$ & $\begin{array}{l}(79) \\
(78) \\
(72)\end{array}$ & $\begin{array}{l}42 \\
40 \\
48\end{array}$ & $\begin{array}{l}18 \\
18 \\
25\end{array}$ & $\begin{array}{l}3 \\
4 \\
3\end{array}$ \\
\hline $\begin{array}{l}\frac{1976}{[104]} \\
\text { July [141] }\end{array}$ & -- & $\begin{array}{l}(71) \\
(80)\end{array}$ & $\overline{40}$ & $\overline{17}$ & -- \\
\hline $\begin{array}{l}\frac{1977}{\text { Before Feb. }[245]} \\
\text { Apr. }[218,220,310] \\
\text { Apr.-May }[218,310] \\
\text { June }[220,310] \\
\text { Aug. [220,310] } \\
\text { Sep.-Oct. }[310] \\
\text { Nov. }[175,310]\end{array}$ & $\begin{array}{l}-- \\
41 \\
44 \\
40 \\
38 \\
40 \\
41\end{array}$ & $\begin{array}{l}(82) \\
(80) \\
(85) \\
(82) \\
(81) \\
(80) \\
(83)\end{array}$ & $\begin{array}{l}-- \\
39 \\
41 \\
42 \\
43 \\
40 \\
42\end{array}$ & $\begin{array}{l}-- \\
16 \\
12 \\
13 \\
13 \\
16 \\
14\end{array}$ & $\begin{array}{l}-- \\
4 \\
3 \\
6 \mathrm{~h} \\
6 \\
4 \\
3\end{array}$ \\
\hline$\frac{1978}{\text { Apr. }}[261]$ & 41 & $(80)$ & 39 & 15 & 5 \\
\hline $\begin{array}{l}\text { b Sample national unle } \\
\text { c Usually sum of "very } \\
\text { gThese data are repor } \\
\text { period, April } 1975 . \\
\text { knowing which are th } \\
\text { h }_{\text {Data reported sum to }}\end{array}$ & $\begin{array}{l}\text { otherwis } \\
\text { erious" a } \\
\text { d by Harr } \\
\text { They are n } \\
\text { accurate } \\
01 \text { percen }\end{array}$ & $\begin{array}{l}\text { e noted. } \\
\text { nd "somewh } \\
\text { is for the } \\
\text { otably dif } \\
\text { figures. } \\
\text { t. }\end{array}$ & $\begin{array}{l}\text { t serious" } \\
\text { same data } \\
\text { erent, but }\end{array}$ & $\begin{array}{l}\text { response } \\
\text { collectio } \\
\text { we have }\end{array}$ & no way of \\
\hline
\end{tabular}




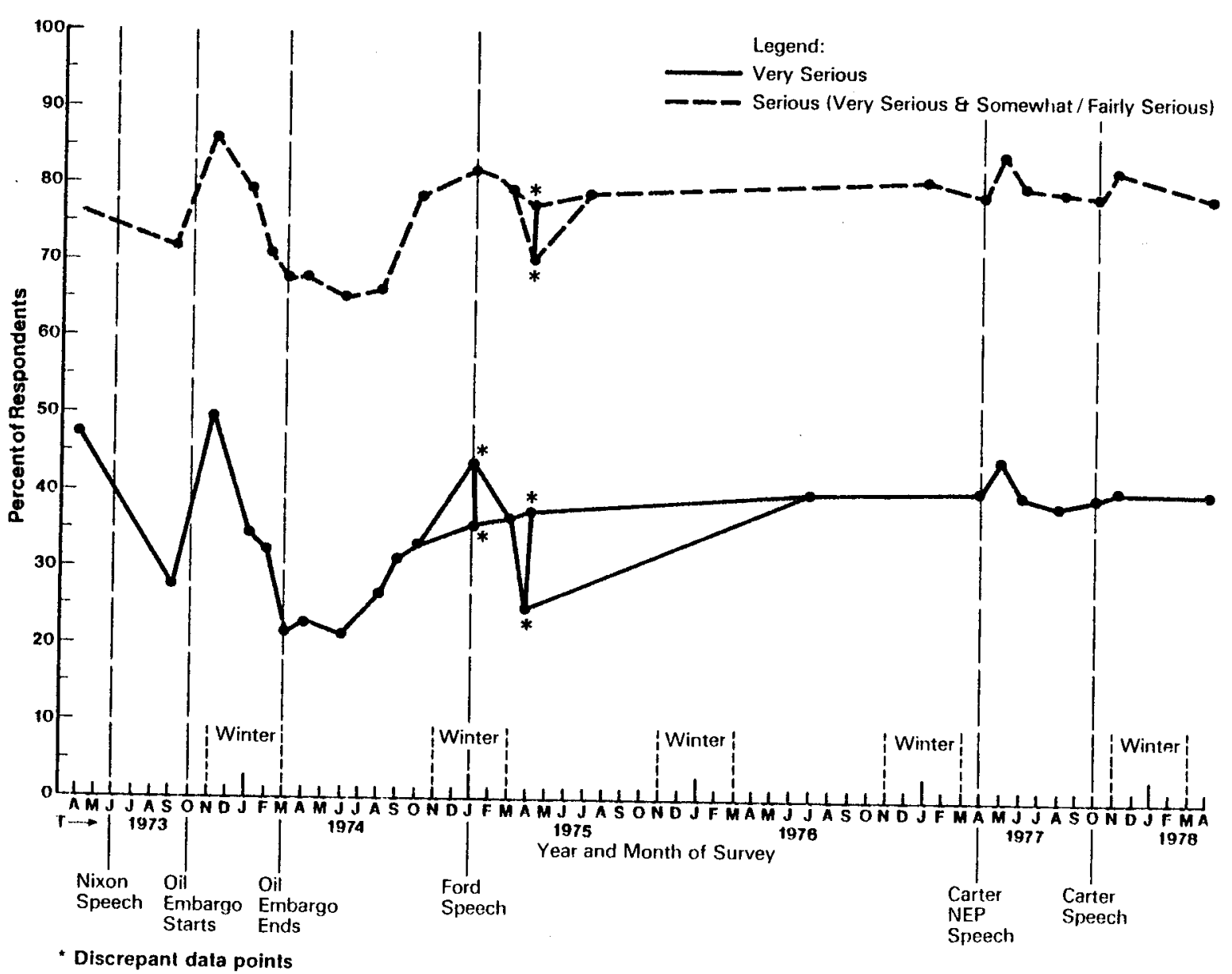

Source: Studies 104, 132, 133, 134, 137, 141, 175, 207, 218, $220,234,240,245,249,260,261,310$.

Figure 3-A. PERCEIVED SERIOUSNESS OF THE ENERGY CRISIS 
initial peak of concern in late 1973, public concern dropped during 1974* and began a slow increase in 1975. The small peak recorded in May 1977 followed President Carter's address.**

Other data bearing on the perception of the seriousness of the energy situation were also collected between 1973 and 1977 using items addressing the issue in various ways. Most of these items dealt with whether the public believed there was an energy shortage. Findings on these items reflect a rather different picture than that suggested by definitions of the seriousness of the situation.

Four national surveys reported data on public perception of energy shortages. In 1974, two Roper surveys asked respondents to look at a list of products and "call off the ones you have heard are or might soon be in short supply" [160]. During August, 81 percent identified oil as in short supply, and 68 percent identified electricity. These proportions increased in December to 93 and 82 percent, respectively. These were the highest proportions reported for perceived shortages of any survey in our review. A Harris poll in the spring of 1975 reported perceived "shortages today": oil, 39 percent; solar energy, 37 percent; nuclear energy, 32 percent; electricity, 32 percent; and coal, 16 percent [141]. However, Harris reported in November 1975 that 65 percent thought oil was then in short supply, and 55 percent thought the same about natural gas [231].

More localized samples reported somewhat fewer respondents believing that shortages existed. In parts of Texas during 1974, 28 percent of survey respondents thought there was "definitely" an energy crisis, 43 percent said "there seems to be one," and 21 percent thought there was not [116]. There seemed to be polarization or confusion among the public, at least in Texas, about whether or not there actually was an energy shortage. ${ }^{\$}$

In Michigan, 63 percent of a 1976 sample said the nation had "an energy-related problem," compared to 28 percent who thought not [119]. But in Ohio one year earlier, when respondents were asked whether there was a shortage of electricity at that time, 13 percent said yes and 77 percent said no [122]. These findings could be reflective of local conditions such as gasoline prices and utility rates at the time the surveys were taken. However, no notable differences by region were found on level of concern or judgment of the seriousness of the energy crisis [154, 175, 218].

During 1973, a Harris survey found 35 percent agreeing that "the federal government will know what's going on and will not allow an energy crisis to take place," with 43 percent in disagreement and 22 percent unsure [234]. This finding suggests a majority lack of certainty that the government is capable of preventing an energy crisis. Furthermore, a survey in parts of Illinois during 1977 found 71 percent thought most people did not have "a realistic view of our energy situation" [108].

On a related item, "How serious would you say the need is to save energy?", a national

*This was probably related to the availability of gasoline which followed the scarcity of 1973.

**The data points for January and April 1975 recorded in Figure 3-A display inconsistent findings. There may have been an error in data or reporting (see footnotes $e$ and $f$ for Table 3-1).

$\S_{\text {Month of data collection not reported. }}$

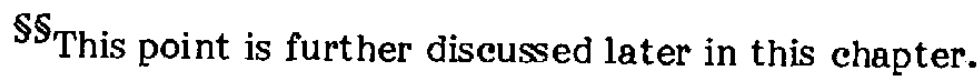


survey reported in 1976 that almost half thought it "very serious" and 39 percent "somewhat serious" [130].

In summary, after considerable fluctuation in public opinion between 1973 and 1975, during the first months following the oil embargo, about 80 percent of the public has come to define the energy situation in the United States as serious, with about two-fifths defining it as very serious. However, some skepticism about the energy problem remains, as will be described in the next section.

\section{ENERGY CRISIS: "REAL" OR "CONTRIVED"?}

At the same time that various credible sources were asserting the reality of the energy crisis, various others were asserting the opposite with equal authority. Some believed the energy problem was a situation contrived by segments of "the establishment" for political or economic gain.

From 1974 through 1978 several survey researchers included items in their studies to assess public opinion on whether the energy crisis was perceived as "real" or "contrived." Data from these surveys and the actual items used to assess opinion are summarized in Table 3-2. Items were not strictly comparable, but results were relatively consistent, enabling a summary of the data.

The public's tendency early on in the energy situation (if 1973 is marked as the beginning) was to view the problem as contrived. The proportion of those who thought the energy shortage was contrived decreased from about 75 percent early in 1974 to about 40 percent late in 1977 (based on surveys from national samples). The pattern of findings from local samples scattered around the country does not display a similar trend, but shows sizable minorities (in the range of two-fifths) indicating a contrived energy problem.

Conversely, national sample respondents defining the energy shortage as "real" increased over time from 18 percent in early 1974 to 56 percent in late 1977. As time passed and events relevant to energy occurred, more of the public began to define the energy crisis as a problem, not to be laid at the doorstep of institutional conspiracy. Nevertheless, a sizable proportion still believed that institutions created the problem.

Roper collected longitudinal data on an item concerning perception of the gasoline and oil shortage [147]. These data are presented in Table 3-3 and Figure 3-B. The item used resulted in a different response than the one reported in the preceding section concerning shortages of products. Using a forced-choice item directly concerning the shortage, and presenting options as to whether a shortage actually existed, Roper found about a third of the respondents in 1974 thought the oil shortage was "real," and this increased to over half by May 1977. The most recent finding on this item is that almost half (49 percent) still believe the oil shortage is real. The proportion believing an oil shortage never actually existed has decreased from over half in 1974 to about a third in 1977.

These findings suggest some discrepancies in public opinion between whether they view the energy situation as serious and whether they believe it is real. Denial that a serious problem exists is often an initial response by an individual to a sudden shock. The response may protect him for a time until he recovers from the shock and can begin to address possible alternative solutions. Short-term denial may be functional, but if prolonged, denial can be a counterproductive defense mechanism. A certain amount of denial could have been operating in American society after the initial shock of the Arab 


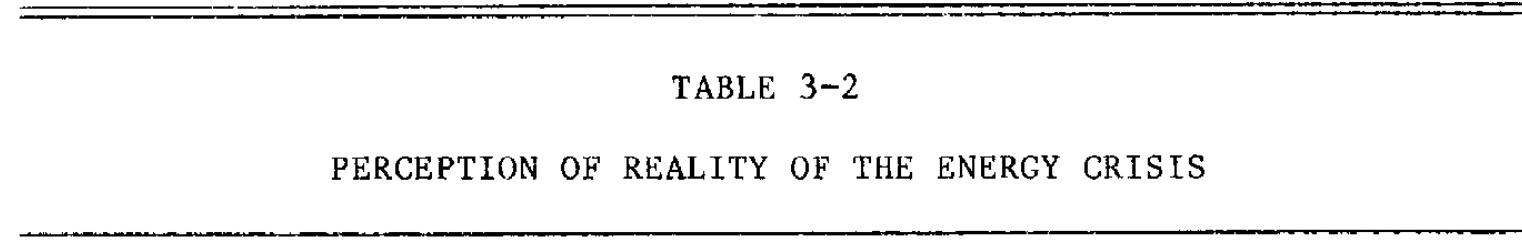

In your opinion, is the current energy shortage real or contrived? (Paraphrased as a generic item.)*

\section{Nationa1 Samples}

Feb. 1974 [162]

Apri1 1974 [132]

May 1974 [147]

Nov. 1974 [132]

Nov. 1974 [147]

June 1975 [147]

Nov. $1976[147]$

May 1977 [147]

Nov. 1977 [147]

Loca1 Samples

Texas, 1974 [116]

Detroit, 1974 [260]

Phoenix, Kansas City, Minneapolis, 1974 [302]

Michigan, 1974 [106]

Colorado Springs, 1974 [105]

Wyoming, 1975 [205]

Texas, 1975 [181]

Arizona, 1976 [201]

Michigan, 1976 [106]

Colorado Springs, 1976 [104]

Chicago, 1977 [127]

Proportion Responding Shortage Shortage other/ Real Contrived Unsure

$18 \% \quad 73 \quad 9$

$25 \quad 66 \quad 9$

$41 \quad 53 \quad 6$

$\begin{array}{lll}40 & 51 & 9\end{array}$

$39 \quad 54 \quad 7$

$44 \quad 47 \quad 9$

$44 \quad 46 \quad 10$

$61 \quad 33 \quad 6$

$56 \quad 39 \quad 5$

*Actual item wording of each study, where provided, was:

162: "Some people say there is a real shortage of gasoline and fuel oil because demand has outrun the supply. Others say there really isn't a shortage of gasoline and fuel oil and big companies are holding it back for their own advantage. What do you think--that there is or is not a real shortage of gasoline and oil?" 
TABLE 3-2 (continued)

132: "In your opinion, is the current energy shortage real, or do you think it is contrived?"

147: "Here is a 1ist of statements about the gasoline and oil shortage (card shown respondent). Which one of those statements comes closest to expressing your opinion? One statement of four was: "There never was any real oil shortage--it was contrived for economic and political reasons." (See Table 3-3 for other statements.)

116: Agree or disagree: "Shortage is part of a political scheme."

260: Item had to do with whether the energy crisis was "mostly" or "all phony," or "entirely real."

302: Item had to do with whether the energy crisis was "real, partially contrived by energy companies or government, or completely contrived."

106: (1974) Item summary: "Do you think there is an energy problem in this country?"

105: Do you believe the energy crisis is: "Fake, we have plenty of energy; Real, but won't directly affect me; Serious, we have to find new energy sources?"

205: "Do you think that the United States is in an energy crisis?"

181: Agree or disagree: "The United States has an energy problem."

201: Agree or disagree: "There is a genuine energy crisis; it is not contrived."

106: (1976) Agree or disagree: "The 'energy crisis' was a 'put on' to raise prices of fuels."

127: Agree or disagree: "The gasoline energy crisis is a phony issue. There is really plenty of gasoline available." 
TABLE $3-3$

PERCEPTION OF OIL SHORTAGE OVER TIME

Here is a list of statements about the gasoline and oil shortage (card shown respondent). Which one of these statements comes closest to expressing your opinion?

\begin{tabular}{|c|c|c|c|c|c|c|c|}
\hline \multirow[b]{3}{*}{ Response } & \multicolumn{7}{|c|}{ Proportion Indicating } \\
\hline & \multicolumn{2}{|c|}{1974} & \multirow{2}{*}{$\begin{array}{l}1975 \\
\text { June }\end{array}$} & \multirow{2}{*}{$\begin{array}{l}1976 \\
\text { Nov. }\end{array}$} & \multicolumn{2}{|c|}{1977} & \multirow{2}{*}{ May } \\
\hline & May & Nov. & & & May & Noy, & \\
\hline $\begin{array}{l}\text { There is a very real oil short- } \\
\text { age and the problem will get } \\
\text { worse during the next } 5 \text { to } 10 \\
\text { years. }\end{array}$ & $21 \%$ & 17 & 26 & 26 & 40 & 33 & 32 \\
\hline $\begin{array}{l}\text { There is a real oil shortage } \\
\text { but it will be solved in the } \\
\text { next year or two. }\end{array}$ & 12 & 12 & 11 & 11 & 15 & 14 & 8 \\
\hline $\begin{array}{l}\text { There was a short-term problem, } \\
\text { but it has been largely solved } \\
\text { and there is no real problem } \\
\text { any longer. }\end{array}$ & 8 & 9 & 7 & 8 & 6 & 9 & 9 \\
\hline $\begin{array}{l}\text { There never was any real oil } \\
\text { shortage--it was contrived for } \\
\text { economic and political reasons }\end{array}$ & 53 & 54 & 47 & 46 & 33 & 39 & 45 \\
\hline None & 2 & 1 & 2 & 2 & 1 & 1 & 1 \\
\hline Don't know & 4 & 6 & 7 & 8 & 5 & 4 & 4 \\
\hline Roper Reports, 7 & -5 & June 1 & $78, \mathrm{Tr}$ & he Rope & $\mathrm{r}$ Or $\varepsilon$ & , , N.Y. & \\
\hline
\end{tabular}




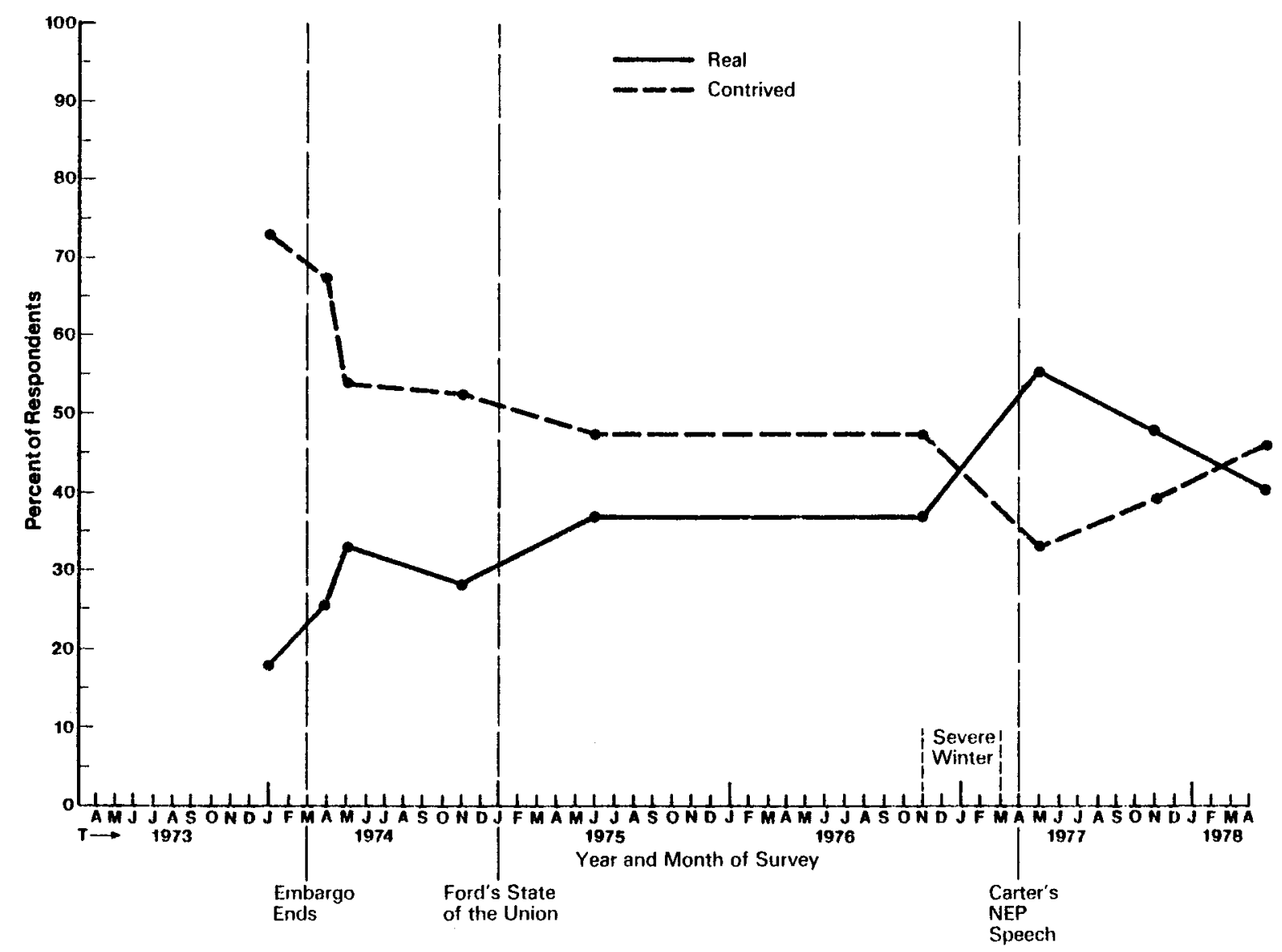

Source: Studies 132, 147, 162.

Figure 3-B. PROPORTION RESPONDING THE OIL SHORTAGE IS REAL VS. CONTRIVED 
oil embargo and its effects during 1973, and this could be reflected in the survey findings. People seemed willing to say the energy situation was serious, but were having a more difficult time saying it was real.

\section{ATTRIBUTION OF CAUSE AND RESPONSIBIIITY}

Before potential solutions to problems can be assessed, causes must be analyzed and responsibility assigned. If causes of the energy problem are perceived as the responsibility of institutions in the society rather than of individual actors, there is little an individual may believe he can do directly to change the situation in the desired direction. To the extent that individuals attribute responsibility to themselves, they may believe they can take action to ameliorate the situation.

The data from several surveys asking the American public what institutions and persons they blamed for the energy situation are summarized in Table 3-4. Since item wording significantly affected the proportion attributing blame to any particular group, these data are grouped by the type of item used to measure response. Items in general were forced choice rather than open-ended.

When an item was designed to elicit a response on who was most to blame for the energy problem, a smaller proportion indicated each potential group than when the item permitted designating a level of responsibility to each group in a list of response categories, or permitted a Likert-type response to statements attributing blame or responsibility. Findings were further affected by differences in the lists of response categories themselves; for example, some lists included the President or the utilities, while others excluded these response possibilities. Given this variety of item wording, a considerable degree of caution is necessary to interpret properly what these survey data reveal about the public's attribution of blame for the energy situation.

Data on the question of blame or responsibility, summarized in Table 3-4, are organized by these three types of item wording. When wording was used necessitating a forced choice of "most responsible" from a list of possibilities, oil companies received the most public blame. Pluralities of a third or more held oil companies most responsible, followed by Congress specifically or "the government" generally. A few blamed the Administration or the President, OPEC countries, the American public, "big business," and environmentalists.

When the item was worded to allow attribution of greater or lesser degrees of responsibility to various groups, oil companies still received a major share of the blame, with sample proportions ranging from 57 percent to 83 percent indicating this response.

Close behind the oil companies in attributed responsibility were Congress and the federal government. Some survey data from 1973 and 1974 showed majorities of from 63 to 75 percent indicating this response. The data are inconsistent however, since Roper, using longitudinal techniques, found proportions ranging around 25 percent of samples blaming Congress in 1974, 1975, 1976, and 1977. For those surveys permitting respondents to indicate whether the responsible group had "major blame" or just "minor blame" in the situation, nearly everyone held oil companies and the government at least somewhat responsible. One study in 1975 asking an open-ended question on blame found a plurality (25 percent) blaming oil companies. The government (23 percent) and the administration (19 percent) were close behind [213] . 


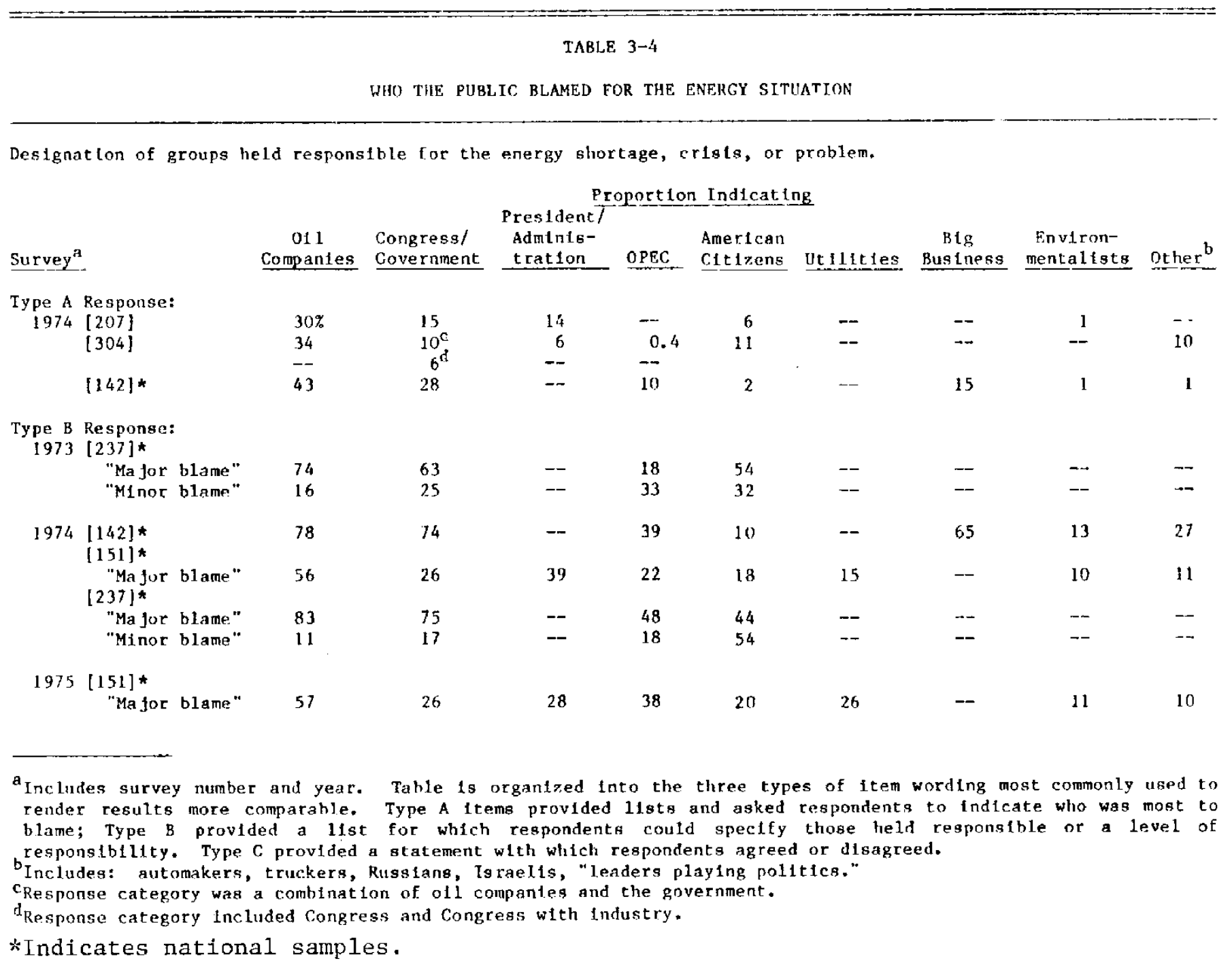


TABLE, 3-4 (cont Inued)

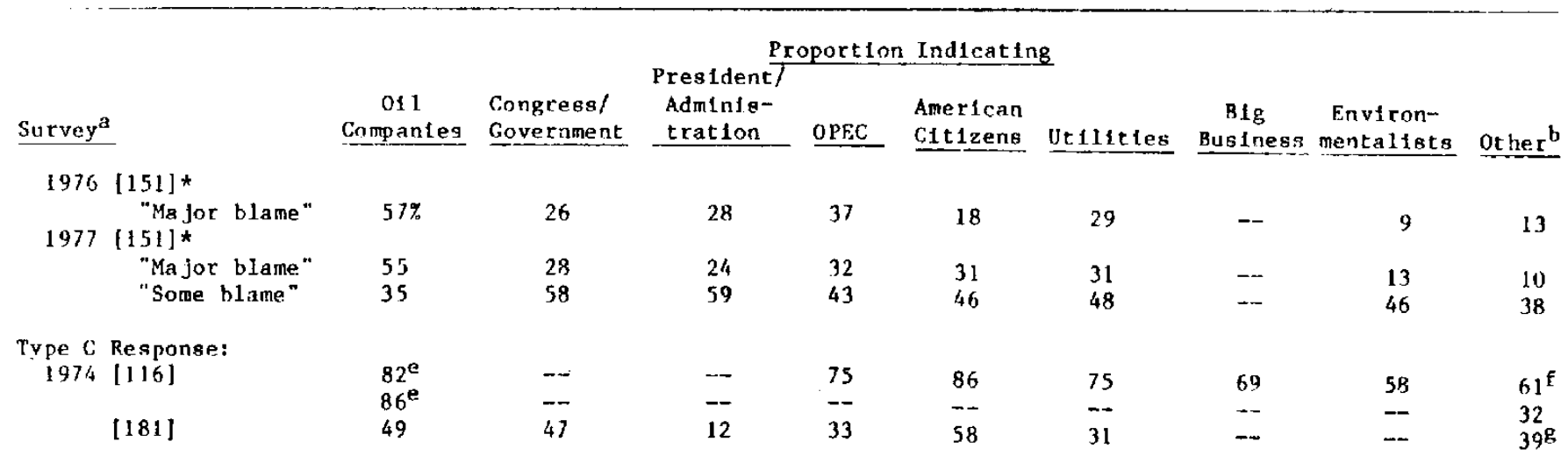

f Data reported both ways.

Automakers.

g Natural gas companies.

* Indirates nat conal samples 
Other groups held responsible by minorities of various samples included the list mentioned earlier, but the findings are so diverse by proportion of sample attributing blame to each group that no overall conclusions can be reached. For example, proportions blaming American citizens (using the same type of questions) varied from 10 to 54 percent (see Table 3-4). A survey using the second type of response found that attribution of blame to oil companies rose from 74 percent in 1973 to 83 percent in 1974 [237].

The extent of blame attributed to groups is too disparate among the surveys to discern a trend. A 1975 survey, using the first type of item (i.e., respondents indicated who was most to blame from a list), reported that attribution of blame to oil companies dropped 13 percentage points from the previous year (from 27 to 14 percent). Roper collected data on this question in 1974, 1975, 1976, and 1977. The findings did not indicate a significant change in the number of people blaming the oil companies during this period (see Figure 3-C) [151]. However, another study, using the second type of item, found the proportion blaming Congress and the government had risen over 10 percentage points (from 63 to 75 percent) between 1973 and 1974 [237].

Dissatisfaction with the American public's efforts to conserve energy increased from 19 percent in March 1974 to 44 percent in February 1975 [133]. The one study which included utilities in the list of those who could be held responsible (type $B$ question), found an increasing proportion choosing utilities over time. The proportion was 15 percent in 1974, 26 percent in 1975, 29 percent in 1976, and 31 percent in 1977 [151]. These results were collected from a national sample using item replication over four years. The data from this study are portrayed graphically in Figure 3-C.

Some survey data were collected about why the public blamed these various institutions and persons. Generally, when responsibility was attributed to a certain group, the main problems identified involved morality (greed, dishonesty), incompetence, or both. Normative violations were involved in either case: institutions or persons were perceived as not performing to the standards of integrity and excellence expected of them by the American public. Nor did the public exonerate itself, accepting some of its own responsibility for wasteful use of energy.

As noted, oil companies received the greatest share of blame for the energy crisis, particularly with regard to gasoline shortages. One national survey found a plurality of 20 percent who felt "the large oil companies are conspiring to raise prices through scaring the public" [234]. Another reported 55 percent giving as a "very important reason" for the energy crisis the withholding of oil and natural gas from the market by oil companies [233]. Respondents in a Texas survey overwhelmingly agreed that oil companies were trying to make greater profits [116]. A sample of Texas and Arizona residents blamed the energy problem on oil companies (blamed by 49 percent), natural gas companies (by 39 percent), and utilities (by 31 percent) charging unnecessarily high prices for energy [181].

Researchers sampling in Colorado during 1977 used an attitude item favorable to the oil companies: "The oil companies are doing all they can to help solve the energy problem and should not be criticized so much." Nineteen percent of the sample agreed; 65 percent disagreed [120]. About 40 percent of a Michigan sample said the oil companies wanted to raise prices for gasoline, and six percent blamed them for poor management, control, and distribution of gasoline [119]. The same survey reported 20 percent gave reasons for perceived future energy shortages related to oil industry monopoly, greed, profit-taking, and the holding-back of supplies. Virtually everyone in another Michigan 


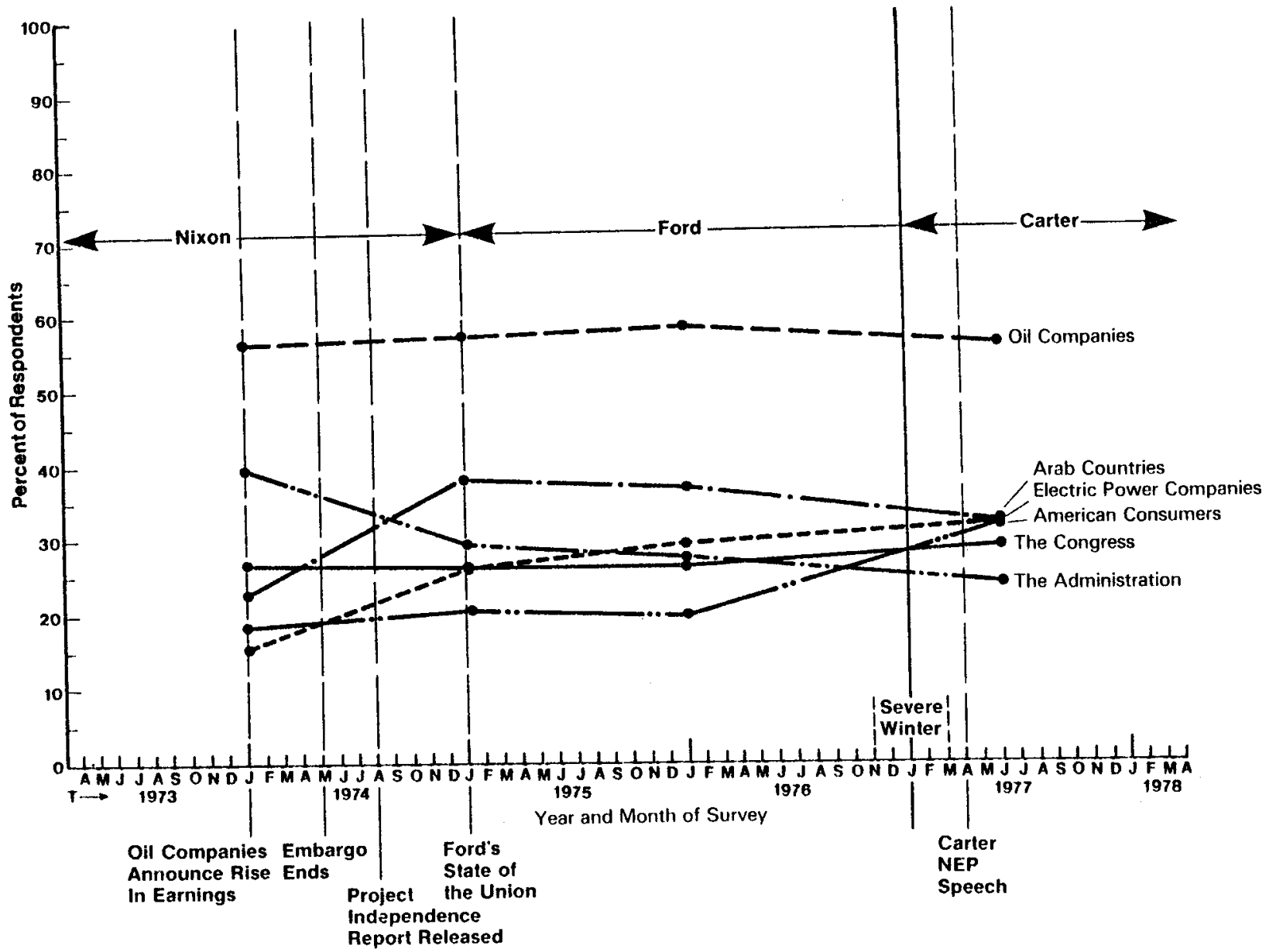

Source: Study 151

Figure 3-C. ATTRIBUTION OF MAJOR BLAME FOR THE ENERGY CRISIS 
sample blamed "manipulation by oil companies" for the energy problem [106]. Researchers in Los Angeles County reported: "In general, Los Angeles residents believed the oil companies were holding back oil in order to increase profits" [207].

A national survey asked respondents how they would "rate the job being done by the oil companies in handling the fuel shortage" [142]. About half the sample rated it as "poor" or "very poor," and 13 percent as "pretty good" or "very good." of those indicating oil companies were doing a poor job, most felt the companies were holding back supplies to create shortages. Additionally, respondents blamed them for making "windfall profits," not investing enough in finding new sources of oil, and not distributing supplies in a fair way.

In Los Angeles, respondents blaming President Nixon for the energy crisis linked his responsibility to his political indebtedness to oil companies [207]. They blamed Nixon for incompetence, lack of control, "political payoff," and possible fraud. Researchers cited such comments as: "The oil companies donated so much money to his re-election that he has no control over them," "He had a price to pay the oil companies as they gave him millions of dollars for his campaign," and "He has money now because the oil companies have paid him off."

Muchinsky (1976) reported that a sample of lowa college students surveyed in the spring of 1974 held oil companies primarily responsible for the energy crisis by withholding petroleum supplies to increase profits and reduce competition. Muchinsky's sample of petroleum company executives in Connecticut (part of the same study) blamed the federal government as primarily responsible for the crisis by "handcuffing" the petroleum industry with taxation, price regulation, and import controls.

In a qualitative study of public attitudes toward the energy crisis, Angell and Associates (1975) found results similar to those of the national and local surveys. They offered this summary of their findings:

While the perception of the energy situation as serious was not uncommon, it was assumed to be due primarily to reasons relating to its monetary impact and to the public's sense of being exploited by powers that are unscrupulously insensitive to its needs. The majority of the respondents were aware that energy, as it is known today, is likely to 'run out eventually,' and that legitimate energy shortages exist. However, very few of the respondents felt that either the immediate or the eventual energy shortages are critical.

The public appears to have interpreted the relationship between higher prices and the availability of more energy as proof that the shortages are a result of a ploy perpetrated on the American public by the Middle Eastern countries and the oil companies as a means of increasing their revenues. The higher earnings reported by the oil companies during the same period only served to reinforce this belief. In other words, while the reported shortages may be legitimate, the relationship of price to availability renders the entire situation suspect (pp. 21-22).

ORC (1974d) reported a majority of 67 percent indicating as an important reason for the energy shortages that "oil companies did not anticipate the growth in demand for energy and did not prepare for supplying it." Half of another national sample agreed that "the oil companies didn't prepare" [137]. Majorities of a national sample felt the following 
were "very important" reasons for the energy crisis: (1) "Oil companies withholding oil and natural gas from the market," and (2) "A reluctance on the part of the oil companies to drill for more gas and oil unless prices are raised" [233].

Oil companies are held by the public as especially responsible for a stable and plentiful supply of gasoline at reasonable prices. When this supply comes into question, oil company competence is then called into question. Because the energy problem initially manifested itself in a shortage of gasoline supplies across the nation, with some power failures linked to oil-powered electricity generating plants, oil companies emerged as the primary targets of public blame.

The federal government, and Congress specifically, also received a share of blame. Researchers in Los Angeles County found that those blaming the federal government gave as their reasons: (1) the government should have anticipated the shortage, (2) it should have controlled the oil companies, and (3) it should have prevented or ameliorated the energy crisis [207]. A national sample expressed similar reasons in explaining "poor" or "very poor" ratings on the job being done by the federal government in "handling the fuel shortage" [142]. Reasons given were that the government (1) is letting the fuel companies raise prices too high, (2) is not doing anything to solve the shortage, (3) is lying - there is no shortage, (4) knew beforehand that we would soon be having a shortage but did nothing, and (5) is in conspiracy with oil companies.

Over half of another national sample blamed the energy shortage on the lack of a "national energy policy by government" [137]. This finding was similar to that from a different national sample reporting a majority indicating "the federal government did not take the energy shortage seriously and did not establish a national energy policy" [139]. A small percentage of a Michigan sample attributed the nation's energy problems to "scare by govemment," but the meaning of this response category is unclear [119]. A few identified the problem as "political," with the "government holding back"-presumably holding back oil supplies for some reason. The same sample also identified waste of energy by the government, foreign problems, and lack of government planning, programs and information. Almost half of another national sample thought the federal government was doing a poor job in "meeting its responsibility to conserve our supplies of natural resources" [139]. Another sample in Texas identified the following as possible causes of the energy crisis; "the United States has exported too many fuel supplies" (74 percent), and "price regulation" (70 percent). The same study reported that a majority, 51 percent, agreed that the energy "shortage is part of a political scheme," while 49 percent disagreed. However, the majority (59 percent) disagreed that the "shortage is actually a political move by government," and 41 percent agreed [116]. As noted earlier, a sample of oil company executives blamed the federal government as responsible by virtue of taxation of the oil industry, price regulation, and import legislation (Muchinsky, 1976).

These findings on perceived governmental responsibility in the energy situation suggest a preferred role for government in preventing monopolistic control of energy sources and in assuring adequacy of energy supplies at reasonable prices.

The American public was perceived to be partially responsible for the energy situation through its wasteful use of energy, as reported in several surveys [106, 119, 122, 133, $134,137,139,205,233,234,246]$. Waste was seen as occurring through the use of too many cars and large cars, a lifestyle with excessive conveniences and appliances, "too many inefficient consumer goods," lack of conservation practices, and apathy and 
selfishness.* About 80 percent of a Michigan sample disagreed with the statement, "The citizens of the United States are entitled to use as much energy as they can afford" [106]. Similarly, 64 percent of a national sample agreed that "consumers do not have the right to use as much energy as they want and can pay for" [133].

A survey in Ohio found the largest portion of respondents (38 percent) agreeing that electricity was being wasted only in nonresidential use. About a third felt it was not being wasted at all, and 11 percent felt both residential and nonresidential users were wasteful. Nine percent felt that electricity was being wasted in residential use only [122]. This finding appears to be consistent with a survey in Lansing, Michigan, where 46 percent agreed with the statement: "The amount of energy all American families could save is unimportant compared to the amount of energy that government and industry could save" [106]. Business, industry, and government were also implicated in inefficiency and waste in energy use in a few other studies $[137,139,199]$.

The findings suggest that energy consumption in the United States is seen as excessive by the majority of the public. Widespread sentiment seems to be that the American public and its institutions can and should cut back on energy use. This does not mean that they will do so, for other factors are involved beyond this sentiment.

The oil exporting countries of the world (OPEC) were also seen as responsible for the nation's energy problems, as reported in several studies. About half of a national sample thought "the high prices charged by the OPEC countries" was a very important reason for the energy crisis [233]. A small minority in a Michigan survey mentioned the decrease in Arab imports and the oil embargo [119].** About 75 percent in a Texas survey mentioned the Arab oil embargo [116]. Angell and Associates (1975) reported from their qualitative study that while the Middle Eastern countries were blamed for exercising their power with the oil embargo in 1973 , they were also seen as having the right to do so, although the prices they charged were considered "outrageous." Over half of a national sample surveyed in early 1974 felt that lifting of the Arab oil embargo would have a short-term positive effect on the energy shortage, while a fifth thought it would "go a long way toward solving it" [142]. In general, some resentment toward OPEC countries was expressed through the surveys, but national institutions came in for a much larger share of the overall blame for the energy crisis.

Big business in the United States also came in for a small share of the blame. American automakers were held possibly responsible by 61 percent of a Texas sample in 1974 [116]. Automakers are thought by many to be responsible for energy shortages because they enthusiastically produce "gas-guzzler" cars, and resist producing smaller cars. In fact, 51 percent of a national sample thought "the production of too many gas guzzling automobiles" was a very important cause of the energy problem [233]. Some observers felt that interlocking corporate directorships among the large petroleum companies and automobile manufacturers led to defense of the status quo and resistance to changes resulting in reduced gasoline consumption. About a third of the same sample thought American truckers were blameworthy. The Michigan sample generated a few responses

*Also mentioned by sample minorities were the following: buildings, stadiums lighted when not in use; too many lights; stores, shopping malls open longer hours, extra days; buildings too hot or too cold; advertising signs; excessive lighting of streets, highways, parking lots; excessive use of residential lighting and appliances.

**This was an open-ended item. 
(11 percent) that industry was stockpiling and otherwise contributing to energy shortages [119]. The business community was seen as doing a poor job of conserving energy by 40 percent of a national sample, and an "average" job by 42 percent [139]. A bare majority of national samples surveyed during 1974 agreed that "industry has developed too many consumer products that do not use energy efficiently" [139].

Environmentalists were blamed in two samples for attempting to control pollution. About 60 percent of a Texas sample blamed "efforts of environmentalists to prevent pollution" [116]. Almost half of a national sample during 1974 agreed that a very important reason for the energy shortage was as follows: "The demands for a cleaner environment have resulted in such things as pollution control devices on cars that use more gas and regulations that have made it difficult to build refineries and drill for oil off our coastlines" [139].

However, not all respondents blamed institutions or persons. Some saw the energy problem as the result of factors having complex interactions among many segments of the society. Responsibility for these factors was not laid at the doorstep of any one group, but was viewed as society-wide. These factors fall under the general rubric of what is to blame for the nation's energy situation.

Some blamed the situation on an increasing scarcity of fossil fuels. In one study "finite resources" was mentioned more often as a cause of the problem than the action of institutions [104]. The scarcity of fossil fuels was mentioned by about 80 percent of two Michigan samples [106], and by 54 percent of a national sample [233]. This factor was also mentioned in a 1973 national survey by 15 percent ("our natural resources are running low") [234] and by 47 percent of a 1977 national survey pointing to a decline in domestic production of oil and natural gas [233].

Two national surveys conducted at about the same time used a forced-choice item to assess public perception of whose responsibility depletion of natural resources should be $[137,139]$. About 45 percent of each sample, the plurality, thought it was the public's responsibility; 20 percent in one sample and 31 percent in the other thought the federal government was most responsible; six percent of each sample attributed responsibility to the business community; about 18 percent thought all three should be responsible.

Population growth and overpopulation were also blamed for the energy problem in three surveys [ORC, 1974; 106; 137]. The dependence on energy of the American lifestyle was also criticized: over half of a national sample identified as a very important cause "the high standards of living in this country" [233], and half said a cause was "the fact that, with only six percent of the world's population, the United States consumes 32 percent of the world's energy" [233].

Other miscellaneous factors, believed by usually small sample minorities in various studies to play a causative role, were:

- lack of knowledge, lack of adequate technology [106, 119];

- expansion of industry [137];

- dependence on foreign energy sources [106, 213, 233];

- "bad planning" [106];

- dishonesty [119]; 
- Israel movement [119];

- various pollution controls [137]; and

- leaders "playing politics" [213].

The tendency to place "major blame" on certain groups varied somewhat by region according to the one study performing this analysis. People in the West and Midwest were much more likely to blame consumers than were people in the South and East. The West was less likely than the South to blame the Administration and Congress. Of the four regions, the West was more likely to blame environmentalists and the Northeast the oil companies. Blaming electric power companies and the Arab countries did not vary by region [151].

In summary, oil companies and the federal government were the institutions bearing the brunt of public blame for the energy problems in the United States from 1973 through 1977. Many felt the Arabs, oil companies, and even government were involved in a conspiracy to increase oil prices. The majority held the public themselves responsible for careless use of energy. Other important factors defined by the public as causative are the finiteness of fossil fuel resources and population pressures.

Attribution of the primary responsibility for the energy problem, then, is to institutions in the society rather than to individual actors or individuals taken en masse. Although much of the public blames itself for squandering energy, there is some evidence that attempts to reduce energy consumption have not met with desired consequences of easing shortages and reducing costs, again because of utility action in increasing the cost-per-unit of energy consumed, over which the individual has no control. For example, Angell and Associates (1975) reported that active energy conservers were discouraged owing to increased utility bills in spite of conservation efforts and lack of feedback that individual conservation was helping the nation's energy situation. As one respondent put it:

Doesn't it strike you kind of funny that they come out and say that you are using too much electricity and you have to cut back. But now they charge me more for units because I am using less, so they have to double the price. (p. 29)

Furthermore, responsibility for such pervasive factors as population growth was not assigned to any particular social institution; institutions as well as individuals may be per ceived as unable to control these causative factors.

Growing from these findings and interpretations, then, is the notion that energy conservation, when perceived as behavior within individual control (e.g., turning down the thermostat), is unlikely to be defined as efficacious in solving the energy problem. To the extent that the cause of the energy problem is attributed to political rather than natural factors, political action would be chosen as the individual response to the problem, assuming relative lack of alienation (e.g., a belief that such action can make a difference).

\section{SAIIENCE}

The perceived salience, or importance, of the energy problem as compared to other national (and personal) problems, has been investigated in a few of the surveys in this 
review. In attempting to define how seriously the public takes the energy crisis, the proportions indicating the situation is "serious" are compared with the proportions who feel energy is serious relative to other issues. A higher proportion of the public can be expected to respond that the energy problem is serious when the question focuses only on energy than when the question places energy in the context of other pressing national problems. Indeed, the survey data display this expected outcome.

It is difficult to compare the data dealing with salience. Responses to items in this category are particularly susceptible to how the question was asked. To measure salience accurately, the questioner has to get the context right, which is extremely difficult. It may be that the only appropriate way to measure salience is through openended items, such as, "What do you think are the three most important issues or problems facing the nation today?" Researchers used a variety of questioning techniques to get at the salience issue (none of them open-ended), and the overall outcome is a marked variation in the findings.

National surveys conducted by Opinion Research Corporation (ORC) [128, 131, 134] examined the salience of the energy question through use of a forced-choice item contrasting the "energy shortage" with "inflation" and "rising unemployment." Data from these surveys are presented in Table 3-5. Unemployment was defined as the most important national problem by the majority of the samples (ranging from 50 to 61 percent), while energy was perceived as most important by a small minority, ranging from seven to 15 percent. No indication of an increase in perceived importance of energy shortages during 1975 is evident in the data.

The findings from the ORC data are undoubtedly influenced by the relatively limited scope of identified problems in the item and by the response mode which specified that only one of the problems could be identified as "most important." The item also does not take into account whether the respondent believed there to be an actual energy shortage. With this type of question, the energy shortage was not perceived to have high salience.

Two other national surveys explored the salience issue using forced-choice items, but with different response possibilities. Harris asked respondents to rank the seriousness of the "energy shortage" along with four other national problems (inflation, unemployment, water pollution, and air pollution) [232]. Data from two periods are presented in Table 36. Using this questioning technique, the energy shortage (specified by Harris as well as ORC) ranked markedly higher in the Harr is data collected at the same time as the ORC data. The difference is, thus, probably due to differential item structure or context. In 1973, about a quarter of the Harris sample rated the energy shortage as very important, and in 1975, when ORC reported ranges of seven to 15 percent ranking the energy shortage as most important, Harr is reported that 44 percent defined the energy shortage as "very serious." The relative ranking of national issues also differs between the two surveys. ORC reported unemployment as the problem perceived as most important by a majority of samples, while Harris reported majorities rating as "very serious" inflation (83 percent) and unemployment (74 percent). From 25 to 31 percent of the ORC samples thought inflation was most important. While Harris did not specify ranking by respondents, the difference in relative position still represents an inconsistency in findings.

Table 3-7 presents trend data from Roper surveys [154] on salience. Roper also used a forced-choice item, but permitted respondents to indicate which two or three choices "you personally are most concerned about today." This item did not stress the national 
TABLE $3-5$

PERCEIVED SALIENCE OF THE ENERGY PROBLEM

Of three major national problems--unemployment, inflation, and the energy shortage--which do you think is most important? (Paraphrase) ${ }^{a}$

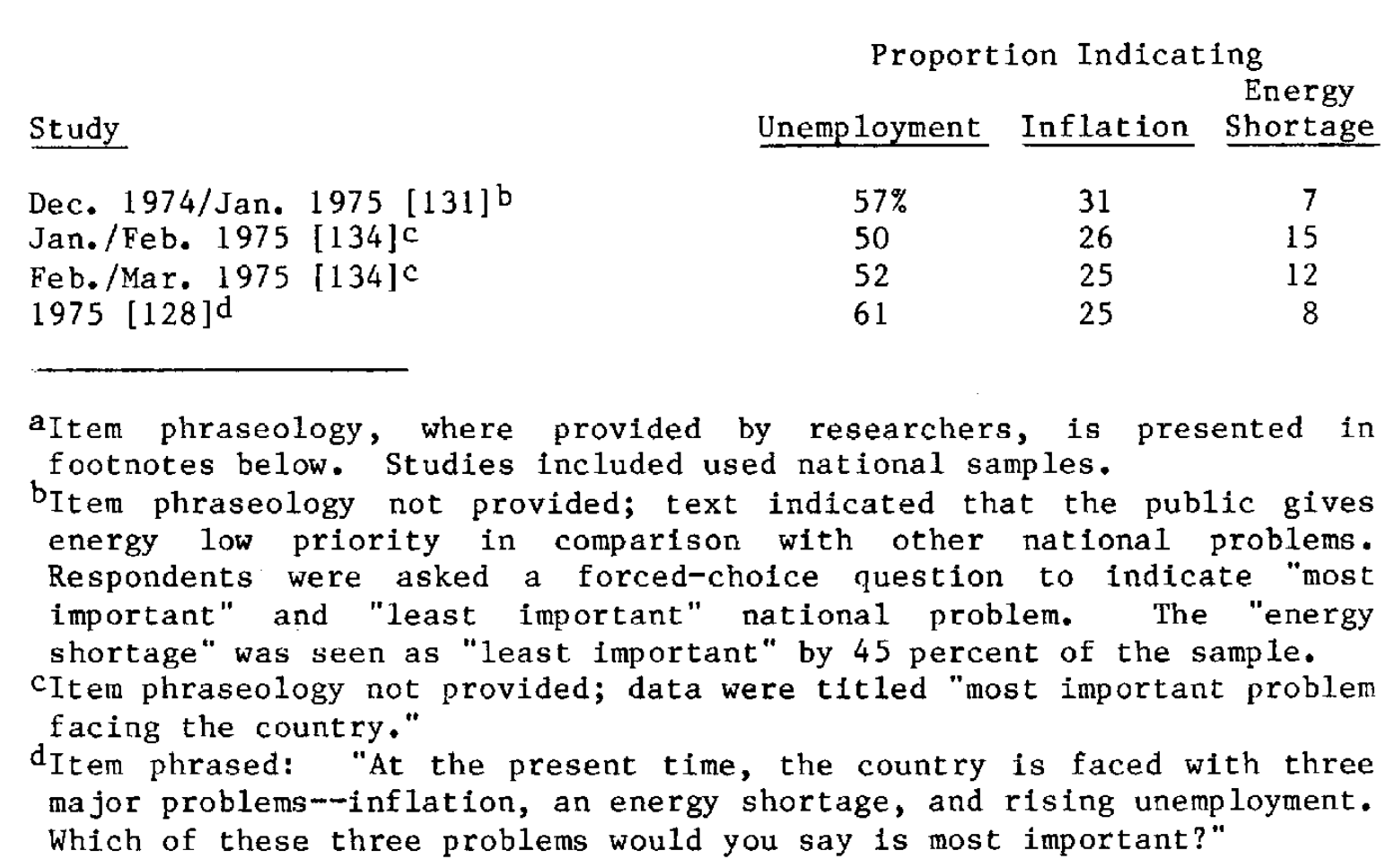


TABLE 3-6

NATIONAL PROBLEMS PERCEIVED AS VERY SERIOUS

How serious do you feel (read list) is in this country--very serious, somewhat serious, or not serious at a11? [232]

Response

Inflation

Unemp loyment

Water pollution

Air pollution

Energy shortage
Proportion Indicating "Very Serious" 1973 1975

$81 \%$

29

40

34

27
83

74

51

46

44 


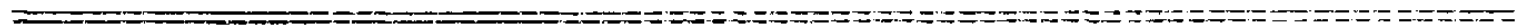

TABLE $\quad 3-7$

NATIONAL ISSUES ELLCITING MOST PERSONAL CONCLRN

Here is a list of things people have told us they are concerned about today (card shown respondent). Would you read over that list and then tell me which two or three things you personally are most concerined about today?

\section{Response Category}

Inflation and high prices Crime and lawlessness

The fuel and energy crisis Money enough to live right and pay bills

The way the courts are run Wrongdoing by elected government officials Drug abuse A recession and $r$ ising unemployment The way young people think and act Pollution of air and water Our relations with foreign countries Getting into another war Alcoholism

None or don't know
Proportion Respondizg Jan. Jan. July Jan. Jan. $1974 \quad 1975 \quad 1975 \quad 1976 \quad 1977$

$\begin{array}{lrrrr}56 \% & 58 & 44 & 4 / 4 & 48 \\ 30 & 34 & 36 & 40 & 40 \\ 46 & 27 & 27 & 22 & 31 \\ 25 & 30 & 30 & 26 & 28 \\ 20 & 22 & 27 & 30 & 27 \\ 40 & 26 & 28 & 32 & 22 \\ 23 & 20 & 21 & 24 & 21 \\ 15 & 33 & 22 & 20 & 19 \\ 10 & 14 & 16 & 15 & 17 \\ 12 & 11 & 12 & 11 & 13 \\ 18 & 10 & 11 & 13 & 9 \\ 7 & 11 & 9 & 10 & 8 \\ 7 & 6 & * & * & -- \\ 1 & 1 & 1 & -- & 1\end{array}$

* Not asked. 
nature of issues, but the response possibilities communicated that idea (e.g., "crime and lawlessness," "a recession and rising unemployment"). The Roper approach is more similar to that of Harris than to that of ORC, but even so, marked differences in the patterns of findings occur.

The Roper data show that by the beginning of 1977, about a third of respondents mentioned "the fuel and energy crisis" as one of the problems concerning them most. This was down 15 percentage points from the proportion exactly three years earlier. While the Harr is data showed 44 percent rating the energy shortage as "very serious" in 1975 , Roper reported 27 percent for the same time period. (ORC's data showed a much lower percentage, as noted.) Similarly, Roper reported that 44 percent defined "inflation and high prices" as a very important problem for the same time period that Harris reported 83 percent. Those concerned about air and water pollution in the Harris sample (46 and 51 percent, respectively) were a much higher fraction than the 12 percent reported by Roper (combined item). These are very large discrepancies for survey data. The Roper item presented 13 possible problems for respondents to choose among, while Harris's presented five. This difference in approach may have diluted the significance of any one possibility in the Roper list (and heightened it in the Harris list) with the result that a smaller proportion of respondents identified it as a problem of most concern. This difference is partially compensated for by the fact that response is given to each item in the Harr is list, but only to the most important two or three in the Roper list. However, the differences reported cannot be assumed to be a reflection only of differential measurement technique. Substantive meaning is involved. The Roper distribution shows that given the context of more options, the energy problem comes out much lower as a personal concern. Apparently the public was concerned about many national issues, and energy is ranked as a highly significant problem by a large proportion only when choices of response are quite limited. This suggests that energy was not perceived as a highly salient issue by a large majority of the American public.

The Harr is and Roper data differ on the relative ranking of significant problem areas. Both reflect the highest proportion mentioning inflation in 1975 (Roper, 44 percent; Harr is 83 percent), but the Roper data show the energy crisis as relatively more important than unemployment (27 percent compared to 22 percent), while the Harris data show unemployment (74 percent) defined as very serious more of ten than the energy shortage (44 percent). The relative significance of the inflation problem found by Harris and Roper is not borne out by the ORC data presented earlier. Thus, for three national samples taken during the same time period but using different measurement techniques, no agreement is found as to what the public defined as the nation's most urgent problem. Together, they show only that it was not the energy situation.

Other studies also attempted to measure the salience of the energy issue using still other items. A survey taken in Lansing, Michigan, during 1976 asked respondents whether they thought the energy problem was "as serious or more serious" than a list of "social problems." The list included inflation, crime, unemployment, and "environmental concerns" [106]. These data demonstrate how energy is perceived relative to each of four other problem areas, not how energy and the other four are related to each other. Thus, the researchers reported that 47 percent thought energy was at least as serious as crime, 60 percent as unemployment, 61 percent as inflation, and 69 percent $s$ environmental concerns. Put another way, 53 percent saw crime as a more important problem than energy, 40 percent thought unemployment more important, 39 percent said inflation was more important, and 31 percent said environmental concerns were more important than the energy problem. 
A 1977 survey in Denver, Colorado, [120] asked respondents to rank from one to 12 (one being top priority) what they thought the national priority should be for each problem listed. Included in the list were slowing down inflation, reducing taxes, "making sure there's enough energy to go around," reducing corruption, reducing "air pollution and environmental damage," providing jobs for the unemployed, caring for the elderly, providing adequate health care, reducing crime, providing education, reducing drug abuse, and reducing social and religious prejudice. The relative positions of the national priorities in terms of response were as listed above, with inflation first, reducing taxes second, and energy third. Sixty percent ranked inflation among the top three priority problems, 40 percent did so for reducing taxes, and 38 percent for the energy problem.

Another study asked a salience-related item in terms of personal life [258]. During 1975, ORC used the following item:

I am going to read a list of eight things that might matter to you in your life. I want you to tell me how much each thing matters to you. Please use a scale of one to five, with one being something that matters very little to you and five being something that matters a great deal. First, I will read all eight things. Then, I will go back and repeat each one separately so that you can rate it one, two, three, four, or five.

The response list, the order of which was systematically rotated during interviews, included: job security, family happiness, saving energy, preventing crime, fighting inflation, U.S. national security, preventing pollution, and helping others. Family happiness mattered a great deal to 89 percent of the sample, followed by preventing crime (76 percent), helping others (64 percent), and fighting inflation (63 percent). Ranking lowest on the list, but still considered as counting a great deal by a sample majority (56 percent), were saving energy, U.S. national security, and preventing pollution.

Roper also collected data on respondent definition of the most important "problems facing our nation today" [151]. With the item phrased in terms of what the government should be spending the most effort on, from a list of 10 options, energy emerged as the number-one problem during 1977. The data are presented in Table 3-8. Following energy closely were inflation and crime, problems which received relatively high rankings in other question contex ts and surveys.

What seems to be significant about these Roper data is that when the question is posed as to the most important problem specifically facing the federal government (as opposed to the nation or the respondent personally), energy emerges as very important, along with inflation and crime.* The finding suggests that energy as a national problem is viewed as primarily within the federal government's domain of responsibility.

This interpretation finds further support in data developed by Roper concerning outstanding problems to which the public would like their Senators and Congressmen to give major attention (Roper, 1978, 78-75). In an item listing "the development of a national energy policy" with five other major national issues, energy emerged by a sizable majority (78 percent), and more than any other issue, as an issue to which major congressional attention should be paid. The data are summarized in Table 3-9.

*It should be noted that the Roper data did not include unemployment among the response categories. 
TABLE $3-8$

PERCEIVED RELATIVE IMPORTANCE OF ENERGY AS A GOVERNMENT CONCERN

There are many problems facing our nation today. But at certafn times some things are more important than others, and need more attention from our federal government than others (card shown respondent). I'd 1ike to know for each of the things on this list whether you think it is something the government should be making a major effort on now, or something the government should be making some effort on now, or something not needing any particular government effort now.

Response Category

Trying to develop new energy sources and find better ways to conserve fuel

Trying to slow down inflation in our economy

Trying to solve the problem of crime and drugs

Trying to seek agreements with other nations to Iimit nuclear weapons

Tryling to solve the problems caused by ghettos, race, and poverty

Trying to establish more controls to protect consumers on the products and services they buy

Seeking ways to protect the privacy of individuals in our society

Trying to improve relations between the United St ates and Russia

Trying to establish more controls on the way products and services can be advertised

Trying to help negotiate a peace settlement between Israel and the Arab nations

\begin{tabular}{|c|c|c|c|}
\hline \multicolumn{2}{|c|}{ Proportion } & \multicolumn{2}{|c|}{$\begin{array}{l}\text { Indicating } \\
\text { Effort" }\end{array}$} \\
\hline June & June & June & June \\
\hline 1974 & 1975 & 1976 & 1977 \\
\hline * & $81 \%$ & 77 & 87 \\
\hline 83 & 83 & 83 & 86 \\
\hline * & 82 & 83 & 84 \\
\hline 56 & 58 & 62 & 69 \\
\hline 60 & 59 & 60 & 66 \\
\hline 58 & 62 & 59 & 51 \\
\hline 54 & 56 & 56 & 51 \\
\hline 33 & 38 & 37 & 42 \\
\hline 38 & 43 & 41 & 36 \\
\hline 36 & 35 & 31 & 28 \\
\hline
\end{tabular}


TABLE 3-9

PERCEIVED RELATIVE IMPORTANCE OF ENERGY POLICY FOR CONGRESS

Here are some things people have said Congress should be working on (card shown respondent). Obviously, one Congressman or one Senator can give major attention to only a limited number of problems. I'd like you to tell rie for each of those things whether it is something you'd like to see your Congressman or Senator give major attention to, or whether you would rather have him devote his attention to more important things? First, the development of a national energy policy. (Roper, 1978, 78-5)

Response Category

Proportion Indicating Give Major Attention March March

1978

The development of a national energy policy

$74 \%$

78

Tax reform

75

67

Stricter regulations on the way dangerous

chemicals can be transported from one place in the country to another

A program to provide national health insurance for everyone

A program to hire the unemployed in government jobs

Stricter labeling regulations for food products 
In yet another attempt to measure salience, Murray et al. (1974) queried several waves of respondents (used as a national sample*) between November 1973 and May 1974 as to how important a problem the energy shortage is to this country [142]. The researchers reported that the proportion of those rating the energy shortage as "very important" fell from about 57 percent in November 1973 to about 50 percent in May 1974. The proportion indicating the energy shortage was the most important problem facing the country dropped about 20 percentage points, from approximately 30 percent to less than 10 percent in the same time period. To speculate, these findings could be correlated to the availability of gasoline during the summer of 1974, as compared to its relative scarcity during 1973.

A South Carolina sample was quizzed during 1977 about how serious they thought it would be not to have enough fuel oil, natural gas, electricity, and gasoline [117]. Data are summarized in Table 3-10. Not having enough of these different kinds of energy was rated as "very serious" by just under half of the sample for fuel oil and natural gas, and by about a third for electricity and gasoline. Almost a third said it was not serious to have shortages of electricity and gasoline, but the pattern of response (we already have enough or even a surplus of electricity and gasoline) suggests that the intended meaning of the item (the hypothetical situation in which we do not have enough) was missed by respondents.

In 1976, Harris asked two items about the quality of life [248]:

As far as you personally are concerned, do you feel (blank) is very important in making the quality of life better in this country, only somewhat important or hardly important at all?

Which two or three (of the things mentioned) are most important to you personally?

"Conserving energy" was rated as "very important" by 78 percent of the sample, and was third on the list following "achieving quality education for children" (89 percent) and "curbing water pollution" (79 percent). Thirty percent designated "conserving energy" as one of the most important things to them personally. Energy conservation followed "curbing air pollution" (41 percent), "achieving quality education for children" (36 percent), and "curbing water pollution" (32 percent).

Roper found that about 45 percent of samples from 1974 to 1978 felt "depletion of natural resources" was a serious threat to our society [180]. This response eategory received the highest proportion of responses; it was followed by crime and decline in quality of education with about a third concerned about each. Furthermore, "depletion of natural resources" was thought likely to happen by almost 60 percent of respondents during the same period. Natural resources depletion was seen as likely to occur by more respondents than any other potential threat.

In summary, the complexity and noncomparability of the survey findings on salience make drawing conclusions about them difficult. A few tentative findings seem to emerge from the overall picture. Although the energy situation is defined as serious by the majority of the American public, it is not clearly defined as a highly salient problem. Energy seems to be perceived more as a problem facing the government, although some

*The Murray sampling technique is not straightforward. The sample sizes, ranging from 610 to 700 to represent the nation, are approximately half of the sizes used by the major national pollsters. 


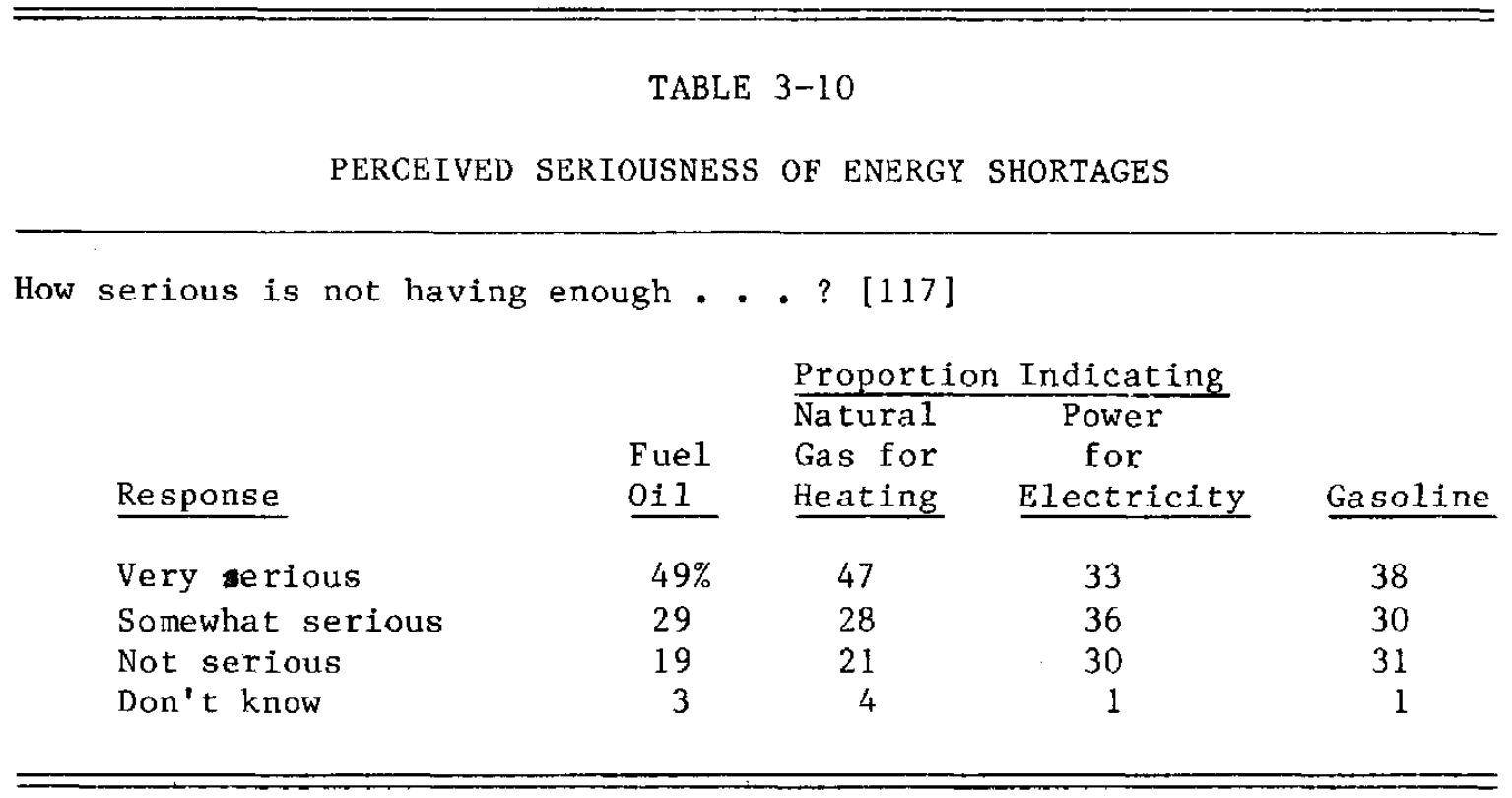


people also appear to feel that it is important for them to help out through practicing energy conservation. Inflation, unemployment, and crime are clearly matters of grave concern to the public. Another set of issues including increasing population, overcrowding, and depletion of natural resources, along with the energy situation, has also been the subject of concern for at least the last four years. Energy is not defined as of paramount importance, nor as a minor matter. It falls somewhere between.

\section{PERCEIVED IMPACTS OF THE ENERGY PROBLEM}

Mast people perceive negative impacts on the nation and on individuals as a result of energy problems. Inflation, economic decline, dependence on foreign sources, and deprivation of other countries and future generations are national and global impacts perceived by the public, as empirically established in surveys. Price increase in "everything," gasoline, and electricity, shortages, closure of schools and businesses, and general inconvenience are impacts individuals have recounted in response to survey questions.

In a 1975 national survey, the majority of respondents said energy problems contributed to inflation [241]. In another 1975 national survey, eight out of ten felt increases in the price of oil and gas had at least a fair amount of impact on the inflation rate and 60 percent felt it had a great deal of impact [262]. During 1973 and 1974, national respondents who believed the economy would probably decline in the coming year tended to think this would be at least partly due to the energy shortage [142]

In addition to economic concerns, about half of the people sampled nationally in 1973 felt the energy problem was serious because "we will have to depend a lot on foreign sources in the near future" [234]. In another study, respondents were offered two global consequences of high energy use for comment. Nearly half felt continuing present high levels of energy consumption in the United States would deprive poorer parts of the world of basic necessities. Two-thirds felt that such consumption would deprive future generations [106].

Most questions focused on individual impacts (e.g., "How much have you personally been affected by the energy shortage?"). In one national surey, nearly one-fourth said "a great deal" and another one-third said "some." Less than one-fifth said they had not been affected at all (ORC, 1974). In Indiana, 36 percent indicated that the energy crisis "had a real effect" on the way they lived [304]. The majority in a Detroit study said that shortages related to the energy situation "bothered" them "a great deal"; one-fourth said they were "not bothered at all" [260]. In Los Angeles, nearly 60 percent of respondents said the energy crisis was affecting them in some way. Life was reported by six percent as "much more difficult" due to the crisis [207].

Attempts have been made to discover if the energy crisis affected some groups more than others. The question has been approached in several ways. One way was to ask people if they believed they suffered more from the energy crisis than other people. In 1974 between January and April, 20 to 30 percent of a national sample felt they were suffering more than people of other income levels [142].

Another way is through estimation using known price increases and group characteristics. One such study by King (1976) concluded that energy price increases from 1973 to 1974 imposed a greater burden on low income households. Evidence of 
greater impacts on low-income persons was also reported by Unseld (1978) and PerIman and Warren (1977).*

Regional differences in impacts might also occur. According to one study, people in New England reported having the most trouble and the longest wait in getting gasoline during the embargo. The Central Northwest region had the least trouble getting gasoline [142].

Most of the specific impacts reported were due to price increases of oil and gasoline associated with the energy crisis. In 1976 a large majority in a national survey felt that the price of gasoline and electricity had gone up more than that of most other commodities [14]]. In Los Angeles, transportation problems were the most frequently mentioned impact in 1974 [207].

In 1974, 93 percent of respondents living in an all-electric community reported that their electric company had increased its rates in the past year. Most people attributed this increase to the energy problem [136]. At about the same time, in August 1974, people were asked what other commodities besides gasoline and heating oil had gone up in price because of the energy shortage. A plurality (37 percent) marked "everything." One-fifth indicated "electricity" and 15 percent said "nothing else" had gone up in price because of the energy crisis [137]. By December, 59 percent answered "everything" and 27 percent "electricity"; the proportion indicating "nothing else" had gone up in price because of the shor tage dropped from 15 to two percent [308].

In Lansing, Michigan, in 1974 and 1976, people were asked, using a forced choice item, "How has the energy problem affected your family?" Sixty-three percent listed increased price of heating fuel, 59 percent indicated increased electricity prices and 58 percent mentioned increased gasoline prices [106]. In 1975, the majority of a national sample mentioned electricity as the energy source which increased most in price [128]. When asked how much electric rates had gone up, one-third of Ohio respondents could not say [122]. No one thought they had gone down and two percent thought there had been no change. Estimates of the increase ranged from more-than-double to less-than-onefourth.

A study by Cunningham and Lopreato in parts of Texas and Arizona found one-fifth saying the $r$ ise in their electric bills had had no effect on their family. A plurality (45 percent) said they had to make a few adjustments but that their lifestyle was not affected. Nearly 30 percent said that their life was made less comfortable and convenient, and seven percent called the changes in daily habits "serious." Fewer people reported being affected by increases in the price of natural gas [181]. The study of allelectric communities reported 58 percent answering yes to the question, "Have you or your family had to give up anything in order to pay for higher electricity bills?" Nearly one-third felt there might be a time when they would have to , move out because of the cost of electricity [136].

Another consequence of the energy problem has been shortages which caused some public inconvenience. In 1974, a national survey asked if respondents had problems getting all the electricity they wanted between May 1973 and May 1974; two percent reported that they had [142]. In the absence of baseline data it is impossible to judge this result; perhaps two percent of the population had such problems before the energy crisis. A Roper study in August 1974 reported that 78 percent said electricity was one of the energy sources which would cause them the most inconvenience if it were in short supply. Oil was listed by 60 percent [161]. 
The most visible inconvenience, long gas lines, disappeared after the initial 1973 boycott. In April 1974, nearly 30 percent of a national sample said they had some difficulty buying gasoline (nine percent reported a great deal of difficulty) [134].

In April and June of 1974 , seven out of 10 people in another national sample said they had not been able to buy gasoline in the amount they wanted or from their usual supplier [260]. By February 1975 two percent nationally reported some difficulty and less than one percent were having a great deal of difficulty getting gasoline [134].

In May 1974, after the gasoline shortage had eased, one-third of national respondents felt Americans could return to their former driving habits. About 60 percent felt people must continue to use less gasoline to avoid a shortage in the summer [172].

In a national survey in 1974,19 to 33 percent of respondents reported increased participation in garnes or hobbies at home because of the energy crisis [132]. Another study in 1974 found 80 percent responding that if they had to give up some amount of driving they would cut down on pleasure driving rather than nonpleasure driving (e.g., work, school, and shopping) [308]. Trips to work and school were mentioned least of ten. Similar results were reported from surveys in Los Angeles and Detroit in 1974 [207, 260]. Sixty-three percent of respondents in Texas in the same year reported they were driving less to work and 91 percent reported reduced recreational driving [116]. In Lansing, Los Angeles, and Detroit, 23 to 39 percent of respondents changed vacation travel after the energy crisis began $[115,207,260]$.

Shortages also resulted in closure of schools and businesses. Although there are no national survey data on reported closures, several local studies asked about this. Half of an April 1974 sample in Indiana said they had heard of a business or industry within their area that had problems as a result of the energy crisis [304]. At the same time, in Detroit, about one out of four household interviews resulted in a report of work layoffs or reduced hours during the period of the energy crisis [260]. In February 1974 and again in July, 11 percent of respondents in Washington, D.C., answered yes to the question, "Because of the energy crisis, have you or anyone in your family been laid off, had overtime cut down, or had your regular work week eut down?" [121]. In February 1977 a national sample was asked, "Which of these things, if any, has happened to you because of the cold weather or because of the fuel shortage?" Ten percent said their place of work had been closed for at least one day because of lack of heat. Schools closing because of lack of heat was mentioned by 21 percent [153].

Although there is evidence of impacts due to the energy shortage, the data from these studies do little to assess the magnitude of the effects. There are few doubts that most, but not all, were affected by energy problems. It is likely that a disproportionate share of negative impacts have been borne by low income groups.

\section{PERCEIVED FUTURE ENERGY SITUATION}

Related to questions of seriousness and impacts of the energy situation in the United States, its salience and its reality, are the expectations Americans have about the nation's future energy picture. A number of surveys have asked the public their estimates about the duration of the energy problem, some with items relating duration to seriousness. The future energy supply is related to three distinct but interrelated factors: (1) political situations internal to the United States, (2) political situations 
between countries having and not having fossil fuels, and (3) the physical supply of fossil fuels in the nation and the world.

Table 3-11 summarizes data from seven data collection efforts between 1975 and 1977 on how serious the public estimated the energy shortage would be five and 10 years in the future. A majority of these samples expected the energy situation to be serious (either very or somewhat serious) at these future times. Based on the survey data, the trend in public perception is for an increasing majority (up to 79 percent) to estimate a serious energy shortage in 10 years.

This trend in public opinion is borne out by other surveys. ORC reported that the energy shortage was expected to be "of long duration" by 29 percent in March 1974 and 51 percent in September 1974 [137]. ORC reported trend data on public estimates of the length of the energy shortage, summarized in Table 3-12.

Roper queried the public about how likely "the chances are that in the next year this country will have another severe energy shortage like the one two years ago?" A majority at all time periods (summer of 1975, 1976, and 1977) projected another energy shortage (70, 59, and 71 percent, respectively) [150]. RUPI, Inc. (1977) reported that the majority (around 80 percent) of both their new and existing homeowner samples strongly agreed that "serious fuel shortages are bound to occur in the next few years." A survey conducted in Grand Rapids, Michigan, during 1976 found that while 66 percent agreed "there will be an energy-related problem in the future in the United States," 62 percent felt that "the problem will be solved in the future" [119]. This finding suggests that definition of energy as a future problem does not necessarily imply pessimism on the public's part about the nation's ability to solve that problem. A national sample polled in January, February, and March 1974 gave mean estimates of the number of years "until we have as much energy as we need" of 6,7 , and 7.3 years, respectively [142]. This finding again expresses optimism about the nation's ability to deal with its energy problems.

On the other hand, Roper reported that 68 percent of a December 1976 sample felt "shortage of energy supplies" will be a serious problem in the year 2000. This was up six percentage points from two years earlier, and followed severe air pollution (73 percent) and severe water pollution ( 72 percent) as the most frequently mentioned serious future problem. Almost a quarter of the respondents felt that energy would not be a serious problem by the year 2000 .

Although energy is defined by sample majorities as a serious and somewhat long-range problem, extending at least to the turn of the century, the public appeared to be neither overly pessimistic nor optimistic about the nation's ability to deal with the problem. The balance of the survey data dealing with the question of future shortages employed items that asked about specific energy supplies, which are discussed in the following paragraphs.

\section{Eleetricity}

During 1974, Roper reported that majorities of two samples (one in August and the other in December) thought electricity was or might soon be in short supply [161]. The proportions indicating this were 68 and 82 percent, respectively, making this a strong response, especially in the context of the item, which listed such other commodities as grains, copper, plastics, and steel. National samples drawn during late 1973 and early 
TABLE $3-11$

PERCEIVED FUTURE ENERGY SITUATION

How serious do you feel the energy shortage here in the United States will be (5) (10) years from now--very serious, only somewhat serious, or not serious at all?

\section{Proportion Responding}

$$
\text { In } 5 \text { Years }
$$

Study

$1975[141]$
$1976[141]$
$1976[245,246]$

$1975[141]$
$1976[141]$
$1976[245,246]$
$1977[246]$
March
Apri1
May
July
Serious

*Usually sum of "very serious" and "somewhat serious" responses.
Very $40 \%$

47

--

Not

Serious* Serious Serious Don't Kno

(66)

(73)

(77)

In 10 Years

33

44

42

(53)

(64)

(66)

20

20

24

19

16

15

26

$-$

(73)

23

(79)

(75)

(77)

24

23

$\begin{array}{ll}26 & 21 \\ 19 & 17 \\ 14 & 20\end{array}$

60

51

54

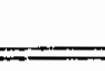




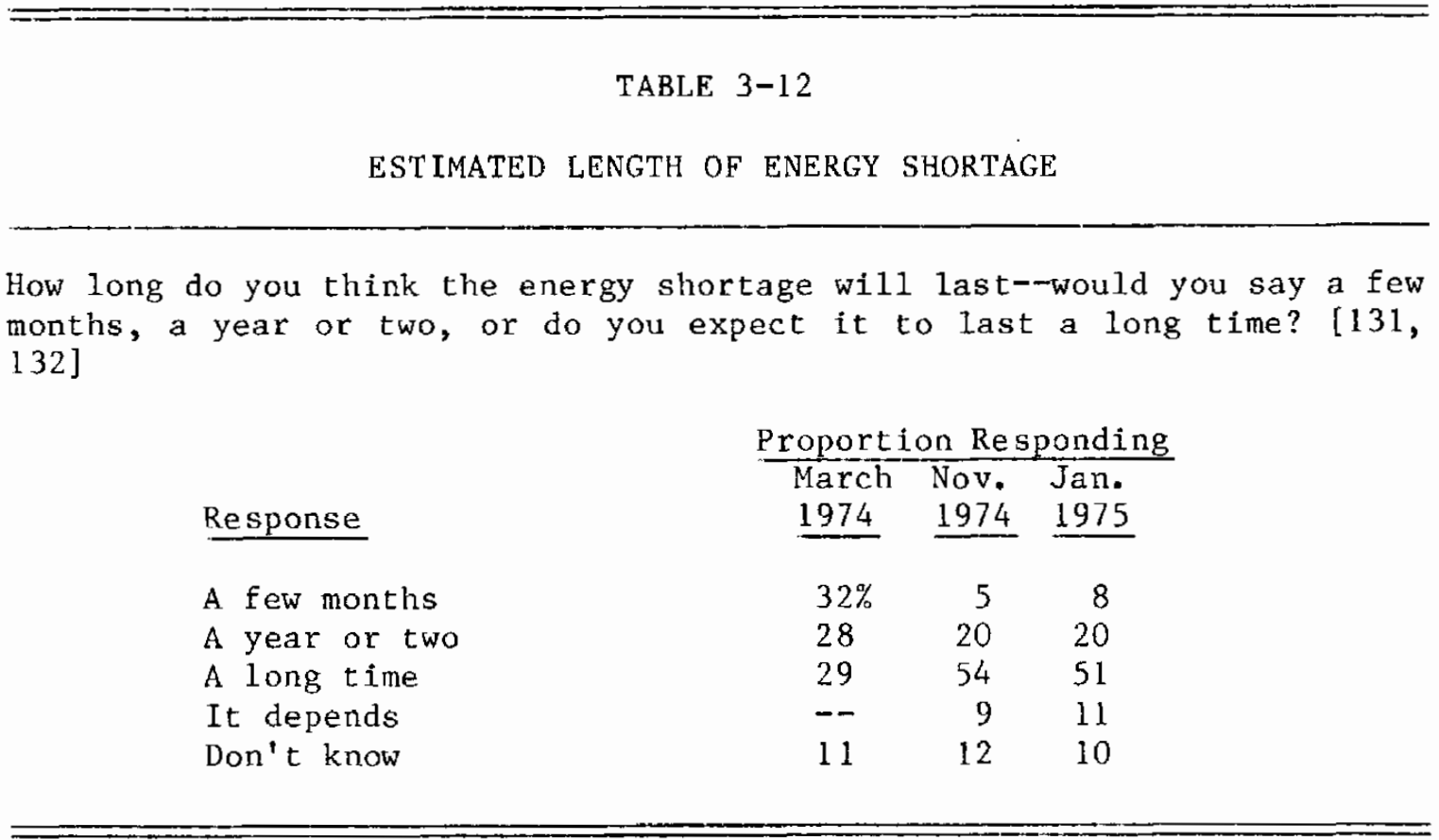


1974 were asked whether they expected problems in obtaining electricity in the next year. At the beginning of the sampling period almost a fif th thought they would, but this had dropped to five percent by the spring of 1974 [142].

Early in 1975, almost half of a national sample expected the largest energy price increases in the coming year to be in electricity (24 percent indicated natural gas; eight percent, oil) [131]. This finding was supported by another 1975 survey producing similar results (electricity, 46 percent; piped gas, 27 percent; and oil, 12 percent) [128]. During the same year an Ohio sample was asked whether there "will be a shortage of electricity in the future," with results polarized between 40 percent yes and 40 percent no. Almost a fif th were unsure. The same sample was almost equally polarized over the question of whether "electric companies are saying there is a shortage so people won't oppose higher rates" (40 percent said yes; 47 percent, no) [122].

In 1976 about two-thirds of a Michigan sample thought we "will not have an electricity shortage" in the future [119]. Among those who thought there would be a shortage (24 percent), most estimated that it would occur five to 10 years in the future. The Michigan sample was also asked about the cost of gas and electricity in the years ahead. Data, summarized in Table 3-13, indicate that people were expecting their energy costs to rise, but that they were unsure as to how much, with greatest uncertainty about projecting costs 10 years. In five years, 30 percent of the sample were expecting to pay $\$ 20$ to $\$ 30 /$ month more for these utilities, and five percent thought they might be paying from $\$ 50$ to $\$ 100 /$ month more. The plurality (41 percent) could not estimate costs 10 years in the future.

That same year, half of a national sample said there would be no shortage of electric power 10 years from now, but a third thought there would be, and 17 percent were not sure [141]. This item was asked as part of a survey on nuclear energy.

The same survey included some specialized samples of political leaders, business leaders, "regulators," and environmentalists. Their opinions on the item differed markedly from those of the total public. Over half of the political leaders, business people, and regulators sampled thought there would be a shortage of electricity 10 years from then, and 38 percent of the environmentalists thought so. These findings are interesting because such subsamples may reflect the sentiment of community "opinion leaders" who are the harbingers of future public sentiment on the issue (Rogers and Shoemaker, 1971).

In 1977 , a national sample majority indicated that it was very likely (21 percent) or fairly likely (31 percent) that "there could be a major power failure like the one in New York City area in your area" [149]. Virtually no one in a Michigan sample during 1977 expected the supply of electricity to be stopped during the winter of 1977-78 [115].

These discrepancies in survey findings, with proportions indicating a belief in future shortages of electricity ranging from 24 to 82 percent, can be partially attributed to differences in item wording and in geographical areas sampled. National surveys seemed to result in the highest proportions of the public indicating future shortages in electricity; local samples were less pessimistic. The considerable disparity in the data prohibits drawing conclusions about public estimates of future shortages of electricity. 


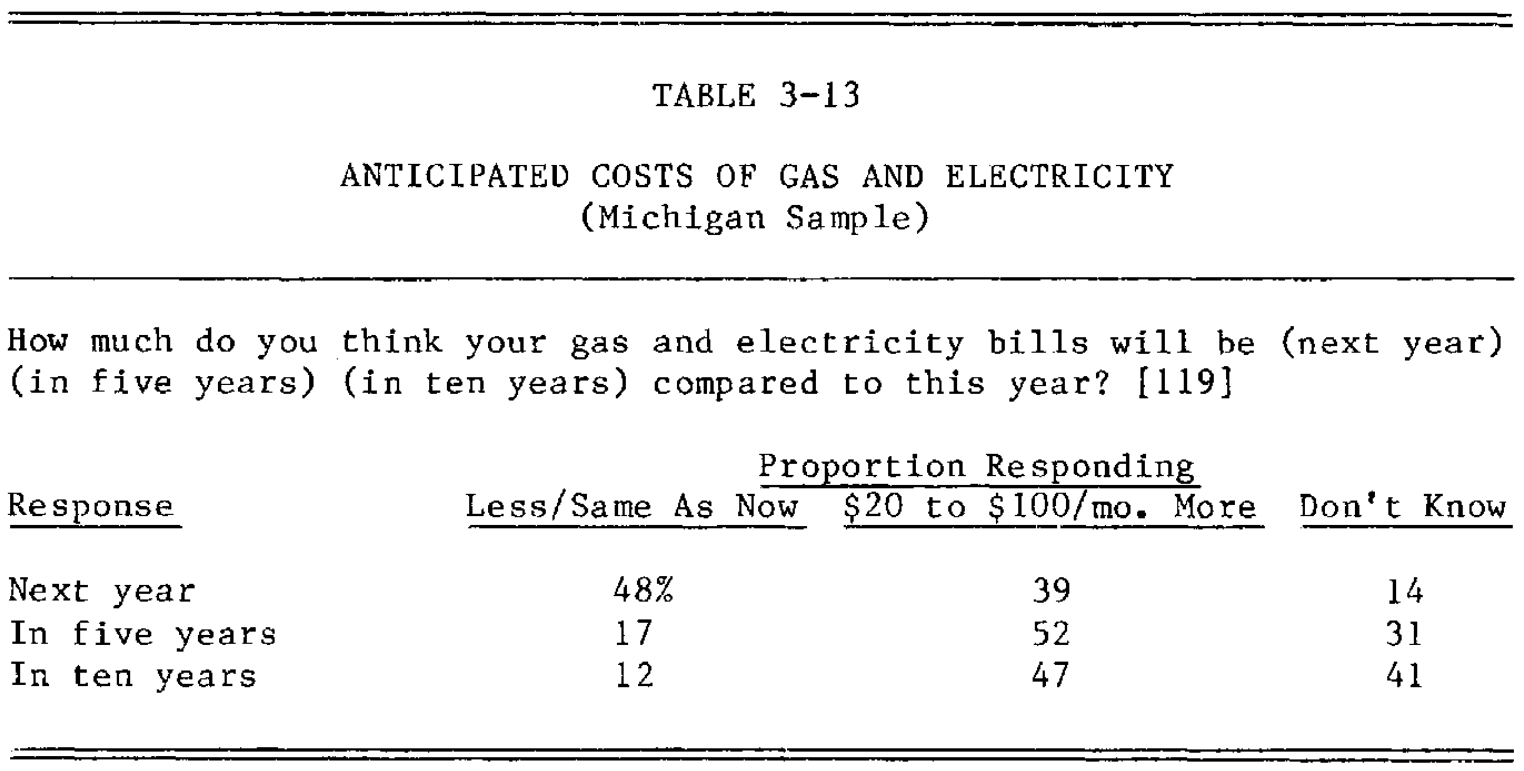




\section{Oil and Gasoline*}

In August 1974, Roper found that 81 percent of a national sample thought oil was then or would soon be in short supply; this proportion had risen to 93 percent by December of that year [161]. A Harris survey reported that 53 percent of a national sample polled in 1976 thought there would be an oil shortage 10 years in the future [141]. The special subsamples included in this survey were even more inclined to think so: 62 percent of environmentalists, 79 percent of political leaders, 70 percent of business leaders, and 81 percent of regulators thought there would be such a shortage.

In late 1974 and early 1975, ORC polled two national samples concerning the likelihood of the nation running out of oil in the next 10 years and in the next 50 years [131, 137]. Results are summarized in Table 3-14. These data are internally inconsistent, with the majority of one sample responding that it is not likely the nation will run out of oil in 50 years ( 58 percent) and a plurality of the second sample (38 percent) expressing the same opinion. Since these samples were surveyed within five months of each other, differences in findings are unlikely to be attributable to change in opinion over time. The items were replicated; therefore, item wording is not the problem. The discrepancy could be caused by a sampling problem: the numbers involved in each national sample are much smaller than those used by other major pollsters. These difficulties throw the survey results into some question.

In 1975 a national sample was asked how likely they thought it was that the OPEC countries "will again cut off oil to the United States sometime within the next 12 months." About a quarter of the sample thought it very likely, and almost a third said it was fairly likely [129].** At the same time, 60 percent of the sample thought it was likely that there would be long gasoline lines again within the next year. This item probably pertains more to the political climate than to the actual condition of fossil fuel reserves in the nation and around the world, although it does have a bearing on whether there would be national energy shortages. Public belief that politically caused shortages are likely to exist can contribute to support for government policies designed to ensure energy self-sufficiency probably quite as much as belief that the supply of fossil fuel is dwindling.

Samples in Texas and Arizona were polled in 1975 concerning their agreement or disagreement with the following statement: "The United States is running out of oil" [181]. Sixty percent agreed (with 18 percent in strong agreement) and about a third disagreed. The following year, about a third of a Michigan sample indicated that they thought the U.S. supplies of oil would, at some time in the future, be "used up," while a majority (54 percent) thought the supplies would never be completely depleted [119]. Of those who thought supplies would be depleted, two-thirds thought this would occur some

*Some of the general public may not be aware that gasoline is produced from oil. No survey items directly addressed knowledge on this point, but certain survey results, taken together, suggest this misunderstanding exists. Thus, responses on shortages of oil and gasoline may be affected in a subtle way by limited knowledge on the part of some respondents. Gasoline may be a commodity more directly relevant in everyday life than oil, which could also affect response.

**It is interesting that although a majority thought it was at least somewhat likely that the OPEC countries would embargo oil to the United States during 1976, this event did not actually occur.

$\$$ Differences by state were not reported; this would be of interest since Texas is "oil country." 
TABLE $\quad 3-14$

PERCEIVED FUTURE OIL SUPPLY

How likely is it that the United States will run out of oil in the next 50 years or so? How about within a shorter time period, say within the next 10 years? [Asked only of those who said it is very/somewhat likely that the United States will run out of oil within the next 50 years or so. ]*

Response

Very likely

Somewhat likely

Not very 11 kely

Don't know
Proportion Responding

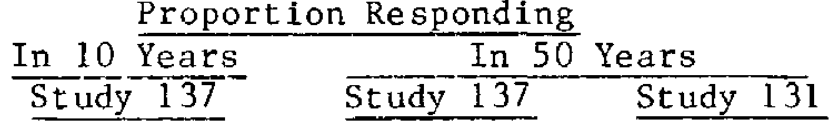

$9 \%$

11

10

1
16

14

58

12
26

30

38

6

ॠSample Ns reported were 608 for Study 137 and 604 for Study 131, less than half the size used by Harris and Gallup, and less than a third the size used by Roper. 
time within the next 100 years. These respondents, however, represented about a fifth of the total sample.

The same sample was asked its assessment of the world's future supply of oil: "Do you think the world supplies of oil will ever be completely used up?" Most thought this would not happen ( 70 percent), and about a fif th thought it would. Of the latter, about a third could not estimate when it might occur, about 40 percent thought it would happen within the next 100 years, and about a quarter thought it would take longer.

The Michigan sample was also asked whether there would be another gasoline shortage. Almost half indicated they thought there would be, and most of them estimated it would occur within the next 10 years, although a sizable proportion could not estimate when it would happen.

Using a similar item, Roper polled a national sample in 1977 on their estimates of how long the world's supply of oil is likely to last [153]. The plurality ( 35 percent) did not know. Others thought 25 years $(20$ percent), 50 years ( 15 percent), and 100 years (10 percent). The balance of response was scattered between five years and longer than 200 years.

Between late 1973 and the spring of 1974, the proportion of householders who anticipated problems obtaining gasoline in the next year decreased from about 65 percent to about 20 percent [142]. Virtually everyone in a 1976 Michigan sample expected the price of gasoline to $\mathrm{r}$ ise in the future [119].

When asked about the role of oil as a fuel to generate electricity in the future, the majority in two studies saw its contribution declining. In 1974 respondents in a national sample perceived a median percentage of contribution by oil to the nation's energy supply dropping from 35 percent contributed in 1974 to 21 percent by 1984 [142]. They saw natural gas falling from a 30 percent to 17 percent contribution by 1984 . In 1976 people perceived the contribution dropping from 28 percent in 1976 to six percent in 10 years and two percent in 25 years [141].* The same study found a third or fewer of respondents agreeing with these statements about the effectiveness of oil as an energy source: will not run out of supply any time soon; is a reliable form of energy for the United States to depend on in the long run; can be produced in almost unlimited quantities.

In summary, with a set of nonidentical but related items, the data from these surveys show that about half of the public expects shortages of oil in 10 and 50 years, about 60 percent think the United States is running out of oil, and small minorities think that at some future time the nation and the world will actually run out of oil.

\section{Natural Gas}

A national survey conducted in the fall of 1975 asked respondents how likely they thought a shortage of natural gas would be in their area during the coming winter [258]. About 45 percent thought it was fairly or very likely that such a shortage would occur, while 42 percent thought it was not. Several possible explanations might account for this

\footnotetext{
*This question was not asked about natural gas.
} 
polarization. The response may reflect actual local conditions of shortage or abundance in various regions of the nation, it may be reflective of a public confused about the facts, or the public could be ideologically divided. Reasons cited for the responses were interesting, particularly since so few survey items delve into respondent rationale for responses given. Those who indicated a shortage was likely said they thought so on the basis of what they had read or heard. A few said there was no real shortage and that it would continue to be contrived to raise prices. Some said the shortage would happen because people had not been conserving energy. A few indicated that a great deal of natural gas was used in their area, and new sources of supply had not been found. Those who thought a shortage was unlikely gave the following reasons for their response: they had not heard anything about an impending shortage; there was no real shortage-it was contrived; they thought there were sufficient supplies for their area; they estimated that their area did not consume very much natural gas.

Another national survey in 1975 found similar results to an identically worded item, with 52 percent indicating there would likely be a shortage of natural gas in their area and 40 percent who thought there would not be [129].

A Lansing, Michigan, sample surveyed in 1977 did not expect their supply of natural gas to be stopped during the winter [115]. These results may have occurred owing to local conditions.

ORC's results on perceived future supplies of natural gas were as discrepant as their results on oil. Data are summarized in Table 3-15. The samples were reportedly national, but two of the reported samples were half the size of a third sample. For two surveys, the data were collected using identical wording at almost the same time, and a third survey was completed within four months; yet the proportions indicating likelihood of running out of natural gas in the next 10 and 50 years were notably different. About 45 percent in one sample thought it likely that the nation would run out of natural gas in 10 years, compared to 25 percent of another sample taken at the same time [137, 139]. Two of the surveys reported about 45 percent response that there was a likelihood the nation would run out of natural gas in $\mathbf{5 0}$ years; the third survey found 64 percent in this response category. These data appear to be of questionable validity. Allowing for the inconsistencies in response, the data suggest that more of the public thinks the nation will run out of natural gas by about the year 2025 than think it will not.

A 1975 survey of samples in Texas and Arizona asked respondents to indicate agreement or disagreement with: "The United States is running out of natural gas." About 60 percent of the sample agreed and almost a third disagreed [180]. About a third of a Michigan sample said the nation's supply of natural gas would some day be entirely used up, and, of those who thought this, most thought it would occur within 100 years [119].

In summary, the data concerning public perception of the natural gas supply focused on more immediate expected shortages and on long-term supplies. During 1975 and 1976, around half of national samples expected shortages in natural gas during the winter; such shortages actually did occur in some parts of the country during these extreme winters. The longer term perspective on natural gas supplies varies between 45 to 60 percent of the public indicating the nation will run out of natural gas in $\mathbf{5 0}$ or more years. These are proportions similar to those who think the same about the future supply of oil.

\section{Other}

A few of the surveys included in this review queried respondents concerning the future of other energy supply sources. One 1976 national survey reported that 27 percent thought 
TABLE $\quad 3-15$

PERCE IVED FUTURE SUPPLY OF NATURAL GAS

How likely is it that the United States will run out of natural gas in the next 50 years or so? How about a shorter time period, say within the next 10 years? How likely is it that we will run out of natural gas--very likely, somewhat likely, or not very likely? [Asked only of those who say it is very/somewhat likely that the United States will run out of natural gas in the next 50 years or so.]

Proportion Responding

Response

Very likely

Somewhat 1ikely

Not very likely

Don't know

In 10 Years $\frac{\text { In } 50 \text { Years }}{\text { Study Study }}$

$\underline{130^{\mathrm{a}}} \quad 137_{\mathrm{b}} \quad 139 \quad 137 \quad 131^{\mathrm{c}}$

$\begin{array}{rrrrr}9 \% & 24 & 21 & 38 & 19 \\ 16 & 21 & 25 & 26 & 28 \\ 18 & 18 & 36 & 28 & 38 \\ 3 & 1 & 18 & 8 & 15\end{array}$

a All three were reportedly national samples. Data collection period "ended September 29, 1974"; $\mathrm{N}=1212$.

bata collection period "ended September 16, 1974"; $\mathrm{N}=609$.

${ }^{c}$ Data collection period reported as December 1974 through January $1975 ; N=604$. 
there would be a shortage of coal in 10 years [141]. This survey, which included special subsamples, found that a smaller proportion of political, business, legal, and environmental opinion leaders thought coal would be in future short supply than the public as a whole. A 1975 survey in the Southwest found about a fifth of their sample in agreement with the statement that the United States was running out of coal, and there were about 70 percent in disagreement [181]. ORC reported less discrepant data on coal than on oil and natural gas. For the three survey periods and samples reported earlier, 32 to 42 percent thought it was likely that the nation would run out of coal in 50 years, while 40 to 52 percent thought it was unlikely this would happen [131, 137, 139]. These data taken together suggest that the public views coal as a longer lasting fossil fuel than either oil or natural gas.

The 1976 Harris survey also collected data on perceived shortages in nuclear power and solar energy [141]. In both of these cases, opinion leaders were markedly different in response from the public as a whole. For nuclear power, 17 percent of the total sample thought there would be a shortage in nuclear energy "10 years from now." In contrast, more of the political (38 percent), business (44 percent), regulatory (67 percent), and environmental (46 percent) leaders foresaw such a shortage. Similarly for solar energy, 19 percent of the total public predicted a shortage 10 years in the future, while opinion leaders were much less sanguine. Estimating future shortages in solar energy were 64 percent of political leaders, 48 percent of business leaders, 47 percent of regulators, and 25 percent of environmentalists.

Perceptions about future energy supplies varied by region. While one study found people in the West to be more inclined than those in the Northeast to think the shortage was real, would get worse, and would require continued efforts to use less gas [172], two other studies found the West to be most optimistic that the United States could be energy self-sufficient and would not run out of fuel in the next 50 years $[137,308]$.

In summary, these data suggest that the public perception of future energy supply sources is markedly more hopeful for coal, nuclear power, and solar energy than for oil and natural gas. The latter, however, are still perceived by a significant proportion of the public as viable sources for some time to come.

\section{PERCEIVED SOLUTIONS TO THE ENERGY PROBLEM}

Survey data included information on the public's level of awareness about what was being done to solve the energy problem, information sources about the problem and their credibility, public evaluation of the adequacy of efforts to solve the energy problem, and solutions preferred by the public. Data on these questions are discussed in this section.

\section{Levels of Awareness}

Somewhat surprisingly, there has been very little effort to determine the public's knowledge about efforts to resolve the energy problem.* In March and April 1975, national samples were asked if the federal government had established some agency responsible for energy policy and practices; 45 percent said they did not know [256]. The

\footnotetext{
*In later chapters what little data exist on knowledgeability about specific energy sources and conservation are discussed.
} 
portion answering yes was less than one-fourth in April. The Federal Energy Administration (FEA) was formed in March 1974.

In November 1976 another national study asked if the federal government had "a plan to conserve present energy sources and develop new energy sources so we will not be dependent on foreign countries for energy." Over half (55 percent) answered correctly that the government was working on a plan, but as many thought the government was doing nothing ( 16 percent) as thought there already was a plan ( 15 percent). More people were willing to say they knew about this issue in 1976 than would answer about a government agency in 1974 [156].

Respondents in three studies indicated they were following what the President said about energy. In late 1974 and early 1975, eight out of ten respondents said they had heard or read President Ford's speeches on energy and inflation [133]. In November 1977, 45 percent said they were closely following President Carter's legislation to deal with the energy problem. Another 42 percent said they were following the legislation casually [147].

\section{Information Sources}

Where people get information and whom they consider credible sources on energy have been investigated in several surveys. Table 3-16 summarizes responses from three local surveys addressing this issue.* In these three studies, more respondents said they obtained their energy information from the media than from any other source. More people in Lansing mentioned television than newspapers while more respondents in the Southwest seemed to rely on newspapers. Table 3-16 also shows that radio was not widely mentioned as a source. It is difficult to learn much more from these data since respondents were not asked to volunteer sources.

Some attention has been paid in the national surveys to the credibility of sources. Table 3-17 compares findings in one national survey and two local studies which inquired about the accuracy and reliability of the information provided. The responses vary widely probably because different response possibilities were provided in these forced choice items. In the national study conducted in 1975 and 1976, more people thought the network news did a good job of reporting on energy matters than felt this way about newspapers or news magazines [141]. Respondents in the Southwest [116] trusted television reports more than newspaper accounts, while those in Grand Rapids, Michigan, were more likely to choose "no one" than any media or other sources in a forced choice item [119]. If other samples had been given the "no one" option, this finding could be better evaluated.

Respondents in a national survey were asked which groups-the federal government, the news media, or consumer groups-they would personally rely on for information on the energy shortage [133, 139]. Table 3-18 displays the results from these 1974 and 1975 surveys. About a third chose the news media, and about a quarter each chose the federal

\footnotetext{
*There were no national data on information sources.
} 


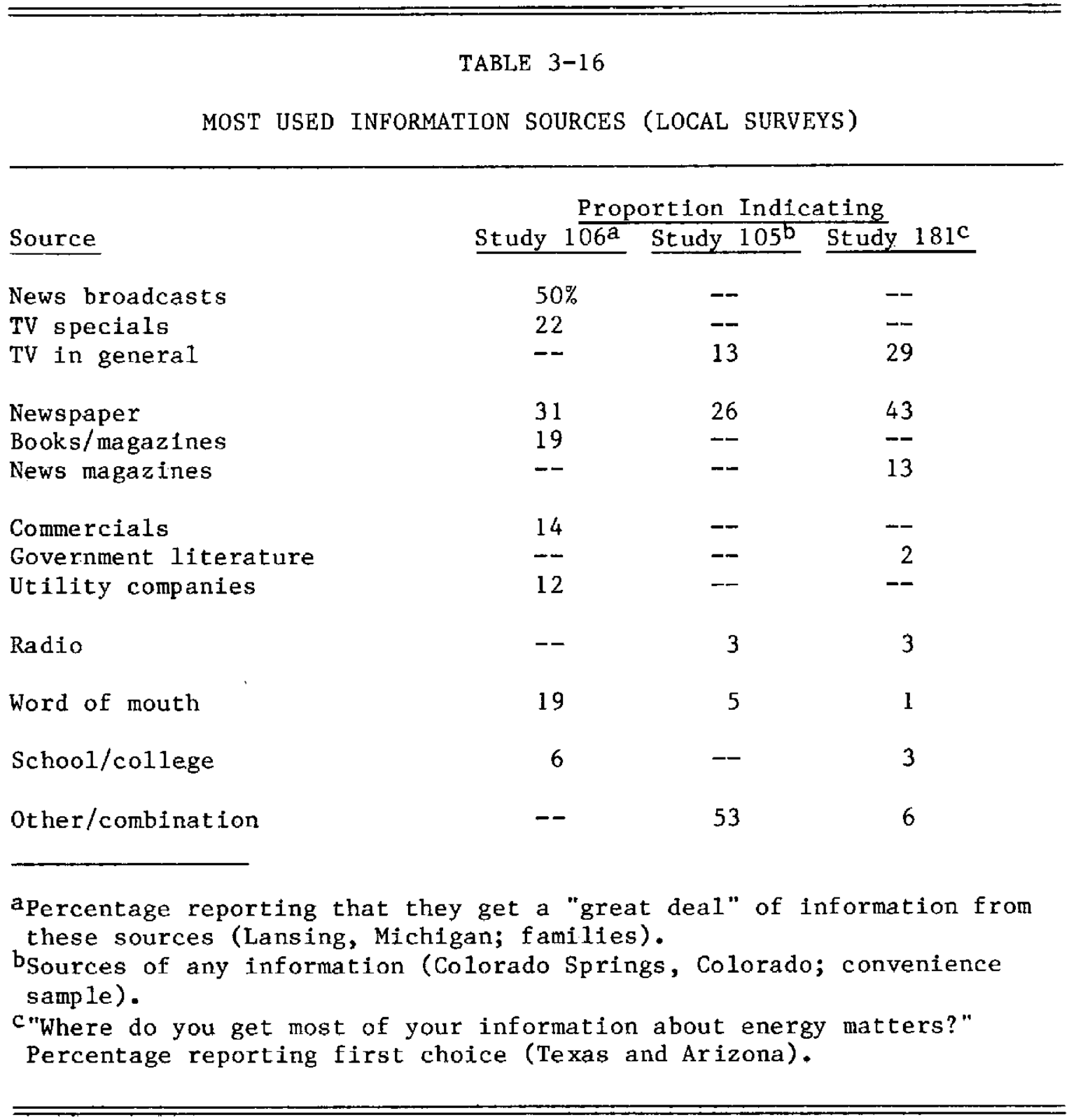


TABLE $3-17$

MOST TRUSTED INFORMATION SOURCES

Source

Network TV news

$\mathrm{TV}$ in genera 1

Daily newspapers

Nationa1 newspapers

News magazines

Magazines in general

Radio

Government literature

Oil company 1iterature

Natural gas company 1iterature

Electric company literature

Politician national

Politician local

No one

Word of mouth

Independent research

School

Other

Don't know

Proportion Indicating Study $1 \overline{41^{\mathrm{a}}}$ Study $116^{\mathrm{b}}$ Study $119^{\mathrm{c}}$

$28 \%$

18

18

--

18

4

4

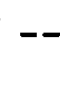

$-$

$-$

$-$

$-$

$-$

$-$

$-$

$-$

$-$

$-$

10
58

39

22

29

-

36

10

10

10

9

$-$

$-$

$-$

$-$

$-$

$-$

$-$

$-$
10

10

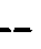

4

--

$-$

8

1

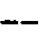

$-$

3

1

21

5

5

1

11

20

a Best job of reporting in full on energy shortages (media only, national sample).

bPercentage agreeing that information sources regarding the energy situation are accurate and honest most of the time (Colorado and Texas).

c"Whom do you trust most as a source of reliable information on energy problems?" (Grand Rapids, Michigan). 


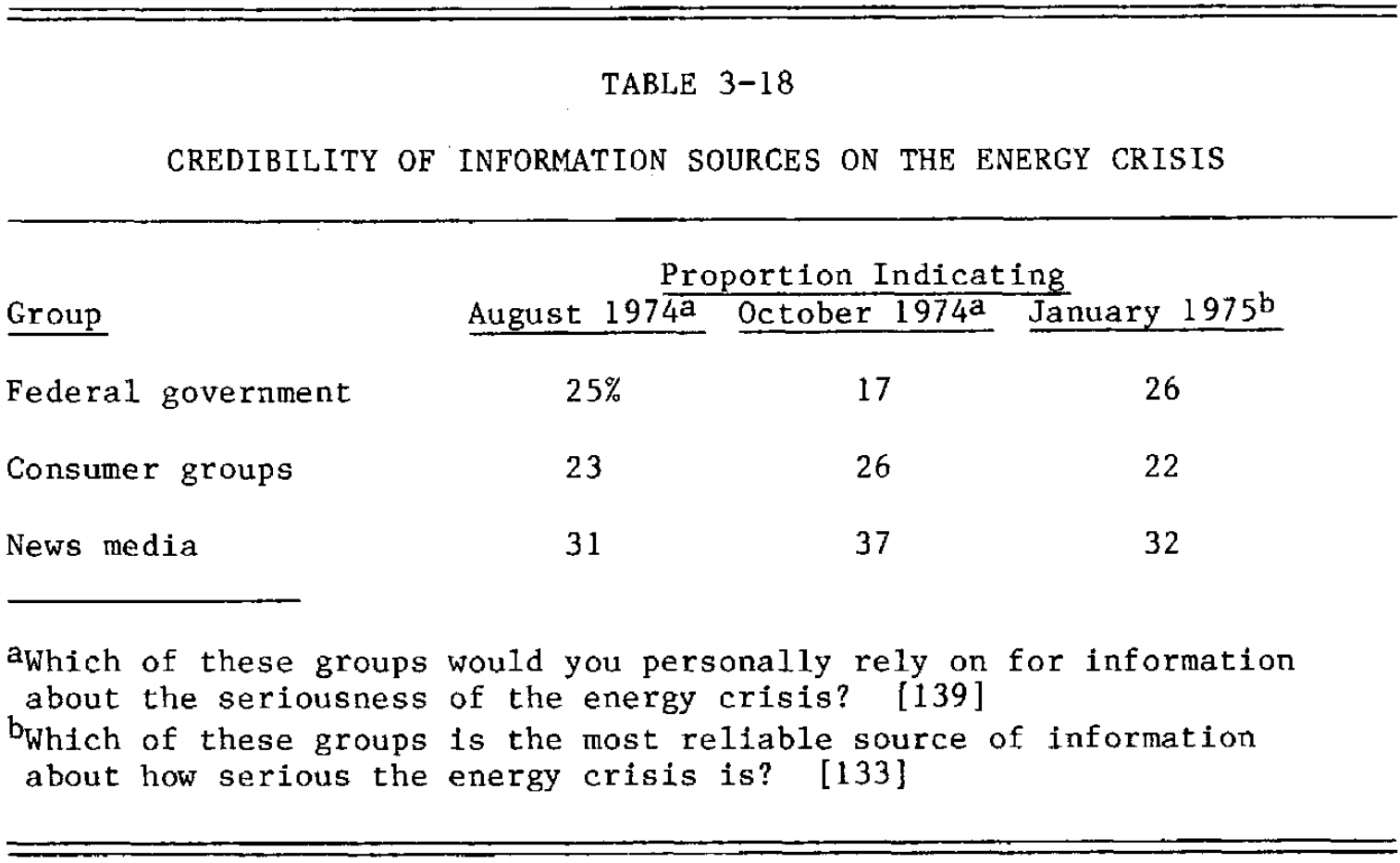


government and consumer groups. In another national survey, researchers offered a list of those who speak out on what needs to be done to solve the energy shortage. They asked respondents to choose which group they expect to find most believable on the subject. In this study, about a third chose government leaders. Responses did not change notably between 1973 and 1974 . Results are presented in Table 3-19.

In 1975 , a national survey asked whom respondents would be most inclined to believe if a statement were issued explaining why gasoline and oil prices had risen in the past year. Nearly one-third said they would believe Ralph Nader's office. The Federal Trade Commission and the Department of Commerce were selected by 15 and 13 percent, respectively. Other choices included major oil companies, the oil workers union, the American Petroleum Institute, and the National Association of Manufacturers, and each was selected by less than 10 percent of the respondents. Fewer people than in other studies (nine percent) listed "none." This item also asked whose explanations of price increases they were least inclined to believe. Over half ( 55 percent) indicated major oil companies. No other group was indicated by greater than eight percent [170].

A 1976 Arizona study asked respondents to agree or disagree with the statement, "I believe the utility companies when they talk about energy problems." A plurality of 41 percent agreed, 35 percent disagreed and 23 percent said they were not sure. Opinion was also divided over whether ecology groups present a biased picture of environmental problems related to energy [201].

In one study, there were no difference of opinion among regions over whom to believe when price increases were explained except when Ralph Nader and oil companies were mentioned. The West and Northeast were more likely than the South and Midwest to trust Ralph Nader. People in the West trusted oil companies less than did people anywhere else [170].

Although the limited data available indicate low public awareness of government efforts to solve the energy crisis, people have indicated that they are interested and that they follow presidential speeches and legislation. Mass media appear to be the major source of information about energy. Insufficient data and mixed findings on credibility of information sources prevent drawing conclusions about the public's trust in information received.

\section{Evaluation of Efforts to Solve the Problem}

Surveys included items asking respondents to evaluate the effectiveness of actions taken to address the energy problem by various groups in society. Most items centered around government action, but a few focused on action taken to ameliorate the problem by the public itself and by industry. Data on the perceived effectiveness of the response of these three-government, the public, and industry-are discussed below.

The Govemment. Most items about actions to help the energy crisis concern the federal government in general or Congress and the President in particular. Studies by Opinion Research Corporation traced public opinion in 1974 and 1975 on the question, "How satisfied are you with the steps taken so far to help relieve the energy shortage-are you very satisifed, fairly satisfied or not very satisfied?" In April 1974 people were asked about Congress and the President. About half responded that they were "not very 
TABLE $\quad 3-19$

CREDIBILITY OF INFORMATION SOURCES ON THE ENERGY SHORTAGE

Now here is a list of various types of people who speak out from time to time on subjects affecting our country. We'd like to know how believable you would find what those types of people have to say when speaking out on various subjects. First, which of those people would you expect to find believable on the subject of what needs to be done to solve the energy shortage? [160]

Type of People

Government leaders

Don't know

TV commentators

Business executives

Leaders in education

Newspaper reporters

None of them

Labor leaders

Religious leaders
Proportion Indicating

$1973 \quad 1974$

$34 \% \quad 33$

$17 \quad 17$

$17 \quad 11$

$15 \quad 12$

$15 \quad 11$

$13 \quad 10$

$12 \quad 12$

$9 \quad 6$


satisfied with steps taken by President Nixon." Slightly fewer (41 percent) said they were not very satisfied with the steps Congress had taken [134]. Another study with continuous interviewing between January and April 1974 showed 45 to 55 percent of the respondents rating the job done by the "government in Washington" as poor. There was an increase to 60 percent in the last week of January, possibly due to extremely cold weather and increased awareness of the problem [142]. A Harris poll in January 1974 found three of four Americans giving a negatve rating to the job the President had been doing in "handling the energy shortage" [237]. In the same month a Roper survey asked people about the sufficiency of steps taken so far by the government to deal with the fuel and energy crisis. Over half ( 54 percent) thought more drastic steps were needed. Thirty-six percent thought steps so far had been sufficient [174]. In May 1974 another Roper study asked people why they thought the gasoline shortage had eased. About 10 percent gave credit to actions of the federal government; many more people saw oil companies' or the public's actions as the reason [172].

When President Ford came to office, about one-fourth of a national sample said they were not satisfied with his steps, and one-third said they had no opinion [134]. In January 1975, 42 percent felt President Ford's recommendations had had some impact on fighting energy problems, as compared to 34 percent who felt there had been no impact [133]. In late 1974 and early 1975 national samples were asked, "How good a job do you think the federal government is doing in meeting its responsibility to conserve our supplies of natural resources-good, average or poor?" More than 40 percent rated the job as poor in both samples, although over one-third rated the job as average [256]. By April 1975, 52 percent indicated dissatisfaction with President Ford and 58 percent with Congress [131, 132]. By the end of President Ford's term, in 1977, nearly three of four respondents in a national survey were dissatisfied with the way Congress was handling the energy crisis. Most (66 percent) also gave the Ford Administration a negative rating on this issue [245].

President Carter's administration began in February with a higher rate of approval than did the Ford Administration (61 percent as compared to 42 percent) $[134,220]$. Yet by September of Mr. Carter's first year, approval of his handling of the energy situation had decreased from 48 to 38 percent in one national survey. As Table 3-20 shows, the public became more divided over how President Carter was handling the energy situation. The latest finding in these studies is for September 1977, but the pattern of increasing disenchantment with the performance of presidents on this question seems clear.*

One national survey asked about the energy plan that the Carter Administration has put forward. In April 1977 over half said their overall reaction to the plan was favorable; less than one-third said it was unfavorable [218]. In August of the same year, the majority of another national survey felt the energy program that had been passed by the House of Representatives would be "only somewhat effective" in getting the country to conserve energy, in providing greater supply of energy, or in decreasing energy use by 10 percent in 1985 [238]. Along the same line, using different items, two national surveys asked respondents if the energy plan goes far enough to help the problem. Table 3-21 displays the results during 1977 from the two questions. About a third indicated the plan was about right or adequate, about a quarter thought it was too stringent, and about another quarter thought it was too lax.

These data indicate that people were slightly more likely late in the year to think stronger measures were needed ( $a$ change of five points in one study and three points in

*This may well be following the pattern of general disenchantment with presidents as their terms progress. 
TABLE $\quad 3-20$

PRESIDENT CARTER'S HANDLING OF THE ENERGY SITUATION

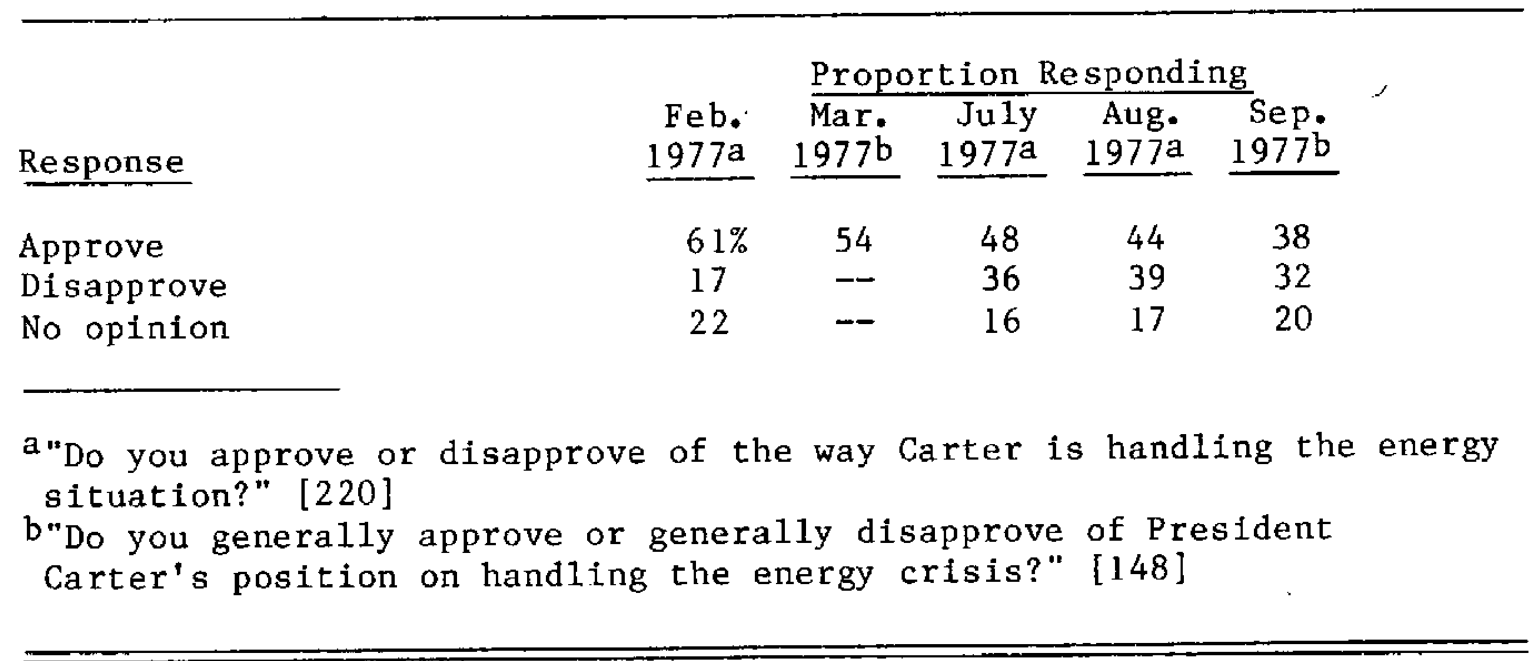




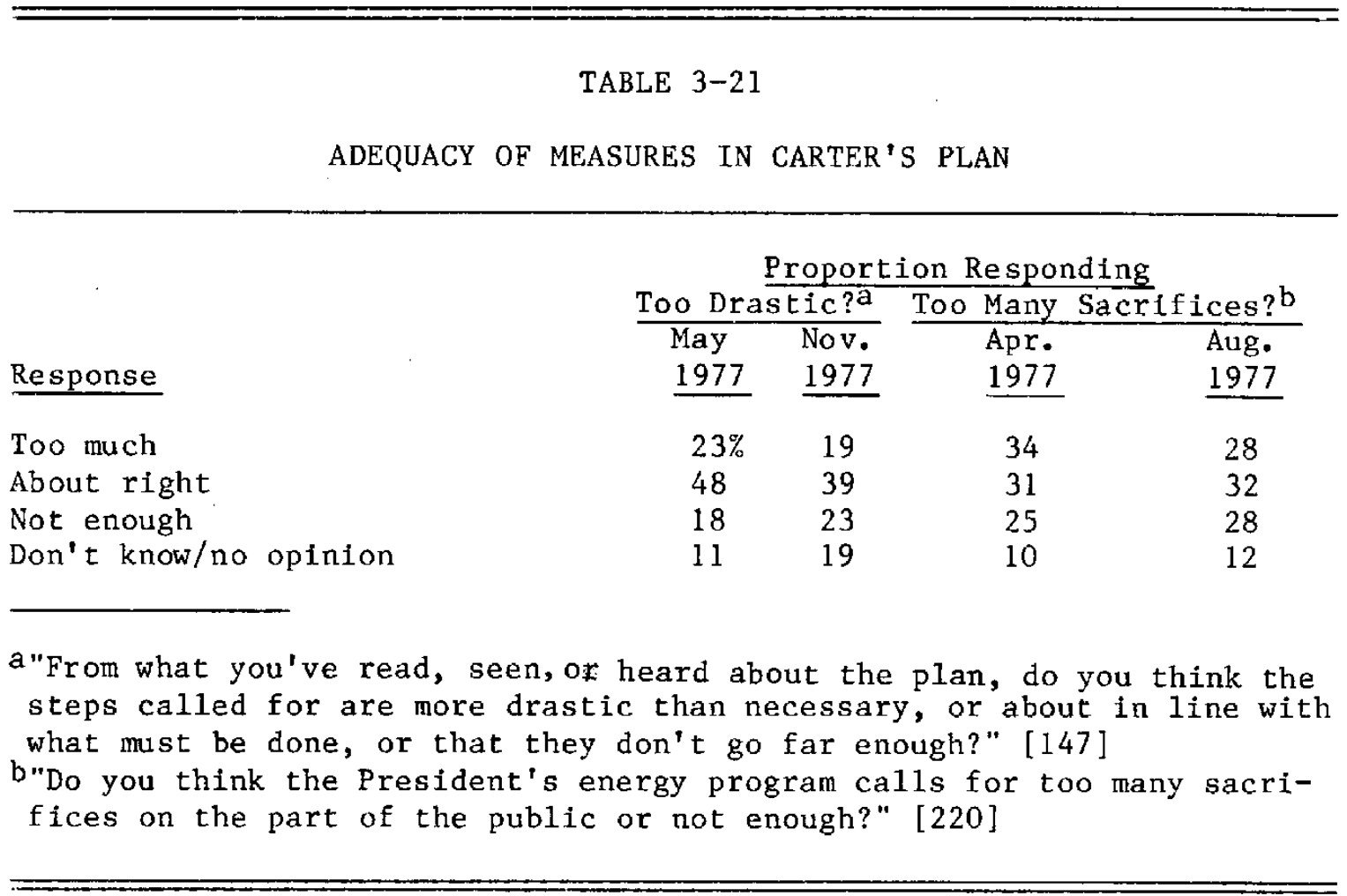


the other), and slightly less likely to think the plan asked too much (a change of four points in one study and six points in the other).

In December 1977, 83 percent of a national survey agreed that "while President Carter's energy program is not a final answer, it is a real beginning at giving this country an energy policy." A majority also agreed that the Carter White House did not do an effective job of selling the President's original energy program [243]. Conversely, a Harris poll in August 1977 found the public more positive than negative (49 to 36 percent) about how Carter was handling Congress to get his energy plan through. At the same time, people were evenly divided ( 40 to 41 percent) over whether the House of Representatives had done a good job in getting the energy program passed [238]. Another survey by Harris four months later found the majority (58 to 61 percent) rating as only fair or poor the job done by the House and the Senate on getting a bill on energy passed [243].

Although President Nixon received the most negative rating on handling the energy crisis, Presidents Ford and Carter eventually got negative ratings from about half of the public. Positive ratings averaged around one-third or fewer of the public. The Congress, too, did not please the majority of the public, especially in 1977. An energy plan, possibly more demanding than those presented, seems to be favored by the public. Since the Nixon Administration, the government has been attempting to deal with the energy crisis but has gained little public satisfaction with its efforts.

The Public. One study showed the public judging its own performance as better than that of other groups; however, satisfaction with this performance has lessened over time. Over one-third of respondents in a May 1974 national survey attributed the easing of the gasoline shortage to actions by the consuming public [172]. Between March 1974 and March 1975 the percentage of respondents saying they were "not very satisfied" with the public's efforts to relieve the energy shortage increased from 19 to 41 percent. But in 1975,52 percent still felt satisfied with the public's efforts to ease the shortage, a much higher rating than either government or industry received.

Industry. In a 1974 national survey, about half of respondents rated efforts by oil companies to relieve the energy shortage as "not very satisfactory." Nearly seven out of 10 respondents thought the shortage was eased because oil companies (due to higher prices) were supplying gas stations with all the fuel they wanted [172]. Although respondents were not satisfied with the job oil companies were doing to ease the crisis, they attributed to them the ability to affect the shortage.

The data available on public perception of their own efforts to respond to the energy situation, and those of oil companies, are too sparse to draw conclusions from them.

\section{Preferred Solutions}

Some attention has been paid in surveys to two major issues surrounding what should be done. First, should the action be predominantly public or private? Second, should action be taken to reduce demand or increase supply? 
Public or Private Action? In February 1977 Roper queried:

Do you think the federal government should set up a program to insure some of those ways of developing energy and to enforce some of those ways of conserving energy, or do you think it should be left to the private companies to explore new energy sources and to the public to voluntarily cut down on the use of energy?

Half of the sample favored a government program, while 41 percent felt things should be left to private companies and the public [153]. There was a different response, however, when conservation was separated from increasing supply. In 1974 about 45 percent of a national sample felt that the public had the most responsibility for seeing to it that natural resources are not used up. About 30 percent felt the federal government had the most responsibility [137, 139]. Three of four respondents in the same year felt the government should closely regulate companies that supply fuel, and the same percentage felt the government should not limit the amount of heating fuel that can be used per household [142].

In June 1974 Roper asked a national sample whom they thought would ultimately solve our energy problems. University research groups (38 percent) and private research centers/consultants ( 36 percent) topped the list. The federal government (33 percent), manufacturers of nuclear power generating equipment (30 percent), electric light and power companies (27 percent), oil companies (26 percent), and manufacturers of electric power generating equipment (22 percent) were also mentioned. As many people expected solutions from private institutions as from public institutions. The federal government and oil companies were singled out as "not working as hard as they should be on solutions" [171].

While these data are sketchy, they appear to indicate that, while government action is expected, private solutions might also be expected and helpful.

Reduce Demand or Increase Supply? The general approach to energy policy at the federal level has been to promote conservation as well as support development of new energy sources. Since 1975,77 to 87 percent of respondents in three national surveys have consistently favored government development of new energy sources and indicated that finding ways to conserve fuel deserves major governmental effort $[131,151,245]$.

There is some evidence in the surveys that people may be more favorable toward supply increases than toward demand reduction. An ORC study in January 1975 asked people about regulating energy production. Fifty-five percent favored such regulation while 36 percent opposed it. The response to regulation of energy use was somewhat more polarized; 48 percent favored regulation while 45 percent opposed it [131]. In a Harris survey conducted in May 1977, 66 percent of the public agreed that a key aspect of a national energy program would be one that "will conserve fuels that are most scarce and use those that are plentiful." In another item, 64 percent approved of a program that would "lead to the development of new, innovative sources of energy" [233].

A Harris survey in February 1977 asked, "Which is more likely to improve the country's energy situation over the next 10 years-a tough program to conserve fuel or a technological breakthrough that would provide new sources of energy?" Over half (53 percent) thought a technological breakthrough was most likely to help. One-fif th thought conservation would be more helpful and another one-fifth volunteered that both were 
likely to improve the situation [245]. Some optimism was expressed in a 1973 national survey that technical know-how would solve our energy problems without too much trouble [234].

Responses to items on "energy self-sufficiency" revealed some public sentiment about the supply/demand distinction. Eight of 10 respondents in 1975 and 1976 national surveys said they would like to see the United States self-sufficient in energy and less dependent on foreign sources. Fewer than 20 percent thought this was not a good idea [141]. Arizona citizens agreed overwhelmingly (85 percent) that "the United States should develop its own energy sources so it is not dependent on other countries to fill its energy needs" [201]. Just over half of sampled residents in the Yellowstone River Basin felt that self-sufficiency is an important goal even if some sacrifice is required to accomplish it [205]. It is not clear whether people thought these sacrifices would be due to demand reduction, supply increases, or both. Since no item offered respondents a choice between increasing supply or reducing demand, it is not clear that a policy of one without the other would be favored.

Data suggest that although people in the East were more likely to indicate correctly that the federal government had set up an energy agency and people in the South were less knowledgeable about the need to import foreign oil, there were no significant differences in opinions about the sufficiency of steps taken so far to help the crisis, favorability toward President Carter's energy proposal, and in responses to many other questions judging what has been done about the crisis $[137,147,174,218]$.

No regional differences were found regarding who has the major responsibility to see to it that we do not use up scarce resources or regarding the level of effort the government should spend to develop new energy sources and ways to eonserve $[137,151]$. People in the West were more likely than people in other regions to think their Congressman should give major attention to developing a national energy policy.

\section{SUMMARY: IS THERE AN ENERGY CRISIS?}

Perceptions about the energy situation in the nation (and extending beyond to the world) are relevant to consideration of public opinion concerning energy alternatives. Public receptivity to and support for government action and public engagement in its own autonomous action depend upon perception that a problem exists. Definition of a problem is requisite to a search for and evaluation of responses and solutions.

In understanding public opinion about energy in the United States, several points should be kept in mind. The survey is an attempt to measure and aggregate the variegated and segmented opinions of the polity. Opinion is known to be segmented by a variety of factors: reference group affiliation, geographical region, social class, occupation, and so on. What these differences mean is that each individual is located in a particular social structural milieu and thus experiences the environment differentially. Experiences relevant to defining whether or not an energy crisis actually exists can include, for example, whether one's own schools and factories have been closed due to fuel shortages, whether gasoline was available, whether utility bills increased, and what information was personally available.

Given these experiential differences, individuals further vary in their responses to experience. Thus, two individuals living in approximately the same life circumstances can respond in completely different ways to those circumstances. One might view an energy crisis as an exciting challenge to his creative ability and altruistic motives; another might perceive it to be a serious threat and seek to deny its existence. 
The reader should keep these complexities firmly in mind when attempting to use results of surveys. Common sense and avoidance of assumptions and truisms about "the public" also aid in enhancing accurate perception of public sentiment about the energy crisis.

Is there, then, in the public's mind, an energy crisis in the United States? The answer appears to be: tentatively, no, there is not an energy crisis; yes, there is an energy problem. About three-quarters of the public have consistently defined the energy situation as serious for the past five years. A plurality hovering around 40 percent defined it as very serious. With the beginning in 1973, more people tended to view the situation as very serious; this dropped off during 1974 and then rose slightly during 1975 to the present 40 -percent level, where it has remained ever since.

Early in the energy "crisis" the majority tended to view the situation as contrived, although by late 1977 the public was near to being polarized on this issue. A majority came to perceive energy shortages as real, but a large minority currently believe the situation has been contrived by various institutions in American society.

Oil companies and the federal government were perceived by many as the institutions most responsible for the energy problem in the nation from 1973 through 1977 . Much of the public was willing to admit that the nation engages in wasteful and unnecessary energy consumption. In addition, smaller proportions of the public blamed the OPEC countries, industry and business, and environmentalists for contributing to energy problems. Other causative factors defined by the public were growing populations and the finiteness of fossil fuel resources.

The government was perceived as responsible for taking action to improve the energy situation, but many also felt that the public and private industry shared the responsibility.

Impacts of the energy problem, varying in degree of severity from inconvenience to job losses, were experienced by most of the public. Some evidence indicates that impacts were borne disproportionately by those in lower income groups.

Survey data on the salience of the energy problem are difficult to summarize. Inflation, unemployment, and crime have clearly emerged from the body of data as grave matters of concern to the American public. Energy has not been viewed as of most nor of least importance, but has fallen somewhere between. For some, energy appears to be related to a set of issues including population growth and depletion of natural resources.

Survey sample majorities tended to feel that the nation faces energy shortages and rising energy costs in the foreseeable future, whether for political or natural reasons. About half of the public appears to be of the opinion that the nation's supply of oil and natural gas is beginning to dwindle, and smaller proportions perceive this trend on a worldwide scale. The public seems to place most faith in solar energy, coal, and nuclear energy as long-term future energy sources. 


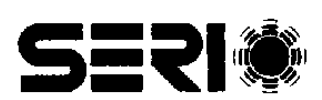




\section{CHAPTER 4}

\section{ENERGY DEMAND REDUCTION: CONSERVATION}

Conservation is a complex political phenomenon. The public has been urged by politicians to practice altruistic conservation because Americans have been world energy gluttons. They have also been asked to reduce consumption out of patriotic duty in a "moral equivalent of war." Programs of incentives and regulation (e.g., rationing) are viewed as alternatives if exhortation for voluntarism fails.

Conservation is not monolithic. It consists of hundreds of separate actions involving many decisiens by many people. Some survey items measured attitudes toward the idea of conservation in general. These are an important backdrop to detailed proposals. Reactions to specific conservation activities (e.g., turning down the thermostat) are also important because they reflect opinions of ten developed through action and experience. Public attitudes toward each conservation action addressed in the surveys are presented in this Chapter under the multivariate categories described in Chapter 2. Conservation actions are alternatives to doing nothing and, therefore, perhaps requiring increases in supply.

For the policymaker to assess the effectiveness of governmental exhortation, it is important to know which personal actions people report they are taking and how they feel about conservation. Favorability toward any given policy option does not necessarily follow from support for voluntary conservation, though this may be a necessary component. In this chapter, survey findings on energy conservation are presented in three sections: (1) perspectives on energy conservation in general, (2) transportation conservation, and (3) residential conservation.

\section{PERSPECTTVES ON ENERGY CONSERVATION}

\section{Perceived Effectiveness}

Few items in the studies reviewed dealt directly with perceptions of the effectiveness of conservation in helping solve the national energy problem. One item allowed Likert-type responses to the question, "How much impact do you think personal conservation efforts have on total consumption of energy?" In 1974 and again in 1976 the findings were similar: nearly three-fourths of the respondents felt personal efforts have at least a "fair amount" of impact on total consumption [ORC, 1974; 258]. Another national survey in 1974 found that six or seven of 10 respondents felt the gasoline shortage could be solved if individual consumers cut down on gasoline consumption. The rest of the sample, a substantial minority, did not think this would eliminate the shortage [142]. In contrast, Melber et al. (1977, p. 252) reported results of a national survey by Cambridge Reports not included in this review. In 1976 one-half of respondents agreed with the statement: "Conservation is a good alternative, but frankly there's not much I personally can do about it." It is not clear whether respondents viewed conservation as an effective solution to national or personal energy problems, or both. No items specifically addressed this issue. It is hypothesized as important to an understanding of conservation behavior to know whether people view saving energy as effective in solving perceived problems at the personal level, national level, or both. Lack of data on belief in the effectiveness of energy conservation as an alternative solution to energy problems is identified as a research gap. 


\section{Relative Advantage}

Little direct information exists on the perceived advantages and disadvantages of conservation in general. Support for national self-sufficiency and decreased dependence on foreign sources could be construed as a general benefit from reduced energy consumption, as could reduction of any of the disadvantages of increasing domestic supplies. One possible perceived disadvantage could be a decreased standard of living. The statement, "Conservation is not a realistic solution to the energy crisis unless we are all prepared to accept a much lower standard of living," drew disagreement from 57 percent of respondents in a Denver, Colorado, survey. A large minority (38 percent) agreed and six percent said "don't know" [120]. This finding indicates that most people in Denver did not think a conservation solution to the energy crisis would reguire a lower standard of living for everyone. There are no national data on this question.

One of the major reasons cited for conserving energy is cost. In 1974, between 50 and 60 percent of respondents in a national survey said they used less energy because of price $[131,132,142]$. More recent data on this question do not exist.

\section{Knowledge and Information Sources}

Knowledge is relevant to conservation in that the accuracy of an individual's understanding of how to conserve may determine the effectiveness of his or her efforts. This type of knowledge was tested in some surveys. Knowledge of specific conservation alternatives will be discussed in the sections to follow. Although empirical data are extremely limited, the existing evidence suggests that objective knowledge about how to conserve energy is not widespread.

In a Lansing survey, a majority agreed with the statement: "Government officials are not providing any clear directions to help families make decisions about energy use" [106]. No survey item asked people directly if they wanted such information.

No one source of information on energy conservation emerged as clearly more credible than other sources. In two national surveys, 83 to 89 percent of the samples favored the federal government, the oil industry, or newspaper and TV as sources of information on how to conserve energy $[131,245]$. Sixty-three percent believed newspaper and TV campaigns or presidential urgings were effective ways to cut consumption. Twenty-nine to 33 percent felt these would not be effective [245].

A Denver study asked respondents who they thought could most credibly request personal sacrifice regarding energy consumption. Scientists and engineers were favored by 19 percent; President Carter, by 17 percent. The third most popular source was "no one" (13 percent). Local political figures were chosen by three to nine percent. The local utility* and a "group of economists" each received three percent. Two percent saw the Energy Research and Development Administration (ERDA) as credibly requesting sacrifice [120].

*Public Service Company of Colorado. 


\section{Behavioral Intention and Action}

The amount and type of effort people make to save energy was the most popular topic of the studies reviewed here. Eighty-five to 95 percent of survey respondents indicated that they have tried to conserve at least a "fair amount" $[106 ; 131 ; 132 ; 134 ; 258 ; 308$; ORC, 1974d. In Lansing 82 percent said they had talked to others about it, with 25 percent indicating that they had tried to persuade neighbors to conserve [106]. One study found people skeptical about their neighbors' willingness to conserve. In July 1973, immediately following the first gasoline shortages, half of the respondents in a national sample disagreed with the statement: "If the public is using up too much of our energy resources, most people will be willing to use less air conditioning, less heating, and drive their cars less." A minority (39 percent) agreed and 12 percent were unsure [234]. More current data on individual perception of others' willingness to conserve energy do not exist.

Residential conservation measures have been consistently ranked ahead of reduced driving, both as preferred and actual actions and as those actions perceived as most effective $[115,116,119,120,133,207,212,240,260,304]$.

\section{Policy Preferences}

The issue of voluntary versus government-controlled conservation action is affected by the question of price. Belief in the energy crisis has been discussed as a potential motivator for conservation.* Price has also been mentioned by respondents as a reason for using less energy. In January 1974 a national poll found that "a sizable majority feels that consumption of gasoline is now being regulated by allowing the price to rise" [237]. Data reported in Chapter 3 indicate that many perceived rising prices as reflecting excessive profit-taking by industry.

Government manipulation of price through taxes may be an alternative for conserving energy. Three-fourths of a national sample believed it was "wrong" to control consumption by raising energy prices. They gave two reasons. First, they felt it is inequitable, favoring the rich and discriminating against middle and lower income families. Second, they felt that after a long period of inflation it is especially hard on consumers to pay more for such a key commodity [237].

Through government action or inaction, conservation might be encouraged by the increased cost of gasoline. Since November 1973, 76 to 88 percent of respondents have opposed the idea of raising gasoline prices to reduce consumption $[131,137,138,153$, $226,245,304]$. The most recent finding in the surveys (February 1977) showed 76 percent opposing this method of promoting conservation [153].

Regulation of energy use may be opposed by the public, even though it may be viewed as an effective means of reducing consumption. Perceived effectiveness and favorability vary with the action involved. In two local studies, about half of the samples felt that passing laws to force conservation would be effective in reducing consumption. However, two percent favored this action when voluntary effort was the alternative [106, 260].** In December 1973, a national survey found about half of the respondents saying

*See Chapter 7.

**Similar findings are discussed by Brown (1977) from the results of a March 1977 Gallup survey not included in our sample. 
that controls on consumption of energy were then about right. A large minority (39 percent) thought they should be stricter [212]. No other data were located on government regulation of energy use in general.

The effectiveness of price increases in encouraging conservation depends, according to the data from three surveys, on the amount of increase. In February 1977, one-half of respondents believed a $\$ 0.10$ per gallon increase would be effective in reducing consumption, 70 percent thought a $\$ 0.25$ per gallon increase would be effective, and 74 percent saw a $\$ 0.50$ increase as effective [245]. The proportion of respondents who said they would use their cars a lot less often because of price increased with the amount of the price increase. In 1975,54 percent said they would drive as much even if the price rose $\$ 0.10$ per gallon, and 22 percent said they would drive the same amount even if the price rose $\$ 0.50$ per gallon [241]. Another study in 1975 recorded 29 percent saying they would not drive less even with a $\$ 0.70$ per gallon price increase [134].

These data provide some limited evidence that increasing prices would reduce consumption. However, as reported, public opinion opposes price increases for gasoline. One study found that, compared to the price of other things they bought, 50 percent thought the price of gasoline was unreasonable (December 1974) [308]. In Lansing, Michigan, an added federal tax on gasoline was acceptable to a minority of 11 percent [106]. Proposals to adjust gas taxes and income taxes so that "people who drove a lot would pay more total taxes, and people who didn't drive a lot would pay less total taxes" were 46 to 58 percent opposing, 27 to 41 percent favoring, and 10 to 17 percent with "no opinion" [131, $132,133]$.

\section{Summary}

The survey data reviewed here on general conservation do not permit any conclusions to be drawn about perceived effectiveness, relative advantage, or knowledge and information sources. The public reports it is engaging in conservation. In seven national surveys, 85 to 95 percent of the public reported conserving at least a "fair amount." There are no data on behavioral intention.

In seven surveys between 1973 and 1977 , the majority (76-88 percent) opposed the idea of raising gasoline prices to reduce consumption. However, three surveys found that increasing proportions of the population indicated they would drive less as gasoline prices increased, suggesting that increasing prices might be somewhat effective in reducing consumption. The general findings on government regulation of consumption are too sparse to permit conclusions to be drawn.

The survey data reviewed in the next two sections address the details of two general categories of conservation: reduction of fuel consumption for transportation and reduction of domestic energy consumption. The different issues involved in these two types of conservation will be described. Within each of these general areas of conservation, specific private actions and government policies are addressed. 


\section{TRANSPORTATION CONSERVATION}

Two general ways of conserving transportation energy are driving less and increasing gasoline mileage. Survey data on each conservation mode are presented below.

\section{Driving Less}

Some alternatives to driving are carpooling, use of mass transit, plannng trips more carefully, and walking or bicycling instead of driving. Data on these alternatives are presented below.

Effectiveness and Relative Advantage. In the absence of recent findings, the perceived effectiveness of gasoline conservation in helping to solve the national problem must be gleaned from the following discussions of specific actions to conserve. In one national survey in October 1977 , a majority (65 percent) felt it important to reduce their driving by one-fourth; 31 percent felt it was not at all important [310]. In this same national survey, 35 percent said that it would be very difficult for them to reduce their driving by one-fourth, and 30 percent said it would be fairly difficult. One-third said it would not be at all difficult to reduce driving that much. Another study in Denver asked about driving less: 42 percent said it would be "almost impossible" to reduce driving and 39 percent said it would be inconvenient [120]. In Lansing, Michigan, about 30 percent sair they would have "great difficulty" reducing their driving, and less than 20 percent saia they could drive less with no difficulty [106]. In a national poll in 1977, nine percent said there is no way to get people to drive less; the rest of respondents were more optimistie [217].

One way to reduce driving is to combine trips with other people, or carpool. This is a voluntary effort by private drivers which can be facilitated by government action, such as the provision of special freeway lanes, reduced tolls, or computerized ride location services. It can also be somewhat coerced by reducing parking lot sizes.

None of the surveys reviewed asked if respondents thought the use of carpools was an effective way to reduce gasoline consumption. When a survey in South Carolina asked people why they would not carpool, 24 percent listed schedule conflicts, 19 percent said they needed their car for business, and 14 percent said it was too inconvenient. Other reasons listed were: live close to work, no one goes my way, car too small, like bus or other means, and don't believe in shortage [117]. There is no information in these studies on the perceived benefits of the use of carpools.

The use of public transportation such as buses and trains is another way to reduce driving. In two national surveys, a majority ( 80 to 86 percent) responded affirmatively to the question: "Do you think that increased use of mass transit will help save gasoline?" [129, 245]. In one survey, over half thought that the United States as a whole would benefit from increased and improved mass transit, while 31 percent believed that only those who use it would benefit [129]. In this same survey, respondents were asked about transportation costs; 61 percent believed that driving their own car to work cost more than using public transportation, and 28 percent felt public transportation cost more than driving [129]. It is not surprising, then, that when a national sample was asked about drawbacks to using public transportation, cost was not a major factor. The main problems involved schedule or route incompatibility, longer or irregular travel times, and overcrowding [255]. 
The pattern of findings with respect to the feasibility and relative advantage of driving less through reduction in trips, carpooling, or using mass transit was that these alternatives were viewed as infeasible and disadvantageous by majorities of survey samples.

Knowledge and Information Sources. In Lansing, Michigan, 24 percent of respondents correctly identified transportation as requiring the most energy for families [106]. None of the national studies contained items on this question.

There are no data on objective knowledge about driving less; instead, surveys record respondents' perceptions of good ways to reduce driving.

The planning of shopping and errand trips was thought to save gas by 94 percent of respondents in a 1975 national sample [144]; indeed, cutting out a shopping trip was preferred by 23 percent as a method to drive 10 fewer miles a week. The cutting of recreational trips was chosen by 22 percent; forming of carpools, 21 percent; public transportation, nine percent; and walking, 19 percent [256]. These 1975 data do not differ drastically from the data of a 1977 survey in which respondents chose the following "best" ways to get people to reduce the amount of gasoline usage by their cars: reduce shopping trips/unnecessary driving, 17 percent; carpools, 18 percent; improve/provide public transportation, 14 percent; and promote walking/bike riding, five percent [310].*

There are also no data in these surveys on knowledge and information sources on ways to drive less, such as carpooling or using mass transit.

Behavioral Intention and Action. Between November 1973 and May 1974, at the peak of the embargo, one continuous national study found 52 to 78 percent of respondents reporting that they had cut down on driving [142]. The peak of reported reduced driving (78 percent) was in late February 1974, with about 62 percent reporting this in late May 1974.

When asked what kind of driving was being reduced during this period, respondents most frequently reported social/recreational/shopping trips [149]. Table 4-1 displays data collected on reported conservation over four years by Roper Reports. These adjustments involved both driving less (e.g., walking on short trips, doing more errands on one trip) and increasing gasoline mileage (e.g., driving at slower speeds, buying a smaller car).

The data on behavioral intention concerned whether respondents would drive less and why. In March and April 1975, 62 percent in a national survey responded that they were willing to drive 10 miles less each week in order to reduce oil imports; 30 percent said they were "not too willing" [256]. In a survey of licensed drivers in Kentucky, 88 percent were willing to drive less [221]. When faced with the alternative of driving 10 miles less each week or facing gas rationing or price increases, 68 to 70 percent of respondents in a national survey preferred driving 10 miles less each week [256]. Roper asked car owners who said they were conserving why they were saving on gas. Table 4-2 shows that over half mentioned cost as at least a partial reason while 29 to 32 percent mentioned concern for the energy crisis [149].

\footnotetext{
* Other alternatives included in this item will be discussed later.
} 
TABLE $4-1$

REPORTED TRANSPORTATION CONSERVATION MEASURES TAKEN

Are you doing anything at the present time to save on the amount of gasoline you use? (If yes) Which of these things, if any, are you doing to cut down on gas?. (Card shown respondent) [149]

$\frac{1974}{\text { August }} \frac{1975}{\text { August }} \frac{1976}{\text { August }} \frac{1977}{\text { August }}$

Yes, saving

Driving at lower speeds

Doing more errands on one trip instead of golng out several times

$\frac{67 \%}{54} \quad \frac{75}{58} \quad \frac{70}{50} \quad \frac{74}{55}$

Having the car tuned and checked more often

Driving more carefully--starting up more slowly, stopping more gradually

Walking on short distance trips instead of driving

Bought a smaller car

Riding a bicycle some instead of driving

Golng to work in a carpool instead of driving alone

Cancelled plans recently for a trip by car

Using public transportation more and the car less for getting to and from work

Using public transportation more and the car less for getting around on errands and shopping

None of these

Don't know

No, not saving

$\begin{array}{llll}48 & 56 & 48 & 54\end{array}$

$\begin{array}{llll}27 & 39 & 37 & 41\end{array}$

$\begin{array}{llll}30 & 39 & 34 & 39\end{array}$

$\begin{array}{llll}25 & 32 & 27 & 31\end{array}$

$\begin{array}{llll}15 & 22 & 25 & 28\end{array}$

$12 \quad 13 \quad 12 \quad 12$

$\begin{array}{llll}11 & 12 & 11 & 11\end{array}$

$\begin{array}{llll}18 & 15 & 9 & 9\end{array}$

$\begin{array}{llll}4 & 5 & 5 & 6\end{array}$

Don't know

$\begin{array}{lrrr}\frac{31}{2} & \frac{24}{1} & \frac{28}{2} & \frac{24}{2} \\ 100 & 100 & 100 & 100\end{array}$


TABLE $4-2$

\section{REASONS GIVEN FOR SAVING GASOLINE}

Are you doing these things to save gas more because you are concerned about the gasoline shortage, or more because you want to save on the cost of gasoline? [149]

$\frac{1974}{\text { August }} \frac{1975}{\text { August }} \frac{1976}{\text { August }} \frac{1977}{\text { August }}$

More because of concern over gas shortage

More to save on cost of gasoline Both equally (volunteered)

Don't know

Not asked--answered no, don't know to

"saving on gas"

$\begin{array}{rrrr}7 \% & 7 & 8 & 8 \\ 34 & 44 & 37 & 39 \\ 24 & 22 & 23 & 25 \\ 1 & 1 & 2 & 2 \\ \underline{33} & \underline{25} & \underline{30} & \underline{26} \\ 100 & 100 & 100 & 100\end{array}$


According to six national surveys, five to 14 percent of the driving population belonged to carpools $[106,115,117,138,212,220]$. In one annual national survey, 11 to 12 percent of those sampled said they were carpooling to work to save energy. This figure was fairly constant from 1974 to 1977 [149]. A Los Angeles survey taken in March 1974 recorded the lowest participation-three percent [207]. In that year 13 percent reported participation in Indiana [304]; 21 percent in Detroit [260]. The reasons for these local variations are not clear, but could bear investigation if the use of carpools is to be encouraged.

Willingness to carpool was investigated in two studies. In Kentucky 82 percent said they were willing, while in South Carolina 52 percent said they would consider it [221, 117].

Public attitudes toward the use of carpools are not clear from these studies. A small proportion of the population appears to participate in carpools.

In 1975,22 percent of respondents in a national survey reported that public transportation was available to them [262]. Of those people who reported having it available, 20 percent said they used it; this was four percent of the total sample [262]. In the Chicago metropolitan area in 1977, where public transit is available, the majority (76 percent) reported that they took no trips on it, and about one-fourth said they used it fairly often [127]. Probably somewhere between four to 23 percent of those who have mass transit available use it $[127 ; 144 ; 262 ; 304 ;$ ORC, $1974 d]$. The data from these surveys indicate that the vast majority did not perceive it as available to them.

In 1975 a national sample was asked "How great is the need for mass transit?" in the 50mile area where they lived and worked. Most saw at least a little need, but about onefourth saw no need at all [129]. In a national sample taken in 1975, nearly half of chief wage earners not served by mass transit said they probably would use it to go to work if it were available, while the other half said they probably would not. Similar results were found regarding use for shopping [255]. In Kentucky a majority said they were willing to use public transportation [22 1]; in Indiana 38 percent of those car owners not served by mass transit said they would use it if it were available [304].

These data indicate that, if mass transit were made available, 38 to 48 percent might be willing to use it, but about half might not even try it. To speculate, the data suggest that about 20 to 25 percent who had it available would actually use it.

Although many people in one study considered reduced driving as an important conservation measure and said they practiced it, a large minority (30 to 40 percent) were skeptical of its value and/or said they could not reduce their driving [237].

Policy Preferences. People have been asked about several possible government actions to encourage carpooling. Reduced charges for bridges, toll roads, and parking spaces were preferred nationally by 55 percent over special lanes on freeways (13 percent) or limiting available parking to people who carpool (11 percent) [132]. In Los Angeles (March 1974), 70 percent favored special carpool lanes as one way to encourage conservation [207]. Compensation for the inconvenience of carpooling (here in the form of cost or travel-time reduction) may be a preferred form of government intervention.

In a national survey taken in August 1974, 62 percent of respondents thought reduced parking was a good way to limit car use and favored such action; 16 percent said that decreased parking areas would encourage them to carpool at least some of the time, and 
nearly half said it would not, while 38 percent did not know [137]. A study in November 1973 found 42 percent of respondents preferred parking limitations to higher prices as a means of encouraging the use of carpools, 32 percent preferred price increases, while 26 percent did not answer [132]. In February 1977 respondents were divided over the effectiveness, as a means of reducing consumption, of reducing parking spaces and increasing parking fees in metropolitan areas; 49 percent felt this would be effective, 42 percent did not [245].

Other factors besides availability could affect willingness to use public transit. Agreement was divided in a national survey taken in 1977 over the statement: "If there is a continuing problem with gasoline supplies, I would depend more on public transportation" [127]. In the same study, respondents were slightly more likely to expect "a lot of people" to switch to public transportation due to gasoline shortages.

Specific changes in the system met with equally divided responses. About $\mathbf{4 0}$ percent of car owners said they would be very likely to use a park-and-ride system, and about 40 percent said they would not be too likely to use it [308]. Shorter trips due to special bus lanes elicited 37 percent likely or very likely to use the system and 52 percent not too likely or not likely at all to use the system. These responses were from households in which a chief wage earner worked away from home and did not use mass transit [255]. A series of questions, directed at a national sample of chief wage earners who had public transit available but did not use it, illustrates the relative importance of various system changes. A 15-minute reduction in trip time or a decrease of the fare by one-half elicited a majority agreeing to the use of buses, but 42 percent remained unwilling. Running buses more frequently coaxed 40 percent to say they would use them [129].

While the evidence indicates that a majority would not use mass transit even if it were available, two national surveys found 60 to 78 percent of all respondents favored using federal money to improve mass transit in 1975 [131, 242]. A third study by ORC found 40 percent favoring government support (city, county, state, or federal) for mass transit. It was felt by 27 percent that users of mass transit should pay for it [255]. The findings were mixed when a choice was required between money budgeted for transit and money budgeted for highways. Two surveys taken in April and August 1975 showed pluralities favoring mass transit over highways. These findings exhibited some evidence of support for government spending on mass transit $[255,129]$.

Another government action which might be taken to promote mass transit is the provision of special freeway lanes. While a majority (81 percent) of national respondents in a 1975 survey thought special treatment for mass transit was a "fair or good" idea, the majority also felt that all travelers should be treated alike on highways, tunnels, and bridges during rush hour [255].

More information is needed on the conditions under which people who perceive mass transit as available to them would use it. The data suggest that up to half of those people who have mass transit available and recognize its disadvantages may be willing to use it if improvements are made.

\section{Increasing Gasoline Mileage}

Improving the efficiency with which gasoline is consumed is a form of conservation that can stretch energy supplies. Driving at slower speeds, driving gas-efficient cars, and eli minating emission control standards are three methods to increase mileage. 
Effectiveness and Relative Advantage. In 1974 and 1975 car owners were asked: "How concerned are you with the mileage your car(s) gets?" Twenty to 25 percent said they were not too concerned, over half were very concerned (49 to 57 percent), and 22 to 25 percent were fairly concerned [134]. This is the extent of survey information available on the perceived effectiveness and advantages of increasing gas mileage. No data exist on the perceived effectiveness of relaxing emission control standards or the 55-mph speed limit in conserving gasoline.

Too few data exist on the perceived effectiveness and relative advantage of increasing gasoline mileage to draw conclusions. This is identified as a research gap.

Knowledge and Information Sources. Some surveys have attempted to determine the effectiveness of information programs about gas mileage. The survey data contained more references to information sources and knowledge on this subject than on many other subjects. In December 1974, 63 percent of national repondents had heard or seen advertisements or read articles about gas mileage for new cars [308]. In December 1975, 56 percent of a national sample had heard of the EPA/FEA mileage figures for cars while 41 percent had not; most of those who had heard of the EPA/FEA figures had seen them on TV; others saw them in newspapers or in magazines [144].

Among car buyers in one study there was a widespread awareness of gas mileage information. By 1976, 82 percent of the new car buyers sampled reported seeing advertisements or information on new car mileage, 72 percent were aware of gas mileage labels on cars, and over half (53 percent) had seen a label on the car they bought [109]. A little less than half of the car buyers reported reading reports comparing gas mileage on 1976 vehicles. They reported seeing these reports in magazines (53 percent), newspapers ( 34 percent), consumer reports (21 percent), other sources (18 percent), and the EPA mileage guide for new car buyers (two percent) [109].

With respect to credibility, two national surveys of car owners in late 1974 and late 1975 found one-fourth of respondents listing auto companies as the most reliable source of information on gas mileage. About half felt that government agencies provided the most reliable information [308, 133]. While half of those (car buyers or not) who had heard of or seen EPA/FEA mileage figures found them at least somewhat believable [144], fewer of the car buyers who were aware of EPA new car mileage labels found them believable [109].

Of all those who had heard of the EPA/FEA mileage figures, half said they would be very important when making the decision on which new car they were going to buy [144]. Of those new car buyers aware of the EPA mileage guide pamphlet (approximately two percent of total buyers sampled), about one-third felt their purchase had been influenced by the guide [109].

Suspending auto emission controls is a possible gasoline-conserving measure. In 1974 and 1975 surveys, consumer groups were listed by one-third of respondents as reliable sources of information on the need for this action. The federal government was mentioned by another one-fourth as a reliable source [133].

The findings on awareness of gasoline mileage figures are too skimpy to permit drawing conclusions about the extent of this awareness in the population. Credibility of information sources-government, consumer groups, and industry-was explored by four studies, 
with each source enjoying some credibility in these survey samples. However, no pattern of findings was located.

Further, no data existed on knowledge or information sources concerning the effects of the 55-mph speed limit (driving slower) or of relaxation of auto emissions control in increasing gasoline mileage.

Behavioral Intention and Action. Buying a smaller, more gas-efficient car is increasingly mentioned as a conservation measure people are using. Since 1974, national samples have recorded a steady increase of people (from 15 percent in 1974 to 28 percent in 1977) who mentioned buying a smaller car as a conservation action [149]. A national survey in 1976 found that 36 percent of respondents who traded an old car for a new one said the new car was smaller, 49 percent kept the same size, and 15 percent got a larger car [109]. Another national poll in 1977 recorded seven percent saying they had bought a gas-saving car [220]. In Lansing, Michigan, in 1977, those who had bought cars since March 1974 were asked, "Was one of the primary reasons for purchasing your new car greater fuel economy?" A third said yes, 35 percent said no, and 32 percent did not respond [115]. Two of the three national studies indicate that about a third were buying smaller, more gas-efficient cars than they had before, while the other study found seven percent who reported doing so.

In 1977, although about one-half of car owners sampled owned full-sized cars, about onefourth of them planned to buy a full-size car next. Twenty-four percent owned intermediate cars, and 23 percent said they would buy an intermediate car next; 13 percent owned compacts, and 20 percent said they would buy a compact; 13 percent owned subcompacts, and 17 percent said they would buy a subcompact [150]. These data reflect "intentions" to buy smaller cars.

In 1975 the majority (67 to 70 percent) said they were very willing to drive a small car if most other people did, and 15 to 16 percent were not too willing [258]. In the same study respondents' assessments of the willingness of others was different. They were asked what percentage of the public would be likely to drive small cars. The average of responses was: 35 percent would be very likely to drive small economy cars, 43 percent would be somewhat likely, and, again, 13 to 15 percent would not be too likely [258].

Willingness to pay for fuel economy was checked in Denver, Colorado. In 1977, 74 percent said they were willing to pay $\$ 200$ more on their next auto purchase to get a device which would increase gas mileage; 19 percent were not willing [120].

Keeping cars in good running condition was recognized by 96 percent of respondents in Lansing, Michigan, as a conservation measure; 38 percent of these people reported that they maintained their cars more in 1976 than they did in 1974 [106]. "Having a car tuned more often" was mentioned by 41 percent of respondents as an action to cut down on gasoline consumption. Among the alternatives listed, only driving at lower speeds (55 percent) and doing more errands on one trip (54 percent) were chosen more often.

These data indicate that more people said they consider fuel economy, plan to buy smaller cars, or are willing to drive smaller cars than have reported actually making such changes (at least by 1977).

In December 1973, after the 55-mph speed limit had been proposed, 62 percent of a national sample said they were driving more slowly [212]. This percentage increased to 
between 67 and 68 percent in 1974 [217, 240] and decreased to 63 percent in 1977 [217]. In one study since 1974,50 to 58 percent of national respondents said they drive more slowly to conserve energy [149]. How slowly they say they are willing to drive has been investigated. In 1975 half said they would be willing to drive $55 \mathrm{mph}$ on major highways to save gasoline, provided everyone else had to drive at the same speed. Another 40 percent said they would drive even more slowly, while 11 percent said they would drive $60 \mathrm{mph}$ or more [258]. Reported actual driving speeds differed from what people said they were willing to drive. In 1975 about half said they were driving at $55 \mathrm{mph}$, in agreement with reported willingness. About 26 to 30 percent, however, reported driving under $55 \mathrm{mph}$, and 15 to 24 percent reported driving over $55 \mathrm{mph}[258,144]$. At the time people expressed willingness to drive at $55 \mathrm{mph}$ (1974), a majority ( 55 to 75 percent) felt that most people were observing the speed limit [142]. In the three studies mentioning it, from seven to 36 percent of respondents said they had switched to a smaller car. Only one item each examined plans to buy smaller cars, willingness to do so if others did and perceived willingness of others to drive smaller cars, thus permitting no conclusions about these variables. A pattern of reported slower driving (55 mph) is supported by the survey data, with four studies finding majority compliance. Behavioral intention and action regarding efficiency in gasoline use, other than driving slower, is a research gap that remains to be explored.

Policy Preferences. The majority of respondents (75 percent) in a Denver study favored government regulation of gas mileage on new cars. This finding coincides with a national survey where 67 to 81 percent of respondents supported this type of regulation [139]. In 1977, one-fourth of a national survey felt banning the production of larger cars which have poor gas mileage was one of the two or three things they were most willing to see done to conserve supplies of energy [152]. These data are sparse, but they suggest fairly widespread support for government regulation of automobile manufacture on gasoline mileage; more data are needed to indicate how far such regulation should go in the public's view.

One government action affecting availability of gas-saving cars is auto emission regulations. As noted, there are no data on the public's perceptions of the effectiveness of this alternative, their knowledge, information sources, or assessment of the costs and benefits.

There is a wealth of data on favorability to changing government policy on auto emissions.

The initial public response to relaxing pollution controls to save fuel was positive. In November 1973, 68 percent favored this action, while 21 percent opposed it [226]. In one study 22 to 39 percent agreed that "We should slow down the clean up of air and water pollution" [141]. Another study showed that 65 percent believed we can stop pollution and solve the energy crisis [232]. Since 1974, 42 to 48 percent of respondents in four studies favored removal of emission controls, while 39 to 45 percent opposed such action $[131,132,138,159]$. The latest result in these studies, from a national survey, was a majority agreement that removal of emission controls from cars is an important step to increasing supply over the next 10 years; 31 percent disagreed [245]. A sample of respondents in Indiana favored removal of controls 67 to 30 percent [304].

Delay of the stricter controls which were proposed in 1975 received even more support. In two studies, 54 to 62 percent approved that action, while 29 to 37 percent opposed it 
[134, 133]. Although the public was somewhat polarized on the issue of removing emission standards to increase gas mileage, sample majorities favor removing emission control standards and delaying stricter standards as an acceptable alternative. This is a pattern with strong empirical support in the survey data.

The most widely recognized form of conservation involving automobiles enforced by the government is reduced driving speeds. Nine out of 10 respondents in Lansing reported driving within speed limits as a possible conservation measure; 65 percent said they practiced it more in 1976 than they did in 1974 [106].

No items in the surveys reviewed asked people how effective they saw the 55-mph speed limit in conserving gasoline, how knowledgeable they were about its effects, or where they got information on the subject. Reported action and policy preferences were the main topics surveys addressed.

Government action to require lower speed limits has been favored since 1973. In June 1973, before the oil embargo, 51 percent of those who believed there was an energy crisis favored reducing the speed limit by $10 \mathrm{mph}$ [211]. By November 1973, before President Nixon's announcement of the 55-mph speed limit, 77 percent of a national sample favored lowering the speed limit to $50 \mathrm{mph}[226,212]$. There was some support for an even lower speed limit. In March 1977, 25 percent listed posting a 50-mph speed limit on highways as one of the two or three things they would be most willing to see done [152]. Favorability toward the 55-mph limit has remained strong since 1973 , never falling below 72 percent [207, 217, 131, 137]. In February 1977, 76 percent favored keeping the 55mph limit [217]. This is one form of government control for conservation, and possibly safety, which is widely supported. The empirical support for this conclusion is strong.

The government can encourage increased gas mileage by raising the cost of using less efficient cars through taxing policy. The main example presented to the public in surveys was a tax on "gas guzzlers," or large cars which get fewer miles per gallon of gasoline. A majority (63 percent) responded in February 1977 that a tax on gas guzzlers would be an effective way to cut consumption [245]. Sample majorities opposed this alternative in 1974, 1975, and $1976[106,131,137,147,153,159,238,242]$. In 1977, however, opposition fell from 62 percent in February to 35 percent in November [153, 147, 238], when 50 percent favored a tax on inefficient cars [147]. Faced with the choice of a tax on inefficient cars versus on gasoline itself, the majority favored the car tax in late 1974 [308]. A tax on gas-consuming luxury features at the time of purchase got equal percentages of favorable and unfavorable responses [131, 138]. Making owners of gas guzzlers pay more for gas was opposed by 79 percent [131].

Although about 70 percent of survey respondents believed gas rationing would be an effective way to cut consumption, sample minorities of 21 to 35 percent favored this alternative when presented by itself $[131,137,153,245,246,310]$. In one study, respondents preferred voluntary rationing (66 versus 21 percent), but 49 percent (versus 34 percent) did not believe voluntary conservation could work to avoid rationing in January 1974 [237]. In November 1973, 71 percent in one survey favored creating a standby rationing system [226]. In another, slightly more respondents thought rationing was not necessary (45 percent) than thought it was necessary (39 percent) at that time [142]. By May 1974 a minority of 12 percent in one survey thought it was necessary to ration gasoline [142].

Of those favoring gasoline rationing, 67 percent said it was the fairest way to sell scarce gasoline, 37 percent because it would force people to conserve, 15 percent said it would 
keep the price of gasoline low, and nine percent said it would eliminate panic buying and long lines [142]. Those people who opposed gas rationing listed the following reasons: there is no real shortage (64 percent), people can cut back voluntarily if necessary (21 percent), it will not be necessary when gas prices increase ( 15 percent), rationing would only create a "black market" (14 percent), I want to be able to buy all I need ( 12 percent), against government regulation (nine percent), and rationing creates too much red tape/ bureaucracy (nine percent) [142].

When people were given a choice between gas rationing and price increases, a larger proportion preferred rationing by four to 38 percentage points* $[119,129,132,133,134$, 246, 261]. The latest finding, in April 1978, showed rationing favored over price increases 55 to 19 percent [261].

\section{Summary}

The following patterns of findings were located in the survey data. These patterns have sufficient empirical evidence to support as conclusions:

- About 85 percent of the public report that they are conserving at least "a fair amount" of energy.

- The public prefers and reports engaging in more domestic energy conservation than in transportation conservation.

- Most of the public (about 80 percent) are opposed to raising prices of gasoline to reduce consumption.

- Driving less through reduction in trips, carpooling, and using mass transit is viewed as infeasible and disadvantageous by most of the public.

- Most of the public report that they are driving slower because of the 55-mph speed limit.

- Most of the public favor the 55-mph speed limit.

- Most of the public believe that gasoline rationing would be effective in decreasing energy consumption. Nevertheless, the public opposes gasoline rationing.

- Gasoline rationing, however, is preferred to price increases.

- Most of the public oppose special taxation for "gas guzzler" cars.

- Although the public is polarized on this issue, slight majorities favor relaxing emission controls on automobiles to increase gas mileage.

The following findings received very limited, weak support in the data. No conclusions are possible from the survey data available, but these findings are suggestive for possible future research.

*The exceptions are an ORC study [131] in January 1975 which found price inereases favored 46 to 45 percent and a Harris study in the same month and year which found rationing favored 60 to 25 percent. 
- The data suggest that, as gasoline prices increase, more people indicate they would use less gasoline. However, price increases are perceived as unfair and hard on consumers.

- The data suggest that willingness to drive more slowly and to buy smaller cars might be partially dependent on what others are doing.

- The data suggest that much of the public might support government regulation of the manufacture of automobiles to increase gas mileage of new cars.

- The data suggest that gas rationing is perceived by a few as a more equitable way to distribute scarce gasoline resources than price increases; however, others feel rationing would result in a "black market" for gasoline, thus undercutting its equity advantages.

The following were identified as research gaps:

- There are no national data on the question of whether energy conservation is thought to result in a reduced standard of living.

- No data exist on public belief in the effectiveness of energy conservation as an alternative solution to energy problems.

- No conclusions are possible concerning perceived relative advantage of conservation behavior.

- No conclusions can be drawn concerning the extent of knowledge on energy conservation.

- A research gap exists on the perceived effectiveness and relative advantage of alternatives to increase gasoline mileage (driving slower, relaxing auto emission controls, and buying smaller cars).

- No conclusions can be drawn concerning behavioral intention and action in increasing gasoline mileage, other than findings concerning compliance with the $55-\mathrm{mph}$ speed limit.

\section{RESIDENTIAL CONSERVATION}

Residential conservation efforts consist of activities to reduce energy used in heating and cooling of buildings and to reduce fuel used by appliances (including lights, hot water heaters, dishwashers, toasters, etc). Conservation activities include capital investments, such as weatherization or purchase of energy-efficient appliances, and lifestyle changes, such as the lowering of room temperature or changing of daily schedules.

\section{Effectiveness}

Assessment of the perceived effectiveness of residential conservation in solving the nation's energy problems or personal energy problems has not been conducted; this is a research gap. 


\section{Relative Advantage}

Consumption of electricity and heating fuels is an indication of space heating, lighting, and appliance use in the home. It is also a subject pursued in several attitude studies. A survey of New Hampshire residents found a majority (65 percent) very concerned about how much electricity they used, 20 percent were somewhat concerned, and 14 percent said they were not too concerned [258]. A Denver study found that a fourth of respondents believed from zero to five percent of personal utility costs could be saved by practicing conservation and installing energy-efficient products. About one-fifth felt as much as 21 to 30 percent could be saved. A plurality of 45 percent felt five to 20 percent could be saved while about 10 percent felt that more than a third of utility bills could be saved [120]. These data exhibit a wide variation in perceptions of the personal dollar benefits of conserving in the home. They suggest that cost savings may not be perceived as a significant benefit of adopting energy conservation, at least in Denver.

The public was asked if they were using less electricity because of its cost. They increasingly responded yes, from 41 percent in April 1974 to 64 percent in March 1975 $[131,132,134]$. A national survey taken in November 1976 found 90 percent saying they were doing something to save electricity. Twenty-nine percent of those who said they conserved volunteered that they did so equally to save on the cost of electricity and because of concern over the energy shortage. Forty-nine percent (up four points from 1974) said they conserved more to save on the cost of electricity, and seven percent (down three points from 1974) said they acted more because of concern over the energy shortage [156].

Of those in an Ohio survey who said they were conserving, 40 percent said they did it both to ease the energy shortage and to save money. Another one-fourth said they conserved primarily to save money; 11 percent said they conserved to ease the energy shortage. In Ohio, 51 percent felt other people conserved primarily to save money [122].

The only item in the surveys reviewed on the relative advantage of using appliances less was directed at the use of fewer lights. In this study, a majority seemed to see this as a useful and low-cost method of conserving. In October 1974, the national survey asked, "Do you think it is really worth the effort to use fewer lights to save energy, or would you rather save in other ways?" Sixty-eight percent thought it was worth the effort, six percent did not know, and 26 percent said they would rather save energy in other ways [139]. The same study asked about disadvantages associated with this activity. It was found that many people (49 percent) felt comfortable with one or two lights on when they were home alone. To others ( 45 percent) it made no difference. Four percent liked to have "lots of lights on" when they were home alone.

No survey items directly asked about the value of effort expended or of discomfort tolerated in home heating conservation. About 40 percent of those who had turned down their thermostats in Indiana said they felt cold or uncomfortable [304]. No information existed about the relative importance of these aspects in individual decisions to conserve. A study in Denver found that most people who had installed storm windows, weatherstripping, insulation, or fluorescent bulbs reported being "very satisfied" with the results [120]. Why they were satisfied was not investigated.

In summary, three studies indicated that the reasons given for taking conservation action were to save on utility bills and out of concern for the energy shortage. One of these suggests that saving money is the more important of the two reasons. However, another study suggests the belief that not a large proportion of utility bills can be saved through 
conservation. One study suggests that a sizable minority are uncomfortable if they turn down their home ther mostats. The empirical evidence on perceived relative advantage of domestic energy conservation is sketchy; no perception of strong advantage is revealed in the limited data available.

\section{Knowledge and Information Sources}

Even if people want to conserve, misinformation could cause them to achieve the opposite effect. There are few data on public knowledge regarding domestic energy conservation. Knowledge of the relative amount of energy saved by various conservation activities was tested in a national sample in early 1975. At that time, 54 percent incorrectly believed it was better to leave a light on than to turn it on and off several times in an hour, 50 percent incorrectly believed showers require more hot water than baths, 32 percent did not know that the hot water heater, over the year, uses more electricity than any other appliance, and so on [131]. In another study, a large proportion (4l percent) incorrectly believed that turning off a color TV for an hour or a black and white TV for two hours saved more energy than turning off five 100-watt light bulbs for an hour [142]. In October 1974, a third of respondents did not know what wattage of light bulb they usually bought, and 16 percent reported buying bulbs of 100 watts or more [139]. Most people did not know the efficiency of their gas water heaters or gas stoves [139]. Replication of these and other questions regarding knowledge of the efficacy of specific conservation actions is badly needed for policy design.

Knowledge levels regarding home heating energy conservation have been explored very little. Information dissemination programs are being tried around the country, and a few items from special population studies addressed reaction to them. In urban areas of South Carolina, interest in "audits" of home energy efficiency was investigated. Half of respondents were interested in audits, whether done by the state energy office or themselves [117]; half said they were not interested. A study by Willenborg (1977) found about 50 to 60 percent of those who had attended an energy workshop saying they planned to weatherstrip, caulk windows and doors, and insulate their attics "as a result of the workshop." About half reported that before attending the workshop they did not fully know what to do regarding these measures. Of course these self-selected respondents probably attended the workshop because they were already interested. About six percent said they planned to do nothing. More data are needed on the types of conservation information people have and want. The effectiveness of programs already operating should be studied to guide future efforts to disseminate energy conservation information.

Few data exist on energy conservation information sources. One national survey found 41 percent listing consumer groups as the most reliable source of advice on how to save energy in the home. Less favored were the news media (25 percent) and the federal government (19 percent) $[133,137]$.

A survey of New Hampshire electric utility customers found that 91 percent said they had an electric meter and 50 percent knew how to read it. Fifty-eight percent said they 
usually noticed how much electricity they used and how much money they owed,* and 66 percent said they read the pamphlets included with electric bills at least occasionally [253]. A study of Ohio residents found the electric company listed by 22 percent (the plurality) as the most reliable source of information about why utility rates have gone up [122].

The subject of schools as an information source was addressed in three surveys. In May 1975, 52 percent of the respondents with school-age children said that the school their children attended emphasized energy conservation at least a fair amount. About a tenth said their children were involved in a special energy conservation program in school [255]. In 1976, 48 percent said that as a result of things their children had learned in school, the children had made special efforts to conserve at home [130]. Utility companies were thought to be appropriate sponsors of special classes or programs devoted to energy saving in the public schools by 77 percent, and the government was thought appropriate by 66 percent [130].

Knowledge levels and infor mation sources on conservation using appliances have not been studied.

In summary, almost no data exist concerning knowledge, information sources, and perceived credibility of these sources for residential energy conservation. The few findings that did exist on credibility were mixed and possibly noncomparable (e.g., 66 percent of one sample and 19 percent of another identifying the government as a credible information source). A slight amount of empirical evidence suggests that the public is not knowledgeable concerning basic energy conservation facts-technical knowledge that would make efforts to conserve more effective.

\section{Behavioral Intention and Action}

As noted, a national survey taken in November 1976 found 90 percent saying they were doing something to save electricity [156]. A national survey in 1973 found 62 percent saying they were using less electricity in their homes [212]. Large majorities of respondents have said they engage in residential conservation $[115,116,119,120,133,207,212$, $240,260,304]$. In 1975 , and again in 1976 , a national survey found a plurality of about 40 percent saying they used "about the same amount" of electricity they used five years ago. About one-fourth said they used "some, but not a lot more." About a fifth said they used less [141].

Most of the surveys which addressed conservation through appliance use presented a list and asked about each appliance. Table 4-3 shows the findings for appliances listed in six national surveys since 1974. Turning out lights and turning off appliances not being used were the activities most often reported. Actions requiring slight changes of habit or planning or adjustment of schedules, such as running only full loads in dishwashers, were practiced less.

More people reported an effort to turn out lights when they were not needed than reported any other single conservation activity; in a list of possible actions, it was always

*This figure seems high considering that most electric bills are fairly difficult to interpret. Perhaps the high absolute level of payment or effective bill design could account for this. 
TABLE $4-3$

REPORTED HOUSEHOLD ENERGY CONSERVATION: APPLIANCES*

Prototypical item wording: Which of these things, if any, have you done so far to cut down on the use of electricity and heating fuel in your home? [145]

Activity

Proportion Responding

Turn off lights when not being used

Been more careful about turning off lights

Turn off TV when no one is watching

Turn off radio when no one is listening

Waiting to run dishwasher or washing machine until there is a full load

Replace Iight bulbs with lower wattage more than used to

Use major appliances less

Use cold water to do laundry

Use fireplace more $197 \overline{4} \quad \underline{1975} \quad 1976 \quad 1977 \quad 1978$

$83 \% \quad 81 \quad 80 \quad 85 \quad--$

$\begin{array}{lllll}71 & 63 & - & 72 & 71\end{array}$

$\begin{array}{lllll}70 & 69 & 67 & 70 & -\end{array}$

$\begin{array}{lllll}58 & 49 & 53 & 55 & --\end{array}$

$\begin{array}{lllll}46 & 35 & 43 & 44 & --\end{array}$

$\begin{array}{lllll}32 & 31 & 33 & 33 & \rightarrow\end{array}$

$\begin{array}{lllll}26 & 26 & -\cdots & 31 & 32\end{array}$

$24 \quad 24 \quad 23 \quad--\quad--$

$\begin{array}{lllll}13 & 11 & - & 14 & 15\end{array}$

*Compiled from studies 134, 142, 145, 147, 156, 170. 
practiced most (by about 80 percent) $[106,115,116,133,134,142,145,170,181,207$, 240,260 ]. In January 1978,71 percent reported engaging in this activity [145]. One national study showed that the percentage of people reporting increased efforts to turn out lights had risen from 81 percent in November 1975 to 85 percent in November 1977 [147].

Replacing bulbs with those of lower wattage was reported as practiced by about a third of respondents [134, 145, 147, 181, 207]. In one study, although a majority recognized that low-wattage bulbs use less energy, a minority of about a fourth indicated willingness to use lower wattage to conserve energy [145].

The hot water heater is the largest household consumer of energy, although evidence suggests most people do not know this. Responses were divided evenly among those who had their hot water heaters set on "hot," those whose heaters were set on "warm," and those who did not know [258]. A majority (61 percent) in this study said they were very willing to turn their hot water heater down to "war $m$ " to save energy. One-fourth were somewhat willing, and 14 percent said they were not too willing. These same respondents felt other people would be less willing than they were to make this adjustment.

The same study investigated willingness to change the timing of household activities to conserve energy. Half of the respondents said they were very willing to do laundry or dishes after 9:00 p.m., when the demand for energy is lower. Those not willing to do this constituted about one-fif th of the sample. Most of these respondents felt others would be less willing than they to make these changes [258].

As Table 4-4 shows, the majority of respondents in four studies reported that they were keeping their houses at a lower temperature. In addition, in an October 1975 survey, a fif th of respondents reported keeping a thermostat setting of under $68^{\circ} \mathrm{F}$, while nearly 30 percent said they would be willing to keep their thermostats that low to save energy provided everyone else did. Half of respondents reported having their thermostats set above $69^{\circ} \mathrm{F}$, and 39 percent said they would choose this setting to save fuel. A third said they would set thermostats at $68^{\circ} \mathrm{F}$ to save heating fuel [258]. Two-thirds of these respondents thought other people would be "very likely" or "somewhat likely" to keep their thermostats set at $68^{\circ} \mathrm{F}$ during the day and $60^{\circ} \mathrm{F}$ at night. From January 1974 to February 1977, the percentage of respondents who reported keeping their house at daytime temperatures below $68^{\circ} \mathrm{F}$ rose 20 points (from 22 percent to 42 percent) [153]. By February 1978, however, this percentage decreased to 25 percent [145]. Proportions reporting that they decreased their house temperature declined slightly from 1973 to 1977 (73 to 61 percent), then rose in 1978 to 67 percent $[134,145,147,164]$.

A national survey in 1975 recorded 62 percent saying that "keeping homes heated at no more than $68^{\circ} \mathrm{F}$ in the winter" is "something we should do" to conserve energy supplies [159]. In March 1977, 35 percent favored keeping homes at $65^{\circ} \mathrm{F}$ or less in the winter [152]. Keeping office buildings and factories at $65^{\circ} \mathrm{F}$ or below was favored by 34 percent.

In four studies, shutting off some rooms and using the air conditioner less have been practiced by about a third of samples as seen in Table 4-4. When asked whether using home air conditioning units only in extremely hot weather in the summer is something we should do to conserve supplies of energy, 79 percent said yes in 1974, 1975, and 1976. This is a considerably larger proportion than those who reported actually conserving on air conditioning [159]. 
TABLE $\quad 4-4$

REPORTED HOUSEHOLD ENERGY CONSERVATON: HEATING AND COOLING*

Prototypical item wording: Which of these things, if any, have you done so far to cut down on the use of electricity and heating fuel in your home? [145]

Activity

Lower house temperature

Shut off some rooms

Use alr conditioner less in hot weather

Put in weatherstripping

Insulation in roof or walls

Installed storm windows or doors
Proportion Responding

$1973 \quad 1974 \quad 1975 \quad 1976 \quad 1977 \quad 1978$

$\begin{array}{llllll}73 \% & 74 & 65 & - & 61 & 67\end{array}$

-- $36 \quad 32 \quad--\quad 35 \quad 39$

$\begin{array}{llllll}- & 34 & 27 & 32 & 36 & -\end{array}$

$\begin{array}{llllll}- & 19 & 19 & - & 27 & 32\end{array}$

-- - $\quad 22 \quad--\quad--\quad-\infty$

$\begin{array}{llllll}- & - & 10 & 11 & 16 & 21\end{array}$

*Compiled from national studies 134, 145, 147, 164. 
Weatherization activities, such as installing insulation, storm doors, or weather stripping, not only require some effort but cost money as well. Fewer respondents (10 to 20 percent) reported these conservation adaptations than the ones described above. There is a minimal amount of evidence that they have become increasingly popular since 1974 (see Table 4-4). This type of conservation activity is done as retrofit to existing buildings and as an extra item in new home construction. Such activity cannot be practiced by everyone. A recent study of senior eitizens in New York (Unseld, 1978) asked if they could weatherize their homes if given the money or material. Nearly half said they could. About 16 percent said it was not necessary. Of the 32 percent who said no, most said they lacked the knowledge, skill, or physical ability, but many said no because they did not need it. About three percent listed "not permitted by landlord" as a reason.

Most surveys have asked questions about weatherization only of homeowners. A study by RUPI, Inc. (1977) found that over half of the new homebuyers sampled in major U.S. cities said they were planning to pay extra for energy-conserving features, such as additional insulation. A study of householders in South Carolina found a third saying they planned to install stor $m$ windows, storm doors, and insulation [117]. When asked about purchase intentions "within the next three months," even people who said their home needed such weatherization did not say it was very likely that they would buy [133]. When asked how long they would be willing to wait to get their money back in fuel savings due to insulation, 45 percent of a sample in South Carolina did not know. Of those who answered, over 70 percent said two years or less [117].

In summary, the data exhibit a pattern of majorities indicating they are practicing residential energy conservation. Most frequently taken conservation actions include turning off lights and appliances when not in use and lowering the thermostat. Used moderately are lower watt light bulbs, shutting off rooms, using air conditioning less, and running full washer and dishwasher loads (by about a third of samples). Less frequent conservation practices employed by approximately 10 percent are cold water laundry, use of fireplaces, weatherization, and insulation.

\section{Poliey Preferences}

Several types of policy options to promote residential conservation have been presented in surveys for public reaction. These include peak-load pricing, tax incentives, appliance labeling, building codes, and daylight savings time.

Incentives. Peak-load or "time of day" pricing proposals are designed to encourage use of appliances at times when energy is more plentiful. This has not been a popular proposal. In three national samples, peak-load pricing was opposed by 73 percent in 1974 [137] and by 63 percent in 1975 [131].* In 1976, 74 percent opposed a proposal to "put a time clock on home electric meters so that electricity used during peak daytime hours costs substantially more" [159]. In New Hampshire people were asked how likely they would be to change the timing of activities to off-peak hours and take advantage of lower electricity costs [253]. About half of respondents in this study said they would be likely to change laundry habits, but most said they would probably not change other habits. A national survey found 72 percent of respondents reporting willingness to schedule energy

*Melber et al. discuss the effect of question wording on response. Questions have been phrased in terms of peak power costing more, rather than off-peak power costing less. 
consuming activities during off-peak hours. Over half felt that others would also be willing to reschedule activities [258].

Positive monetary incentives appear to be the most popular policy option to promote conservation. In an Illinois study in 1977 , the majority judged tax incentives for energy savers and the publication of energy-saving tips as the most effective government measures. About half felt that regulation would be effective, and less than one-fourth said that higher prices would be effective in getting people to conserve energy [108]. A study of California, New York, and Michigan residents found a tax rebate plan preferred to mandatory action and utility rate schemes to urge energy conservation [123]. About 80 percent of respondents in one local and two national surveys favored a tax credit or deduction of up to $\$ 400$ on home insulation [106, 238, 243]. A national survey in 1976 asked if, given an income tax credit (unspecified amount), respondents would install weatherization features in the next year or two. About 11 percent said they would [164]. In 1975 those people who said they did not have attic insulation were asked how likely they would be to buy some within the next three months if the federal government gave back one-half of the cost. A third said they would be "very likely"; a fifth, "somewhat likely"; and half, "not too likely" [133]. When asked the same question about storm windows, one-half said they would not be too likely to buy [133].

Regulation. Regulation to promote conservation through appliance use has been proposed. The majority ( 83 percent) of a national sample favored requiring appliance manufacturers to inform consumers how much electricity a product uses [13l]. In Denver, 81 percent favored labeling appliances concerning energy use and half favored setting standards by law for how much energy home appliances could use [106].

Regulation to promote home energy conservation was the topic of several survey questions. A South Carolina study found a sample majority favoring standards of energy efficiency for buildings. Codes for new buildings were most favored ( 91 percent), with new houses ( 87 percent) and existing buildings (64 percent) following. A large minority (35 percent) opposed such standards for houses at the time they are sold [117]. A study in Denver also found a large minority (42 percent) opposed to a law prohibiting houses from being sold unless they had proper levels of insulation [120]. A law specifying a maximum home ther mostat setting of $65^{\circ} \mathrm{F}$ was opposed in Denver by about 80 percent of respondents [120]. About 13 percent in a national survey in March 1977 supported banning the use of air conditioning unless the temperature went above $90^{\circ} \mathrm{F}$ [152].

A form of government action which affects both timing of appliance use and heating requirements is year-round daylight saving time. On February 1, 1974, this proposal went into effect. This controversial action was addressed in several surveys. The data suggest that energy saving has little to do with whether people favor or oppose year-round daylight saving time. A national sample majority (73 percent) in May 1974 said they favored year-round daylight saving time even if it did not save energy [142]. In fact, 14 percent of this sample believed that more energy was used during daylight saving time. In another study, a majority reported that they were not doing anything differently in the evening because of daylight saving time [256]. Although the level of support varied greatly over even one month's time, sample majorities favored daylight saving time [106, $131,137,142,212,226,2561$. The latest data, from March 1977, showed about onefourth approving year-round daylight saving time as one of the three things they would be most willing to see done to conserve supplies of energy [152]. 
Schedule changes involving work or school were favored by less than 20 percent of respondents in one national and one Kentucky sample [152, 221]. In 1973, a national survey found that half supported closing schools in the winter to save fuel [226].

In summary, mast of the existing data on preferred government policy to encourage or require energy conservation consists of one or two items; conclusions cannot be drawn from these data. One pattern located was majority opposition to peak-load pricing. Another was majority favorability toward tax credits on deductions for installing insulation. Considerable data revealed a pattern of majority favorability toward daylight saving time, but virtually no evidence exists that this favorability is related to its energy-conserving effects.

Summary. The following conclusions concerning residential conservation are supported by patterns identified in the survey data.

- Most people report they are practicing some form of residential energy conservation.

- The practices most frequently engaged in are those which are least inconvenient and least effective. As the conservation measure increases in inconvenience and/or cost, it is practiced by fewer people. Practiced most frequently (by 70 to 75 percent) are turning off lights and appliances when not in use and lowering thermostats. Practiced by about a third are use of lower watt bulbs, running full washer and dishwasher loads, shutting off rooms, and decreasing air conditioner use. About one in 10 use cold water for laundry, use fireplaces for heat, weatherize, and insulate their homes.

- Policy options preferred by most of the public were daylight saving time and tax credits or deductions for home insulation. Opposed by much of the public was peak-load pricing.

Although the following findings are not conclusions, a slight amount of empirical evidence suggests that they may be fruitful areas for further research.

- The data suggest that, among the general public, levels of technical knowledge concerning how to conserve energy effectively are low.

- The data suggest that perceived decreases in utility bills may be a more important motivation for engaging in energy conservation than concern about an energy crisis.

- The data suggest greater willingness to engage in domestic energy conservation if others do so as well.

The following were identified as research gaps.

- No data exist on the perceived effectiveness of residential energy conservation practices in helping individual or national problems.

- Very little data exist on information sources for residential energy conservation information or on the perceived credibility of conservation information sources.

Differences in conservation-related attitudes by geographic region of the country are summarized below. 
No notable regional differences were found in attitudes toward conservation policy. In one study, mandatory plans were equally opposed in all regions [123]. In another, the importance of reduced driving and perceived best ways to do this did not vary by region [310]. Support for the $55-\mathrm{mph}$ speed limit did not vary nor did opposition to gas rationing. No regional differences were found in willingness to perform most home conservation tasks in response to tax credits. One study found that people in the Midwest were much more likely to say they would weatherstrip.

Reported home conservation efforts illustrate a difference attributable to climate. In two studies, respondents from the South were much less likely to say they had turned down their thermostat than people in other regions [212, 220]. There have been no such differences noted for reported reductions in electricity use [212].

Belief that fuel economy is the most important feature of a car was least likely to be a response in the East and most likely in the West [109]. One study found that people in the East were less likely to say they had reduced driving speed to conserve while those in the West were more likely to say they had done so [217]. Another study, however, reported no significant differences among regions on driving speed, reduced car use, or use of carpools [212]. 


\title{
CHAPTER 5
}

\author{
SOLAR ENERGY
}

Solar energy has received little attention in surveys of the American public. Several questions on solar energy have been asked in 14 national surveys contained in this review. Solar energy is of ten included in lists of energy sources for people to approve. Most of the information discussed in this section, however, comes from 12 detailed studies of local samples and subgroups of the population. The subgroups were usually defined by researchers as representing the "potential market" for solar energy devices. The samples were homeowners, homeseekers, or people who said they would buy a home within a few years. These samples of ten were not randomly drawn and the percentages reported in findings cannot be interpreted as representing the general public. What these studies can reveal is the opinion of potential customers located through special sampling. They can also shed light on the major concerns of respondents about solar energy.

\section{EFFECTIVENESS}

Very few survey items asked about judgment of solar energy's technical effectiveness and feasibility. A Harr is study in 1975, and again in 1976, asked a national sample whether or not they thought the United States had at that time the technical know-how to build enough solar energy plants to meet our electric power needs. In both years about equal portions of the public felt the know-how existed or did not exist. The general public differed markedly on this question from political leaders, business leaders, and regulators, most of whom said the technology was not yet developed. Most environmentalists also thought the technology was not yet developed, although by 1976 nearly onethird felt the United States had the know-how. The majority thought it would take 10 years or more to build enough solar power plants to meet a major part of our electric power needs. Most political leaders, business leaders, and regulators expected it to take more than 25 years [141].

A study in Arizona found about half the sample agreeing that solar energy is practical today, and one-fourth said they were not sure. When asked if solar energy was predictable enough to be dependable for widespread use, 40 percent were not sure, while about 40 percent said it was sufficiently predictable [201]. A survey of homeowners by RUPI, Inc. (1977), found a large majority agreeing with the statement, "The most promising energy source of the future is the sun," with one-fourth indicating it was then likely that they could get residential systems which made economic sense. A study of San Diego homeowners found just over half saying that solar equipment for homes was available at the time of the study. About one-third thought it would be five years or more before it was available [252].

One item addressed solar space cooling. In 1974 a little over half of a national sample thought it sounded reasonable, and 45 percent said it sounded "pretty far-fetched" [142]. Climate was seen by some as a drawback to solar energy's feasibility in several areas.* In San Diego over half of homeowners sampled agreed with the statement, "Solar may not

\footnotetext{
*E.g., Phoenix; Kansas City; Minneapolis; New York; Washington, D.C.; and San Diego.
} 
work in your area because of too many clouds or fog." Three out of four thought solar power might not work because of cold temperatures [252]. Climate problems were mentioned by respondents as a major disadvantage of solar power (see Table 5-2). Climate was also mentioned as a disadvantage of solar applications in three other studies [209; 302; Scott, 1976].

Other concerns about the feasibility and effectiveness of solar energy mentioned by repondents in seven studies included: (1) solar energy is still experimental [117; 209; 252; Scott, 1976]; (2) it would not produce enough heat [104, 209, 252]; and (3) storage problems $[252,302]$.

In summary, about half of two national samples and one local sample thought solar energy was technically ready now to produce electrical power or other energy needs. Another local study found half perceiving solar energy as a future but not necessarily a present option. Special samples of political, business, regulatory, and environmental leaders thought solar energy was not currently feasible as reported in one study. Climate, storage, and need for back-up were perceived by sample minorities as problems associated with solar feasibility. The suggestion from these findings is that solar energy was perceived by many as not currently capable of producing much of the nation's energy supply, due to construction needs and its experimental status.

\section{RELATIVE ADVANTAGE}

Some data addressed the advantages and disadvantages of solar energy for the nation as a whole and for individuals. Advantages of solar energy have received more attention in surveys than disadvantages.

Table 5-1 displays factors that might enter into a solar purchase decision as they were ranked by a large sample of homeseekers using a forced choice item. Perceptions of the advantages and disadvantages of solar energy on each of these issues have been explored in other studies as well. The discussion below presents findings on each of these factors.

\section{Initial Price}

The cost of a solar system was mentioned in studies most often as a disadvantage. Cost can be broken down into several components; when items permitted, respondents of ten made these distinctions. Initial price has several aspects, such as increased down payment, increased mortgage payments, problems getting loans, etc. A study of Denver and Philadelphia homeseekers found people more concerned about increases in first cost and mortgage payments than increases in down payment and problems getting loans [Scott, 1976]. The proportion mentioning cost as a disadvantage in this study was 28.2 percent. These same homeseekers said that monthly payments or increases in initial cost were the most important factors to them in comparing solar to conventional homes. Respondents in Colorado Springs, Colo. listed initial cost as the most important financial concern (and second most important overall concern), followed by operating costs, maintenance costs, and insurance rates [105].

Tables 5-2 and 5-3 show that cost ranked first as a volunteered disadvantage of solar energy and as a reason given for negative solar purchase intentions among homeowners, homebuyers, and small local samples of the general public. The proportion mentioning cost varied from 21 to 59 percent in the different samples, and among those who chose 


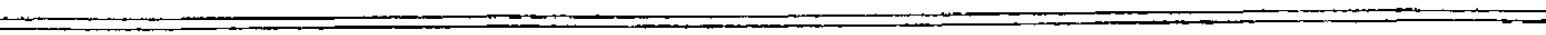

TABLE 5-1

PURCHASE DECISION FACTORS

Assume that you are considering a solar hot water system for your new home. Listed below are a number of factors that might enter into your decision on whether or not to purchase the system. Please indicate the FOUR characteristics that would be most important to you in making your decision by placing a "1" next to the most important, a "2" next to the second most important... (RUPI, Inc., 1977)

\section{Decision Factor}

Initial price of system Reduction of utility bills

Reduced dependence upon utility companies

Repair and upkeep cost of the system Civic duty to help conserve energy Number of years system will last Desire for a cleaner environment Amount of (heat) hot water provided Increase in the resale value of the house Manufacturer's reputation Availability of financing for the system Solar collector's appearance on the outside of the house
Proportion Ranking lst or 2nd

$59.7 \%$

56.4

14.2

13.4

9.5

8.7

8.2

7.0

6.7

5.7

3.8

3.1 
TABLE 5-2

VOLUNTEERED DISADVANTAGES OF SOLAR ENERGY

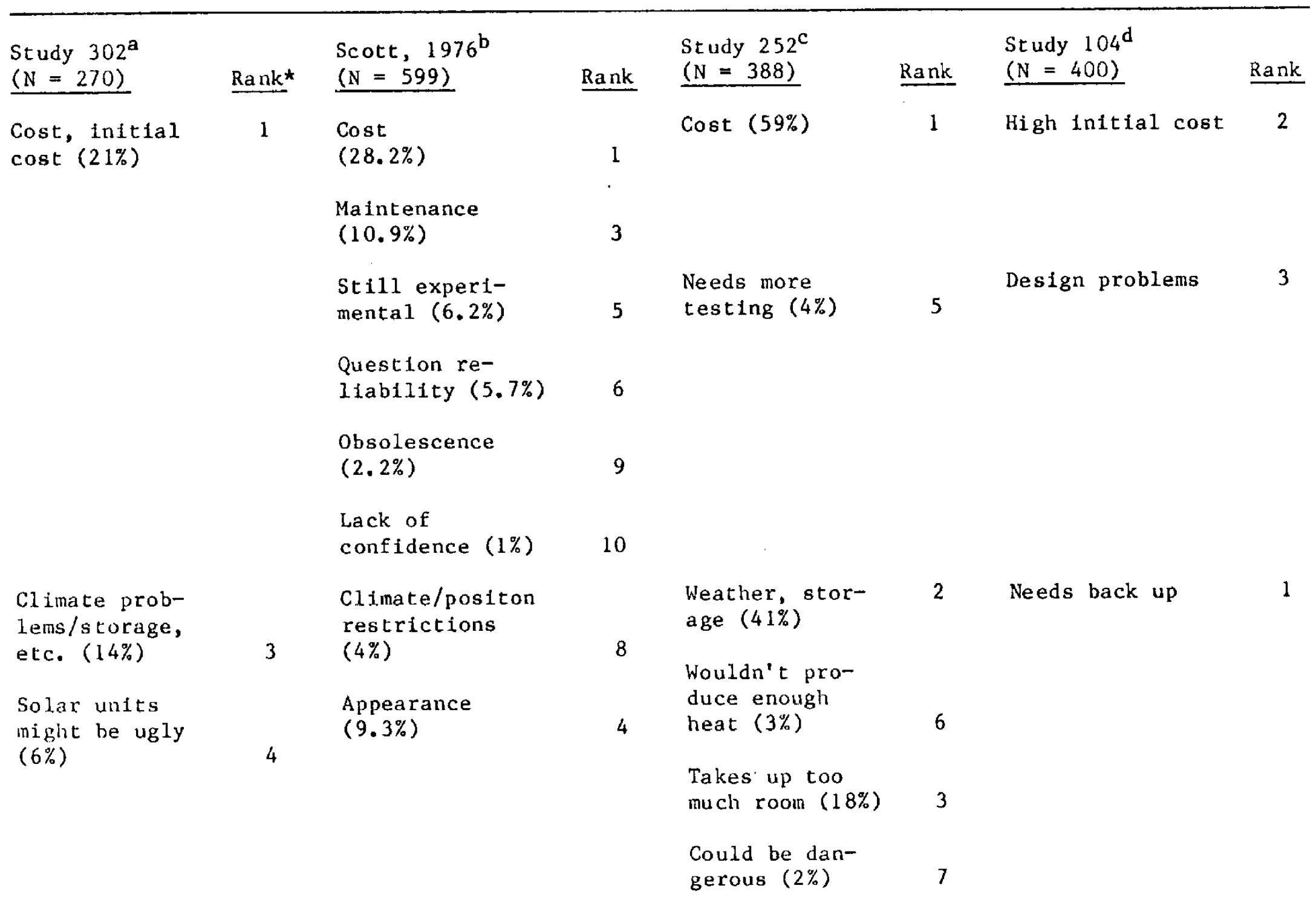


TABLE 5-2 (continued)

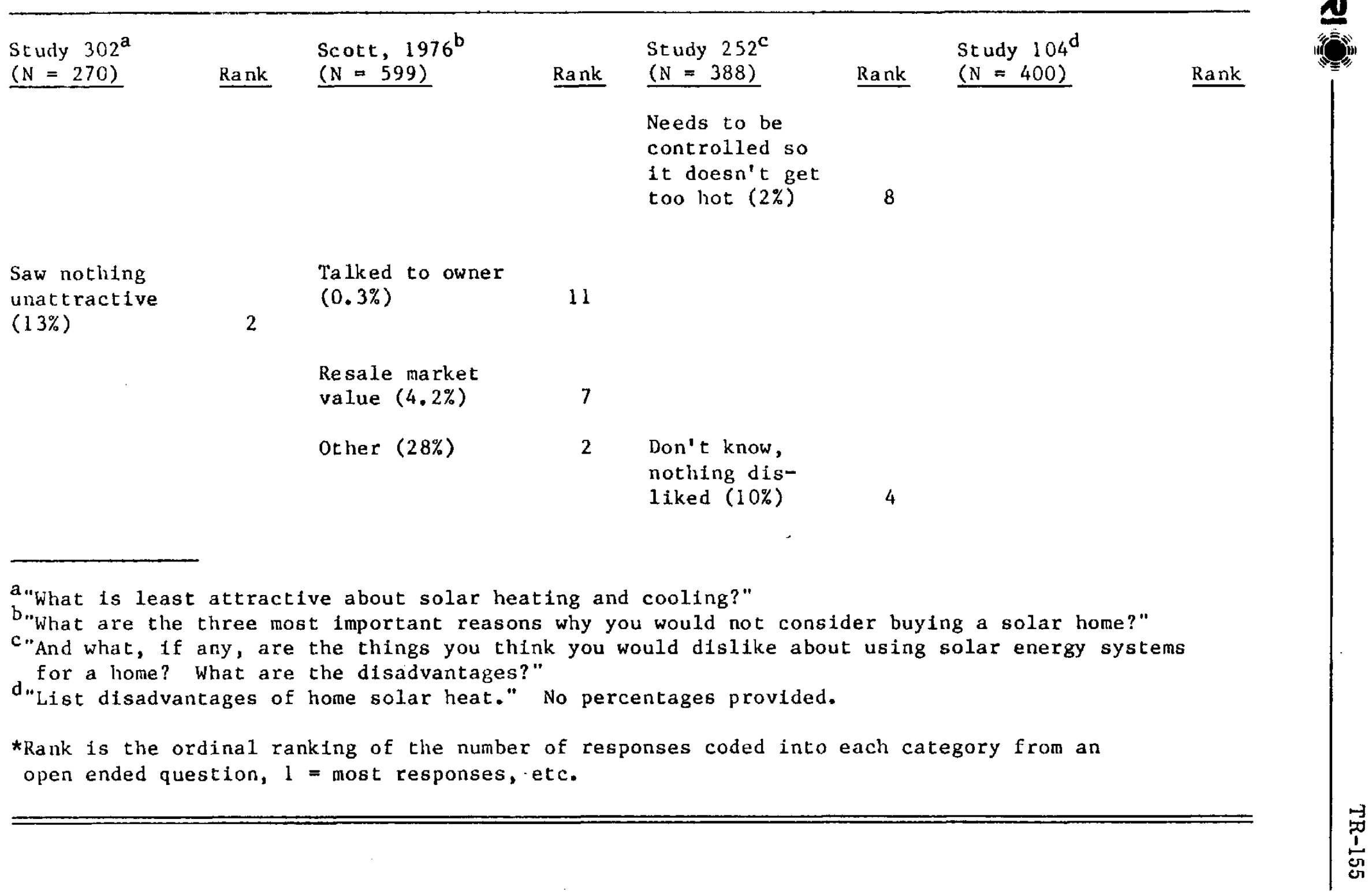


TABLE $5-3$

VOLUNTEERED EXPLANATIONS OF NEGATIVE SOLAR PURCHASE DECISIONS

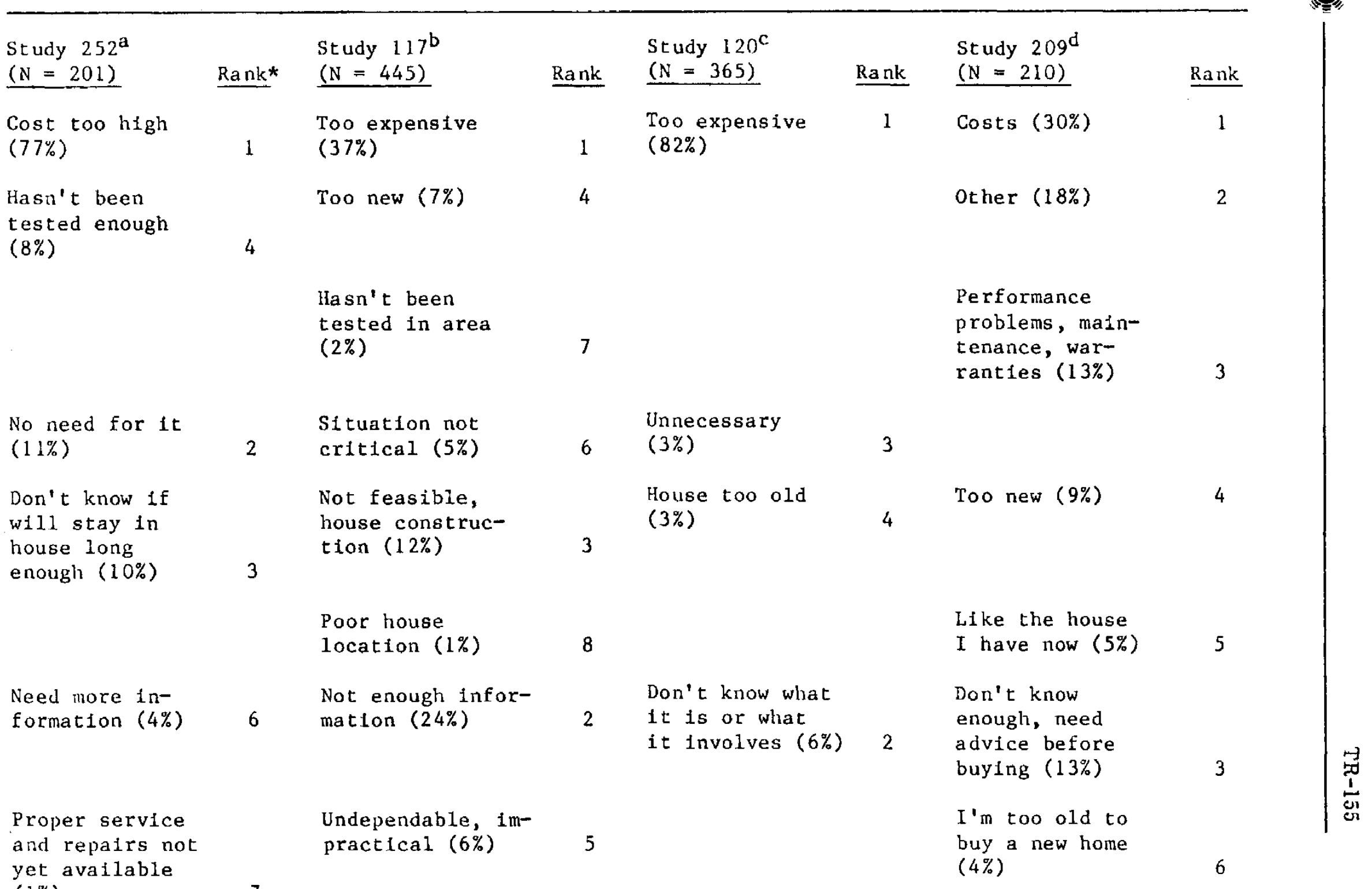


TABLE 5-3 (continued)

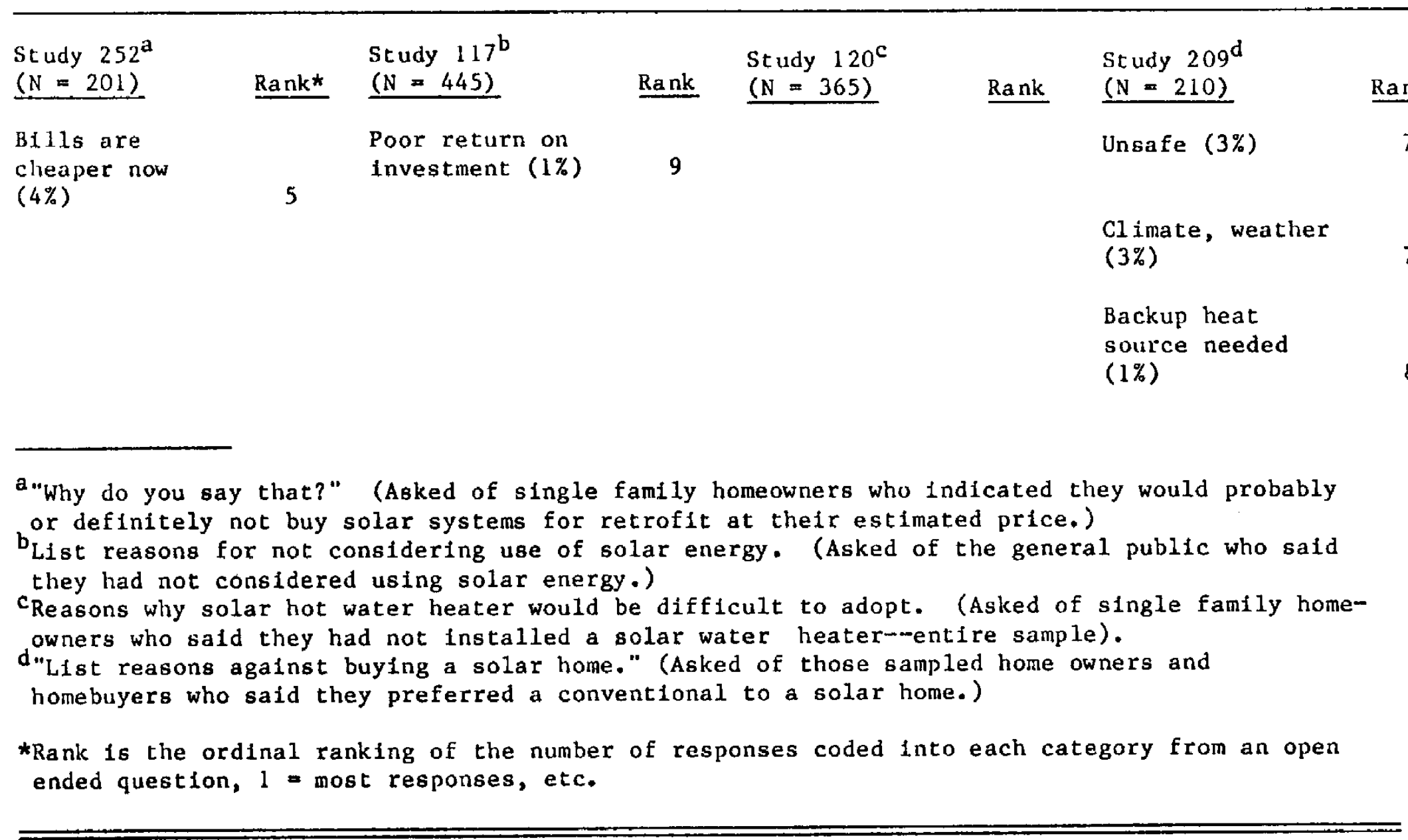


not to purchase solar energy, from 30 to 82 percent of the subsamples. Cost was, in all cases, mentioned more frequently than other perceived disadvantages.

A study by R UPI, Inc. (1977) asked homeowners and homebuyers in eight U.S. cities about perceptions of solar heating and hot water systems. Respondents felt (by about two to one) that the price of a solar water heating system would be too high. No clear findings on expectations about increases in mortgage payments or down payments were found. More of this sample tended to agree than disagree that it would be easy to obtain financing. These findings indicate that first cost of a solar system is a major disadvantage perceived by homeowners. Since surveys have not asked people about the relative importance of the several aspects of this cost (down payment, mortgage payments, and loan requirements) it is impossible to determine which are perceived as most important.

\section{Reduction of Utility Bills}

Perceived advantages of residential solar energy are summarized in Table 5-4. Scott (1976) found homeseekers (39.4 percent) to be very concerned about the amount of fuel savings they could expect from a solar-heated and cooled house. They ranked this factor second only to increases in initial home cost as important in judging alternative solar and conventional homes. Data summarized in Table 5-4 indicate that 76 percent of another sample [252] mentioned cheaper utility bills as a perceived advantage of solar energy (compared to 59 percent mentioning cost as a disadvantage).

Studies which asked about utility bills found most people expected the use of solar energy to lower these bills for the homeowner. Over half of the San Diego County homeowners sampled believed strongly that with solar energy their utility bills would be lower [252]. RUPI, Inc. (1977) found more than half of their sample agreeing with the statement; "A solar system would lower my utility bills substantially." The most of ten volunteered advantages in Table 5-4 are saving resources, saving energy, and cost savings. These were mentioned by 17 to 31 percent of samples. In addition, low cost was mentioned by 16 percent in one of these samples. These advantages may have been tied to expected reduced utility bills. Reduction of utility bills was perceived by homeowners and homebuyers in five studies as an important advantage. There are no data on how the general public views this factor [209; 252; 302; Scott, 1976; RUPI, Inc., 1977].

\section{Redueed Dependence on Utility Companies}

Reduced dependence, when offered as a choice to respondents in the RUPI study, was chosen by many people as an important factor in their purchase decision. This advantage of solar energy systems was also volunteered in two of the five studies represented in Table 5-4.* Most respondents in the RUPI study agreed that a solar water heating system would protect them from future energy shortages. Such protection and reduced dependence were seen as advantages of solar energy systems.

\section{System Maintenance}

Scott (1976) found maintenance (especially costs) to be of greatest concern to people in deciding to purchase a solar home. Three studies in Tables 5-2 and 5-3 mention system

\footnotetext{
*This item could have fallen into the "other" category of the remaining three.
} 
maintenance as a specified disadvantage of solar systems. Scott found this to be the second most often mentioned disadvantage, noted by 10.9 percent. Responses like "question reliability," "too new," "hasn't been tested enough," "still experimental," and "cost" could express concerns about maintenance, performance, and effectiveness. Maintenance specifically and the uncertainty of experimental systems generally seem to be common concerns. Yet, respondents in the San Diego Gas and Electric study (1976) seemed to have confidence in solar systems. Over half agreed strongly with statements that solar heating is reliable, rarely breaks down, and that maintenance is simple and relatively inexpensive. The RUPI study found opinion divided on whether repair and upkeep costs for a solar system would be low. A plurality of respondents did not know how to answer. Another item in this study asked people how likely they thought it was that they could currently obtain reliable and dependable residential solar water heating systems. Again, response was equally divided between those who thought it was likely and those who thought it was not. A large number did not know.

One of the explanations given by San Diego respondents who would not buy solar systems was that proper service and repairs were not yet available [252]. About one-third of respondents in the RUPI study agreed with the statement, "Manufacturers of solar systems would be little companies that would be here today and gone tomorrow." About half disagreed with this statement. This concern may also have been represented in some of the responses about maintenance, reliability, and newness of solar systems.

On the other hand, two of the five studies in Table 5-4 show "low maintenance" as a volunteered advantage of solar energy systems. This notion could also be included in other general statements respondents made about advantages of low cost and high efficiency in solar systems.

Some respondents identified maintenance as a disadvantage of solar energy systems, while others identified easy maintenance as an advantage. The studies do not permit a conclusion about what portions of the general population or of homebuyers hold these different views.

\section{Civie Duty to Help Conserve}

Although this item, when presented to respondents in the RUPI study, was selected as an important factor, it was not volunteered as an advantage in the studies listed in Table 54. Probably such general responses as "saves resources," "fuel savings," and "saves energy" could include civic as well as economic concerns.

\section{Number of Years System Will Last}

Although RUPI found concern for system lifetime mentioned less of ten than other cost considerations, Scott found homebuyers more concerned about the expected life of a system than its cost and effects on their payments. Short system life was not a volunteered disadvantage, nor was long system life volunteered as an advantage, as seen in Tables 5-2 and 5-4. Such concerns, again, could be included in responses listing the untested and experimental nature of solar power as a disadvantage. Most San Diego homeowners agreed that systems would last a long time [252], and most respondents in the RUPI study felt solar systems would last as long as any other system.

Although system life is a concern to people when making a purchase decision, it is not clear from the existing data whether solar energy is perceived to have the advantage or not. 
VOLUNTEERED ADVANTAGES OF SOLAR

\begin{tabular}{|c|c|c|c|c|c|c|c|}
\hline $\begin{array}{l}\text { Study } 302^{a} \\
(N=270) \\
\end{array}$ & Rank* & $\begin{array}{l}\text { Scott, } 1976^{b} \\
(\mathrm{~N}=533)\end{array}$ & Rank & $\begin{array}{l}\text { Study } 252^{C} \\
(N=392) \\
\end{array}$ & Rank & $\begin{array}{l}\text { Study } 104^{d} \\
(N=400) \\
\end{array}$ & Rank \\
\hline $\begin{array}{l}\text { Saves resources } \\
(17 \%)\end{array}$ & 1 & $\begin{array}{l}\text { Fuel savings } \\
(39.4 \%)\end{array}$ & 1 & $\begin{array}{l}\text { Saves energy } \\
(31 \%)\end{array}$ & 3 & & \\
\hline $\begin{array}{l}\text { No pollution } \\
(12 \%)\end{array}$ & 3 & $\begin{array}{l}\text { Ecology }(30 \%) \\
\text { Clean heat }(3.9 \%)\end{array}$ & 2 & $\begin{array}{l}\text { Clean, no pol- } \\
\text { lution, good } \\
\text { for enviroment } \\
(46 \%)\end{array}$ & 2 & $\begin{array}{l}\text { Environmentally } \\
\text { sound }\end{array}$ & 1 \\
\hline Low cost $(16 \%)$ & 2 & $\begin{array}{l}\text { Efficient, } \\
\text { practical }(3.4 \%)\end{array}$ & 5 & $\begin{array}{l}\text { Cheaper } \\
\text { utt11ty bills } \\
(76 \%)\end{array}$ & 1 & Economical & 3 \\
\hline & & & & $\begin{array}{l}\text { Always avail- } \\
\text { able }(22 \%)\end{array}$ & 4 & $\begin{array}{l}\text { Sunlight aval1- } \\
\text { able }\end{array}$ & 2 \\
\hline & & & & $\begin{array}{l}\text { Depend less on } \\
\text { ut1lities }(8 \%)\end{array}$ & 6 & & \\
\hline & & & & $\begin{array}{l}\text { Low maintenance } \\
\text { cost }(8 \%)\end{array}$ & 7 & & \\
\hline $\begin{array}{l}\text { Nothing good } \\
\text { about it at all } \\
(3.3 \%)\end{array}$ & 5 & Comfort $(0.9 \%)$ & 6 & $\begin{array}{l}\text { Safer, no ra- } \\
\text { diation or gas } \\
\text { fumes }(10 \%)\end{array}$ & 5 & & \\
\hline
\end{tabular}


TABLE 5-4 (continued)

\begin{tabular}{|c|c|c|c|c|c|c|c|}
\hline $\begin{array}{l}\text { Study } 302^{a} \\
(N=270) \\
\end{array}$ & Rank & $\begin{array}{l}S c o t t, 1976^{b} \\
(N=533) \\
\end{array}$ & Rank & $\begin{array}{l}\text { St udy } 252^{c} \\
(\mathrm{~N}=392)\end{array}$ & Rank & $\begin{array}{l}\text { Study } 104^{\mathrm{d}} \\
(\mathrm{N}=400)\end{array}$ & Rank \\
\hline & & & & Safer & 5 & & \\
\hline other $(7 \%)$ & 4 & other $(22.3 \%)$ & 3 & & & & \\
\hline
\end{tabular}

a"What is most attractive about solar energy use?" (general public)

b"What are the three most important reasons why you would consider buying a solar home?" (homeowners)

"What, if any, are the things you think you would like about solar energy systems for a home? That is, what would you say its advantages are?" (single family homeowners)

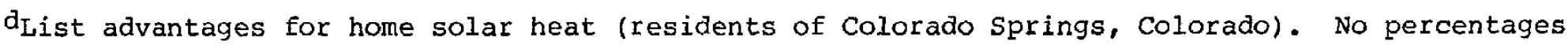
given.

*Rank is the ordinal ranking of the number of responses coded into each category from an open enced question, $1=$ most responses, etc. 


\section{Desire for a Cleaner Environment}

This concern was not offered to respondents in the Scott study for comment about its importance in a purchase decision, but respondents did list it second only to fuel savings as a major advantage of solar energy. Four of the five studies in Table 5-4 found people volunteering "no pollution," "clean heat," or "environmentally sound" as an important advantage of solar heat. Nearly every respondent in the San Diego study agreed strongly that solar energy is a clean and nonpolluting source of energy [252]. A national study in 1977 found a majority believing solar energy to be a clean and nonpolluting source of energy (77 percent) [228]. Three-quarters of the respondents in another study felt that solar heat would contribute to a cleaner environment [Scott, 1976].

It is not clear what effect this advantage has on purchase decisions, but the "clean" aspect of solar energy was an advantage mentioned by four to 46 percent of samples, and was ranked as the top advantage in one study [104].

\section{Amount of Heat and Hot Water Provided}

This factor is related to fuel savings and performance concerns. San Diego respondents (three percent) were the only ones who mentioned this specific disadvantage of solar energy [252]. Worries about required back-up systems, storage, and climatic problems could be related to this perceived problem. RUPI drew disagreement from half their sample with a statement that a solar hot water heating system would not provide enough heat to be worthwhile. A sizable minority did not know how to respond.

Performance was identified as important to the purchase decision and low output was seen as a disadvantage of solar systems by a few respondents.

\section{Inerease in the Resale Value of the House}

Scott found concern about the effect of a solar heating system on the resale value of homes (mentioned by about four percent of the sample). Poor return on investment was mentioned in one study by one percent [117] (see Table 5-3).

Other studies indicate that most people believed solar systems would increase the value of their home. Higher home resale value was an advantage volunteered by a few respondents in one of the five studies in Table 5-4. Scott (1976) found more than half agreeing that installing a solar system would increase the resale value of their homes. About three-fourths of those sampled in Colorado Springs and San Diego felt that having solar energy would increase the value of their house [252, 104]. Owners of solar hot water heaters in San Diego told Marylander Marketing (1976) that they believed the value of their homes was increased by the systems.

These studies present mixed results as to how important resale value changes are to purchase decisions, with the weight of the evidence somewhat on the side of perceived relative advantage in resale value. For some, at least, increased resale value is an expected advantage of solar energy. 


\section{Solar Collector's Appearance on Outside of House}

Six percent of respondents in a study by TRW in Phoenix, Kansas City, and Minneapolis volunteered appearance as a major disadvantage of solar systems [302]. Although other studies have not found this disadvantage suggested, RUPI found that people disagreed two to one with a statement that solar collectors would be an attractive addition to their homes. Scott found that people were more concerned about the appearance of a system on the home (9.3 percent of the sample) than they were about problems with getting a loan to buy it. Most self-selected visitors to a Colorado Springs solar home said they liked everything about its appearance that was questioned (City of Colorado Springs, 1974). A national study in 1974 found that over 60 percent felt a solar energy unit made no difference in the overall appearance of a building, while about a third said the solar unit was unattractive [142]. A study of Nebraska farmers who viewed a photovoltaic irrigation demonstration found respondents unwilling to agree or disagree that the system was visually unattractive [Lilien, 1977]. This response was the same before and af ter viewing the display. These farmers thought combustion-powered and electric systems were less unattractive, but there was no indication of how important farmers felt this feature to be.

The appearance of solar collectors and other solar devices was not considered pleasing by minorities in two studies, and a majority in one. Solar systems were considered attractive by majorities in two studies. These findings are too inconsistent to permit conclusions, except that for some, aesthetic features of solar systems may be considered advantageous, while for others they may be disadvantageous.

\section{Other Factors}

One advantage of solar energy volunteered in the Campbell study was that it was innovative [209, Table 5-4]. Indeed, Marylander Marketing (1977) found that many owners of solar systems liked being thought of as pioneers by their neighbors and friends. This may be an important advantage of solar systems to those who actually make purchase decisions. The other studies considered here represent the opinions of homeowners and homebuyers, not actual adopters of solar systems. Some effort was made to determine how people would feel about the reactions of others to their purchase of a solar system. Scott found people saying they would have very little concern over the opinions of friends and neighbors in deciding to buy a solar system. RUPI did not ask about the importance of others' opinions; instead, statements were presented and respondents asked if a friend noticing their new solar collector would be likely to make such a statement. Most respondents expected neighbors to comment that solar systems would increase their property value, save them money, and show they were environmentally responsible. Most people expected friends to say things like, "It looks like a good idea, but only time will tell," and "In a few years I'll be able to get a better system at a lower price." People were equally divided over whether a friend would say, "Boy, is that ugly." These respondents probably tended to expect friends to respond the way they actually did to solar energy.

Comfort was an advantage of solar energy mentioned by one percent in the Scott (1976) study. This issue was not mentioned in the other studies. For people who stated that they would not consider a solar system, the feeling that it was unnecessary was expressed 
by three to 11 percent (see Table 5-3).* Unsuitability of present home and unwillingness to make a change were also mentioned.

In summary, while the perceived cost of solar energy was mentioned most frequently as a disadvantage of solar systems (by up to 82 percent of samples), savings in fuel and costs were mentioned most frequently as an advantage (by up to 76 percent of samples). Other perceived advantages of solar energy identified in these studies were: (1) environmentally desirable, (2) aesthetically pleasing, (3) plentiful, (4) decreased dependence on utilities, (5) saving resources, (6) safe, and (7) higher resale value of homes. Other perceived disadvantages were: (1) maintenance cost and reliability, performance, (2) climate problems, (3) storage, (4) aesthetically displeasing, (5) lower resale value of homes, and (6) dangerous.

\section{KNOWLEDGE AND INFORMATION SOURCES}

A frequently mentioned explanation given by people who said they would not consider buying a solar system was that they did not know enough about it or needed more information, mentioned by four to 24 percent of samples [117, 120, 209, 252]. On the other hand, a few ( 0.3 percent) said they would not consider a solar system because they had talked to an owner of such a system (Scott, 1976). Information could affect purchase decisions positively or negatively. The evidence from these studies suggests that persons needed more information about solar energy before they could make a decision about it.

A national study in May 1974 found nine percent of respondents had seen, in person, a "unit that transformed heat from the sun into energy." About 42 percent said they had never seen such a unit [142]. RUPI, Inc. (1977) found that two-thirds of their sample of homeowners and homebuyers had never seen a house with solar collectors on the roof or in the yard. About the same number, however, said they had read articles about it. The Scott study (1976) also found about two-thirds of their homeseeker respondents saying they had read some articles and/or other material about solar energy.

In a national sample, 83 percent said they had heard something about plans to use solar energy to heat buildings; fewer had heard of using solar energy to cool buildings [142]. A study of attitudes toward wind energy conducted in five parts of the country found threequarters of the sample had heard something about using solar energy to generate electricity and a little over half had heard of using wind energy this way [303].

Majorities in two special studies and one national survey had heard something about using solar energy for space heating and for generating electricity. Other uses appear to be less widely known. Even among the group considered the most likely to use solar energy,** awareness of other uses was lower than for space heating. In one study, these people were asked to list other ways solar energy can be used. About half listed water heating, slightly fewer mentioned cooling and pool heating. About one-fourth mentioned running electric appliances [252].

Most respondents in two studies tended to underestimate the actual cost of solar heating. A national study in 1974 found over half of respondents guessing a cost of less than $\$ 3,500$ to equip an average home for hot water and space heating. A third answered

\footnotetext{
*This response would agree with findings in Chapter 3 about belief in the energy crisis.
}

**Homeseekers, hom eowners, and potential homebuyers. 
correctly that the cost would be between $\$ 3,500$ and $\$ 10,000$. Another 15 percent thought it would cost over $\$ 10,000$ [142]. A survey of San Diego homeowners showed about five percent correctly guessed the cost of installing solar hot water and space heating in their homes. Most people guessed low [252].

The proportion of respondents who knew about other aspects of solar energy was also low compared to those who said they will consider buying it. In Denver, 92 percent of citizens sampled could define "solar energy" but less than 16 percent knew about life-cycle costing, degree days, retrofitting, energy cost of ownership, or sunshine rights of way [120].

Only one study asked people to define what information they would like to have before making a decision to buy a solar-heated and cooled home. In the Scott study (1976) most answers to this question were categorized as "other" (35 percent). This makes interpretation of the listed responses difficult. Table 5-5 lists these responses in rank order. These are similar to the purchase decision factors mentioned in Table 5-1. Information about cost and reliability was frequently mentioned in this study.

In the San Diego study, homeowners were asked from whom they would seek information on solar energy. More than half said they would go to federal energy agencies first. The local utility* was chosen as the second place to go. Local heating and air conditioning contractors were chosen next, followed by plumbing contractors. Of the people who listed "other" places (just under half), less than 10 percent said they would go to "a company that 'specializes' in solar energy," indicating a fairly low level of preference (possibly because of low awareness) for such companies, as compared to public entities and local heating and plumbing contractors [252].

\section{CONCERN ABOUT RISK}

This issue was addressed in three studies. Most homeowners sampled in San Diego believed solar energy to be a safe and unlimited source [252]. Two studies in Table 5-2 found minorities mentioning "unsafe" or "could be dangerous" as a disadvantage. Some people were explicit: they said solar heating "needs to be controlled so it doesn't get too hot." Some respondents in this same study listed "safer" as an advantage, most likely an implicit comparison to conventional systems. These data do not indicate whether the safety of solar energy is perceived as an advantage or a disadvantage.

Other aspects of concern about risk were discussed in preceding sections on the relative advantage of solar energy. Questions of reliability and maintenance express concern about the individual risks involved in adopting a system. Conviction that solar energy use is clean and non-polluting is the inverse of such concern from an environmental perspective. Each of these were mentioned in response to open-ended items in several of the studies reviewed.

\section{BEHAVIORAL INTENTION AND ACTION}

Three surveys in this review asked people if they used solar energy in their homes [209, Roper, 1979]. These surveys showed that, nationwide, few people had actually installed solar heating. Roper (1979) used the item:

*San Diego Gas and Electric Company. 
TABLE 5-5

HOMESEEKERS' DESIRED INFORMATION ABOUT SOLAR ENERGY

What information would you like to have before making a decision to buy a solar heated and cooled home? (Scott, 1976)

Information Needed
Other**
Initial cost
Maintenance
Longevity
Reliability
Fuel cost savings
Performance
Warranty
See a solar home
Alternatives
Comfort

$(\mathrm{N}=599)$

\begin{tabular}{cc}
$\%$ & Rank* \\
\hline 35.5 & 1 \\
16.8 & 2 \\
13.1 & 3 \\
8.9 & 4 \\
7 & 5 \\
6.7 & 6 \\
5.0 & 7 \\
4.0 & 8 \\
1.9 & 9 \\
0.6 & 10 \\
0.6 & 11
\end{tabular}

*Rank is the ordinal ranking of the number of responses coded into each category from an open ended question, 1 = most responses, etc.

**"Other" responses not defined. 
Here are some fairly new things that not too many people have. [Card shown respondent, listing: (a) microwave oven; (b) video-tape recorder; (c) solar-powered heating unit (to provide either heat or hot water); (d) refrigerator that keeps making ice automatically without your having to fill the trays; (e) electric food processor (slices, chops vegetables, etc.].

Which of these things, if any, do you happen to own?" Fewer than 0.5 percent of the sample responded that they owned a solar heating system in January 1979, with no measurable change since January 1978 when earlier data on this item were collected. In examining the cross-tabulations on this item, however, the following patterns of solar ownership emerged*:

- One percent of the sample aged 18-29 and one percent of those 30-44 owned systems. Thus, approximately one percent of the younger adult age categories (18-44) already own solar systems.

- About one percent of those in the Northeast and one percent in the West owned solar systems, compared to less than $\mathbf{0 . 5}$ percent in the Midwest and South.

- One percent of those in the most rural counties (minor markets with populations under 35,000 ) reported owning systems, with less than 0.5 percent of those in more populated geographic areas (including major markets) reporting solar ownership.

- Of the four income categories, none showed more than 0.5 percent solar ownership except those earning $\$ 7,000$ to $\$ 15,000$ a year, one percent of whom reported owning a solar system.

- One percent of those with any college education were solar owners compared to less than 0.5 percent of all other educational categories.

- For occupational categories, one percent of executive/professional workers reported solar ownership as did one percent of blue collar workers. Less than $\mathbf{0 . 5}$ percent of white collar workers reported ownership.

- Republicans reported one percent solar ownership; Democrats and Independents reported less than 0.5 percent.

- One percent of political liberals reported solar ownership compared to less than 0.5 percent of conservatives and moderates.

- Political and social activists (Roper characterizes these respondents as "thought leaders") reported two percent solar ownership.

*Demographic categories were as follows: (a) Age: 18-29, 30-44, 45-59, 60+; (b) Income: $\$ 7 \mathrm{~K}, \$ 7-15 \mathrm{~K}, \$ 15-25 \mathrm{~K}, \mathrm{~S} \$ 25 \mathrm{~K}$; (c) Geographic area: NE, MW, SO, WST; (d) Education: any college, high school graduate, nonhigh-school graduate; (e) Occupation: executive/professional, white collar, blue collar; (f) Religion: Protestant, Catholic; (g) Political affiliation: Democratic, Republican, Independent; (h) Political philosophy: conservative, moderate, liberal; (i) Market size: Major (all counties comprising the 25 largest metropolitan areas); Medium (all countries having a population of $35,000+$ and all counties that either have a population of 150,000 or more but are not part of major markets or form part of a metropolitan area having an aggregate population of 150,000 or more); Minor (all remaining counties in the country). 
- Families with children 13-18 years of age reported one percent ownership, with less than 0.5 percent ownership by families with children under 13 years of age.

- One percent of the employed females category (including both full time and parttime workers) reported solar ownership.

- No difference in solar ownership was found by the following characteristics: gender, race, religion, union membership, and one to two-person families. All these categories reported less than 0.5 percent ownership.

Although interpretation of these results, which were based on cross-tabulations, must remain speculative, they seem to show that there are currently more than two types of solar users in the country. This is due to the fact that demographic characteristics correlated in known ways, and the patterns of solar ownership partially violate these known correlations. For example, one percent of both Republicans and political liberals reported system ownership, yet these categories are to an extent mutually exclusive. Similarly, executives and blue collar workers are mutually exclusive occupational categories.

What the data might mean is that present solar owners come from several walks of life. One group could be the upper middle class executive or professional family, perhaps Republican in party affiliation; another could be a liberal, young, middle-income group; yet another might be rural in residence and perhaps blue collar in occupation. Solar ownership by opinion leaders (as measured by political and social activism) is probably distributed among these kinds of solar users.

Study 209 estimated that 0.01 percent of current homes have solar systems. The Domestic Policy Review Committee estimated that there are 40,000 solar homes in the United States.* Statistical Abstracts of the United States (1977) reports 80 million housing units. If this figure is used as a base, there are about 0.05 percent solar homes, or about one solar home for every 2,000 homes.

A Gallup poll [219] queried respondents about their interest in using a solar energy system for heating their homes. About one-fourth said they were definitely interested. Nearly half said they probably or definitely were not interested. Only one national survey addressed action regarding solar energy so it is difficult to assess actual numbers of solar users.

Four studies asked about behavioral intention concerning solar energy. Roper (1979) asked about solar buying plans as well as solar ownership. Immediately following the question quoted earlier, the following was also asked: "Of course, all of those things are fairly expensive, but which of them, if any, do you think you might buy in the next two or three years?" Six percent of the sample indicated possible buying plans for the solar heating unit, compared to five percent one year earlier, in January 1978. The demographic characteristics of those who might buy solar systems are summarized in Table 5-6.

In an Arizona citizen survey, nearly 45 percent strongly agreed with the statement "I would live in a solar home." Another 35 percent agreed and less than 10 percent disagreed [201]. A Denver study of homeowners, however, found less than one-fif th saying

*Status Report on Solar Energy Domestic Policy Review, Department of Energy, August 25, 1978. 


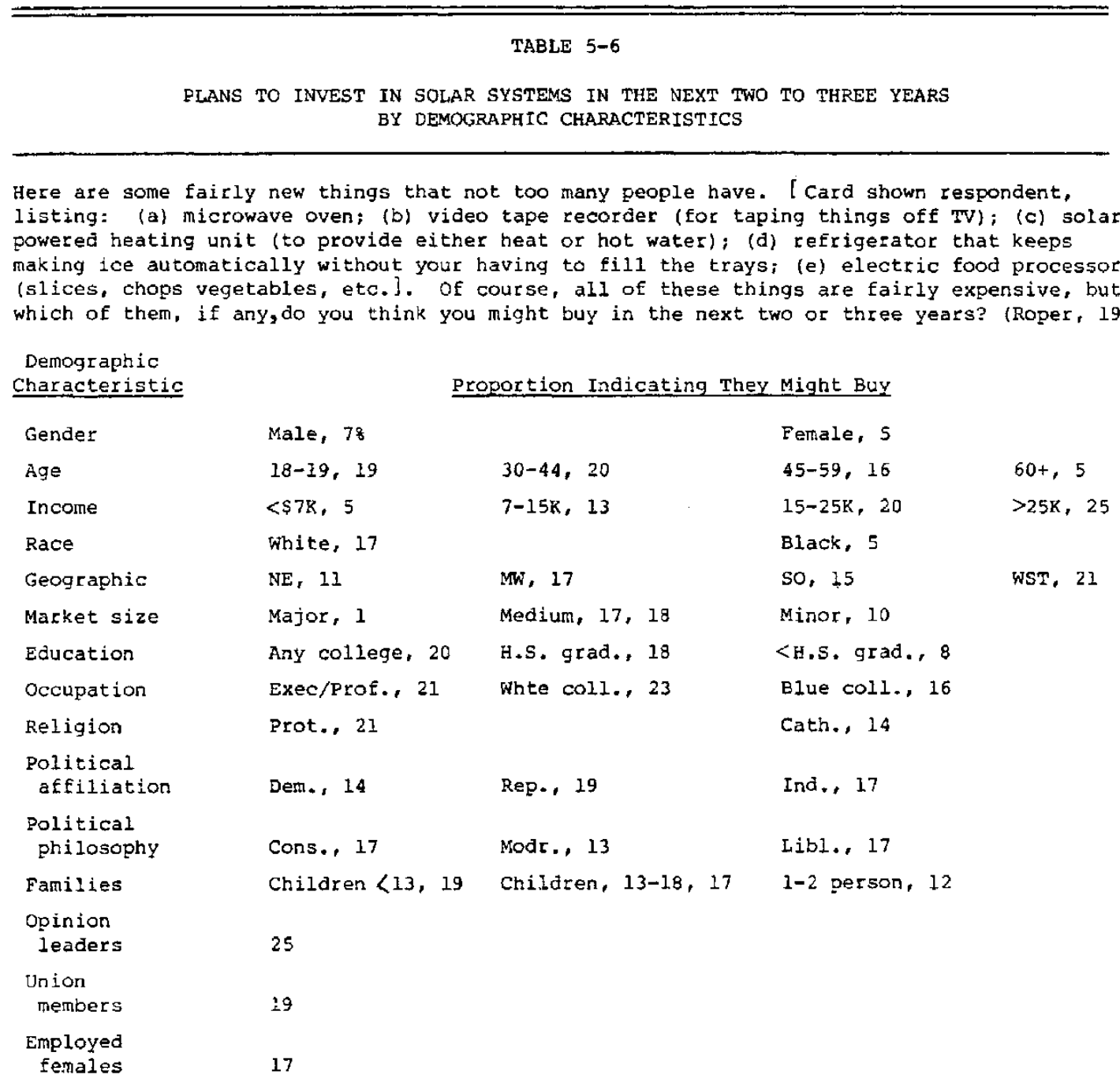


they would consider installing a solar hot water heater [120], and the RUPI homeowner sample contained less than two percent who said they had decided to install solar equipment.

Many San Diego homeowners expressed intentions of buying solar systems for new homes (59 percent) and as retrofit to existing homes (21 percent); however, these people said they would probably buy at their estimated price. Evidence described earlier suggests that many underestimate the actual cost of solar systems, and that cost is a major purchase decision factor. It is possible that, knowing the actual price of solar systems, fewer people might say they were willing to buy.

Marylander Marketing (1976) asked people who had bought solar water heaters why they had done so. The most frequently mentioned reason was to save on fuel, although most people had not performed sophisticated financial analyses before purchase. They believed there would be a savings and the first cost "seemed reasonable" so they made a purchase.

People's intended actions, given various cost scenarios, were investigated in three studies. Majorities indicated they would consider solar energy if the price were equal to that of other systems $[104,302,306]$.

In Table 5-7, data are presented on response to solar systems if cost were the same as for other units. Homeseekers in these samples appeared to be more willing to consider the idea of solar systems than the general public in the local surveys reported above. Over a third indicated they would "consider seriously" and 34 percent "would consider" a solar system if the cost were the same [302]; 53 percent would consider it in another study [104]; 83 percent in another (Scott, 1976).

Five studies examined consumer sensitivity to price increases and decreases. When solar energy was said to cost an unspecified amount more than other energy, the number of people saying they would consider and seriously consider solar systems dropped 24 percentage points from favorability at equal cost [302]. The Campbell et al. (1977) study of eitizens in several parts of the country also found the percentage willing to consider solar heating dropped 24 points when units were said to cost $\$ 20$ more per month rather than the same as other systems [209]. In both studies around 40 percent said they would consider solar systems even at the higher price. Gottlieb (1974), in a study of the residents of parts of Texas and Colorado, found that nearly half of respondents (47 percent) agreed or agreed strongly with the statement: "I would pay for more costly solar energy to decrease demand for new sources of petroleum" [106]. These data seem to indicate a substantial minority who say they would consider solar energy even at somewhat higher prices than the alternatives, perhaps because of perceived nonmonetary advantages of saving resources and reducing pollution.

The Campbell study showed less citizen sensitivity to decreases in the cost of solar energy. When solar energy was said to cost $\$ 20$ dollars less per month, those saying they would consider it rose 11 percent. To speculate, this may be due to the fact that those who said they would not consider solar energy at equal cost were very concerned about the disadvantages and did not consider life-cycle costs as likely true costs. As noted, performance, maintenance, and climate problems may contribute to the perceived "riskiness" of investing in solar systems. In the Campbell study, homeowners were asked if they felt solar heating was currently too new and experimental to risk buying it. Over half thought it was and about $\mathbf{4 0}$ percent thought it was not. Of those who thought it was too risky, half said they would purchase solar systems if life cycle costs were equal. To 
TABLE $5-7$

REACTION TO SOLAR ENERGY SYSTEMS IF THE COST IS THE SAME

\begin{tabular}{|c|c|c|c|}
\hline \multirow[b]{2}{*}{ Reaction } & \multicolumn{2}{|c|}{ Proportion Responding } & $\frac{\text { sponding }}{\text { Homeseekers }}$ \\
\hline & Study $302^{\mathrm{a}}$ & Study $104^{\mathrm{b}}$ & $S \operatorname{cott}(1976)^{C}$ \\
\hline $\begin{array}{l}\text { Would consider } \\
\text { seriously }\end{array}$ & $35 \%$ & -- & 18 \\
\hline & (69) & & $(83)^{d}$ \\
\hline Would consider & 34 & 53 & 65 \\
\hline Would not consider & 11 & 35 & 6 \\
\hline Don't know & 20 & 12 & 11 \\
\hline
\end{tabular}

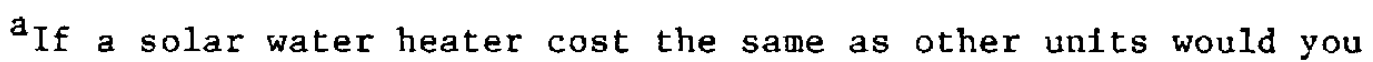
consider buying one? (Citizens of Kansas City, Phoenix, Minneapolis)

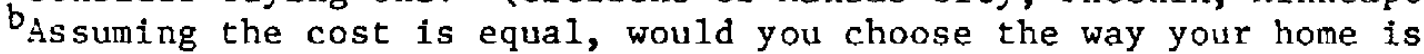
presently heated, or would you choose solar? (Citizens of Colorado Springs)

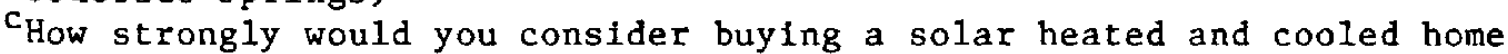
for your next home if fuel savings exactly matched the increased mortgage costs at today's fuel price? (Homeseekers of Denver and Philadelphia)

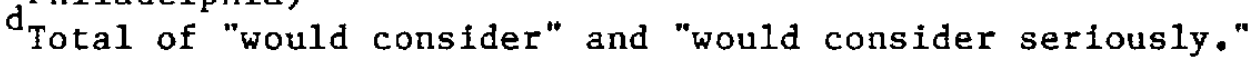


speculate, a certain amount of personal discounting of life cycle cost figures may be operating in responses regarding purchase decisions, given certain costs, just as per ceived nonmonetary benefits of solar energy may be operating in stated purchase intentions.

The Scott study asked in detail about fuel savings and mortgage payments in connection with solar systems. The results seem to be contradictory. Respondents were asked how much in average monthly fuel bills a system would have to save, given an increased monthly mortgage payment, for them to consider choosing it. One-fourth said they would have to save as much on fuel as the increase in the mortgage payment. Over onethird said they would have to save more than the increased mortgage payment to consider a solar system. When asked if they would. spend an extra $\$ 1,000$ on reducing their mortgage payments or on reducing fuel bills, three out of four said they would invest in fuel savings and one out of four chose reducing mortgage payments. To speculate, this could mean that people value reducing fuel bills more than reducing their current mortgage level but find increased mortgage payments more of a disadvantage than fuel savings are an advantage per dollar.

People's willingness to make other than monetary sacrifices to have solar energy has been investigated in two studies. Over half the sampled residents of Lansing, Michigan, said they would give up living space to install a solar heating and cooling system in their houses [106]. The Scott study, however, found smaller rooms to be the least acceptable requirement of a solar heating and cooling system. Schedule changes required by solar hot water heaters were acceptable to about half of the residents sampled in Minneapolis and Phoenix [302].

\section{BVALUATION}

Public attitudes toward the idea of solar energy can only be described as positive. Solar energy was a preferred source for production of electricity for over 90 percent in local studies [303]. Homeowners in San Diego rated solar energy as an excellent idea [252]. Homeseekers in Denver and Philadelphia found solar systems appealing overall, even considering first costs, performance, fuel savings, appearance, etc. (RUPI, Inc., 1977). Renters in several cities favored solar heating of homes (85 percent) [209]. Although only one study addressed attitudes toward windmills, a majority felt it was a "good" idea to use them to generate electricity [303].

This positive attitude is expressed when people are asked about expanding efforts in solar technology. In June 1978, 94 percent of a sample indicated they would like to see "work on solar energy expanded" (Atomic Industrial Forum, Inc., 1978). In February 1977 the most popular step toward developing new sources was: "Set up a government program to develop solar energy" [153]. Another national study at the same time asked people about the importance of various steps to increase energy supply. Again, "expanding work on solar energy" was considered very important by more people than any other step (69 percent) [245]. In 1974 a large majority (86 percent) thought that equipping public buildings with units that "transform the heat from the sun into energy for heating and cooling" was a good idea [142]. Arizona citizens in 1976 favored putting more money into development of solar energy 80 to six percent [201]. In four local studies and three national studies, majority favorability to solar energy was expressed. 


\section{Poliey Preferences}

Government incentives for solar energy were favored in several samples. Most citizens surveyed in a study by TRW said they supported or probably would support tax incentives to encourage the use of solar heating and cooling [302]. Another study of citizens in several cities found three out of four people saying they favored federal financial programs to help install solar units [209]. About half of the Arizona citizen sample favored tax incentives for solar energy development and use [201].* A Roper poll in November 1977 found that tax deductions for homeowners and businesses who add insulation, better heating systems or solar power was favored by more people ( 73 percent) than any of the other listed steps to conserve [147]. In December of the same year, favorability toward a specific proposal for a tax credit of up to $\$ 2,150$ for money spent on installing solar energy equipment alone was favored by 69 percent [243]. Three out of four homeseekers interviewed by Scott (1976) agreed that the federal government should change the tax laws and/or provide some form of incentive to the homebuyer to encourage the purchase of solar homes. In all, six studies indicated strong citizen support for tax incentives to promote solar energy use.

Probable response to such incentives was examined in a few studies, which included items asking people if they would invest in solar systems at varying levels of incentive. They also asked which types of incentives were preferred. These findings are discussed below, organized around three types of incentives: tax credits, low interest loans, and leasing schemes.

Tax Credit. One national survey asked respondents which of a list of changes they would make to their homes if there were an income tax credit. Five percent said they would be likely to install solar heating equipment [164].

Both the Scott and RUPI surveys of homeseekers found an immediate tax credit to be the preferred incentive when dollar amounts were equal. Tax deductions stretching over time were less favored, but slightly more popular than low-interest loans.

In the RUPI study, respondents were asked if they would like to do the paperwork for the federal government and receive the tax credit themselves or have the builder or installer of the equipment submit the papers and credit the rebate to the purchase price. Over two-thirds preferred the "self-received rebate."

Low Interest Loans. Respondents in the RUPI study answered two to one that they would be more likely to use a low-interest loan if it were available through a bank than if it were available through a government agency; to one-third of the people it made no difference. An equal number of people said they preferred to include the solar loan in their mortgage as said they preferred to have a separate loan on solar equipment. About one-fif th had no pref erence for either plan.

* Over one-third of that sample were not sure of how to respond. This could be due to the question wording which required disagreement to show favorability toward tax credits [201]. 
Leasing. Leasing was an option discussed in the RUPI study; it was the least appealing to respondents of four general approaches mentioned. RUPI asked respondents if they would prefer to lease an entire system from a utility company with the possibility of buying it in the future, or to purchase and own the system themselves. More people had a preference than in other questions, and owning a system was preferred two to one over leasing one.

\section{REGIONAL DIFFERENCES}

Solar energy is a supply option favored by national majorities. Two national surveys included questions about solar energy and performed regional tabulations. They showed that the West was more inclined to view solar energy as a long-term source and the South was less inclined [152]. People in the South were also much less likely than the rest of the nation to see development of solar energy as an important step to solve the energy crisis [141]. Information from the few studies which sampled more than one region and from comparison of local findings supports this result.

Roper (1979) reported solar ownership by one percent of Western and one percent of Northeastern respondents, with less than 0.5 percent solar ownership in the rest of the nation. Californians (Santa Clara County) were much more likely to say they were willing to buy a solar-heated home ( 80 percent) than those in Washington, D.C., New York City, or Nobles County, Minnesota (60 to 64 percent). Californians also were more inclined to say that installing solar heat in their present home would demand too much of their time and effort (91 percent compared to 57 percent for other areas) [209].

The effect of experience with solar energy on attitudes toward it was measured in a study by TRW [302]. Two cities with demonstration projects (Phoenix and Minneapolis) were compared to one without such a project (Kansas City). In Kansas City people expected it to be longer before solar energy was used by the city and were less inclined to say they would consider it seriously even if the cost were the same.

The local studies reviewed in this chapter are not comparable even along major issues for purposes of regional analysis. There appears to be an equally high awareness of the existence of solar energy in all areas. A relatively lower proportion in South Carolina said they would consider solar systems (26 percent) compared to samples in Arizona (79 percent), Michigan (47 percent said they would pay more), or samples of various cities across the country [104, 106, 117, 201, 252]; this may be a further illustration of lower favorability toward solar energy in the South.

These differences on general favorability toward solar energy do not seem to be related to concerns about climate. The level of concern about climate in various regions has not been explored. The Scott study (1976) compared concerns about appearance and found those in the West to be less worried about this aspect of solar energy than those in other regions.

There are many other variables in the purchase decision regarding solar energy which have been identified in isolated local studies but have never been applied to the nation as a whole. As it stands, the data on regional variations identify the West as most positive toward solar energy and the South as least positive, and there is some limited evidence that the existence of demonstration projects in an area may increase favorability. 


\section{Summary}

The ability of current solar technology to meet electric power needs and to provide space heating was questioned by nearly half the respondents in the studies reviewed. Performance, design, and maintenance problems constituted a disadvantage of solar heating mentioned by citizens. Not surprisingly, getting information about maintenance, longevity, reliability, and performance is of high priority in making solar purchase decisions. There is evidence that the perceived risk of purchasing solar systems probably affects purchase decisions.

A small amount of evidence suggests that most respondents underestimated the initial dollar cost of installing solar heating systems. Questions about adopting solar systems which did not specify initial costs may have elicited responses based on unrealistic perceived cost mentioned in these studies. Concern expressed over initial cost (a major concern) might have been even greater if the cost had been specified in the question.

Although cost and reliability were frequently mentioned concerns, about 40 percent of respondents in a few studies said they would consider solar energy even if it cost more per month in the long run than alternatives. Nonmonetary benefits attributed to solar energy in several studies were that it saves resources and does not cause pollution. To speculate, these aspects of solar energy may have been an important reason to adopt solar energy for the large minority who said they were willing to consider solar systems even at greater cost. Attitudes toward the idea of solar energy appear to be very positive, although a very small proportion of the total public has actually purchased solar heating. Majorities in several studies supported federal efforts to develop solar energy and incentive programs to encourage its use.

Data on regional differences suggest that those in the western part of the country may be more favorable to solar energy than the rest of the nation, and those in the southern part less favorable. 


\section{S=PI}




\section{CHAPTER 6}

\section{CONVENTIONAL ENERGY SUPPLY SOURCES}

Expanding conventional energy supply sources is a national or regional problem; relevant decisions are made at the organizational and collectivity (community) levels. In this sense, decisions about conventional energy supply are different from decisions to engage in energy conservation and to adopt solar energy, which are ultimately made by individuals. As noted in Chapter 1, public opinion thus has a somewhat different meaning for conventional energy supply decisions than for energy conservation and solar energy. To affect conventional energy supply decisions, public opinion must find avenues of expression that are essentially political. If nothing is done, decisions are made at the institutional level and the public lives with the consequences of these decisions, for better or worse. Action to affect these decisions may take the form of letter writing (to media and legislators), testifying, joining organizations, lobbying, public demonstrations, and so on, but the use of these energy sources is not within the control of any one individual. With respect to these energy technologies, public opinion surveys seek to measure public satisfaction with decisions to site nuclear power plants, engage in strip mining for coal, and similar activities.

Using the multivariate categories, survey data are examined regarding oil, coal, and nuclear energy.* This chapter also presents findings on energy/environment trade-offs and regional differences in public opinion about conventional energy supply sources. Results from surveys which asked respondents to indicate their preferences for various energy supply sources in a comparative fashion are presented in a section on comparative findings at the end of the chapter.

OIL

\section{Effectiveness}

Perceived availability of supply is becoming an important indicator of the effectiveness and feasibility of oil as an energy supply source. As discussed in Chapter 3, public concern exists about the future of oil supplies in the nation and globally.

Oil supplies can be increased through a variety of means; e.g., enhanced oil recovery through sophisticated technological developments, importing more oil, increasing the search for undiscovered oil supplies, oil shale development, and offshore oil drilling. In the studies included in this review, few data existed on these various alternatives.

In a February 1977 national survey, just over half of respondents felt that importing more oil would be an important step to increase supply in the next 10 years. One-third felt this would not be an important step for supply [245]. The issue of self-sufficiency is important to perceptions about domestic supply. In 1974 about 60 percent of a national

*Very few survey items directly addressed opinion about natural gas as an energy supply source. These items were described in Chapter 3. As mentioned in Chapter 1, virtually no data on hydropower were located in the literature search. 
sample thought the United States could be energy self-sufficient; more current data on this question are not available [131]. A national study in 1975 found three-fourths agreeing that we should import less oil [214]. Although a national study in 1977 found a majority believing that importing more oil would be an important step to increase supply in the next 10 years, in that same year about half opposed importing more oil. A large minority (43 percent) favored increasing imports [131]. More data are needed on this question to know if any trends have developed. Taxing foreign oil to discourage imports was opposed by majorities in the surveys addressing the issue $[133,134,231,249]$.

In another study, of those people who did not list oil as a preferred energy source (about two-thirds of the sample), the majority listed limited supplies as the major disadvantage. Nearly half of those who favored oil, however, listed large supplies as a reason [303].

A national survey in February 1977 reported that 83 percent thought offshore oil drilling was an important step to increase supply in the next 10 years [245]. As will be discussed in the section on comparative findings, drilling for offshore oil was not rated as the most preferred energy source, nor the least preferred one.

Although domestically produced oil may be seen as an important element in national energy supply, the survey data here and in Chapter 3 suggest that, because of dwindling supplies, there may be serious doubts about its long-term contribution.

\section{Relative Advantage}

The reported costs and benefits perceived from use of oil as an energy source are related to the key issues of dependency on foreign sources and cost of production. No items directly addressed the advantages of using domestic supplies over foreign. Using foreign oil, especially at high prices, received less support in two studies than "developing our own supplies" or "cutting back on consumption" [133, 201]. In Arizona, 85 percent agreed or strongly agreed with the statement, "The United States should develop its own energy sources so it is not dependent on other countries to fill its energy needs" [201]. To speculate, increased use of oil (with source unspecified) may be seen as increased dependency, a disadvantage which was not specifically addressed in surveys.

Oil was seen by respondents in one study as a high-priced energy alternative. Of those who favored use of oil for generating electricity, six percent specified low cost as a reason, compared to 44 percent specifying large supplies [303]. Of those who opposed the use of oil, one-fifth mentioned high cost as a reason.

In summary, very few survey data exist on public opinion about the relative advantage of using oil, domestic or imported, in meeting the nation's energy supply needs. On one hand, it might appear obvious that oil is needed, particularly for transportation. However, public opinion on the perceived costs and benefits of using the variety of possible techniques for enhancing oil supply has not been explored. This is identified as a research gap.

\section{Concern about Risk}

Concerns about environmental risks involved with using oil were investigated in four studies. Between 71 and 80 percent of national respondents thought that power plants 
and oil refineries cause air pollution $[131,309]$. Fewer respondents indicated pollution as a disadvantage for oil than for coal and nuclear energy in another study [303]. More people listed "a clean source" or "nonpolluting source" as an advantage of oil than for coal but less of ten than for nuclear $[141,303]$. No items addressed concern about oil spills directly. Opinion was polarized (48 percent in favor, 40 percent opposed) on removal of restrictions from offshore drilling [131]. In a 1975 national survey, concern for environmental impacts of oil production and consumption was indicated, through preference of two to one, to have new refineries and power plants built in areas already polluted rather than in areas currently not polluted [308].

In summary, so few data exist on concern about risks of using oil as an energy supply source that no conclusions are possible. Perceived risk would likely affect the perceived relative advantage of using oil. This is identified as a research gap.

\section{Knowiedge and Information Sources}

Knowledge of oil importation was addressed in two studies. Over one-third of respondents in 1976 thought oil for electric power could be obtained almost entirely within the United States. The same number felt using this oil would make us less dependent on foreign sources [141].

One-third of national respondents in May 1977 and again in April 1978 believed incorrectly that the United States does not have to import oil from other countries. Over half answered correctly and 15 percent did not know [218]. No items addressed knowledge and information sources on environmental questions for oil supply increases. No items tested knowledge about the consequences of foreign dependency.

What little data exist suggest a sizable minority who are not well informed about fundamental facts concerning energy in the nation. The question of public knowledge levels remains inadequately explored, however, for convincing and accurate conclusions to be drawn.

\section{Action}

No items addressed actions relevant to oil as an energy supply source.

\section{Evaluation and Policy Preferences}

Most of the items contained in these surveys addressed preferences for action either to increase oil supplies or to control oil companies.

Similar items on opinion about offshore oil drilling have been asked in several studies [131, 137, 141, 159, 207, 242]. Figure 6-A shows that favoràbility ranged from 77 percent in 1973 to 80 percent in 1974 to 62 percent in 1976. Opposition has remained fairly constant at about 20 percent, with a slight decrease in late 1974.

Increasing efforts to produce oil shale in western states was supported by 67 percent of a national sample in 1975 [141]. Using United States oil reserves on government property for consumption was favored by a small margin in 1973, 1974, and 1975 [141, 226]. From 1973 to 1975, large majorities of two samples felt the Alaska pipeline was needed and favored speeding up development [141, 201]. 


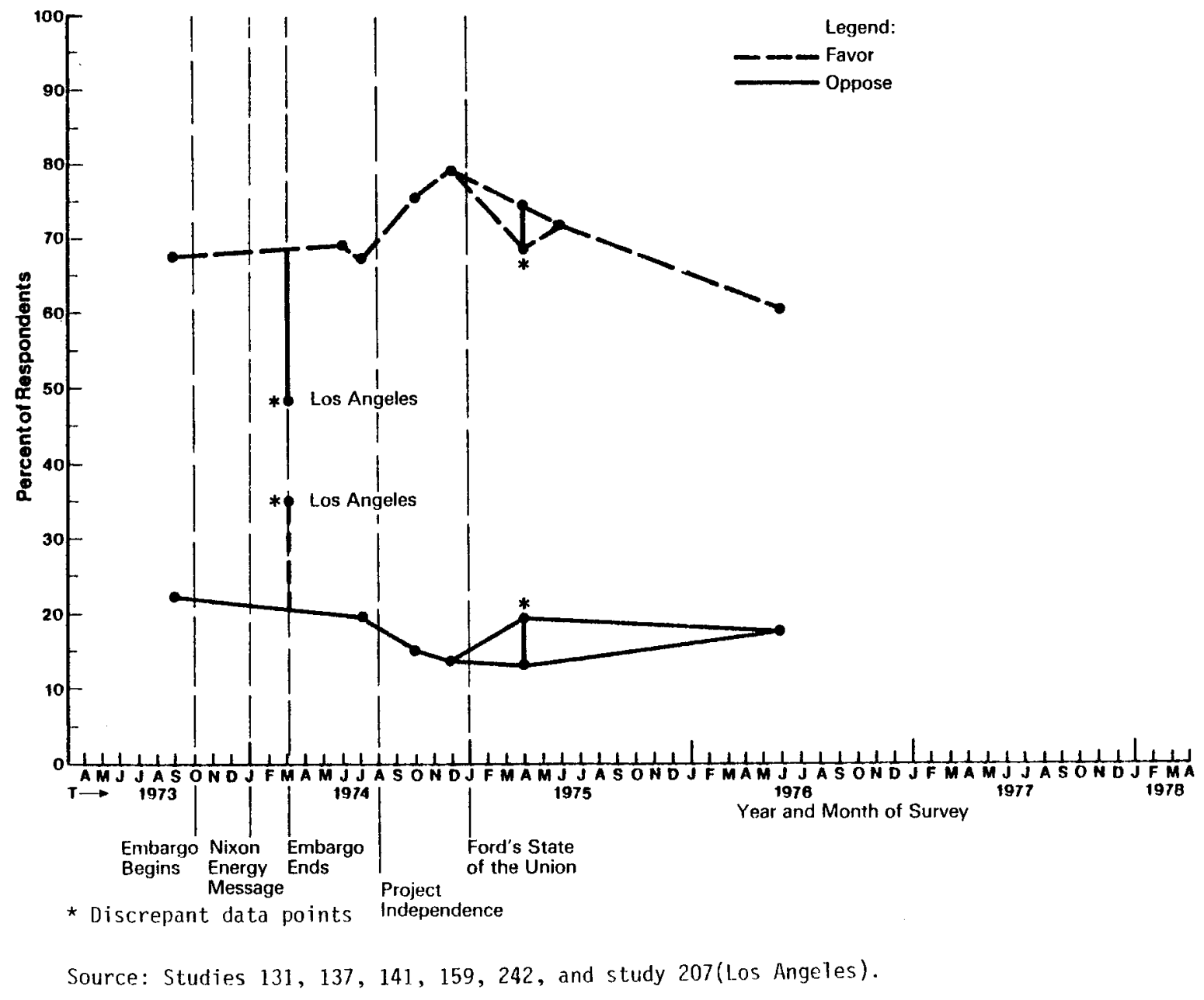

Figure 6-A. ATTITUDES TOWARD MORE OFFSHORE DRILLING BY OIL COMPANIES 
The use of foreign oil, especially Arab oil, has brought issues of international policy into the energy picture. Two studies investigated public sympathies in the Middle East conflict. Expressed sympathy for Israel rose 13 percentage points from November 197 ? to January 1975 (from 39 to 52 percent) [249]. Agreement with the statement, "If we yield to Arab restrictions over oil now, we will soon find the Arabs dictating much of U.S. foreign policy," rose from 58 percent in October 1973 to 76 percent in January 1975 $[227,249]$. The same studies found an increasing majority opposing the idea of reduced support for Israel in order to get along better with the oil-producing Arab countries (from 50 percent in 1973 to 68 percent in 1975 ).

Another issue addressed was the proper level of government involvement in oil production. The majority (61 percent) of a national sample felt the oil industry is "absolutely essential" to the United States in July 1976 and another 33 percent said it is "very important." This ranking was second only to the electric power industry [158].

In another national survey, respondents were asked if there was too little competition in various industries. Oil companies rated third behind telephone companies and utilities. Between November 1973 and November 1976, the percentage feeling that there was too little competition in the oil industry rose from 33 to 41 percent [156]. In March 1975, 73 percent of national respondents felt that "oil companies as a whole are making too much profit" [134]. In the same study, 72 percent agreed with the statement, "Federal government should limit oil company profits during an energy shortage." Another study in November 1975 found 56 percent saying there should be a profits tax on oil companies [231].

Deregulation of prices was also favored by a fairly large margin in 1975. The items usually specified deregulation as a way to increase supply without mentioning accompanying price increases [230, 231, 241, 242]. In 1977, however, one item concerning deregulation mentioned the associated price increases. A majority of a national sample in December 1977 opposed deregulation when a 40 percent price increase was specified [243]. An earlier study in February 1977 found a plurality (47 percent) feeling there was not enough regulation of the price of oil and natural gas.

There were items addressing tax policy to encourage increases in supply. Question wording probably played an important role in how people viewed these options. In 1974 and 1977 about three-fourths of respondents in one national and one local survey opposed allowing oil companies to "raise their prices and profits so that they will have more money to invest in new wells and refineries" [153, 207]. In 1975 and 1976, about half of the national sample opposed giving oil companies "tax incentives for development of new sources" [131, 201]. In late 1975, however, another study found a little over half favoring "allowing oil companies to pay lower taxes on profits if they plow the profits back into exploration for oil and natural gas" [231].

Although a majority (66 percent) of a national sample favored government exploration for oil [131], more drastic government involvement in the form of ownership was favored by one-fourth or fewer of respondents in four studies $[141,162,207,242]$. The most recent finding on government ownership was 69 percent opposed and 19 percent in favor of this action [141]. Requiring a federal charter for oil companies received a little more support in a national survey but was opposed by over half [162]. 


\section{Summary}

The perceived effectiveness of oil as an energy source is probably determined by perceptions of the availability of this resource. Perceived relative advantage of using oil is likely influenced by its cost, the political implications of importing it, and concern about the environmental impacts of producing and using it. The paucity of data on all these questions reveals a research gap.

A few studies showed that sizable minorities do not realize that the United States must import oil. None have asked why the nation should strive to be energy independent, although several studies show that opinion was divided about the feasibility of selfsufficiency. A few studies indicate support for resisting Arab demands and continued support for Israel. So few data exist on favorability toward reducing oil imports that conclusions are not possible.

Technical methods of increasing domestic oil supply received majority support in a few studies. Price increases or incentives to oil companies were generally opposed. The data suggest that oil companies were perceived as taking excess profits. Options such as a profits tax or controls on profits were favored while government ownership was opposed by study majorities. Deregulation of prices was favored, except when resultant price increases were mentioned in one item, whereupon a majority was opposed. When "deregulation" was discussed as an incentive to increase supply, about half of the responses were favorable.

\section{COAL}

\section{Effectiveness}

As was the case with oil, questions about the effectiveness of coal as an energy source for the United States have centered on perceptions of quantity of reserves and their location within the United States. Two items dealt with the perceived need to develop coal. In February 1977, a national survey found 66 percent agreeing that expanding strip mining is an important step to increase energy supply over the next 10 years [245]. In an Arizona sample about 15 percent agreed that developing high sulfur coal was necessary to meet our energy needs, while 47 percent disagreed; 38 percent were unsure if this was necessary [201]. A study in the Yellowstone River Basin found one-third agreeing that coal was needed to pull the nation out of a recession, while 41 percent disagreed [205]. In one national survey, supplies of coal were seen as larger and more reliable than those of oil, but not as great as supplies of nuclear energy [141]. In another study large supplies were indicated as advantages for coal more frequently than for any other source, including solar and nuclear energy [303]. Limited supplies were indicated as a disadvantage almost as seldom for coal as for nuclear energy [303].

The contribution of coal to the nation's energy usage was perceived in 1974 as dropping 10 percentage points in the next 10 years [142]. By 1976 , people saw the use of coal by local electric power companies dropping five percentage points in 10 years, and another 10 points after 25 years [141]. Perceptions about the usefulness of coal seem to have changed. In 1975, 22 percent of those who thought foreign oil could be replaced felt coal was a realistic substitute. In March 1977, 61 percent of a national sample saw coal as a realistic substitute. Solar energy followed at $\mathbf{5 2}$ percent and oil from offshore wells at 42 percent [152]. 
Coal was seen by two sample majorities in 1975 and 1976 as coming almost entirely from within the United States and as making the nation less dependent on foreign sources. This advantage and the one of availability for using coal to generate electricity were mentioned much less often for oil and slightly more often for nuclear energy [141].

\section{Relative Advantage}

More research has been done on perceptions of the harm from coal development than on perceptions of the benefits. Decreased dependency on foreign sources was assumed by researchers to be a benefit in and of itself and this is reflected in question wording. Majorities of respondents in two studies defined coal as a domestically available source which will reduce dependency $[141,303]$. Low cost is also a potential advantage of coal as an energy source. One study found that people who preferred coal as a source of electricity mentioned low cost less of ten than large supplies as an advantage. Low cost was mentioned more of ten as an advantage of strip-mined coal than of oil, natural gas, or nuclear energy. Fewer people saw deep-shaft-mined coal as a low-cost alternative [303].

In a recent national survey (1977), 70 percent were at least somewhat worried that the cost of converting to coal would be great and drive up prices [228]. Communities bordering coal development areas may experience most directly the costs and benefits from coal projects. Among the benefits discussed in a Yellowstone River Basin survey, majorities expected more tax money for better schools, more jobs so young people would not have to move away, and higher incomes for local people. Less than a third expected improved community services [205].

In summary, few studies explored the perceived relative advantage of using coal as an energy supply source. The limited data available suggest that coal is perceived to be domestically available and, thus, would decrease the nation's dependence on imported oil. Perception of the economic costs of using coal remains a largely unexplored research question.

\section{Concern about Risk}

Attention has been given in surveys to the perceived damage caused by the extraction of coal, mainly strip mining. A national survey in July 1977 found about one-fifth of respondents "very worried" that the land will be ruined where strip mining takes place. About a third were "only somewhat worried" and 36 percent were "not worried at all" [228]. Another national survey in 1975 found opinion polarized over whether "it is more important now to have strip mining regulations to protect the environment or to keep the price of electricity lower" [128]. A study in the Yellowstone River Basin where the decision to begin large-scale coal development was pending in 1975 provides detailed information on the perceived advantages and disadvantages of such development. Nearly 80 percent of the respondents believed, "We can have more coal development and still have a quality environment." More than half of this sample said new industry and jobs were not as important as a clean environment and beautiful scenery; between 20 and 30 percent disagreed. Opinion was mixed on whether groundwater supplies would be seriously disrupted by strip mining, but the majority did not think that adequate reclamation of strip-mined land would be impossible. Over half thought there would be pollution which would affect crops and grazing [205].

A large majority of national respondents were worried that increased air pollution and reduction in environmental standards would result from greater use of coal [228]. In 
1977, 75 percent of a national sample identified coal as a "dirty" energy source [228]. Of the 64 percent who said they did not want a coal-fired electric plant near them, 88 percent listed pollution as a reason. Other reasons given, such as "bad for our health" or "bad for our environment," can also be attributed to expected pollution [142].

A question asking about protecting the environment versus getting more coal through strip mining found opinion divided on which was more important in 1975 [131]. The study in the Yellowstone River Basin found considerably greater support for environmental protection. A majority of 88 percent agreed with the statement, "The strip mines should be developed only when we have good standards and enforcement procedures to assure that the land will be reclaimed" [205].

Although air pollution was the effect of coal development about which the most people expressed concern, 54 percent in Indiana in 1974 felt it makes sense to switch to coal even if it makes the air dirtier [304]. In a May 1977 survey, as many respondents favored relaxing air pollution standards to allow coal as those who favored maintaining current standards ( 43 percent). Six percent volunteered that standards should be made stricter [218].

The evidence suggests that there may be regional variation in how people perceive the environmental effects of coal production, with those from the West more likely to favor environmental protection than those from the Midwest. The data suggest that persons in energy-impacted communities might be somewhat aware of the social impacts of coal development. In general, the evidence suggests majority concern about the environmental effects of coal as an energy supply source.

In July 1977, over half of respondents in a national survey were at least somewhat worried about putting even more power in the hands of a few big companies and giving them windfall profits. Concern was evenly split over a statement that using more coal would reduce incentives for oil companies to explore for more oil and that one part of the country would have an unfair advantage over the other [228]. In the Yellowstone River Basin, half felt that a large increase in population with proper planning (due to coal development) would not hurt the area, and 40 percent disagreed. Over half expected an increase in crime. Opinion was split on whether newcomers would cause people to be less united and friendly and on whether local people would lose control over important decisions that affect community life. Less than a third expected a depression in the area due to closure of mines in the future [205].

\section{Knowledge and Information Sources}

Only one item addressed information about coal use. In the Yellowstone River Basin study, 70 percent responded that they were not satisfied with the amount of public information available concerning the plans of the power and mining industries [205]. This area is identified as a research gap.

\section{Behavioral Intention and Action}

Possible actions regarding coal are probably confined to support for or protest against government and industry actions. In the Yellowstone River Basin, 94 percent of respondents said they did not belong to organizations which had taken a stand for or against coal development. Another item stating, "People who object to coal development in this 
area can move somewhere else," drew disagreement from 64 percent [205]. These were the only items in the surveys that touched the question of personal action. No conclusions are possible on the basis of these data.

\section{Evaluation and Policy Preferences}

In July 1977, respondents were asked if they favored a 66 percent increase in the use of coal. Three out of four said "yes" [288]. The surveys focused on strip mining as a way to get this coal. Figure 6-B shows that, while a plurality favored allowing more strip mining, opposition stayed at about 35 percent until 1977 when it decreased to about 20 percent. Increased strip mining, while still protecting the environment, was favored by 80 to 90 percent of respondents and opposed by less than 10 percent [221, 228, 238] . Removing the restrictions on strip mining was opposed by 45 to 48 percent of respondents and favored by less than $a$ third in surveys in 1974 and $1975[131,137,138]$.

\section{Summary}

Although many people have viewed coal, especially strip-mined coal, as a possible way to expand energy supplies, there is some evidence in local surveys that it may not be seen as necessary. The evidence suggests that coal is perceived as an effective energy supply source through domestic availability. One perceived benefit of coal use is a decrease in dependence on foreign oil. Support for strip mining was found to increase in three studies. Public awareness and information sources concerning coal as an energy supply source are identified as a research gap. The data suggest some degree of environmental concern about the production and use of coal as an energy source, with some regional variations. Those in the West appeared to be more concerned than those in the Midwest. Large majorities of three samples supported using coal if no environmental da mage would result.

\section{NUCLEAR ENERGY}

\section{Effectiveness}

Nuclear power plants currently produce a lower proportion of total electric power than oil and coal power plants. When asked in 1975 and 1976 "whether the United States now has the technical know-how to build enough nuclear plants to meet our electric power needs," nearly 70 percent nationally felt the technical know-how exists. About one-fifth felt the technology was not yet developed, and the rest were unsure [141]. In 1974, 14 percent of a national sample felt the main reason why there were not more nuclear power plants being built was that "There are many technical problems in building such electric plants" [142].

When people were asked to name the two or three main disadvantages of nuclear power plants, about seven percent of the total public sampled indicated "lack of technical knowledge, uncertainty of consequences." This was selected much less frequently than other disadvantages, which will be discussed later [141]. This same national sample was 


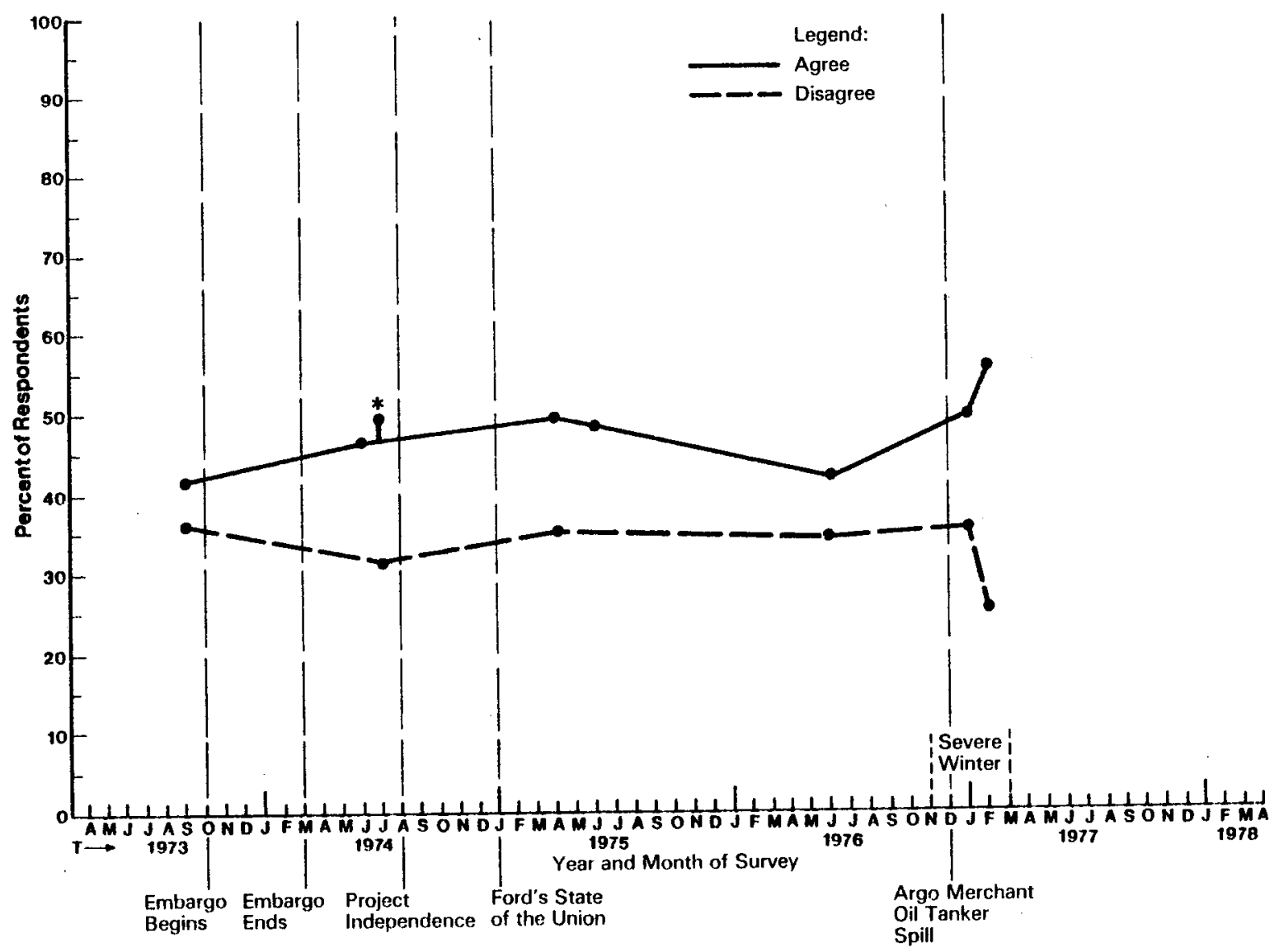

* Discrepant data point

Source: Studies 141, 153, 159.

Figure 6-B. FAVORABILITY TOWARD INCREASED STRIP MINING 
asked how long they thought it would take to build enough nuclear plants to meet a major part of our electric power needs. The median number of years given by those who answered was 13; one-fourth were not sure.

In 1976, a national sample thought that three percent of current electric supply was provided by nuclear energy [141]. About a third of this sample estimated that nuclear energy would provide the largest share of any source of electricity in 10 years. This response represented an eight-point increase over the proportion indicating nuclear energy one year previously [141]. About a third were unsure of the current and future sources of electricity.

A 1974 study found people (33 percent) expecting nuclear energy to be the greatest contributor to electric power by 1984 [142]. A Harris study in February 1977 found 80 percent agreeing that building more nuclear plants was an important step to the expansion of supply over the next 10 years [245].

These data on the perceived effectiveness and feasibility of nuclear energy are too sparse to permit conclusions to be drawn. More information on public perspectives on nuclear energy's potential and desired contribution to energy supply is presented in the section on comparative findings.

\section{Relative Advantage}

The benefits associated with nuclear power development defined in surveys were: individual benefits from reduced utility bills, economic benefits to the immediate community, and societal benefits from a clean domestic fuel supply.

Reduced cost of electricity to the individual was a benefit identified in two studies. Just over half of respondents in 1974 agreed with the statement, "In places where nuclear power is being used to produce electricity, people's electric bills are lower" [142]. A national survey conducted in 1975 and again in 1976 found that half of respondents thought nuclear energy will be a cheaper form of energy in the future than at present, and a majority (60 percent) thought that nuclear plants would make electric power a better buy for the money [141]. Other items in this study asking about advantages of nuclear power resulted in over 70 percent saying cheaper power was a major advantage.

Table 6-1 shows the two or three major advantages of nuclear power listed by respondents in the same 1976 national survey. Mentioned most frequently (by 32 percent) was inexpensive electricity, followed by lack of pollution (24 percent) [141].

The same national survey presented a list of community benefits which could result from development of a nuclear power plant for respondent reaction. A majority responded that if a nuclear power plant were built in their community, it would be more likely that new business would create increased employment opportunities in the community. A majority considered this a "major advantage" rather than a "minor advantage." This did not necessarily make the community a better place to live; a little over one-third thought this was more likely, while about one-fif th thought it was less likely. A plurality ( 42 percent) were not sure or said there would be no real change. When asked to list the two or three main advantages of nuclear power plants, three percent volunteered "would create jobs" [141]. 
TABLE 6-1

VOLUNTEEREE ADVANTAGES OF NUCLEAR POWER

Two or three main advantages of nuclear power plants. Answers volunteered, national sample. [141]

Proportion Indicating

Cost

Cheap; produced more cheaply, less expensive to use $32 \%$ Cheaper in the long run

Nationa1

Clean energy, less pollution than gas and oil Unlimited supply, abundant source, reusable

More powerful, efficient; high output of energy

We need energy; good source of energy

Make United States independent of foreign oil

Alternative to oil, gas, and coal

Helps save natural resources
It's avallable immediately

10

Progress; modern, advanced technology

Community Benefits

Would create jobs

More reliable, dependable

It's safer; not dangerous

Compact, self contained; less storage space necessary 
Respondents in Tennessee were asked about community benefits in much greater detail. Table 6-2 shows some results of a 1975 survey in Hartsville and Trousdale County [143]. This area had been proposed for nuclear-power plant construction. It is interesting to note that "cheap electricity," although one of the most desirable perceived effects of plant construction, was determined least likely to occur of any of the proposed effects. This result differs from that of a national sample which showed cheap energy as an expected advantage of nuclear plants. Very desirable outcomes such as increased business, more jobs, and better paying jobs were thought to be fairly likely to happen [142].

Another 1975 local study of two communities which had nuclear power plants found the majority (60 percent) responding that the construction or operation of the nuclear power plant in their area had not affected their lives in any way. The 40 percent who said they had been affected were asked about effects experienced. A majority of samples from both communities said their taxes were lower and listed other economic benefits. Between 10 and 15 percent said the plant had positively affected their feelings about the community. Most people said there had been no effect on their feelings or did not answer. The majority of respondents said they would permit construction again with the primary reason the increase in the tax base and resulting stabilization of tax rate [222]

In May 1974, three out of four respondents who felt nuclear power should be used to generate electricity listed "enables the United States to conserve its natural resources" as a benefit of nuclear energy. This reason was selected more frequently than others. Providing a source in places where other fuels are not available (64 percent), provides cheap electricity ( 50 percent), provides opportunity to develop atomic energy for peaceful purposes (42 percent), and represents an increase in scientific and technological know-how (36 percent) were other reasons mentioned [141]. Avoiding a shortage in the future was seen by over $\mathbf{7 0}$ percent as a major advantage of building more nuclear power plants. About the same number saw nuclear power as a domestically supplied source of energy and as decreasing dependence on foreign sources. Similar responses were found in 1975 and 1976. Advantages related to energy supply and energy independence were listed most frequently when people were asked to list two or three main advantages of nuclear power (see Table 6-1).

Another advantage of nuclear power mentioned frequently was decreased pollution of air and water. This issue was approached several ways in the Harris polls of 1975 and 1976. "Clean energy, less pollution than gas, oil, and coal" was volunteered by one out of four respondents as one of the two or three main advantages of nuclear power plants. Sixty percent answered "think so" to the statement, "Nuclear power is a clean source of energy and doesn't pollute the air so much." About 46 percent thought nuclear power does not pollute water [141]. More respondents expected less air pollution than expected less water pollution from nuclear power production ( 52 versus 42 percent). About one-fifth did not expect reduced air and water pollution if nuclear plants were built, between 13 and 14 percent expected no change, and another one-fif th were not sure. When asked if the possibility that "nuclear power plants created no pollution of the air and water, such as that created by electric power plants using oil or coal" was a major advantage of nuclear power, a majority thought it was a major advantage (62 percent), some thought it was a minor advantage (16 percent), and nine percent thought it was no advantage at all [14l].

The data reported in this section came from one local and two national surveys [141, 142 , 143]. These data suggest that perceived benefits of nuclear energy are economic advantages for local communities through more favorable tax rates and employment 
TABLE $6-2$

LIKELIHOOD AND DESIRABILITY OF POTENTIAL EFFECTS

OF A NUCLEAR PLANT: DESIRABLE EFFECTS*

\section{Effects}

Meet new people

Public recognttion of town

Increased business

Increased land value

More jobs

Better paying jobs

More stores/shopping

Industrial development

More recreation areas

More public entertainment

More billboards

Town/tourist attraction

Better schools

Cheap electricity
Mean Ratings of Potential Effects $\frac{\text { Likely }}{\underline{\text { Scale Rank }}} \frac{\text { Desirable }}{\text { Scale }}$

$\begin{array}{llll}2.3 & 1 & 5.6 & 6\end{array}$

$\begin{array}{llll}2.5 & 2 & 4.9 & 8\end{array}$

$2.5 \quad 2 \quad 5.6 \quad 4$

$\begin{array}{llll}2.6 & 3 & 5.0 & 7\end{array}$

$\begin{array}{llll}2.6 & 3 & 5.7 & 3\end{array}$

$\begin{array}{llll}2.7 & 4 & 6.0 & 1\end{array}$

$\begin{array}{llll}2.8 & 5 & 5.5 & 5\end{array}$

$3.0 \quad 6 \quad 5.2 \quad 6$

$\begin{array}{llll}3.1 & 7 & 5.5 & 5\end{array}$

3.2 8 5.2 6

$\begin{array}{llll}3.4 & 9 & 3.4 & 10\end{array}$

$\begin{array}{llll}3.4 & 9 & 4.4 & 9\end{array}$

$\begin{array}{llll}3.7 & 10 & 5.9 & 2\end{array}$

$\begin{array}{llll}4.6 & 11 & 5.9 & 2\end{array}$

* Study 143. Actual question wording not provided.

$a_{1}=$ certain to happen, $7=$ almost impossible

$b_{1}=$ extremely undesirable, $7=$ extremely desirable

cordinal ranking of scale values: 1ikely to not likely

dordinal ranking of scale values: more destrable to less desirable 
opportunities. Nuclear energy was also defined by sample majorities as environmentally desirable. Majorities indicated that they thought nuclear power would become less expensive over time. These data are too limited to permit definitive conclusions.

\section{Concem about Risk}

The major disadvantages or costs associated with nuclear power as an energy alternative are perceived threats to personal safety and anticipated environmental damage. Table 6-3 shows the disadvantages volunteered by a national sample and by those respondents in another national sample who said they were unfavorable to a nuclear power plant. Health and safety concerns were mentioned by both groups more of ten than environmental or other disadvantages.

In 1974, people who opposed using nuclear power to generate electricity listed "it's dangerous to health and environment" most of ten (70 percent) [142]. These health concerns seem to be related to radioactivity and the waste disposal problem. The Harris study in 1976 found 67 percent of respondents labeling "the disposal of radioactive waste materials which remain radioactive for many centuries to come" as a major problem. Escape of radioactivity was judged a "major" problem by 57 percent. A majority felt the chance of an explosion in case of accident was a problem. Warm-water thermal pollution was a major problem to half of the respondents, with threat of sabotage, danger of meltdown, and potential for air pollution considered major problems by fewer than half of the sample. About 40 percent worried about plutonium being stolen by radicals [141].

In 1974 respondents in a national survey were asked why they thought there were not more electric plants fueled by nuclear energy being built. Over half chose the following reason: "The public has many concerns about the possible dangers to health and safety such plants may bring" [142].

Table 6-4 illustrates some of the concerns at the local level in Tennessee where a nuclear plant has been proposed; although radiation hazards were one of the least desirable effects (but not quite as undesirable as increased crime and drugs in schools), it was also considered one of the least likely [143].

Figure 6-C illustrates findings from survey items on the perceived safety of nuclear power plants. Results from the national surveys were not consistent [141, 148, 311]. One study found from 40 to 45 percent indicating that nuclear power would present danger, between 1973 and 1977. About 35 to 40 percent indicated that nuclear power was safe across the same time period [148]. Another study in 1975 and 1976 found about 20 percent perceiving danger and 65 percent indicating that nuclear power was safe [141]. However, the item used in the former study elicited opinion on a nearby nuclear facility, while the item in the latter study asked about safety of nuclear power plants in the abstract. This difference in item meaning might account for the difference in response. A third study, which asked about nuclear safety in the abstract, found about 35 percent in 1974 indicating that nuclear power was safe. These data suggest that nuclear plants are perceived to be safer if they are not nearby. Melber et al. (1977), in examining several other studies, found similar variations in the data. Results from a Roper survey over five years, taken in the same month each year with item replication, showed a plurality feeling that a nearby atomic energy plant would present dangers [148]. The proportion feeling there were dangers rose slightly from 41 percent in 1973 to 47 percent 
TABLE $6-3$

VOLUNTEERED DISADVANTAGES OF NUCLEAR POWER--NATIONAL SAMPLES

Two or three main disadvantages of nuclear power plants (Answers volunteered, total public) [141].

Health Concerns

Proportion

Indicating
Why are you unfavorable toward having an electric plant fueled by nuclear energy located here?

(Answers volunteered, asked of those who said they were unfavorable--33 percent of sample) [142] .

Proportion Indicating

Unsafe, dangerous, health hazard

Bad for our health

$26 \%$

Danger of radiation contamination

21 Danger of radiation

40

Danger of accidents, explosions, earthquakes

Need stringent controls, safeguards

16 Dangerous

$7 \quad$ Afrald

11

People would/could not live 5

Danger of sabotage nearby

Danger to workers in nuclear plants

Env1ronmenta1 Concerns

problems with radioactive waste disposal

Pollution, damage to environment, wildlife

13 Bad for our environment

Causes pollution

Causes atr pollution

Causes water/thermal

Thermal pollution, kills

marine life

8

pollution

Unsightly

Noisy

Other Concerns

Initfal expense high, financing

Other

Expensive, high cost

8

7 Not economical, too expensive

Lack of technical knowledge 
TABLE 6-3 (continued)

Proportion

Proportion

Indicating

Indicating

Other Concerns (Continued)

Public anxiety over safety, objections of environmental groups

Shortage, lack of plutonium

$4 \%$

Sites not available

Inefficient, breaks down

Puts people out of work

1 Lowers property values

2 
TABLE $6-4$

LIKELIHOOD AND DESIRABILITY OF POTENTIAL EFFECTS

OF A NUCLEAR PLANT: UNDESIRABLE EFFECTS--LOCAL SAMPLE*

\begin{tabular}{|c|c|c|c|c|}
\hline \multirow[b]{2}{*}{ Effects } & \multicolumn{4}{|c|}{$\frac{\text { Mean Ratings of Potential Effects }}{\text { Likely }^{a}}$} \\
\hline & Scale & Rank & Scale & Rank" \\
\hline Traffic congestion & 2.1 & 1 & 2.6 & 7 \\
\hline Housing shortages & 2.2 & 2 & 2.5 & 6 \\
\hline Crowding in schools & 2.4 & 3 & 2.1 & 3 \\
\hline Increased noise & 2.5 & 4 & 2.4 & 5 \\
\hline More taverns and bars & 2.5 & 4 & 2.6 & 7 \\
\hline Drugs in schools & 2.7 & 5 & 1.9 & 1 \\
\hline Increased crime & 2.8 & 6 & 1.9 & 1 \\
\hline Increased taxes & 3.1 & 7 & 2.3 & 4 \\
\hline Pollution of lake & 3.5 & 8 & 2.3 & 4 \\
\hline Air pollution & 3.5 & 8 & 2.3 & 4 \\
\hline Foggy days & 3.9 & 9 & 2.6 & 7 \\
\hline Radiation hazard & 4.0 & 10 & 2.0 & 2 \\
\hline Sabotage of plant & 4.5 & 11 & 2.1 & 3 \\
\hline \multicolumn{5}{|c|}{$\begin{array}{l}\text { *Study 143. Actual question wording not provided. } \\
a_{1}=\text { certain to happen, } 7=\text { almost Impossible } \\
b_{1}=\text { extremely undes } 1 \text { rable, } 7=\text { extremely desirable } \\
c_{\text {Ordinal ranking of scale values: likely to less 11kely }} \\
d_{\text {Ordinal ranking of scale values: most undesirable to least }} \\
\text { undesirable }\end{array}$} \\
\hline
\end{tabular}




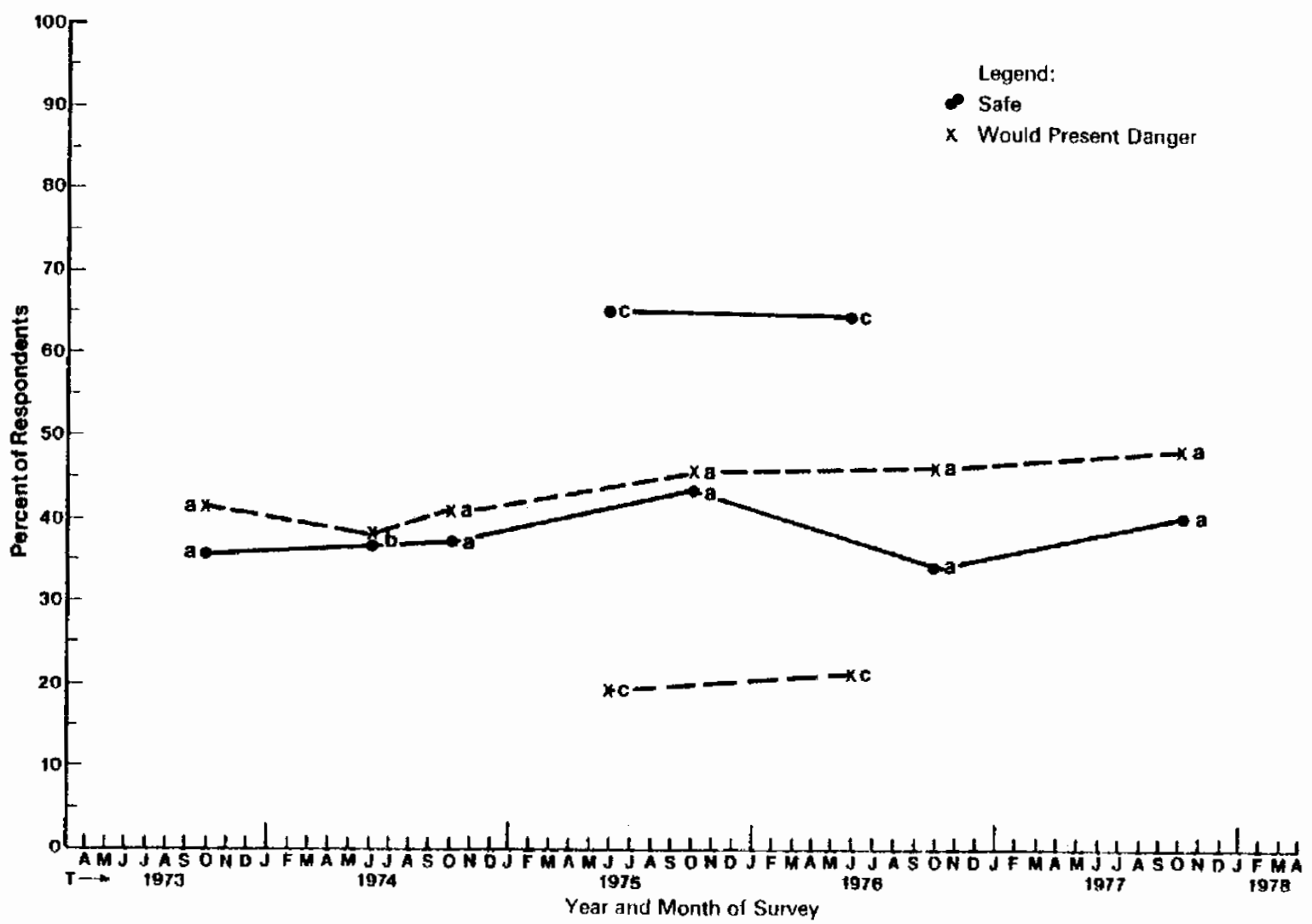

Source: Studies $141,148,311$.

Figure 6-C. PERCEIVED SAFETY OF NUCLEAR POWER PLANTS

NOTES TO FIGURE 6-C

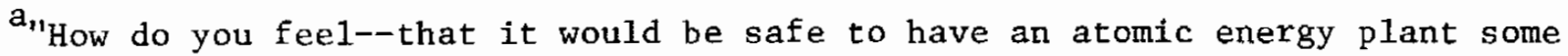
place near, or that it would present dangers?" [148]

b"Nuclear plants are safe. There is no danger of explosion." Agree, but not strongly; disagree, but not strongly; and strongly disagree [311].

c"How safe are nuclear power plants?" Very safe, somewhat safe, not so safe" [141].

The volunteered response "dangerous" was also included in the coding. In this figure, those responding "not so safe" or "dangerous" were coded as "would present danger." 
in 1977. The Harr is surveys in 1975 and 1976 showed more people believing nuclear plants were very or somewhat safe (63 percent), with a slight rise from 18 to 23 percent saying they were not so safe or dangerous.

Although majorities in three samples have listed health and safety concerns as disadvantages to nuclear power, the public appears polarized on the issues of nuclear plant safety. National survey data, however, may not reflect local sentiment on nuclear power plant siting. A recent Harris poll in New York state found a plurality opposing construction of more nuclear power plants (46 to 35 percent in favor), with a plurality indicating that nuclear plants are safe (44 to 35 percent) (Harris, 1978).

In 1974, Becker found that 38 percent of a national sample agreed or strongly agreed with the statement, "Nuclear plants should not be built because of the possibility that a serious accident could result in the death or injury to thousands of people within a hundred miles of here." Forty-four percent disagreed or strongly disagreed with this statement [311]. Similar polarization was found in Arizona in 1976, with nearly one-third indicating they were not sure [201]. In June 1976 Gallup asked a national sample, "Do you feel that nuclear power plants operating today are safe enough with the present safety regulations, or do you feel that their operations should be cut back until more strict regulations can be put into practice?" A plurality (40 percent) said operations should be cut back. About one-third thought plants were safe enough and over one-fourth had "no opinion" (Gallup, 1976).

These findings indicate that about 40 percent of respondents in one local and two national surveys in 1974 and 1976 were concerned enough about nuclear plant safety to favor curtailing construction or operation until the danger could be reduced. A Harris poll found that fewer respondents in 1976 than in 1975 said it was worth the risk to build nuclear power plants. These respondents were asked about plants which met tough government standards for nuclear waste disposal: having the government certify they will not pollute air and water, having the government regularly inspect for radioactive leakage, having proper security against theft of plutonium or sabotage, prohibitions of dumping warm water into streams, and inspections against accidental explosion. The percentage of people saying it was worth the risk even with each type of control decreased (by seven to 10 percentage points), those saying it was not worth the risk increased (by five to eight percentage points), and the number who were not sure increased (by one to four percentage points). However, a majority of between 67 and 72 percent felt that building plants was worth the risk in both years [141].

The 1974 national study, which found 38 percent agreeing that nuclear plants should not be built because of the danger, found 67 percent agreeing ( 34 percent strongly) that "On the whole, the electric companies have done an excellent job of building and operating nuclear power plants and protecting the safety of the public." About 10 percent disagreed, and nearly one out of four had "no opinion" [311]. In 1975 and 1976 majorities opposed government ownership of utilities (61 and 64 percent respectively), and over onefif th said they favored this action [141]. To speculate from these data, public safety concerns may not stem from perceived negligence on the part of utilities.

While respondents in two national samples showed greater concern between 1975 and 1976 for problems connected with nuclear power plants, such as threats of sabotage, accident, and disposal of wastes, slightly fewer nuclear plant neighbors thought these were "major" problems in 1976 than thought so in 1975. When asked, "How safe are nuclear power plants?" 42 percent of plant neighbors felt they were "very safe," compared to 25 percent of others. Fewer neighbors thought plants were not safe 
(16 percent, compared to 23 percent of others) and fewer neighbors had no opinion (eight compared to 14 percent) [141].

In summary, seven surveys examined public response to perceived risk of nuclear power plants. The pattern of findings revealed in these somewhat inconsistent data appears to be a public divided on the question of nuclear safety. Some samples result in majorities perceiving such risks, and others in sizable minorities. The data suggest that those living near nuclear plants may be less concerned about risk than others, but they are too sparse for firm conclusions. Concerns about risk relevant to nuclear energy identified by the public included: radioactivity leakage, waste disposal, thermal pollution of water, sabotage and theft, and explosion or accident. Negative indirect effects of a nearby nuclear plant that were identified included increased traffic congestion, housing shortages, crowding in schools, noise, crime and drugs in schools, all energy-related boom town community impacts.

It can be hypothesized that increased public concern about the risk of nuclear power plants will tend to result in increased opposition to them, and possibly to protest against them.

\section{Knowledge and Information Sources}

Awareness or knowledge of the existence of nuclear plants nearby was not high in one local and two national studies. In 1973 and 1974 people were asked, "As far as you know, is there a nuclear power-generating plant now operating within 100 miles of where you live?" The percentage answering correctly rose from six to 13 percent. Those answering incorrectly remained constant at about 12 percent, and the majority said they did not know [311]. In May 1975, of those who lived in states where there are nuclear power plants, about half were aware of the fact [255]. About half of a Tennessee sample, in an area proposed for a nuclear plant, correctly answered questions about acreage required, size, number of workers, and time required to build. Less than a third knew the correct cost and about one-fourth knew the plant would last less than 50 years [143].

An Arizona study found nearly three out of four people disagreeing with the statement, "I don't need to know more about nuclear power before its use is widespread" [201]. Gallup (1976) reported that 77 percent of a national sample were following discussions regarding nuclear energy development in June 1976. This was around the time of the California nuclear referendum. In the far West, Gallup reported 90 percent were following these discussions. Another national survey about this found that two out of three Americans had not heard of the California referendum to change the state regulation of the nuclear industry [14l].

The sources of information on nuclear energy used most frequently were television and newspapers [141]. The Tennessee study also found a majority saying they got information about the proposed plant from newspapers and 40 percent saying they used television to get information [143].

One item in a national survey addressed the evenness of media coverage related to safety. The item stated, "The news media, including radio, TV, and newspapers, always gives front page coverage to every little problem that occurs at a nuclear plant and 
never gives any mention to them when they are running as usual." One-third of respondents strongly agreed with this statement. Another 29 percent said they "agree but not strongly" and 17 percent disagreed (six percent strongly). About one-fifth said they had no opinion [311].

Credibility of information sources about nuclear energy was examined in one national survey [141]. Table 6-5 displays the percentages of respondents who said they placed ${ }^{a}$ great deal" of confidence in various sources of information (rather than "a little" or "none"). Scientists were mentioned most frequently (by 58 percent). Federal agencies, environmentalists, and the president were chosen more frequently than most other groups (by about a third of the sample).

A national study in 1975 asked respondents about the effect on their opinions of people and groups who favored and opposed nuclear power. Between half and three-quarters of respondents said none of the people or groups mentioned made much difference in how they felt about nuclear power plants. About a third said the Atomic Energy Commission made them more favorable to nuclear power, and 22 percent said Gerald Ford influenced them favorably. Of nuclear opponents, environmental groups made 27 percent of respondents more opposed, and Ralph Nader influenced 20 percent in this manner. Other response categories were individual senators, the Vice President, and the Sierra Club, each of whom influenced fewer than 15 percent of respondents [141].

The data suggest that knowledge about location of existing nuclear plants is not widespread, but in areas where new plants are proposed, knowledge and awareness are higher. Melber et al. (1977) found in local studies that increased knowledge leads to community polarization. So few findings existed on information sources and their credibility that conclusions are unwarranted. The evidence suggests that scientists, federal agencies, and environmentalists were perceived as credible sources of information on nuclear energy.

\section{Behavioral Intention and Action}

Action being taken by citizens with regard to nuclear power has increased lately. Opposition or favorability can be expressed through voting, campaigning, lobbying, and even more visibly through demonstrations and protest. In the national studies reviewed, one item asked about voting on nuclear energy. Respondents were asked how they would have voted in the Calif ornia referendum on nuclear regulation. The results were polarized, with 38 percent indicating they would have voted against it, and 31 percent indicating they would have voted for it. Nearly a third (31 percent) said they were not sure [141].

No studies in the review included items about intended or actual actions of campaigning, lobbying, or demonstrating. Attitudes toward this kind of activity were explored in a national study in 1974 [311]. The items and responses are presented in Table 6-6. Opinion on electric companies, the AEC, and protest groups was polarized, with sizable minorities (about 20 percent) unsure of how they felt.

\section{Evaluation and Policy Preferences}

Unlike the surveys directed at other energy alternatives, studies of feelings toward nuclear power have asked about general favorability toward the concept. The question has been presented in two major ways. First, questions asked for opinions about nuclear 
TABLE $6-5$

CONFIDENCE IN INFORMATION SOURCES

How much confidence do you have in what various people or groups say on matters concerning nuclear energy development? (national sample) [141]*

People or Groups

Proportion

Responding

"A Great Dea1"

Scientists

$58 \%$

Nuclear Regulatory Commission (formerly Atomic Energy

Comm1ssion)

Energy Research and Development Administration 36

Leading environmentalists $\quad 34$

The President of the United States $\quad 24$

News commentators on television $\quad 22$

Ralph Nader and his consumerist organization 22

Foundation reports 21

Heads of electric power companies 19

News commentators in newspapers 18

Companies which produce equipment for nuclear power plants. 12

State governors 11

$\mathrm{U} . \mathrm{S}$. Congressmen 8

Ads in newspapers by those who support nuclear power 8

U.S. Senators 7

Ads in newspapers by those who oppose nuclear power 7

Candidates for President of the United States 5

Labor union leaders 5

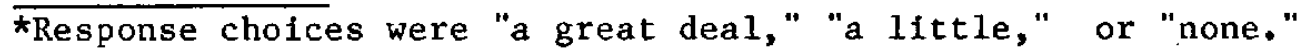




\begin{tabular}{|c|c|c|c|c|c|}
\hline \multicolumn{6}{|c|}{ TABLE $6-6$} \\
\hline & \multicolumn{5}{|c|}{ Proportion Responding } \\
\hline & $\begin{array}{c}\text { Agree } \\
\text { Strongly } \\
\end{array}$ & Agree & Disagree & $\begin{array}{l}\text { Disagree } \\
\text { Strong1y }\end{array}$ & $\begin{array}{l}\text { Don't } \\
\text { Know }\end{array}$ \\
\hline $\begin{array}{l}\text { You cannot depend } \\
\text { upon the electric } \\
\text { companies and the } \\
\text { AEC to build and } \\
\text { run nuclear plants } \\
\text { the safest possible } \\
\text { way, unless we have } \\
\text { nuclear protest groups } \\
\text { to force them to do } \\
\text { this. }\end{array}$ & $\begin{array}{l}15 \% \\
\quad 35\end{array}$ & 20 & 22 & 5) & 20 \\
\hline $\begin{array}{l}\text { The nuclear protest } \\
\text { groups are irresponsible } \\
\text { alarmists who in the } \\
\text { energy crisis should } \\
\text { step aside and stop } \\
\text { obstructing the building } \\
\text { of nuclear plants. }\end{array}$ & $\begin{array}{l}15 \\
\qquad(38\end{array}$ & 23 & 24 & (1)) & 22 \\
\hline$\overline{\star S t u d y ~} 311$ & & & & & \\
\hline
\end{tabular}


power in general or for the nation as a whole. Second, questions focused on favorability or opposition toward a nuclear plant in local areas. Table 6-7 shows the results of 10 national surveys. These findings indicate majority favorability toward the idea of nuclear power in general. Opinion on nuclear power in local communities is polarized. Although the percentages varied slightly, probably due to differences in question wording, within each study and taking the studies together, the pattern holds.

Other data provide additional evidence on majority favorability toward national development of nuclear power. In 1974, 80 percent of respondents nationally agreed with the statement, "Nuclear power should be used to produce electricity" [142]. In 1974 and 1976, 70 percent said they would like to see continued advances and developments in nuclear power for peaceful purposes in the future. About 20 percent thought development had gone far enough or too far [157].

These findings notwithstanding, Roper found a decline in favorability toward increased government spending on nuclear power from 57 percent in June 1974 to 53 percent in 1975 and 47 percent in June 1976 [159]. In Indiana in 1974, 67 percent favored increased spending on nuclear power [304].

Figure 6-D displays findings from seven national surveys over five years regarding favorability toward increased development of nuclear technology, building more nuclear plants, and speeding up construction of nuclear plants. Less than one-third of respondents opposed expansion of nuclear energy and sample majorities favored it. Since question wording varies, it is impossible to evaluate a trend apparent in Figure 6-D toward decreased favorability and increased opposition. Results from local studies varied. In 1974, 57 percent of Los Angeles respondents favored increased development of nuclear energy [207]. In $1975 \mathrm{Kentucky}$ respondents favored increased development 85 to 15 percent $[221]$.

A Harris survey conducted in 1974, and again in 1975, asked people "whether it would be worthwhile to have a nuclear power plant in their own community," depending on how different electric power rates would be from those generated by other fuels [141]. Figure 6-E displays the results for "worthwhile" and "not worthwhile" responses in the two years. In 1976 consistently fewer people than in 1975 felt a nuclear plant would be worthwhile in their community at all power rates; correspondingly, more people felt a plant would not be worthwhile in 1976. These data suggest that people are incorporating other features of nuclear power besides utility rates into their judgments about worthwhileness, if the assumption is made that perceptions of utility rates did not change in the intervening year.

The data in Figure 6-D also show that at no difference in cost, the 1975 and 1976 samples were increasingly polarized on the desirability of nuclear power. In 1975, about 35 percent thought nuclear power was not worthwhile at no change in cost, and about 53 percent thought it was worthwhile. In 1976 , about 42 percent thought it was not worthwhile at no cost difference, and about 47 percent thought it was worthwhile.

It might be expected that the attitudes of people living near nuclear plants would differ somehow from the general public. Their first-hand experience with its characteristics makes their responses more "informed." Indeed, the findings show a fairly consistent direction of difference although the magnitude does vary. Those living near nuclear plants were more optimistic about the technical effectiveness and future contribution of nuclear energy to our electricity-generating capacity. They tended to be less concerned about health and safety problems and more convinced that nuclear power is a clean 
TABLE $6-7$

FAVORABILITY TOWARD NUCLEAR POWER FOR THE NATION AND COMMUNITY

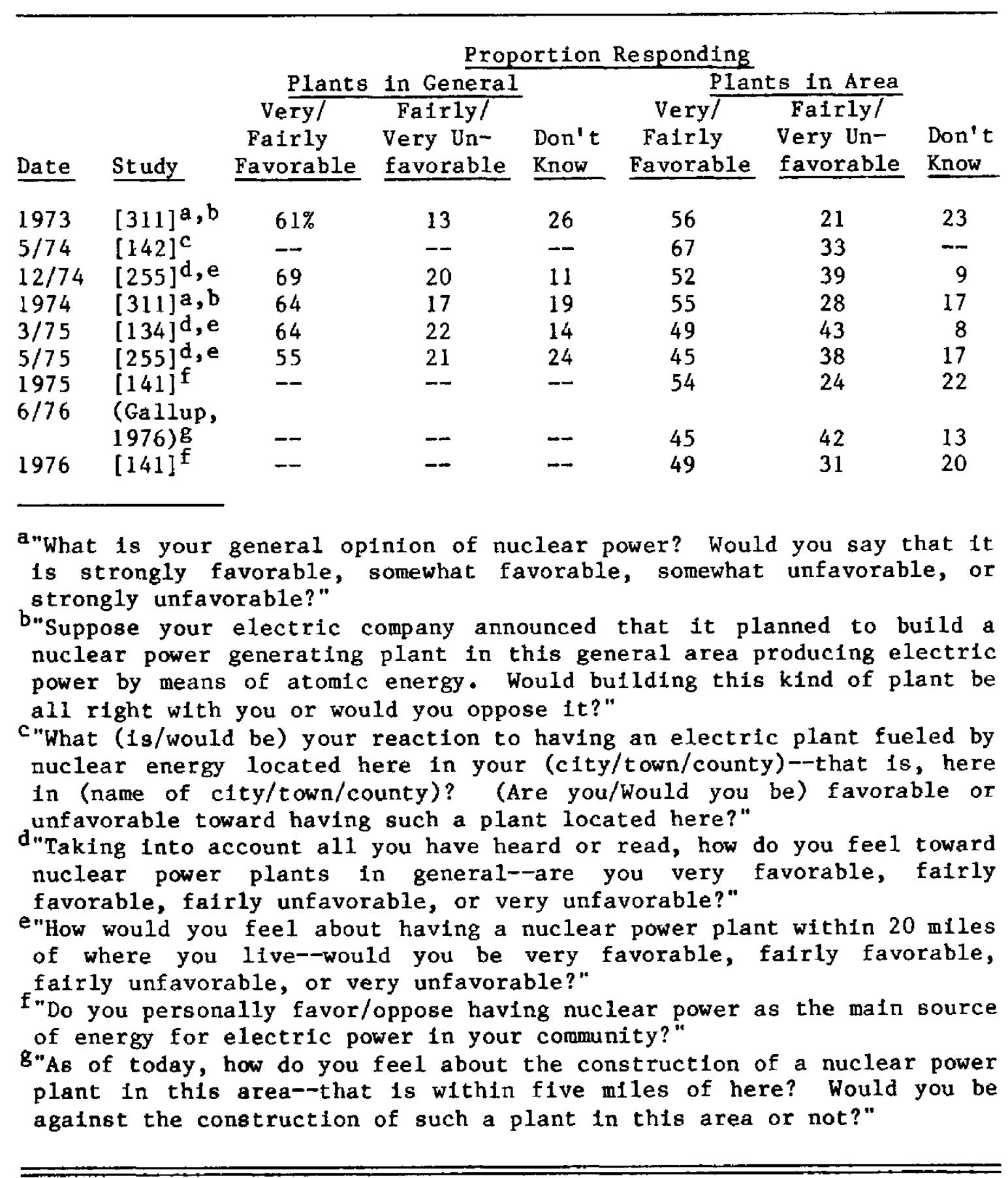




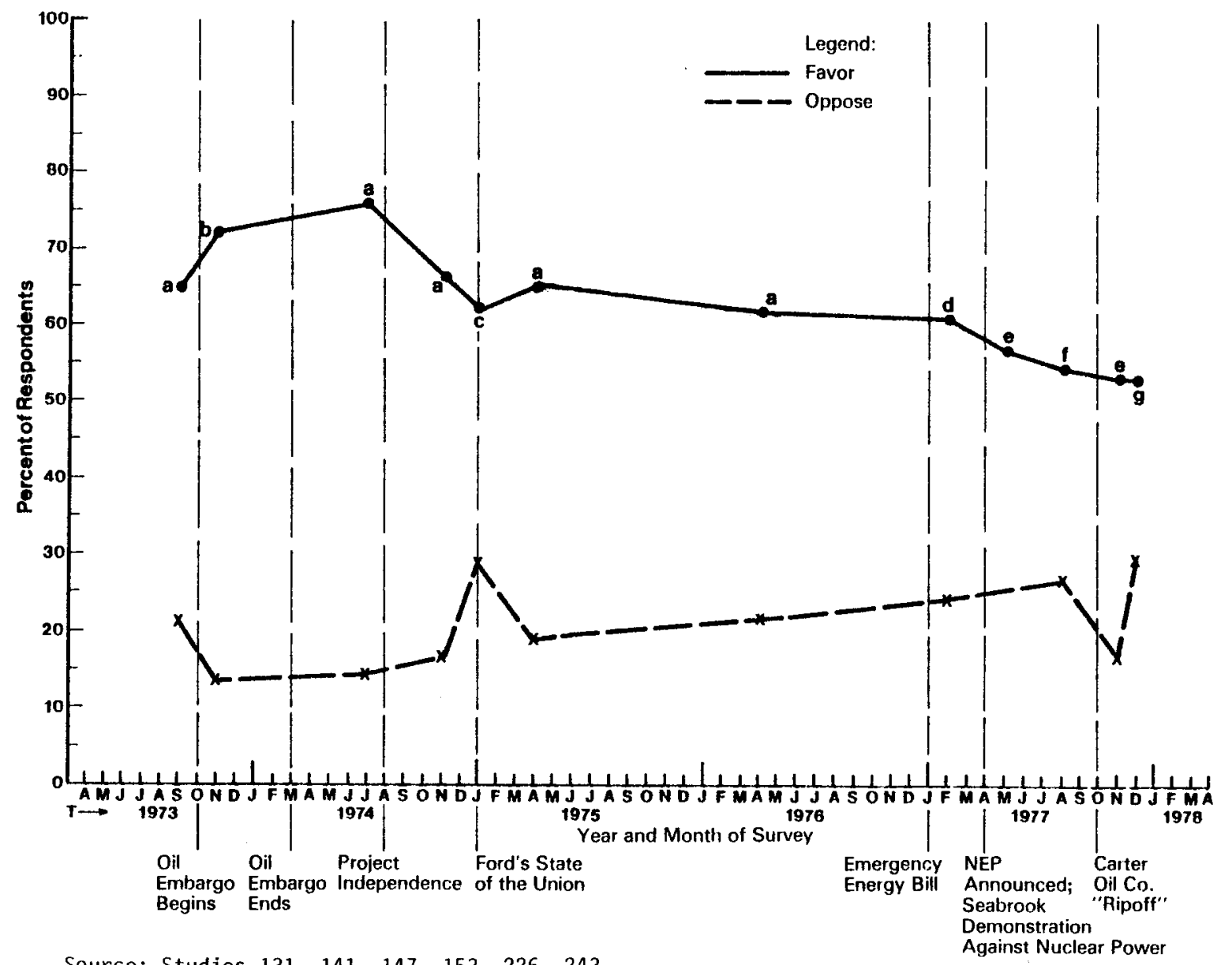

Source: Studies 131, 111, 147, 153, 226, 243.

Figure 6-D. ATTITUDES TOWARD SPEED-UP IN CONSTRUCTION

AND BUILDING OF MORE NUCLEAR PLANTS 
a"Do you favor or oppose these steps to solve the energy crisis?--Speed up the building of new nuclear power plants" (not sure, 17 percent). [141]

b"steps to help solve the energy crisis-nspeed up the development of more nuclear power plants from 10 years to six years" (not sure, 16 percent). [226]

c"More nuclear power plants should be built" (no opinion, 11 percent). [131]

d". - tell me whether it is something you think should or should not be done?--Go into a greater increased program to develop nuclear energy" (don't know, 16 percent). [153]

e"We'd like to ask you about the specific steps Carter has proposed. Here are the major steps he has proposed. Would you tell me for each one whether you think it is something that should be done, or something that should not be done?--Streamline the licensing and review procedures so that a nuclear power plant can be approved and built in three to four years instead of 10 to 12 years" (don't know, 12 percent). [147]

f"Recently, the House of Representatives passed most of what President Carter requested in his energy program. Let me ask you if you favor or oppose each of the parts of that energy program passed by the House of Representatives-Speeding up the construction of conventional nuclear power plants" (not sure, 17 percent). [238]

g"Let me ask you about some provisions of the new energy bill that is likely to be passed by Congress. For each, tell me if you favor or oppose that provision--Speeding up construction of nuclear power plants (not sure, 12 percent). [243] 


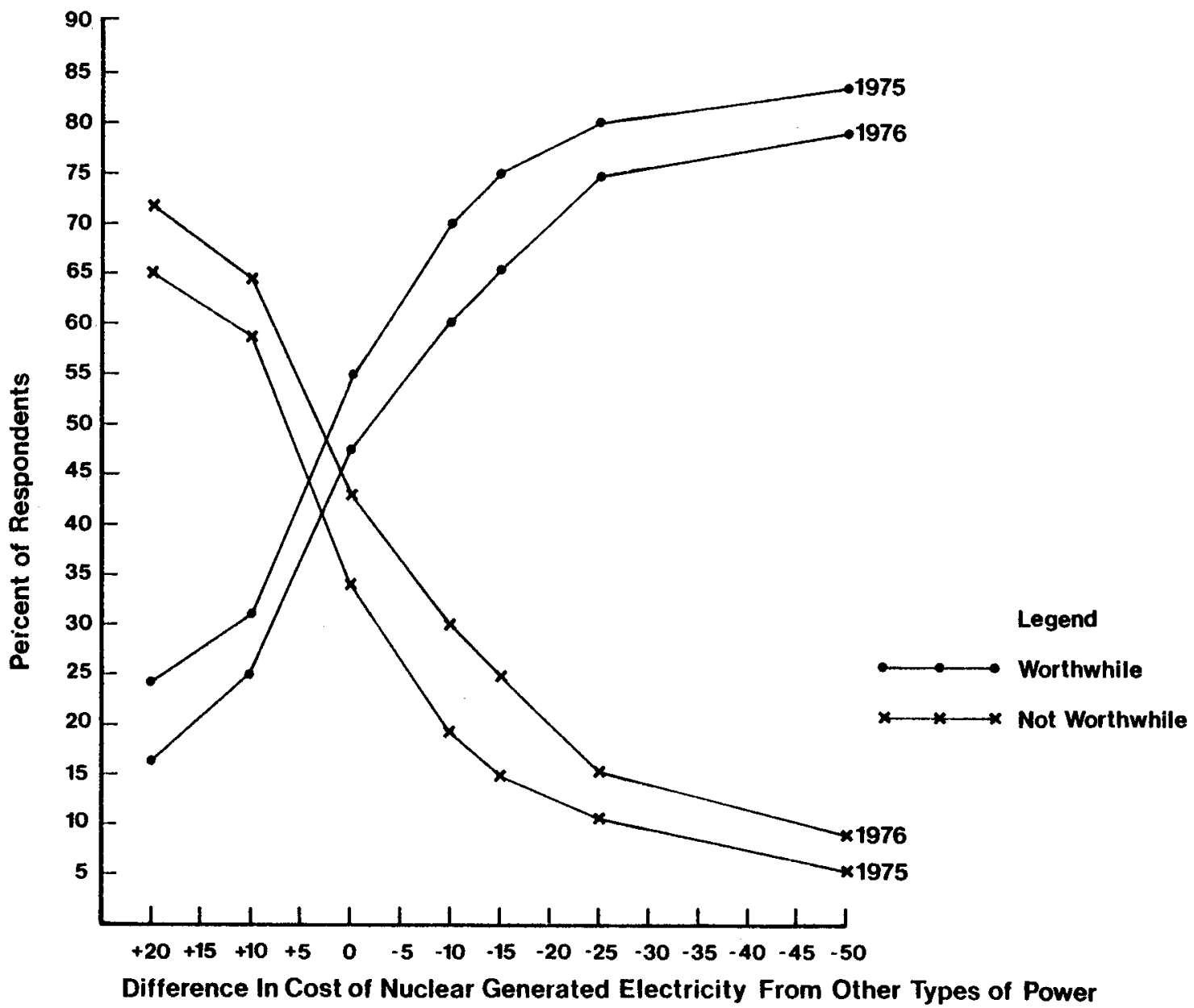

Source: Table 68, Study 141.

Figure 6-E. PERCEPTION OF NUCLEAR POWER PLANTS AS WORTHWHILE AT DIFFERENT COST LEVELS 
source of energy. They were, however, more skeptical about proposed benefits to their community than was the general public. New business, better jobs, and a better buy for electric power were thought likely by less than half (42 to 47 percent), compared to majorities of the general public ( 55 to 64 percent). Nuclear plant neighbors expected less damage in aspects of community life than did the general public.

General favorability toward nuclear plants was higher among nuclear plant neighbors than among the general public. From 1975 to 1976 favorability increased slightly among neighbors but declined slightly among the general public. In 1976 more nuclear plant neighbors thought it would be worthwhile to have a nuclear power plant in their community than the public at all variations of increased and decreased utility bills [141].

Over half (55 percent, compared to 38 percent of the public) of plant neighbors said they would have voted against the California referendum on nuclear regulation. Although almost as many neighbors would have voted for the measure as those in the general public (28 to 31 percent), many fewer said they were not sure (17 to 31 percent).

These findings suggest that a smaller proportion of people living near nuclear plants are concerned about the disadvantages of nuclear power, and a larger percentage are optimistic about the advantages, than of the general public.

\section{Summary}

Majorities of national samples viewed nuclear energy as technically feasible and expected it to assume a major role in electric power generation in the future, although a sizable minority (up to one-third at times) were unsure. In one study, half of those sampled thought nuclear-generated electricity would be cheaper than other types of power, but fewer of those living near nuclear plants thought this would be a likely result. A majority in this study expected the benefit and cost of general economic growth to result from nuclear power development in their community. Reduced dependency on foreign oil and conservation of nonrenewable resources as well as reduced air and water pollution are advantages of nuclear power perceived by the majority of respondents.

The major problems perceived as associated with nuclear power development are safety and environmental damage from radioactivity and waste disposal. These problems have been considered serious by large majorities and the number of people saying they are concerned has increased. Yet the findings are mixed when people must judge how "safe" nuclear power is. In spite of concerns, majorities have consistently favored continued construction of nuclear power plants. However, the data suggest that opinion on nuclear power may be becoming increasingly polarized. When construction in one's own community was specified, findings were mixed, with small majorities to pluralities favoring construction. This finding, combined with the varying results of local samples, makes judgments about attitudes of local populations toward nuclear plants in their areas very risky without surveying each locality. The generally increased favorability of nuclear plant neighbors toward nuclear power i: not necessarily an indicator of response to new proposals in other communities.

There is majority concern about risks of using nuclear power which is increasing, and there is majority general favorability to increased development, with much variation in results at the local level. 


\section{REGIONAL DIFFERENCES}

In one study, increasing energy supply was seen by majorities in all regions as causing at least a fair amount of environmental damage [308]. All regions responded equally that power plants and refineries cause air pollution [131, 308]. When asked which environmental problems would result from energy independence there were no differences in responses except that the East and the West were more likely to recognize air pollution as a major problem [308]. Although people in the West were more likely to think that environmental standards had gone too far [148], they were less favorable than other regions toward relaxing air quality standards to allow coal to be used and were less favorable to slowing the cleanup of air and waste pollution $[141,218]$. When energy needs were pitted against environmental concerns, the South was more likely than other regions to prefer energy [148].

Fossil fuels as a supply alternative were favored least in the West. As noted before, the West was more concerned about air pollution, and the West also contains offshore oil, strip-minable coal, and oil shale. The West was less likely to see offshore oil as a longterm source and to approve of its expanded development [141, 152]. Westerners were also less enthusiastic about oil shale exploration [141]. The Northeast and the West were more reluctant about coal as a long-term source than the South and the Midwest [152]. But the largest regional difference found in this review occurred over the strip mining of coal to solve the energy crisis. The national finding was reversed with a plurality in the West opposing this solution while majorities in other regions favored it [141].

Nuclear power is a supply alternative which elicited regional differences in responses. The general, favorable opinion of nuclear power and its importance as an energy source showed no variation by region [Gallup, $1976 ; 308 ; 311]$. The West was more inclined to see it as the best long-term source, perhaps because it would replace coal and oil [152]. Many more people in the West reported that they were following discussions on nuclear power (Gallup, 1976). This could have been the result of referenda which raised awareness. Indeed, those in the West and Northeast were much more likely to state correctly whether there was a nuclear plant in their area [311]. Three out of four studies showed they were also more likely to say they opposed a plant in their area [141; Gallup, 1976; $308 ; 311$. The East was less favorable to building nuclear plants for the nation's energy supply, but in the same study there was not a significant difference among regions on building nuclear plants to solve the energy crisis [141].

Although the West and the East appear to be aware, concerned, and less supportive of nuclear development, two studies indicate that the West is more inclined to see nuclear power as safe and less inclined to see additional safety standards as necessary [148; Gallup, 1976]. Three studies indicate that Easterners are most concerned among the regions about safety and safety standards [141, 148; Gallup, 1976]. In keeping with these results, people in the Northeast were significantly more likely to think the voting public should decide about disposal of atomic wastes and location of nuclear plants [141, 152].

\section{ENERGY/ENVIRONMENT TRADE-OFFS}

Environmental degradation is one of the concerns mentioned in connection with the conventional energy supply sources discussed in this chapter. In this section, survey findings from items which addressed trade-offs between energy production and use and their environmental impacts are described. 
In a November 1974 national survey over half of respondents felt there would be at least a fair amount of damage done to the environment if the United States were to produce more energy for its own use [308]. Table 6-8 shows which environmental problems people expected to be most serious if the United States tried to be self-sufficient. Air pollution and strip mining were chosen most frequently, by 20 and 18 percent respectively.

Although no national survey asked people if they opposed creating such problems, local studies in Arizona and Lansing, Michigan, showed divergent opinions on this question. Nine out of 10 Lansing respondents agreed with the statement, "The natural environment should be preserved even if I must change my way of living" [106]. In Arizona, however, 30 percent were unsure of how to respond to the statement, "Our energy needs are more important than environmental considerations" [201]. The plurality disagreed, but another 30 percent agreed that energy was more important.

Table 6-9 and Figure 6-F display the data collected over five years on this question. Opinion is polarized on the energy/environment issue. Between October 1976 and September 1977 the proportion of respondents who felt adequate energy was most important increased by 10 percentage points, and the proportion urging environmental protection decreased by nine percentage points.

The existing data appear to indicate that public opinion about energy/environment tradeoffs is polarized. with sizable minorities favoring each side of the issue. Public concern seems to lean toward adequate energy supplies (over the environment) when shortagerelated events occur.

\section{COMPARATIVE FINDINGS ON SUPPLY SOURCES}

The survey data reported on each energy alternative do not permit a composite judgment like "The public prefers X energy source to $\mathrm{Y}$ energy source." Even items which asked people to choose among sources usually focused on one aspect of the decision about it, such as, "Should we expand work on it?" or "Which is in greatest supply?" From the preceding sections the separate opinions about each technology can be compared and results discussed in light of the few items which asked respondents to choose one energy source over others.

\section{Effectiveness}

A national survey in February 1977 found 83 percent agreeing that offshore oil drilling is an important step to increase supply in the next 10 years [245]. When asked which energy sources "are realistically possible to use for replacing foreign oil during the next five years," those choosing "oil from offshore United States oil wells" rose from about one-fifth in 1975 to 42 percent in 1977 [152]. Coal and solar energy were chosen more of ten. Nuclear energy followed. When asked about a long-term source of energy on which we should spend the greatest effort, those choosing oil from offshore U.S. wells fell from 18 percent in 1975 to 12 percent in 1977; it was below solar energy, nuclear energy, and coal on the list [152]. Oil extracted from shale was seen as a near-term source by 16 percent and as a long-term source by three percent [152].

A 1975 national study asked what energy supply source could be a realistic substitute for foreign oil [152]. About a fifth thought coal was a realistic substitute. When the item was repeated in 1977,61 percent chose coal, 52 percent chose solar energy, and 42 percent chose oil from offshore oil wells. 


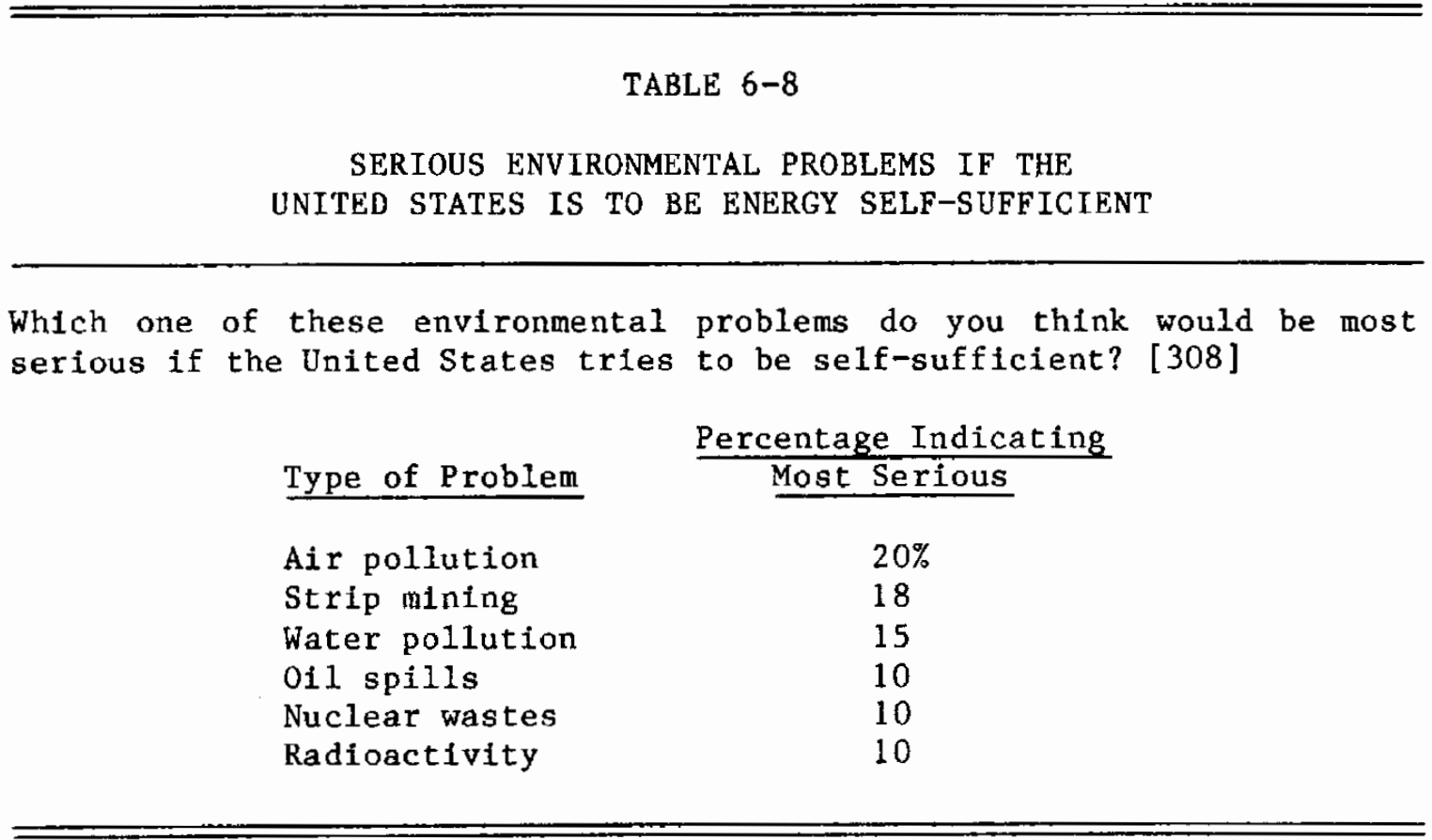


TABLE 6-9

PREFERENCES FOR ADEQUATE ENERGY

VERSUS THE ENVIRONMENT

There is continuing talk about an energy crisis and the idea that there won't be enough electricity and other forms of energy to meet consumer demand in the coming years.

Some people say that the progress of this nation depends on an adequate supply of energy and we have to have it even though it means taking some risks with the environment. Others say the important thing is the environment, and that it is better to risk not having enough energy than to risk spoiling our environment. Are you more on the side of adequate energy or more on the side of protecting the environment? [148]

\begin{tabular}{|c|c|c|c|c|c|c|c|c|}
\hline & \multirow{2}{*}{$\frac{1973}{\text { oct. }}$} & \multicolumn{3}{|c|}{1974} & 1975 & \multicolumn{2}{|c|}{1976} & 1977 \\
\hline & & oct. & May & Jan. & $\overline{\text { oct. }}$ & Oct. & Jan. & Sep. \\
\hline Adequate energy & $37 \%$ & 41 & 37 & 47 & 40 & 33 & 39 & 43 \\
\hline Protect environment & 37 & 39 & 42 & 34 & 39 & 44 & 39 & 35 \\
\hline $\begin{array}{l}\text { Ne1ther--no conflict } \\
\text { (volunteered) }\end{array}$ & 12 & 12 & 14 & 13 & 13 & 13 & 14 & 14 \\
\hline Don't know & 14 & 8 & 8 & 8 & 9 & 11 & 8 & 8 \\
\hline
\end{tabular}




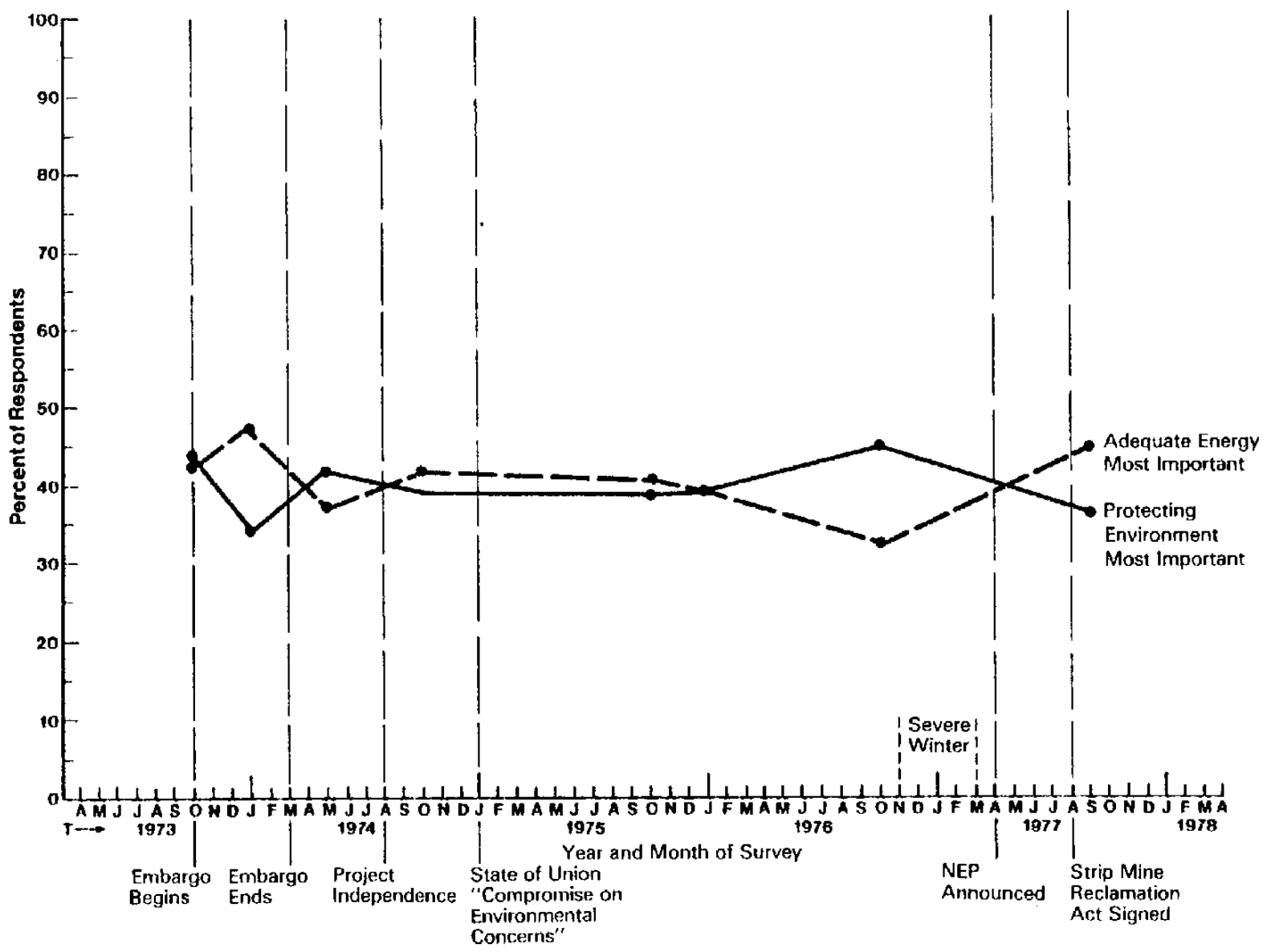

Source: Study 148.

Figure 6-F. PREFERENCES FOR ADEQUATE ENERGY VERSUS THE ENVIRONMENT 
Another national study in 1975 and 1977 asked people which sources they thought could realistically be used for replacing foreign oil in the next five years. In 1975, of those respondents who thought foreign oil could be replaced, more people listed nuclear energy than any other replacement (24 percent). Coal was a close second, and solar energy third. By 1977 nuclear energy had fallen to fourth place in number of mentions [152].

The conventional supply sources are considered to be technically effective ways to generate electricity or heat homes. Questions of availability relate to the perceived effectiveness of fossil fuels as energy alternatives, while questions of technical effectiveness pertain to nuclear and solar energy. More people defined nuclear power plants as technically feasible than see solar power plants this way. The data suggest public expectations that it would require more than 10 years to build enough of either to meet our power needs.

For size and reliability of supply, nuclear energy was seen as the most realistic replacement for foreign oil. In one study, nuclear energy was also thought to be the largest contributor to electric power generation in the future followed closely by solar energy. Coal was seen in abundant domestic supply but perceived as a nonrenewable resource. Its contribution was expected to fall in the future, although not as rapidly as that of oil. Solar energy was viewed in one study as abundant in supply although its projected contribution in the future to generate electricity was below nuclear energy and coal until 25 years in to the future.

\section{Relative Advantage}

There are several issues common to these sources which can be used as a basis for comparison. The advantages and disadvantages peculiar to each source were discussed earlier and will not be repeated here.

Dependency on foreign sources of energy is assumed to be a disbenefit in the surveys although, as mentioned earlier, explicit questions about the impact of dependency were not asked. Relying on oil was seen as increasing energy dependency. Nuclear energy, coal, and solar energy were viewed as good solutions to the dependency problem since they are available domestically.

Solar energy and hydroelectricity were seen to have cost advantages by more people than any other technology [303]. The disadvantage of high cost was mentioned less of ten for coal than for the other sources [303]. As a cheaper form of energy in the future, coal ranked ahead of oil but behind nuclear energy in numbers mentioning this advantage [141].

Low cost is an advantage mentioned more for strip-mined coal than for any other energy source. Some see nuclear power as providing a cheaper energy source in the future, and many people see the main advantage of today's nuclear energy as low cost. Oil is seen as an increasingly expensive source of energy. Expense seems to be a greater concern for oil than for nuclear energy or coal. There are few data on the perceived costs of solar energy as a producer of energy for the nation. High concern for the cost of currently available domestic systems and low expectations about price reductions in the future indicate that solar energy may be perceived as the most costly alternative currently.

Table 6-10 presents data from a sample in several local areas [303] and a national survey on perceived relative advantage and concerns about risk for oil, natural gas, coal, nuclear 


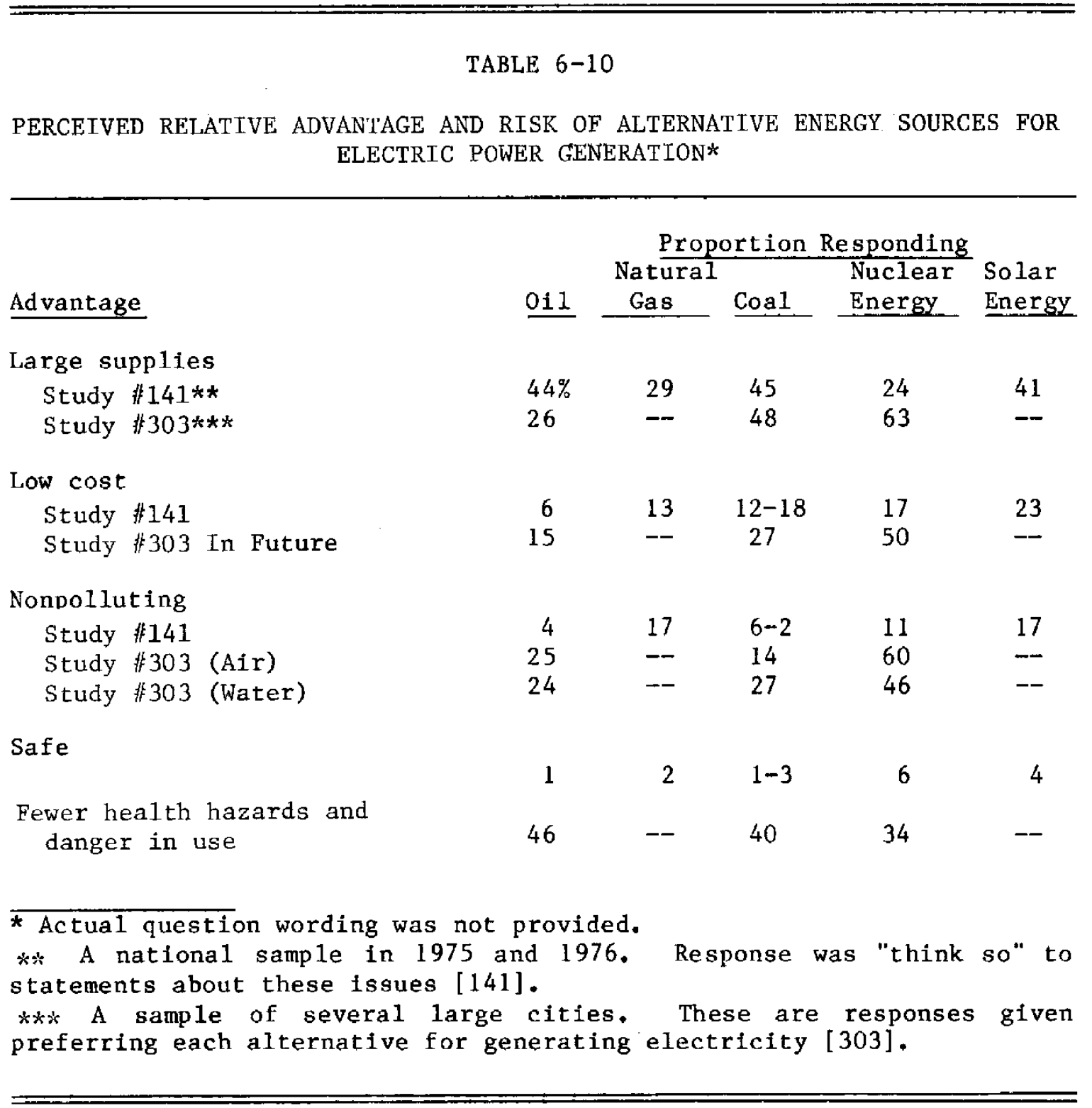


energy, and solar energy. For availability of supplies, oil, coal, and solar energy were mentioned most frequently. For low cost, solar energy was mentioned most frequently.

In comparing nuclear energy, oil, and coal, nuclear energy was mentioned most frequently as nonpolluting for air and for water. Among the same three sources, nuclear energy was also more frequently perceived as posing fewer health hazards than oil or coal.

\section{Concern about Risk}

Environmental impacts of energy production were addressed of ten in the surveys. Solar energy undoubtedly is considered the "cleanest" energy source by the general public. Indeed, this was seen as a major advantage in studies of special populations which may even outweigh some perceived monetary disadvantages. The data suggest that coal is considered the "dirtiest" source. In July 1977, three out of four respondents in a national sample thought of coal as a "dirty" source of power, while one out of four felt that way about nuclear energy [228]. Strip mining, seen as the extractive method of the future, causes concern. Air pollution due to the combustion of coal is also recognized as a major problem. The relative positions of oil and nuclear energy are harder to interpret. While oil is seen as causing less air pollution than coal, there is concern over refinery emissions and pollution from combustion. Nuclear energy is hailed as a "clean" source because it does not pollute air and there are fewer extractive problems than with coal or oil. Several recent surveys, however, marked growing concern over waste disposal and radiation hazards which affect the environment and public safety. An overall rating of environmental concerns was not elicited from the public. Until this is done on a national level it is not clear how important the perceived air and water pollution impacts of coal and oil are compared to the perceived waste and radiation effects of nuclear energy.

\section{Knowledge and Information Sources}

It is interesting to note that researchers included questions on knowledge and information sources about only nuclear and solar energy. The same is true for questions about action. These two sources are the most recent and controversial additions to supply options. People were asked whether the United States must import oil, and these perceptions may have affected opinions about effectiveness of the oil supply option. Studies attempted to determine information needs and trusted sources of information.

Survey questions provided data on knowledge, information needs, and trusted sources, but there were very few items on actual or intended actions regarding nuclear power. The public does not appear to be more knowledgeable about any one energy source over another, but data on this question are too limited to identify a pattern of findings.

\section{Evaluation and Policy Preferences}

In a 1976 national study, 35 percent of respondents thought nuclear power would provide the largest share of energy in 10 years [141]. Fif teen percent thought coal would provide the most energy. When the projection was extended to 25 years, nuclear energy was chosen by 32 percent and solar energy by 25 percent. 
As a long-term energy source for the year 2000, nuclear energy ranked second to solar energy as the source "we should spend the greatest effort to develop" in a national study. Fewer people chose nuclear energy in 1977 than in 1975 (35 versus 47 percent), although it was still mentioned more of ten than coal, oil, and other sources [152].

A 1978 Harris study in New York state asked respondents, "Which do you prefer to see as a means of getting our future energy needs: using more coal, more nuclear power, more solar power, or do you think we should conserve more energy (or not sure)?" Sample pluralities of 44.7 and 42.5 percent chose energy conservation and solar energy; 14 percent chose coal, 8.8 percent chose nuclear, and 5.2 percent were unsure.

Favorability toward expansion of each alternative energy source was examined in surveys. Strip mining of coal was favored least. Offshore oil drilling and building more nuclear plants were favored by nearly equal numbers-between 60 and 70 percent. Although items have not been replicated over time about expanding work on solar energy, recent studies showed between 80 and 90 percent favoring this.

Solar energy is favored in the abstract by sizable majorities, yet concerted action (e.g., purchase of solar heating systems) has so far involved less than one percent of the population. Special studies and local surveys included questions about knowledge, information needs, and trusted sources of information. They also contained detailed questions about behavioral intention and action to adopt solar systems.

Attitudes toward government involvement in development of energy sources were explored for oil, nuclear energy, and solar energy. Although the public was never asked, "Should the government be involved?" responses to specific types of government involvement in oil production indicate majority favorability toward regulation of production without ownership or investment.

For nuclear energy, majority favorability and intense (minority) opposition has existed for several years. Favorability toward increased government spending on nuclear power declined slightly between 1974 and 1976 from 57 to 47 percent. In 1976, 70 percent said they would like to see continued advances and development in nuclear power for peaceful uses. Regulation was favored by majorities suggesting considerable support for government action. The most recent findings indicate that the greatest favorability for government action is to develop solar energy. In February 1977, the most popular step toward developing new sources was, "Set up a government program to develop solar energy." Encouraging domestic use of solar energy through tax credits was also favored by a majority of national respondents.

\section{Summary}

It is a tricky business to compare public assessments of these supply options. Surely no one option would be preferred to the exclusion of the others, although a question along these lines might yield interesting results. Table 6-1l summarizes the rankings of each technology along the common issues discussed in this section.

It should be stressed that these rankings are not additive because they do not represent the relative importance of each issue to the public or the margin of difference between technologies on any one issue. What Table 6-11 does provide is a summary of the relative position of each technology within the categ ories used to describe the survey data. Each technology has been perceived as having positive and negative aspects. 


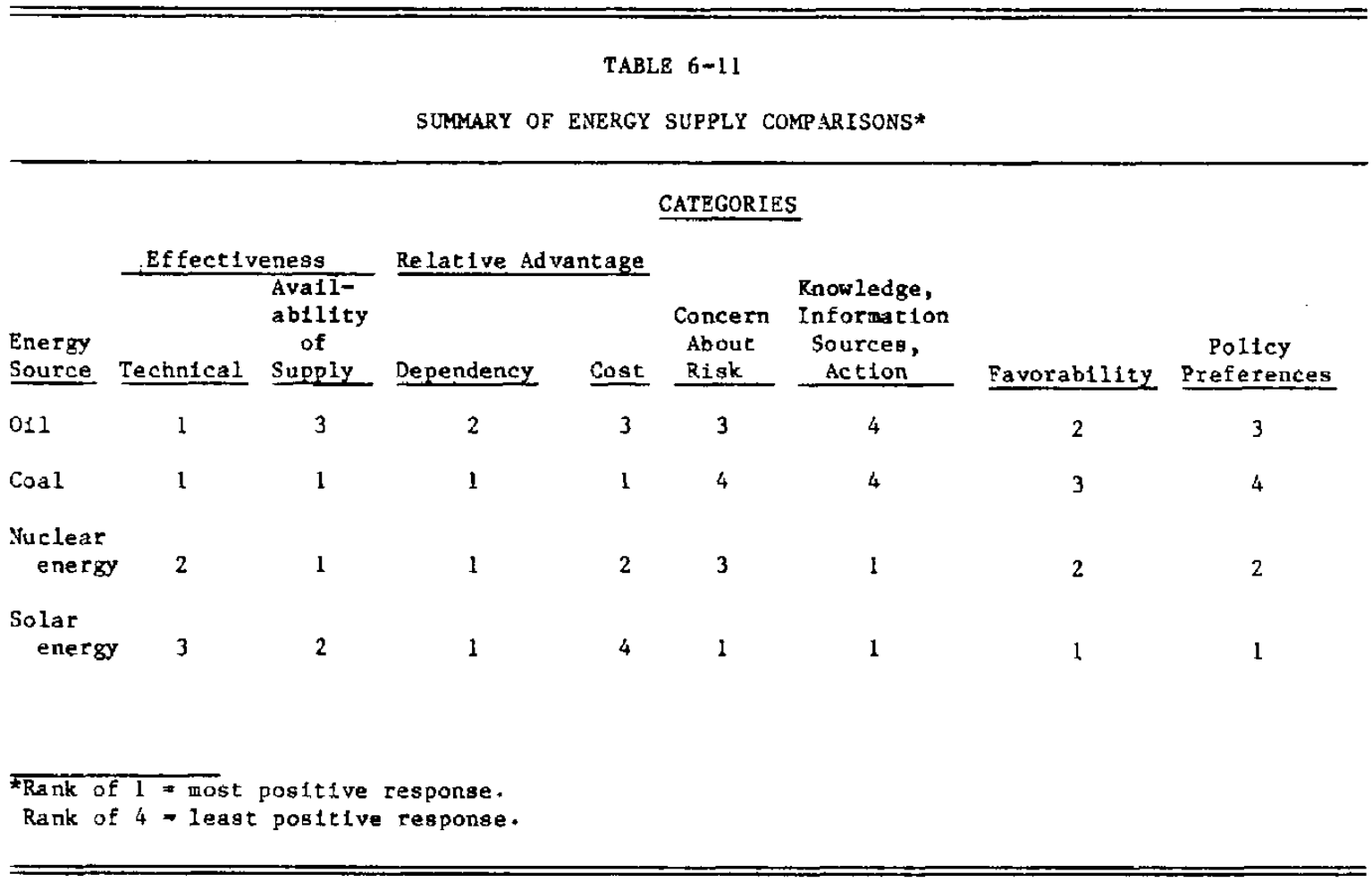




\section{CHAPTER 7}

\section{ANALYTICAL FINDINGS SUMMARY OF SOCIODEMOGRAPHIC ANALYSES}

Appendix $B$ of this report contains detailed analysis of public opinion data according to 10 major sociodemographic variables: gender, age, education, income, occupation, race, political orientation, religious affiliation, lifestyle characteristics (marital status, housing characteristics, home ownership, and transportation characteristics) and urban/rural residence. This chapter summarizes that sociodemographic analysis.

The summary is organized according to the six categories employed to organize the sociodemographic data: (1) perception of the energy situation, (2) energy and the environment, (3) knowledgeability and information sources about energy, (4) attitudes about solar energy, (5) attitudes about nuclear energy, and (6) attitudes about energy conservation.

Within each of the six content categories, summary information on survey findings are presented for each demographic variable (with the exception of religious affiliation, for which data were too scarce to permit any statements about patterns of findings). Where the summary refers to "patterns of findings," this generally indicates that the available data pointed to the likelihood of a correlation between the sociodemographic variable and an energy-related behavior or attitude. Where the summary states that no patterns of difference were discovered, this indicates that the evidence was mixed or contradictory, or that insufficient evidence was available to determine patterns.

In most cases, the survey results on energy policy options fell into the latter category. The lack of replicability of specific items measuring attitudes about various policies made the information on this topic nearly impossible to summarize.

The following summary is intended as a guide to the reader interested in sociodemographic differences in the attitudinal data reviewed in this report. Greater detail and explication of the sociodemographic patterns are found in Appendix B.

\section{PERCEPTION OF THE ENERGY SITUATION}

\section{Gender - Patterns of Difference}

Data suggested that women tended to be somewhat more concerned than men about our nation's energy future, although the findings on this were mixed. Females were slightly more likely than males to approve of policy options involving limiting energy usage. Males tended to react more negatively to President Carter's handling of the energy situation.

\section{Gender - No Patterns of Difference}

No patterns of difference by gender were discovered for:

- perceived seriousness of the energy situation, 
- perceived reality of the energy crisis,

- the salience of the energy situation,

- perceived effects of the energy shortage,

- the desirability of a national policy of energy self-sufficiency,

- preferences for conserving gasoline versus paying higher prices for unlimited use,

- preferences for various national policies (with the exception noted above concerning options limiting energy use), and

assessment of the adequacy of steps taken to deal with the energy situation, and of whether too many or not enough sacrifices had been requested.

\section{Age - Patterns of Difference}

In general, younger age groups were found to view the possibility of future energy shortages as more likely than were older groups. Younger groups tended to think a policy of national self-sufficiency in energy was less likely to occur than did older groups. In general, data indicated that older people reported more adverse effects of the energy situation than did younger people. On a number of policy options, older groups tended to support policies which held costs down, while younger groups were less supportive, particularly if rationing was proposed as a means of controlling costs.

\section{Age - No Patterns of Difference}

No patterns of difference by age were discovered for:

- perceived seriousness of the energy situation,

- perceived reality of the energy crisis,

- attribution of responsibility for the energy crisis,

- attitudes toward electric utilities,

- salience of the energy situation,

- a range of proposed policy options (with the exception that older groups appeared to favor rationing if this kept costs down), and

- $\quad$ assessment of the adequacy of steps taken to deal with the energy situation.

\section{Education - Patterns of Difference}

Findings indicated that, in general, higher educational levels correlated with perceived seriousness of the energy situation and perceived reality of the energy crisis. Higher educational attainment also was related to perceived salience of the energy situation. Although findings were mixed, there was a tendency for groups with higher education to be more pessimistic about future energy supplies. More educated groups appeared to be less supportive of gasoline price maintenance with rationing, and more supportive of 
policies of somewhat higher prices with some limitations on supply than were less educated groups. There was a tendency for more highly educated groups to have less belief in the possibility of energy self-sufficiency for the United States.

\section{Education - No Patterns of Difference}

No patterns of difference by education were found for:

- perceived responsibility for the energy situation,

- perceived impacts of the energy situation,

- approval of President Carter's handling of the energy situation, and

- attitudes toward policies regarding production versus importation of fuels.

\section{Income - Patterns of Difference}

Data indicated that higher income groups generally expressed a greater belief in the seriousness and reality of the energy crisis than did lower income groups. Higher income groups also tended to attribute greater salience to the energy situation. The lowest income groups exhibited a tendency to find steps taken to deal with the energy crisis inadequate, and to reject the idea of personal sacrifice. There was a tendency for higher income groups to expect energy shortages in the longer term. Lower income groups tended to favor policies that would keep consumer prices low.

\section{Income - No Patterns of Difference}

No patterns of difference by family income were found for:

- perceived responsibility for the energy crisis,

- expectations of near-term energy shortages, and

- a variety of policy options (with the exception noted above).

\section{Occupation - Patterns of Difference}

The data indicated a general trend for perception of and belief in the reality of an energy-related problem to increase as skill level increases. Pessimism about future shortages also tended to increase with skill level.

\section{Occupation - No Patterns of Difference}

No patterns of difference by occupation were found for:

- perceived responsibility for the energy situation, and

- approval of Carter's handling of the energy situation. 


\section{Race - Patterns of Difference}

Data indicated that nonwhites experienced more negative financial impacts due to the energy shortage than did whites. Nonwhites tended to show more concern for such issues as unemployment and inflation than for the energy crisis, as compared to whites.

\section{Race - No Patterns of Difference}

No patterns of difference by race were found for:

- perceived seriousness of the energy situation,

- belief in the possibility of future energy shortages,

- perceived responsibility for the energy situation, and

- sufficiency of steps taken to deal with the energy situation.

\section{Political Orientation - Patterns of Difference}

Democrats were somewhat more inclined than Republicans to view the energy situation as serious. Democrats were more likely than Republicans to approve Carter's handling of the energy situation.

\section{Political Orientation - No Patterns of Difference}

No patterns of difference by political orientation were found for perceived responsibility for the energy situation. Political philosophy was not found to be related to any items dealing with perceptions of the energy situation.

Lifestyle Characteristics (Marital Status, Housing Characteristics, Home Ownership, and Transportation Patterns)

Few items relating to perception of the energy situation were analyzed by these variables; no patterns of difference were found.

\section{Urban/Rural Residence}

No patterns of difference by place of residence were discovered for items relating to perception of the energy situation.

\section{ENERGY AND THE ENVIRONMENT}

\section{Gender}

Women were found to consistently favor the environment in energy-environment tradeoffs; the opposite pattern held for men, who favored adequate energy supply. Men also 
tended to be less likely than women to associate negative environmental impacts with energy production.

$\underline{\text { Age }}$

On nearly all items in which support for environmental quality was gauged or in which energy-environment tradeoffs were posed, younger people, particularly the youngest group, showed consistent support for the environment, especially when compared to the oldest group.

\section{Education}

There were strong positive relationships between educational level and preference for regulating strip mining, as well as for willingness to pay for lowered pollution levels. There were no other clear differences by educational level regarding tradeoffs between adequate energy supplies and environmental protection.

\section{Ineome}

The pattern of findings regarding energy-environment tradeoffs revealed that lower income groups consistently showed greater environmental support than higher income groups, except where environmental quality is posed as entailing higher consumer costs.

\section{Occupation}

No pattern of findings was found in the few items relating occupational status to energyenvironment tradeoffs.

\section{Race}

Nonwhites appeared to be slightly more concerned than whites about environmental quality, as revealed by a number of items measuring energy-environment tradeoffs.

\section{Political Orientation}

Data suggested that liberals tend to be more favorable to the environment than are conservatives.

\section{Lifestyle Characteristics}

Insufficient data were available to discover patterns by lifestyle characteristics regarding energy-environment tradeoffs. 


\section{Urban/Rural residence}

Data indicated that, in general, rural residents were more likely than urban residents to favor adequate energy supply over environmental protection when tradeoffs were posed between these concerns.

\section{KNOWLEDGEABIITY AND INFORMATION SOURCES ABOUT ENERGY}

\section{Gender}

Data indicated that men are exposed to more information about energy-related topics than are women. Men were somewhat more knowledgeable than women about these topics. No patterns of difference by gender were discovered for sources of information used. Assessment of credibility of various sources of information about energy matters did not differ by gender.

\section{Age}

No patterns of difference by age were discovered for knowledge of energy-related issues, or for perceptions of the credibility of various information sources.

\section{Education}

In general, surveys found that educational level is positively related to knowledge about the energy situation and awareness of sources of energy information. There were no clear patterns of difference by educational level on credibility of information sources.

\section{Income}

Survey findings showed a strong pattern of increasing knowledgeability about the energy situation with increasing income. No clear relationship between income and credibility of various sources of information was evident in the findings.

\section{Occupation}

A strong positive relationship between occupational level and knowledgeability about the energy situation and about alternative energy sources was revealed in the survey data. No pattern of difference by occupation was discovered for credibility of information sources.

\section{Race}

Data indicated a clear pattern of greater reported objective knowledge by whites than by nonwhites concerning energy issues. No pattern of difference by race concerning credibility of information sources was discovered. 


\section{Political Orientation}

No strong differences by political orientation were revealed for objective knowledge about the energy situation or for credibility of information sources.

\section{Lifestyle Characteristics}

No strong patterns of difference by lifestyle characteristics were discovered regarding knowledgeability about energy issues or credibility of information sources.

\section{Urban/Rural Residence}

No patterns of difference by place of residence were evident for knowledgeability about energy issues or credibility of information sources.

\section{ATTTTUDES ABOUT SOLAR ENERGY}

\section{Gender}

No strong patterns of difference by gender were discovered for attitudes about solar energy.

\section{Age}

Several items intended to gauge attitudes toward solar energy indicated a pattern of greater support for solar energy among younger age groups.

\section{Education}

No patterns of difference by educational level were discovered regarding attitudes toward solar energy.

\section{Income}

A strong pattern of difference by income was found regarding attitudes toward solar energy, with greater support found among higher income groups.

\section{Oceupation}

A general pattern of greater support for solar energy among professional and managerial groups than for lower skill level groups was discovered. 


\section{Race}

A pattern of greater support for solar energy among whites than nonwhites was discovered.

\section{Political Orientation}

No patterns of difference by political orientation were discovered regarding attitudes toward solar energy.

\section{Lifestyle Characteristics}

No patterns of difference by lifestyle characteristics were discovered regarding attitudes toward solar energy.

\section{Urban/Rural Residence}

No patterns of difference by place of residence were discovered regarding attitudes toward solar energy.

\section{ATTITUDES TOWARD NUCLEAR ENERGY}

\section{Gender}

Data indicated greater general support among men than women for nuclear energy, while women showed greater general opposition than men. Men were also more favorable to the idea of having a nuclear power plant in the vicinity of their homes. Females were found to be more coneerned than males about the safety of nuclear power plants.

\section{Age}

A general pattern of more opposition and less support for nuclear power among younger than older age groups was discovered. Younger groups were also found to be less supportive of having nuclear power plants in their vicinity than were older groups. The younger age groups showed consistently higher concern over nuclear safety than did most older groups, except that the oldest group also showed higher concern than those in the middle age ranges.

\section{Education}

Data indicated a slight pattern of greater favorability toward nuclear energy development and of positive attitudes toward nuclear power among more highly educated groups than among those with less education, although the results were mixed. No relationship was found between educational level and the desirability of having nuclear power plants in one's vicinity or perceived safety of nuclear power plants. 


\section{Income}

Income was found to be positively related to general favorability toward nuclear energy, and to the desirability of having more nuclear power plants in one's vicinity. Higher levels of income were also associated with higher levels of perceived safety of nuclear power plants.

\section{Ocerpation}

In general, survey data indicated that professional and managerial groups were more favorable toward nuclear energy and more likely to perceive nuclear power plants as safe than were those at lower occupational skill levels.

\section{Race}

Whites were found to be generally more supportive than nonwhites of nuclear energy development. Whites were also generally more supportive than nonwhites of having more nuclear power plants in one's general vicinity. On many of these items, nonwhites tended to be unsure or have no opinion than to be in opposition to nuclear power.

\section{Political Orientation}

No clear pattern of difference by political orientation was discovered regarding attitudes toward nuclear energy.

\section{Lifestyle Characteristics}

No clear pattern of difference by lifestyle characteristics was discovered regarding attitudes toward nuclear energy.

\section{Urban/Rural Residence}

The data indicated a slight pattern of greater support for nuclear power among rural residents than among those in large cities.

\section{ATTITUDES ABOUT ENERGY CONSERVATION}

\section{Gender}

Survey data indicated that women may be slightly more favorable to energy conservation than men. Men and women who engaged in conservation behaviors tended to do so in activities consonant with their sex roles. 


\section{Age}

Data indicated a pattern of doubt among younger age groups regarding the efforts of government and industry to conserve energy. Older groups showed generally greater support for gasoline rationing, particularly when this option was posed against policies that entailed higher prices. No obvious patterns of age-related differences in energy conservation behavior were discovered.

\section{Education}

More highly educated people were found to practice more conservation with regard to lowered thermostat settings. No other differences by education were discovered for other conservation behaviors or for conservation attitudes. More highly educated people were found to be generally more in favor of transportation related conservation policiesthey were generally more favorable toward mass transit (although they were not more inclined to use it). This group also tended to favor policies that would raise gasoline prices but not restrict their driving.

\section{Income}

Lower income groups tended to report engaging in less conservation-related behavior than higher income groups. No patterns of difference were apparent by income regarding perceived efficacy of personal efforts to conserve or with regard to ratings of conservation efforts in such sectors as government or business. No patterns of difference by income were discovered for driving behavior or attitudes. Lower income groups tended to favor rationing of gasoline accompanied by lower prices, while higher income groups consistently opposed limits on the availability of gasoline. No clear differences by income were discovered regarding attitudes toward or use of public transportation.

\section{Lifestyle Characteristics}

Data suggested that unmarried people are somewhat more likely to find infringement on personal mobility a hardship than are married people. No patterns of difference in energy-conserving behavior by marital status were discovered, however. No patterns of difference by housing characteristics and living situations were discovered regarding energy conservation. There was some evidence that homeowners are more concerned than renters with reducing energy consumption.

\section{Urban/Rural Residence}

No strong patterns of difference by place of residence were discovered regarding attitudes toward energy conservation. Specific conservation behaviors engaged in varied by place of residence. Urban residents appeared to be more favorable than others to mass transit. 


\section{Occupation}

No patterns of difference by occupation were discovered with regard to conservation attitudes and the extent to which conservation was practiced. There were differences by occupation in the specific conservation behaviors which individuals practiced.

\section{Race}

No clear patterns of difference by race were discovered with regard to energy conservation attitudes or behavior.

\section{Political Orientation}

Various survey items indicated a possible pattern of greater favorability toward energy conservation among Democrats than among Republicans, and among liberals than among conservatives. 


\section{SEPr}




\title{
CHAPTER 8
}

\author{
ANALYTICAL FINDINGS \\ SOCIAL-PSYCHOLOGICAL VARIABLES
}

This chapter addresses the relationships among social-psychological variables analyzed in the surveys. As previously noted, survey data collection has not generally been guided by explicit theoretical constructions. Nevertheless, some theoretical ideas are implicit in the survey data; the purpose of this chapter is to analyze these data and to make the theoretical notions underlying them clear. The presentation in this chapter is organized around major independent variables. Thus, the discussion below is organized around the following headings: (1) accounting for belief in the energy crisis, (2) belief in the energy crisis as an explanatory variable, (3) perceived impacts of the energy crisis, (4) knowledge, (5) belief in the effectiveness of energy conservation, (6) concern about risk, (7) evaluation of nuclear energy, and (8) environmentalism.

These variables are termed social-psychological to distinguish them from demographic descriptions of individuals (age, gender, etc.) and to highlight the fact that they pertain to individual knowledge, attitudes, and practices. Most of ten, no tests of statistical significance were run; therefore, data were examined to locate marked (possibly significant) differences in response by independent variable categories. These differences would be around 10 percent or greater for national samples and 15 to 20 percent or greater for local samples. Differences noted are not statistically significant (unless specified) and only suggest an association between two variables. When "no differences" are reported, the variation in response was less than the values mentioned above. Few of the studies controlled for third variables, and very few employed analytical techniques beyond cross-tabulations.

Table 8-1 summarizes the analyses of the explanatory (independent) variables and the variables (dependent) these might explain. While many surveys in this review analyzed no social-psychological variables, of those that did present such analyses, by far the most frequently used explanatory variable was belief in the energy crisis. Belief was usually measured as repondent assessment of the reality or seriousness of the energy problem. Belief was cross-tabulated with a wide array of dependent variables usually pertaining to acceptability of alternative solutions (such as favorability toward energy conservation). As Table 8-1 shows, belief in the energy crisis was also used frequently as a variable to be explained.

The first section of this chapter discusses the findings that attempted to explain why people believed there was an energy crisis.

\section{ACCOUNTING FOR BELIEF IN THE ENERGY CRISIS}

Implicit in many of the survey analyses performed was the idea that if persons believed there to be a serious national energy problem, they would be more willing to practice energy conservation, adopt solar energy, and accept various other alternatives, such as nuclear power. It was clear, however, that not everyone believed the energy problem was serious (see Chapter 3). A few investigators attempted to determine what distinguished those who believed in an energy crisis from those who did not. Results of these analyses are described below, organized by four independent variables used in survey analyses. These are: perceived causes of the energy crisis, perceived impacts of the energy crisis, knowledge, and environmentalism. 
TABLE $8-1$

SUMMARY OF RELATIONSHIPS BETWEEN VARIABLES ANALYZED

Independent Variable by

Belief in the energy crisis

Perceived causes of energy crisis

Percelved impact of energy crisis

Knowledge and information sources

Belief in the effectiveness of conservation

Concern about risk

Favorability toward nuclear energy

Environmentalism
Dependent Variable

Conservation norms

Energy self-sufficiency

Conservation policies

Knowledge (conservation)

Conservation behavior

Favorability toward nuclear energy

Favorability toward use of fossil fuels

Favorability toward solar energy

Belief in the energy crisis

Belief in the energy crisis

Conservation behavior

Favorability toward solar energy

Favorability toward policy options

Belief in the energy crisis

Conservation attitudes and behavior

Favorability toward nuclear energy

Favorability toward solar energy

Conservation behavior

Favorability toward nuclear power

Perceived salience of nuclear power

Concern about risk

Acceptable conditions for nuclear power

Perceived impacts of nuclear power

Credibility of information sources

Favorabllity toward coal

Favorability to policies

Belief in the energy crisis

Attribution of responsibility

Credibility of information sources

Knowledge 


\section{Perceived Causes of the Energy Crisis}

The hypotheses examined by these analyses were: (1) those who defined energy shortages and rising prices as a consequence of industrial and political action (e.g., "contrived") would be less likely to believe there is an energy crisis, and (2) those who defined the symptoms as due to causes beyond institutional control (e.g., decreasing availability of fossil fuels) would be more likely to believe there is an energy crisis.

A Texas study conducted in 1974 examined the relationship of "perceived causes of the energy crisis" by "level of belief in the energy crisis," finding statistically significant differences by each perceived cause $(p \leq .001)$ [116]. Respondents who believed the world was running out of fuel supplies were significantly more likely than those who did not believe so to feel that the nation had an energy crisis. Those who thought oil companies were trying to make a profit through the energy situation were three times more likely to indicate there was not a crisis than those who did not think so. This pattern of findings held for the rest of the variables, with those who thought that companies were holding fuel to raise prices, that the shortage was part of a political scheme, and that the "energy crisis" was actually a political move by government being significantly less likely to believe in the crisis than those who did not perceive these causes.

Another study reported that 32 percent of believers in the crisis and 86 percent of nonbelievers agreed that "the 'energy crisis' was a 'put on' in order to raise prices of fuels" [106]. In 1974, reasons related to whether the "energy shortage" was assessed as "very serious" or "not at all serious" were as follows: "public increasingly wasteful" (believers, 70 percent; nonbelievers, 49 percent), "too many inefficient consumer goods" (believers, 62 percent; nonbelievers, 44 percent), "oil companies didn't prepare" (believers, 54 percent; nonbelievers, 36 percent), and "no national energy policy by government" (believers, 51 percent; nonbelievers, 42 percent) [137]. For other reasons, little difference between the two groups was found; these were "expansion of industry," "various pollution controls," and "population growth." Those defining as causal wastefulness, inefficient and excessive consumer goods and lack of national energy policies, all of which are sociopolitical and economic reasons, were more likely to view the situation as "very serious."

Thus, two analyses had results supportive of the hypotheses, and one had results unsupportive of them. The latter analysis suggests a hypothesis that those attributing the energy crisis to institutional problems are more likely to view the problem as very serious.

\section{Perceived Impacts of the Energy Crisis}

Several investigators attempted to assess the hypothesis: those whose lives were most affected by energy-related problems are most likely to believe in the seriousness of the energy crisis.

ORC replicated an item in national surveys in September and December 1974 to measure perception of price increases by belief in the energy crisis [139, 308]. The item was: "Aside from gasoline and heating oil, are there any other things you buy whose price has gone up because of : the energy shortage?" Response categories included: electricity, food, plastics, other, everything, nothing, and don't know. In September, those who 
perceived price increases in "everything" were slightly more likely to view the energy shortage as "very" or "somewhat" serious than as "not at all" serious. No other differences by perceived price increases were found in September. The findings for December resulted in no differences in belief by perceived price increases [308].

Unseld (1978), using a purposive sample of the elderly in New York state, found a significant correlation ( $\leq \leq .05$ ) between a high percentage of experienced increases in energy costs over the previous year and strong beliefs in seriousness of the energy crisis. Unseld reported that perceived increases in energy costs were associated with greater number of lifestyle changes experienced $(\mathrm{p} \leq .05)$.

ORC queried respondents late in 1974: "Compared to the prices of most other things you buy, do you think gasoline prices today are reasonable or unreasonable?" [308] The sample was about evenly divided on this question, but those who thought prices were unreasonable were slightly more likely to perceive the energy situation as "not serious at all." In the same survey, respondents were asked, "How much impact do you think increases in the price of oil and gasoline have had on the rate of inflation-a great deal of impact, a fair amount, or only a little impact?" No difference was found for this item by belief in the energy crisis. When respondents were asked whether they thought the price of gasoline had gone up "a great deal," "a fair amount," or "a little" during the previous year, no difference by belief was found except for a slight tendency for believers to think it had increased a "fair amount" and nonbelievers a "little" [308].

Results from the 1976 Lansing, Michigan, survey indicated that, even though energy costs had increased, almost half the sample did not believe in an energy problem, and more than half perceived no reduction in their own energy consumption [106].

A 1975 survey in Texas and Arizona resulted in differences in belief by electric and natural gas bill increases [181]. Response categories on impact of increasing bills were "it really had no effect on us," "we had to make a few adjustments, but our style of life was not affected," and "our life was less comfortable and convenient, but it was not serious." Those who reported that they were less comfortable were slightly more likely not to believe in the energy crisis than the others. The authors explained this outcome by indicating that higher income respondents would be less likely to experience inconvenience or discomfort, and higher income was found to be associated with belief [181].

In summary, the hypothesis found limited support in three analyses and no support in two. The suggestion was made that other variables might intervene to confound the posited relationship (such as income).

\section{Knowledge}

The basic hypotheses involving knowledge and information sources explored in these analyses were: (1) the more informed an individual is about energy issues, the more likely $\mathrm{s} / \mathrm{he}$ is to believe in an energy crisis, and (2) belief will vary by sources of information used. Policymakers might be concerned that the public is unaware of basic facts about energy, such as how much of the nation's oil is imported, with difficult implications for finding politically acceptable solutions to energy problems.

A 1977 Gallup survey cross-tabulated knowledge (treated as an independent variable) about whether the nation must import oil by belief in the energy crisis. Those aware that the United States must import oil from other countries were more likely to view the 
energy situation as "very serious" (61 percent) than those who thought the nation produces enough oil to meet "our present energy needs" (25 percent) [218]. Similarly, 52 percent of the uninformed thought the situation was "not at all serious" compared to 36 percent of the informed. However, no difference was found by knowledge of the proportion of domestic needs that was filled by imported oil and belief in the crisis [218]. Results are summarized in Table 8-2. Those who did not know what proportion was imported were slightly more likely to view the energy problem as not serious.

Part of the reason for public misinformation about energy facts might lie in the inconsistency of information available to them. (See also the discussion in Chapter 3 on this point). Table 8-3 documents information from three credible sources concerning the proportion of oil consumed in the United States that is actually imported. Although an expert might be able to reconcile the differences in reported figures (perhaps some figures refer to crude oil and others to refined oil), the public likely has no such expertise to evaluate disparate information. What appears to be public ignorance may in fact be partially a function of the array of contradictory information publicly available. In part, the public may also not have paid enough attention to energy information to know accurately the nation's energy picture.

ORC reported findings from 1976 resulting in slight differences in belief by those who had children exposed to energy conservation information in school [130]. Parents of these children were slightly more likely to perceive the "need to save energy" as "very" or "somewhat serious."

A 1976 survey conducted in Lansing, Michigan, queried respondents about their sources of information on energy. Those using newspapers were slightly more likely to be believers (37 percent) than those using books and magazines (25 percent), but they were also slightly more likely to be nonbelievers ( 27 percent compared to 15 percent of those using books and magazines) [106].

These findings seem to be contradicted by others from a 1976 Grand Rapids, Michigan, survey which reported higher levels of belief in oil and natural gas shortages among those relying for information on national magazines (from 38 to 48 percent) than among those relying on newspapers (from 18 to 28 percent) or television news (from 13 to 23 percent). Of all groups, those relying on the federal government and national magazines for information were most likely to think oil and natural gas supplies will run out eventually [119]. No data, however, exist as to whether these relationships might be confounded by other variables, such as respondent educational level and preference for information sources.

In summary, the hypothesis concerning the relationship of knowledge and belief was supported in two analyses. This relationship warrants further research before any conclusions may be drawn. Little empirical evidence exists in support of the hypothesis on variability in belief by information sources. Results from two analyses suggest that such variability may exist, but these were inconsistent in which information sources were associated with higher belief levels.

\section{Environmentalism}

The basic hypothesis explored in one study was that those concerned about the environment would be more likely than others to believe in an energy crisis. This hypothesis was found to be supported. 
TABLE $8-2$

KNOWLEDGE OF OIL IMPORTS BY BELIEF IN ENERGY CRISIS

From what you have heard or read, do you think we produce enough oil in this country to meet our present energy needs or do we have to import some oil from other countries? (Asked of those who said we need to import oil to meet our energy needs: About how much--that is, what percent--of the oil used in this country do we presently import from other countries?") [218]*

Estimate of

Percentage of $0 i 1$

Imported

Up to 9 percent

10-29 percent

30-39 percent

40-49 percent

50-59 percent

60-69 percent

70 percent and over

Don't know

\begin{tabular}{ccc} 
& \multicolumn{2}{c}{ Proportion Indicating } \\
\cline { 2 - 3 } Very & Fairly & Not at \\
Serious & Serious & all \\
Situation & Situation & Serious \\
\hline
\end{tabular}

$2 \%$

13

6

19

12

10

7

32

$\begin{array}{rr}3 & 6 \\ 17 & 10 \\ 10 & 10 \\ 16 & 16 \\ 11 & 13 \\ 8 & 7 \\ 3 & 2 \\ 34 & 41\end{array}$

*This item was asked in April-May of 1977. The actual proportion of oil imported during 1976 was 39.2 percent, and during 1977 it was 44.5 percent (Lange, 1978). 
TABLE $8-3$

OBJECTIVE DATA ON OIL IMPORTS

Proportions of oil consumed in the United States actually imported.

\begin{tabular}{|c|c|c|c|}
\hline Year & $\begin{array}{l}\text { Lange }(1978) \\
\text { (Crude oil) } \\
\end{array}$ & $\begin{array}{l}\text { Sources of Data } \\
\text { Statistical Abstracts } \\
\text { of the United States } \\
(1977)(0 i 1)^{b}\end{array}$ & $\begin{array}{l}\text { New York } \\
\text { Times c }\end{array}$ \\
\hline 1965 & -- & $11.28 \%$ & $20 \% \mathrm{~d}$ \\
\hline 1968 & $12.4 \%$ & -- & -- \\
\hline 1969 & 13.2 & -- & -- \\
\hline 1970 & 12.0 & 9.48 & $23^{d}$ \\
\hline 1971 & 14.9 & 11.63 & -- \\
\hline 1972 & 18.9 & 14.27 & $27^{\mathrm{d}}$ \\
\hline 1973 & 26.0 & 19.7 & $35^{\mathrm{d}}$ \\
\hline 1974 & 28.6 & 22.0 & -- \\
\hline 1975 & 32.9 & 26.54 & -- \\
\hline $\begin{array}{l}1976 \\
1977\end{array}$ & $\begin{array}{l}39.2 \\
44.5\end{array}$ & 32.12 & $\begin{array}{l}\$ 36 \text { billion } \\
\$ 45 \text { billion }\end{array}$ \\
\hline $1980^{\circ}$ & - & -- & $40-60 \% \mathrm{~d}$ \\
\hline
\end{tabular}

ap. 131 .

bpp. 594, 597.

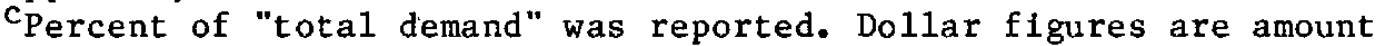
spent on imported oil.

dApri1 17, 1973.

eApril 19, 1977, p. 24.

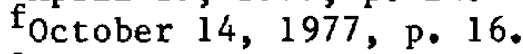

grojected. 
"Environmental activists"* were found to be somewhat more likely than the total public to view the energy shortage as "very serious," "of long duration," and to expect it to become "more severe in the next few months" [137]. These results were from an ORC national survey in 1974. Activists were also more likely than the total sample to feel that one important reason for the energy shortage was "too many inefficient consumer goods," and they were less likely than the total sample to identify "various pollution controls" as a cause of the energy shortage [137].

\section{Summary}

The hypotheses for further exploration emerging from these findings are:

- Those attributing energy shortages to political and economic contrivance are less likely than those attributing it to declining availability of fossil fuels to believe in an energy crisis.

- Those experiencing negative lifestyle consequences from energy-related problems are more likely than those who do not to believe in an energy crisis.

- Those more informed about energy facts and issues are more likely than the uninformed to believe in an energy crisis.

- Belief in the crisis varies by energy information sources used.

- Those with greater environmental concern will be more likely than those with less concern to believe in the energy crisis.

None of these posited relationships is supported by a strong pattern of empirical findings. They are identified as possible questions for future research.

\section{BELIEF IN THE ENERGY CRISIS AS AN EXPLANATORY VARIABLE}

Belief was measured in two different ways (as described in Chapter 3) involving asking about perceived seriousness of the "energy crisis" or the "energy situation." As discussed in this section, "believers" are those indicating a perception that the energy shortage, crisis, or situation was "very serious," and "nonbelievers" are those indicating that the situation was not serious. Findings are presented as dichotomized between these two groups, essentially eliminating consideration of those in the middle ground who indicated that the situation was "somewhat serious," and ordinarily fell between the other two. Where some notable finding involves the middle group, this is discussed.

Belief in the energy crisis was posited as a predictor of conservation norms, attitudes toward energy self-sufficiency, preferences on conservation policies, conservation behavior, favorability toward nuclear power, and favorability toward solar energy. The following discussion is organized by these dependent variables.

*Activists were defined as "people who either belong to an environmental accented organization or have written a letter on an environmental subject to a newspaper, legislator, or other government body, or have done both. About one respondent in six is classified as an Environmental Activist" [137]. 


\section{Conservation Norms}

Using the item, "The Arabs have more than doubled the price of gasoline sold to the United States. Do you think Americans should conserve gas so they don't have to pay so much to the Arabs, or should Americans go ahead and pay the higher prices and use all the gas they want?" ORC found that nonbelievers were slightly less likely than believers to indicate that Americans should conserve gasoline, although 70 percent or more of each category agreed with conservation $[133,308]$. Similarly, in 1974 believers (77 percent) were more likely than nonbelievers (66 percent) to agree with the statement, "Some people have suggested that Americans are using up too much of our country's natural resources and that now is the time to cut back on buying things and conserve our resources for future generations" [308]. These items are confounded by double ideas (Arabs-conservation; buying things-conserving resources); they also have the drawback of being "apple pie" statements with which most persons would agree. They are, thus, of limited usefulness in assessing whether belief in an energy crisis is associated with conservation norms.

Gallup addressed a similar issue in 1977 by comparing assessment of seriousness (belief) by the perceived importance of conserving gasoline through reduced driving [310]. About two-thirds of nonbelievers said it was "not at all important" that they reduce their driving by one-fourth, compared to 17 percent of believers (those assessing the energy situation as "very serious"). Among believers, 40 percent indicated it was "very important" to cut back driving.

These findings provide very limited supporting evidence on the hypothesized relationship between belief in an energy crisis (or in the seriousness of the situation) and belief that energy should be conserved. This relationship is hypothesized, but remains a question for future research.

\section{Energy Self-sufficiency}

Belief in the crisis was cross-tabulated with belief in energy self-sufficiency using 1974 data [308]. The item was: "President Ford has urged that the United States be completely self-sufficient in energy supplies so that we will not have to import oil from other countries. Do you think the United States can be completely self-sufficient in energy supplies?" Of those indicating the energy shortage was very serious, about twothirds thought the nation could be self-sufficient and 27 percent thought not. Of those who thought the shortage was "not serious at all," about 75 percent thought selfsufficiency could be attained, and 18 percent thought it could not. Very similar results were obtained when the item was repeated about a month later [131]. This suggests that believers are slightly less optimistic in assessing the nation's chances for energy selfsufficiency, but one item from one survey constitutes very little empirical support for the relationship.

\section{Conservation Policies}

Data from a national sample in 1977 were used to cross-tabulate belief with favorability to "a gasoline rationing law that would require people to drive one-fourth less" [310]. Believers were polarized between favorability and opposition (45 to 46 percent); 
nonbelievers tended to be opposed (69 percent compared to 22 percent favorable). In a 1976 Michigan survey, believers were more likely (46 percent) than nonbelievers (14 percent) to indicate that gasoline rationing was "acceptable" or "very acceptable" to them [106]. These findings show that nonbelievers will not accept gasoline rationing and that a majority of believers are not favorable to it either. Thus, if an increase in belief occurs in the population, more absolute numbers of people might favor gasoline rationing, but the majority would likely still oppose it (unless it were contrasted to higher prices).

ORC queried respondents on how concerned they were about gas mileage [133, 308]. Belief was associated with such concern, although 40 to 52 percent of nonbelievers were also concerned about mileage (compared to 60 to 62 percent of believers).

Believers ( 56 percent) were found more likely than nonbelievers ( 31 percent) to want their congressman to vote for an increase in gas taxes and a tax rebate [219]. ORC reported that neither believers nor nonbelievers favored a gasoline tax. On the other hand, believers (73 percent) were more favorable than nonbelievers ( 59 percent) toward an extra tax on purchase of large cars [131]. However, no difference was found using the same item at almost the same time, according to a different ORC report [308]. Gladhart found that the proportion of believers finding tax deductions for small cars acceptable rose from 36 to 61 percent over the course of a two-year study [208]. Nonbelievers had not changed their opinions. A proposal to increase taxes on gasoline while cutting income taxes was supported by about a third of believers and a fifth of nonbelievers [139]. These findings taken together suggest a very slight tendency for believers to favor various taxing schemes designed to decrease gasoline consumption, but the data are weak and inconclusive.

Much the same situation emerges from findings on proposals to decrease gasoline consumption by increasing prices. ORC found no differences between believers and nonbelievers during 1974 on these items: (1) Should people who drive cars that get less than 15 miles per gallon pay higher prices for gas than people who have cars that get better mileage per gallon? and (2) Should people who drive more than 200 miles per week pay higher prices for gas than people who drive less? [308] In 1974, ORC found a very slight tendency for nonbelievers to prefer higher prices with unlimited availability of gasoline over other alternative responses to severe energy shortages (29 percent compared to 13 percent for believers) [308]. No difference between believers and nonbelievers on this item was reported a few months later by ORC [129]. In a choice between gas rationing or price increases, nonbelievers were more likely to choose "neither" (30 percent) than believers, and they were less likely to choose rationing [220].

Several items cross-tabulated by belief in the energy crisis pertained to opinion about mass transit. ORC found no difference by belief in the following items: (1) Which means of traveling to and from work would you say costs you more-using public transportation or driving your own car? (2) If public transportation got you to work 15 minutes faster, would you use it? (3) If the fare were half as much money, would you use public transportation? [129]

ORC found differences by belief in willingness to use "park and ride" systems of mass transit. Those believing in the crisis were more likely to indicate they would use such a system (46 percent) than nonbelievers (24 percent) [308]. Believers were found to be slightly more likely than nonbelievers to think that increased use of mass transit would "help save gasoline" [129]. They were also much more likely than nonbelievers to prefer spending tax money on more mass transit than on more highways (67 to 36 percent) [129]. A marked difference was found between believers ( 72 percent) and nonbelievers 
(nine percent) in whether they would be willing to use public transportation if it ran twice as of ten [129]. Similarly, believers were more likely than nonbelievers to indicate that the nation as a whole would benefit from more and better mass transit rather than only those who used it (61 percent compared to 41 percent) [129]. Another study done in Michigan reported that two-thirds of believers and 42 percent of nonbelievers found tax-supported mass transportation acceptable [106]. Taken together, these findings suggest a slight tendency for those who believe in the energy crisis to express more favorability toward public transportation than those who do not and to express slightly more willingness to use it.

A small amount of evidence suggests that believers (more than nonbelievers) may perceive both environmental and economic advantages from energy conservation. ORC asked a national sample in 1974 whether "if people drove their cars 20 percent less," would it "help lower air pollution or not?" Believers were almost totally inclined to say that it would (91 percent) while nonbelievers were somewhat less likely to agree (74 percent). [308]. In the same study, believers were more likely than nonbelievers to feel that the general rate of inflation would be decreased if people drove their cars 20 percent less (69 percent compared to 48 percent) [308]. To speculate, believers might feel that the secondary advantages of conservation for the environment and the economy are more important than the primary effect of direct savings of energy supplies.

Belief in the energy crisis was cross-tabulated by acceptance of a number of other policies designed to conserve energy in a 1976 study in Lansing, Michigan [106]. Results are summarized in Table 8-4. In every case for the Lansing sample, believers were more likely than nonbelievers to find the energy conservation policy measures acceptable, although some (such as tax deductions for single car families and for insulating older homes) were more popular in both groups than others (such as added federal tax on gasoline). The largest differences between believers and nonbelievers occurred on tax deductions, the inverted rate structure and peak-load pricing for utilities, and gasoline rationing. The findings from this study exhibit more frequent systematic differences between believers and nonbelievers than studies using national samples.

\section{Knowledgeability}

Belief in the energy crisis was cross-tabulated with conservation knowledge items in two surveys. ORC reported that nonbelievers were slightly more likely than believers in late 1974 to have "seen or read articles about gas mileage for new cars" (72 percent compared to 61 percent) [308]. From the same survey, nonbelievers were reported as slightly more likely than believers to find government agencies more eredible sources of information on gas mileage than automobile companies. These differences were so slight that no conclusion can be reached about the relationship between belief in energy crisis and knowledge or credibility of information sources concerning gas mileage. The data suggest that believers might expose themselves to more energy information.

The Lansing, Michigan, study in 1976 included a cross-tabulation of knowledgeability on 10 "energy awareness" items by belief in the energy crisis [106]. Believers were somewhat more knowledgeable than nonbelievers on four of the 10 items; otherwise, there was no difference between the two groups. Believers were more likely than nonbelievers to know that beef is the protein requiring the most energy to produce, an apartment is the type of housing that uses the least energy, more oil was imported at the time of the interview than during 1973-74, and natural gas was the fuel in shortest supply. No difference by belief was found in knowing that transportation requires the most energy 
TABLE $8-4$

BELIEF IN ENERGY CRISIS BY ACCEPTANCE OF ENERGY CONSERVATION POLICIES*

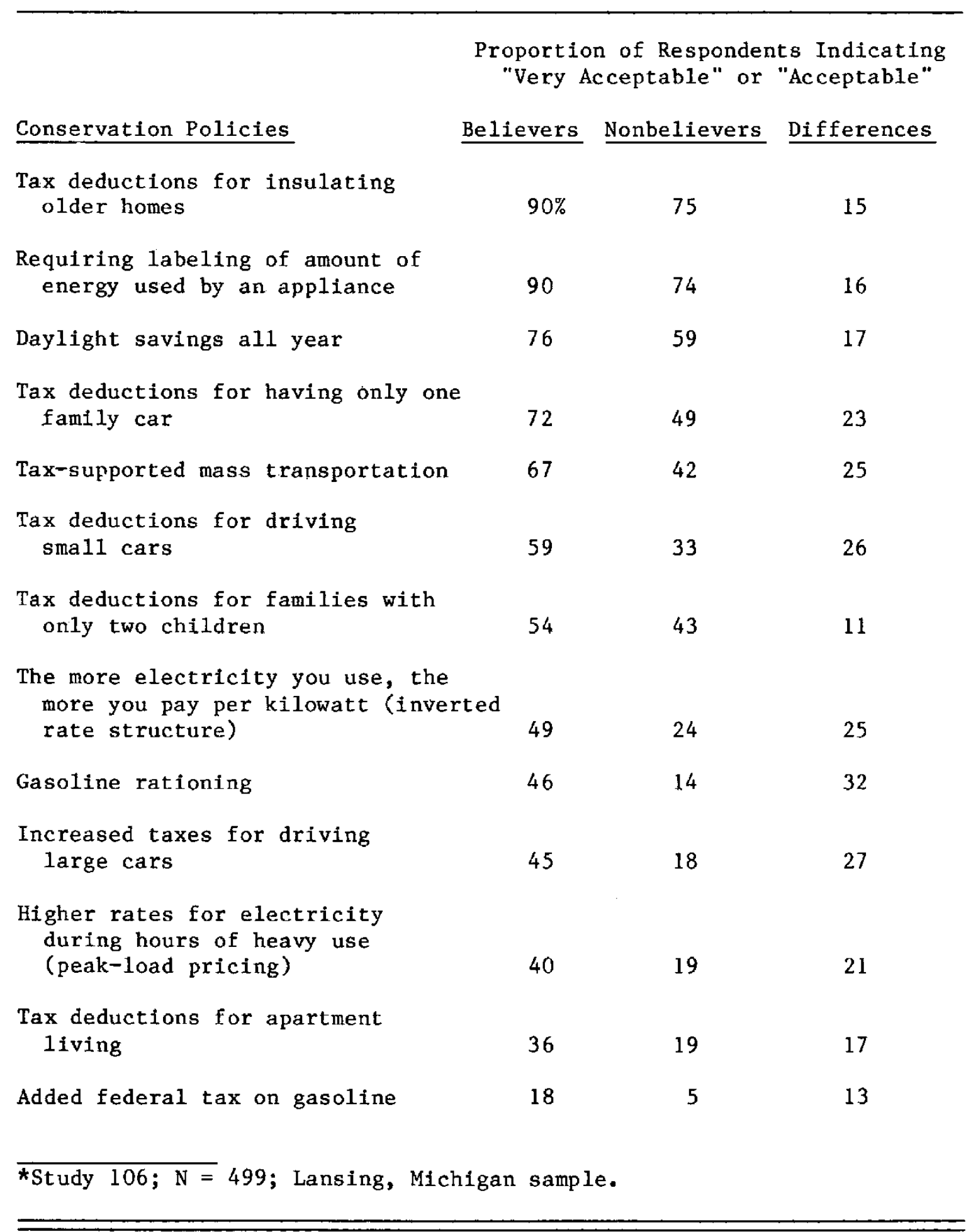


for families, the hot water heater uses the most household energy, throwaway aluminum is the beverage container wasting most energy, ceilings lose the most heat, microwave cooking is the cooking method using the least energy, and buses are the cross-country travel mode using the least energy.

Gallup found in 1977 that believers (51 percent) were much more likely than nonbelievers (eight percent) to know that the nation must import oil [218]. A third of believers and 45 percent of nonbelievers thought that the nation produces enough oil for its own needs.

No other knowledgeability items were cross-tabulated with belief as the independent variable. These three analyses are insufficient for conclusions to be drawn. A suggested hypothesis is that those believing in an energy crisis seek out more information and are more knowledgeable than those not believing in an energy crisis.

\section{Conservation Behavior}

In a few surveys, conservation behavior was cross-tabulated with belief. The implicit hypothesis was that belief in the energy crisis would motivate such behavior.

Morrison [106] found no statistically significant difference in Btu consumed in households by whether the heads of households and/or their spouses believed in the energy crisis. Texas researchers in 1974, using self-report on energy conserving behavior, found slight differences by belief in the energy crisis [116]. Believers were slightly more likely than nonbelievers to indicate that they had reduced use of air conditioners, curtailed use of electric lights, and reduced thermostat settings. No differences between the two groups were found in such other conservation practices as reducing work or pleasure driving, use of hot water, or amount of television watching.

The Michigan study [106] reported cross-tabulating 24 conservation behaviors by belief in the energy crisis. Respondents were asked whether they practiced these behaviors in 1976 , and whether they had increased their practice of these behaviors since the previous interview in 1974. Of the 24 variables, differences by belief in the energy crisis were found in the current practice of three variables and in the increase of practice of five. Walking or bicycling for short trips instead of driving was more of ten mentioned by believers (24 percent) than nonbelievers (11 percent). Choosing recreation that requires physical activity rather than motor vehicles was mentioned by half of believers and a third of nonbelievers. Maintaining daytime temperatures of $68^{\circ} \mathrm{F}$ or less during winter was mentioned by 71 percent of believers and 60 percent of nonbelievers. No difference by belief in the energy crisis was found for practicing the other 21 energy conservation measures listed. The haphazard nature of these differences suggests that no meaningful differences in conservation behavior existed by belief.

With respect to reported increases in conservation behavior, differences by belief were found for five of the 24 variables. Believers (38 percent) were more likely than nonbelievers (28 percent) to mention that they had increased walking and biking. They were less likely than nonbelievers to mention increased limitations on domestic hot water use (48 to 64 percent). Believers were more likely to mention an increase in recycling activity for bottles and cans (44 percent compared to 33 percent for nonbelievers). Increases in turning down the thermostat (73 percent of believers and 56 percent of nonbelievers) and turning off lights not in use (78 percent of believers and 64 percent of nonbelievers) were also reported as differences between the two groups. No other differences in self-report of increases in conservation behavior were found. As Morrison 
reported, "Belief in the energy problem did not have the impact on actual reduction of energy consumption expected" (1978, p. 10). In fact, actual energy consumption confirmed for study households was reduced more in households where respondents did not believe in the energy crisis, although the difference in reduction between those who believed and did not believe was not statistically significant.

No notable difference was found by the Michigan researchers in belief in the energy crisis by proportions reporting difficulty or no difficulty in practicing five conservation behaviors. These included lowering home temperature during the day and at night, reducing electricity use and driving, and buying fewer goods [106].

Researchers surveying in Grand Rapids, Michigan, in 1976 compared perceived energy shortages (belief in the crisis) to number of conservation measures taken from a list of nine. These listed measures were as follows: lower house temperature, less electricity use, less car use, less hot water use, carpooling, buying a smaller car, driving at lower speed, walking more, and building a fireplace. Those reporting adoption of one or more conservation measures were more likely to believe in a current energy shortage, more likely to expect a future energy problem, and slightly more likely to think that United States oil supplies will run out. Those who had adopted four or more conservation measures were somewhat more likely to believe that the United States would run out of natural gas and that the world supplies of oil and natural gas would run out [119].

Murray reported an analysis of self-reported conservation behavior by expectation of trouble getting energy supplies [142]. The analysis revealed slight differences in reduction of driving in three out of five sampled time periods between November 1973 and May 1974, with those expecting trouble obtaining gasoline slightly more likely to report conservation behavior. Very little difference by expectation of shortage was found in reduction of daytime temperature and in major appliance use. The same analysis was performed for those who reported trouble getting gasoline, fuel oil, and electricity, but too few respondents reported trouble getting fuel oil and electricity to permit meaningful conclusions. No apparent difference in conservation behavior existed for those who had experienced trouble getting gasoline [142].

The perceived salience* of the energy shortage was analyzed with respect to reported conservation activity [142]. Data on this cross-tabulation are presented in Table 8-5. The rather marked contrast in reported decreases in driving and reduced daytime temperatures between those perceiving very high salience for the energy problem and those perceiving low salience suggests that salience may be a more important predictor of conservation behavior than belief in the crisis. However, difficulties in measuring salience should be kept in mind in evaluating the current findings as well as the feasibility of this approach in future research.

Researchers who surveyed a Detroit, Michigan, sample in the spring of 1974 concluded that the extent to which people believed the energy crisis was real had little effect on how much they conserved energy [260]. In comparing perception of reality of the crisis to reported number of energy conservation actions taken, no association was found. Those who thought the crisis was "mostly real" to "totally real" reported a mean of 4 to 4.6 measures taken; those who thought the crisis was "phony" reported a mean of 3.95 to 4.59 actions taken. Beliefs in the energy problem and in future energy problems were not found to be related to buying plans for size of car [119].

*See discussion of salience, or perceived importance of the energy issue as compared to other issues of national importance, in Chapter 3. 
TABLE $8-5$

PERCEIVED SALIENCE BY REPORTED CONSERVATION BEHAVIOR

$\begin{array}{llc} & \text { Reduced } & \text { Reduced Daytime } \\ \text { Conservation Behavior: } & \text { Driving } & \text { Temperature }\end{array}$

\begin{tabular}{lccccc} 
Energy Shortage Is: * & $\begin{array}{c}\text { Not a } \\
\text { Problem }\end{array}$ & $\begin{array}{c}\text { Most Important } \\
\text { Problem }\end{array}$ & $\begin{array}{c}\text { Not a } \\
\text { Problem }\end{array}$ & $\begin{array}{c}\text { Most Important } \\
\text { Problem }\end{array}$ \\
\cline { 1 - 2 } Nov.-Dec., 1973 & $36 \%$ & 62 & & & \\
Jan., 1974 & 67 & 87 & 45 & 66 \\
Feb., 1974 & 48 & 74 & 30 & 60 \\
Mar., 1974 & 39 & 79 & 33 & 56 \\
May, 1975 & 38 & 81 & -- & -
\end{tabular}

*Data for response categories "fairly important problem" and "very important problem" omitted for simplification; Study 142. 
Bartell, surveying in Los Angeles County in 1974, found no statistically significant relationship between belief in the crisis (perceptions of seriousness and duration) and energy-reducing measures taken [207].

These analyses provide mixed evidence on the relationship between perception of an energy problem and adoption of conservation behavior. The variability in findings might be due to various item wording, item context, and sample noncomparabilities. The most persuasive study (Morrison et al.) found no relationship between belief and actual conservation in use of Btu in the home. On the basis of the evidence, it is not possible to conclude either that belief has no impact on energy conservation behavior or that it has such an impact. If a relationship between the two variables exists, it is more than likely affected by one or more intervening variables. There is little evidence of a direct relationship between belief in an energy crisis and adoption of energy conservation measures. The evidence suggests that perceived salience of the energy problem may be a more important predictor of conservation behavior than belief in the energy crisis.

\section{Nuclear Energy}

Three items employed in two surveys (one national, one Michigan) on nuclear energy were cross-tabulated by belief in the energy crisis. No differences between believers and nonbelievers were found $[106,308]$. The items were: "Taking into account all you have heard or read, how do you feel toward nuclear power plants in general-are you very favorable, fairly favorable, fairly unfavorable, or very unfavorable?"; "How would you feel about having a nuclear power plant within 20 miles of where you live--would you be very favorable, fairly favorable, fairly unfavorable, or very unfavorable?"; and agreement or disagreement on "I would accept 'possible risks' to health and safety from nuclear power plants, rather than severely restrict my energy use." Belief was found not to be significantly related to support for nuclear energy in Los Angeles County [207]. No evidence exists of a relationship between belief and favorability toward or tolerance of nuclear power; however, the question has apparently been insufficiently explored to warrant ruling out such a relationship.

\section{Use of Fossil Fuels}

Belief in the crisis, measured as perceived seriousness of the energy shortage, was crosstabulated with support of burning high-sulfur oil in factories and electric power plants, with statistically significant results for a Los Angeles sample (believers supported it more than nonbelievers) [207]. In the same study, no difference was found by belief in support for drilling off-shore oil wells within sight of Los Angeles County. Belief was not related to support of government takeover of oil companies, but those who felt that the energy crisis had made life more difficult were significantly more likely than those who did not to support government takeover [207]. ORC reported no difference by belief for the item: "Overall, do you think oil refineries and power plants should be built in areas that already have air pollution, or should they be built in areas that do not have pollution now?" [308]. In the same national study, very slight differences were found by belief on assessment of how much environmental damage would be caused "if the United States is to produce more energy for its use." Believers were very slightly more likely than 
nonbelievers to perceive a "fair amount" of environmental damage and less likely to perceive only "a little" damage.

In a 1977 national survey, believers were far more likely than nonbelievers to feel that there should be stricter air pollution standards ( 62 percent compared to seven percent) [218]. Believers ( 82 percent) were more likely than nonbelievers ( 49 percent) to agree in a Michigan survey that: "Stopping pollution is more important than lower prices for products" [106]. Believers were found to be slightly more likely than nonbelievers to view water pollution as a national problem rather than one affecting only a few states [308]. The same result occurred with respect to air pollution [308]. No difference occurred by belief in the energy crisis in response to the following item in a 1977 national survey: "It has been recommended that wherever possible industry convert to the use of coal from oil and natural gas. Do you think environmental standards concerning air pollution should be relaxed to permit the greater use of coal or do you think they should be kept as they are now?" [218] Believers were reported more likely than nonbelievers to think that "power plants and oil refineries cause air pollution" $[131,308]$. No differences by belief were found in assessments of which of the following environmental problems would be most serious if the United States tried to be self-sufficient: strip mining, oil spills, nuclear wastes, radioactivity, air pollution, or water pollution [308]. Both groups may have foreseen widespread use of coal, thus contributing to their definition of air pollution and strip mining as serious problems.

These are the only findings relating belief in the energy crisis to attitudes toward use of fossil fuels for energy. No conclusions about public opinion on the perceived consequences or desirability of these uses by belief can be drawn with so few findings. The data suggest that believers may be more environmentally concerned than nonbelievers.

\section{Solar Energy}

Belief in the energy crisis was cross-tabulated by several items on solar energy using survey data collected in 1974 in Phoenix, Kansas City, and Minneapolis [302]. According to the study authors, respondents who believed in the reality of the crisis exhibited more "blanket support" for solar energy use than those who did not. Believers in the reality of the crisis were more likely than nonbelievers to think that solar energy would be in widespread use in 10 to 20 years (about 40 percent compared to 25 percent), but no difference existed in the proportion between the two groups who thought solar energy would be in widespread use sooner (about a third of each group). Favoring a tax incentive for solar adoption significantly more frequently were believers $(p \leq .05)$. Believers were more likely than nonbelievers to indicate they would "seriously consider" buying a solar water heater, even if it cost more than their conventional source, but the difference was not statistically significant. The Lansing, Michigan, study reported similar findings, with believers ( 61 percent) more likely than nonbelievers ( 35 percent) to agree with the item: "I would pay for more costly solar energy to decrease the demand for new sources of petroleum" [106]. The Phoenix-Kansas City-Minneapolis study reported a statistically significant difference $(p \leq .001)$ between believers in a crisis and nonbelievers in how seriously they would consider buying a solar water heater if the cost were the same as conventional sources [302]. Believers indicated that solar energy's most attractive points were savings of fossil fuels and "availability" and its least attractive aspect was cost; nonbelievers tended not to have an opinion on solar energy's advantages or disadvantages. 


\section{Summary}

This review of the existing survey analyses demonstrates that no clear pattern of findings establishes a direct relationship between belief in an energy crisis, or perception of its seriousness and reality, and any other variable. Most analyses using belief as the independent variable addressed various aspects of energy conservation, but they employed so many different dependent variables with differences in findings among investigators that general conclusions are not possible. The most persuasive study [106] used as the dependent variable Btu actually consumed in households rather than self-report of conservation measures taken.

Belief in the energy crisis was not found to be related to energy-conserving behavior. Perceived salience of the energy problem was, however, found to be related to conservation behavior in one study. In the very few studies that related belief to preferences concerning nuclear energy, fossil fuel energy sources, and solar energy, no convincing differences by belief were found.

To maintain consistency in their reports to interviewers, respondents may have felt compelled, once having taken a stand on belief in the energy problem (assuming this item came early in the interview), to indicate favorability toward a number of conservation practices and policies about which they may not have felt strongly.

While belief that a problem exists would be a motivating precondition to problem-solving behavior, individuals may have difficulty perceiving how their opinions and actions can affect a problem as vast as the nation's energy supply and demand. The problem was most frequently phrased as a national rather than an individual one. Collective decisions are required to solve problems of the collectivity. Thus, the juxtaposition of belief in a national problem with individual solutions seems not to "fit." Moreover, action beneficial to individuals may not necessarily benefit society as a whole.

A useful approach to providing meaningful public attitude data for policymakers is to ask whether people even perceive a problem and to assess their definition of the situation. The fit between what policymakers define and what the public defines as the situation can then be examined for congruence. Further, the social desirability of alternative solutions can be assessed.

The findings in this section and in Chapters 3 and 4 show that the public itself has not decided to conserve energy in a big way. The data in Chapter 3 demonstrate clearly that the public is skeptical about the existence of a problem and its nature. "Turning off lights when not in use" is unlikely to be seen as a very effective solution to a problem perceived as largely sociopolitical and economic in origin. People are constrained by the structure of their everyday lives from conserving large quantities of energy. Most individuals cannot single-handedly perform rather heroic feats "out of synch" with the structure of their society. Based on available evidence, belief in the energy crisis does not lead to conservation behavior.

\section{KNOWLEDGE}

A few studies analyzed respondent knowledgeability of various kinds, exposure to information sources, and credibility of sources, with dependent variables. These findings are organized by favorability toward type of alternative solution (conservation, nuclear energy, and solar energy), the dependent variables to be explained. 


\section{Energy Conservation}

The perceived effectiveness of specific domestic energy conservation behaviors was found by ORC to be affected by technical knowledge [139]. Those aware that light bulbs of lower wattage meant decreased electricity usage were more likely than those unaware to feel it "worth the effort to use fewer lights" (72 percent compared to 59 percent).

Perceived credibility of Environmental Protection Agency/Federal Energy Administration (EPA/FEA) gas mileage figures was found associated with subjective assessment of importance of these figures in car-buying plans [144]. Those who thought the figures were "very believable" (70 percent) also tended to think they were "very important" in buying plans (37 percent thought the figures were "not too believable").

Abt Associates, evaluating the effectiveness of the "Fuel Economy Information Program," reported an analysis of survey data on awareness of gas mileage labels on new cars and mileage guides cross-tabulated with car-buying plans [109]. A slight difference was found between aware and unaware groups on the importance of "good fuel economy" in new car purchase, with 19 percent of aware buyers rating it as the most important factor compared to 12 percent of the unaware buyers. As part of this study, aware buyers reportedly obtained a 20.4 percent increase in their gas mileage, at 17.1 miles per gallon, compared to a 0.7 percent increase for unaware buyers who averaged 14.5 miles per gallon. The authors estimated the actual savings in fuel as a result of the EPA/FEA information program to be 893 million gallons of gasoline.

In New Hampshire, it was found that those who regularly read pamphlets sent out with utility bills were somewhat more likely to score correctly on the following four "awareness items": (1) able to read electric meter, (2) able to read kilowatt-hour usage from utility bills, (3) aware of special electric water heater rates, and (4) aware of how block rate structure affected cost per kilowatt hour [253]. Potentially confounding variables (such as educational level) were not included in this analysis; the findings must be viewed with caution in terms of policy implications.

From a 1977 survey in South Carolina, which included in its sample a subset of energy conservation workshop attendees, no significant differences were found by workshop attendance and plans for energy conservation retrofit activities [117]. The mentioned activities were: insulate, weatherstrip, caulk, and install attic fans, roof turbines, storm windows, and storm doors. Significant differences were found between workshop attendance and "performance of retrofit activities" up to a year after attendance, with attendees more likely to have engaged in conservation retrofit activity than nonattendees. The effectiveness of the workshop on performance of conservation retrofit was not considered demonstrated. Those attending the workshop were self-selected and may well have retrofitted without exposure to the workshop.

The findings suggest that technical information about energy conservation may be helpful to those interested in conserving energy, but there is no evidence that such information alone would motivate anyone to conserve energy. Knowledge concerning how to go about conserving energy from a technical standpoint would be a necessary but not a sufficient condition to do so. Moreover, such information might well fall on deaf ears unless its recipients have already been motivated to absorb it. 


\section{Nuclear Energy}

The relationship of source of information about a proposed nuclear power plant and support or opposition to the plant was examined for a Tennessee sample in 1975 [143]. For 10 information sources, the only statistically significant relationship found was that supporters were more likely than opponents to mention the Tennessee Valley Authority (TVA) office as an information source $(\mathrm{p} \leq .01)$.*

A 1975 ORC study examined the relationship of knowledge ("knowing of nuclear plants in their states") and favorability ("Taking into account all you have heard or read, how do you feel toward nuclear power plants in general-are you very favorable, fairly favorable, fairly unfavorable, or very unfavorable?") [255]. Results for knowledgeable respondents were compared to total public results; no tests of significance were run. Forty percent of knowledgeable respondents were "very favorable" compared to about a quarter of the overall sample; about a third of knowledgeable respondents and of the total sample were "fairly favorable."

In the same study, knowledgeable respondents were somewhat more likely than the total sample to identify "serious problems associated with nuclear power plants." They were slightly more likely to mention "radiation discharge" and "disposal of radioactive wastes" than nonknowledgeable respondents.

A 1974 study using a national sample cross-tabulated knowledge of whether a nuclear power plant was operating within 100 miles of the respondent's home and favorability ("general opinion of nuclear power") [311]. No difference on favorability emerged between those defined as "correct" and those as "incorrect." Those who thought there was not a nuclear plant in their area (regardless of correctness) were slightly more likely to favor nuclear power than those who thought there was a nearby nuclear facility [311]. In their review analysis of survey data, Melber et al. (1977) did not find knowledgeability (as ordinarily measured in surveys) to be a significant predictor of general attitudes toward nuclear power.

In summary, the evidence linking knowledge to favorability toward nuclear power is sufficiently sketchy that drawing overall conclusions from them seems unwarranted.

\section{Solar Energy}

Before telephone data collection was begun on a survey in New York, Minnesota, California, and Washington, D.C. in 1977, one quarter of the sample were sent printed information on solar heating. The remaining 75 percent of the sample did not receive information. The investigators analyzed results for the groups sent and not sent the information, without controlling for whether respondents had read the information, and they found no difference between the two groups in favorability toward solar heating. The authors then reported that respondents who had read the information had more positive attitudes toward solar heating than those who had not read it [209]. Of course, not having read the information was tantamount to not having received it, and the analysis should have compared those who read the information with all other respondents.

* Other information sources included in the list were local newspapers, other newspapers, magazines and other printed media, television, local radio, friends/acquaintances/ coworkers, libraries, meetings of organizations. The TVA was purportedly distributing pro-nuclear brochures at the time. 
A survey conducted in Phoenix, Kansas City, and Minneapolis in 1974 examined the relationship between "level of knowledge about or exposure to solar energy" and belief that the energy crisis was real, willingness to buy a solar water heater if it cost more than and if it cost the same as conventional ones, most and least attractive features of solar heating and cooling systems, favorability toward tax incentives, and favorability toward solar energy [302]. Knowledgeability was significantly associated with identification of most attractive features ( $p .01$ ), but the direction and substance of the relationship was not specified. Knowledgeability was also significantly associated with identifying least attractive features of solar systems ( $p$.05), with knowledgeable respondents more frequently mentioning cost and "architectural features" as the most negative features of solar systems than nonknowledgeable respondents.

Overall, knowledgeability did not emerge in the analyses examined as an important predictor of favorability toward various energy alternatives. Technical knowledge would be necessary before adoption would occur of energy conservation or of decentralized solar energy systems, but no pattern of empirical evidence exists linking knowledge to adoption behavior.

\section{PERCEIVED IMPACTS OP THE ENERGY CRISIS}

Belief in the "energy crisis" in the abstract might be more meaningful to the individual respondent if he or she personally experienced impacts of the crisis. Such impacts would include direct inconvenience, increased costs for utilities and transportation, having schools closed, and even losing one's job through shortage-related layoffs. Indirect impacts of the energy crisis perceived by respondents might include inflationary trends, especially in prices of consumer goods. A few studies investigated the relationship between perceived impacts of the energy crisis as an independent variable and favorability toward alternative solutions, including willingness to adopt solar energy, adoption of energy conservation behavior, and willingness to support various actions to alleviate the energy problem.

The basic hypothesis implicit in these analyses is similar to the "belief in the energy crisis" hypothesis: to the degree that an individual has personally experienced or anticipated negative energy-related impacts, then that individual will be more favorable to energy conservation, solar energy, nuclear power, etc.

\section{Energy Conservation}

A survey in Los Angeles County during 1974 found statistically significant differences by perceived future impact of the energy situation on employment and energy conservation behavior [207]. Anticipated future impact was the "only significant predictor" of personal energy conservation in the multiple regression analysis used in this study. As noted above, no difference by perception of energy cost increases and reduction in energy consumption was found in the Lansing study [106].

Researchers conducting a survey in Detroit in 1974 reported that, "The extent to which people indicated they were bothered by the problem of energy shortages had an effect on how much people conserved energy. Those who were 'not at all' bothered saved least; those bothered 'some' and 'a great deal' saved most" [260]. Conservation behavior was 
measured by self-report using a checklist of eight conservation measures (e.g., "sharing a ride to work" and "turning out lights and things like that").

\section{Solar Fnergy}

The Phoenix-Kansas City-Minneapolis survey in 1974 resulted in a significant difference between impact and willingness to buy solar systems $(p \leq .05)$. "Those who had experienced some inconvenience from the energy shortage were more likely to consider buying solar equipment even if it cost more than conventional equipment than were those who had no direct contact with the energy crisis" [302].

Unseld (1978) reported that a significant (and counterintuitive) finding for the New York sample of the elderly was that people with lower utility bills rated solar energy higher than people with higher utility bills. (Ratings on solar energy ranged from "excellent" to "poor.")

\section{Other Solutions to the Energy Problem}

A 1973 Ft. Collins, Colo., study yielded findings relating perceived impacts to other variables [210]. Researchers employed correlational and regression analyses using a set of scales on blame, environmental behavior, energy behavior, and perceived personal effects of present and future energy shortages.* Results from these analyses employing perceived immediate and future personal effects of the energy crisis were: (1) present personal effects were positively related to more support for voluntary actions that would ameliorate both energy and environmental problems; (2) personal effects were not related to support for "remedial energy actions" that damaged the environment or to support for mandatory solutions; (3) perception of future personal effects correlated positively with support for mandatory actions intended to solve the energy problem while not damaging the environment; and (4) anticipation of future personal effects was a significant predictor of increased support for voluntary actions to alleviate the problem [210].

In summary, the findings on perceived and anticipated impacts of the energy crisis suggest, on the basis of a very small amount of empirical evidence, a possible relationship between personally experienced impacts of energy shortages and favorability toward alternative solutions (e.g., conservation and solar energy), but virtually no evidence exists that these impacts are related to behavioral intention or actual behavior. The possible relationship between personal impacts of the present energy situation and attitudes and behavior regarding alternative solutions warrants further investigation.

*There may be some problems in these analyses with scale construction; also, significance was attributed at $\mathrm{p} \leq .10$ for the multiple regression analysis, rather than at the more widely accepted $\mathrm{p} \leq .05$. 


\section{BELIEF IN THE EPFICACY OF ENERGY CONSERVATION}

One analysis was located on the relationship between belief in the effectiveness of voluntary energy conservation and self-reported conservation behavior from a 1974 Detroit study [260]. No relationship was found between attitudes toward voluntary versus governmentally controlled action and mean number of energy conservation actions taken by the respondent. Those who thought voluntary conservation was "working fine" were engaging in about the same number of energy-saving techniques as those who thought the "government should do it, more laws needed."

Very little data exist on whether people see energy conservation as an effective solution to either the nation's energy problems or their own (see Chapter 4). The relationship between belief in the effectiveness of energy conservation and favorability, behavioral intention, and actual behavior should be investigated further.

\section{CONCERN ABOUT RISK}

Three analyses, all of them from studies on public attitudes toward nuclear energy, examined the relationship between concern about $r$ isk and ( 1 ) favorability toward nuclear power plants in the nation and near their homes, and (2) the importance of having nuclear plants. One study, conducted in Tennessee in 1975, employed a multiple regression analysis using impact factors generated through factor analysis [143]. The factors were: (1) disruptive effects of population growth (e.g., traffic congestion, increased taxes); (2) hazards to safety and the environment (e.g., radiation, water pollution); (3) increased business and new facilities (e.g., more stores, more recreation areas); (4) attention from outside the area (e.g., industrial development, tourist attraction); (5) economic benefits of growth (e.g., increased land value, more jobs); (6) other effects (cheap electricity). These factors were used as the predictor variables for the criterion, which was a composite index of favorability to the nuclear power plant proposed for the area. The factor "hazards to safety and the environment" was the most important single predictor variable, accounting for 39 percent of the variance in the criterion $(p \leq .01)$. Other significant predictors were "economic benefits of growth," accounting for eight percent of the variance, and "disruptive effects of population growth," accounting for another three percent of the variance $(\mathrm{p} \leq .01)$.

A 1976 Harris survey yielded findings on the relationship between an item asking, "How safe are nuclear power plants?" and favorability toward more nuclear plants in the United States [141]. Those who viewed nuclear plants as "not so safe" and "dangerous" were much more likely to oppose more such plants in the nation; those regarding them as "somewhat safe" were two to one in favor of more plants; and those who said nuclear plants were "very safe" tended to favor them [141].

Gallup 1976 reported that those respondents uneasy about safety standards for nuclear plants opposed nearby construction of such plants. The results are summarized in Table 8-6. Cross-tabulation of concern about risk by salience of nuclear power reveals a marked pattern of difference, with those concerned about safety more likely to view the role of nuclear energy in meeting the nation's energy needs as less important.

Melber et al. (1977) reported in their review of citizen attitudes toward nuclear energy that although the past safety record of nuclear plants is perceived as "very good": 
TABLE $8-6$

CONCERN ABOUT RISK BY FAVORABILITY TO NUCLEAR POWER PLANTS*

Do you feel that nuclear power plants operating today are safe enough with the present safety regulations, or do you feel that their operations should be cut back until more strict regulations can be put into practice?

As of today, how do you feel about the construction of nuclear power plant in this area--that is, within five miles of here? Would you be against the construction of such a plant in this area or not?

Favorability

Against plant near home

Not against plant near home
Proportion Indicating $\frac{\text { Nuclear Power Plants . }}{\text { Should Be }}$

Are Safe Should Be No
Enough

$20 \%$

57
Cut Back

60

25
Opinion

20

18

In order to meet the future power needs of the nation, how important do you feel it is to have more nuclear power plants--extremely important, somewhat important, not too important, or not at all important?

Salience

Extremely important Somewhat important Not too important Not at all important

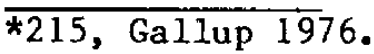

\begin{tabular}{lll} 
& \multicolumn{2}{c}{ Proportion Indicating } \\
\cline { 2 - 3 } Are Safe & No \\
Enough & Cut Back & Opinion \\
\hline
\end{tabular}

$61 \%$

30

11
26

45

64

74
13

25

25

19 
Nuclear power plant safety is the major nuclear power concern of many Americans and is a major reason for opposing nuclear power. This concern over safety decreases public willingness to live near nuclear plants . . . [andl to allow the building of more nuclear plants, and increases public willingness to cut back the present operating capacity of nuclear plants (p. 168).

They also found that disposal of nuclear wastes had emerged since 1973 as a major reason for opposing nuclear power (p. 177).

No analyses were located on concern about risk by other energy sources (conservation, solar energy, use of fossil fuels), yet there is no logical reason to exclude investigation of perceived risks for solutions to the energy problem other than nuclear energy. The relationship between concern about risk and opposition to nuclear energy constitutes a clear pattern of findings from the survey data.* The potential importance of concern about risk for favorability toward other energy alternatives requires further research.

\section{EVAIUATION OF NUCLEAR ENERGY}

Favorability and opposition toward nuclear energy in general and toward nearby nuclear power plants were employed as independent variables in several analyses, with dependent variables as follows: identification of serious problems associated with nuclear power, conditions under which nuclear plants might be acceptable, perceived impacts, credibility of information sources, behavioral intention on voting, position toward tax-free bonds to finance nuclear power, position toward coal-burning power plants, and other dependent variables. Most of these analyses were performed on survey data from national samples in 1974 [311] and 1976 [141].

Harris queried national samples in 1975 and 1976 as to whether each of the following problems were "major" or not:**

- the disposal of radioactive waste materials which remain radioactive for many centuries to come;

- the escape of radioactivity into the atmosphere;

- the chance that the escape of radioactive materials can affect human life, causing deformed babies and other physical abnormalities;

- the chance of an explosion in the case of an accident;

- the discharge of warm water into lakes and rivers that could endanger fish and other water life;

- the threat of attempts to sabotage nuclear power plants;

*This relationship has been noted for other technologies; e.g., weather modification (Farhar and Mewes, 1976; Krane, 1976).

**No attempt is made here to investigate the state of scientific knowledge on these problems; the public perception is the point. It should be noted that Harris did not ask whether respondents defined these as problems of nuclear energy; however, other studies have ascertained that several on the list are perceived as problems of nuclear energy. 
- the chance that a nuclear power plant could melt down and release radioactive clouds that could contaminate hundreds of square miles;

- giving off fumes that can pollute the air; and

- the possibility that plutonium, which is made in a nuclear power plant, could be stolen by radical revolutionaries.

Such a shopping list of horrors is not designed to elicit dispassionate responses; even a third or more (up to 61 percent) of those favoring nuclear power were forced to agree that these indeed were major problems. Those opposed were even more inclined to view these as major problems (ranging from 58 to 86 percent) [141].

ORC cross-tabulated opposition to nuclear power "in general" and "near home" with "serious problems associated with nuclear power plants" [134]. The only difference found was a very slight tendency for those opposed to nuclear power "in general" to mention "radiation discharge" more frequently.* Favorability toward nuclear plants in the respondent's own community was cross-tabulated with conditions under which nuclear plants would be tolerated [141]. About a third of those who were opposed to nuclear power in their own communities indicated they would favor a nuclear power plant if:

- it were located offshore or in a place where not many people live;

- a special report of scientists said it was safe to be built and to be operated;

- it meant that electric power rates would not be going up for many years; and

- it meant new industry would be attracted here, which would provide more jobs.

Virtually all favorable respondents favored nuclear power under these conditions. Most opponents would still oppose a nuclear power plant if:

- Ralph Nader opposed it;

- your local government opposed it; and

- your state government opposed it.

However, a majority of favorable respondents would still favor a nuclear power plant under these conditions.

Both those favorable and those opposed indicated they would oppose a nuclear power plant if:

- it were declared by environmentalists to have a bad polluting effect on the environment; and

- $\quad$ it were reported as unsafe by federal government regulatory agencies.

Thus, "offshore location" was the most persuasive positive condition, and "federal government regulatory agencies" was the most persuasive negative factor for nearly everyone.

\footnotetext{
*The other response possibilities were: "disposal of wastes," "nuclear accident," and "thermal pollution." No difference was found for these.
} 
Opponents to construction of power plants were reported as slightly more likely to tolerate them if they were 20 to 99 miles away, and even more if they were 100 or more miles away [143]. Those opposed to nuclear plants were found much less likely than those favorable to them to perceive positive impacts from a local nuclear plant [141].

Those opposed to more nuclear plants in the nation were much less likely than those favorable to view the following as credible information sources on "matters concerning nuclear energy development": (1) scientists, (2) Nuclear Regulatory Commission (NRC, formerly Atomic Energy Commission), (3) Energy Research and Development Administration (ERDA), and (4) the President of the United States [141]. Opponents were more likely than those favorable to believe leading environmentalists and "Ralph Nader and his consumerist organization." The only information source on the list in which majority of the total sample had "a great deal of confidence" was "scientists" (58 percent). The majority of those opposed did not indicate credibility for any information source; the majority of those favorable indicated only scientists and NRC as credible sources. Percentages decreased from 44 to three percent for both groups on the other sources.

In the Harris survey, those favoring more nuclear plants in the nation were more likely (50 percent) than those opposed ( 25 percent) to indicate that they would have voted against the California referendum on nuclear regulation [141]. Harris reported that favorability toward more nuclear plants was associated with favorability toward "giving private power companies the right to sell tax-free bonds, with the interest paid to bondholders tax-free as with municipal bonds, to finance the high costs it takes to finance new nuclear power plants" [141].*

Opponents to a proposed nuclear power plant in Tennessee were somewhat more likely than those favorable to oppose a coal-burning power plant as well [143].

Favorability and opposition to nuclear power ("What is your general opinion of nuclear power?") was cross-tabulated with several other variables [311]. Opponents were somewhat less knowledgeable about nuclear power, were more likely to oppose a local plant, and were less likely to express "confidence" in the Atomic Energy Commission than those favorable.

Generally, evaluation of specific nuclear power plants (i.e., favorability or opposition toward them) is treated as the dependent variable that other factors are thought to explain. The general direction of the analyses reported here is that evaluation was hypothesized as the independent variable explaining other attitudes and perceptions. What the findings taken together appear to show is that supporters and opponents of nuclear power believe different sources of information and that they vary on conditions under which they would find nuclear plants acceptable. Evaluation of nuclear power does not appear to be a sensible predictor of concern about risk; no theoretical reason for positing a causal relationship in this direction has been presented. The most that can be said is that those opposed are more likely to define problems associated with nuclear energy as major. Employing evaluation as an independent variable would be useful in future research on how public opinion affects collective and organizational adoption decisions, on differences in perceived credibility of information sources, and on conditions of social acceptability.

*It is possible that many respondents did not understand this item. 


\section{ENVIRONMENTALISM}

One of the questions addressed in the survey literature was, assuming a person believed in an energy problem, would $\mathrm{s}$ /he be more or less likely to favor approaches to solve the problems that were damaging to the environment? The $1973 \mathrm{Ft}$. Collins study addressed this issue by constructing a scale on "present environment behavior" to use as a predictor variable in a multiple regression analysis [210]. One of the criterion variables was a "single trade-off involving cleaner air but more gasoline consumption from auto emission controls." No significant difference, however, was found; rather, the authors wrote that "the key to sustaining and promoting pro-environment actions may lie with perceived blame for the energy crisis ... the more the person blamed environmentalists, the more the person supported actions that helped energy problems but damaged the environment" [210]. The researchers also found that blaming individual consumers was related to support for mandatory controls on energy use.

The 1976 Lansing, Mich., study employed an "eco-consciousness" scale [208]. Scale scores were cross-tabulated with 15 specific energy-saving policies; those with high scores were significantly more likely than those with low scores to find these policy options "acceptable" in 14 of the 15 cases.

Activists were more likely than the total public to select consumer groups as the "most reliable source of information" on electricity used by appliances, how to save energy in the home, the need to suspend auto emission controls, and the importance of strip mining [137]. Activists were somewhat more likely than the total public to be aware of the EPA/FEA mileage figures for cars [144]. They were reported as more likely than the total public to favor requiring appliance labeling and to favor federal government involvement in developing new energy sources, but no difference was found by activism on other policy options [131].* Activists were more likely to favor federal government regulation of energy production and involvement in exploration for oil, taxes for gasguzzling cars, and decreased oil imports, and more likely to oppose removal of restrictions on strip mining [131]. No differences by activism were found on beliefrelated items [131].

Research on environmental activism and its relationship to opinion about energy issues has only suggested that this might be a fruitful avenue for future investigation. Where people stand on the environmental/economic issue may well be related to how they view various energy alternatives.

\section{OTHER ANALYSES}

A scattering of other analyses using a variety of other independent and dependent variables was located in the literature. Used as independent variables were (1) whether $a$ respondent was a low or high energy user [132, 308], (2) what energy sources respondents were using [115], (3) evaluation of solar energy [252], (4) favorability to tax incentives for

*These included mandatory recycling, mandatory conservation information programs by oil companies, federal government development of mass transit, federal government information programs on energy conservation, and maintenance of the 55-mph speed limit. 
use of solar energy [252], (5) behavioral intention to buy solar systems [252], and (6) price (Scott, 1976). Since analysis involving these variables was conducted in one study apiece, ${ }^{*}$ no pattern of findings could emerge from them.

\section{SUMMARY}

The most frequently employed variable, both as an independent and a dependent variable, in survey analyses was respondent belief in an energy crisis. Implicit in analyses employing the belief variable was the hypothesis that if persons believed there to be a serious national energy problem, they would be motivated to conserve energy, adopt solar energy, and accept various other alternatives, such as nuclear power or gasoline rationing.

However, not everyone was convinced of an energy crisis (see Chapter 3), and some investigators sought to account for why some people defined the situation as critical and others did not. No systematic conclusions are possible from the survey data available, but several hypotheses for future research were suggested by the data. These are that belief in the energy crisis was caused by (1) attribution of the energy problem to the declining availability of fossil fuels rather than to sociopolitical and economic causes; (2) negative energy-related impacts experienced or anticipated; (3) awareness of energy facts and issues; (4) information source; and (5) environmental concern.

Belief in the energy crisis was not found to be related to energy-conserving behavior. A hypothesis for future research is that the perceived importance of energy as an issue compared to other issues may be predictive of conservation behavior. Survey findings show that the public is skeptical about the existence of an energy problem and its nature and etiology. They have not made a major commitment to energy conservation.

No clear pattern of findings establishes a direct relationship between belief in an energy crisis, or perception of its seriousness and reality, with favorability to solar energy, nuclear energy, or the use of fossil fuels. A hypothesis for further research is that believers in the energy crisis may be more environmentally concerned than nonbelievers. The findings on perceived and anticipated impacts of the energy crisis suggest a relationship between experienced impacts and favorability to conservation and solar energy. However, no data exist linking these impacts to behavioral intention or actual behavior. These possible relationships warrant further investigation.

Energy knowledge of individuals (e.g., how to conserve energy, costs of solar energy, location of nuclear power plants) was not found to be an important predictor of favorability toward various energy alternatives.

Virtually no analyses exist on perceived effectiveness and feasibility of energy conservation and solar energy as solutions to national and individual problems and favorability, behavioral intention, and actual behavior regarding these alternatives.

Concern about risk was found to be clearly associated to opposition to nuclear energy. No research has focused on concern about risk concerning solar energy, energy conservation, and use of fossil fuels; these relationships warrant future investigation.

*Studies 132 and 308 are both ORC studies. 
Findings appear to show that supporters and opponents of nuclear energy believe different sources of information and have different definitions of conditions under which they would find nuclear power plants acceptable. Employing favorability toward nuclear power as an independent variable would be useful in future research on how public opinion affects such policy decisions as power plant siting and government subsidization of nuclear energy.

Preferences on the energy-environment trade-off issue were explored very little in the survey data. The data suggest that those who blamed environmentalists for the energy problem tended to favor actions that helped energy problems but damaged the environment. Another hypothesis suggested by the data is that the environmentally concerned tend to favor energy-conserving policies and practices and to oppose environmentally damaging solutions, such as removing restrictions on strip mining, and auto emissions.

About five years have elapsed since the 1973 oil embargo. It is increasingly clear over time that energy prices are not declining and oil imports continue to be necessary. Energy-related problems have not been solved in such a way that the nation can return to the era of inexpensive and readily available sources of power for $i$ ts needs. The success of what the public and policymakers do about this situation will depend in part on the congruence of their respective analyses of it and of the desirability of various alternative solutions. Despite the plurality of views, some common ground needs to be found for assessment of the situation and ways to deal with it. Inevitably, trade-offs will be involved, and information is needed on the desired balance to be achieved in the complex question of what is possible, what is acceptable, and what is optimal. 


\section{CHAPTER 9}

\section{GENERAL FINDINGS}

Many kinds of conclusions can be drawn from a study of this scope and complexity. Gaps in existing knowledge can be identified. Policy questions can be raised and policy implications can be drawn from the findings. For this report, the conclusions presented are an attempt at a cogent statement about what was found in this analysis of existing survey data. They fall short, however, of a full synthetic interpretation. Following the general outline of the report, this chapter summarizes findings from the literature review.

\section{RELEVANCE OF ATTTUDE SURVEYS TO POLICY}

The existing literature on the relationship between attitudes and behavior was reviewed, and the conclusion was drawn that attitudes are causally related to actual behavior, but that the correlation is less than perfect. Survey data are or should be relevant to energy policy analysts and decision makers. The relevance of survey data to policy varies by the energy supply source in question and the type of behavior a policy is designed to elicit. Citizen attitudes are more directly relevant for solar energy and energy conservation than for other energy supply sources. The suggestion was made that citizen attitudes are more a parameter for than a target of policy decisions.

\section{PUBLIC DEFINITIONS OF THE SITUATION}

The evidence indicates that, in the public mind, there is not an energy "crisis." Instead, the public perceives a serious energy problem. With the Arab oil embargo in 1973 more people tended to view the situation as very serious; this proportion decreased during 1974, then rose slightly to the present 40 percent level where it has remained.

Many thought the energy crisis had been contrived. Over time, a majority came to perceive energy shortages as real, but a sizable minority presently believe the situation has been contrived by various institutions in American society for their benefit. Oil companies and the federal government were thought to be most responsible for the nation's energy problems from 1973 through 1977. Among national problems, energy has been viewed as neither the least nor the most important problem. Inflation, unemployment, and crime have been perceived as matters of more importance than energy. Majorities of survey respondents felt that the nation faces energy shortages and rising energy costs for the foreseeable future, whether for political or natural reasons. The public seem to place most faith in nuclear energy, solar energy, and coal as long-term future energy sources.

There is evidence in surveys of negative impacts experienced by individuals and by the nation due to energy shortages, but not enough information is provided to assess the magnitude of the impacts. Although administrations from Nixon through Carter have been attempting to deal with the energy crisis, they have not been successful in gaining public satisfaction with their efforts. The public is more satisfied with its own efforts and less satisfied with the actions of oil companies. 
The public recognizes a responsibility to conserve energy. Evidence such as majority support for government action on supply and the expectation of a technical breakthrough that will solve the problem suggests that the public is slightly more favorable toward alternatives that increase supply rather than reduce demand.

\section{ENERGY CONSERVATION}

The majority identified personal conservation as having an impact on total consumption and as a "good" alternative to meeting energy problems. Saving money and conserving natural resources are perceived benefits and reasons given for actions to conserve.

Residential conservation measures have been consistently listed ahead of reduced driving as actions preferred and performed most of ten. The majority of the public reported engaging in both types of action.

Opposition is widespread to increasing prices to decrease energy consumption. Government controls such as gasoline rationing or mandatory home conservation were opposed by large majorities, but they were preferred to price increases. Less restrictive controls like the $55 \mathrm{mph}$ speed limit and daylight saving time are favored by majorities.

\section{SOLAR ENERGY}

Although less than one percent of the public have purchased solar systems, attitudes toward the idea of solar energy are very favorable. The majority of the public appears to support federal efforts to develop solar energy and incentive programs to encourage its use.

The ability of the current solar technologies to meet electric power needs and to provide space heating in all climate areas was questioned by nearly half the respondents in these studies. Cost, performance, reliability, and maintenance problems are other of tenmentioned disadvantages of solar heating. Not surprisingly, getting information about solar systems was identified as important in solar purchase decisions. Some evidence suggests that solar energy may be perceived as economically and technically risky, as too experimental to use now.

In addition, most respondents in special studies underestimated the initial dollar cost of installing solar heating systems. In assessing the relative advantage of adopting solar energy, citizens may have inadequate access to information, even though information may exist. Expression of concern over initial cost might be even greater if real costs were known, thus changing the perceived relative advantage of adopting a solar system in a negative direction. About 40 percent of respondents said they would consider buying solar devices even if the cost were greater per month in the long run than alternatives. Included among perceived characteristics of solar energy valued by respondents were conservation of natural resources and decreased environmental pollution.

\section{CONVENTIONAL ENERGY SUPPLY}

Findings are summarized for oil and natural gas, coal, and nuclear energy. 


\section{Oil and Natural Gas}

The public expects a declining contribution of oil as a fuel for generating electricity. Several studies reported that large minorities are unaware that the United States must import oil. None of the surveys asked respondents why imports should be reduced, and the evidence suggests the public was divided over whether the nation can achieve energy self-sufficiency. About half of respondents favored reducing oil imports, but a large minority thought more should be imported. Price increases or incentives to oil companies were opposed; majorities felt that oil companies make too much profit. Options such as a profit tax or controls on profits were favored, while government ownership was opposed by majorities. In one item concerning deregulation of natural gas, when concomitant price increases were mentioned, a majority was opposed; when deregulation was mentioned as an incentive to increase supply, at least half of samples were favorable.

\section{Coal}

Although many have viewed coal, especially strip-mined coal, as a way to expand energy supplies, local surveys indicate that it may not be defined as desirable. The most frequently mentioned advantage of coal was its domestic availability. There has been increased acceptance of coal and strip mining to produce it as a realistic substitute for foreign oil.

Coal was perceived as a lower cost alternative than oil. Even though half of national respondents were worried about effects of strip mining and three-quarters concerned about air pollution from coal, majorities favored its increased use. Large majorities supported using coal if no environmental damage would result. National pluralities accepted environmental damage as necessary to achieve that increase, while local majorities did not.

\section{Nuclear Energy}

Most people perceive atomic energy as technically feasible and expect it to assume a major role in electric power generation. A sizable minority (up to one-third of samples), however, were unsure of how to answer questions on nuclear energy. A larger proportion of national than local samples expected nuclear power to be cheaper than other sources of energy. People expect both benefits and costs (associated with general economic growth) to result from nuclear power development in their communities. Reduced dependency on foreign oil and conservation of nonrenewable resources, as well as reduced air pollution, were advantages perceived by majorities.

The major problems perceived in nuclear power development were safety and environmental concerns over waste disposal and radioactivity. These problems were considered serious by large majorities and the number of people indicating concern increased over time. Overall, findings were mixed when people were asked to judge how "safe" nuclear power is.

In spite of concerns, the majority have favored continued construction of nuclear plants, with about one-fourth opposing increased development. Evidence suggests increasing polarization in public opinion about nuclear energy. When construction in one's own community is specified, the findings have been mixed, with small majorities to large minorities favoring construction. Judgments about the attitudes of local 
populations toward nuclear plants in their areas are very risky without surveying each locality. The generally increased favorability of nuclear plant neighbors toward nuclear power is not necessarily an indicator of response to new proposals in communities.

\section{ANALYSIS OF TRENDS}

This analysis examined how changes in public opinion were related to events over time. The analysis showed that some attitudes probably were affected by discrete, dramatic events while others were affected, if at all, by a combination of events.

The first energy shortage (beginning in April 1973) increased both perceptions of the seriousness of the problem and skepticism about the reality of the crisis. By the second shortage, more people were defining the problem as "real." Conservation behavior remained unaffected, and the shortages, perhaps with the Project Independence Report, seemed to increase willingness to sacrifice the environment. This willingness may figure in an increased favorability toward nuclear power during and af ter the second crisis.

Presidential speeches were so proximate that their effect on public opinion is difficult to discern. Nixon's energy plan was followed by a decline in the perceived seriousness of the situation. Speeches by Ford and Carter seemed to have the opposite effect. Carter's introduction of the National Energy Plan produced a small, temporary rise in belief in an energy crisis. Public opinion did not vary radically as the result of any one occurrence.

\section{REGIONAL DIFFERENCES}

Belief in the energy crisis and other definitions of the energy problem did not vary by region; however, impacts were experienced differentially in geographic regions of the nation.

Westerners were more concerned about the environmental effects of energy supply than people in other parts of the country, although the East was very close in level of concern. The use and extraction of fossil fuels was a greater source of concern in the West. Strip mining of coal was opposed by Westerners while the rest of the nation favored it.

Those in the East showed a higher level of concern over nuclear power when risk factors were mentioned. The data suggest that Southerners are somewhat less concerned about enviromental problems associated with energy development. They were also less likely to view solar energy as a viable alternative.

\section{DIFFERENCES BY SOCIODEMOGRAPHIC CHARACTERISTICS}

Results of analytical findings by 14 sociodemographic characteristics are summarized below by each independent variable.

\section{Gender}

No differences by gender were found on belief in the seriousness or reality of the energy crisis, or in other definitions of the energy problem. Some evidence suggested that 
women tend to be more concerned than men about the nation's energy future. Women were found to be more in favor of environmental protection than men. Men were exposed to more information sources about energy than women and were somewhat more knowledgeable. Women were somewhat more favorable to domestic energy conservation than were men. Men and women who engaged in conservation behaviors tended to do so in activities consonant with their sex roles.

\section{Age}

Younger age groups were more likely than older ones to report belief in the seriousness of the energy crisis; younger age groups were also more likely to report a greater belief in the likelihood of future energy shortages. Data on perceived impacts of the energy situation revealed a pattern of greater reported impacts among older people. Older groups tended to oppose policy options that would increase consumer costs. A clear and consistent pattern of greater support among the young for protecting the environment was revealed in a number of surveys.

A pattern of greater support for solar energy among younger groups was revealed. The opposite pattern held for nuclear energy: younger groups tended to be less supportive than older groups of this energy option, although there was some evidence of a curvilinear relationship with greatest support among middle age groups. Older groups also tended to be more supportive of development of fossil fuel energy sources than younger groups. Several of the findings indicated that income is an important.confounding variable influencing age-related differences in energy attitudes and behavior.

\section{Edreation}

In general, the higher the education level, the more likely that a serious and real energy problem was perceived as well as belief that it would continue. The performance of the business community in handling responsibility during the energy crisis was judged more harshly by the more educated groups.

Educational level was positively related to favoring the speed-up of solar energy development and energy conservation, but it was found in one study to be negatively related to the development of other energy sources or technologies. Those with more education were more likely to favor nuclear energy and to consider nuclear plants as safe in another study. Highly-educated individuals resisted proposals that would interfere with their personal mobility.

The higher the educational level, the less likely the individual was to think that energy self-sufficiency was possible for the United States. Higher educational levels were found to be positively associated with higher levels of knowledgeability on a variety of energy items. Education was found in most cases to be positively related to environmental protection attitudes, even in cases where it would cost the person more.

\section{Income}

Higher income groups generally expressed greater belief in the reality of the energy crisis. No clear patterns by income were discovered concerning perceived responsibility for the energy situation. Lower income groups tended to favor policies that would keep 
consumer prices low. Lower income groups also tended to be more supportive of environmental quality, except where this was posed as entailing higher consumer costs; in such a case, lower income groups generally favored lower costs over environmental quality.

A clear pattern of difference by income was revealed with regard to knowledgeability about energy issues, a difference probably confounded by educational level.

Higher income groups expressed a consistently greater preference for solar energy as a power source than did lower income groups. The same consistent pattern was found regarding nuclear energy. Lower income groups reported more general efforts to conserve (indicative most likely of a concern for energy costs) but generally reported fewer energy conservation efforts or changes in behavior than others (most likely due to a pattern of minimal energy use). There is some indication of a curvilinear relationship between income and conservation efforts, however, with most conservation occurring among middle-income groups. High-income groups appeared to be most insensitive to price-induced conservation. The lowest income groups tended to express confusion or to be of mixed opinion on matters of energy conservation. Lower income groups tended to favor any policies that resulted in lower prices even if these entailed gasoline rationing, while higher income groups clearly favored policies that did not limit availability.

\section{Ocerpation}

Occupations are important in knowledgeability about the energy situation and attitudes toward nuclear power. Perception of an energy-related problem and its seriousness increased as skill and occupational levels increased. Higher occupational levels were found to be somewhat more favorable toward solar energy as a long-term source of energy, although solar energy was the first choice for most groups. All occupational groups preferred that U.S. production of energy be maximized, usage limited, and imported oil reduced. Professional and white-collar workers were more likely to say that nuclear plants are safe and that they would not oppose construction of one in their area. Conservation attitudes and extent of reported conservation behavior did not differ appreciably across occupational groups. White-collar workers were more favorable than other occupational groups to development of local public transportation.

\section{$\underline{\text { Race }}$}

There was a pattern of greater reported energy-related impacts among nonwhites than whites, probably as a function of the generally lower incomes of the former racial group. The salience of the energy situation appeared to be greater among whites, particularly when this was measured in comparison with economic problems (which were perceived as more serious by nonwhites). Nonwhites tended to show stronger support than whites for environmental concerns, except where environmental quality issues were posed as competitive with low consumer costs. There was a strong, consistent pattern in the data of greater reported objective knowledge among whites than nonwhites on energy-related issues. Solar energy received greater support among whites than nonwhites, while the latter tended to support development of conventional energy sources. Support for nuclear energy appeared to be consistently greater among whites than among nonwhites; the latter group revealed a consistent pattern of doubt or indecision on this issue. There were no apparent racial differences in attitudes or behavior in regard to energy conservation. 


\section{Political Orientation}

Variance in opinion by partisan political affiliation tended to be elicited by items mentioning famous political personalities (Nixon, Ford, Carter). In general, the survey findings show Democrats to be slightly less knowledgeable about energy issues, somewhat more likely to view the energy crisis as quite serious, less favorable to nuclear energy and coal development, and more favorable toward energy conservation than Republicans. Republicans were slightly more concerned about maintaining centralized energy sources and not having their own lives affected, which may translate into a desire to maintain what has become the traditional American lifestyle and its energy use patterns. Their slightly greater knowledge of issues has not resulted in a willingness on their part to act.

Variance in opinion by political philosophy (conservative, moderate, liberal) tended to extend and complement the findings by party affiliation. Though these findings cannot be viewed as conclusive proof of important differences on energy attitudes by political philosophy, an interesting pattern emerged. Liberals tended to be somewhat more favorable to the environment and to solutions to the energy problem involving energy conservation and solar energy (although this last difference was not marked). Conservatives tended to find major corporations credible sources of information, to blame environmentalists for the energy crisis more frequently than liberals, and to favor nuclear energy more than liberals. The suggestion of these findings, taken together, is that traditional, centralized energy systems are somewhat preferred by Republicans and conservatives and innovative, decentralized systems and energy conservation by Democrats and liberals. Nevertheless, political orientation does not appear to be as germane to energy attitudes and behavior as other demographic characteristics, such as income.

\section{Religious Affiliation}

Not surprisingly, in general religious affiliation (Protestant and Catholic) is most likely not an important predictive variable in accounting for public response to energy issues or public preferences among energy policy options. What differences are found by religion are probably attributable to other correlates of the variable, such as socioeconomic status. The interesting exception is a possible correlation between religious affiliation and perceived risk of neighboring nuclear power plant facilities (Catholics were more likely than Protestants to be concerned about risk). This potential correlation warrants further study. The possibility of religious affiliation emerging as a relevant variable would be enhanced if organized religion in the United States adopted energy as an issue.

\section{Marital Status}

There would be little reason to expect differences in opinion on energy issues by marital status, and, for the most part, such differences were not reported in the data. What differences in opinion did occur by marital status clustered around items having to do with conservation. Taken together, the findings suggest that unmarried persons are somewhat more likely to find infringement of their personal mobility a hardship than married persons. Singles are more likely than those married to be able to function domestically with less energy use by living in smaller residences, but not through adopting domestic energy conserving practices. 


\section{Housing Characteristics}

Concern about the amount of electricity being used increased with the size of the house, as measured by the number of rooms. Willingness to buy a solar-heated house did not vary for multifamily versus single family dwellers. Although home value had a significant positive relationship to support for tax incentives for solar energy, it was not related to willingness to buy. Concern about conservation was more likely among families with five or more members than among smaller households; singles and couples were much less interested in conservation retrofit than others. Housing characteristics are a variable relevant primarily to energy conservation and solar energy alternatives.

\section{Home Ownership}

Home ownership, confounded as it is by income and marital status, is probably not an important predictive variable in explaining energy attitudes. It may be germane in considering adoption of solar energy. Homeowners were more likely than renters to have heard about solar energy, to express concern about the amount of electricity they used, and to express willingness to accept additional cost to install solar systems. Owners also were found to prefer individually oriented solutions to energy generation.

\section{Transportation Characteristics}

This variable pertains primarily to gasoline conservation. Noncar households expressed more environmental concern than households with cars. Car owners felt the effects of the energy crisis more than nonowners and made more attempts to keep themselves informed on mileage standards for cars. Car owners were more optimistic about the future of energy supplies than were noncar owners. Car ownership is confounded by income levels, which is probably the more significant variable.

\section{Urban/Rural Residence}

Rural persons were somewhat more likely than urbanites to regard the energy crisis as "contrived." Rural residents were more likely than other groups to feel that the voting public should make the decisions on various energy-related issues. Daylight saving time had a larger impact on driving in urban areas but was most disliked on farms and in small towns. Knowledgeability was about equal across residential groups, but rural and urban people had more accurate information on different specific issues. Rural residents expressed more concern than city residents about the availability of energy than about environmental problems. Urban residents were more likely than other groups to consider paying for solar energy. Those in cities were more concerned about the risk of nuclear power plants. They were also more favorable to energy conservation and mass transit.

\section{SOCIAL-PSYCHOLOGICAL VARIABLES}

The variable most frequently employed in analyses as an independent predictor of other attitudes and actions was belief in the energy crisis. The survey analyses using belief with a wide range of dependent variables were examined to determine if a significant pattern of findings emerged. 
The review demonstrates that no clear pattern of findings establishes a direct relationship between belief in an energy crisis, or perception of its seriousness and reality, and any other variable. Most analyses using belief as the independent variable addressed various aspects of energy conservation, but they employed so many different dependent variables with differences in findings among investigators that general conclusions are not passible. The most persuasive study used as the dependent variable Btu actually consumed in households rather than self-report of conservation measures taken. This study found an inverse, but not statistically significant, relationship between belief and energy actually conserved.

Belief in the energy crisis was not found to be related to energy conserving behavior. In the few studies relating belief to preferences concerning nuclear energy, fossil fuel energy sources, and solar energy no convincing differences were found.

It is possible that bias from funding sources of surveys on energy attitudes might have affected the frequency with which the belief variable was employed in comparison with other theoretically possible variables (such as belief in efficacy or relative advantage). Conviction on the part of governmental agencies and energy companies and utilities that the public shouId engage in energy conservation seems to be behind the pattern of questions asked and analyses performed on the variables.

Several hypotheses for future research were suggested by the data and outlined in Chapter 8. In general, many of the factors affecting favorability toward various energy alternatives and actual behavior with respect to adoption of energy conservation and solar energy are not well understood. Although existing data suggest what some of the important factors might be (e.g., experienced impacts of energy shortages, perceived salience of the energy problem), the exploration of their importance and relevance to energy policymaking awaits further investigation. 


\section{SEPY}




\section{BIBLIOGRAPHY}

Abelson, Philip H. 1977

Abt Associates 1976
Ajzen, I., R. K. Darroch, M. Fishbein, and
J. A. Hornik 1970
Angell and Associates, Inc. 1975

Atomic Industrial Forum, Inc. 1978

Babbie, Earl R. 1973
Bailar, Barbara A., and
C. Michael Lanphier, 1978
Barnaby, David J., and
Richard C. Reizenstein 1975
Bartell, Ted 1974

Becker Research Corporation 1974 Blakely, Edward J.
1976

Boffey, Philip 1976
"Public Opinion and Energy Use." Science 197: 1 .

Impact of the FEA/EPA Fuel Economy Information Program, for FEA, Washington, D.C., June.

"Looking Backward Revisited: A Reply to Deutscher," Amer. Soc. 5: 267-272.

Qualitative Study of Consumer Attitudes Toward Energy Conservation, for FEA, Office of Energy Conservation and Environment, Washington, D.C., November.

"Reviews of National Energy Programs," Nuclear Info, No: 40, June, p. 40.

Survey Research Methods, Belmont, Calif.: Wadsworth Publishing Co.

Development of Survey Methods to Assess Survey Practices. American Statistical Association, Washington, D.C.

"Profiling the Energy Consumer: A Discriminant Analysis Approach," Paper presented at ORSA/TIMS Conference, Chicago, April.

The Effects of the Energy Crisis on Attitudes and Life Styles of Los Angeles Residents. University of California, Los Angeles, August.

The Electric Utility Industry: A National Survey of Public Knowledge and Attitudes, for Electric Companies Public Information Program, July.

"Energy, Public Opinion, and 1976 Public Policy-A Survey of Urban, Suburban, and Rural Communities." California Agriculture $30: 4-5$.

"Nuclear Power Debate: Signing Up the Pros and Cons." Science 192: 120-122. 


\author{
Bogardus, Emory \\ 1976 \\ Booz, Allen, and Hamilton, \\ Inc. \\ 1975 \\ Brown, Rex V., et al. \\ 1975 \\ Brown, Roger \\ 1965 \\ Bultena, Gordon \\ $1976 a$
}

Bultena, Gordon $1976 \mathrm{~b}$

Burdge, Rabel J., et al. 1975

Campbell, Vincent N., et al. 1977

Carson, Rachel 1962

Cheskin, Louis and Assoc. 1977

Colorado Springs, City of 1975

Curtin, Richard 1975
"A Social Distance Scale." Sociology and Social Research 17: 265-271.

Social Energy Utilization in Florida, for the Florida Energy Committee, Florida Solar Energy Center, Cape Canaveral, June.

Analysis of Residential Fuel Conservation Behavior, for FEA by Decisions and Designs, Inc., McLean, VA, October.

Social Psychology. New York: Free Press.

Public Response to the Energy Crisis. Sociology Report 130. Department of Sociology, Iowa State University, Ames, July.

Public Response to the Energy Crisis: A Study of Citizens' Attitudes and Beliefs in the Southwest, Center for Energy Studies, The University of Texas, Austin.

"Public Opinion on Energy." Issues Facing Kentucky. Dept. of Sociology, University of Kentucky, Lexington, December.

An Attitudinal Study of the Home Market for Solar Devices, for F $\overline{E A}$, by Decisions and Designs, Inc., McLean, VA, September.

The Silent Spring. Greenwich, Conn.: Fawcett.

Social Attitude Penetration Study: Attitudes of the People of Illinois Toward Energy, for State of Inlinois Division of Energy, Springfield, April.

"Assessment of a Single-Family Residence Solar Heating System in a Suburban Development Setting, Project Phoenix." Solar Heated Residence Annuel Report, July.

Consumer Adoption to Energy Shortages, Unpublished Manuscript, University of Michigan Survey Research Center, Ann Arbor. 
Darnstadter, Joel, and

Stephen Rattien 1976

Davis, Donald L. 1978

Decisions and Designs, Inc. 1977

Debury, George E., ed. 1974

DeFleur, M. L. and

F. R. Westie

1958

Deutscher, Irwin 1966

Deutscher, Irwin 1973

Doering, Otto C., III, et al. 1974

Energy Research and Development Administration 1977

Farhar, Barbara C., and Julia Mewes 1976

Farhar, Barbara C., Grant Johnson, Jack A. Clark, Julia Mewes, Ronald Rinkle, and Susan Shoulders 1978
"Social and Institutional Factors in Energy Conservation." Annual Review of Energy. Berkeley: Annual Reviews, Inc., pp. 535-551.

Attitudes of Lansing Area Residents Toward Energy Use: Consumer Adoptions Since the Oil Embargo. School Labor and Industrial Relations, Michigan State University, East Lansing, April.

An Attitudinal Study of the Home Market for Solar Devices, for F $\overline{E A}$, Washington, D.C., September.

1974 Edition-World Almanac and Book of Facts. New York: Doubleday and Co., Inc.

"Verbal Attitudes and Overt Acts: An Experiment on the Salience of Attitudes," Am. Soc. Rev. 23, 667-673.

"Words and Deeds: Social Science and Social Policy," Soc. Probs. 13, 235-265.

What We Say/What We Do. Glenview, CA, Scott, Foresman and C.

Indiana's Views on the Energy Crisis. Agricultural Economics Department, Cooperative Extension Service, Purdue University, West Lafayette, Ind., September.

Proceedings of the Public Meeting to Review the Status of the Inexhaustible Energy Resources Study. Springfield, Va.: National Information Service, July.

Social Acceptance of Weather Modification: The Emergent South Dakota Controversy. Monograph 23. Institute of Behavioral Science, University of Colorado, Boulder.

Technology and Society: Weather Modification in South Dakota. Boulder, CO, Institute of Behavioral Science, University of Colorado. 

Farhar, Barbara C., Charles T. Unseld, Richard Caputo, and James Easterling 1979

Faulkner, Lee G. 1976

Festinger, Leon 1957

Frankena, Frederick n.d.

Frankena, Frederick, Frederick H. Buttel, and Denton E. Morrision 1978

Gallup, George 1973
Gallup, George $1974 a$

Gallup, George $1974 \mathrm{~b}$

Gallup, George 1975

Gallup, George 1976
Citizen Participation in the Domestic Policy Review of Solar Energy, SERI-TR53-126, Golden, $\overline{C O}$, January.

Issues and Opinions on the Social Effects of Water Allocation for Coal Development in the Yellowstone River Drainage. JUJWRRC Report No. 78. Montana University Joint Water Resources Research, Center, Montana State University, July.

A Theory of Cognitive Dissonance, Row, Peterson, $\mathrm{NY}$.

Behavioral Experiments in Energy Conservation: An Annotated Bibliography. Council of Planning Librarians, Exchange Bibliography, \# 1330, Monticello, IL.

"Energy/Society Annotations: A Comprehensive Bibliography of Behavioral-Empirical Studies," in Sociopolitical Impacts of Energy Use and Policy. National Academy of Sciences, Washington, D.C.

"Energy Crisis/Reduction of Speed Limits." The Gallup Opinion Index. Princeton: American Institute of Public Opinion, September.

"Energy Curbs/Usage." The Gallup Opinion Index. Report No. 103. Princeton: American Institute of Public Opinion, January.

"Energy Crisis Responsibility." The Gallup Opinion Index. Report No. 104. Princeton: American Institute of Public Opinion, February.

"Transportation: Oil Import Policy." The Gallup Opinion Index. Report No. 116. Princeton: American Institute of Public Opinion, February.

"Environment: Importance of Nuclear Power Plants." The Gallup Opinion Index. Report No. 134. Princeton: American Institute of Public Opinion, September. 
Gallup, George
1977 a

Gallup, George $1977 \mathrm{~b}$

Gallup, George $1977 \mathrm{c}$

Gallup, George $1977 \mathrm{~d}$

Gallup, George $1978 \mathrm{a}$

Gallup, George $1978 \mathrm{~b}$

Gallup Organization, Inc. 1976

Gallup Organization, Inc. $1977 a$

Gallup Organization, Inc. $1977 \mathrm{~b}$

Gast, Paul F. 1973

Gill, Richard R. 1977

Gladhart, Peter Michael, James J. Zuiches, and Bonnie Mass 1976
"Carter Energy Policy." The Gallup

Opinion Index. Report No. 141.

Princeton: Am erican Institute of Public Opinion, April.

"Energy." The Gallup Opinion Index. Report No. 142. Princeton: Ámerican Institute of Public Opinion, May.

"Energy." The Gallup Opinion Index. Report No. 143. Princeton: American Institute of Public Opinion, June.

"Public Remains Unconvinced of Energy Problem," The Gallup Opinion Index. Report No. 149. Princeton: American Institute of Public Opinion, December.

"Carter Energy Policy." The Gallup Opinion Index. Report No. 152. Princeton: American Institute of Public Opinion, March.

"Carter Effort to Educate Public on Energy Fails." The Gallup Poll. Princeton, April 30.

Group Discussions Regarding Consumer Energy Conservation, for FEA, March.

"Energy Crisis-The Public Concerned But Not Well Informed." The Gallup Report, Vol.l, June.

"Belief that the Energy Situation is Very Serious Declines." The Gallup Report, Vol. 1, August.

Divergent Public Attitudes Toward Nuclear and Hydroelectric Plant Safety. Argonne National Laboratory, Laboratory Program Planning Office, Argonne, IL, June.

RTA Awareness and Attitude Survey, for Regional Transportation Authority, Chicago, June.

"Impacts of Risking Prices Upon Residential Energy Consumption, Attitudes, and Conservation Policy Acceptance." Unpublished Paper. Michigan State University, East Lansing. 
Golin, Albert E. 1976

Gottlieb, David, and Marc Matre 1975

\section{Gottlieb, David, and Marc Matre 1975 \\ Gottlieb, David, and Marc Matre 1976 \\ Greider, William 1977 \\ Grier, Eunice 1976} $\underset{1944}{\text { Guttman, Lewis }}$

Hannon, Bruce 1975

Hardin, Garett 1968

Harr is, Louis $1973 \mathrm{a}$

Harr is, Louis $1973 \mathrm{~b}$

Harr is, Louis $1974 a$
Energy Consumers' Awareness and Preferences in New Hampshire: A Comparative Assessment, for Franklin Pierce Law Center by the Bureau of Social Science Research, Inc., Washington, D.C., May.

"Conceptions of Energy Shortages and Energy Conserving Behavior." Paper presented at American Sociological Association Annual Meeting, San Francisco, Calif., August.

Sociological Dimensions of the Energy Crisis: A Follow-Up Study, The Energy Institute, University of Houston.

Sociological Dimensions of the Energy Crisis: A Follow-Up Study, The Energy Institute, University of Houston.

"Good News and Bad on Energy Plan-An American Contradiction." Washington Post, July 31 , p. 1.

"Changing Patterns of Energy Consumption and Costs in U.S. Households." Paper presented at Allied Social Science Associations Meeting, Atlantic City, NJ, September.

"A Basis for Scaling Qualitative Data," American Sociological Review 9: 139-150.

"Energy Conservation and the Consumer." Science 189: 95-102.

"The Tragedy of the Commons." Science 152: 1243-1248.

"Energy Shortage Regarded as 'Serious' by by Most Americans." N.Y.: The Harris Survey. Chicago Tribune-N.Y. News Syndicate, Inc., NY, July 26.

"Americans Willing to Make Sacrifices to Conserve Energy." The Harris Survey. N.Y.: Chicago, Tribune-N.Y. News Syndicate, Inc., December 3.

"Americans Less Certain About Seriousness of Energy Shortage." The Harris Survey. N.Y.: Chicago Tribune-N.Y. News Syndicate, Inc., February $?$. 
Harris, Louis $1974 \mathrm{~b}$

Harris, Louis $1974 \mathrm{c}$

Harris, Louis 1974d

Harris, Louis $1974 \mathrm{e}$

Harris, Louis $1974 \mathrm{f}$

Harris, Louis $1975 a$

Harris, Louis $1975 \mathrm{~b}$

Harris, Louis $1975 \mathrm{c}$

Harr is, Louis $1975 \mathrm{~d}$

Harris, Louis 1975e
"Arab Actions on Oil Only Reinforce ProIsrael Sentiment in U.S." The Harris

Survey. New York: Chicago Tribune-N.Y. News Syndicate, Inc., February 14.

"Most Americans Prefer System of Voluntary 'Gas' Rationing." The Harris Survey. N.Y.: Chicago Tribune-N. Y. News Syndicate, Inc., February 18.

"Year-Round Daylight Savings Time Lacks Public Approval." The Harris Survey. N.Y.: Chicago Tribune-N.Y. News Syndicate, Inc., April 22.

"Public Continues Voluntary Restraint in Energy Consumption." The Harris Survey. N.Y.: Chicago Tribune-N.Y. News Syndicate, Inc., September 2.

"Public Would Accept 'Gas' Tax Under Certain Conditions." The Harris Survey.

N.Y.: Chicago Tribune-N.Y. News Syndicate, Inc., December 19.

"The Oil Import Tax: Even Rationing Is Preferable." The Harris Survey. N.Y.: Chicago Tribune-N.Y. News Syndicate, Inc., January 27.

"Oil and Politics" Blaming the Petropowers." The Harris Survey. N.Y.: Chicago Tribune-N.Y., News Syndicate, Inc., February 10.

"Economy, Energy, Environment Wanted: Progress on All Fronts." The Harris Survey. N.Y.: Chicago Tribune-N.Y. News Syndicate, Inc., March 3.

"Food and Energy: A Spirit of Sacrifice." The Harris Survey. N.Y.: Chicago Tribune-N.Y. News Syndicate, Inc., March 13.

"Public Finds Energy Shortage Less Serious." The Harris Survey. N.Y.: Chicago Tribune-N.Y. News Syndicate, Ine., May 5. 
Harris, Louis $1975 \mathrm{f}$

Harris, Louis $1975 \mathrm{~g}$

Harris, Louis $1975 \mathrm{~h}$

Harris, Louis $1975 \mathrm{i}$

Harris, Louis $1976 a$

Harris, Louis $1976 \mathrm{~b}$

Harris, Louis $1976 \mathrm{c}$

Harris, Louis 1977 a

Harris, Louis $1977 \mathrm{~b}$

Harris, Louis $1977 \mathrm{c}$

Harris, Louis $1977 \mathrm{~d}$

Harris, Louis $1977 \mathrm{e}$

Harris, Louis $1977 f$
"Public Favors Deregulation of Oil." The Harris Survey. N.Y.: Chicago Tribune-N.. $\bar{Y}$. News Syndicate, Inc., August 4.

"Business Gets Inflation Blame." The Harris Survey. N.Y.: Chicago Tribune

-N.Y. News Syndicate, Inc., October.

"Ford's Rating Slumps." The Harris

Survey. N.Y.: Chicago Tribune-N.Y. News Syndicate, Inc., November 3.

"Decontrol: Incentive for Oil and Gas Production" The Harris Survey. N.Y.: Chicago Tribune-N.Y. News Syndicate, Inc., November 30 .

"Candidate Missed Some Issues." The Harris Survey. N.Y.: Chicago Tribune -N.Y. News Syndicate, Inc., November 4.

"The Issue: Quality of Life." The Harris Survey. N.Y.: Chicago Tribune -N.Y. News Syndicate, Inc., November 8.

"Top Concerns: Abuses of Power." The Harris Survey. N.Y.: Chicago Tribune

-N.Y. News Syndicate, Inc., November 18.

"Americans Concerned About Energy." The Harris Survey. N.Y.: Chicago Tribune -N.Y. News Syndicate, Inc., February 14.

"Solar Energy Tops the List." The Harris Survey. N.Y.: Chicago Tribune-N.Y. News Syndicate, Inc., February 17.

"Bigger Role for Coal Approved." The Harris Survey. N.Y.: Chicago Tribune -N.Y. News Syndicate, Inc., August 1.

"Energy Crisis Has Many Causes." The Harris Survey. N.Y.: Chicago Tribúne -N.Y. News Syndicate, Ine, August 11.

"Taxes Win Over Rationing." The Harris Survey. N.Y.: Chicago Tribune-N.Y. News Syndicate, Inc., August 29.

"Most of the Energy Program Approved." The Harris Survey. N.Y.: Chicago Tribune $\overline{-N}$. Y. News Syndicate, Inc., September 22. 
Harris, Louis $1977 \mathrm{~g}$

Harris, Louis $1977 \mathrm{~h}$

Harris, Louis and Associates, Inc. 1975

Harris, Louis and Associates, Inc. 1976

Harris, Louis, and Associates, Inc. 1978

Hass, Jane, and Gerrold Bagley 1975

Heberlein, Thomas 1975

Henderson, Hazel 1978

Hill, John A. 1975

Hitlin, Robert 1974

Hummel, Carl F., et al. 1978
"Public Pro-Energy Bill." The Harris

Survey. N.Y.: Chicago Tribune-N.Y. News Syndicate, Inc., December 12.

"Action in Energy Insufficient." The Harris Survey. N.Y.: Chicago Tribune -N.Y. News Syndicate, Inc., December 29.

A Survey of Public and Leadership Attitudes Toward Nuclear Power Development in the United States, for Ebasco Services, Inc., August.

A Second Survey of Public and Leadership Attitudes Toward Nuclear Power Development in the United States, for Ebasco Services, Inc., November.

A Study of New York State Voters' Attitudes Toward Nuclear Power Plants, for Long Island Farm Bureau and Suffolk for Safe Energy, N.Y., N.Y., February.

"Coping with the Energy Crisis: Effects of Fear Appeals Upon Attitudes Toward Energy Consumption." Journal of Applied Psychology 60: 754-756.

"Conservation Information: The Energy Crisis and Electricity Consumption in an Apartment Complex." Energy Systems and Policy 1, 105-117.

Creating Alternative Futures, Berkeley Windover, NY.

"RX for Natural Gas Shortage: Deregulation and Emergency Actions." Public Utilities Fortnightly 96: 17-20.

"Energy Crisis Restricts Travel for FortyTwo Percent of D.C. Residents," News from Georgetown University. Washington, D.C., August.

"Perceptions of the Energy Crisis: Who is Blamed and How Do Citizens React to Environment-Lif estyle Trade-Offs?" Environment and Behavior, March 10, 37-87. 
Jones, Edward E., and Victor A. Harris 1967

Jones, E. E., et al. 1972

\section{Kilkeary, Rovena 1975}
King, Burt T., and Irving L. Janis 1956

King, Jill 1976

Krane, Sigmund 1977

\section{Lange, David} 1978

La Piere, Richard T. 1935 (1934)

Lazarsfeld, Paul F. 1948

Lewis, Larry 1977

Likert, Rensis 1932

Lilien, Gary L. 1978
"The Attribution of Attitudes," J. Exp. Soc. Psych. 3: 1-24.

Attribution: Perceiving the Causes of Behavior, Morristown, N.J, General Learning Press.

The Energy Crisis and Decisionmaking in the Family, for the National Science Foundation. Herbert H. Lehmann College, N.Y., January.

"Comparison of the Effectiveness of Improvised Versus Non-Improvised Role-Playing in Producing Opinion Changes." Human Relations 9: 177-186.

Impact of Energy Price Increases on Low Income Families, for FEA by Mathematica, Inc., Washington, D.C., December.

"Social Implications of the National Hail Research Experiment: A Longitudinal Study," Ph.D. Diss., University of Colorado, Boulder.

"1978: Oil's Biggest Volume Year Yet," Oil and Gas Journal 76: 119-137.

"Attitudes vs. Actions," Social Forces 13: 230-237 (1934-35).

The People's Choice, Columbia University Press, NY.

Energy Conservation Study 1974-1977. Consumers Power Company, Rate Research Department, Jackson, MI, September.

"A Technique for the Measurement of Attitudes." Archives of Psychology 22: 5-55.

"The Diffusion of Photovoltaics: Background, Modeling, and Initial Reaction of the Agricultural Irrigation Sector." Unpublished Paper. Department of Urban Studies and Planning, The Energy Laboratory, Massachusetts Institute of Technollogy, January. 


\author{
Linn, Lawrence S. \\ 1965 \\ Liska, Allen E. \\ 1974
Lopreato, Sally Cook, and Marian Wossum Meriweather 1976

Lucas, William A. 1974

Malecki, Edward 1977
Marylander Marketing Research, Inc. 1976
Mazur, Allan, and Eugene Rosa 1974

Melber, Barbara, Stanley Nealey, Joy Hammersla, and William Rankin 1977

Merton, R. K. 1940

Merton, R. K. 1957

Milstein, Jeffrey 1976
"Verbal Attitudes and Overt Behavior: A Study of Racial Discrimination," Social Forces 43: 353-364.

"Emergent Issues in the Attitude-Behavior Consistency Controversy." American Sociological Review 39: 261-272.

Energy Attitudinal Surveys: Summary, Annotations, Research Recommendations. Final Report for ERDA. Center for Energy Studies, University of Texas, Austin, November.

The Case Survey Method: Aggregating Case Experience. Rand Report R-1515-RC, Santa Monica, $\overline{C A}$, October.

"Socioeconomic Impact Analysis for Policy Research," Paper presented at the Regional Economic Modeling Conference, Denver, Colo., 30 November. Science and Public Policy Program, University of Oklahoma.

Attitudes, Usage Patterns, and System Characteristics Among Owners of Solar Pool Heaters and Owners of Solar Water Heaters, for San Diego Gas \& Electric Co., December.

"Energy and Life-Style." Science 186: 607-610.

Nuclear Power and the Public: Analysis of Collected Survey Research. Battelle Memorial Institute, Seattle, WA, November.

"Fact and Factitiousness in Ethnic Opinionnaires," Am. Soc. Rev. 5: 13-28.

Social Theory and Social Structure, N.Y.: Free Press.

Attitudes, Knowledge, and Behavior of American Consumers Regarding Energy Conservation with Some Implications for Governmental Action. Office of Energy Conservation and Environment, FEA, October. 
Milstein, Jeff rey 1977 a

Milstein, Jeffrey $1977 \mathrm{~b}$

Milstein, Jeffrey 1978

Montgomery, David B., and Dorothy Leonard-Barton 1977

Morrison, Bonnie Maas, L. Joanne Keith, and James J. Zuiches 1976

Morrison, Bonnie Maas 1977

Morrison, Bonnie Maas 1978

Muchinsky, Paul M. 1976

Murphy, Pamela Page 1974

Murray, James R., et al. 1974
How Consumers Feel About Energy: Attitudes and Behavior During the Winter and Spring of 1976-1977. Office of Conservation and Solar Applications, U.S. Department of Energy, Washington, D.C., June.

Energy Conservation and Travel Behavior. U.S. Department of Energy, Washington, D.C., October.

"Soft and Hard Energy Path: What People on the Streets Think." Unpublished Paper. Office of Energy Conservation and Solar Applications, U.S. Department of Energy, Washington, D.C., March.

Toward Strategies for Marketing Home Energy Conservation. Graduate School of Business, Stanford University, Palo Alto, CA, June.

Energy Impacts on Michigan Families. Report to the Sociopolitical Risk/Impact Resource Group of the Committee on Nuclear and Alternative Energy Systems, National Research Council, National Academy of Science, Washington, D.C., December.

"Residential Energy Consumption: Sociophysical Determinants of Energy Use in Single Family Dwellings." The Behavioral Basis of Design, Book II, Suedfeld and Russel, eds., ERDA, Community Development Series, Dowden, Hutchinson, and Ross, Inc.

"Impacts on Household Energy Consumption: An Empirical Study of Michigan Families." Sociopolitical Impacts of Energy Uses and Policy Contents. National Academy of Sciences.

"Attitudes of Petroleum Company Executives and College Students Toward Various Aspects of the 'Energy Crisis'," J. Soc. Psych. 98: 293-294.

"Harnessing the Atomic Juggernaut: The Need for Multi-Lateral Input in Nuclear Energy Decision Making." Natural Resources Journal 14: $412-422$.

"Evolution of Public Response to the Energy Crisis," Science 184: 257-263. 
National Demographics, Ltd. 1977

Newman, Dorothy, and Dawn Day 1975

New York Times $1973 a$

New York Times $1973 \mathrm{~b}$

New York Times $1973 \mathrm{c}$

New York Times $1973 d$

New York Times 1975

New York Times 1977 a

New York Times $1977 \mathrm{~b}$

New York Times $1977 \mathrm{c}$

New York Times 1977d

New York Times 1977 e

Newsweek $1974 \mathrm{a}$

Newsweek $1974 \mathrm{~b}$

Newsweek $1974 \mathrm{c}$

Newsweek 1975
Attitudes and Behavior Related to Energy Conservation, Denver, CO, October.

The American Energy Consumer, Bollinger Publishing Co., Cambridge, MA.

"Energy Crisis: Shortages Amid Plenty," April 17, p. 1.

"Energy Crisis: Shortages Amid Plenty," April 17, p. 17.

"Energy Crisis: Paradox of Shortage Amid Plenty," April 17, p. 26.

"Love is Doubtful on 'Gas' Rationing," November 9, p. 27.

"Ford's State of the Union Message," January I6, p. 24.

April 18, p. 15.

"A Rare Call for Sacrifices," April 19, p. 24.

"President Attacks Oil Industry for Opposition to Energy Plan," October 14, p. 1.

"Carter Denunciation Angers Oil Industry," October 14, p. 17.

"Schlesinger Attacks Oil Executives for 'Paranoia' on Energy Program,"

November $16, p .1$.

"Energy: A Question of Strategy," August 26, p. 65.

"Energy: A Question of Strategy," August 26, p. 68 .

"Energy: The Road to Independence," November 4, p. 76 .

"Energy Policy," March 24, p. 76. 
Novic, Kenneth, and
Peter M. Sandman
1974
$\frac{\text { Nuclear Info }}{1978}$
Opinion Research Corporation
$1974 a$

Opinion Research Corporation $1974 a_{1}$

Opinion Research Corporation $1974 \mathrm{~b}$

Opinion Research Corporation $1974 b_{1}$

Opinion Research Corporation $1974 \mathrm{c}$

Opinion Research Corporation $1974 c_{1}$

Opinion Research Corporation $1974 d$

Opinion Research Corporation $1974 \mathrm{e}$
"How Use of Mass Media Affects Views on Solutions to Environmental Problems," Journalism Quarterly 51: 448-452.

Atomic Industrial Forum, Inc., Washington, D.C., No. 40, June, p. 20.

General Public Attitudes and Behavior Toward Energy Saving, September Report, Vol. I, for FEA, National Technical Information Service No. PB-244 979, September.

Public Attitudes and Behavior Regarding Energy Conservation Waves 12 and 13, for FEA, National Technical Information Service No. PB-259 342, September.

Public Attitudes and Behavior of Residents in All-Electric Homes, for FEA, National Technical Information Service No. PB-244 981 , November.

Public Attitudes and Behavior Regarding Energy Conservation: Detailed Tabulations by U.S. Population and Population Segments, for National Technical Information Service No. PB-259 612, November.

General Public Attitudes and Behavior Toward Energy Saving, October Report, Vol. II, for FEA, National Technical Information Service No. PB-244 980, October.

Public Attitudes and Behavior Regarding Energy Conservation Waves 14 and 15, for FEA, National Technical Inf ormation Service No. PB-259 343, October.

Energy Consumption and Attitudes of the Poor and Elderly, Highlight Report, Vol. IV, for FEA, National Technical Information Service No. PB-244 982.

Trends in Energy Consumption and Attitudes Toward the Energy Shortage, Highlight Report Vol. V, for FEA, National Technical Information Service No. PB-244 983, December. 
Opinion Research Corporation $1975 a$

Opinion Research Corporation $1975 b$

Opinion Research Corporation $1975 b_{1}$

Opinion Research Corporation $1975 \mathrm{c}$

Opinion Research Corporation $1975 c_{1}$

Opinion Research Corporation $1975 d$

Opinion Research Corporation $1975 \mathrm{e}$

Opinion Research Corporation $1975 e_{1}$

Opinion Research Corporation $1975 \mathrm{f}$
Consumer Attitudes Toward Gasoline Prices, Shortages, and Their Relationships to Inflation, Highlight Report, Vol. VI, for FEA, National Technical Information Service No. PB-244 984, January.

Consumer Attitudes and Behavior Resulting from Issues Surrounding the Energy Shortage, Highlight Report, Vol. VII, for FEA, National Technical Inf ormation Service No. PB-244 985, February.

Public Attitudes and Behavior Regarding Energy Conservation. Detailed Tabulations by U.S. Population and Population Segments. Waves 20 and 21 , for FEA, National Technical Information Service No. PB-254 305, January.

Consumer Behavior and Attitudes Toward Energy-Related Issues. Highlight Report, Vol. VII, for FEA, National Technical Information Service No. PB-244 986, March.

Public Attitudes and Behavior Regarding Energy Conservation Waves 22 and 23, for FEA, National Technical Inf ormation Service No. PB-254 589, February.

General Public Attitudes and Behavior Regarding Energy Saving, Highlight Report, Vol. IX, for FEA, National Technical Information Service No. PB-244 989, April.

General Public Attitudes and Behavior Regarding Energy Saving, Highlight Report, Vol. X, for $\overline{\mathrm{FEA}}$, Technical Information Service No. PB-244 988, May.

Public Attitudes and Behavior Regarding Energy Conservation. Waves 25 and 27 , for FEA, National Technical Information Service No. PB-254 588, April.

The Public's Attitudes Toward and Knowledge of Energy-Related Issues, Highlight Report, Vol. XI, for FEA, National Technical Information Service No. PB-244 987, June. 
Opinion Research Corporation $1975 \mathrm{~g}$

Opinion Research Corporation $1975 \mathrm{~g}_{1}$

Opinion Research Corporation $1975 \mathrm{~h}$

Opinion Research Corporation $1975 \mathrm{i}$

Opinion Research Corporation $1975 i_{1}$

Opinion Research Corporation $1975 i_{2}$

Opinion Research Corporation $1975 \mathrm{j}$

Opinion Research Corporation 1975k

Opinion Research Corporation $1975_{1}$
General Public Behavior and Attitudes Regarding Vacation and Business Travel, Beverage Containers, and Reasons for Using Mass Transit, Highlight Report, Vol. XI, for FEA, National Technical Inf ormation Service No. PB-244 969, July.

Public Attitudes and Behavior Regarding Energy Conservation. Waves 30 and 31 , for FEA, National Technical Information Service No. PB-259 346, May.

Energy-Related Attitudes and Behavior of the Poor and the Elderly, Highlight Report, Vol. XIII, for FEA, National Technical Information Service No. PB-255 990, Washington, D.C., August.

How the Public Views the Nation's Dependence on Oil Imports: A Possible Natural Gas Shortage This Winter; The Overall Need to Save Energy, Highlight Report, Vol. $\mathrm{XV}$, for FEA, National Technical Infor mation Service No. PB-245 828, October.

Public Attitudes and Behavior Regarding Energy Conservation for FEA, National Technieal Information Service No. PB-254 304, August.

Public Attitudes and Behavior Regarding Energy Conservation. Waves 1 and 2, for FEA, National Technical Information Service No. PB-255 003, June.

Conservation of Energy in the Home, Highlight Report, Vol. XVII, for FEA, National Technical Information Service No. PB-254 628 , September.

Consumption and Conservation of Natural Gas, Highlight Report, Vol. XVIII, for FEA, National Technical Information PB-254 629 , September.

Public Attitudes and Behavior Regarding Energy Conservation. Waves 3 and 4, for FEA, National Technical Information Service No. $\mathrm{PB}-254$ 591, August. 
Opinion Research Corporation $1976 \mathrm{a}$

Opinion Research Corporation $1976 a_{1}$

\section{Opinion Research Corporation 1976b}

Opinion Research Corporation $1976 \mathrm{~b}_{1}$

Opinion Research Corporation $1976 \mathrm{c}$

Osgood, Charles E. 1969

Osgood, C. E., G. J. Suci, and P. H. Tannenbaum 1957 Otway, Harry J.
1976

Oxtoby-Smith, Inc. 1973

Oxtoby-Smith, Inc. 1974
Private Individual's Willingness to Make Energy-Saving Efforts and Their Perceptions of Others Doing the same, Highlight Report, Vol. XIX, for FEA, National Technical Information Service No. PB-255 946, February.

Public Attitudes and Behavior Regarding Energy Conservation. Waves 9 and 10 , for National Technical Information Service No. PB-259 341, October.

Parent's Perceptions of Their Children's Sources of Energy Information and EnergyRelated Activities, Highlight Report, Vol. XXII, for FEA, National Technical Information Service No. PB-261 164, April.

Public Attitudes and Behavior Regarding Energy Conservation: Detailed Tabulations by U.S. Population and Population Segments. Waves 17 and 18 , for FEA, National Technical Information Service No. PB-259 344, February.

Driving and Energy Conservation Highlight Report Vol. XXI, for FEA, National Technical Information Service No. PB-261 162, March.

"The Nature and Measurement of Meaning," in Semantic Differential Technique: $\mathbf{A}$

Source Book, James G. Synder and Charles Osgood (eds.), Aldine Publishers, Chicago, 3-14.

The Measurement of Meaning, University of Illinois Press, Urbana.

Public Attitudes Toward Nuclear Power International Atomic Energy Agency 18: 53-59.

How Influential Citizens View Offshore Drilling, for the American Petroleum Institute, Washington, D.C., September.

How Influential Citizens in East and Gulf Coast Cities View Offshore Drilling: Trends in Sentiment Since 1972, for the American Petroleum Institute, Washington, D.C., October. 


\author{
Owen, Ken \\ 1977 \\ Parisi, Anthony \\ 1977 \\ Perlman, Robert, and \\ Roland L. Warren \\ 1975 \\ Perlman, Robert, and \\ Roland L. Warren \\ 1977 \\ Phillips, Kevin \\ 1978 \\ Primack, Joel \\ 1974
}

Purdy, Bruce J., et al. 1977

Response Analysis Corp. 1976
Revyl, John S., et al. 1977
Rogers, Everett M., and Floyd Shoemaker 1971
Roper Organization, Inc. $1974 a$
Roper Organization, Inc. $1974 \mathrm{~b}$
Roper Organization, Inc. $1974 \mathrm{c}$
Roper Organization, Inc. $1974 d$

"Sagging Credibility Is 'Sof $t$ ' Spot in Energy Battle," Electric Light and Power 55: $6-9$.

"Poll Finds Doubt on Energy Crisis," New Y ork Times, September 1, p. 1 .

Energy Solving by Households of Different Incomes in Three Metropolitan A reas, Heller Graduate School of Advanced Studies in Social Welfare, Brandeis University, Waltham, MA.

Families in the Energy Crisis: Impacts and Implications for Theory and Policy, Ballinger Publishing Company, Cambridge.

"The Energy Battle: Why the White House Misfired," Public Opinion 1: 9-140.

"The Nuclear Safety Controversy," Chemical Engineering Progress 70: 26-34.

A Post Licensing Study of Community Effects at Two Operating Nuclear Power Plants, for U.S. Nuclear R egulatory Commission, Oak Ridge National Laboratory, September.

1975 National Survey-Lifestyles and Household Energy Use, for Washington Center for Metropolitan Studies, Princeton, February.

Solar Energy in America's Future, for ERDA, Stanford Research Institute, Menlo Park, CA, March.

Communications of Innovations, 2nd Edition, Free Press, N.Y.

Roper Reports, N.Y., January.

Roper Reports, N.Y., February.

Roper Reports, N.Y., May.

Roper Reports, N.Y., June. 
Roper Organization, Inc. 1974 e

Roper Organization, Inc. $1974 f$

Roper Organization, Inc. 1975a

Roper Organization, Inc. $1975 \mathrm{~b}$

Roper Organization, Inc. 1976a

Roper Organization, Inc. 1976b

Roper Organization, Inc. $1976 \mathrm{c}$

Roper Organization, Inc. 1976d

Roper Organization, Inc. $1976 \mathrm{e}$

Roper Organization, Inc. $1976 \mathrm{f}$

Roper Organization, Inc. 1977 a

Roper Organization, Inc. 1977b

Roper Organization, Inc. $1977 \mathrm{c}$

Roper Organization, Inc. $1977 \mathrm{~d}$

Roper Organization, Inc. 1977e

Roper Organization, Inc. $1977 \mathrm{f}$

Roper Organization, Inc. $1977 \mathrm{~g}$
Roper Reports, N.Y., August.

Roper Reports, N.Y., December.

Roper Reports, N.Y., January.

Roper Reports, N.Y., March.

Roper Reports, N.Y., March.

Roper Reports, N.Y., June.

Roper Reports, N.Y., July.

Roper Reports, N.Y., August.

Roper Reports, N.Y., November.

Roper Reports, N.Y., December.

Roper Reports, N.Y., January.

Roper Reports, N.Y., February.

Roper Reports, N.Y., March.

Roper Reports, N.Y., June.

Roper Reports, N.Y., July.

Roper Reports, N.Y., August.

Roper Reports, N.Y., September. 
Roper Organization, Inc. $1977 \mathrm{~h}$

Roper Organization, Inc. $1977 \mathrm{i}$

Roper Organization, Inc. $1977 \mathrm{j}$

Roper Organization, Inc. $1977 \mathrm{k}$

Roper Organization, Inc. 1978 a

Roper Organization, Inc. $1978 \mathrm{~b}$

Roper Organization, Inc. $1978 \mathrm{c}$

Roper Organization, Inc. 1979

Rosenberg, M. J., C. I. Hovland, W. J. McGuire, R. P. Abelson, and J. W. Brehm 1960

Roth, Julius A. 1965

Rupi, Inc. 1977

Ruttenberg, et al. 1975

San Diego Gas and Electric Co. Marketing Research Development 1976
Roper Reports, N.Y., November.

Roper Reports, N.Y., December.

Roper Reports, N.Y., May.

Roper Reports, N.Y., May.

Roper Reports, N.Y., January.

Roper Reports, N.Y., March.

Roper Reports, N.Y., June.

Roper Reports, N.Y., March.

Attitude Organization and Change, Yale University Press, New Haven.

"Hired Hand Research," Amer. Soc. 1: 190-196.

Federal Incentives for Solar Homes, An Assessment of Program Options, for Division of Energy, Building Technology and Standards Office of Policy Development and Research, U.S. Department of Housing and Urban Development, Washington, D.C., November.

Survey of Attitudes and Opinions of Electric Power Consumers in Ohio, for Ohio Electric Utility Institute, Columbus, Ohio, September.

Solar Background Attitude and Awareness Study, San Diego, October. 


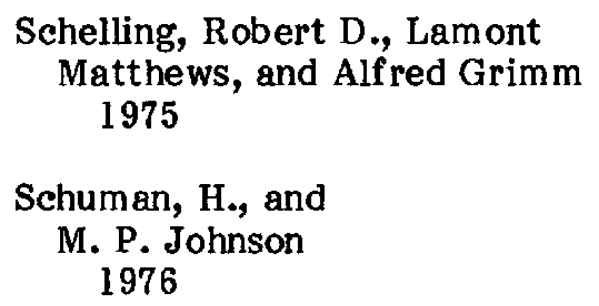

Science 1975

Scott, Jerome E. 1976
Scott, R. A. and A. Share 1974
Scott, William A. 1968
Seaborg, Glenn T. 1975
Sewell, Derrick W. R., and Harold O. Foster 1977

Simon, W. E. 1976

Smith, William D. 1975

Sommers, Paul 1975

Stearns, Mary D. 1975

Survey Research Laboratory 1977
"Solid Waste Problems Need Regional Solutions," American City and County 90: 38-41.

"Attitudes and Behavior," Annual Review of Sociology, 2, Annual Reviews: 161-207.

"A Conversation with Frank Zarb" 189: 533-535.

Consumer Demand Analysis: Solar Heating and Cooling of Buil dings, University of Delaware, Newark, September.

"Sociology and Social Policy Analysis," Amer. Soc. 9: 51-59.

"Attitude Measurement." Handbook of Social Psychology 2: G. Lindsey and E. Aronson, AddisonWesley, Reading, Mass., 204-257.

"Opportunities in Today's Energy Milieu," The Futurist 9: 22-24.

"Perceptions, Attitudes, and the Diffusion of Solar Energy Technology." Unpublished Paper. Dept. of Geography, University of Victoria, B.C.

"Damned Socialists and Bleeding Hearts; Interview." N. Thimmesch, ed., Saturday Evening Post 248: (October 1976), p. 37 .

"Mobil Finds Spreading Out Pays." New York Times, August 12, p. 12.

Social Science Literature on the Environment: Review and Prospects for Energy Studies-A Preliminary Literature Survey, for ERDA, Institute for Social and Policy Studies, Yale University, New Haven.

The Social Impacts of the Energy Shortage: Behavioral and Attitude Shifts, U.S. Department of Transportation, Washington, D.C.

Public Reactions to Wind Energy Devices, for National Science Foundation and the Department of Energy, Washington, D.C., University of Illinois, Urbana, October. 
Talarzyk, W. Wayne, and Glenn S. Omura 1975

Taylor, James B. 1961

Technical Analysis and Communications, Inc. 1977

Thompson, Phyllis T., and John Mactarish 1976

Thurstone, L. L., and E. J. Chove 1929

TRW Systems Group 1974

Unseld, Charles T., et al. 1978

Vollintine, Larry, and Olen Weres 1976a

Vollintine, Larry, and Olen Weres $1976 \mathrm{~b}$

Walker, Nolan E., and E. Linn Draper 1975
"Consumer Attitudes Toward and Perceptions of the Energy Crisis," pp. 316-322 in Ronald C. Curhan (ed.) American Marketing Association 1974 Combined Proceedings, University Microfilms, Ann Arbor, MI.

"What do Attitude Scales Measure: The Problem of Social Desirability," J. Abnor. Soc. Psych. 62: 386-390.

Summary of Findings, Energy Conservation Study Among Homeowners in California, Michigan, New York, for OWens-Corning Fiberglas Corp., Toledo, March.

Energy Problems: Public Beliefs, Attitudes, and Behaviors, Urb an and Environmental Studies Institute, Grand Valley State Colleges, Allendale, MI.

The Measurement of Attitude, University of Chicago Press, Chicago.

Solar Heating and Cooling of Buildings, Phase 0, Volume III Appendices, for National Science Foundation, Washington, D.C., May.

The Impact of Rising Energy Costs on the Elderly Poor in New York State, Welfare Research, Inc., Albany, January.

Public Opinion Concerning Geothermal Development in Lake County, California, for ERDA by Lawrence Berkeley Laboratory, Energy and Environment Division, Berkeley, March.

Public Opinion Concerning Geothermal Development in Lake County, California, for Lawrence Berkeley Laboratory, Energy and Environment Division, Berkeley, June.

"The Effects of Electricity Price Increases on Residential Usage in Three Economic Groups: A Case Study," in Texas Nuclear Power Policies, Vol. V: SocialDemographic and Economic Effects, Policy Study No. 1, Center for Energy Studies, the University of Texas, Austin. 
Walsh, John
1975

Warkov, Seymour, and the

Energy Institute, University of Texas 1976

Warkov, Seymor 1976

Warren, Donald I., and David L. Cliff ord 1975

Webb, Eugene J., Donald T. Campbell, Richard D. Schwartz, and Lee Sechrest 1966

Weigel, Russell, and Joan Weigel 1978

Weigel, Russell, Verson Woolston, and David Gendelm an n.d.

Welch, Susan, and Alan Booth 1977

Willenborg, John F., and

Kelly F. Shuptrine 1978

Yankelovich, Daniel, et al. 1977
"Opposition to Nuclear Power: Raising the Question at the Polls." Science 190: 964-966.

Energy Conservation in the HoustonGalveston Area Complex: 1976; Preliminary Results from the Houston Metropolitan Area Project, University of Houston Institute for Urban Studies, Houston.

Energy Conservation in the HoustonGalveston Area Complex: 1976, University of Houston Institute for Urban Studies, Houston.

Local Neighborhood Social Structure and Response to the Energy Crisis of 1973-74, Program in Community Effectiveness, Institute of Labor and Industrial Relations, University of Michigan, Ann Arbor, draft, January 2.

Unobtrusive Measures: Nonreactive Research in the Social sciences, Rand MCNally and Co., Chicago.

"Environmental Concern: The Development of a Measure." Environment and Behavior 10: 3-14.

Psychological Studies of Pollution Control: An Annotated Bibliography, Amherst College, Amherst, MA.

Nebraskans and Their Natural Environment, Bureau of Sociological Research, Department of Sociology, University of Nebraska, Lincoln, October.

South Carolina Energy Management Office Energy Survey 1978, South Carolina Energy Management Office, Columbia, February.

The Impact of Scarcities: The United States, Sweden, and the Federal Republic of Germany, for the Ford Foundation, Graduate Faculty of Political and Social Science, New School for Social Research, N.Y., February. 
Zimmerman, Dan, Richard Chase, and Marcia Simmons 1977

Zuiches, James J. 1975
Alternative Energy Workshop Participants: Who Are They? Department of Technical Journalism, Colorado State University, Fort Collins, and the Jefferson County Cooperative Extension Service, Golden, CO, July.

Energy and the Family, Michigan State University, Department of Agricultural Econ., East Lansing. 


\section{APPENDIX A}

FUNDING SOURCES FOR PUBLIC OPINION POLLS ON ENERGY TOPICS

Organization

Number of

Studies

Major Pollsters

Roper

Harris

Gallup

Federal Agencies

Federal Energy Administration

Energy Research and Development Administration

Nuclear Regulatory Commission

National Science Foundation/RANN Program

National Science Foundation/Department of

Transportation-Federal Energy Administration

National Institute of Mental Health

Department of the Interior, Office of Water Research and Technology

State/Local Agencies and Universities

Colorado State University Experiment Station

Illinois Division of Energy

Regional Transit Authority of Chicago

Kentucky Rural Development Advisory Council

Michigan State University

Michigan Agricultural Experiment Station

Michigan Agricultural Experiment Station and the National Academy of Sciences

University of Nebraska and 10 State/Local Agencies

New Hampshire Energy Consum ers Project

South Carolina Energy Management Office

Private Organizations

Ebasco Services

Electric Companies Public Information Program

Ohio Electric Utility Institute

Owens-Corning Fiberglass Institute

Private Individual

San Diego Gas and Electric

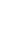


Combination of Federal Agencies and Private Sources

ERDA and Union Carbide Corporation ERDA and Southern Union Gas Company

1

Not Reported

Total N

115

NOTE: These surveys contained items relevant to energy, but may not have been limited to energy topics. 


\section{APPENDIX B}

\section{SOCIODEMOGRAPHIC VARIABLES}




\section{SEPI}


CONTENTS

Page

Introduction $\ldots \ldots \ldots \ldots \ldots \ldots \ldots \ldots \ldots \ldots \ldots \ldots \ldots \ldots \ldots$ B-1

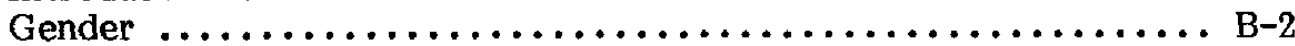

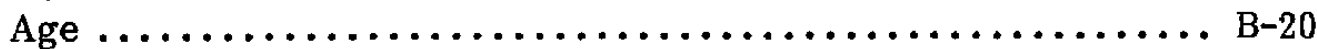

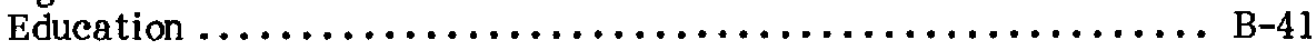

Income $\ldots \ldots \ldots \ldots \ldots \ldots \ldots \ldots \ldots \ldots \ldots \ldots \ldots \ldots \ldots \ldots \ldots, \ldots \ldots \ldots$

Occupation $\ldots \ldots \ldots \ldots \ldots \ldots \ldots \ldots \ldots \ldots \ldots \ldots \ldots \ldots \ldots \ldots,{ }_{B}-86$

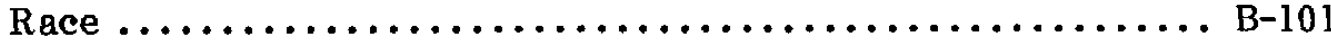

Political Orientation............................... B-107

Religious Affiliation ................................ B-113

Lif estyle Character istics $\ldots \ldots \ldots \ldots \ldots \ldots \ldots \ldots \ldots \ldots \ldots \ldots$ B-115

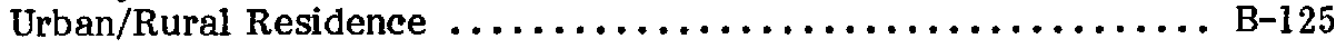


SEPI*ㅜ 


\section{TABLES}

B-1 Expectations about Supply of Natural Gas by Gender ............ B-5

B-2 Perception of Future Supplies of Oil and Natural Gas by Gender .............................. B-6

B-3 Disapproval of President Carter's Handling of the Energy Situation by Gender ........................ B-8

B-4 Perceived Environmental Har m through Energy Production by Gender . .......................... B-9

B-5 Preferences for Various Energy Sources by Gender .............. B-12

B-6 Position Toward Nuclear Power Plant Development by Gender......... B-14

B-7 Perception of Serious Problems Associated with Nuclear Energy by Gender ........................... B-15

B-8 Preferred Future Energy Sources in New York

State by Gender.................................. B-17

B-9 Perceived Adequacy of Environmental Regulations by Age .......... B-27

B-10 Perceived Environmental Harm through Energy

Production by Age................................ B-29

B-11 Perceived Seriousness of the Energy Situation

by Education ....................................... 42

B-12 Shortage Perceived as Excuse for Higher Utility

Rates by Education .............................. B-44

B-13 Gasoline Price and Supply Preferences by Education ............. B-48

B-14 Acceptance of Energy-Related Policies by Education.............. B-49

B-15 Response to a Suggested Policy to Reduce Income

Tax and Increase Gasoline Taxes by Education................ B-5l

B-16 Belief that U.S. Energy Self-Sufficiency Is

Possible by Education ............................. B-52

B-17 Perceived Environmental Problems if the United States

Attempts Energy Self - Sufficiency by Education $\ldots \ldots \ldots \ldots \ldots \ldots \ldots$ B-55

B-18 Preferences for S trip-Mining Regulatons Versus

Cheap Coal by Education ........................... B-56

B-19 Awareness of an Energy Agency by Education ................ B-58

B-20 Percentages Having Heard Anything about Solar and

Wind Energy as Sources of Electricity by Education . . . . . . . . . . B 59

B-21 Knowledge of Energy Terms by Education $\ldots \ldots \ldots \ldots \ldots \ldots \ldots \ldots \ldots$ B-61

B-22 Perceived Attributes of Solar Energy by Education. . . . . . . . . . B-63

B-23 General Opinion of Nuclear Power by Education $\ldots \ldots \ldots \ldots \ldots \ldots \ldots \ldots$ B-65

B-24 Attitude Toward the Building of More Nuclear Power

Plants in the United States by Education .................. B-66

B-25 Perceived Safety of Nuclear Power Plants by Education ........... B-67

B-26 Preferences for Spending Transportation Funds

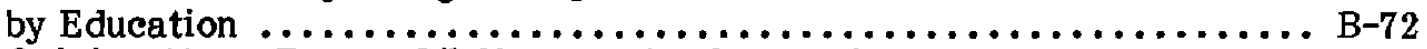

B-27 Opinion About Future Oil Shortage by Occupation $\ldots \ldots \ldots \ldots \ldots \ldots \ldots$ B-88

B-28 Attitudes on the Environment-Energy Trade-off by Occupation .................................... B-92

B-29 Perception of Domestic and Imported Oil Needs

by Occupation $\ldots \ldots \ldots \ldots \ldots \ldots \ldots \ldots \ldots \ldots \ldots \ldots \ldots \ldots \ldots \ldots \ldots$ B-93

B-30 Estimated Cost of Solar System by Occupation ................ B-95

B-31 Attitudes Toward Construction of Hartsville Plant

by Occupation $\ldots \ldots \ldots \ldots \ldots \ldots \ldots \ldots \ldots \ldots \ldots \ldots \ldots \ldots \ldots \ldots$ B-97 
B-32 Perceived Difficulty of Reducing Driving by One-Fourth by Occupation. .......................... B-99

B-33 Concern about Gas Mileage by Mileage Achieved ............... B-122

B-34 Driving Speed by Concern with Car Gas Mileages ................ B-123

B-35 Perceived Seriousness of U.S. Energy Situation by Size of Community (May 1977) ..................... B-127

B-36 Likelihood of a Natural Gas Shortage by Urban/Rural Residence ............................ B-128

B-37 Perceived Responsibility for U.S. Resources by Urban/Rural Residence . .............................. B-131

B-38 Decision-Making Responsibility by Urban/Rural Residence . . . . . . . . B-132

B-39 Extent to Which Business Community Is Meeting Energy Responsibilities by Urban/Rural Residence .............. B 8 -133

B-40 High Performance Rating of Public Officials and Institutions by Urban/Rural Residence.............. B-1 34

B-4l Attitudes Toward Government Intervention by Urban/Rural Residence .................................... 36

B-42 Favorability Toward Conservation-Related Energy Policies by Urban/Rural Residence ........................ B-1 42

B-43 Potential Use of Public Transportation by Urban/Rural Residence 


\section{INTRODUCTION}

Most of the analytical work using survey data involved cross-tabulations between major sociodemographic variables and a vast array of energy-related items. These analyses explored zero-order relationships between the independent and dependent variables; very rarely were the variables used in multivariate analysis or in analyses controlling for third variables. This body of analytical findings is of direct interest to the social researcher seeking to enhance the predictive or explanatory capability of his/her models, to the marketing specialist interested in knowing what segments of the population comprise likely markets, and to policymakers for a variety of reasons. Diffusion theory would lead us to expect that any idea or innovation will diffuse through various subelements of the population. Understanding whether significant differences exist by major population categories permits tailoring of policy options to enhance their effectiveness and social acceptability in the components of the population they are designed to reach. For example, if it can be shown that men and women have different interests in information concerning solar energy systems, information programs relevant to both kinds of interests can be fashioned.

The sociodemographic variables used as independent variables in the surveys were:

- Gender;

- Age;

- Education;

- Income;

- Occupation;

- Race;

- Political orientation;

- $\quad$ Religious affiliation;

- Lif estyle characteristics;

- Marital status;

- Housing characteristics/stages in family life cycle;

- Home ownership;

- Transportation characteristics; and

- Urban/rural residence.

The amount of material available on each variable varied widely. Used most of ten in survey analyses were gender, age, education, income, and occupation. Used fairly frequently were urban/rural residence, race, religious affiliation, and political orientation. Used least were the lifestyle characteristics: marital status, housing characteristics, home ownership, and transportation characteristics.

These variables differ in their applicability to different energy alternatives. Housing characteristics, for example, might be germane to solar energy or energy conservation 
issues, but probably not to nuclear energy. These differences become more explicit in the discussion of findings for each variable.

Frequently cross-tabulations were run with no tests of statistical significance, which left us to answer the question: When does a difference make a difference? A rule of thumb was devised to use in reporting findings.* For national surveys with samples greater than or equal to 1500 , differences of seven to 10 percentage points between groups were considered "slight." Those from 10 to 20 percentage points were termed "somewhat" different, and those greater were termed "different" or "very different." Where "difference" is reported, the variation in response was less than these values. For local samples of smaller size, the differences found between groups had to be greater than or equal to 10 to 12 percent before they were discussed. Differences noted are not statistically significant (unless specified) and should be taken to suggest an association between two variables. Where tests of significance were reported, the convention of assigning statistical significance at $a \leq .05$ was used.

In examination of the survey analyses, patterns of difference or relationships between variables found across many studies were sought. Item replication rarely occurred, except in longitudinal data; thus, concern was for the substantive meaning of items. Several explanations are possible to account for lack of patterns of difference and mixed results. The most likely are differences in item wording, item context (its placement in the data collection instrument relative to other items), samples (local or national), and data collection period. Where patterns of findings occur in spite of all these problems, there can be somewhat more confidence that an actual relationship is being measured by the different surveys than if a finding is supported by only one item or if the findings are mixed.

The following sections present the findings organized by sociodemographic variables. The findings for each sociodemographic variable are organized into seven categories, the latter dictated by the variables analyzed in surveys rather than by the organization of this report. The seven categories are as follows: (1) perception of the energy situation, (2) energy and the environment, (3) knowledge and information sources about energy and their credibility, (4) attitudes about solar energy, (5) attitudes about nuclear energy, (6) attitudes about energy conservation, and (7) summary of findings for the sociodemographic variable.

\section{GENDER **}

A great deal of analytical attention has been paid to differences between men and women on a wide variety of energy-related issues. This tendency is intriguing, for although everyday observation provides evidence about the differences between the sexes, systematic empirical information gbout these differences is more difficult to obtain. Moreover, no middle-range theory ${ }^{3}$ exists to predict how men might differ from

*SERI's statistician, Bill Belew, agreed that this rule of thumb was reasonable.

**Gender is used here interchangeably with the more frequently used "sex."

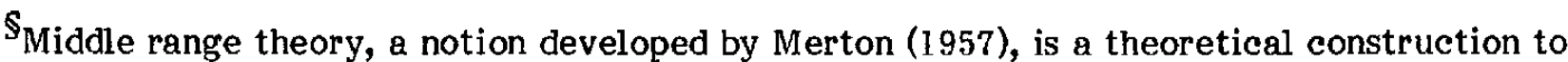
bring together diverse empirical findings and discrete hypotheses into a more general statement concerning a substantive area; e.g., the family, reference groups, and energyrelated behaviors. Middle range theory falls between grand theories of society (e.g., that of Parsons) and specific discrete hypotheses. 
women on matters related to energy. In the present universe of surveys, 52 (or 45 percent) used respondent gender in various analytical treatments of 167 different variables. Where differences by sex have been found, little effort has been devoted to examining what those differences might mean and what their implications, both for theory and for policy, are.

\section{Perception of the Energy Situation}

In four recent surveys, no difference by gender was found in belief in the seriousness of the energy crisis [108, 122, 175, 218]. In an earlier study, however, females were somewhat more likely to believe there was an energy problem [181]. This difference may be accounted for by change over time rather than by a long-standing and consistent difference between the sexes. The pattern found in the data is agreement by gender on the seriousness of the energy situation.

A 1974 study in Phoenix, Kansas City, and Minneapolis reported no difference between men and women on whether or not the energy crisis was perceived as real [302]. This finding contradicts that of Zuiches (1975) who reported that females were more likely to believe the energy crisis was real.

Surveys report somewhat inconsistent findings on differences by gender in perception of who or what is to blame for the energy crisis. Three surveys conducted between 1973 and 1977, one national, one in Ohio, and one in llinois found no difference on this variable [108, 122, 213]. A 1974 survey in Los Angeles County found males less likely than females to attribute responsibility to the President and more likely to blame oil companies for the crisis [207]. A 1977 nationwide survey found no differences among response categories except that males were somewhat more likely to place "major blame" on Congress than females ( 31 to 24 percent) and males (42 percent) were more likely than females (29 percent) to attribute "no blame at all" to Israel [15l]. Taken together, these findings suggest a pattern of little difference by gender on assessing responsibility for the energy situation, with a suggestion that males might be slightly more frustrated with oil companies and Congress than females.

A few survey items attempted to measure the salience of the energy issue-its importance relative to other major national issues. In one study men ranked the energy issue higher than women [120], and this finding was borne out by another study demonstrating interesting differences in salience by the sexes. Respondents were asked to which things people wanted their congressman or senator to give major attention [168]. Findings were as follows:

Development of national energy policy

Program to hire unemployed in government jobs

Stricter labeling regulations for food products

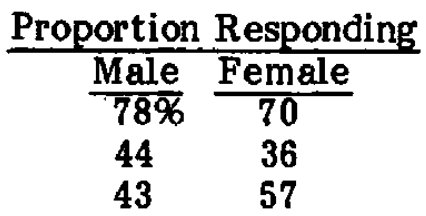

Both men and women were more likely to want Congressional attention focused on developing an energy policy than on unemployment or food labeling problems, with men slightly more concerned than women about developing an energy policy. Two other surveys [15], 154 found no difference by the sexes on ranking energy an important 
issue.* The evidence for differences by sex on the salience of the energy issue is not compelling enough to conclude that this is a consistent pattern.

Three surveys asked whether prices had gone up as a result of the energy shortage, and females were more likely to mention that food prices had increased ( 28 to 16 percent), while males said the prices of "everything" had gone up (43 to 32 percent) [137, 139, 309]. One study found no difference by sex in respondent assessment of how much impact increases in the price of oil and gas would have on the rate of inflation [308]. Thus, no major difference existed in perspectives between the sexes on the effects of the energy shortage.

Expectations about the future energy supply in the nation were examined in several surveys. Five studies found men more sanguine about the future prospects of energy supplies than were women $[122,129,137,139,172]$. Men tended to say the nation is not likely to run out of coal in the next 50 years (63 compared to 44 percent for women), nor out of oil in the same time span (45 percent compared to 34 percent for women) [139]. Findings for a similar item on natural gas are presented in Table B-1.

In 1975 women were more likely than men to think that OPEC countries "will again cut off oil to the United States sometime in the next year" (62 percent said "fairly" or "very likely" compared to 51 percent of men) [129]. Men were less likely than women to think there will be a shortage of electricity in the future (45 to 35 percent). In guessing whether there would be a gas shortage during the summer of 1974,37 percent of men thought not, compared to 29 percent of women.

However, this pattern of female concern about the security of the future energy supply was not consistently supported by all surveys. A 1974 survey in Michigan reported that males were more pessimistic about our future supplies [119]. Findings are reported in Table B-2.

Three other studies reported no differences by gender on estimating chances for another severe energy shortage [150], on whether our energy situation will be better or worse [108], and about whether oil shortages will worsen in the future [172]. Since the findings are mixed, it is impossible to conclude that major differences exist by gender in perceptions about the national energy future. The data do suggest that women tend to be somewhat more concerned than men about our nation's energy future.

No difference by gender was found on the desirability of a policy of energy selfsufficiency for the nation $[214,308]$. Further, men and women did not differ in preferences for various national strategies, except in one case. Females were slightly more likely $(\mathrm{p} \leq .01)$ to approve of policy options mentioning limiting energy usage in the United States than were males [303]. Males were favorable toward maximizing U.S. production of energy. Another study reported that for an item asking whether we should conserve gasoline or pay higher prices and use all we want, no difference in preference was found by sex [308].

* One of these studies [154] reported no difference by sex in concern about inflation, with 28 percent of the sample concerned about having enough money to pay their monthly bills (both men and women). About a third defined energy as a major issue. 
TABLE B-1

EXPECTATIONS ABOUT SUPPLY OF NATURAL GAS BY GENDER

How 1ikely is it that we'11 run out of natural gas . . [137]

Proportion Responding

$\begin{array}{llll}\text { in the next } 10 \text { years? } & \text { in the next } & 50 \text { years? } \\ \text { Very } & \text { Not Very } & \text { Very } & \text { Not Very } \\ \text { Likely } & \text { Likely } & \text { Likely } & \text { Likely }\end{array}$

Male

$15 \%$

22

31

34

Female

32

15

46

21 
TABLE B-2

PERCEPTION OF FUTURE SUPPLIES OF OIL AND NATURAL GAS BY GENDER

Are we going to run out of...?[119]

Proportion Responding

$\begin{array}{lll} & \text { U.S. World } \\ \text { U.S. Natural World } & \text { Natural }\end{array}$

Male $36 \%$ *

Female 25

42

21

30

29

14

₹The proportion indicating "yes." 
Two 1977 studies reported no difference by sex in respondent assessment of the adequacy of steps taken to deal with the energy situation, and on whether too many or not enough sacrifices had been called for $[174,218]$. But three national surveys found males more likely than females to disapprove President Carter's handling of the situation [147, 217, 309]. Table B-3 shows the findings on this variable. Taken together these findings suggest somewhat more negativism on the part of males to President Carter. As will be seen in the section on political orientation, response is influenced by the naming of famous politicians in survey items. The inclusion of Carter's name likely had a confounding effect on response to these latter three items. Thus, findings are mixed on differences in respondent assessment of national policy by gender.

\section{Energy and the Environment}

Some methods of dealing with an energy shortage have fewer environmental implications than others. As previously noted, the two major options available are (1) decreasing energy demand through conservation, and (2) increasing energy supply using one or more of several alternatives. The first approach has few, if any, known environmental disadvantages associated with it; the second may bring in its wake a variety of undesirable effects, depending on the energy source considered. Thus, researchers have sought to measure the relative value the public attaches to energy supply on the one hand and environmental effects on the other. What tradeoffs would the public prefer? A consistent pattern of difference by gender is found on this question.

When respondents were asked, "Have environmental regulations gone too far or not?", males were more likely than females to say that they had ( 25 percent compared to 16 percent) [148]. The same survey reported that in response to an item forcing a choice between energy and environment, 48 percent of males chose "adequate energy" compared to 38 percent of females. About 40 percent of females chose to "protect the environment" compared to about a third of males. Women were more likely than men to perceive that environmental problems exist involving air pollution, soil quality, and "natural resources" [125]. They were also more likely to connect energy production with environmental harm (see Table B-4). Using a similar item, another survey reported the same general pattern of findings [308].

When asked which would be the most likely environmental problem if the United States tried to be energy self-sufficient (air pollution, oil spills, etc.), respondents displayed no difference in response by gender. Nor was there male/female difference on the question of whether the country should use more "pollution-free" sources of electricity (about 75 percent agreed that it should).

When examining environmental tradeoffs associated with specific energy sources, however, a clear pattern of difference emerges from the data. Males were more likely to favor burning high-sulfur oil in factories and power plants than were females [207]. Men more of ten thought environmental standards should be relaxed to permit industry conversion from oil and natural gas to coal [218]. Women tended to favor banning strip mining more than men [221], although men tended to favor strict laws regulating strip 


\begin{tabular}{ccc} 
TABLE B-3 & $\begin{array}{c}\text { CARTER'S HANDLING OF THE ENERGY SITUATION } \\
\text { BY GENDER }\end{array}$ \\
DISAPPROVAL OF PRESIDENT & Proportion Disapproving \\
Year and Study & $\frac{\text { Ma1e }}{44 \%}$ & 34 \\
$1975[309]$ & 21 & 14 \\
$1977[217]$ & 27 & 19 \\
$1977[147]$ & & 3419 \\
\hline
\end{tabular}




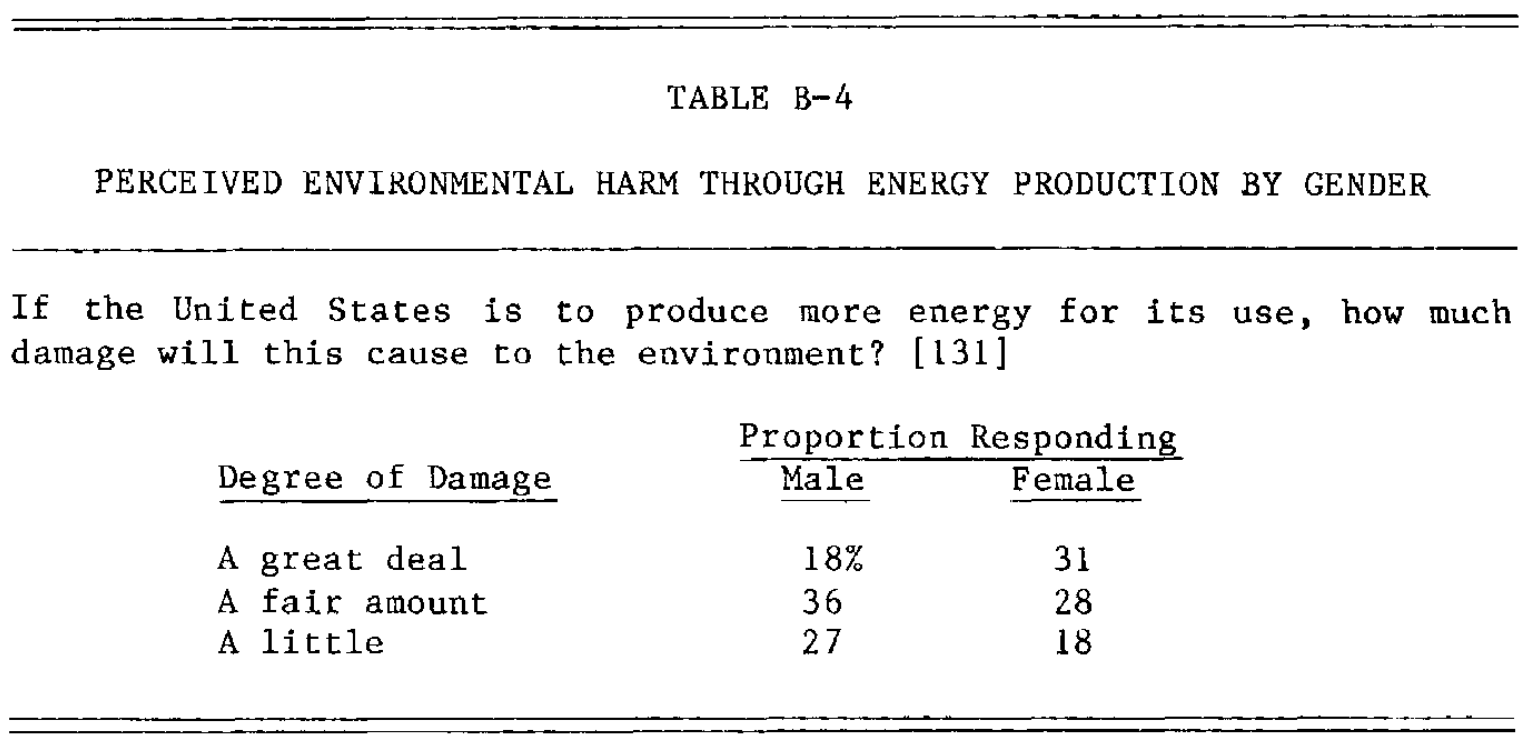


mining more than women, given the alternative of "getting coal at the cheapest possible cost" [131].*

Melber et al. (1977) reported that women were less in favor than men of all the possible alternatives to increase energy supply (e.g., offshore oil drilling, developing nuclear energy, more strip mining, and relaxing pollution standards). They reported that males were more in favor of increasing energy supply than women, and that men were much more in favor of building more power plants when the choice is cutting back on electrical use. Women, in the Melber study, were found to be more strongly in favor of environmental protection and conservation than were men. The findings reported here support the conclusions of the Melber review of the literature.

\section{Knowled zeability and Information Sources}

A significant pattern of differences by gender emerges from the empirical data conceming aw areness of energy-related matters and exposure to information sources. In one study testing objective knowledgeability that analyzed data by gender, males were more likely than females to say the nation imports oil (60 percent compared to 45 percent). In $1975 \mathrm{men}$ were more aware than women of an energy agency established by the federal government (55 to 38 percent) [256]. Men were also more able than women to respond accurately on 10 "energy awareness" items [106].**

Scott (1976) reported that males tended to indicate they had read more about solar energy than females. Similarly, another study reported that males were more likely to have "heard som ething about solar energy and wind energy" $(p \leq .01)$ [303]. Men were more likely than women to report that they had been following media discussions on nuclear energy developm ent (Gallup, 1976). Males were much more likely to state they had seen or read advertisements and articles concerning gasoline mileage (79 percent compared to 48 percent for females) [308]. Men were somewhat more likely than women to be aware of a nuclear power plant within 100 miles of where they live [311]. Males were far more likely than females to claim awareness of EPA/FEA mileage figures for cars (73 percent compared to 40 percent) [144]. No difference by gender was found in proportions of a sample reporting regular reading of utility company pamphlets [253].

*The breakdown in response for this item was:

\begin{tabular}{lll} 
& Male & Female \\
\cline { 2 - 3 } Strict laws & $48 \%$ & $32 \%$ \\
Cheapest price & 38 & 38 \\
Don't know & 14 & 30
\end{tabular}

Males were more likely to say that power plants and oil refineries do not cause air pollution [308].

**Two superbly constructed charts present data on variables in this study that control by gender, and presenting findings for income, education, age, rural-urban residence, and beli ef in the energy crisis. Since Melber et al. (1977) noted that these types of data were largely absent from survey analyses they reviewed, researchers may be interested to know of their existence. 
These findings support an overall conclusion that men are exposed (or expose themselves) to more information about energy-related topies, and that they are somewhat more knowledgeable than women about these topics. The sex role expectations for males in our society would lead to a prediction that they, as an aggregate compared to females, would be som ewhat more knowledgeable about energy technologies and issues.

Men and women did not use different sources of information, according to self-report $[108,122]$. Moreover, there has been very little difference by gender in the assessment of credibility of various sources of information about energy matters $[120,122,170,308]$.

\section{Solar Energy}

A few studies included demographic analysis on items relating to solar energy. A statistically significant but not substantive difference $(p<.05)$ was found on preference for solar energy as a source for production of electricity ( 96 percent of men compared to 93 percent of women) [303]. The same study, however, reported the data presented in Table B-5 showing no difference between the sexes in relative preference for solar energy. Similar findings were reported in a survey which asked, "Looking ahead to the year 2000, which offer the best long-term sources of energy?" Solar energy was chosen by 68 percent of the males and 65 percent of the females [152]. Nuclear energy was mentioned by 40 percent of males and 30 percent of females.

Melber et al. (1977) reported that men were stronger supporters of solar energy than women. The findings reported here, however, do not support such a conclusion. When the definition of solar power was extended to include hydropower and wind, then, as the data in Table B-5 show, 76 percent of women favored solar sources compared to 67 percent of men. If men were more supportive of solar power than women, it could have been a function of their somewhat greater preference for increasing energy supply rather than reducing energy demand.

No difference by gender was found in willingness to buy a solar water heater if it cost the same as other units or if it cost more than other units [302]. Females reportedly guessed the cost of a solar system as lower than males $(\mathrm{p} \leq .05)$, and males were more likely to think solar system installation was not "simple and fast" [252]. Women were slightly more likely to think solar systems would "last a long time," and that such systems "can only be installed in new homes" [252]. Roper (1979) found that one percent of employed females owned solar heating systems in January 1979. About five percent of females and seven percent of males said they might invest in a solar system in the next two to three years.

Scott (1976) reported statistically significant differences between the sexes on four variables concerning the purchase decision for solar systems. Females were more concerned than males about (1) increase in first cost and mortgage payment, (2) increase in down payment, (3) increase in fuel savings, and (4) warranty coverage. This set of findings shows a greater overall female concern about the impacts of solar systems on the household budget.

Since widespread adoption of solar energy is urged in part on the grounds that anyone can understand solar systems, men decidedly have the advantage over women in this regard by virtue of socialization and experience. Women may be more concerned about how adoption of solar energy affects their households than in understanding how it works. 


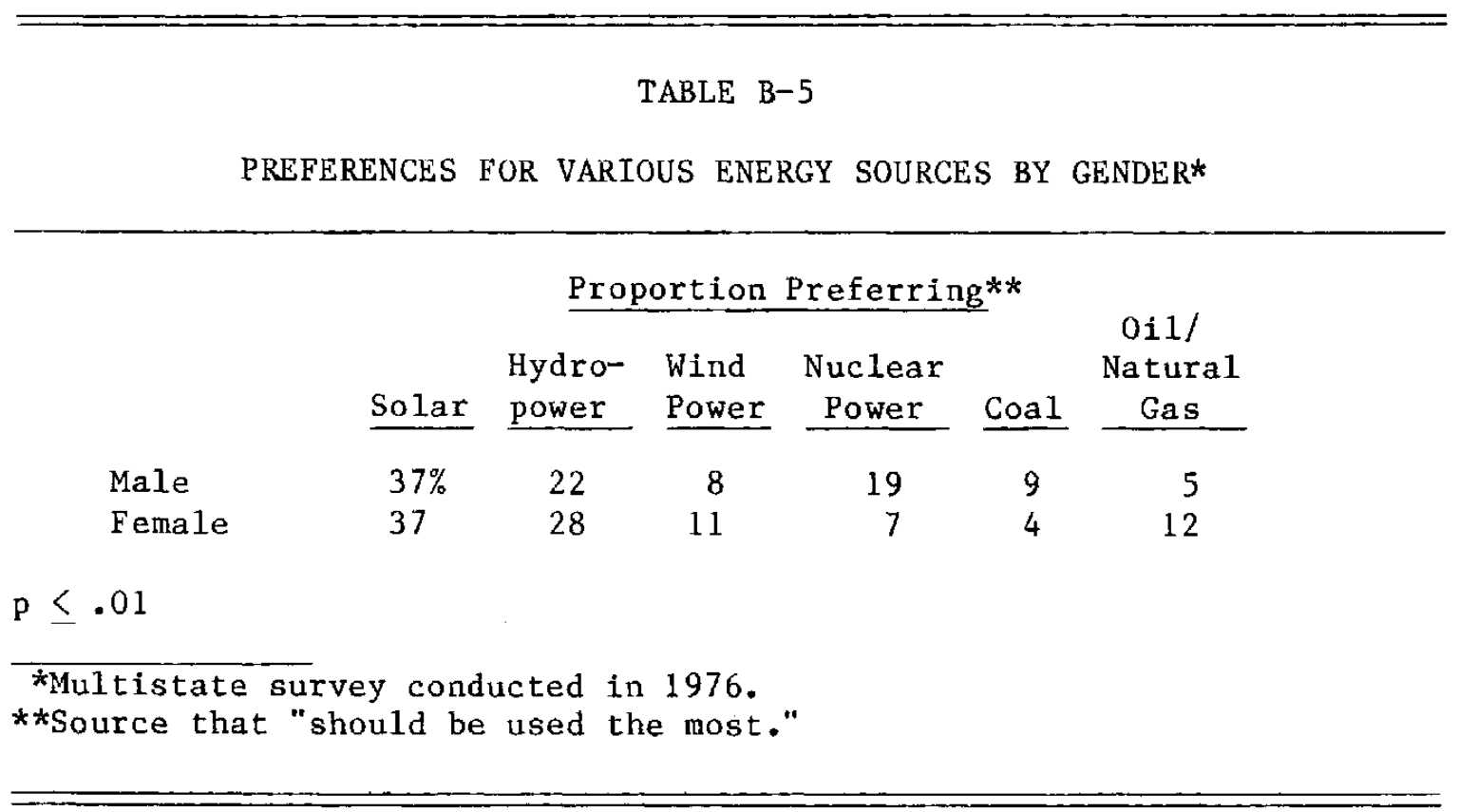


Adoption is also promoted with the argument that solar energy is more environmentally benign than other energy sources. If women were persuaded that solar energy is more benign than other sources, judging from survey data, their support of solar energy woulc be even more enthusiastic.

\section{Nuclear Energy}

Although both men and women preferred solar energy to nuclear energy, a clear pattern of difference between the sexes arose over the issue of nuclear energy itself. Men were consistently more favorable toward nuclear development than were women. Data are summarized in Table B-6. The same pattern of male support for nuclear energy has been borne out by other surveys [Gallup, 1976; 221]. The "need for power" as a reason for supporting nuclear energy was mentioned by 29 percent of women and 20 percent of men in one survey [142].

Consistent with their favorable position toward nuclear energy, males were also more favorable than females about the idea of having a nuclear power plant in the vicinity of their homes. Various surveys reported spreads of 12 to 27 percentage points in greater male favorability to this idea [141; 143; 207; 308; 311; Gallup, 1976].

Related to this lack of female willingness to live near nuclear power plants is theil significantly greater concern that nuclear plants may be unsafe. About a third of males characterized nuclear plants as "very safe" compared to 16 percent of females in one study. Females were more likely than males [141] to wish nuclear power plants were "cu1 back," and to think that they were not safe enough with the safety regulations current a1 the time of the survey (Gallup, 1976). One study reported that a majority of women (54 percent) thought a nearby atomic energy plant "would present dangers" (compared to $3 \varepsilon$ percent of men) [148]. Almost half of women (and about a third of men) agreed tha1 "nuclear power is unsafe with great danger of accidents" (Melber et al., 1977). Serious problems associated with nuclear power, as perceived by the public, are reported in Table B-7.

Several other studies cited by Melber et al. (1977) bear out this striking pattern of difference between the sexes. Melber et al. reported, "Sex differences in response to nuclear power questions were more clear-cut and consistent than those associated with any of the other demographic classifications." Although both male and female respondents favored nuclear power, males were much more supportive, somewhat more opposed, and much less uncertain than were females" (p. 74). We, however, find females consistently more opposed than males to nuclear energy. This apparent discrepancy may be due to our reliance on more national samples, as compared to the reliance of the Melber et al. review on regional and local samples.

\section{Conservation}

Virtually no items in the surveys included in this review queried respondents directly on how favorable they were to energy conservation, nor on how effective they felt conservation would be in aiding the nation's energy supply situation. Motivation to engage in conservation behavior is not limited to economics. As one respondent put it:

We conserved so well that our electrical bill went up because we were not using enough electricity. (Bee Angell and Associates, 1975, p. 33) 


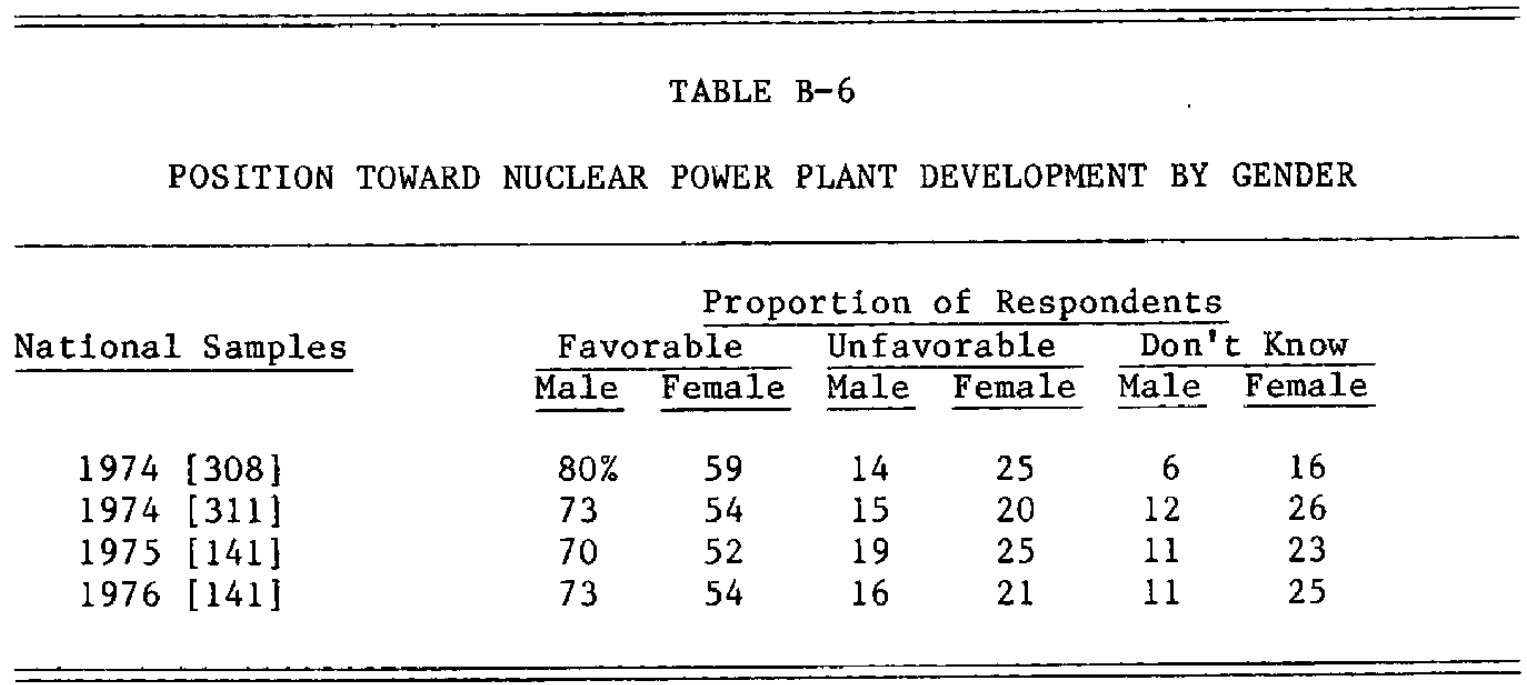




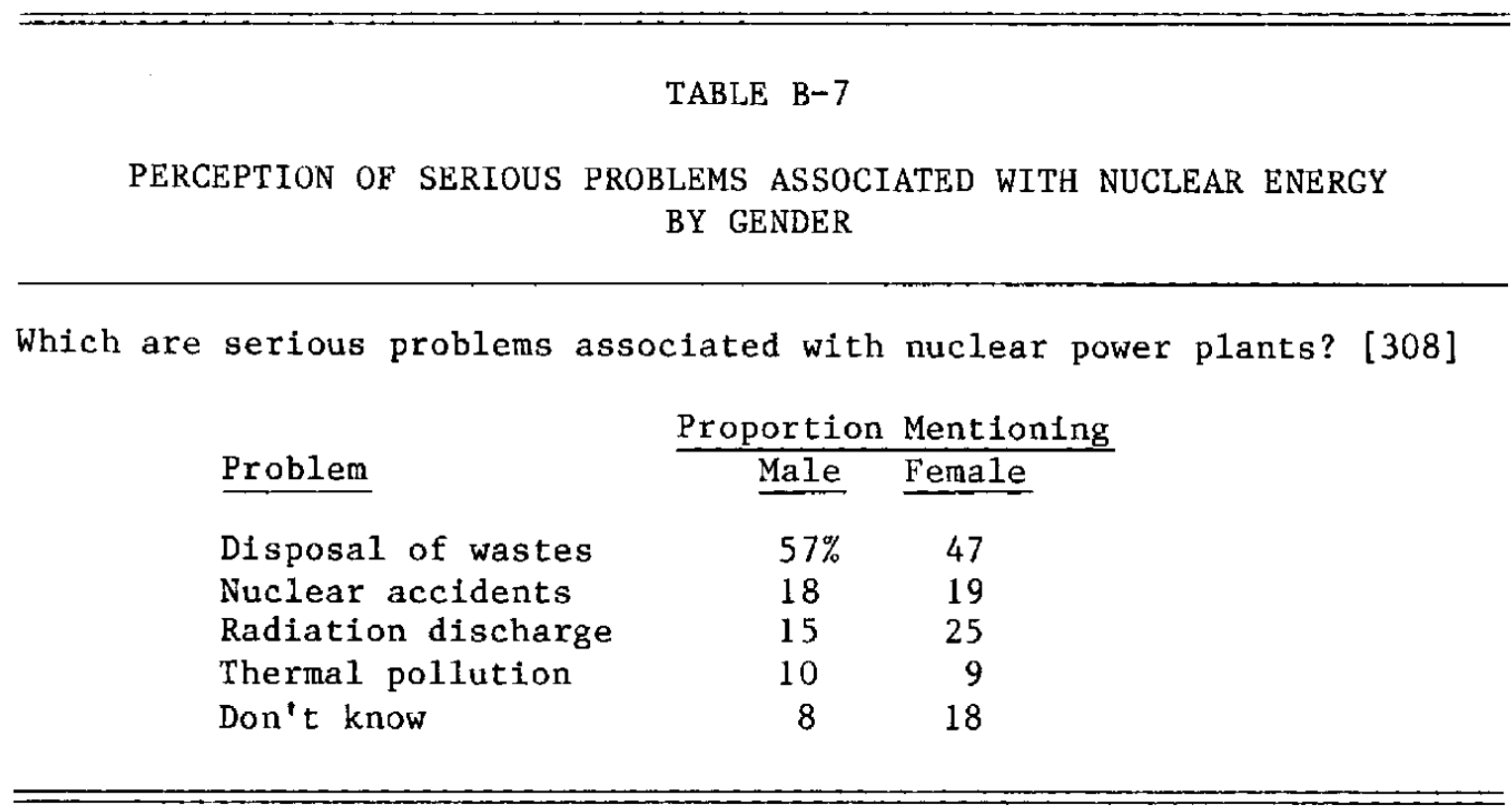


Economic incentives for energy conservation are not present when people believe their utility bills will go up whether they conserve or not. There are few data on citizen belief that engaging in conservation will actually assist the nation's energy supply (see Chapter 6). One study reported little difference by sex in estimates of median percentage of present utility costs that could be saved through conservation (males, 13.5 percent; females, 12.3 percent) [120].

Thus, findings from a survey in New York state during January 1978 (Harris, 1978) are of particular interest. Respondents were asked their preferred energy source. The results are presented in Table B-8.

These findings are significant in illuminating how energy conservation stands relative to various modes of enhancing energy supply. As the data illustrate, females tended to favor conservation somewhat more than males, and the sexes were about equally favorable to solar energy. Coal and nuclear energy fall far behind as preferred choices for both sexes. The data in our review provide some evidence that women have been slightly more favorable to conservation all along.

A national study in 1975 found differences by sex in how important saving energy was viewed at that time [258]. About two-thirds of males (and one-third of females) said it mattered "very little"; a majority of females said it mattered "a great deal" (56 percent). Another study reported that, given the choice of paying higher prices or conserving gasoline, 87 percent of females thought Americans should conserve, compared to 69 percent of the males [133]. Women were slightly more inclined to define the need to conserve as "somewhat serious" [130]. Females were also more likely to agree that if we continue "our high levels of energy use, future generations will not be able to have a level of living like ours" (74 percent compared to 61 percent of males) [106].

One survey found no difference by sex on whether most people think they waste energy, on willingness to limit energy use, on how people waste most energy, and on ways to get people to conserve energy [108]. Another study found no difference by gender on whether controls on energy should be made more strict [212]. Perceptions about whether "most people are doing anything to save electricity" were not found to vary by gender [122].

An Ohio survey conducted in 1975 found that females were less likely than males to think "big companies are doing things to save electricity" (27 percent compared to 41 percent) [122]. A national survey completed during 1974, however, resulted in a higher proportion of males ( 52 percent) than females ( 37 percent) assessing as "poor" the job the business community was doing in meeting its responsibilities toward conservation [137]. No difference by sex was found in respondent assessment of how important domestic energy conservation was compared to the amount government and industry could save.

Further, no difference by sex was found concerning a number of attitude items relevant to conservation. These were as follows [106]:

- Maintaining a satisfying way of living even with fewer material goods.

- The natural environment must be preserved even if I must change my way of living.

- If we continue these high levels of living we'l deprive people in poorer parts of the world. 
TABLE B-8

PREFERRED FUTURE ENERGY SOURCES IN NEW YORK STATE BY GENDER

Which do you prefer to see as a means of getting our future energy needs--using more coal, more nuclear power, more solar power, or do you think we should conserve more energy (or not sure)? (Harris, 1978)

Preferred Source

Need to conserve

Solar power

Coal

Nuclear power

Not sure

Proportion Mentioning

Male Female Total

$40.2 \% \quad 48.7 \quad 44.7$

$42.9 \quad 42.0 \quad 42.5$

$17.3 \quad 11.1 \quad 14.0$

$\begin{array}{lll}14.3 & 3.8 & 8.8\end{array}$

$\begin{array}{lll}5.5 & 5.2 & 5.2\end{array}$


- Our family is entitled to as many material goods as we can afford regardless of the energy required to produce them.

- The citizens of the United States are entitled to as many material goods as we can afford regardless of the energy required to produce them.

- Government officials are not providing any clear directions to help families make decisions about energy.

- The only way to get families to conserve energy is by improving government controls.

- I would accept possible risks to health and safety from nuclear power rather than severely restrict my energy use.

No difference by sex was found in interest in membership in energy-conservationoriented organizations [120].

Additionally, no difference by gender was found for the following variables:

- what conservation actions respondents would be likely to take in the next two years if a tax credit were given [164];

- feelings about a more austere life caused by energy shortages [150];

- $\quad$ size of car owned and car-buying plans [150];

- reported energy use reduction [101, 106, 207];

- $\quad$ reported willingness to engage in gasoline conservation [221];

- preferences for rationing versus price increases to reduce gasoline consumption $[220,308]$;

- favorability or opposition to gasoline rationing that would reduce driving by 25 percent, and opinions on how important such a measure is and how difficult it would be to implement [310];

- favorability or opposition concerning the $55 \mathrm{mph}$ speed limit [217] or on proposals to reduce the speed limit [211];

- $\quad$ preference for tax on gas-guzzlers versus tax on gasoline [308];

- concern about gasoline mileage performance of cars [308]; and

- preference for tax on gas-guzzler cars versus heavy gasoline users [308].

In sex-role related activities, men and women reported somewhat different patterns of conservation behavior. Females were more likely than males to indicate they were using washing machines, dryers, and dishwashers less [122]. Females were also more likely to report cooking several dishes in the oven at one time, buying fresh fruit and vegetables only in season, and limiting hot water use [196]. Women were more likely to state they planned shopping so that they made one trip to the store rather than several [144]. They were somewhat more likely to report in 1977 that they were reducing their use of appliances [220]. Males were more likely to indicate maintenance of a daytime temperature at $68^{\circ} \mathrm{F}$ ( 70 percent compared to 60 percent of the females) [106]. Males were more likely than females to report they had their cars tuned every six months or more of ten [144], and to say they would use public transportation if it got them to work 15 minutes faster than other means [129]. 
Males perceived less difficulty in reducing the number of miles they drove than did females [106]. Men tended to report they usually drove at a faster speed than females (a third drove over $56 \mathrm{mph}$ compared to 15 percent of women) [258], but men reported more often than women that the $55 \mathrm{mph}$ speed limit had reduced the speed with which they drove ( 67 percent compared to 60 percent) [217].

A significant positive correlation was found among women more frequently than among men in willingness to adopt solar energy and conservation, even if it meant changes in lifestyle and family income [208]. Environmental consciousness was positively correlated to family income for women, but not for men $(p \leq .05)$ [208]. Such findings might be explained by the sex role expectations that the woman should create a comfortable domestic environment for her family in terms of food, clothing, temperature, furnishings, and so on. If adopting energy-conserving practices interfered seriously with this role performance, which is less likely with high income at her disposal, she stands to suffer loss of self- and family esteem. She might thus be less favorable. Males are assumed to be less responsible for direct family comfort and more responsible for the family income level itself by virtue of sex role expectations. This may account for the lack of association between male gender and willingness to adopt solar energy and practice domestic conservation.

Another interesting finding was that women were more willing to turn down the thermostat on their hot water heaters than were men [258]. Melber et al. (1977) reported a study finding sex differences by the relative rank given, among other values, to "a comfortable life." The authors implied that males value comfort more highly. These sex-linked differences in value may be related to differences in willingness to conserve energy, as well as to differential perceptions by sex on whether we should reduce demand or increase supply.

In one study, women were somewhat more compassionate than men as a group in their response to whether poor people and the elderly should have special electrical rates. About 85 percent of women and 70 percent of men thought this was a good idea [122].

Morrison et al. (1976) reported some differences by gender in their study of attitudes toward energy conservation. Inquiry as to approval of the following policies was made: (1) tax deductions for apartment dwellers and small-car owners, (2) gasoline rationing, (3) single-car deductions, and (4) free mass transit. Respondents in order of decreasing favorability to these policies were as follows: (1) urban women, (2) urban men, (3) rural women, and (4) rural men. While the urban/rural dichotomy is more important in accounting for the difference, females in both cases were more favorable than males to conservation policies.

In summary, the data exhibit support for a tendency for women to favor conservation more than men. Men and women who engage in conservation behaviors tend to do so in activities consonant with their sex roles. The differences between the sexes on conservation were not major, but they were substantial. Virtually no data exist on technical knowledge levels about conservation that has been analyzed by gender.

\section{Summary}

The analysis of survey findings by gender resulted in the following findings. No difference by gender was found on these variables: 
- belief in the seriousness or reality of the energy crisis;

- salience of the energy situation;

- attribution of responsibility for the energy situation;

- perception of effects and impacts of the energy crisis;

- desirability of a policy of energy self-sufficiency; and

- favorability toward solar energy, although men may be more concerned about how solar systems work and women about how solar systems would affect their households.

There is some evidence in the survey data suggesting that women tend to be somewhat more concerned than men about the nation's energy future. Women were found to be more in favor of environmental protection than were men. Evidence exists that men are somewhat more exposed to information sources about energy and are somewhat more knowledgeable about energy matters than are women. However, no difference by gender was found on perceived credibility of various information sources. Men were found to be consistently more favorable to nuclear energy than were women. Women were somewhat more favorable to domestic energy conservation than were men. Men and women who engaged in conservation behaviors tended to do so in activities consonant with their sex roles.

\section{AGE}

The age of respondents is quite often used to provide sociodemographic analysis of survey results. While analysis of results by age categories can lead to insights valuable for interpretation of survey research, this sociodemographic category is troublesome for several reasons. One major structural problem is the differing age categories employed by various surveys. Seldom did two surveys employ the same categories; for example, one might have as its oldest category "50 or over"; another, "60 or over"; another, "65 or over." Aside from the problem of differing categories among different surveys, a few of the major national surveys have changed their age categories over time. This lack of internal consistency makes trend analysis difficult.

In many cases, categories include groups with quite different sociodemographic status (e.g., income, employment, marital status). For example, those over 65 would more likely be retired, have lower and fixed income, and be widowed than those in their low 50 's. Thus, age is quite of ten confounded by other sociodemographic variables, making straightforward interpretation of results by age difficult.

A final problem relates to the number of age categories employed. While most surveys employed four categories, some employed three or even two. In many cases, where four age categories have been employed, curvilinear age relationships have been revealed on certain variables. Yet when age is dichotomized in other surveys (e.g., "40 or younger," "over $40 "$ "), it is impossible to discern such trends.

Despite these problems, analysis of data by age can be valuable to policymakers. If one is concerned with equity, for example, data on variables such as the financial impacts of 
energy pricing policies on the elderly can be invaluable. Similarly, responses of younger groups might be interpreted as indicating changing social attitudes that might become more prevalent over time.*

\section{Perception of the Energy Situation}

Two recent national surveys [175, 218] found little difference by age in belief in the seriousness of the energy crisis. In the earlier survey, there was a slight tendency for more of those in the 25-29 age group to rate the problem "very serious," compared with those over 50 years of age. The former age group (25-29) was the only group to show a divergence from the views of the total sample, and this slight difference (in rating the problem "very serious") disappeared by the time of the second survey. In general, over 80 percent of those sampled rated the problem "fairly serious" or "very serious."

A 1974 study in Phoenix, Kansas City, and Minneapolis also found no difference by age in belief in the reality of the energy crisis [302], nor did a 1974 survey in Lansing, Michigan [106]. However, a 1976 followup to the Lansing survey revealed that somewhat more of those under 40 believed in the crisis than did those over 40 [106]. Similarly, a 1975 survey in Texas and Arizona revealed a pattern of slightly greater belief in an energy crisis among those under 30 than among those in the 30-60 age group. An even more pronounced difference was found when those under 30 were compared to those over 60 [181]. Contradicting this pattern is the finding of a 1975 survey in Texas that those reporting no belief in the crisis tended to be younger than those reporting belief (Gottlieb and Matre, 1976). Two surveys inquired about belief in shortages of specific energy sources. A 1977 survey of the Chicago metropolitan area, which asked if "the gasoline energy crisis is a phony issue," revealed that those in the 45-64 age group were notably more skeptical about the gasoline shortage than those under 24 , while those over 65 were somewhat more skeptical [127]. A 1975 survey in Ohio revealed no age difference in belief in an electricity shortage, with close to 80 percent of all age groups believing there was no shortage [122]. From these studies, it is not possible to determine the relationship between age and belief in the reality of the energy crisis.

Belief in the energy crisis may be related to personal experience with shortages or increased costs. Such a relationship was revealed in a 1977 study of elderly poor residents in New York State, in which high inereases in energy costs (as a percentage of income) correlated significantly with belief in the seriousness of the crisis (Unseld et al., 1978). One would thus expect older people on fixed incomes to report greater belief in the crisis, yet there is survey evidence both to support and to contradict this conclusion. This suggests that the influence of age as a predictive variable is confounded by other variables such as income.

Two national surveys, conducted in 1973 and 1974 [213; Talarzyk and Omura, 1975], and one conducted in Los Angeles in 1974 [207] found no differences by age in attribution of responsibility for the energy crisis. A 1977 national survey found several differences by age groups when respondents were queried about eight possibly responsible groups [151]. No differences by age were found in blaming either the Administration or Israel. Those

*Again, it is necessary to point out that such interpretations must be made with care, due to confounding variables. For example, younger groups may differ from older groups in income, marital status, family size, or education, to name a few. As these statuses change with age, attitudes would also be expected to change. 
over 30 were slightly more likely to attribute blame to Congress than were those 18-29. Those over 60 exhibited a slightly lesser tendency to attribute "major" blame to electric power companies than those under 44. Similarly, those over 60 exhibited a somewhat lesser tendency to blame oil companies for "major" responsibility than did all other age groups, with those 18-29 placing the most blame. Those over 60 were slightly less likely than those under 30 to attribute "some" blame to environmentalists and also somewhat less likely to attribute "no blame at all" with no differences in attribution of "major" blame. Those over 60 were more likely to respond "don't know" to nearly all of these items. Those 18-29 were somewhat more likely to attribute "major" blame to American consumers and Arab countries than were those over 60.

The general pattern of resul ts of this survey is that the youngest age group had a greater tendency to attribute blame to each group than did those over 60 , with the middle age groups generally falling between these positions. There is no clear pattern of differences by age in attribution of responsibility for the energy crisis. A 1977 survey in four cities in Illinois, however, revealed that those between 18-35 years of age were slightly more likely to attribute the energy shortage to overuse of limited natural resources than were those over 35 [108].

A 1976 survey in Grand Rapids, Michigan, [119] inquired about reasons for energy price increases, with the following results:

- Production costs: those under 25 were notably less likely than those 25-44, and som ewhat less likely than those $45-64$, to cite this reason.

- Greed: those under 25 were notably less likely to cite this reason than all other groups.

- Increased demand: those 25-44 were notably more likely than all groups to cite this reason, while those under 25 were somewhat more likely than those 45-64 and 65 and over.

- Shortages: those 25-44 were notably more likely than those under 25 or over 65 to cite this reason, and somewhat more likely than those 45-64.

A 1974 national survey asked respondents "how good a job the federal government is doing in meeting its responsibility to conserve our supplies of natural resources" [137]. Fewer than seven percent of all age groups rated government performance "good"; those 18-29 were slightly more likely than those 50 or over to rate it "average"; those 30-39 were more apt to rate it "poor" (48 percent) than either those 18-29 (33 percent) or those 50 or over ( 31 percent). A survey a month later that asked the same question with regard to the business community showed no age differences in "good" ratings (less than 13 percent); those 50 or over were slightly more likely to rate it "average" than other groups; those 18-29 were somewhat more likely to rate it "poor" (48 percent) than were those 50 or over (30 percent) [139].

A 1977 survey in Ohio revealed a consistent pattern of differences between the oldest and youngest age groups in attitudes toward electric companies [122]. The youngest group rated the companies somewhat lower than did the oldest on the following characteristics: "active in community affairs" and "friendly." The youngest group also rated the companies somewhat higher on the following: "pollutes the atmosphere," "cares more about profits then keeping its rates down," and "makes too much profit." Those in their 30's and 40's generally fell between the youngest and oldest groups. The oldest group again exhibited a tendency to respond "don't know" to many of the questions [122]. 


\section{Expectations About the Future Energy Situation}

Seven surveys measured expectations about future energy supplies. A 1974 national survey, which inquired about the possibility of a future oil shortage, revealed that those over 60 were slightly more likely than those 18-29 and somewhat more likely than those 30-44 to express the opinion that there never was a shortage, that it had been contrived. This oldest group, however, was slightly less likely than those 30-44 and 45-59 to report the belief that there would not be a gasoline shortage that summer [172]. A 1975 national survey revealed that both those 18-29 and 30-49 were somewhat more likely than those over 50 to rate the possibility of an oil embargo very likely or fairly likely [129]. There were no age differences in those rating it not very likely or not likely at all (combined categories), while those $\mathbf{5 0}$ or over were more likely than both other groups not to know. Those over 30 were somewhat more skeptical than thase younger than 30 about the possible re-emergence of long gasoline lines. Again, those over 50 were slightly more likely than those $18-29$ to report they did not know. Results from the same survey indicate that the youngest group was slightly less likely to rate a natural gas shortage very or fairly likely. A 1975 Ohio survey revealed slightly greater skepticism regarding a future shortage of electricity among those in their 20's than among those over 50, while the latter group was somewhat more likely than bth those in their 20's and those in their 30 's and 40 's not to know [122].

A 1976 survey in Grand Rapids, Michigan, revealed an inverse relationship between age and belief in future shortages of oil and natural gas for both the United States and the world [119]. A 1977 national survey, however, found those over 60 to be slightly more likely than other groups to believe that another severe energy shortage in the next year was very likely [150]. Finally, Stearns (1975) reported that older people were more likely to view the energy problem as one of short duration.

While together these findings contain contradictory evidence, the evidence seems to indicate that younger groups generally view the possibility of future energy shortages as more likely than do older groups.

Three national surveys, conducted in November-December 1974, December 1974-January 1975 , and January $1975[131,133,308]$, inquired whether respondents believed the United States could be self-sufficient in energy supplies. In the first survey those 18-29 were slightly less likely than those 50 or over and somewhat less likely than those 30-49 to express such a belief. In the second, the youngest group again expressed slightly less belief in this possibility, but so did those 50 or over, who were somewhat more likely than the younger groups to report that they did not know. In the third survey, again the youngest group reported somewhat more disbelief than the middle group, and notably greater disbelief than the oldest group, while the oldest group again exhibited a somewhat greater tendency not to know. This lack of belief in the possibility of selfsufficiency supports the pattern, noted earlier, that younger groups tend to attribute greater reality to the energy crisis and the possibility of future shortages.

A 1977 survey in four minois cities revealed that those 18-35 were slightly less likely than those over 35 to believe that "most people have a realistic view of our energy situation," suggesting that younger people not only perceived the situation as more serious than others, but also were aware that older groups did not share this perception [108]. This survey revealed no age differences, however, in answer to the question, "Do most people think they waste energy?", and in agreement with the statement: "Over the next five years, most people think the energy situation will be progressively better or progressively worse." 
Two national surveys conducted in 1975 attempted to gauge the salience of the energy issue by comparing its perceived importance with that of unemployment and inflation $[134,128]$. In both surveys, the energy shortage ranked last for all age groups, being considered most important of the three by no more than 13 percent of any age group. In the first survey, there was no age difference in ranking of the energy shortage, but in the second slightly more of those 18-29 rated the energy shortage as most important than did those 65 or older. In a 1976 national survey that asked to which of three issues people wanted their congressman or senator to give attention, there were no age differences in opinion on the importance of developing a national energy policy. Those 18-29 favored hiring the unemployed in government jobs more than did other age groups, while those over 60 favored stricter labeling of food products, indicating a greater expressed concern with problems of greater immediate impact [168].

A 1977 national survey, which inquired about the two or three things about which people were most concerned, revealed that those in the 45-59 age groups were slightly more likely to name the energy crisis than were those $30-44$ or those over 60 [153]. Interestingly, the energy crisis in this survey outranked recession/unemployment for all age groups. On this variable, those 18-29 showed somewhat more concern than did those over 60 .

Finally, a 1977 survey in Denver, which asked respondents to rank the energy issue among 12 issues, revealed that those 55 and over gave it a higher rank than did those 35-54, who in turn ranked it higher than those under 35 [120]. These findings suggest no consistent pattern for salience of the energy situation by age.

\section{Perceived Impacts of the Energy Situation}

Several surveys attempted to assess the perceived impacts of the energy situation by inquiring about price increases and more direct impacts such as job losses. Grier (1976) and Unseld et al. (1978) have documented the fact that rising energy costs are a serious and growing burden on the elderly, particularly those who are also low-income. These findings are contradicted by a 1975 survey in Houston which found that cost as a worrisome consequence of the energy situation is inversely related to age, while shortages are directly related (Gottlieb and Matre, 1976). This result is inconsistent with a body of literature revealing that financial impacts are greater for the elderly than for other age groups, and it may be attributable to the sample employed in the study.

A 1976 survey in Lansing, Michigan, found there was no difference between those under and over 40 in citing increased heating fuel or electricity prices as an effect of the energy crisis on one's family; although those under 40 were slightly more likely to cite the increased price of gasoline [106]. Again, the method of analysis employed here, in which all those over 40 are grouped together, masks the severity of impacts on those elderly who are out of the work force and living on fixed incomes.

A 1974 national survey conducted in August and September revealed that those 30 or over were somewhat more likely than younger individuals to report that the price of "everything" had gone up because of the energy shortage [137]. When the same question was asked in September-October and in November-December, again those in the middle age group were somewhat more likely, and those in the oldest group were notably more likely to report that the price of "everything" had risen due to the energy shortage [139, 308]. In the November-December survey, however, the youngest group was slightly more likely than the middle, and somewhat more likely than the oldest, to report that the price 
of food had risen. A 1974 national survey found no difference by age in perception of how much the price of gasoline had $r$ isen [308]. Another national survey in 1974 revealed that slightly fewer of those 50 or over felt that increases in the price of oil or gasoline had had a great deal or a fair amount of impact on the rate of inflation than did those in younger age groups, while the former were slightly more likely to report that they did not know [308]. A 1974 survey in Washington, D.C., revealed that those under 30 were more likely than those over 30 to report that a family member had been laid off, that overtime had been cut down, or that their regular work week had been cut [121].

A survey conducted in 1975 in Ohio inquired in some detail about electric rate increases [122]. Those in their 20 's were somewhat more likely than those in their 30 's and 40 's to report they did not know how much electric rates had increased over the past two years. This younger group was also somewhat more likely than those over 50 to report that they did not know if excessive costs were responsible for increases in rates and they were somewhat more likely to attribute increases to wages and labor costs than were those in their $30^{\prime} \mathrm{s}, 40$ 's, or $50^{\prime}$ 's. None of the other possible reasons revealed any age differences in attribution.

There were no age differences in responses to whether one "got one's money's worth" in buying natural gas or electricity, but as respondents increased in age, they were less likely to report getting their money's worth. It is difficult to discern a clear pattern of differences by age in perceptions of the severity of the crisis (as measured in these items), but in general these results suggest support for the hypothesis that the oldest, and possibly the youngest, adult age groups experience more personal impacts due to the energy situation.

\section{Policy Preferences}

A 1974 national survey found that those over 60 were slightly more likely than those 4559 to rate as sufficient the steps taken to deal with the energy situation [174]. No consistent pattern of opinion on President Carter's handling of the energy situation was revealed by age in several national surveys that inquired about this. In August 1975 slightly fewer of those 50 and older than those 18-24 or 30-49 approved of Carter's actions, while the oldest group was slightly more likely than those under 24 to have no opinion. There was no age difference in disapproval [309]. In February 1977, slightly more of those 25-29 than those 18-24 approved. Those 50 and older were slightly less likely than those 25-49 and somewhat less likely than those 18-24 to disapprove. Those 50 and older were somewhat more likely than all others to have no opinion [217]. In April-May 1977 there were no differences of opinion by age in approval or disapproval; however, as to whether too many or not enough sacrifices were called for, those 50 and older and those 25-29 were somewhat more likely than those 18-24 to see things as "about right." Those 18-24 were somewhat more likely than those 50 or over to say there were not enough sacrifices; there were no differences by age among those seeing too many [218].

A later survey revealed no differences in opinion on the steps called for in Carter's plan, with the exception that those 60 and over were more likely to have no opinion [147]. Again, no clear or consistent pattern of differences by age on these items is apparent.

A number of surveys attempted to assess preferences for various energy policy options. Differences by age were found on the following policy options: 
- Substantially higher gasoline prices with unlimited availability (slightly greater support among those 18-29 than 50 and over) [131].

- Somewhat higher gasoline prices with somewhat limited availability (those under 50 more supportive) [131].

- Maintaining current prices and rationing (those 50 and over more supportive) [131].

- Exporting food to pay for imported oil, even though this increases the domestic price of food (younger groups more likely to support) [128, 139].

- Rationing energy use to prevent importing energy supplies (those 60 and over much more supportive) [303].

- Maximizing domestic production and importing whatever else is needed (those 45 and older significantly more likely to support, $\mathrm{p} \leq .05$ ) [303].

No differences by age were found for:

- Producing as much energy as possible but limiting usage in order to reduce imports [303].

- The amount of effort that should be directed toward developing new energy sources and promoting conservation [151].

\section{Energy and the Environment}

In contrast to opinions regarding belief in the energy crisis and related issues, a distinct pattern of greater concern among younger people for protecting the environment is evident in the results of a number of surveys. When respondents were asked, "Have environm ental regulations gone far enough?", younger age groups were more likely to say they had not, while older groups were more likely to say they had gone too far, or were about right [148] (See Table B-9).

The same survey revealed that, in response to an item forcing a choice between energy and environment, those 18-29 were somewhat less likely than all other age groups to choose "adequate energy" and somewhat more likely to choose "protect the environment." A 1973 Colorado survey also found age to be positively correlated with a "help energy-hurt environment" indicator [210]. Further evidence to support the proenvironment stance of the young is the finding of a 1975 national survey that those 18-29 were somewhat more likely than those 30-49 and notably more likely than those 50 and over to favor a law requiring all soft drinks and beer to be sold in returnable containers [133]. Contradicting this trend are results from a Michigan study which found no age difference in agreement with the statement: "The natural environment should be preserved even if I must change my way of living" [106].

With regard to awareness of environmental problems, a 1977 Nebraska survey found that the youngest group (18-34) were slightly more likely than the middle (35-54) and somewhat more likely than the oldest ( 55 and over) to believe that problems existed in the areas of air pollution, water pollution, water shortages, soil quality, and natural resources [125].

A national survey in November-December 1974 found no age difference in associating power plants and oil refineries with pollution [308]. When this question was repeated 
TABLE B-9

PERCEIVED ADEQUACY OF ENVIRONMENTAL REGULATIONS BY AGE

Have environmental regulations gone too far or not? [148]

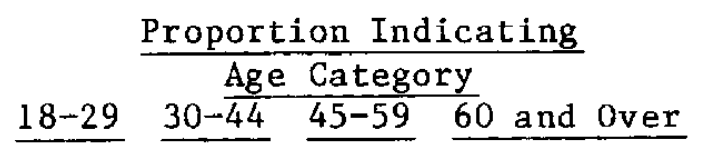

Too far

$13 \% \quad 20$

Not far enough

$36-25$

24

About right

36

Don't know

39

12

25

$25 \quad 20$

$35 \quad 37$

$15 \quad 19$


shortly thereaf ter, however, the youngest group (18-29) were somewhat more likely than the middle (30-49) and markedly more likely than the oldest (50 and over) to draw this association [131]. Moreover, these same surveys found that the youngest group expected that increased energy production would cause greater environmental damage than did the older groups (see Table B-10).

The youngest group was also somewhat more likely to support a policy of building oil refineries and power plants in already polluted areas (as opposed to unpolluted areas) than were either of the older groups [308]. When asked which would be the most serious environmental problems if the United States tried to be energy self-sufficient, the youngest and middle groups were slightly more likely than the oldest to cite strip mining, while the youngest was somewhat more likely than either group to eite air pollution [308].

This trend-of the youngest group to exhibit a notable and consistent favorability toward environmental protection-was borne out in several surveys which examined tradeoffs associated with specific energy sources. Older people were more likely than younger people to favor burning high-sulfur coal in power plants and factories and to support drilling offshore oil wells [207]. Those over 50 were notably more likely (49 percent) than those 18-24 (29 percent) to favor relaxing environmental standards to permit industries to convert from oil and natural gas to coal, with those 25-29 and 30-49 falling between these positions [218]. Again, when asked to compare strict laws governing strip mining to "getting coal at the cheapest possible cost," those 18-29 were more likely to favor strict laws.*

In response to an inquiry as to whether it is "more important to have strip mining regulations to protect the environment, or to keep the price of electricity lower, " the youngest group favored regulations ( 53 percent), while those $30-49$ were nearly as supportive (47 percent). The two older groups were much less supportive, and the oldest group (65 and over) favored lower prices (5l percent) [128]. In a similar question, which asked if pollution-free sources should be used even if it meant the cost of electricity would rise by 10 percent, the same pattern of greater support among younger groups for environm ental quality was revealed [303].

In summary, on nearly every item in which support for environmental quality was gauged or in which energy-environment tradeoffs were posed, younger people, particularly the youngest group, showed consistent support for the environment, particularly when compared to the oldest group. One might speculate that this support derives from greater environmental awareness, from a larger stake in the quality of the environment (due to their longer expected tenure on the earth), or perhaps from the fact that younger people with fewer financial burdens find it easier to support policies that might result in some financial sacrifice. The lack of support by older groups may reflect the precarious financial condition of many of these respondents, particularly those in the oldest group.

*There was little age difference in support for getting coal at the cheapest possible cost, due to the substantial proportions (25 and 27 percent) of the older groups who claimed they did not know [131]. 


TABLE B-10
PERCEIVED ENVIRONMENTAL HARM THROUGH ENERGY PRODUCTION
BY AGE

If the United States is to produce more energy for its use, how much damage will this cause to the environment? [131, 308]

Degree of Damage

A great deal

A fair amount

A little

None at all

Don't know
Proportion Responding

$\begin{array}{llllll}18-29 & \frac{30-49}{30} \text { and Over } \\ 28 \% *(30) * * & 19 * & (22) * * & 11 * & (23) * * \\ 44 & (41) & 36 & (35) & 34 & (21) \\ 16 & (21) & 22 & (24) & 17 & (22) \\ 5(4) & 12 & (9) & 12 & (12) \\ 7 & (4) & 11 & (12) & 26 & (22)\end{array}$

* Resu1ts from Study 308.

**Results from Study 131 . 


\section{Knowledgeability and Information Sources}

No clear pattern of differences by age is evident from the empirical evidence on awareness of energy-related issues. Awareness that the nation must import oil was slightly greater among those 30-49 than those 25-29, as revealed by a 1977 national survey [218]. In 10 "energy awareness" items employed by a Michigan survey, seven items revealed no age differences (those over 40 were able to respond more accurately on two items; those under 40 , on one) [106].

A 1974 survey in three cities revealed that the under-25 age group was the least knowledgeable about solar energy systems, while age groups over 26 were roughly comparable in knowledge [302]. A 1976 survey in five states, however, revealed that knowledge of solar energy as a source of electricity was inversely and significantly related to age, with those 60 or over displaying slightly to somewhat less knowledge than younger groups. With regard to wind as an electricity source, the results were the opposite: those 60 and over displayed somewhat greater knowledge than those under 30 , with the middle groups falling between these extremes [303].

Those 18 to 24 were somewhat less likely than older age groups to report themselves as following discussions on nuclear energy development in the media (Gallup, 1976). Those 18-29 and 30-49, however, were more likely than those 50 and over to report that they had seen or read articles or advertisements about gasoline mileage [308]. Similarly, those 18-29 were slightly more likely than those 30-49, and notably more likely than those 50 and over, to have seen or heard of EPA/FEA gas mileage figures [144]. There were no differences by age group in correct knowledge of a nuclear power plant within 100 miles of where respondents lived [311].

These findings reveal a lack of any clear relationship between age and knowledge of energy-related issues, which is surprising given the consistent pattern of support for environmental issues by the young revealed in the earlier section of this chapter. One might hypothesize that environmental support derives in part from knowledge about the energy-environment situation, but these limited findings do not provide support for that hypothesis.

An Ohio survey that inquired about exposure to sources of energy information revealed no differences by age [122]. With regard to credibility of information sources several age differences were evident. When a 1974 national survey asked about reliability of information on gas mileage, there were no age differences in citing auto companies (with no more than 27 percent of any age group citing this source); those 18-29 were somewhat more likely to believe government agencies than those 30-49 and markedly more likely than those 50 or over. This last group tended not to know who provided more reliable information ( 28 percent) [308]. The same pattern was revealed when the question was asked again in 1975, with even stronger differences [133]. A 1977 survey in Illinois and a 1975 Ohio survey revealed no differences by age in credibility attributed to a variety of information sources; in the latter survey those 50 and over were more likely than younger groups to report they did not know [108, 122]. The Ohio survey revealed that those in their 20's to 40's were somewhat more likely than those 50 or over to report that they believed that electric companies "mislead the public." A 1977 Denver study revealed that younger groups were more inclined to believe ERDA, a group of university economists, or radio stations than were older groups; for seven other sources there were no age differences [120]. Finally, a 1975 national survey revealed that of eight groups or organizations, the only age differences revealed were that those 18-29 were slightly more likely to believe Ralph Nader than those over 60, and, further, those over 60 were 
slightly to somewhat less inclined than younger groups to disbelieve major oil companies [170]. The above findings do not suggest any clear patterns of differences by age on credibility of information sources.

\section{Solar Energy}

Several surveys analyzed age as a factor in attitudes toward or knowledge of solar energy. A 1976 survey in five states revealed a significant and inverse relationship between age and preference for solar energy as a source of electricity: those 60 and over were the least likely to favor this source although 89 percent still favored solar energy [303]. This survey found no age differences in preference for wind as an electricity source ( 84 to 88 percent of all age groups favored it). A more specific item in this same survey which inquired about the idea of using windmills to generate electric power revealed strongest support among those 30 to 44 , followed by those 60 and over, with least support among the 45 to 59 age group. When this survey asked respondents to name one of a variety of sources that "should be used the most," there was an inverse relationship by age for preference for solar energy, with the youngest group notably more in favor of this source than the oldest, while the latter were somewhat more in favor of hydroelectricity and slightly more in favor of coal than the former. There were no differences by age in preference for wind, nuclear energy, or oil and natural gas.

When a 1977 national survey inquired about the "best long term source of energy" for the year 2000, a similar pattern was found: support for solar energy declined with age, with the youngest (18 to 29) notably more supportive of solar energy than the oldest (60 and over). A similar pattern was found with regard to nuclear energy, with the oldest group slightly less in favor of this source. The opposite pattern held for coal: the oldest group was somewhat more supportive of this source than the youngest. Overall, support for solar energy was stronger than for all other sources (ranging from 53 to 74 percent); nuclear support ranged from 29 to 38 percent; coal, 12 to 24 percent [152]. Similarly, a 1977 Illinois survey found greater support for solar energy among those 18-35 than those over 35. There was little difference in support for nuclear energy, and this source was less preferred than solar energy. In this survey the older group revealed a preference for increased development of natural resources, as compared to the younger group (consistent with the findings reported in the earlier discussion on energy and the environment) [108].

Roper (1979) found that one percent of their January 1979 sample age 18-29 and another one percent of those aged 30-44 owned solar heating systems. Indicating possible solar purchase plans were about a fifth of those in the 18-44 age categories, 16 percent of those 45-59, and five percent of those over 60 .

In one study, no difference by age was found in willingness to buy a solar water heater if it cost the same as other units, or if it cost more than other units. Nor were there age differences in favoring the use of tax incentives to support use of solar energy, nor in factors related to what people found most attractive or least attractive about solar heating and cooling. There were also no differences by age in factors related to the public's expectations of when solar energy would be in general use in their area [302]. This last survey did reveal, however, that those 26 to 41 tended to be most knowledgeable about solar energy systems, and those 25 or under tended to be least knowledgeable. 
A 1976 California survey revealed that those 55 and over tended to give higher estimates of the costs of solar systems than did younger groups; they were also more apt to consider solar energy to be available 10 or more years from now and less apt to think it available now than were younger people; and they were more likely to believe solar systems could only be installed in new houses. Thus, it is not surprising that intent to purchase retrofit systems or systems for new homes declined with age: those 44 or below were significantly more likely to purchase new or retrofit solar systems than were older groups. This study also found greatest support among those under 45 for the idea that solar energy would lower utility bills. Least supportive of this idea were those 45-54 [252]. The pattern here, though it is not conclusive, is that solar energy finds greater support among younger age groups. One hypothesis that might explain this pattern is that it relates to the greater support for environmental quality among this age group, as reported in an earlier discussion in this section. This hypothesis is based on the assumption that solar energy is perceived as environmentally benign, though there is no strong empirical evidence to support this assumption.

\section{Nuelear Energy}

The previous section revealed that all age groups preferred solar to nuclear energy, but that there were important age differences in attitudes toward nuclear energy. Whereas, in general, younger groups tended to be more supportive of solar energy, they were generally less supportive of nuclear energy than were older groups. A 1974 national survey revealed that those 18-29 were slightly less likely than older groups to be "very favorable" to nuclear power plants, while those 18-29 and 30-49 were somewhat more likely than those 50 and over to be "fairly favorable." There were no age differences in those rating themselves "fairly unfavorable," but the youngest group was somewhat more likely than others to be "very unfavorable"; the oldest group had a somewhat greater tendency to have no opinion [308].

A 1975 national survey revealed no age difference in support for building more nuclear power plants in the United States, although the youngest group (18-29) was slightly more likely than those $\mathbf{5 0}$ or over to oppose this option, and the latter group was slightly more likely to be unsure [141]. When this question was repeated in 1976 there was again no difference in support, but the youngest group was slightly more likely than those 30-49 and somewhat more likely than the oldest group to be in opposition. A 1976 (Gallup, 1976) national survey revealed similar findings: those 18-24 were least likely to consider nuclear power plants "extremely important to meeting the future power needs of the nation" (25 percent); all other groups were somewhat more supportive, with greatest support ( 38 percent) among those 30-49. Those 50 and older and 30-49 were slightly less likely than younger groups to find this "somewhat important." There were no age differences in those finding this either "not too important" or "not at all important," although when these categories were combined those 18-24 were slightly more likely than all other groups to report a lack of support. Also, those 50 and older tended to have no opinion slightly more often than did the two youngest groups (Gallup, 1976).

This general pattern of more opposition and less support for nuclear power among the younger respondents is supported by resul ts of surveys that inquired about having nuclear power plants in the vicinity, as opposed to general attitudes toward nuclear power. Although a 1974 national survey found slightly greater support among those 30-44 than 65 or older for building a nuclear plant "in this general area" and no difference by age in opposition, this finding contradicts the findings of most similar questions [311]. Another 1974 national survey found those 18-29 somewhat less likely than older groups to be "very favorable" to a plant "within 20 miles of where you live" and slightly more likely than the 
oldest group to be "very unfavorable." Those 30-49 had a slight tendency to rate themselves either "fairly favorable" or "fairly unfavorable" more of ten than those 50 or over, while the latter group again tended to be slightly more undecided than the youngest [308].

The findings of a 1974 Los Angeles study were that age was positively correlated with support for building nuclear plants in the county [207]. A national survey asked in 1975 and 1976 about support for "having nuclear power as the main source of energy for electric power in your community" [141]. In 1975 there were no age differences in those favoring or opposing this, although those 50 or over had a slightly greater tendency to be unsure than those 30-49. By 1976, however, those 18-29 were slightly less likely to favor and slightly more likely to oppose such a plan than were those 50 and over. Another 1976 national survey showed declining support by age for a plant "within five miles of here," with 58 percent of those 18 to 24 against construction (as opposed to 40 percent of those $30-49$ ), and only 30 percent in favor of construction (as opposed to 49 percent of those 30-49) (Gallup, 1976).

In most surveys, younger groups were less supportive of nuclear power in general and less supportive of having nuclear plants in the vicinity than were older groups. One explanation for this trend may be related to concern about the risk of nuclear power. A 1976 (Gallup, 1976) national survey, which asked if nuclear power plants were safe enough or whether their operations should be cut back until more strict regulations were put into effect, revealed that those 18-24 were least likely to regard them as safe enough (22 percent), while those $30-49$ were most likely (38 percent). Similarly, the youngest group favored cutbacks (51 percent) somewhat more than did those 30-49 or 50 and over (36 and 35 percent) (Gallup, 1976). A 1977 national survey also revealed that the 18-29 age group judged atomic energy plants as slightly less safe than did other groups [148].

Two surveys attempted a more detailed delineation of perceptions of nuclear safety. A 1974 national survey found that those 30-49 were slightly more concerned about radiation discharges than were those 18-29, yet both these groups expressed somewhat more concern with nuclear waste disposal than did the 50 and over group. The oldest group tended to offer no opinion slightly more of ten than the youngest [308]. A 1976 national survey revealed that of nine possible "problems associated with nuclear power plants," waste disposal, radioactive discharge into the atmosphere, mutations and physical abnormalities from radiation, thermal pollution of waters, and "fumes that can pollute the air" were regarded somewhat more of ten as "major" problems by those 18-29 than by older groups. Threat of attempts to sabotage plants, and the possibility of plutonium theft by radical revolutionaries were regarded as major problems by slightly more of those 50 and over than by younger groups [141]. To speculate, this last finding may relate to the greater incidence and fear of crime among older people.

In a 1977 national survey that asked respondents whether the voting public or other groups should make decisions on specific issues associated with nuclear energy, slightly more of those 18-29 than 60 or over preferred to have the voting public decide where plants are built; there were no age differences regarding decisions about how atomic wastes should be disposed of [152].

In general these results are consistent with those reported by Melber et al. (1977) that there is a:

curvilinear relationship between age and support for nuclear power, with the strongest support appearing among middle age respondents.... 
Respondents in the 18 to 25 year age group exceeded the over 65 group in opposition to nuclear power .... . Support for nuclear power appears strong across all age groups. (p. 80)

\section{Energy Conservation}

The subject of energy conservation has received a great deal of attention in survey research, and much of this data has been categorized by age. This section is organized as follows: attitudes toward conservation, domestic conservation behavior, gasoline policies, driving and related behavior, and public transportation.

The surveys employed in this study contained no questions which provided information on attitudes toward conservation in general. A few questions, however, give some insight into age differences on this subject. A 1976 New Hampshire survey, which inquired about "concern about the amount of electricity used in the home," revealed that thase under 25 years of age showed great divergence from other age groups, from the total sample, and, in fact, from any other socioeconomic group in their lack of concern. About 36 percent of this group were "very concerned," compared with 69 percent of those 25-44, and 65 percent of the total sample [253]. It would be inappropriate to generalize from this one finding from a small survey in one state. To speculate, however, it is possible that a lack of concern among the young could relate to a relatively smaller energy use pattern (if they are single or have small families), and may not reflect attitudes toward conservation in general.

A 1977 national survey indicated somewhat greater interest among those under 35 than those 55 or older in membership in energy conservation-oriented organizations, with the middle group falling between these positions [120]. Another study indicated that preteenagers and teenagers viewed adults, and not themselves, as responsible for energy conservation; moreover, they viewed adults as wasteful, lazy, unconcerned, and unwilling to be inconvenienced (Gallup, 1976).

A 1977 Chicago study, which attempted to measure assessment of other people's attitudes toward conservation (by inquiring if the respondent believed that " $a$ lot of drivers would pay $\$ 1.00$ a gallon for gas if they had to"), revealed that agreement was inversely related to age, ranging from 92 percent agreement among those 24 or under to 64 percent among those 65 or older [127]. This finding, again, is difficult to interpret in isolation. A 1977 Denver study revealed no age differences in estimates of utility costs which could be saved through conservation [120]. A 1977 Illinois study revealed that more of those over 35 tended to believe that "people waste the most energy" by unnecessary driving, while more of those 35 or under cited unnecessary heating/airconditioning [108]. These perceptual differences may be a function of age-related lifestyle differences but, again, there is too little information available to conclude anything.

A 1973 national survey revealed no age differences in opinion on whether "controls on the use of energy should be made more strict, less strict, or kept the same." Thirty-nine percent of the total sample favored "more strict"; 49 percent, "about the same." The 50or-older group, however, showed the greatest within-group divergence, with 37 percent favoring "more strict," and 51 percent "about the same" [212]. A 1977 mlinois survey also showed no difference by age in preferred measures for "getting people to conserve energy" (tax incentives, government regulation, higher prices, publicizing energy saving tips) [108]. A Michigan survey revealed no age differences in belief that "the only way to get families to conserve is by imposing government controls" [106]. 
It is possible that individual attitudes toward conservation are shaped in part by one's perception of the efficacy of one's individual efforts in the context of the national effort. Several surveys provided insight into this question. These reveal a pattern of greater skepticism among the young regarding the conservation efforts of both government and business. A Michigan study revealed that 64 percent of those 40 and under and 54 percent of those over 40 agreed that "government officials are not providing any clear directions to help families make decisions about energy use." By an even stronger margin ( 55 percent to 37 percent), those 40 and under believed that "the amounts of energy all American families could save is unimportant compared to the amount of energy that government and industry could save" [106].

A 1975 Ohio survey used a series of questions to measure. respondents' belief in the efficacy of government and industry in their conservation efforts, as well as respondent's attitudes toward motivation of government and industry. When asked if "the electric company is doing as much as it should to help people save on electricity, those in their $20 \mathrm{~s}, 30 \mathrm{~s}$, and $40 \mathrm{~s}$ were slightly more likely to say no than were those 50 and over. Fewer than half of all groups said yes, while about one-third of the oldest group did not know. When asked if "most big companies and institutions are doing anything to save electricity," about one-third of each group said yes; those in their 20s were somewhat more likely to say no (47 percent) than those 50 and over ( 35 percent). Over one-third of the oldest group did not know. Of those who believed these groups were making efforts, those in their 20s were slightly more likely to see their motivation as one of "saving money," as compared to those $\mathbf{5 0}$ and over.

This series of questions was repeated to elicit attitudes about whether and why "most people" made efforts to conserve. Over half of all groups believed most people did make efforts; somewhat more of those in their 20s than did those 50 and over felt they did not, and slightly more of the latter than the former did not know. About one-third of each group saw people's motivations as "saving money" and "easing the shortage." Slightly more of those 50 and over saw motivation as primarily that of easing the shortage (12 percent) than did those in their 20s (five percent). Those in their 20s (61 percent) were somewhat more likely, and those in their $30 \mathrm{~s}$ and $40 \mathrm{~s}$ (52 percent) were slightly more likely, than those over 50 (43 percent) to attribute motivation to saving money.

When asked if they believed electricity was being wasted or used unnecessarily, those 50 and over were slightly more likely to say no than were either of the other groups (38 percent). Twenty percent or fewer of any group saw electricity being wasted either in residential use or in both residential and nonresidential use. Those in their 20s (44 percent), 30 s and 40 s (40 percent) were slightly more likely to see waste in nonresidential use than were those 50 and over (32 percent). Nonresidential electric was the sector seen by all age groups as most wasteful. Of those who believed energy was wasted in this sector, the predominant use cited was "buildings, stadiums lighted when not in use. Too many lights." Here, about one-third of the younger groups cited this waste, slightly more than the oldest group [122].

These findings suggest a pattern of doubt (perhaps cynicism) about the effort of government or industry to conserve, which is more prevalent among the young. These attitudes might be expected to influence individual attitudes and behavior with regard to conservation.

A few studies measured attitudes toward energy conservation with regard to consequences of not conserving. A Michigan study found no age differences in belief that "if we continue our high levels of energy use, future generations will not be able to have 
a level of living like ours" [106]. A 1977 national survey found that there were no age differences in attitudes toward a "more austere life caused by shortages"; 59 percent of all respondents responded that this would be a good development [150].* Finally, there were no age differences in levels of agreement with the position that "I would accept 'possible risks' to health and safety from nuclear power plants, rather than severly restrict my energy use" [106].

Talarzyk and Omura (1975) reported that older people exhibited the least attitudinal resistance to conservation pleas, but that the oldest and youngest age groups made the least change in their activities.

The results of attitudinal surveys on conservation reveal primarily a lack of sufficient data to determine age differences.

There were important differences by age in attitudes toward special electricity rates for certain groups, as revealed in a 1975 Ohio survey [122]. Those in their 30s and 40s were somewhat less supportive of low rates for "people who can't afford it" than were those in their 20s or over 50 . The middle groups were also slightly less supportive than the youngest group of these rates for "people like the elderly." Overall, over 70 percent of all groups supported low rates for the elderly and 32 to 44 percent supported such rates for those who could not afford it. When asked who should pay for the lower rates, the youngest group tended to cite the government or utilities slightly more of ten than did those in their $30 \mathrm{~s}$ and $40 \mathrm{~s}$.

Data on actual conservation behavior, or attitudes toward the potential for engaging in such behavior, yield interesting age-related differences. As noted earlier, one would expect some relationship between actual behavior and attitudes, but such behavior is mediated as well by age-related factors such as income or health.

A 1974 survey reported no age-related differences in behavior as measured by a nineitem "Changed Practice Inventory" (Kilkeary, 1975). A 1974 Los Angeles study also reported no age differences in energy use reduction [207]. Several other studies have revealed age-related differences, however. A 1975 national survey inquired about "effort made by you or your family to save energy" [134]. In this study those 50 and over were far more likely (46 percent) to report "a great deal" of effort than were those 30-39 (39 percent) or 18-29 (27 percent). Fewer than 17 percent of any group reported "little" or "no effort at all." A specific question on use of lights in a 1974 national survey revealed that six percent of those 50 and over kept their house "lit up," compared to 24 percent of those 30-49 and 10 percent of those 18-29. A 1977 national survey revealed that those 50 and older were somewhat more likely than any other group to report "general conserving." In this survey those 25-29 and 30-49 were slightly more likely than those 18-24 to report turning down thermostats. The latter group were slightly more likely than the oldest to report having bought a gas-saving car or to participate in a carpool.

\footnotetext{
*The large percentage responding favorably to this item most likely is due to some extent to the social desirability built into the phrasing of the question. This item read: "On another subject, there's been talk about various kinds of shortages which may mean we will have to live a more austere life than we have grown accustomed to. Some people say this is bad because life will be more difficult without some of the important conveniences of life. Others say there are some good things about it, and that a simpler life would be better. What do you think-that on the whole, doing without some things and living a more austere life would be a bad thing or a good thing?"
} 
Those 25-29 were slightly more likely than the oldest group to walk or bicycle to work. Those 50 and older, as well as those 30-49, were slightly less likely than those 25-29 to report turning off lights to reduce energy use [252].

Carpooling and walking or bicycling to work are most likely related to health and/or employment status, and thus the lower reports for the oldest group probably reflect little about their attitudes toward conservation. A second observation relates to the juxtaposition of several of these results: older people reported having their houses "lit up" much less frequently, reported more general efforts at conservation, but reported less turning off of lights. This seeming inconsistency most likely can be explained by taking into account baseline energy use. A review of the literature, confirmed by an empirical study, showed that the elderly, particularly those who are poor, in general use minimal amounts of energy yet pay higher proportions of their incomes for energyrelated costs (Unseld et al., 1978). Thus, one would expect that this group would report greater efforts to conserve (out of necessity) but would also report fewer changes in behavior, such as turning out lights, since in many eases there is simply no room for additional conserving. This interpretation should help to place some of the following findings on conservation behavior in perspective. A 1975 national survey, for example, found slightly greater willingness to reduce the temperature of hot water among those over 50; this probably indicates a desire to save money [258]. A 1975 Ohio study revealed that slightly fewer of this older group than of the younger age groups reported doing things to save electricity, specifically in cutting down use of lights, most likely a function of the oldest group's minimal use. Similarly, somewhat fewer of those over 50 reported cutting back on heat or air conditioning than did those in their 30 s and $40 \mathrm{~s}$ [122].

A 1976 Lansing, Michigan, study is more difficult to interpret in this context since age was dichotomized at 40 . However, when asked how difficult it would be to reduce electricity use, those over 40 reported substantially more difficulty ( 26 percent) than did the younger group (11 percent) [106]. This study examined energy-conserving behavior and reported changes in that behavior in some detail. More of those over 40 than those under 40 (52 percent to 42 percent) reported turning thermostats down to 60 or below when sleeping, and more (56 to 38 percent) reported not heating some rooms in winter (this last finding may be a function of the household-size to house-size ratio). The older group was also more likely to have heating equipment cleaned or serviced regularly (77 to 60 percent for the younger group). The younger group reported more sharing of equipment such as lawn mowers and power tools (32 to 20 percent for the older group). No age-related differences were found in the practice of the following behaviors: sealing windows or doors, maintaining daytime temperatures at $68^{\circ} \mathrm{F}$ or less, drving clothes on a line, keeping cars in good running order, carpooling, planning errand trips, using buses or trains rather than cars, walking or bicycling, vacationing close to home, or limiting hot water use. There were no age differences in a series of seven food-related conservation behaviors.

Consistent with what has been said previously, this study found that substantially fewer of the older group reported reducing use of electricity (11 to 28 percent), and fewer (36 to 47 percent) reported sealing windows or doors. In two categories in which physical ability seems a determining factor, the younger group reported more changes of behavior: walking or bicycling for short trips (25 to 39 percent) and choosing recreation requiring physical activity rather than motor vehicles ( 27 to 38 percent). In no other categories were there differences in changes in behavior.

This same study reported an overall decrease in energy use in the period 1974-76, but found no age-related differences. Those households headed by people 30-45 had the 
greatest energy consumption, followed by those over 45, and then by those under 30 . Finally, this survey inquired about acceptance of 15 conservation-related policies; of these, only one (year round daylight savings time) showed an age-related difference in acceptability. Those under 40 preferred this policy by 73 percent, compared to 59 percent for those over $\mathbf{4 0 .}$

A 1977 national survey revealed that those over 60 were more likely to say they would install none of the following if given a tax credit: weather stripping, insulation, storm doors/windows, or solar heating equipment. Those 30-34 were slightly more likely than those 18-29 to say they would install storm doors or windows [164].

One important area of energy conservation is transportation. This subject area, including gasoline-pricing policy and public transportation, has received rather extensive treatment in the surveys reviewed. Two national surveys in 1974 and 1975 measured concern with gas mileage of one's car [133, 308]. In both surveys, concern declined with age. The reported incidence of having one's car tuned at least every six months also declined with age [144]. In 1975 those 30-49 were somewhat more likely than those 18-29 to drive a full-size car; those 18-29 were somewhat more likely than those 50 or over to drive a mid-size car; and those 18-29 were somewhat more likely than either other group to drive an economy-size car [258]. A 1977 national survey revealed a similar pattern: those 45-59 were most likely to own (and to plan to buy) a full-size car, followed by those 30-44, 60 or over, and 18-29 [150]. (It should be noted that car size most likely relates in part to family size, a function of age).

A 1974 national survey revealed somewhat greater support among those 18-29 and 30-49 than among the oldest group for a policy of having people who drive cars that get less than 15 miles per gallon pay more for gasoline (but 70 percent or more of all groups supported this). This same survey asked respondents if they favored a tax on gasoline for large cars or an extra purchase tax on these cars. Those 30-49 were slightly more supportive of the gasoline tax than those 18-29. The latter were somewhat more likely than either other group to support the tax on cars, and this policy in general had much greater support than the gasoline tax [308].

A number of surveys inquired about gasoline rationing, of ten in comparison to alternative policies. A somewhat consistent pattern of age differences was found. One 1974 national survey found widespread support (over 75 percent) for the general idea that Americans should conserve gasoline rather than use all they want and pay higher prices. Another 1974 survey posed the policy of increasing gasoline taxes and cutting income taxes, so that those who drive more pay more total taxes. Notably more of those 18-29 and somewhat more of those 30-49 approved this policy, than did the oldest group [139]. A third 1974 survey found somewhat greater opposition among those 30-49 than among other groups to a policy of having those who drive over 200 miles per week pay higher gasoline taxes [308]. This same survey revealed that those 30-49 were slightly more likely to favor a policy of maintaining current prices and rationing; those 18-29 were somewhat more likely to favor "somewhat higher prices and somewhat limited availability." "Substantially higher prices and unlimited availability" was the least favored by all age groups.

In a 1975 national survey this last policy was again least favored. Those over 50 were somewhat more likely than those 18-29 and slightly more likely than those 30-49 to favor maintaining current prices with rationing (over 40 percent of all groups favored this policy). The oldest group was least likely to favor somewhat higher prices and somewhat limited availability [129]. 
Probably because of their driving habits and their general concern with prices mentioned earlier, the oldest group consistently favored rationing or other policies over price increases. In a 1977 national survey, those over 50 were more opposed to price increase than any other group, while those 30-49 most favored this and were somewhat more likely to oppose rationing [220]. Another 1977 survey revealed somewhat higher support for rationing among those 50 and over than all other groups [310]. When this same survey offered a choice of eight methods of reducing gasoline consumption, those over 50 were somewhat more likely than the younger groups to oppose raising prices or taxes; those 30-49 and over 50 were slightly to somewhat more favorable than other groups to eliminating "unnecessary driving." There were no differences by age in support for carpooling, building gas-saving cars, improving public transportation, promoting walking or cycling, or "technological improvements."

A number of studies surveyed real or hypothetical driving habits. A 1975 national survey revealed that those 50 and over were somewhat less likely to report driving their own car to work than were younger groups [149]. A 1977 national survey revealed that the over 50 group were slightly less likely than those $18-24$ or 25-29 to report that they considered it very important to reduce their driving by one-fourth (perhaps reflecting their already limited driving habits). Those 25-29 were slightly more likely to consider it "not at all important" than were other groups [310]. When this survey asked how difficult it would be to make a one-fourth reduction in miles driven, those 30-49 had a slightly greater tendency to report that it would be very difficult than did those 18-24; those over 50 had a slightly greater tendency to report that it would be "not at all difficult" than did those $30-49$.

A 1974 Washington, D.C., study asked if the energy crisis had caused people to "postpone or cancel or shorten trips." Those 25-29 (53 percent) reported the most travel restrictions, followed by those 18-24 (49 percent), 40-49 (47 percent), 30-39 (46 percent), 50-59 (41 percent), 60-64 (32 percent), and 65 or over (22 percent). A 1975 national survey revealed that willingness to "cut out a trip to save money on gas" declined with age [262]. This survey also revealed that, in response to the question, "If gas were rationed so you were allowed only 10 gallons per week, would you still have made that trip?", those 50 and over were slightly more likely than those 30-49 and notably more likely than those 18-29 to report yes, perhaps indicating that this oldest group does the least "unnecessary" driving.

A 1973 national survey revealed that those over 50 and 18-24 were most likely to believe that reducing the speed limit by $10 \mathrm{mph}$ to save gasoline was a good idea. The oldest group was least likely to consider it a poor idea [211]. A 1977 survey showed increasing support by age group for retaining the $55-\mathrm{mph}$ speed limit, with somewhat more of those 50 and over ( 81 percent) favoring it than those 18-24 or 25-29 (70 and 72 percent). In this survey there were no differences by age in reports of whether the new speed limit had changed driving habits (over 60 percent of all groups reported reducing their driving speed). Those 25-29 were more likely than other groups to favor higher speed limits for trucks [217].

When a 1975 national survey inquired if people would use public transportation if it ran twice as of ten, those 18 to 29 were somewhat more likely than older groups to report that they would not [129]; however, when this survey asked if public transportation would be used "if it got you to work 15 minutes faster," this same group was somewhat more likely to report that they would use it. When a 1974 survey inquired about use of a "park and ride system," those 30-49 were somewhat less likely than those over 50 and slightly less likely than those 18-29 to report that they would use it [308]. A 1974 national survey 
asked if people would be forced to carpool if their company reduced its parking by 25 percent; those $\mathbf{5 0}$ and over were notably more likely than the younger groups to report that they would not carpool [137].

A 1977 Chicago survey inquired about several attitudes toward public transportation [127]. Those 45-64 were most likely to agree that "public transportation can be most effective only if it is coordinated over a broad area"; those 24 or under were least likely. Those 65 or over were most likely to believe that people will switch to public transportation if the gasoline problem continues; those 25-44 were least likely.

The idea of using a gasoline tax to subsidize public transportation was supported more by those 25-44 and 45-64, followed by those 65 and over, than by those 24 and under. Those 65 and over were most likely to believe that public transportation users should pay the full cost of service, followed by those $25-44,45-64$, and 24 and under. This finding may be somewhat surprising, especially given the prevalence in many places of reduced fares for the elderly. To speculate, the elderly may have a strongly ingrained negative attitude against policies with the appearance of "welfare" (as revealed in Unseld et al., 1978). It will be recalled that the oldest group also tended to be least supportive of special electric rates for the elderly.

\section{Summary}

There are a wealth of data available by age categories, but the number and variety of age categories employed by the present universe of surveys examined made it difficult to discover clear and consistent patterns of age-related differences.

Although there is some contradictory evidence, it appears that younger age groups were more likely than older ones to report belief in the seriousness of the energy crisis. It also appears that younger age groups were more likely to report a greater belief in the likelihood of future energy shortages.

No clear pattern of age-related differences in attribution of responsibility for the energy crisis was evident in the data surveyed, nor was there a clear pattern regarding the salience of the energy situation by age.

Data on perceived impacts of the energy situation reveal a pattern of greater reported impacts among older, and possibly younger, people.

No consistent age-related patterns were revealed with regard to attribution of responsibility for the energy situation.

A clear pattern and consistent pattern of greater support among the young for protecting the environment was revealed in a number of surveys. This pattern held for items in which energy-environment tradeoffs were posed as well.

No patterns of age-related differences were found for knowledgeability about the energy situation or perceived creditability of information sources.

A pattern of greater support among younger groups for solar energy was revealed in the data analyzed. The opposite pattern held for nuclear energy: younger groups tended to be less supportive than older groups of this energy option although there is some evidence of a curvilinear relationship with greatest support among middle age groups. Older 
groups also tended to be more supportive of development of fossil fuel energy sources than were younger groups.

Attitudinal data on energy conservation are numerous, but do not lend themselves to ease of interpretation; a pattern is not of ten obvious in the data.

There were no obvious patterns of age-related differences in energy conservation behavior, probably owing to the failure of many surveys to take into account baseline energy use.

There appeared to be no age-related differences on a variety of policy options, with the expression that older groups tended to oppose options that would increase consumer costs.

A clear pattern of greater support for gasoline rationing among older groups emerged, particularly when this option was posed against policies that entailed higher prices.

Several of these findings indicate that variables such as income, family size, and occupational status confounded age-related differences in energy attitudes and behavior.

\section{EDUCATION}

Education is one of the primary sociodemographic variables analyzed in the surveys. Aggregating or comparing findings from different surveys is difficult, however, since the educational levels are defined in various ways. The most general and most frequently used categories are those used by Gallup and by Roper-"college," "high school," and "grade school." The categories used by ORC are somewhat more precise-"some college," "high school complete," and "less than high school complete."

Other one-time surveys used very general eategoreis (e.g., high vs. low education) [106] or very detailed categories. One five-region survey [303] used the following: "12 years or less," "12 years and noncollege," "college, no degree," "college, B.A. degree," and "college, advanced degree." A study by Becker Research Corporation [311] used "grade school," "high school incomplete," "high school graduate," "some college," and "college graduate or more."

Because of these different ways of categorizing educational level, overall conclusions from the surveys must be couched in general terms.

\section{Perception of the Energy Situation}

In general, individuals with college education or higher are more likely than others to believe in the energy crisis and to feel it is more serious than those with less education. As shown in Table B-11, a November 1977 Gallup survey [175] found college-educated individuals more likely than other groups to believe the U.S. energy situation is serious.

A two-wave study in Michigan [106] found that the difference by educational level became more marked from 1974 to 1976 . Those with education beyond high school stayed at the 60-percent belief level. Belief by persons with a high school education or less dropped from 46 percent in 1974 to 34 percent in 1976. A 1975 survey in Texas and Arizona found 67 percent of those with graduate or professional degrees, 64 percent with 


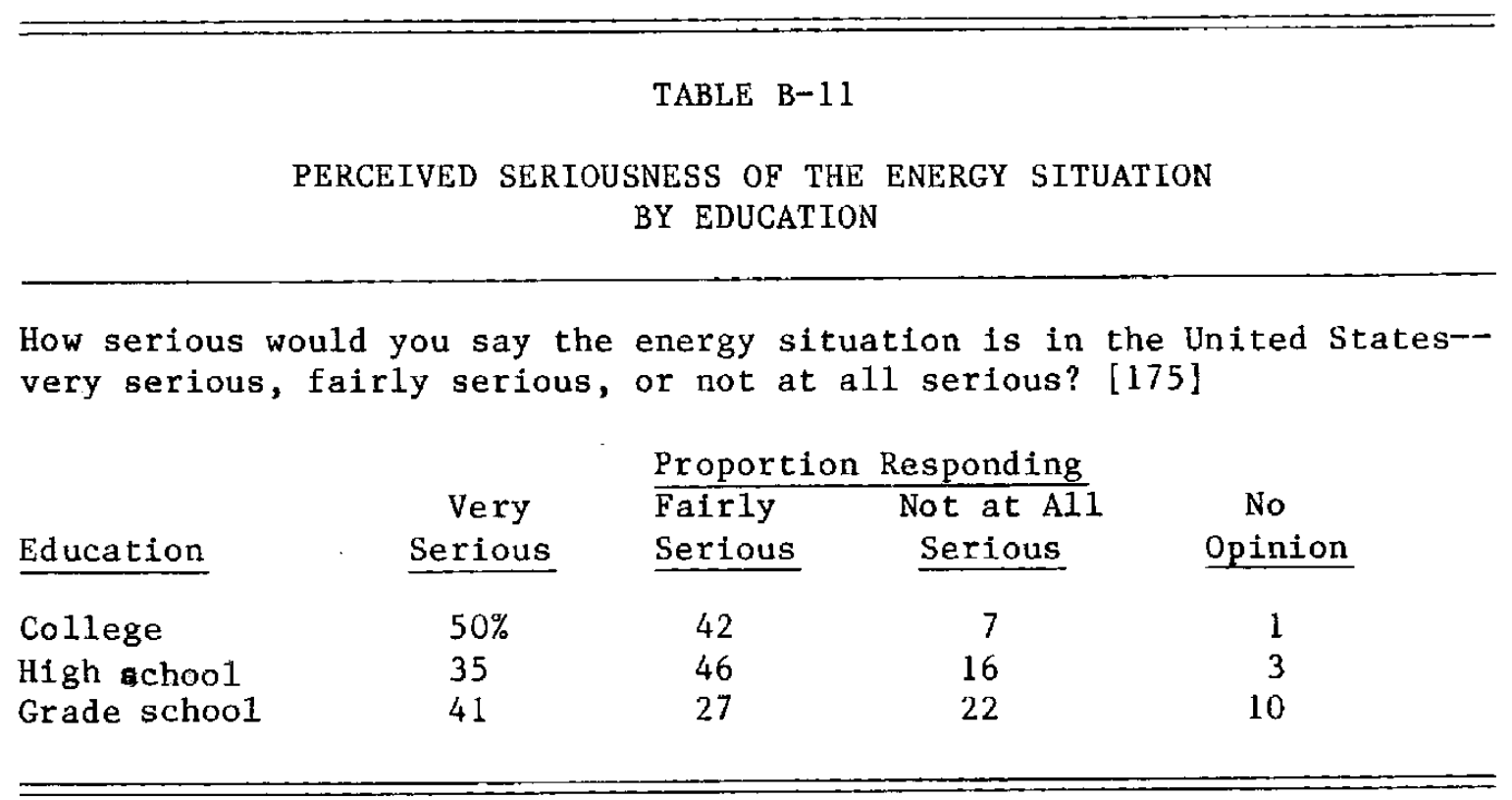


college, 45 percent with high school diplomas and 49 percent with less education expressing belief in the energy problem [181].

Two other regional surveys (in South Carolina and Michigan) also found a relationship between level of education and belief in an energy problem. The 1977 South Carolina survey [117] introduced a possible bias into the results by assuming there were shortages in fuel oil, natural gas, electricity, and gasoline and asking how serious they were. For all four shortage questions, the higher the education level, the more likely that a serious or very serious problem was perceived. In response to the question "Is there an energy problem now ?", the Michigen respondents showed the same pattern [119]. The scores ranged from 52 percent of persons with an elementary education responding yes to 83 percent for those with a graduate degree.

A Roper survey in January 1977 [154] found college-educated individuals to be slightly more concerned about the energy and fuel crisis (34 percent versus 29 percent for high school and 27 percent for grade school). An Opinion Research Corporation (ORC) survey in 1976 [130] asked about the energy situation in a somewhat different way: "How serious would you say the need is to save energy?" Again, those with higher education levels perceived the energy situation as more serious.

Two surveys sought to get an idea of the salience of the energy situation relative to other national problems. An ORC survey in February and March 1975 [134] asked individuals about the perceived importance of the energy shortage, unemployment, and inflation. For all three groups, unemployment was most important, inflation next, and the energy shortage ranked in third place (with less than 20 percent). The higher education levels were slightly more concerned about the energy shortage (some college, 17 percent; high school complete, 13 percent; less than high school complete, six percent).

A survey in 1977 in Denver [120] asked individuals to rank-order 12 issues according to priority and found that the higher the education level, the higher the ranking for the energy problem (11th grade or less, 6.2; high school graduate and some college, 5.0; college grads and post-grad, 4.5). (The highest possible ranking was 1.0. . $^{*}$

A number of studies asked specifically about the possibility of future shortages. A survey in Ohio in 1975 [122] asked individuals for responses to the following items: (1) whether there was an electricity shortage at that time, (2) whether there would be a future electricity shortage, and (3) whether they felt the electric companies were saying there was a shortage so people would not oppose higher rates. While people at higher education levels were somewhat more likely to agree that there was an existing energy shortage than were lower education groups (18 versus eight percent), approximately three-quarters of all groups said there was not a shortage. Those with higher levels of education were more likely to agree on a future electricity shortage, while the less educated groups were more uncertain. Since the higher education groups tended to believe more in the energy crisis and in its seriousness, it is not surprising that in one item they were also less likely to feel that the shortage is only a ruse to cover higher utility rates (see Table B-12).

*This relationship between education and belief in or concern about an energy crisis is supported by three studies described and abstracted in Lopreato and Meriweather (1976). The studies are those by Cunningham and Lopreato in 1975-76, Stearns in 1975, and Zuiches in 1975. 
TABLE B-12

\section{SHORTAGE PERCEIVED AS EXCUSE FOR HIGHER UTILITY RATES BY EDUCATION*}

\begin{tabular}{lccc} 
& \multicolumn{3}{c}{ Proportion Responding } \\
Education & Yes, Feel & Don't Know/ \\
Less than H.S. graduate & $\frac{\text { That Way }}{41 \%}$ & $\frac{\text { No }}{39}$ & $\frac{20 \text { Dends }}{20}$ \\
H.S. graduate & 42 & 46 & 13 \\
More than H.S. graduate & 38 & 53 & 9 \\
*Study 122 & & & \\
\hline
\end{tabular}


A Michigan survey in 1976 [106] found that those with lower educational levels were more likely to agree with the statement: "The 'energy crisis' was a 'put on' in order to raise prices of fuels" (70 percent of the low education group versus 50 percent of the high education group).

A 10-wave national survey in 1973 to 1974 [142] showed a relationship between level of education and expected trouble getting gasoline, with the better educated being more pessimistic. An ORC survey in 1975 [129] found that this pessimism did not carry over to expectations that oil exporting countries would again cut off oil to the United States within the following 12 months. High school graduates were the most likely to feel such a cutoff was very or fairly likely (61 percent), followed by those with some college (55 percent), and those with less than high school completed (52 percent).

In an ORC study in August through September 1974 [137], more educated individuals were somewhat less likely to think that the United States would run out of natural gas in the next 50 years (71 percent of those with some college felt it was not very likely versus 62 percent of the high school graduates and 57 of those with less than high school).

Roper surveys in May 1974 [172], July 1977 [150], and April through May 1978 (Roper, $1978 \mathrm{c}$ ) asked about expected fuel shortages. In 1974 more than half of all education groups expected the gasoline shortage to continue through the summer, with a slight tendency for those with more education to be more pessimistic (college, 66 percent; high school, 58 percent; grade school, 51 percent). Thirty-four percent of those with a college education felt that there was a real oil shortage and it would get worse (versus 16 percent of the high school group and 14 percent of the grade school group). A large percentage of all groups, however, tended to think the shortage was not real, but only contrived (college, 43 percent; high school, 58 percent; grade school, 54 percent). The 1977 survey found no differences between educational levels on the chances in the next year of another severe energy shortage. About two-thirds or more of each group felt such a shortage was likely.

By 1978 the number of people believing that there was a real shortage had increased 13 percent for the college and high school groups and seven percent for the grade school group, with a continued positive relationship between education and belief (college, 47 percent; high school, 29 percent; grade school, 21 percent). The percent of the college and high school groups still believing it was a contrived shortage decreased nine and 11 percent respectively (college, 34 percent; high school, 47 percent). The grade school group stayed constant (54 to 55 percent).

Perceived responsibility for the energy crisis was analyzed by education level in only two studies. A Gallup survey in December 1973 [213] asked individuals, "Who or what do you think is responsible for the energy crisis?" No significant differences were found by level of education. A Roper survey in June 1977 [151] found more highly educated persons somewhat more likely than others to place blame on the Administration, the Congress, electric power companies, oil companies, environmentalists, American consumers, and the Arab countries. They were less likely than others to blame Israel.

Two ORC surveys in 1974 asked how well the federal government and the business community were carrying out their responsibility of protecting the U.S. supplies of natural resources. The August to September wave [137] found no difference between educational levels on evaluation of the federal government's performance (more than 85 percent of all groups felt the performance was average or poor). The business community's performance was also seen as average or poor by 80 percent or more of all 
the groups, with the higher education levels being slightly more negative about business performance (less than high school complete, 83 percent average or poor; high school complete, 92 percent; some college, 94 percent).

The September through October wave [139] found that the evaluation of the business community had improved slightly for those with up to a high school diploma. The other two groups stayed about the same (less than high school complete, 80 percent average or poor; high school complete, 83 percent; some college, 90 percent).

In summary, the findings indicate that higher levels of educational attainment correlate positively with belief in the reality and seriousness of the energy situation, and with pessimism about future shortages. The findings on educational differences concerning blame or responsibility for the energy situation were mixed, with little or no difference in most cases.

\section{Perceived Impacts of the Energy Situation}

The impacts of energy shortages may not necessarily be seen as negative. In a July 1977 survey [150] one half or more of all education groups felt that the more austere life caused by an energy shortage would be a good thing. The response was positively related to educational level (college, 66 percent; high school, 56 percent; grade school, 50 percent).

For many people, the energy situation may be most apparent in price rises for energy and for other items requiring energy to produce. The August-September 1974 ORC survey [137] asked individuals the following question: "Aside from gasoline and heating oil, are there any other things you buy whose price has gone up because of the energy shortage?" The connection between prices and an energy shortage is not apparent in the results (12 percent or less said "electricity"). The question was repeated in a November through December 1974 wave [308] with no differences by educational level, (10 percent or less said "electricity"). The survey also asked individuals what impact they felt the price increases for oil and gasoline have had on the rate of inflation. Level of education was slightly and positively related to the perception that the price increases had had a great deal or a fair amount of impact (less than high school, 82 percent; high school complete, 91 percent; some college, 93 percent). The same relationship held for perceptions that the price of gasoline relative to other things had gone up a great deal or a fair amount (less than high school, 85 percent; high school complete, 88 percent; some college, 93 percent).

Another survey in Michigan in May 1976 [106] also checked perceptions of energy price increases. Persons with a high school education or less were more likely to see gasoline, heating fuel, and electricity price increases as a great problem (gasoline, 49 percent of the high education group versus 66 percent of the low education group; heating fuel, 56 percent versus 68 percent; electricity, 53 percent versus 65 percent). These findings indicate no clear difference by education on perceived impacts of the energy situation.

\section{Policy Preferences}

A Roper survey in June 1977 found more than 80 percent of all groups felt that a major effort should be placed on developing new energy sources and energy conservation measures [151]. The groups did differ, however, on whether they wanted their 
Congressman or Senator to give major attention to developing a national energy policy (college, 81 percent; high school, 73 percent; grade school, 61 percent). By March 1978, the desire for Congress to give major attention to the development of a national energy policy had increased for all groups (college, 85 percent; high school, 74 percent; grade school, 71 percent) [180].

Four ORC surveys in 1974 and 1975 asked the following question on price and supply tradeoffs: "A number of ways have been suggested for dealing with energy shortages. Assuming that energy shortages became very severe, which of the following would you prefer: (1) substantially higher prices for gasoline, but unlimited availability; (2) maintaining prices at the current level and rationing; (3) or somewhat higher prices for gasoline and somewhat limited availability? (see Table B-13). The October and December 1974 surveys [132, 308] found that all groups were most likely to choose the maintained prices with rationing with the high school graduates slightly more favorable than the other groups in the December survey. For the third choice, both surveys found about onethird of those with some college indicated a preference versus about one-quarter or less of the other groups. In the December through January wave, the educational levels showed a marked difference in preferences [131]. The educational level was negatively related to a preference for the alternative of maintenance of prices and rationing and positively related to the alternative of somewhat higher prices and limited supply. In the later 1975 survey [129] these same two relationships held, although the first was not as strong.

Two surveys in 1976 explored acceptance of a variety of energy policy options. A national survey by Harris found educational level positively related to favoring the speedup of solar energy development [141]. There were negative relationships between educational level and a number of other policies, however. These included: speeded-up construction of the Alaska pipeline, increased oil shale production in the western states; offshore oil drilling in the Atlantic, Pacific, and Gulf coasts; a speedup of nuclear power plant construction; increased strip mining of coal; and a slowdown in air and water cleanup efforts. A regional survey in Michigan found a moderate to strong relationship between education level and acceptance of all but two of the energy conservation policies presented (see Table B-14) [106].

A Gallup survey in November and December 1973 asked individuals whether they felt controls on the use of gasoline, oil, and electricity should be more strict, less strict, or about the same [212]. Those with a college education tended to feel that the controls should be stricter, while those with a high school or grade school education preferred that the controls remain about the same as they were.

Three ORC surveys in 1974 and 1975 explored attitudes about the use of tax policies to encourage a reduction in driving. In September and October 1974 educational level was found to be positively related to a preference for keeping gasoline taxes the same or increasing them, and negatively related to a preference for lower taxes (some college, 62 percent for same or increased versus 34 percent lowered; high school complete, 48 percent versus 49 percent; less than high school complete, 34 percent versus 64 percent) [139].

The two other ORC surveys explored attitudes about a suggested policy to reduce income taxes and increase gasoline taxes in order to reduce driving. In the December/January wave, all groups opposed the suggested tax change [131]. Surprisingly, given the preference for conservation-minded policies expressed in other surveys, the more highly educated individuals were more opposed than were those with less than a high school education. Only a month later, however, an ORC survey did not find this 


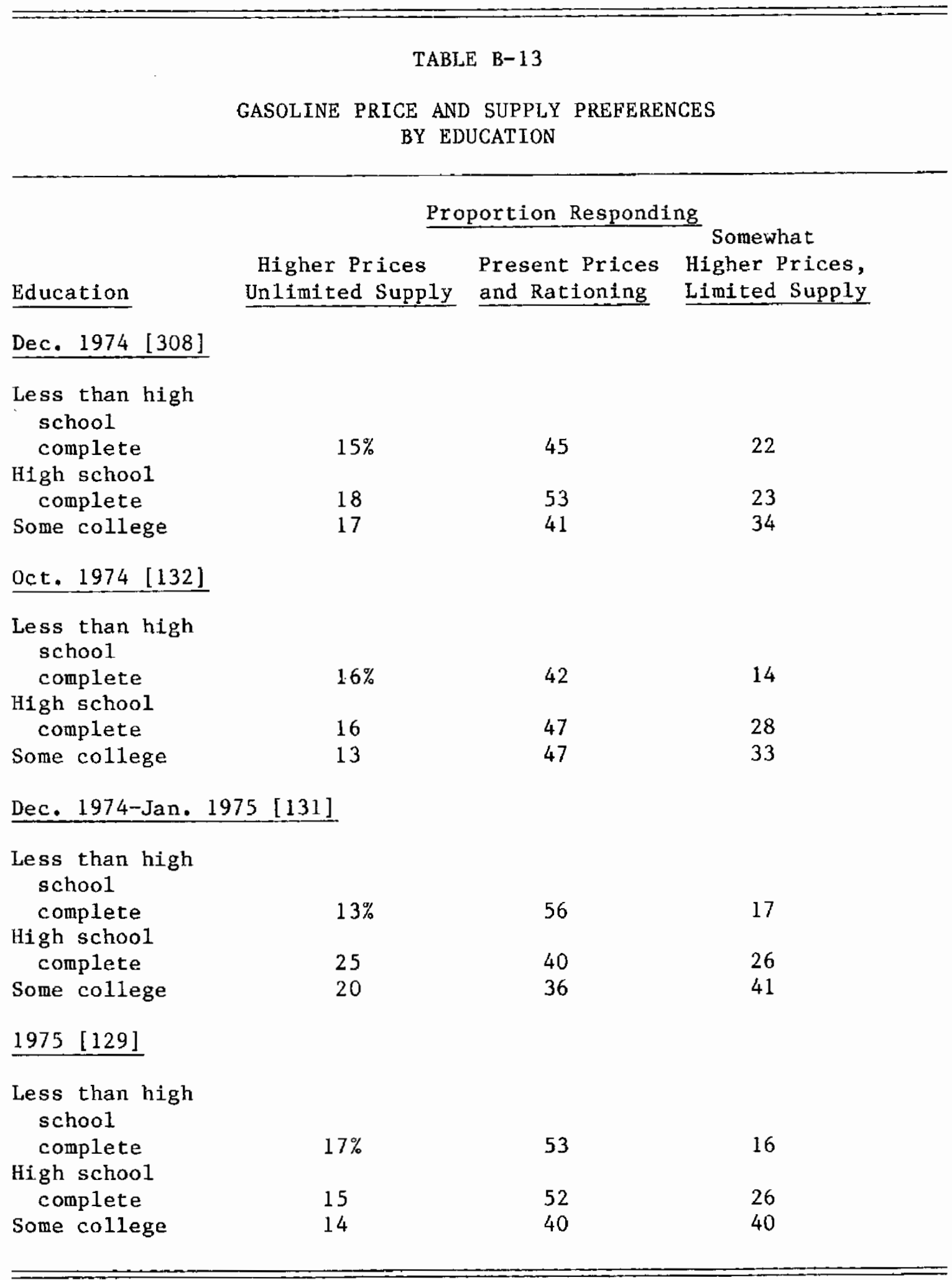


TABLE B-14

ACCEPTANCE OF ENERGY-RELATED POLICIES

BY EDUCATION*

Policy

Gasoline rationing

Year-round daylight savings time

Tax deductions for only one car

Tax deductions for insulating older homes

Tax deductions for families with only two children

Tax deductions for driving small cars

Increased taxes for more than two children

Tax deductions for apartment living

Increased taxes for driving large cars

Required energy labeling of appliances

Added federal tax on gasoline

Peak load pricing of electricity

Inverted rate structure for electricity

Government help for utility bills of poor and elderly

Tax-supported mass transportation
Proportion Responding

Education

High Low

$39 \%$

69

63

86

21

$65 * *$

56

78

$53 \quad 45$

$59 \quad 35$

$23 \quad 15$

$37 \quad 19$

$43 \quad 21$

$89-75$

$19 \quad 5$

$44 \quad 16$

$47 \quad 26$

$68 \quad 65 * *$

$68 \quad 42$

\footnotetext{
*Study 106

**Difference is in the right direction but too small to be meaningful.
} 
relationship [133]. Those who had not completed high school had stayed about the same, but the more educated groups had shif ted to a more favorable view of the tax change (see Table B-15).

A survey in Ohio in 1975 asked about special electric rates for the poor and elderly [122]. The higher the education level, the less likely was this considered to be a good idea. For the poor, about half of the less-than-high-school-graduates liked the idea versus about one-third of the other groups. For the elderly, 83 percent of the less educated liked the idea versus about three-quarters of the other groups. There were no differences between educational groups as to who should make up the difference if lower rates were charged the poor and elderly.

Over the years covered by the surveys in this review, questions were asked about the performance of Presidents Ford and Carter and about their proposals or programs. An ORC survey in December 1974 through January 1975 found educational level negatively related to satisfaction with the steps President Ford had taken to help relieve the energy shortage [131]. Forty-seven percent of those with less than a high school degree were not very satisfied, as compared to 53 percent of the high school graduates and 63 percent of those with some college.

A Roper survey in January 1974 found slight differences between educational groups on the sufficiency of steps taken to deal with the energy crisis [174]. Slightly more than half of each group felt that more drastic steps were needed. However, 35 percent of the college group and 37 percent of the high school group felt the measures were sufficient, as compared to 28 percent of the grade school group.

An ORC survey in February through March 1975 found educational level positively related to favoring President Ford's proposal to increase the oil import tax as a way of reducing U.S. dependence on foreign oil and decreasing consumption (28 percent of those with less than a high school education, 41 percent of the high school graduates, and 47 percent of those with some college) [134]. The difference between the groups is made up not by increased opposition on the part of the less educated, but by a larger number of people with no opinion in the lowest education group ( 76 percent) than in the other groups (seven to nine percent).

Three ORC surveys between November 1974 and February 1975 reminded the respondent of President Ford's urging that the United States be completely self-sufficient in energy supplies and asked whether this was possible. In the first survey there was no difference between groups, with slightly less than two-thirds of each group responding "yes" [308]. There was, however, a tendency for there to be more "no's" as the educational level increased $(23,30$, and 32 percent, respectively). The second survey [131] found that the higher the educational level, the less likely was the individual to believe that selfsufficiency was possible. The third survey found a similar, though less strong relationship (see Table B-16) [133].

A Gallup survey in January 1975 found that educational level was strongly related to feelings that the United States should try to reduce the amount of oil bought from foreign nations (79 percent of those with a college education, 76 percent of those with a high school education, and 62 percent with a grade school education) [214].

A Roper survey in March 1978 found those with more education somewhat more likely to think that the United States would need foreign oil during the next five years [180]. Fifty-four percent of the college group said the United States could not get along without foreign oil during the next five years versus 49 percent of the high school group and 38 percent of the grade school group. 
TABLE B-15

RESPONSE TO A SUGGESTED POLICY TO REDUCE INCOME TAX AND INCREASE GASOLINE TAXES

BY EDUCATION

Some people have suggested increasing gas taxes and cutting income taxes in such a way that the total taxes the whole population paid would remain the same. If this were done, people who drove a lot would pay more in total taxes, and people who didn't drive a lot would pay less total taxes. Do you favor or oppose this idea?

Proportion Indicating

December-January [131]
No

Education

$\begin{array}{llllll}34 \% & 52 & 14 & 34 & 49 & 17\end{array}$

Less than high school complet

High school complete

Some college

$\begin{array}{ll}29 & 62 \\ 31 & 64\end{array}$

62
64

9

38

43

55

49

7

8 
TABLE B-16

BELIEF THAT U.S. ENERGY SELF-SUFFICIENCY IS POSSIBLE BY EDUCATION

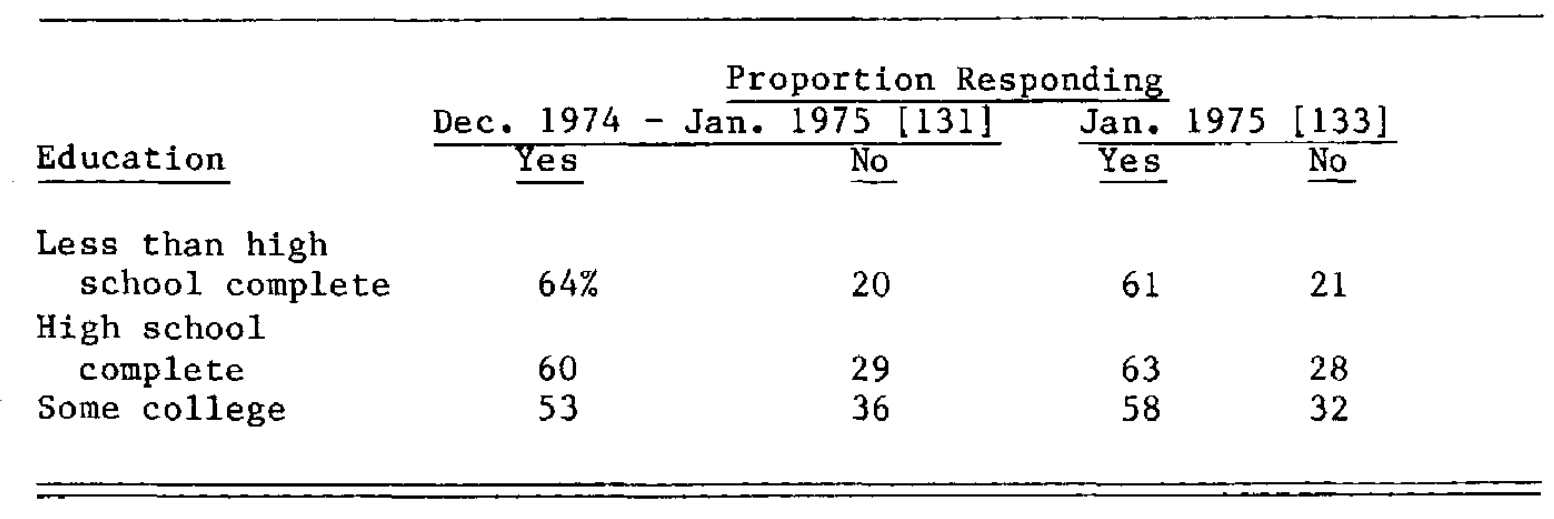


In February and in August of 1977, Gallup surveys asked individuals whether they approved or disapproved of President Carter's handling of the energy situation [217, 3091. In February all groups were about equally likely to approve (60 to 64 percent). Differences between college, high school, and grade school education groups showed in level of disapproval: the more educated were more likely to disapprove $(23,17$, and eight percent, respectively) and those with lower education levels were more likely not to express an opinion (17,22, and 28 percent respectively). The level of approval dropped markedly by August, so that the approval and disapproval categories were fairly balanced for the groups. Those with a college education were somewhat more likely to express approval than the high school and grade school groups (49, 43, and 39 percent) and those with a grade school education were still more likely than others not to express an opinion (13, 17, and 25 percent for the groups). By March 1978, a Roper survey found the more educated groups more likely to disapprove of Carter's handling of the energy crisis [180].

A Gallup survey in April through May 1977 found those with more education more favorable in their overall reaction to Carter's energy plan (college, 63 percent; high school, 54 percent; grade school, 48 percent) [218]. Those with more education were also less likely to say that the energy program called for too many sacrifices (26 percent versus 37-39 percent for other groups) and more likely to say there were not enough sacrifices asked (37 percent versus 23 and 11 percent). A Roper survey in November 1977 obtained similar results [147].

A survey of five regions in the spring and summer of 1975 asked individuals which energy source "should be used the most" [303]. Solar energy and hydroelectric were the first two choices for all education groups. Those with less than a high school degree favored hydroelectric over solar energy (32 to 21 percent) while the high school graduates and those with some college favored solar energy over hydroelectric ( 38 to 26 percent, and 46 to 22 percent). Three policies were presented which included various mixes of production and importation of fuels: (1) maximizing U.S. production while importing the remainder, (2) maximizing U.S. production while limiting use, and (3) rationing U.S. energy use and importing none. No differences were found for the first alternative (three-quarters or more of all groups approved). For the second alternative, those with lower educational levels were more approving with 82 percent of those with some high school or less. The third policy met with 33 percent approval from those with some high school or less, and 22 percent approval from the other groups. When all three policies were compared, no differences by educational level were found, with over half of all groups preferring the maximum production with limited usage alternative.

A Roper survey in March 1977 asked individuals which energy sources offered the best potential for the year 2000 [152]. Solar energy was the first choice for all groups (college, 77 percent; high school, 67 percent; grade school, 40 percent); nuclear energy was the second choice for the college and high school groups (40 and 36 percent); coal was the second choice for the grade school group ( 23 percent).

The surveys differed too much in their questions to determine clear policy preferences in many cases. Those with more education were more likely to be concerned about developing a national energy policy, less likely to believe that the United States could be self-sufficient in energy, and more favorable toward the development of solar energy. Those with some college were consistently more likely than other groups to prefer the policy alternative of higher prices and limited supply for gasoline; the less educated were more likely to favor holding the price of gasoline at current levels and rationing. 


\section{Energy and Environment}

ORC surveys in November through December 1974 and in December 1974 through January 1975 explored the perception that increased U.S. energy production would damage the environment $[1-31,308]$. In the earlier study, those completing high school felt there would be more chance of a great deal or a fair amount of environmental damage than did either the less-than-high-school-degree or some-college groups (63, 53, and 52 percent, respectively). In the second survey, the less-than-high-school-degree group perceived less possible damage than did either of the other two groups, which were equal (47 percent versus 62 percent for high school graduates and some college).

The November-December survey then asked which of a number of environmental problems would be most serious if the United States tried to be self-sufficient. The first three choices (in order) were air pollution, strip mining, and water pollution. There was little difference between high school graduates and those with some college in designating the seriousness of these problems, Slightly fewer of those at lower educational levels defined them as problems (see Table B-17).

When asked whether power plants and oil refineries cause air pollution, 74 percent of those with less than a high school education said yes as compared to 82 percent of the high school graduates and 87 percent of those with some college. Individuals who said yes were then asked whether plants and refineries should be built where there is already air pollution or in areas without air pollution. High school graduates were strongest in their feelings that they should be built in polluted areas (37 percent versus 21 percent for the less-than-high-school-diploma group, and 30 percent for those with some college).

A Roper survey in September 1977 found the college group evenly split between favoring development of adequate energy sources and protection of the environment. In contrast, the high school and grade school groups were much stronger in their support for adequate energy than for protection of the environment [148]. All groups were likely to feel that environmental regulations had struck about the right balance, with that feeling stronger as educational level increased.

Questions about relaxing pollution standards to conserve fuels in short supply were asked in two surveys. An ORC study in February through March 1975 found high school graduates slightly more favorable than other groups toward President Ford's proposal to grant the auto industry a five-year delay on stricter pollution regulations in order to improve gas mileage [134]. However, 59 to 66 percent of all groups favored the proposal. A Gallup survey in April through May 1977 found no differences by educational level in feelings that industry should convert from oil and natural gas to coal whenever possible [218].

The issue of strip mining is one of the clearest cases of energy versus environment for many people. Two ORC surveys in 1974 and 1975 asked about tradeoffs between strip mining regulations and lower coal (and thereby electricity) prices. Both surveys found a strong positive relationship between level of education and preference for regulating strip mining (see Table B-18) [131, 128].

Two surveys brought the tradeoff to the personal level of willingness to pay for less pollution. A Michigan survey in 1976 found 76 percent of the high education group and 56 percent of the low education group agreeing with the statement: "Stopping pollution is more important than lower prices for products" [106]. The same positive relationship between level of education and willingness to pay for lowered pollution levels was found 
TABLE $B-17$

PERCEIVED ENVIRONMENTAL PROBLEMS IF THE UNITED STATES

ATTEMPTS ENERGY SELF-SUFFICIENCY

BY EDUCATION

Which one of these environmental problems do you think would be most serious if the United States tries to be self-sufficient--strip mining, oil spills, nuclear wastes, radio-activity, air pollution, or water pollution? (Asked only of those who say there will be at least a 11ttle environmental damage if the United States produces more energy.) [308]

Education

Less than high school complete High school complete

Some college
Proportion Indicating

Air Strip Water

Pollution Mining Pollution

$13 \%$

26

14

22

17
9

19 
TABLE B-18

PREFERENCES FOR STRIP-MINING REGULATIONS VERSUS CHEAP COAL BY EDUCATION

\begin{tabular}{|c|c|c|c|c|}
\hline Education & $\begin{array}{c}\text { Lec. } 1974- \\
\text { Strip } \\
\text { Mining } \\
\text { Regulations }\end{array}$ & $\begin{array}{l}\text { Proportion } \\
\text { Jan. } 1975[131] \\
\text { Cheapest } \\
\text { Coal } \\
\text { PrIce } \\
\end{array}$ & $\begin{array}{l}\frac{\text { ndicating }}{\text { June } 1} \\
\text { Strip } \\
\text { Mining } \\
\text { Regulations } \\
\end{array}$ & $\begin{array}{l}\frac{975[128]}{} \\
\text { Lower Coal and } \\
\text { Electricity } \\
\text { Prices } \\
\end{array}$ \\
\hline $\begin{array}{l}\text { Less than } \\
\text { high school } \\
\text { complete }\end{array}$ & $26 \%$ & 51 & 28 & 53 \\
\hline $\begin{array}{l}\text { High school } \\
\text { complete } \\
\text { Some college }\end{array}$ & $\begin{array}{l}44 \\
52\end{array}$ & $\begin{array}{l}33 \\
28\end{array}$ & $\begin{array}{l}47 \\
58\end{array}$ & $\begin{array}{l}35 \\
32\end{array}$ \\
\hline
\end{tabular}


levels was found by a five-region survey in 1976 [303]. When asked if the country should use pollution-free sources of energy even if it meant a 10 percent increase in the cost of electricity, 56 percent of those with some high school or less, 72 percent of the high school graduates and 82 percent of those with some college or more agreed.

\section{Knowledgeability and Credibility of Information Sources}

In general, the surveys found that more highly educated individuals were more knowledgeable about the energy situation. According to ORC surveys in 1974 and 1975 $[139,256]$, those with more education were much more likely to be aware that a federal government agency or department responsible for energy policy and practices had been established (see Table B-19).

Awareness of the amount of oil imported by the United States was explored by a Gallup survey in April through May 1977 [218]. A positive relationship was found between level of education and the response that the United States must import oil from other countries to meet its needs (college, 62 percent; high school, 51 percent; grade school, 39 percent). It is surprising, however, that 27 percent of those with a college education did not seem to be aware that the United States imports oil. When asked what percent of the oil used in the United States is imported, all groups responded with similar patterns of estimates. However, 55 percent of those with grade school education did not respond, compared to one-fifth of those with a college education not responding.

Awareness of alternative energy sources (i.e., wind and solar energy) was measured by a survey in five regions in spring and summer, 1976 [303]. Knowledge of wind and solar energy as sources of electricity was found to be significantly and positively related to the level of education $(\mathrm{p} \leq .01)$ (see Table B-20).

A Michigan study in 1976 [106] checked the accuracy and awareness of energy-related information. Those with higher education answered the following items correctly more of ten than did those with less education:

- Most heat lost? Ceiling. (79 percent versus 66 percent)

- Protein requiring most energy to produce? Beef. (81 percent versus 65 percent)

- Housing type using least energy? Apartment. (74 percent versus 50 percent)

- Amount imported oil? More than 1973-74. (51 percent versus 36 percent)

- Fuel in shortest supply? Natural gas. (5l percent versus 39 percent)

No differences were found for the other items:

- Uses most household energy? Hot water heater. (56 percent versus 57 percent)

- Beverage containers that waste most energy? Throwaway aluminum. (25 percent versus 23 percent)

- Cooking method using least energy? Microwave. (62 percent versus 63 percent) 


\begin{tabular}{|c|c|c|}
\hline \multicolumn{3}{|c|}{$\begin{array}{l}\text { TABLE B-19 } \\
\text { AWARENESS OF AN ENERGY AGENCY } \\
\text { BY EDUCATION }\end{array}$} \\
\hline \multicolumn{3}{|c|}{$\begin{array}{l}\text { Has the federal government established some type of agency or depa } \\
\text { to be responsible for energy policy practices? } \\
\text { Proportion Indicating }\end{array}$} \\
\hline $\begin{array}{l}\text { Less than high school complete } \\
\text { High school complete } \\
\text { Some college }\end{array}$ & $\begin{array}{l}33 \% \text { yes } \\
27 \\
65\end{array}$ & $\begin{array}{r}6 \\
24 \\
46\end{array}$ \\
\hline
\end{tabular}




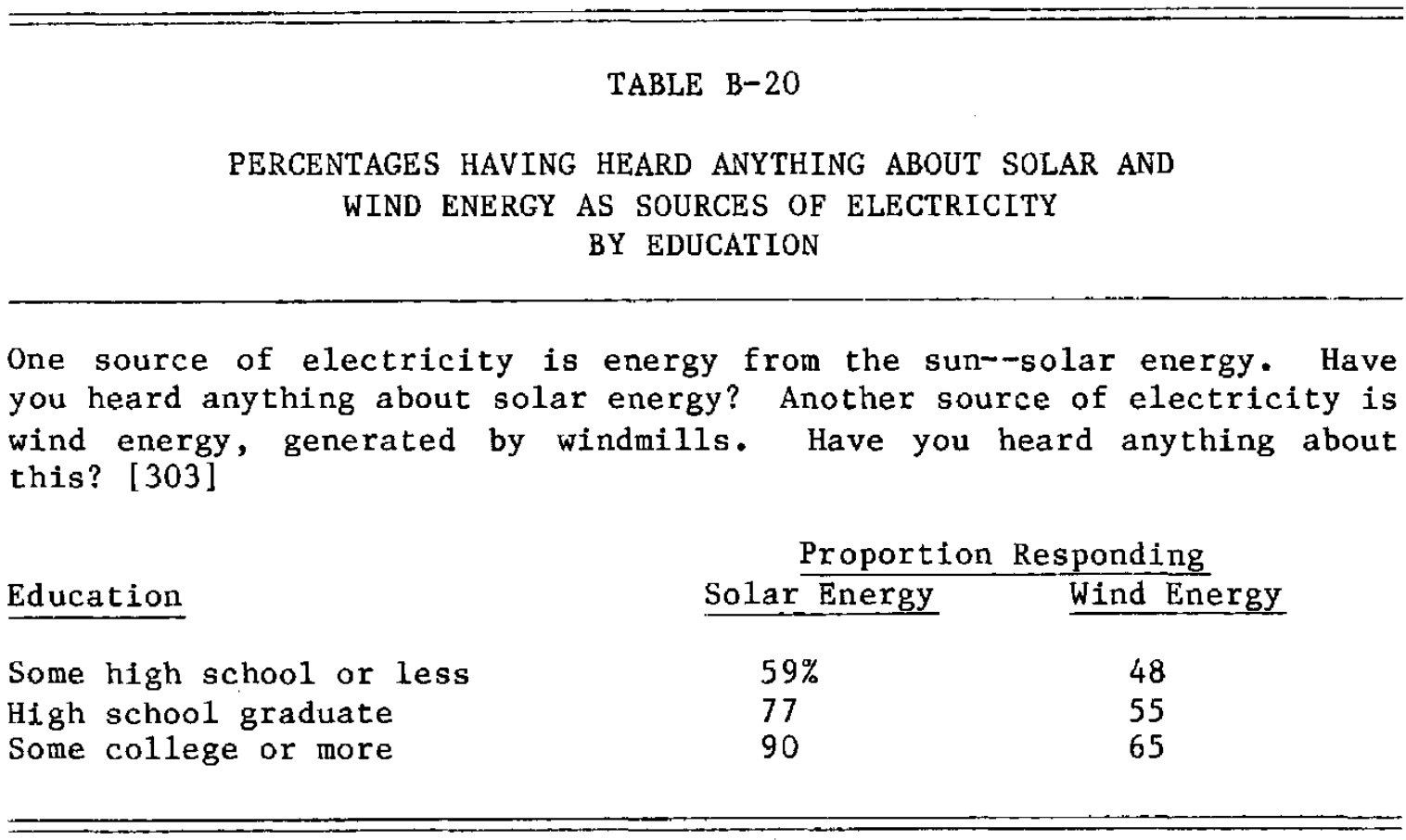


- Cross country travel method using least energy? Bus. (28 percent of both groups)

A 1977 survey in Denver asked individuals to rank 10 household items on the amount of energy used $(1=$ high, $10=$ low) [120]. The only items on which there were differences were central air conditioning, water heater, and color television. Those with high education ranked the first two items as using less energy than did those with low education, but ranked the color television as using more energy.

The study also checked knowledge of various energy terms. As indicated in Table B-21, those with high education were more of ten correct on all items but "energy efficiency rating (EER)" and "degree day" (the difference on those items was too small to be significant).

A 1975 survey in Ohio checked perceptions of the amount of and reason for an increase in the electric rate [122]. There were no differences between groups in estimating the amount of increase, except that the less educated tended more of ten to say they did not know. Those with more than a high school education tended more of ten to give wages and labor costs, price of fuels, and cost of new plants and equipment as reasons for the rate increase.

Awareness of the EPA mileage figures was found to be positively related to education level in a survey by Abt Associates in 1976 and an ORC survey in November and December $1975[109,144]$. In the Abt survey, 60 percent of those with more than a high school education and 39 percent of those with a high school education or less were aware of the EPA figures. The ORC survey found that 74 percent of those with some college, 58 percent of the high school graduates, and 40 percent of those not completing high school had seen or heard of the EPA/FEA mileage figures.

The general pattern revealed in the above findings is for knowledge of energy issues to increase with education.

The credibility of information sources was explored in a number of surveys. A survey in Michigan in 1976 found trust in energy information sources low at all educational levels (less than 15 percent for any source) [119]. Television was considered a more trustworthy source than national magazines and independent research by persons with less than a college degree. Those with a graduate school education preferred national magazines and independent research.

The 1975 Denver survey found no differences in perceived reliability of information sources except for newspapers, where those with less than a high school diploma were less likely to think this source was reliable [122].

A Michigan survey in 1976 found no difference by educational level regarding the statement that government officials were not providing any clear directions to help families make decisions about energy use [106].

An ORC survey in January 1975 asked who provided the more reliable information on gas mileage, including as choices the auto companies, government agencies such as the Federal Energy Administration or the Environmental Protection Agency, and other sources [133]. All three groups were most trusting of the federal agencies, the percent increasing with educational level (less than high school complete, 33 percent; high school graduate, 54 percent; some college, 60 percent). Auto companies were seen more positively by less educated groups $(27,29$, and 15 percent). 


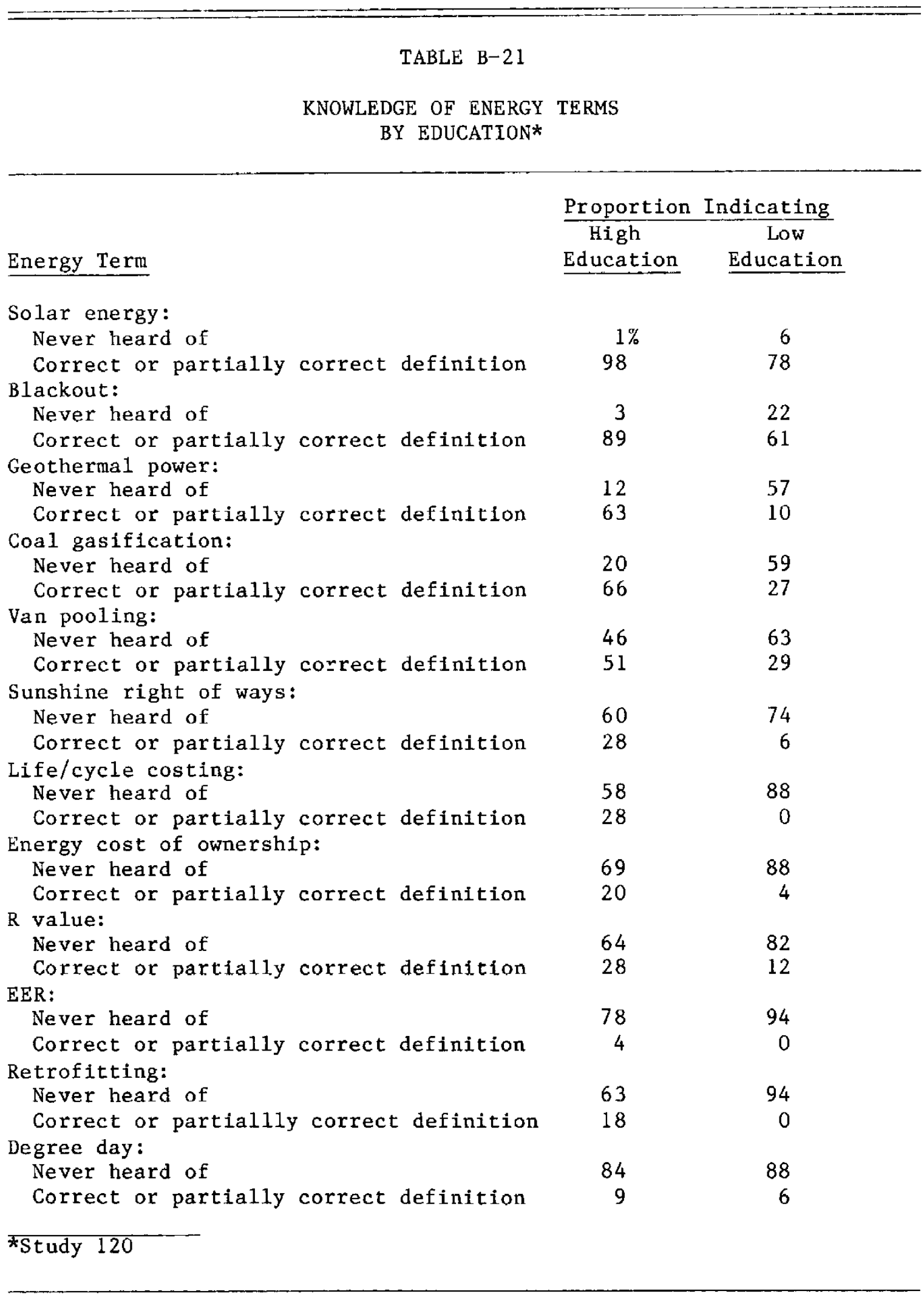


A Roper survey in January 1975 explored which groups or organizations would be believed if different statements were issued to explain a price rise of gas and oil [170]. All were more likely to believe Ralph Nader's office than any other organizations, including government agencies and industry (college, 44 percent; high school, 30 percent; grade school, 16 percent). Education was positively related to trust in Nader's office, but this difference occurred in part because many more (36 percent) of the grade school group responded don't know/no answer. All groups were least likely to believe the major oil companies. However, 41 percent of the grade school group responded don't know/no answer.

The trust placed in decision-making groups is related to the credibility of an information source. A Roper survey in March 1977 found that those with higher education were most favorable toward expert groups deciding on the disposal of nuclear waste, the speed limit on the highways, and the siting of atomic power plants [152]. However, all education groups preferred the expert groups over the voting public for handling these issues. In general, the surveys found educational level to be positively related to knowledge about the energy situation and awareness of sources of energy information. There were no clear patterns of difference by educational level regarding credibility of information sources.

In most cases, there were no clear differences by educational level regarding the tradeoff between adequate energy and protection of the environment. However, there were strong positive relationships between educational level and preference for regulating strip mining, and between level of education and willingness to pay for lowered pollution levels.

\section{Attitudes Toward Solar Energy}

A five-region survey in 1976 found educational level slightly but positively related to preference for generating electricity by using solar energy, although all groups were very positive (some high school or less, 89 percent; high school graduate, 95 percent; some college or more, 97 percent) [303]. A survey by the San Diego Gas and Electric Company in August 1976 explored the perception of the availability and attributes of solar energy [252]. Those with some college or a bachelor's degree were more likely than those with more or less education to think that solar energy is available now. They were also slightly more likely than other groups to agree that "solar is a safe form of energy." Those with a bachelor's degree were more likely to agree that it "is reliable-rarely breaks down" and less likely to agree that it "can now be installed in both new and already-built houses." Those with some college were least likely to think that "installation is simple and fast" (see Table B-22).

A national survey in January 1979 reported that one percent of those with at least some college education were solar owners compared to less than 0.5 percent for other educational groups (Roper, 1979). Indicating possible solar buying plans in the next two to three years were about a fifth of those with at least a high school education compared to eight percent of others.

A Michigan survey in 1976 found those in the high education group more willing to say they "would pay for more costly solar energy to reduce the demand for new sources of petroleum" (63 percent versus 35 percent for the low education group) [106]. Not enough surveys analyzed attitudes toward solar by educational level to determine any patterns. 
TABLE B-22

\section{PERCEIVED ATTRIBUTES OF SOLAR ENERGY \\ BY EDUCATION}

I'd like to read you a list of statements which you might or might not agree apply to solar energy systems as could be used for a home today. Please use this card and as I read each statement to you, would you please tell we whether you agree or disagree and whether you feel strongly or slightly about your answer. [252]

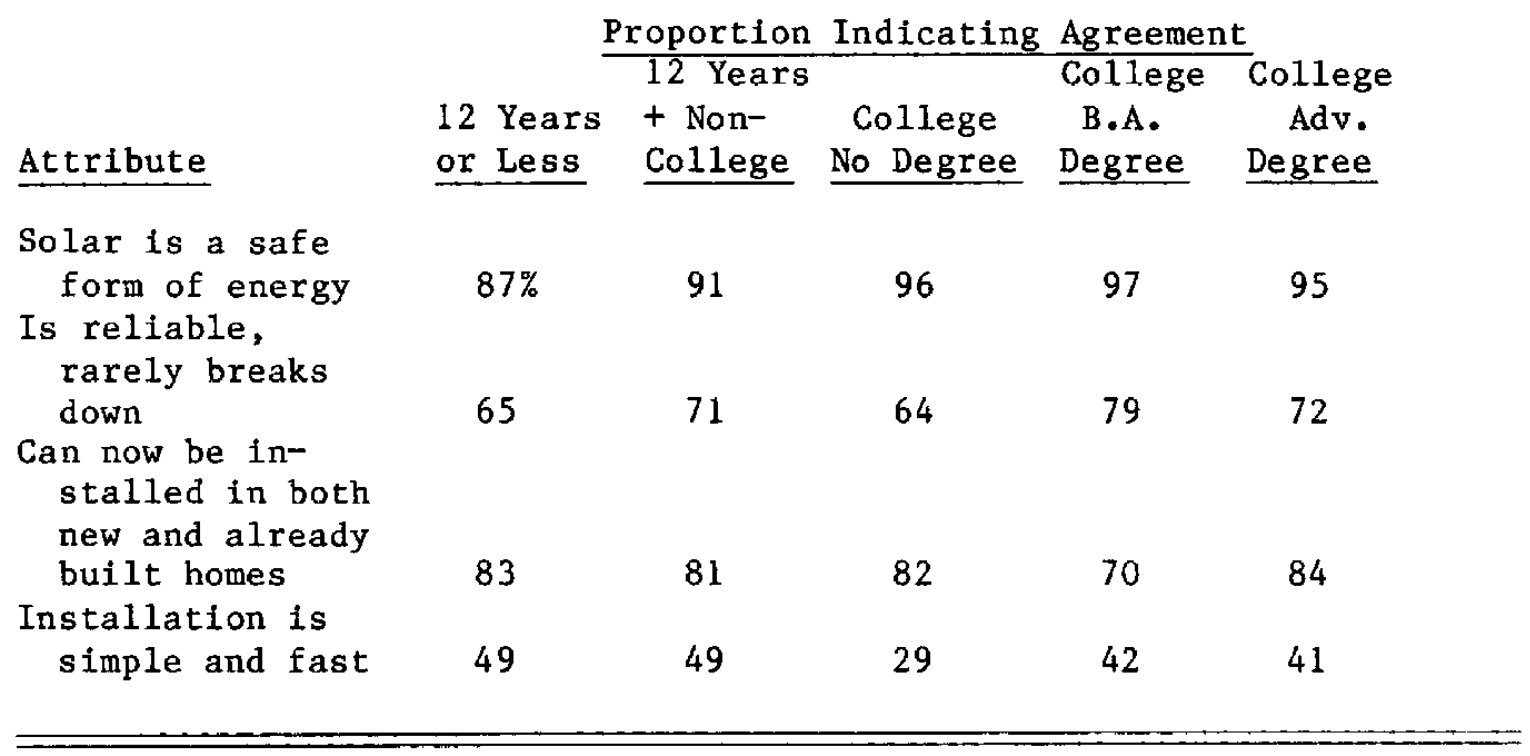




\section{Attitudes Toward Nuclear Energy}

Awareness of nuclear energy issues raised in media discussions and the political arena is positively related to level of education. A Gallup survey in June 1976 found 89 percent of the college educated persons, 74 percent of high school graduates, and 66 percent of those with a grade school education had been following the media discussions on nuclear energy development (Gallup, 1976). A Harris survey in 1976 found that a much larger proportion of college graduates ( 56 percent) had heard about the California referendum on regulation of nuclear plants than had persons in the less educated groups (29 percent of the high school graduates and those with some college, and 16 percent of those with some high school or less) [141].

Only a slight difference by educational level was found in overall opinion of nuclear power by an ORC survey in November-December 1974 [308]. High school graduates were less favorable than those with either less or more education (65 percent felt very or fairly favorable versus 70 percent for grade school and 73 percent for college). A direct positive relationship between educational level and favorable opinion of nuclear power was found in a 1974 national survey by Becker Research Corporation [311] (see Table B23).

A Gallup survey in June 1976 also found education level positively related to a perceived importance of having more nuclear power plants (Gallup, 1976). Seventy-eight percent of the college group felt that more nuclear power plants were extremely or somewhat important versus 70 percent of the high school group and 59 percent of the grade school group.

A two-wave Harris survey in 1975 and 1976 found conflicting results on the relationship between education and favoring of nuclear power plant construction in the United States [141]. In the 1975 wave, there was no difference between high school and college graduates, both being slightly more favorable than those with some high school or less. In the 1976 wave, however, the high school graduates were slightly more favorable than either of the other two groups and the college graduates were most opposed (see Table B-24.)

A study in Kentucky in 1975 also found more support for the development of nuclear power among those with more education [221].

The safety of nuclear power plants was an issue for extensive questioning in two surveys. As shown in Table B-25 a Gallup survey in June 1976 found each education group split between whether the plants are safe enough with present regulations or need stricter regulations (Gallup, 1976). Persons with more education were more likely to state an opinion, with the result that the data show them to be most in favor of both positions.

The Harris survey in 1976 found education positively related to perceived safety of nuclear power plants [141]. Percentages of respondents perceiving the plants to be very or somewhat safe were 68 percent for college graduates, 66 percent for high school graduates or some college, and 55 percent for some high school or less. Individuals were asked which problems connected with nuclear power plants they considered major. The college graduates were less concerned than other groups about all but two of the problems: disposal of radioactive waste (70-71 percent of the college graduates and the high school graduates perceived it as major versus 60 percent of the less educated group) and discharge of warm water into lakes and rivers (50 to 51 percent of all groups 
TABLE $\quad B-23$

GENERAL OPINION OF NUCLEAR POWER

BY EDUCATION

What is your general opinion of nuclear power? Would you say that it is strongly favorable, somewhat favorable, somewhat unfavorable, or strongly unfavorable? [311]

\begin{tabular}{cccccc} 
& $\begin{array}{c}\text { Strongly } \\
\text { Favorable }\end{array}$ & $\begin{array}{c}\text { Somewhat } \\
\text { Favorable }\end{array}$ & $\begin{array}{c}\text { Somewhat } \\
\text { Unfavorable }\end{array}$ & $\begin{array}{c}\text { Strongly } \\
\text { Unfavorable }\end{array}$ & $\begin{array}{c}\text { No } \\
\text { Opinion }\end{array}$ \\
$\begin{array}{c}\text { Grade } \\
\begin{array}{c}\text { school } \\
\text { Figh school } \\
\text { incomplete }\end{array}\end{array}$ & $15 \%$ & 27 & 14 & 7 & 37 \\
$\begin{array}{c}\text { High school } \\
\text { graduate }\end{array}$ & 26 & 29 & 16 & 4 & 28 \\
$\begin{array}{c}\text { Some college } \\
\text { College }\end{array}$ & 31 & 43 & 11 & 5 & 15 \\
$\begin{array}{c}\text { graduate } \\
\text { or more }\end{array}$ & 43 & 45 & 11 & 5 & 8 \\
\hline
\end{tabular}




\begin{tabular}{|c|c|c|c|c|c|c|}
\hline ATTITUDE & \multicolumn{4}{|c|}{$\begin{array}{c}\text { TOWARD THE BUILDING OF MORE NUCLEAR } \\
\text { IN THE UNITED STATES } \\
\text { BY EDUCATION* }\end{array}$} & R POWER & PLANTS \\
\hline Education & Favor & $\begin{array}{l}\text { Pror } \\
1976 \\
\text { Oppose }\end{array}$ & $\begin{array}{l}\text { ortion } \\
\text { Not } \\
\text { Sure }\end{array}$ & $\begin{array}{l}\text { Respondi } \\
\text { Favor }\end{array}$ & $\begin{array}{l}\frac{\mathrm{ng}}{1975} \\
\text { Oppose }\end{array}$ & $\begin{array}{l}\text { Not } \\
\text { Sure }\end{array}$ \\
\hline $\begin{array}{l}\text { Some high } \\
\text { school or less } \\
\text { High school } \\
\text { graduate/some } \\
\text { college } \\
\text { College graduate }\end{array}$ & $\begin{array}{l}64 \\
57\end{array}$ & $\begin{array}{l}21 \\
31\end{array}$ & $\begin{array}{l}15 \\
12\end{array}$ & $\begin{array}{l}66 \\
68\end{array}$ & $\begin{array}{l}20 \\
23\end{array}$ & $\begin{array}{r}14 \\
9\end{array}$ \\
\hline *Study 141 & & & & & & \\
\hline
\end{tabular}




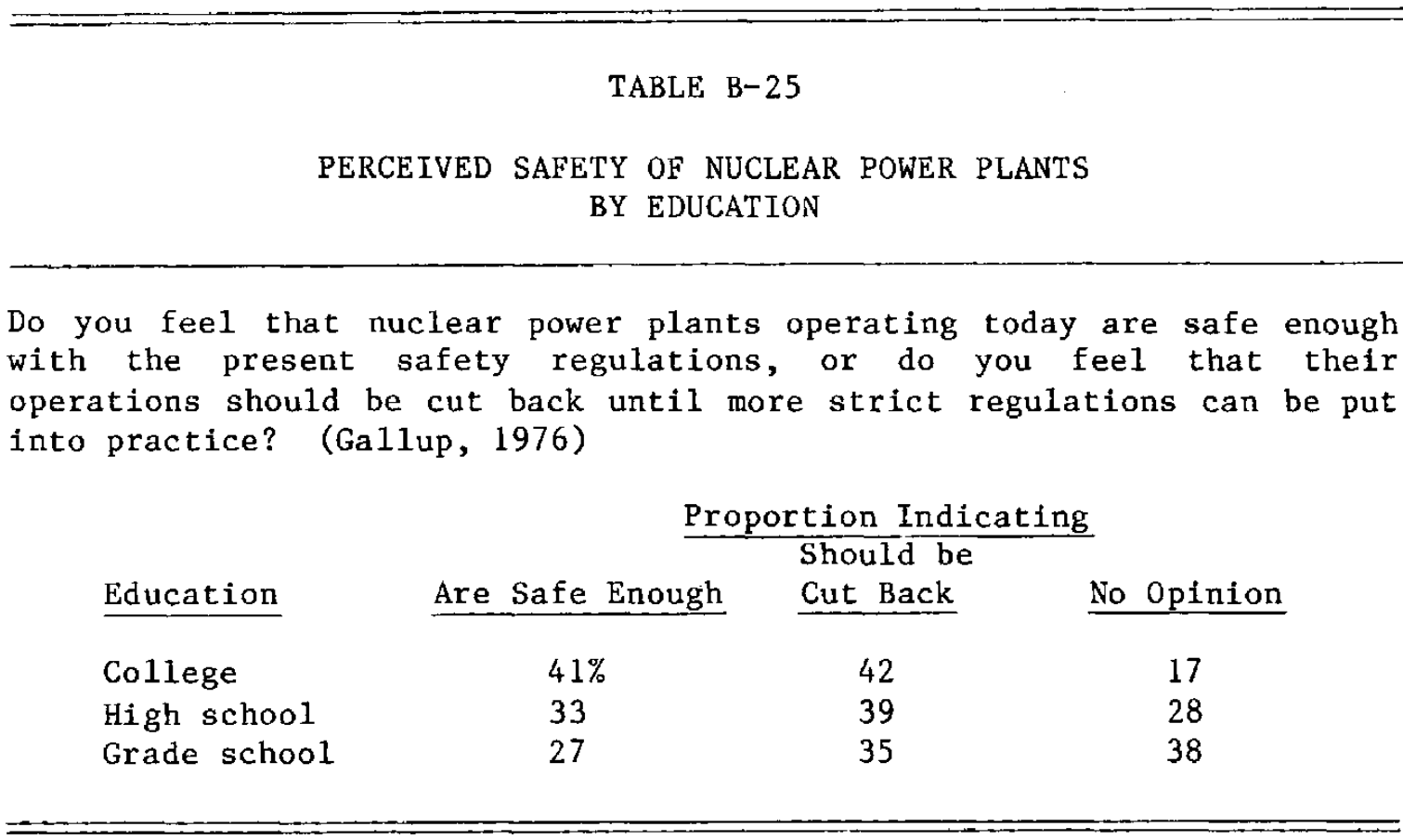


perceived the problem). The items on which the college graduates expressed less concern than the other groups were atmospheric escape of radioactivity, mutagenic effects of radiation, explosions and core melt downs, polluting fumes, sabotage, and theft of plutonium.

A third survey found no differences by educational level in accepting nuclear risks rather than severely restricting energy use [106].

A national survey in 1974 found highly educated individuals were more aware of the presence of nuclear plants within a 100-mile radius of their homes; however, they were also slightly more likely to be incorrect about or unable to tell its name or location [311]. The survey also found that more educated individuals were more likely to think construction of a nuclear plant in their general area was alright. Approval ranged from 43 percent for those with a grade school education to 69 percent for those with a college degree or more. A Roper survey in September 1977 also found the college-educated group more likely to feel that a nearby nuclear plant would be safe ( 47 percent versus 36 percent of the high school group and 30 percent of the grade school group) [148].

A Gallup survey in June 1976 found the opposite result (Gallup, 1976). The more educated the person, the more likely that he or she would be against the construction of a nuclear plant within a five-mile radius (college, 50 percent; high school, 44 percent; grade school, 40 percent). This shift may have been a result of the smaller area being discussed (100-mile compared to five-mile radius), but the data do not permit a check on that possibility.

Two waves of a Harris survey in 1975 and 1976 asked whether the person favored or opposed having nuclear power as the main source of energy for electric power in his or her community [141]. In the 1975 wave, those with a high school diploma or more were 57 to 59 percent in favor, while the less educated were 46 percent in favor. The 1976 wave, however, showed minor differences in approval (47 to 52 percent), but strong opposition (40 percent) from the college graduates (versus 27 to 29 percent from the others).

Only one study asked about the sale of nuclear power plants to other countries [180]. All groups were negative, with the less educated groups more negative.

Level of education was found to be positively related to awareness of the nuclear energy issues raised in the media. There were conflicting results concerning the desirability of nuclear energy development. However, the studies more of ten tended to show a positive relationship between level of education and positive attitudes toward nuclear energy and the development of nuclear power plants. The data are mixed, however, regarding desirability of nuclear plants in one's immediate neighborhood. There were no clear differences by educational level on perceived safety of nuclear power plants.

The positive relationship between educational level and favorable nuclear energy attitudes was also found in a review and secondary analysis of survey data by Melber et al. (1977). In general, they found that more highly educated individuals were more supportive of nuclear power and more likely to consider it safe.

\section{Attitudes Toward Conservation}

A two-wave survey in Michigan in 1974 and 1976 found a reduction in household energy consumption, which did not vary significantly by educational level [106]. The survey also 
found that less educated persons were more likely to feel that home conservation was unimportant compared to possible energy savings by government and industry ( 57 percent versus 32 percent for the more educated group). A Denver survey in 1977 found only minor differences between educational levels in the perception of utility costs that could be saved through conservation [120]. However, persons with a college degree or above were more likely to express interest in joining an energy conservation-oriented organization ( 34 percent versus 18 to 19 percent for the less educated groups).

An Ohio survey in 1975 asked people whether they saw electricity being wasted or used unnecessarily [122]. Those with education beyond high school were more likely to see waste and to see it in nonresidential use (45 percent versus 27 to 37 percent for the other groups).

An ORC survey in December 1975 through January 1975 asked individuals what impact they felt personal conservation efforts had on the national consumption of energy [131]. Those with at least a high school diploma were more likely to say "a great deal" (less than high school complete, 30 percent; high school complete, 42 percent; some college, 38 percent). Comparing their conservation efforts to those of other people they knew, the less education they had the greater the personal effort they perceived (less than high school complete, 43 percent; high school graduate, 32 percent; some college, 25 percent). The same comparisons produced similar results in another ORC survey in February-March (less than high school complete, 46 percent; high school graduate, 35 percent; some college, 33 percent) [134].

Several surveys asked what energy conservation behaviors the family had adopted or changed. An ORC survey in 1976 found that those with less than a high school education were more likely to say that their children had made an effort to save energy as a result of things they had learned in school [130]. A national survey in 1973 through 1974 found that the better educated tended to turn down the thermostat more [142]. An Ohio survey in 1975 found only minor differences on all conservation behaviors but cutting back on heat and air conditioning, with more-than-high-school graduates, 34 percent; high school graduates, 28 percent; less-than-high-school graduates, 22 percent [122]. The most frequent conservation behavior for all groups was to reduce usage of lights. A Michigan survey in 1976 found no differences by educational level for use of storm windows and doors, turning down thermostats, having heating equipment cleaned and serviced, turning off lights, use of motor vechicles, recycling bottles and cans, use of oven, reduction in use of beef, using fresh fruits and vegetables only in season, not heating some rooms in winter, limiting use of hot water, and sharing equipment with friends and relatives [106]. Differences were found for maintaining daytime temperatures of $68^{\circ} \mathrm{F}$ or less (72 percent for above high school, 59 percent for high school and below), drying clothes on clotheslines (2l percent for above high school, 41 percent for high school or below), choice of physical activity rather than use of motor vehicles for recreation (55 percent for above high school, 30 percent for high school or below), use of thrifty grade of beef (54 percent versus 39 percent), and use of powdered milk (nine percent versus 20 percent). No differences were found for reported difficulty in pursuing energy conservation, including reducing the number of miles driven, the temperature in the house, and the number of material goods purchased. There was a marked difference in reducing the amount of electricity used (12 percent of the high education groups said they would have great difficulty versus 23 percent of the low education group). A Gallup survey in 1977 found differences only in turning down the thermostat and minimum use of the air conditioner, where the educational level was positively related to the behavior [220]. 
A Roper survey in March 1976 asked homeowners what they would do in the next two years if a tax credit was given [164]. The more educated groups were more likely to do all of the things suggested, but the only sizable difference was on installing wall and roof insulation (college, 23 percent; high school, 20 percent; and grade school, nine percent).

The less educated groups may be more in need of increased insulation, however. An ORC survey in March through April 1975 found that people with less than a high school education were less likely to have insulated homes (56 percent versus 72 percent for the high-school-complete group and 70 percent for the some-college group) [256].

An ORC survey in August and September 1974 found that persons with higher education were less likely to say they would switch from driving their own cars to carpooling if their company reduced the available parking space [137].

The time and money tradeoffs for use of mass transit were explored by an ORC survey in 1975 for families with public transportation available, but in which the head of the household drove a car to work or carpooled [129]. Those with more education were less likely to say they would change to public transportation if it ran twice as of ten or if the fare were half as much. They were somewhat more willling than other groups to use it, however, if it got them to work 15 minutes sooner. The survey also found that more educated individuals were more likely to feel that the United States as a whole would benefit from more and better mass transit (some college, 76 percent; high school complete, 52 percent; less than high school complete, 49 percent). There were no clear differences by educational level on attitudes toward conservation or on most conservation behaviors which individuals reported. There were differences, however, in turning down the thermostat with the more educated individuals practicing more conservation.

Most of the conservation policies explored in the surveys dealt with transportation. An ORC survey in January 1975, however, asked about returnable bottle and can laws [133]. Preference for such a law was positively related to educational level, with 81 percent of those with some college, 73 percent of high school graduates, and 68 percent of those with less than high school indicating favor.

Attitudes toward alternative policies to encourage conservation of gasoline were explored in a number of studies. A Gallup survey in November 1977 found persons with higher education more likely to favor carpools, building gas-saving cars, improving public transportation, and raising the price of or taxes on gasoline [310]. They were less likely to favor reducing unnecessary driving. An earlier Gallup survey in April through August 1977 also found persons with a college. or high school education more likely to favor a price increase than persons with a grade school education (48, 47, and 33 percent, respectively) [220].

An ORC survey in October 1974 found no difference by education on preference for gasoline tax or tax on large cars, or on alternative means of encouraging carpools [132]. In August and September 1974 [137], persons with some college were more likely than other groups to feel that gasoline taxes should be kept the same or increased and less likely to feel they should be reduced. The November-December 1974 ORC survey asked whether, given the doubling by the Arabs of the price of gasoline sold to the United States, Americans should conserve gas, or pay the higher prices and use all they want [308]. Three-quarters or more of all groups said that Americans should conserve gas rather than pay the higher prices, with those having less than a high school degree slightly less in favor (74 percent versus 82 percent for high school complete and 81 percent for some college). 
A Gallup survey in November 1977 found more highly educated individuals were more likely to oppose a gasoline rationing law that would require people to drive one-fourth less (college, 62 percent opposed; high school, 55 percent opposed; and grade school, 41 percent opposed) [310].

When asked how important they thought it was to reduce their driving by one-fourth, college-educated individuals were slightly more likely than those with high school educations to feel that it was very or fairly important $(70$ percent versus 62 percent for those with a high school diploma and 64 percent for those with a grade school education). Those with a high school or college education were also more likely than those with grade school education to say that it would be very or fairly difficult to reduce the miles they drove by one-fourth (college, 69 percent; high school, 65 percent; grade school, 54 percent).

An ORC survey in November and December 1975 found that more educated individuals were slightly more concerned than high school graduates, but not than those at lower educational levels, with the gas mileage their cars got (78 percent of those with some college were very or fairly concerned versus 70 percent of the high school graduates and 75 percent of those with less than high school) [144].

Gallup surveys in June 1973 and in February 1977 provided before-and-after attitudes toward a $55 \mathrm{mph}$ speed limit $[211,217]$. In 1973 college-educated individuals were more likely than less educated groups to think that the reduced speed limit was a good idea ( 58 percent versus 49 percent for the high school group and 48 percent for the grade school group). However, 35 percent of the grade school group did not respond to the proposal and indicated that they had not heard or read about the "energy crisis." In 1977 education was positively related to a perceived reduction in one's own driving speed (college, 72 percent; high school, 61 percent; and grade school, 54 percent) and slightly related to a preference for the same speed limit for trucks. There were no differences between groups on whether to keep the $55 \mathrm{mph}$ speed limit, with three-quarters or more of each group saying yes.

An ORC survey in 1975 found those with more education more likely to feel that it was more important that money be spent on mass transit than on highways (see Table B-26) [129]. Persons with more education were more favorable toward mass transit in general and toward policies which would raise the price of gasoline but not otherwise restrict their driving. Their positive attitudes toward mass transit were not supported, however, by their responses as to whether they would use it.

\section{Summary}

In general, the educational level of the individual seems to be an important correlate of energy attitudes and behaviors. Persons with more education were shown in a number of studies to be more likely to believe in an energy problem and its seriousness [106, 117, $119,120,130,134,154,175,181]$. The more educated individuals were also more likely to expect future shortages [142; 172; Roper, 1978c]. The higher the educational level, the less likely the individual was to think that energy self-sufficiency was possible for the United States [131, 133, 308].

Educational level was positively related to favoring the speed-up of solar energy development, and negatively related to the development of other energy sources or technologies [141]. Solar energy was, in fact, among the first two long-range energy 


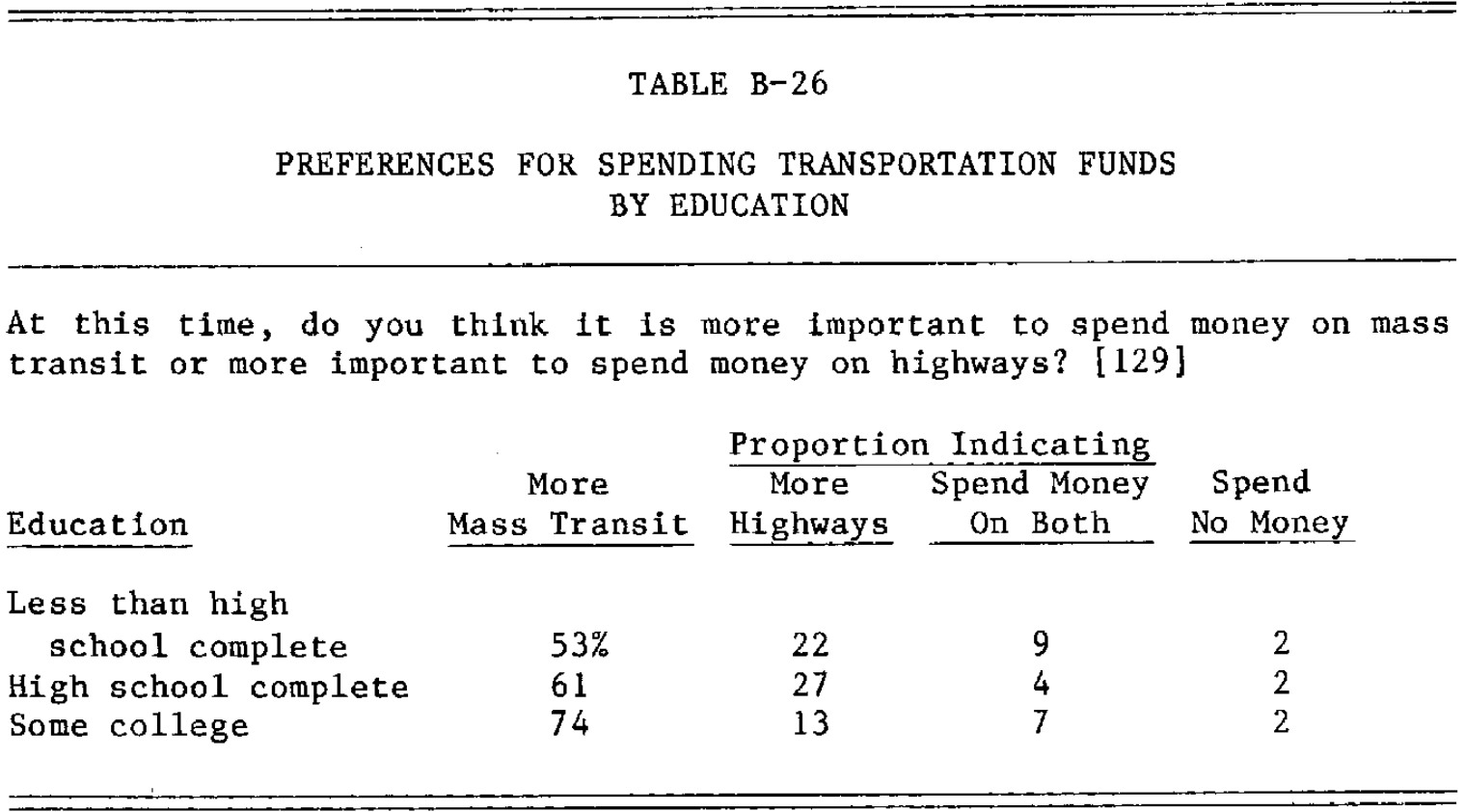


supply choices for all education groups [152, 303]. Educational level was also positively related to favoring energy conservation policies.

Those with more education were somewhat more likely to express approval for Carter's handling of the energy crisis and for his energy plan. The performance of the business community in handling responsibility during the energy crisis was judged more harshly by the more educated groups [137, 139].

Level of education was positively related to knowledge about the energy system, such as the presence of a federal energy agency, awareness that the United States must import oil, knowledge about wind and solar energy, and awareness of energy-related information $[106,109,120,139,144,218,256,303]$.

Education was found in most cases to be positively related to environmental protection attitudes, even in cases where it would cost the person more [106, 128, 131, 134, 303].

Awareness of nuclear energy issues raised in the media and the political arena was positively related to the level of education $[141,215,308,311]$.

Those with more education were more likely to favor the development of nuclear power $[141,221]$. They were also more likely to consider nuclear plants as safe $[141,311]$.

Education was found to be positively related to a preference for generating electricity by using solar energy and to a more favorable appraisal of the attributes of solar energy $[106,252,303]$.

Persons with more education were more likely to think that home conservation efforts can make a difference [106, 131]. Those with less education, however, felt that they were conserving more than other people and were more likely to say that reducing the electricity they used would be difficult $[106,130,131]$.

Persons with higher education were more likely to favor carpools, building gas-saving cars, improving public transportation, and raising the price of or taxes on gasoline [310]. The highly educated individuals tended, however, to resist measures that would limit their ability to drive, such as rationing of gasoline or voluntary reduction of their driving by one-fourth [310].

More educated individuals were more likely to feel that money should be spent on mass transit rather than highways and that improved mass transit would benefit the United States as a whole [129].

\section{INCOME}

Family income was frequently used as a sociodemographic variable in the present universe of surveys. However, the surveys varied widely both in the number and type of income categories employed, making the task of discerning patterns of findings difficult. In addition, family income is not a clear measure of the relative economic status of a respondent. In particular, family size would be expected to exert a confounding influence on the relationship between income and economic well being.

Recently, more attention has been directed to the issue of equity in energy policy, indicating that analyses of energy attitudes and behavior by income will become an increasingly important analytical task. 


\section{Perception of the Energy Situation}

A national survey in the spring of 1977 revealed that there was little difference of opinion by income level among those rating the energy situation "not at all serious," with slightly more of those in the $\$ 5,000$ to $\$ 6,999$ range of this opinion than those making $\$ 20,000$ or over. Those making under $\$ 3,000$ were most likely to rate it very serious (58 percent), followed by the highest income group ( $\$ 20,000$ or over, 49 percent); 45 percent or fewer of all other groups saw it as very serious.

However, when one combines those rating it very or fairly serious, the highest group was slightly more likely than those in either the $\$ 5,000$ to $\$ 6,999$ range or under $\$ 3,000$ to rate the problem as serious [128]. In November of that year, those under $\$ 3,000$ were slightly less likely to see the problem as very or fairly serious than were those in the $\$ 10,000$ to $\$ 14,999$ or the $\$ 20,000$ or over ranges. Those in the $\$ 15,000$ to $\$ 19,999$ range were slightly more likely than those in the $\$ 3,000$ to $\$ 4,999$ range to report it "not at all serious" [175]. It appears from these two surveys that belief in the crisis bears no monotonic relationship with income.

However, a number of other surveys, employing fewer income categories, revealed greater belief among those with higher incomes [Perlman and Warren, 1975; Gottlieb and Matre, 1976; 106; 181; Stearns, 1975]. One study reported no difference by income in rating the seriousness of the crisis (Opinion Research Corporation, 1974). Although the evidence is somewhat mixed, it suggests that belief in the crisis is somewhat related to income, with higher income groups generally expressing greater belief.

Two 1975 national surveys asked respondents to decide which of unemployment, inflation, and the energy shortage was the most important problem [128, 134]. In both surveys, unemployment ranked first, followed by inflation and the energy shortage for all income groups. In the first, those over $\$ 15,000$ we:e slightly less likely to cite unemployment than the two lower groups, those under $\$ 10,000$ were slightly less likely than the others to cite inflation, and those over $\$ 15,000$ were slightly more likely to cite the energy shortage. In the second, those over $\$ 15,000$ were slightly less likely to cite unemployment, those under $\$ 7,000$ were somewhat less likely to cite inflation, and there were no differences in those citing the energy shortage. When a 1976 national survey asked to which issues respondents wished Congressional representatives to pay attention, those under $\$ 6,000$ were somewhat less likely than others to cite development of a national energy policy, while those over $\$ 18,000$ were less likely to cite hiring the unemployed in government jobs or stricter labeling of food [168].

A 1977 national survey inquired about the two or three issues of most concern to respondents. There were no differences by income in citing recession/unemployment; money to pay bills declined as a concern with rising income; the fuel and energy crisis increased with income as an issue of importance, with greatest support among groups making over $\$ 12,000$; pollution of air and water was somewhat more important to the group making under $\$ 6,000$ than to more affluent groups [154]. A 1977 Denver survey found that average ranking of the energy issue declined with rising income [120]. These findings on the relative salience of the energy issue provide slight support for the notion that its perceived importance is positively related to income.

Talarzyk and Omura (1975) reported no relationship between income and attributed responsibility for the energy crisis, nor did a 1973 national survey [213]. Bultena (1976) found that upper class respondents (defined by educational attainment, occupation, house value, and average rent), saw energy shortages as due to dwindling energy supplies, 
wasteful energy use, and population growth, while middle and lower classes blamed large oil companies and government favoritism to these companies. A 1976 Colorado Springs study found that, of those believing the crisis to be serious, there was an inverse relationship between income and mention of finite resources as a cause [104].

A 1977 national survey found the following differences in attribution of blame: those under $\$ 7,000$ were somewhat less likely to blame the Administration and Congress, electric power companies, environmentalists, American consumers, and Arab countries than were higher income groups; on all of these, the percentage attributing blame increased with income. Those over $\$ 25,000$ were somewhat less likely than other groups to blame oil companies. Those over $\$ 25,000$ were somewhat more likely than those in the $\$ 15,000$ to $\$ 25,000$ range to blame Israel [151].

These findings permit no conclusion to be drawn about the relationship between income and attribution of responsibilities for the energy crisis. The evidence suggests, however, that higher income persons may be somewhat more likely than those with lower incomes to blame impersonal factors such as population growth and finiteness of supply, and less likely to blame institutions and persons in society. A 1974 national survey found those under $\$ 12,000$ were slightly less likely than those over $\$ 12,000$ to consider sufficient the steps taken to deal with the energy crisis; those in the $\$ 6,000$ to $\$ 12,000$ range were slightly more likely than all others to believe more drastic steps were needed; those under $\$ 6,000$ were slightly more likely to report they did not know [174]. In 1975, those under $\$ 3,000$ were most likely to approve of "the way Carter is dealing with the energy situation" ( 57 percent), followed by those over $\$ 20,000$ (48 percent). Least support (34 percent) was found among those in the $\$ 7,000$ to $\$ 9,999$ range [309]. When this same question was repeated in 1977 , least support (57.percent) was found among those over $\$ 20,000$, and the most support was found among those $\$ 5,000$ to $\$ 6,999$ (68 percent) [217].

Later in 1977, most favorable reaction to Carter's energy plan was found among those over $\$ 20,000$ (63 percent), least among those under $\$ 3,000$ (47 percent) [218]. The same survey found those $\$ 3,000$ to $\$ 4,999$ ( 43 percent) most likely to feel there were too many sacrifices in the plan; those over $\$ 20,000$ were least likely to be of this opinion (27 percent). Those $\$ 7,000$ to $\$ 9,999$ were most likely to consider the plan "about right" (42 percent), those under $\$ 3,000$ least likely (22 percent). The highest income group were most likely to report not enough sacrifices (36 percent), the $\$ 3,000$ to $\$ 4,999$ group least likely (13 percent). The lowest income group was most likely to have no opinion. Another 1977 survey found the largest disparities between the lowest and highest income groups: those over $\$ 25,000$ were slightly more likely than those under $\$ 7,000$ to consider the plan "about in line," and somewhat more likely to feel it did not go far enough. The lowest group was somewhat more likely to have no opinion [147]. It is difficult to discern a pattern of opinion by income on President Carter's plan due to the number and diversity of income categories, as well as the absence of monotonic relationships.

A 1974 survey revealed no differences of opinion by income on the possibility that the United States could be self-sufficient in energy supplies [308]. A 1974 survey revealed no difference by income in opinion on whether the United States would run out of natural gas or oil in the next ten years [137]. Another study found no difference in opinion in expectations about whether the energy shortage would become more severe over the next few months (Opinion Research Corporation, 1974). A 1977 survey found no difference in expectations for a severe shortage next year [150]. A 1975 Ohio study found no difference by income in expectations about a future electricity shortage [122]. 
Several studies did report income differences on expectations regarding the shortage, however. The 1974 study cited above found those under $\$ 10,000$ and those $\$ 10,000$ to $\$ 15,000$ somewhat less likely to expect a natural gas shortage in the next 50 years, and the lowest group was found to be slightly less likely than the middle and somewhat more likely than the highest to expect an oil shortage in that time period [137]. Another study found the same pattern for coal as that found above for oil [139]. A 1974 survey found those $\$ 12,000$ to $\$ 18,000$ to be slightly more likely and those over $\$ 18,000$ somewhat more likely than lower income groups to feel that the oil shortage was real and would get worse [172]. A 1975 Texas study, however, reported that lower and middle income groups were more likely to agree that the energy problem would persist over the next five to 20 years [181]. Those over $\$ 15,000$ were slightly less inclined to expect another oil embargo to be "very likely" when compared to lower income groups, as revealed in a 1975 national survey, and they were somewhat less inclined to expect re-emergence of long gasoline lines [129]. Another 1973-74 national survey revealed that more affluent groups were more pessimistic about the possibility of getting gasoline [142]. A 1974 survey revealed that those in the $\$ 6,000$ to $\$ 12,000$ range were slightly more likely to be of the opinion that there would not be a gasoline shortage the next summer [172]. These findings reveal no consistent pattern of difference of opinion by income of the possibility of future energy shortages. There is a tendency in the data toward higher income groups expecting longer-term shortages, which would be consistent with their greater reported belief in the crisis, but the evidence is not entirely consistent with this conclusion.

A 1976 survey in five states revealed no difference by income regarding opinions on the following policy options: producing as much as possible, importing the rest; producing as much as possible, but limiting use [303]. This survey found that support for a policy of rationing energy so that none need be imported declined significantly with income. A 1977 national survey found that somewhat fewer of those under $\$ 7,000$ felt that a major effort should be put into developing new energy sources and conservation [151]. Two national surveys, one in 1974 and one in 1975, revealed that higher income groups tended to be more supportive of a policy of exporting food to pay for oil, even if this meant higher food costs [128, 137].

This greater concern among lower income groups for lower food prices most likely reflects the fact of their greater inability to absorb energy-related price increases. Several studies have documented that lower income groups experience more financial strain due to energy price increases [181; Newman and Day, 1975; Unseld et al., 1978; Grier, 1976]. A Michigan study revealed that more low income people perceived gasoline price increases as a great problem, but that there were no differences for heating oil or electricity [106]. A 1973-74 national survey found that feelings of relative deprivation decreased at higher income levels [142]. Unseld et al. (1978) reported that among the elderly poor a variety of negative impacts (lifestyle, safety, health) were more likely to be found among those of lower income.

Three national surveys, one in 1974 and two in 1975 , inquired if prices had increased because of the energy shortage $[137,139,308]$. In the first, there were no incomerelated differences. In the second two, those under $\$ 10,000$ were more likely to report food price increases. In the second of these, those in the $\$ 10,000$ to $\$ 15,000$ range were slightly more likely than the other groups to report that the price of "everything" had gone up. A 1974 Washington, D.C. study found that lower income groups were more likely to report that a family member had been laid off or had overtime or working hours cut due to the energy crisis [121]. A 1974 national survey found that those under $\$ 10,000$ were slightly less likely to believe that oil and gasoline price increases had a great deal or a fair amount to do with the rate of inflation, and it found no income differences in 
rating the relative price increase of gasoline, as compared with other commodities [308]. A 1975 Ohio study revealed no income differences in reports of "getting one's money's worth" in buying natural gas or electricity, but found those under $\$ 10,000$ somewhat more likely to report not "getting one's money's worth" on gasoline [122].

These findings indicate that a disproportionate share of impacts from the nation's energy problems have been borne by the lowest income groups.

\section{Energy and the Environment}

A 1977 national survey revealed no differences by income in response to the question of whether or not environmental regulations had gone far enough, nor was there a difference by income revealed for preference for environmental quality versus increased energy production [148]. A 1974 national survey showed no differences by income in association of power plants and oil refineries with pollution, nor with judgments of how much increased energy production would damage the environment [308]. This same survey showed that those over $\$ 15,000$ were slightly more likely to name water pollution and oil spills, and somewhat more likely to name strip mining, as the most serious problems if the United States tried to be self-sufficient. There were no differences regarding air pollution, nuclear wastes, or radioactivity. This survey found greatest support for building power plants and refineries in already polluted areas among those making $\$ 10,000$ to $\$ 15,000$, somewhat more support than found among the higher and lower income groups. A 1977 national survey revealed that support for relaxed air standards to permit industrial conversion to coal increased with income [218].

Bultena (1976) reported that upper classes tended to support environmental quality while lower classes favored low energy. In a similar tradeoff of environmental quality versus personal impacts, Barnaby and Reizenstein (1975) reported higher income groups tended to prefer less home heating if it meant less pollution.

When asked if they would favor use of pollution-free energy if this entailed cost increases, lower income groups were significantly more likely to oppose such a policy, as revealed in a 1976 survey conducted in five states [303]. Similarly, a 1975 national survey showed that lower income groups felt it was more important to keep electricity prices lower than to have strip-mining regulations [128], and a 1974-75 survey showed lower income groups to be more supportive of "getting coal at the cheapest possible cost" than of strict laws for strip mining [131]. A 1975 Kentucky study showed slightly more low income people in favor of banning strip mining [221] and a 1975 study in the Yellowstone River Basin showed that the poorest group (under $\$ 3,000$ ) was least supportive of developing new coal mines [205]. These findings suggest a pattern of greater environmental support among low income groups except where environmental quality is posed as entailing higher consumer costs.

\section{Knowledgeability and Information Sources}

A clear pattern of differences by income on knowledgeability about energy issues was revealed in a number of surveys: those of higher income generally reported greater knowledge about energy issues. A 1977 national survey revealed that objective knowledge about the fact that this country imports oil increased steadily with income, ranging from 41 percent for those under $\$ 3,000$ to 65 percent for those $\$ 20,000$ or over. of those who knew we imported oil, the lowest group was somewhat less likely to give 
correct estimates of what percentage was imported [218]. In two surveys that inquired if respondents were aware that the government had established an agency to be responsible for energy policy, the lowest group was somewhat or notably less knowledgeable than the higher groups, and knowledge increased directly with income [139, 256]. A 1975 national survey showed the lowest income group to be slightly less aware than the middle, and notably less aware than the highest income group, of EPA/FEA mileage figures for cars [144]. The same pattern was found in a 1974 national survey that inquired if respondents had seen or read articles or advertisements about gas mileage for new cars [308].

A 1975 Ohio study revealed that lower income groups were more likely to report they did not know how much electric rates had increased over the past two years [122]. A 1976 Michigan study, however, revealed little differences by income groups (dichotomized at $\$ 15,000)$ on ten energy awareness items [106]. A 1976 survey in five states revealed no differences in knowledge of wind as a source of electricity, but found that income was significantly and directly related to knowledge of solar energy as such a source [303]. A 1976 Colorado Springs study indicated that higher income groups reported knowing or having read more about solar energy [104], while a national survey showed that the percentage of those following media discussions on nuclear energy development increased directly with income (Gallup, 1976). A 1976 New Hampshire study found that the percentage of those who read information from the electric company increased directly with income [253]. Two other studies reported that income exerts a positive influence on energy knowledge (Kilkeary, 1975; Gottlieb and Matre, 1975). These findings show a strong pattern of greater knowledgeability with increasing income.

A 1975 Ohio study showed no income differences in sources of information used or in ratings of the credibility of seven sources of information [122]. A 1975 national survey found that those $\$ 12,000$ to $\$ 18,000$ and above $\$ 18,000$ were slightly more likely than those below $\$ 18,000$ to believe the FTC on reasons for price increases. Belief in Ralph Nader increased with income. Citing major oil companies as a source one is least inclined to believe was markedly higher for all groups above $\$ 6,000$ than for those below [170]. A 1974 national survey showed that those under $\$ 10,000$ were somewhat more likely than higher income groups to believe that auto companies provide more reliable information on gasoline mileage, and were somewhat less likely to cite government agencies [308]. A 1975 survey also showed this group to be somewhat less inclined to cite government agencies as a reliable source, while they were somewhat more likely than other groups to say they did not know who was more reliable [133]. A 1977 Denver study showed declining credibility ratings for local television stations with increasing income, and increased credibility by income for ERDA and a group of scientists and engineers [120]. No clear relationship between income and credibility of various sources is evident in these findings.

\section{Solar Energy}

The present universe of studies included a large amount of information on attitudes toward solar energy that was broken down by income categories. A 1976 survey conducted in five states indicated a significant $(\mathrm{p} \leq .01)$ positive relationship between income and preference for solar energy as a source of production of electricity [303]. No such relationship was found in preference for wind as an electricity source in that survey. ' However, when respondents were asked, "In general, what do you think about the idea of using windmills to generate electric power?", a significant ( $p \leq .01$ ) difference by income group was found. Those in the $\$ 12,000$ to $\$ 19,999$ category showed the most preference, followed by $\$ 7,000$ to $\$ 11,999$, then $\$ 20,000$ or over, and finally under 
$\$ 7,000$. When this survey asked "Which one source should be used the most?", preferences were again significantly different by income level $(p \leq .01)$. Preference for solar energy and nuclear energy was positively correlated with income; hydroelectricity, wind energy, and oil and natural gas showed an inverse relationship with income; while coal was most preferred by the five mid-income groups. A 1977 national survey also showed that preference for solar and nuclear energy increased with income, while preference for oil from offshore wells decreased with income [152]. A 1976 Colorado Springs study also showed an increase with income of preference for solar energy and nuclear energy, while preference for coal decreased. Preference for geothermal energy and wind showed no income relationships. Preference for wood showed generally declining support with income, with the exception that those in the $\$ 20,000$ to $\$ 24,999$ bracket showed a somewhat greater preference than all other groups [104]. These surveys showed a clear and consistent trend for greater support for nuclear and solar energy among higher income groups, with the opposite holding for fossil fuel sources. One might hypothesize that lower income groups, who experience the most difficulty paying for energy costs, tend to see solar and nuclear energy as incapable of providing significant amounts of energy in a time frame that could ease their energy cost burdens.

The Colorado Springs study (1976) asked respondents if they would choose their present heating system or a solar system if costs were equal and why [104]. Over half chose the solar system, while 35 percent chose their present system. No discernible patterns by income for reason for the choice of a solar system were apparent. Two other questions revealed that, while there was no relationship between income and additional costs respondents were willing to accept for a solar system in their present or a new home, in both cases higher income groups would be willing to accept a longer recovery time for initial costs. When asked the same question regarding a supplemental heating system for the present home, higher income people were willing to accept both higher costs and longer recovery periods. This survey found no relationship between income and belief that the law should protect a solar house owner from shading resulting from a house, trees, etc. on a neighbor's property. There was a weak relationship between income and belief in individual versus utility ownership: higher income groups tended to favor private ownership, while lower groups tended to prefer utility ownership. A similar pattern held for preference for individual systems versus central collectors, with higher income groups tending to favor individual systems.

A 1975 study in Texas and Arizona revealed that for those above $\$ 3,000$, there is little difference in maximum acceptable time to recover investments in solar energy [181].

A 1976 study in San Diego County indicated no clear relationship between income and estimated cost of solar systems, or agreement with the statements that a solar system "would look good when installed on your roof," that "installation is simple and fast," or that one "will last a long time" [202]. Belief that "solar will increase the value of your home" appeared to decline with income. While over 50 percent of all income groups in that survey believed that solar energy is "available now," there was a tendency for belief that solar would be available in 10 or more years to be held more frequently by lower income groups.

A national survey in January 1979 asked respondents about current ownership of solar systems (Roper, 1979). Of all income categories, none showed more than 0.5 percent solar ownership except those earning $\$ 7,000$ to $\$ 15,000$, one percent of whom reported solar ownership. Considering solar system purchase in the next two to three years were 
25 percent of the highest income group $(\triangle \$ 25,000), 20$ percent of those earning $\$ 15,000-$ $25,000,13$ percent of those earning $\$ 7,000-15,000$, and five percent of those with incomes less than $\$ 7,000$.

\section{$\underline{\text { Nuclear Energy }}$}

Nuclear energy was also a topic frequently analyzed by level of income. A 1974 national survey revealed that those feeling very or fairly favorable toward nuclear energy increased with income: the highest group (over $\$ 15,000$ ) were somewhat more likely (80 percent) to take such a position than the lowest (under $\$ 10,000,63$ percent). Those considering themselves fairly or very unfavorable declined with income, while the lowest group was slightly more likely to report no opinion [308]. Two national surveys in 1975 and 1976 also reported increasing support for the idea of building more nuclear power plants in the United States; opposition showed no clear relationship to income in these surveys, while lack of an opinion increased with declining income [141]. Another survey, which asked how important respondents felt it was to build more nuclear power plants "in order to meet the future power needs of the nation," tended to support this pattern (Gallup, 1976).

A 1974 national survey inquired into feelings "about having a nuclear power plant within 20 miles of where you live" [308]. Favorability increased with income, with notably more of those over $\$ 15,000$ (69 percent) very or fairly favorable than those under $\$ 10,000$ (45 percent). Feelings of unfavorability declined with rising income, as did lack of opinion. Two national surveys in 1975 and 1976 showed increasing favorability with increasing income toward "having nuclear power as the main source of energy for electric power in your community" [141]. Opposition was not as clearly related to income, but uncertainty declined with increasing income. Another survey also showed increasing support with income of feelings about a nuclear power plant "within five miles of here," no pattern by income for opposition, but increasing lack of opinion with declining income (Gallup, 1976). A 1974 study in Los Angeles County showed family income to be positively related to support for building more nuclear power plants in the county [207].

These findings, together with those reported in the previous section where nuclear energy was compared with other power sources, show a pattern of increasing favorability toward nuclear power with increasing income, and also greater reported uncertainty among lower income groups. This is consistent with the conclusions of the review by Melber et al. (1977) who hypothesized that this pattern is due to differences among income groups in concern about economic growth and energy needs to support growth. This hypothesis is difficult to understand, however, since one would expect lower income groups to be at least as concerned with economic growth as higher income groups.

With regard to perception of safety of nearby atomic energy plants, a 1977 national survey showed those over $\$ 25,000$ to be notably more likely to consider one safe than those under $\$ 7,000$, while low income groups were again more likely not to know [148]. No strong patterns by income were evident in a 1974 national survey that asked about "serious problems associated with nuclear power plants" [308]. But another survey showed that belief that nuclear plants "are safe enough" declined with declining income: notably more of those $\$ 20,000$ or over (44 percent) believed they were safe than those under $\$ 3,000$ (20 percent) (Gallup, 1976). These findings suggest that differing perceptions of nuclear safety account at least in part for income-level difference in attitudes toward nuclear power as a source of energy. 
A 1977 national survey showed that for both the issue of making decisions on atomic plant siting and that of atomic waste disposal, higher income groups were notably less in favor of having the voting public make these decisions than were lower income groups [152].

\section{Energy Conservation}

To interpret survey results in the appropriate context, it is important to consider the energy use patterns of various income groups prior to examining attitudes and behavior with regard to energy conservation. Newm an and Day (1975), in their extensive survey of energy consumption patterns, discovered that the poor used less energy and paid more for it (as a percentage of income) than did other income groups. Warkov (1976) similarly found that in the Houston metropolitan area, the higher was the income, the higher the consumption of energy and the lower the relative proportion of household budget spent on energy. Unseld et al. (1978) confirmed this pattern of minimal energy use and high proportion of income devoted to energy costs among a sample of elderly poor residents of New York State. This pattern of usage can be expected to influence conservation behavior and attitudes.

A 1973 national survey asked respondents if they thought "controls on the use of energythat is, gasoline, oil, and electricity-should be made more strict, less strict, or kept about the same as they are now?" [212]. Support for more strict controls increased with income: those over $\$ 20,000$ were notably more likely to support such a position (49 percent) than were those under $\$ 3,000$ (29 percent); the latter group were notably more likely (61 percent) to favor "about the same" controls than the former (41 percent). Few (no more than seven percent of any group) favored less strict controls.

A 1976 New Hampshire survey indicated that support for time-of-day pricing for electricity increased with income [253]. Thís suggests less perceived flexibility in energy use patterns among lower income groups, most likely reflecting minimal usage. This survey found little difference by income in concern expressed about the amount of electricity being used in the home. A 1973-74 national survey found the lowest preference for daylight savings time in the lower income classes, again perhaps reflecting less flexibility in time patterns of energy use among this group [142].

A Michigan survey found no difference by income in eight of 10 items measuring attitudes toward conservation [106]. More low income people (50 percent) than high (40 percent) agreed that "If most Americans continue their present high level of living they will deprive people in poorer parts of the world of basic necessities." A 1977 Denver study showed no income differences in interest in membership in conservation-oriented organizations [120].

A 1977 national survey found slightly more of those making over $\$ 15,000$ than those making under $\$ 7,000$ agreed that a more austere life due to energy shortages would be a good thing (see description of this item in section on age) [150].

One survey found those making under $\$ 7,000$ to be more inclined to report making a "great deal of effort to save energy, compared with other people you know" (Opinion Research Corporation, 1974). A 1975 national survey that asked this same question revealed the same pattern [134]. A 1977 Denver study revealed that higher income groups gave higher estimates of utility costs that could be saved through conservation. One survey revealed no difference by income in opinion on "how much impact personal 
conservation efforts have on total consumption of energy" (Opinion Research Corporation, 1974d). A Michigan study showed that low income groups were more likely to believe that "the amount of energy all American families could save is unimportant compared to the amount of energy that government and industry could save" [106]. These findings suggest that lower income groups, most likely because they have little room to curtail energy use, see little potential for significant savings through conservation by consumers, yet they reported more effort to conserve, probably out of economic necessity.

A 1974 national survey revealed that the lowest income group (under $\$ 10,000$ ) was slightly more likely than the middle $(\$ 10,000$ to $\$ 15,000)$ to see "the public" as having the most responsibility to see to it "that we do not use up our supplies of natural resources" [137]. Similarly, somewhat fewer of the lowest than the highest group rated the federal government's job in this effort "poor"; the same pattern held for ratings of "the business community" and "the public" [139]. Another survey conducted in Ohio in 1975 again revealed that more high income than low income people believed that "the electric company is doing as much as it should to help people save on electricity" [122]. The lowest income group was least likely to say that "most big companies and institutions" were not doing anything to save electricity; however, this group was also least likely to believe they were, while 30 percent did not know. This survey also found the lowest group slightly less inclined to believe that "most people" are doing anything to save electricity. The lowest group was least inclined to believe that electricity was "being wasted or used unnecessarily." Belief that electricity was being wasted in nonresidential use tended to increase with income. It is difficult to discern a clear pattern of income difference regarding perceived efficacy of personal efforts to conserve, or with regard to ratings of efforts in various sectors. Low income groups appeared to be confused or of mixed opinion on these issues.

Survey results on energy conservation behavior are numerous and difficult to interpret. A Michigan study indicated that on all five items in which respondents were asked how difficult it would be to reduce energy consumption, low income groups reported more difficulty, particularly in reducing the temperature of homes in winter when sleeping, probably indicating already reduced use [106]. Similarly, a 1974 national survey showed a somewhat greater tendency for low income groups to report keeping specific rooms lighted, while a preference for keeping the whole house "lit up" increased with income [139]. These findings tend to confirm a pattern of already minimal use among lower income groups who would therefore be less likely to report new energy conservation behaviors.

A 1974 Los Angeles County study revealed no variance by income in energy use reduction [207]. A 1975 study in New York revealed a significant positive correlation between income and conservation behavior, as revealed in a five item "Changed Practice Index" ( $\leq$.05) (Kilkeary, 1975). A 1974 national survey also showed increasing energy conservation actions with increasing income, in particular, for turning off household lights and adjusting thermostats downward [260]. Talarzyk and Omura (1975) reported that highest income groups are most likely to report changes in activities to conserve energy. Warren and Clifford (1975) similarly reported more conservation efforts with increasing income, with a sharp break at $\$ 10,000$. Grier (1976) reported that energy conservation measures were directly and positively related to income, with some exceptions in the middle income categories. A 1975 Ohio study showed that higher income groups reported increased cutting back on heat or air conditioning [122]. In this study, the middle group reported more cutting back on use of washing machine/dryer/dishwasher (probably reflecting differential ownership of these 
appliances). A Michigan study similarly showed higher income groups reporting more limiting of hot water for bathing, dishwashing and washing clothes, and for sharing equipment such as lawn mowers and power tools. Lower income groups reported more cleaning and servicing of heating equipment [106].

Taken together, the above findings can be interpreted as indicating that lower income groups reported less conservation behavior than higher groups because they are already using minimal energy. A 1975 Texas study, however, revealed that lower income groups claimed greater conservation efforts. A 1976 national survey showed that the lowest income category was somewhat more likely than other groups to report that their children had made special efforts to save electricity or heat "as a result of things they learned in school." A 1975 Texas study showed that upper income groups will continue to consume energy despite price increases, while low groups are already at a minimum. The middle groups have the most flexibility and show the greatest decrease in use in response to price increases (Walker and Draper, 1975).

A 1977 national survey showed that driving less to reduce energy use increased with income [220]. On 11 other items, differences showed no clear pattern of income relationship; it did appear that middle income groups had a tendency to report more conserving behavior than other groups in general.

The pattern revealed in these results is the following: higher income groups tend to report more conservation than lower income groups in general; this most likely is a function of their higher absolute levels of consumption and consequent ability to cut back. There appears to be a level of income above which conservation decreases, most likely due to insensitivity to energy costs.

\section{Energy Conservation in Transportation}

A large number of surveys inquired about conservation in the transportation sector by income categories. A 1977 national survey revealed that the only difference in size of car ownership by income was that those over $\$ 25,000$ were slightly more likely than those under $\$ 7,000$ to own a full-size car. The former group was also somewhat more likely than the latter to plan to buy one [150]. However, a 1978 national survey revealed no income differences in concern with gasoline mileage [308]. A Michigan study also reported no differences in keeping cars "in good running order" [106]. But a 1975 national survey showed that those under $\$ 10,000$ were somewhat less likely to get cars tuned every six months than were higher groups [144].

A 1973 national survey showed somewhat more of higher than lower income groups believing a $55 \mathrm{mph}$ speed limit was a good idea, and they were also somewhat more inclined to consider it a poor idea, while lower income groups were notably more inclined not to have heard of the energy crisis [211]. A 1977 national survey found opposition to the $55 \mathrm{mph}$ speed limit increasing with income, though most $(69$ percent or more of all groups) favored it [217]. Lower income groups tended to report less compliance with this law; however, a Michigan study found no difference in compliance [106]. The 1977 survey also found increasing support by income for a $55 \mathrm{mph}$ or higher limit for trucks [217]. Reports that it would be very difficult to reduce driving by one-fourth increased with income, with the highest group notably more likely than the lowest to report this, as revealed in a 1977 national survey [310]. This survey found no clear pattern of difference by income on opinion regarding the importance of reducing driving by one-fourth, but higher income groups tended to consider it less important than did lower groups [310]. A 
1974 Washington, D.C., study reported increasing travel restrictions among higher income groups [121]. But a 1975 Kentucky study found that poverty groups were more likely than high income groups to say they would voluntarily use a car less of ten [221]. A 1973-74 national survey showed that of four methods to cut down on use of gasoline (tune-up car, drive slower, buy car with better mileage, cut amount of driving), all were positively related to income [142]. A Michigan study found that of eight possible transportation-related behaviors, on only one (taking vacations close to home) was there an income difference: lower income groups were more likely to report this [106]. A 1976 national survey showed those over $\$ 15,000$ to be slightly to somewhat less likely than lower income groups to report that they did not drive their children around less "because of things they learned in school" [130]. These findings on driving behavior or attitudes suggest no compelling differences by income.

Eight surveys looked at various policies for saving gasoline. A 1974 national survey showed declining support by income for a policy of higher gasoline prices for those driving over 200 miles per week [308]. Higher income groups were also least supportive of higher gasoline prices for those with cars getting less than $15 \mathrm{mpg}$, but this survey showed no difference in preference for higher taxes on gasoline as opposed to higher taxes on cars with low mileage. A 1974 national survey found the same lack of difference on the latter item [132].

A 1974 national survey showed those in the $\$ 10,000$ to $\$ 15,000$ range to be somewhat more supportive than the lower group and slightly more supportive than the higher group of conserving gasoline as opposed to paying higher prices and using as much as one wants [308]. Three national surveys, one in 1974, one in 1974-75, and one in 1975, showed the highest income group to be least favorable to rationing with maintenance of current prices, while support for higher prices and somewhat limited availability increased with income. Few of any group favored substantially higher prices with unlimited availability $[129,131,308]$. Another 1974 survey showed a similar pattern, but in this the middle income group most favored rationing [132]. A 1975 Kentucky study also showed that lower income groups favored rationing [221]. A 1975 national survey also showed increasing support by income for paying higher prices with no rationing. It showed also that higher income groups felt that raising prices was the most effective method of solving the energy problem [134]. A 1977 national survey also showed increasing opposition to rationing with income [310], while another survey in that year showed increasing support with income for price increases as opposed to rationing [220]. Another 1977 national survey showed no clear differences by income on nine alternatives proposed as ways to reduce gasoline consumption; there were differences between various income groups on various proposed measures, but no direct relationships with income were apparent [310]. The obvious and compelling pattern in these revealed attitudes toward gasoline policy is one of self-interest: lower income groups favor rationing with lower prices, while those who are better able to afford higher prices consistently oppose limits on availability of gasoline.

A 1975 national survey revealed that higher paid individuals were more likely to drive themselves to work, as did a 1973-74 national survey [142, 144]. The latter survey showed no clear pattern of use of public transportation by income. A 1975 national survey showed the highest income group to be notably more likely than the lowest to consider driving one's own car more expensive than using public transportation; the latter were slightly more likely than the former to consider public transportation more expensive [129]. This survey showed no difference by income among those reporting they would not use public transportation if it ran twice as of ten; the highest income group was notably more likely than the lowest to say they would, while the lowest group was more 
likely not to know. The highest income group was somewhat more likely and the middle slightly more likely than the lowest to believe that "more and better mass transit" would benefit the United States as a whole as opposed to only those who use it. Again, the lowest group was more likely not to know. With regard to use of a "park and ride" system, a 1974 national survey showed that those of higher income were more inclined to say they were "not too likely" to use it [308]. No difference by income was found in preference for carpooling, as revealed in a 1974 national survey [132].

\section{Summary}

Because of the varying number and types of income categories employed in the present universe of surveys, firm patterns of attitudinal or behavioral differences by income group are few. Nevertheless, it was possible to discern several income-dependent patterns of findings.

It appears that belief in the energy crisis was somewhat related to income level, with higher income groups generally expressing greater belief in the reality of the crisis. Data on perceived salience of the energy issue in relation to other issues, as differentiated by income, also tend to support the above conclusion.

No clear patterns were discovered concerning perceived responsibility for the energy situation, as differentiated by income level.

There appeared to be a weak, but inconclusive, pattern of differences by income regarding future long-term energy shortages, with higher income groups tending to express greater belief in such a possibility.

Lower income groups tended to favor policies that would keep consumer prices low; for other policy options, no consistent income-dependent patterns were evident.

Lower income groups tended to be more supportive of environmental quality, except where this was posed as entailing higher consumer costs; in such a case, lower income groups generally favored lower costs over environmental quality.

A clear pattern of difference by income was revealed with regard to knowledgeability about the energy situation: those of higher income generally reported greater knowledge about energy issues.

Higher income groups expressed a consistently greater preference for solar energy as a power source than did lower income groups. The same consistent pattern was found regarding nuclear energy.

Lower income groups reported more general efforts to conserve (indicative most likely of a concern for energy costs), but generally reported fewer new energy conservation efforts or changes in behavior (most likely due to a pattern of already minimal energy use). There is some indication of a curvilinear relationship between income and conservation efforts, however, with most conservation among middle income groups. High income groups appeared to be most insensitive to price-induced conservation. The lowest income groups tended to express confusion or to be of mixed opinion on matters of energy conservation. 
There were no clear pattems of differences by income regarding driving behavior. A clear pattern was evident, however, with regard to gasoline pricing policy: lower income groups tended to favor any policies that resulted in lower prices even if this entailed rationing, while higher income groups clearly favored policies that did not limit availability.

\section{OCCUPATION}

The occupation of the respondent was used in many of the surveys to analyze attitudes tow ard energy policies and practices. The occupational categories used by the various major survey firms are different, however, and not comparable in all cases. Gallup surveys use "professional and business," "clerical and sales," manual workers," and "nonlabor force." ORC surveys use the most general categories-"blue collar," "white collar," and "not employed."

The Roper occupational categories are similar to those of ORC-"executiveprofessional," "white collar," and "blue collar."

Other surveys included particular occupational groups such as "craftsmen-operative" [303], "laborer" [303], "farmer/farm laborer" [143], manager/ proprietor" [143] and "military" [252].

One of the most difficult comparisons is between the general eategories of blue and white collar workers and the more specific job categories, particularly when the latter may include both white- and blue-collar individuals. Additional problems occur with trying to order occupational categories by income or other characteristics likely to influence energy attitudes and behaviors.

\section{Perception of the Energy Situation}

A 1976 study in Grand Rapids, Michigan, found sizable differences in perception of and belief in an energy-related problem between the large business professionals and other occupations sampled (77 and 53 percent, respectively) [119]. Small business white collar workers and manual workers were not appreciably different in their responses, although the data showed the perception of an energy-related problem to increase as skill levels inereased.

Gallup polls in the spring and late fall of 1977 asked respondents whether they felt the energy situation in the United States was serious, fairly serious, or not at all serious [175, 218]. There were minor diff erences between occupational groups in the earli er poll, with 52 percent of the professional and business persons saying the situation was very serious and 38 percent saying it was fairly serious. The data showed an increased perception of seriousness as skill levels increased. The discussion of the spring poll reported the percentage changes following President Carter's appearance on television. The professional and business group had not changed, but there was a 10 percent increase in the clerical and sales workers saying that the situation was very serious and a four percent increase in the manual workers. The fall poll reflects a drop in the professional and business category (52 to 43 percent), but no change for the other groups. The perception of a fairly or very serious situation was high for all groups in both polls (78 percent or greater). 
A Roper poll in January 1977 found 31 percent of the people concerned about the fuel and energy crisis, with a slight tendency for higher occupation and skill levels to be more concerned [154. These results are consistent with the findings of Thompson and Mactavish (1976) that the two percent who believe in a real and persistent shortage and have adopted a variety of conservation measures tend to be at the skilled and professional occupational levels.

In December of 1973, with the oil embargo and the energy crisis fresh in mind, a national Gallup poll found nonsignificant differences between occupational categories when asked, "Who or what do you think is responsible for the energy crisis?" [213] In 1975 an ORC study asked a related question concerning the likelihood that the oil exporting countries would again cut off oil to the United States during the following 12 months [129]. White collar workers were somewhat more likely than blue collar workers to feel that such a cutoff was very or fairly likely (62 percent and 52 percent, respectively). A Roper poll in June 1977 explored in more detail where groups lay the blame for the energy crisis[151]. Patterns for all occupational groups were very similar, with major or some blame on the Administration, Congress, electric power companies, oil companies, American consumers, and the Arab countries, and some or no blame on the environmentalists and Israel. The only sizable difference between groups was that blue collar workers were less likely to blame the American consumer than were other groups.

Only one study asked whether there had been actual job losses due to the energy crisis. This study, limited to the Washington, D.C., area, found that somewhat more blue collar workers than professional or white collar workers (23 and 16 percent) had experienced layoffs or job hour cuts in their families [121]. This may not reflect the national pattern, since the Washington, D.C., area is heavily professional and white collar, with limited industry.

Expectations for future shortages of oil and national gas were addressed by surveys in $1974,1975,1977$, and 1978. A Roper poll in May 1974 asked individuals whether they felt there would be a gas shortage during the summer [172]. More than half of all groups agreed with the need to continue to use less gas with a slight tendency for the executiveprofessional group and the white collar workers to agree more of ten than the blue collar workers $(65,62$, and 55 percent, respectively). A Michigan survey in 1975 found that professionals and managers in large businesses were more likely than any other occupational group to say that the U.S. and world supplies of oil and natural gas would run out in the near future; the skilled labor group was almost as likely to say that U.S. natural gas would run out [119]. Roper polls asked the same question about the future oil shortage in 1974 and 1978 [172; Roper, 1978c]. In both cases, blue collar workers were more likely than other groups to say that the shortage was never real, only contrived, and less likely to say that the oil shortage was real and would get worse (see Table B-27).

In July of 1977, however, a Roper survey did not find any differences between occupational groups in perceiving a severe energy shortage during the following year [150]. Over two-thirds of all groups felt that a severe shortage was somewhat or very likely.

A number of studies explored perceptions of and preferences for long-term energy sources. A 1975 Roper survey found that the executive-professional group was most favorable toward solar energy (67 percent) and the white collar was most favorable toward nuclear energy (60 percent) [212]. In March 1977, Roper found that higher occupational levels were more favorable toward solar energy as the best long-term source of energy, (executive-professional, 79 percent; white collar, 73 percent; and blue collar, 67 percent) [152]. 
TABLE $\quad B-27$

OPINION ABOUT FUTURE OIL SHORTAGE BY OCCUPATION*

Here is another list of statements about the gasoline and ofl shortage which one of those statements comes closest to expressing your opinion?

Response

Proportion Responding
Executive/
Professional
$\underline{1974 \quad \text { White Co11ar }} \quad$ B1ue Collar

There is a very real

oil shortage and

the problem will

get worse during

the next 5-10 yrs.

There is a real oil

shortage but it will

be solved in the

next year or two.

There was a short-term

$33 \% \quad 43$

$25 \quad 39$

$15 \quad 28$

problem but it has

been largely solved

and there is no

problem any longer.

There never was a real

oil shortage, it was

contrived for eco-

nomic and political

reasons.

None

Don't know/no

answer

$9 \quad 13$

14

9

$11 \quad 7$

49

$8 \quad 8$

$7 \quad 9$

*1974 study: $172 ; 1978$ study: Roper, $1978 \mathrm{c}$ 
A 1976 survey in five regions [303] asked individuals which sources of electrical energy they felt should be used the most. All occupational groups selected solar and hydroelectric sources as their first two choices. For solar energy, professional and white collar workers were more favorable than craftsmen and laborers $(44,45,31$, and 28 percent, respectively). There was no difference between groups on hydroelectric preferences.

Skill and occupational levels were found to be positively related to perception of an energy problem and its seriousness, and pessimism about future shortages. There was no clear pattern of relationship regarding perceived blame for the energy situation, however. Higher occupational levels were more likely than other groups to perceive solar as the best long-term source of energy.

\section{Policy Preferences}

The 1976 survey in five regions also explored approval of and preferences among energy policy options. No difference was found among occupational groups on approval of two policies: (1) maximizing U.S. production of energy and importing whatever else was needed, and (2) maximizing U.S. production while limiting usage. The third policy, rationing energy usage and importing none, produced a difference between the professional/managerial group and the craftsman and laborers (19 percent versus 28 and 29 percent, with white collar at 24 percent) [303].

When asked which of these three policies they felt was the best, there was no difference between occupational groups. About half of each group voted for producing the maximum and limiting usage, and about one-third voted for producing the maximum and importing the rest.

A 1975 Gallup survey of attitudes toward oil import policies found no differences among occupational groups [214]. About three-quarters of all labor force groups said that the United States should try to reduce the amount of oil imported from other nations. A 1978 Roper survey, however, did find differences among occupational groups on perceived ability to get along without foreign oil during the next five years, with blue collar workers most positive (percentage saying we cannot get along without foreign oil during the next five years: executive/professional, 56 percent; white collar, 53 percent; blue collar, 44 percent) [180]. Another Roper survey (1978c) found blue collar workers more likely than other groups to feel that more controls, especially price controls, were needed on gasoline.

The perception of the government's handling of the energy situation was a frequent topic in the surveys. Gallup polls in February and August of 1977 explored public approval for President Carter's handling of the energy situation [217, 309]. In February the professional and business group and the manual workers were somewhat more likely than clerical and sales workers to be approving of Carter's energy management $(62,64$, and 53 percent, respectively). By August these differences had faded, and approval by all three groups was between 42 and 49 percent. The drop in approval showed in disapproval of the President's management rather than in the no opinion response. For clerical and sales workers, and for manual workers the percent approving and disapproving were about equal (41 to 44 percent), while the professional and business group was still somewhat more positive ( 49 percent approved and 38 percent disapproved). 
Reactions to Carter's energy plan were solicited by Gallup in late spring of 1977 [218]. The professional and business group was slightly more likely than manual workers to view the plan favorably (59 and 53 percent), while the clerical and sales workers were somewhat less favorable (49 percent). There were only minor differences between the three groups concerning whether the energy plan required too many sacrifices: 31 to 38 percent said too many; 29 to 33 percent, about right; and 24 to 32 percent, not enough.

A Roper survey in November 1977 found the executive-professional group more likely than the other groups to feel that the steps called for in Carter's national energy plan did not go far enough (32 percent versus 21 percent of the white collar group and 23 percent of the blue collar group) [147]. A later Roper survey in March 1978 [180] found the executive-professional group still more disapproving than other groups of Carter's positions on and handling of the energy crisis.

Roper found in 1977 that the executive-professional and white collar groups were slightly more likely than blue collar workers to say that a major effort should be devoted to developing new energy sources and conservation methods $(92,91$, and 86 percent, respectively) [151]. In another survey during the same year [168] and in 1978 [180], Roper found a similar tendency for higher occupational levels to want Congressmen and Senators to give major attention to developing a national energy policy.

The surveys as a whole did not find differences by occupational group on policy preferences. There are also no clear differences on approval of Carter's handling of the energy situation.

In March 1977 Roper pursued the question of whether major energy issues should be decided by the voting public or by other groups (such as expert groups) [152]. Blue collar workers were less likely to trust groups other than the voting public to decide how atomic wastes should be handled and what the speed limit on highways should be. No difference was found between groups as to who should decide on nuclear power plant sites.

\section{Energy and the Environment}

A survey by ORC in 1975 found white collar workers more favorable than blue collar workers toward strip-mining regulations ( 52 to 40 percent) [128]. The percent responding that it was more important to have lower electricity prices was 37 percent for white collar and 44 percent for blue collar workers.

A survey of five regions in spring and summer of 1976 [303] found professional and white collar workers more likely than craftsmen and laborers to approve a 10 percent increase in the cost of electricity to pay for pollution-free energy (79 percent and 76 percent versus 68 percent and 69 percent).

However, no occupational differences were found by Gallup in late spring of 1977 when a national sample was asked whether the air pollution standards should be relaxed to permit greater use of coal or should be kept as they are [218].

A Roper study in September 1977 also found no occupational differences when individuals were asked whether they favored adequate energy or protection of the environment in a crunch [148]. (The preferences were somewhat polarized with a total of 43 percent for adequate energy and 35 percent for environmental protection.) No difference between occupational groups was found on whether environmental regulations had gone too far. 
Table B-28 summarizes an analysis of a Roper study in October 1976 reported in Melber et al. (1977) which compared attitudes on the energy-environment tradeoff in 1975 and 1976. F or all occupational groups there was a shif toward the environment.

Six studies analyzed attitudes towards the energy-environment tradeoff by occupational level. The only repeated finding was that white collar workers were more favorable toward environmental protection than blue collar workers in cases where energy costs would increase.

\section{Knowledgeability and Information Sources}

A survey in three major urban areas (Phoenix, Kansas City, and Minneapolis) found a nonsignificant relationship between occupation and level of knowledge about solar energy systems [302].

A Gallup poll in late spring of 1977 found that professional and business workers were less likely than other groups of workers to think that domestic oil production was sufficient to meet current needs and more likely to state that we need to import oil from other countries (see Table B-29) [218].

A related question asked what percent of oil used in the U.S. was currently imported from other countries. The patterns of estimate for the professional and business group and the clerical and sales group were similar, with the largest number of responses for both groups in the 40 to 49 percent and 50 to 59 percent categories. The pattern of responses for manual workers was somewhat different with the peaks in the 20-29 percent and 40-49 percent categories.

The percentage of workers following the discussions in the media on nuclear energy development was 75 percent or above for all categories (Gallup, 1976). Professional and business workers were very high (94 percent).

Survey samples from five regions were asked whether they had heard anything about solar energy and wind energy as sources of energy [303]. Professional-managerial and sales-clerical workers were more likely to have heard about solar energy ( 85 percent and 87 percent versus 75 percent for craftsman-operative and 66 percent for laborer). The professional-managerial and craftsman-operative were also more likely than the other groups to have heard about wind energy (62 and 58 percent versus 52 for sales-clerical and 51 percent for laborer).

A Roper survey in January 1975 explored what would happen if different statements were issued by different sources on the reason for a price rise of gas and oil. All groups were most inclined to believe Ralph Nader's office and least inclined to believe the major oil companies [170]. Blue collar workers were not as favorable toward Nader as other groups, even though he was their first choice; they were also less negative toward major oil companies.

The surveys show a positive relationship between occupational level and knowledge about the energy situation and about alternative energy sources. Not enough studies addressed credibility of information sources for a pattern to emerge. 
TABLE $\quad B-28$

ATTITUDES ON THE ENVIRONMENT-ENERGY TRADE-OFF BY OCCUPATION*

\begin{tabular}{|c|c|c|c|c|c|c|}
\hline \multirow[b]{3}{*}{ Occupation } & \multicolumn{6}{|c|}{ Proportion Responding } \\
\hline & \multicolumn{3}{|c|}{ Energy } & \multicolumn{3}{|c|}{ Environment } \\
\hline & 1975 & $19 \overline{76}$ & Difference & 1975 & 1976 & Difference \\
\hline \multicolumn{7}{|l|}{ Blue } \\
\hline collar & $40 \%$ & 32 & -8 & 41 & 44 & +3 \\
\hline White & & & & & & \\
\hline collar & 40 & 31 & -9 & 40 & 49 & +9 \\
\hline \multicolumn{7}{|l|}{$\begin{array}{c}\text { Executive/ } \\
\text { profes- }\end{array}$} \\
\hline sional & 50 & 39 & -11 & 33 & 43 & +10 \\
\hline
\end{tabular}




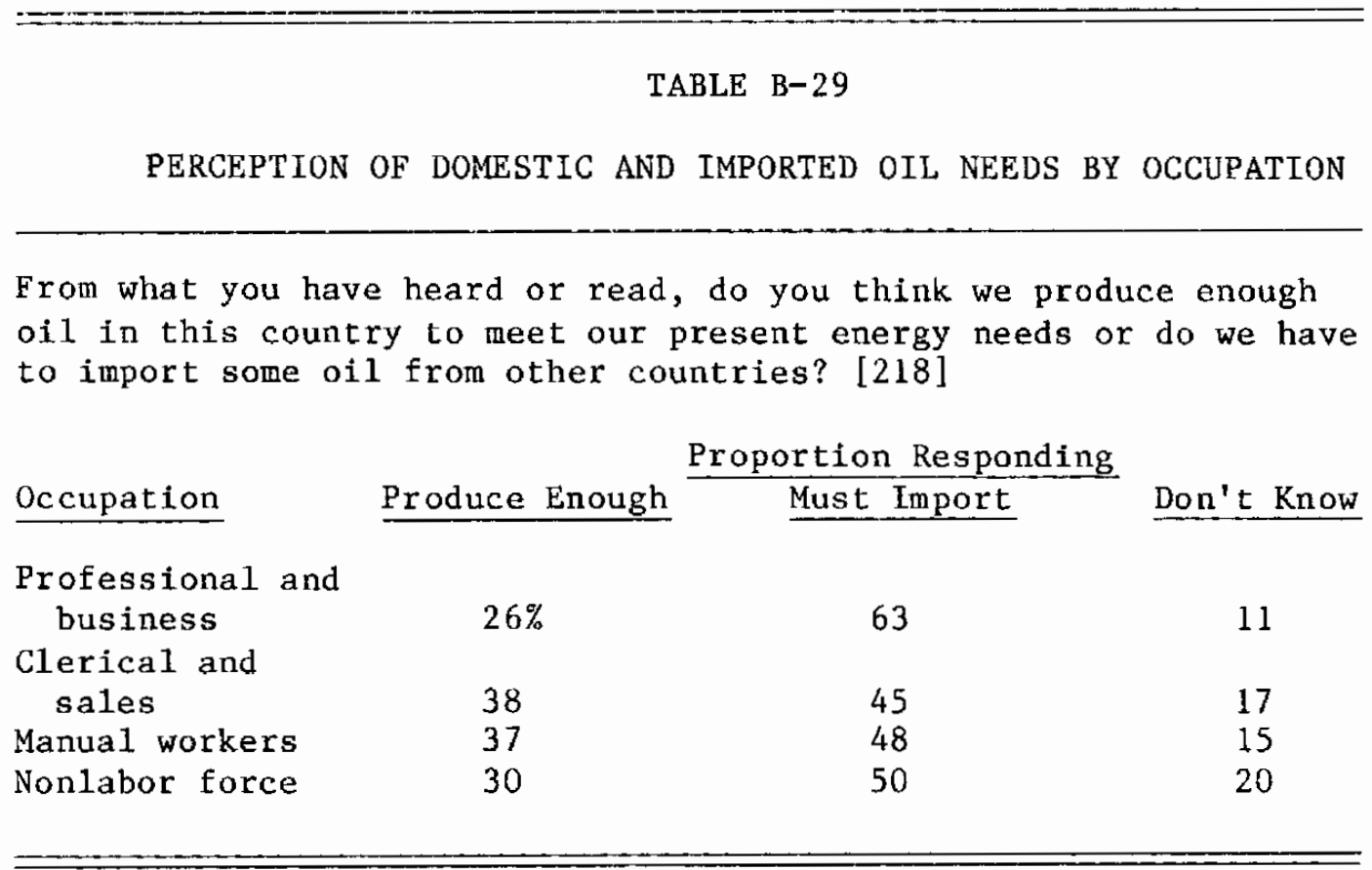




\section{Attitudes Toward Solar Energy}

In the spring and summer of 1976, five regional samples were asked about their preference for solar and wind energy as sour ces for production of electricity [303]. Using the pooled data, there were no marked differences between occupational groups for either solar or wind energy preferences. For all occupational groups, however, 90 percent or more responded favorably to solar energy as a source and 82 percent or more responded favorably to wind energy. In both cases, the professional-managerial group was slightly more likely than the others to respond favorably. Roper surveys in 1975 and 1977 [152, 212] also found the executive-professional group most favorable toward solar energy (67 and 79 percent, respectively).

Workers in three major urban areas were asked for their estimates of when solar energy would be in general use [302]. Professional workers were more likely to say 10 to 20 years than 10 years or less (43.4 versus 28.3 percent); white collar workers were more likely to say 10 years or less (46.7 versus 29.3 percent for 10 to 20 years); and blue collar workers were fairly evenly split between the choices $(28.9$ percent for 10 years or less and 33.9 percent for 10 to 20 years). For all three categories between five and 10 percent of the workers felt that solar energy would never be in general use.

A 1974 survey of Phoenix, Kansas City, and Minneapolis explored attitudes about the attractiveness of solar energy and the willingness to buy solar devices [302]. Occupation was found to be significantly related to what people found attractive or unattractive about solar heating and cooling. The blue collar workers mentioned no attractive features, and mentioned cost as the least attractive feature. Professionals were more likely than other groups to mention cost as the least attractive feature, but mentioned three attractive features: availability, savings in fossil fuels, and no pollution (in descending order of importance). A nonsignificant relationship was found between occupation and willingness to buy a solar water heater if it cost the same as other units. The relationship was significant, however, if the cost of a solar heater was higher than other units, with professional workers more likely to consider purchase. A nonsignificant relationship was also found between occupation and favoring the use of tax incentives to support use of solar energy.

When asked to estimate the cost of installing solar heating and cooling systems in their homes, each group was most likely to guess $\$ 1,001$ to $\$ 5,000$ [252]. The managerialadministrative group and the military group were somewhat more likely than the others to guess over $\$ 5,000$. Actual figures are shown in Table B-30.

A January, 1979 national survey showed that one percent of executive/professional workers reported solar ownership, as did one percent of blue collar workers. Less than 0.5 percent of white collar workers reported ownership (Roper, 1979). The same survey showed that about a fifth of executive/professional and white collar workers might buy a solar system in the next two to three years compared to 16 percent of blue collar workers.

In general, the professional and managerial groups were more favorable toward solar energy.

\section{Attitudes Toward Nuclear Energy}

In June 1976 a Gallup poll on the importance and safety of nuclear power plants found small differences between occupational groups on the importance of having more nuclear 
TABLE B-30

ESTIMATED COST OF SOLAR SYSTEM BY OCCUPATION

Understanding that it would probably be a rough guess, what would you estimate it would cost to have a solar energy system installed in your home which would take care of room heating and supplying water? [252]

Proportion Responding

\begin{tabular}{|c|c|c|c|c|c|}
\hline Cost & $\begin{array}{c}\text { Professiona1, } \\
\text { Technica1 } \\
\end{array}$ & $\begin{array}{l}\text { Proportio } \\
\text { Managerial, } \\
\text { Administrative }\end{array}$ & $\begin{array}{c}\text { Respondi } \\
\text { Sales, } \\
\text { Clexical } \\
\end{array}$ & $\begin{array}{l}\text { ng } \\
\text { Operative, } \\
\text { Craft, Labor }\end{array}$ & Military \\
\hline $\begin{array}{l}\$ 1,000 \\
\text { or }\end{array}$ & & & & & \\
\hline $\begin{array}{l}\text { less } \\
\$ 1,001 \\
\text { to }\end{array}$ & $25 \%$ & 21 & 23 & 21 & 16 \\
\hline $\begin{array}{l}\$ 5,000 \\
\text { Over } \\
\$ 5,000\end{array}$ & 56 & 46 & 62 & 58 & 46 \\
\hline
\end{tabular}


plants (Gallup, 1976). The professional and business group was somewhat more likely than other groups to state that plants operating under current regulations were safe enough (44 versus 32 percent for clerical and sales workers and 35 percent for manual workers). The professional and business people and manual workers were also somewhat less likely than clerical and sales workers to oppose the construction of a nuclear plant within a five-mile radius $(43,42$ and 59 percent, respectively).

A similar finding resulted when a sample of Tennessee residents were asked about construction of a nuclear power plant near Hartsville [143]. The results are shown in Table B-31.

A September 1977 Roper survey found the executive-professional group somewhat more likely than other groups to say that atomic power plants were safe [148]. Blue collar workers felt they were the most dangerous. A Roper study in March 1978 found blue collar workers less likely than other groups to favor the selling of nuclear power plants by the United States to other countries [180].

In general, the studies consistently show the professional and managerial groups to be more favorable about the construction of nuclear plants. They also were more likely than blue collar workers to feel that nuclear plants were safe.

The survey of the literature by Melber et al. (1977) found that, in general, the more prestigious the occupation, the more support for nuclear power and the less uncertainty about it. Variations in opposition across occupational levels were minimal.

\section{Attitudes Toward Conservation}

A two-year study in Lansing, Michigan found a reduction in household energy consumption from 1974 to 1976 [106]. The overall decrease was not, however, found to vary significantly by occupational status.

A Gallup poll in the summer of 1977 asked what people were doing to conserve energy [220]. Professional and business people favored driving less and turning down the thermostat. Clerical and sales persons favored turning off lights in the home and general conserving behaviors, and manual workers favored driving less and turning off lights. In all groups, 10 percent or fewer of the people were insulating their homes, limiting their use of hot water, or participating in carpools.

Policies to force controls on energy consumption or to provide incentives for conservation were explored in a variety of surveys. A national Gallup poll in 1973 found about half of the persons in the professional and business group and the clerical and sales group favored stricter controls on the use of energy, with about one-third of the manual workers favoring stricter controls [212]. No more than seven percent in any of the groups favored less strict controls, however.

All labor force groups strongly favored reducing the consumption of gasoline through price increases rather than through rationing [220]. They also overwhelmingly favored keeping the $55 \mathrm{mph}$ speed limit (about three-quarters of each group was in favor). This is consistent with a 1973 survey in which about half of professional, business, and white collar groups (and 65 percent of the farmers) favored a lowered speed limit[211].

When asking people whether energy conservation would be more effectively pursued by raising prices slightly across the board or raising only the price of gasoline a lot, an ORC 


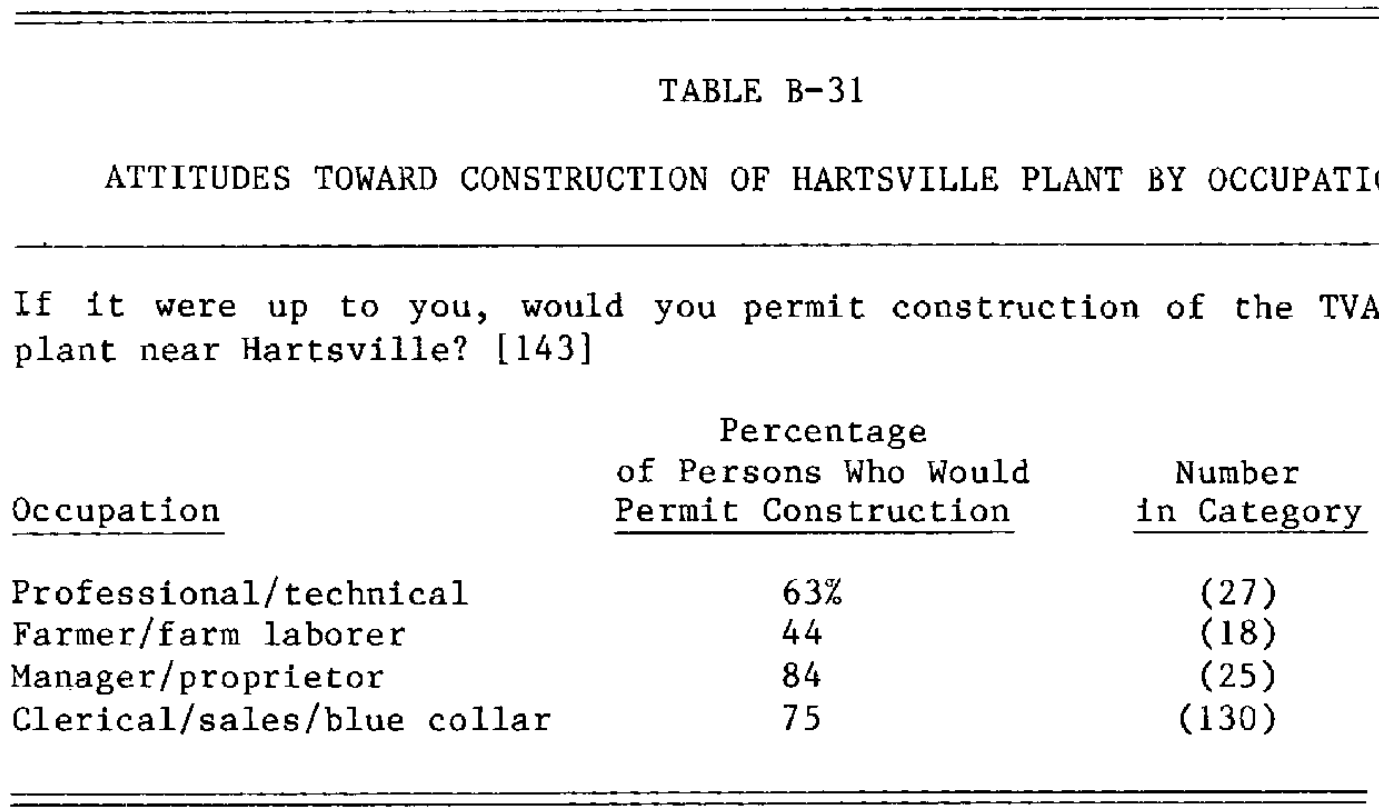


study in 1975 found white collar and unemployed persons favoring the gasoline price rise over the general price increase (white collar, 44 to 30 percent, and unemployed, 40 to 29 percent) [128]. Blue collar workers were about evenly split, with about a third preferring each policy. Fif teen to 20 percent of the workers in all three categories thought neither policy would be effective.

A Gallup poll in fall 1977 explored possible ways of reducing gasoline use [310]. Professional and business persons slightly preferred carpools, building gas-saving cars, and improving public transportation. Clerical and sales workers preferred carpools and reducing unnecessary driving. Manual workers slightly preferred the same two al ternatives.

When asked how difficult it would be to reduce their driving by one-fourth, the nonlabor force group was much more likely than other occupational groups to say it would not be difficult. The responses are given in Table B-32.

The respondents were then asked how important a personal reduction in driving by onefourth was. All three groups were more likely to say that it was fairly important rather than very or not at all important. (Twenty-three to 29 percent of all groups said that it was very important.)

A Gallup poll in February 1977 found that the 55-mph speed limit had reduced people's driving speed and that there were differences between occupational groups [217]. The percentages of drivers whose speed had been reduced were as follows: professional and business, 73 percent; clerical and sales, 58 percent; and manual workers, 62 percent. More than half of each group was in favor of applying the same speed limit to trucks (professional and business, 62 percent; clerical and sales, 66 percent; and manual workers, 54 percent). A Gallup survey in November 1977 found no difference between occupational groups in whether they favored or opposed a gasoline rationing law that would require people to drive one-fourth less [310].

An ORC survey in 1975 explored attitudes toward and perceptions about mass transit and highway tradeoffs [129]. Both blue and white collar workers were overwhelmingly in favor of spending money on mass transit rather than highways (white collar, 67 percent for mass transit versus 18 percent for highways; blue collar, 56 percent versus 28 percent). White collar workers were more likely than blue collar to perceive a great need for mass transit within a 50-mile area of where they lived and worked (41 to 26 percent). They were also more likely to say that mass transit would benefit the United States as a whole rather than just those who used it (66 percent for white collar versus 46 percent for blue collar), and that driving their own car cost more than using public transportation (66 percent versus 45 percent for blue collar).

An August 1976 survey in San Diego County explored attitudes toward retrofitting [252]. The professional/technical and operative craft/labor groups were somewhat more likely than other groups (management/administration and sales/clerical) to indicate an intention to retrofit their homes (25 and 23 percent versus nine and 14 percent).

A study in Kentucky in the latter half of 1975 asked people about transportation changes they would be willing to make [221]. Only farmers stood out as a separate occupational group in the analysis. They tended not to want to use a smaller car or to walk or ride a bike, and they said that the nature of their work and living location kept them from using a carpool. They were also more likely to say they would not use home air conditioning (64 percent of the farmers versus 56 percent of the total population and 40 percent of the metropolitan residents). 
TABLE $\quad B-32$

PERCEIVED DIFFICULTY OF REDUCING

DRIVING BY ONE-FOURTH BY OCCUPATION

Suppose you had to reduce the number of miles you drive by one-fourth. How difficult would it be for you to meet this requirement--very difficult, fairly difficult, or not at all difficult? [310]

Occupation

Very Fairly Not at All Don't

Professional

and business

Clerical and sales

Difficult Difficult Difficult Know

Manual workers

$36 \%$

43

36

Nonlabor force

17

32

30

33

29

$\begin{array}{ll}31 & 1 \\ 27 & * \\ 29 & 2 \\ 51 & 3\end{array}$

* one percent. 
A Roper survey in March 1976 asked what homeowners would do in the next two years if a tax credit were given [164]. The only differences by occupation were that blue collar workers said they were less likely to install insulation in walls and under roofs, while white collar workers said they were somewhat more likely to install new storm windows and doors.

Attitudes toward conservation did not differ appreciably by occupational level, but specific conservation behaviors did. Only one survey addressed specific attitudes toward mass transit, so no patterns can be discerned.

\section{Summary}

The general finding of the analysis is that occupational level is an important variable in studying attitudes toward nuclear power and awareness of and knowledge about the energy situation. Studies are consistent in finding that the perception of an energyrelated problem and its seriousness increased as skill and occupational levels increased $[119,154,175,218]$. White collar workers were also somewhat more likely than blue collar workers to feel that shortages of gas or oil could recur $[119 ; 150 ; 172$; Roper, $1978 \mathrm{c}$. Blame for the energy situation, however, was explored in only a small number of studies and no clear pattern of relationships was found $[129,151,213]$.

Those at higher occupational levels were found to be somewhat more favorable toward solar energy as a long-term source of energy, although it was in many cases the first choice for all groups [152, 212, 303].

There were no differences among occupational groups on preference for broad energy policies, with all groups preferring that U.S. production be maximized, usage limited, and imported oil reduced $[214,303]$.

The professional and business groups were somewhat more likely than others to approve of President Carter's handling of the energy situation and of his energy plan. They felt, however, that the handling should be stronger [147, 180, 217, 218, 309]. Those at higher occupational levels were more likely to feel that a major effort should be devoted to developing energy sources and conservation methods and that Congress should give major attention to developing a national energy policy $[151,168,180]$.

Those at higher occupational levels were more likely to follow the media discussions of nuclear energy development and to have heard of solar and wind energy [Gallup, 1976; 303]. Only one study explored credibility of energy information sources. No difference was found by occupation.

In some surveys, professional and white collar workers were more likely than other occupational groups to favor the environment in an environment-energy crunch [128, $303]$. In other studies, no occupational difference was found $[148,205,218]$.

All groups were very favorable toward solar energy, with the higher occupational levels slightly more so [303]. Professional workers, however, had a somewhat longer time horizon for solar energy to be in general use than did other white collar workers [302]. Professional groups were the most likely to consider solar energy if the costs were higher than other units [302]. 
Professional and white collar workers were more likely than other groups to say that nuclear plants are safe and that they would not oppose construction of one in their area [143; 148; Gallup, 1976].

Conservation attitudes and the extent to which conservation was practiced did not differ appreciably across groups, but the specific conservation behaviors did differ [211, 220, 310]. All workers were overwhelmingly in favor of spending money for mass transit; however, white collar workers were more likely to perceive a greater need for mass transit in their area and were more likely to say it would benefit the United States as a whole [129].

\section{RACE}

Demographic data on race found in the present universe of surveys is generally organized by the categories "white" and "black," or "white" and "nonwhite." The latter, more generic category will be employed here, except in instances where more specific categorization is employed (e.g., "Mexican-Americans"). It should be noted that because nonwhites tend to be poorer, findings regarding low-income groups can provide some insight regarding attitudes of nonwhite racial groups.

\section{Perception of the Energy Situation}

A 1975 survey in Texas and Arizona found that whites were slightly more likely to believe that "the United States currently has an energy problem" (61 percent) than were blacks (52 percent) or Mexicen-Americans (54 percent) [181]. A 1976 national survey found nonwhites somewhat more likely to describe the need to save energy as "very serious" (55 percent to 43 percent) but over 80 percent of both groups termed it "somewhat" or "very serious" [130]. A national survey in the spring of 1977 found no difference by race in ratings of the seriousness of the situation [218], but when the same question was repreated in the fall, somewhat more whites rated the situation as "very" or "fairly serious" [175]. These few and somewhat inconsistent findings lead to no conclusive pattern of findings on this question.

A 1974 national survey reported no racial differences in opinion about the possibility of a future oil shortage [172]. Another 1974 survey, however, found whites markedly more inclined than nonwhites to say that it was "not very likely" that the United States would run out of oil in the next 50 years (61 to 38 percent); nearly one-third of nonwhites reported they did not know [137]. The same pattern of response was found a few months later with regard to coal [139]. Whites, in a 1975 national survey, were somewhat more likely to expect another oil ernbargo within the next year, while one-fourth of nonwhite respondents did not know; however, nonwhites were somewhat more likely to expect long gasoline lines to re-emerge [129]. In this same survey, nonwhites were somewhat more likely than whites to expect a natural gas shortage in the next winter. A 1976 Michigan survey found that whites were markedly more likely than nonwhites to expect that the United States would have future energy problems (69 to 44 percent) [119]. A 1977 survey found whites somewhat more likely to believe that Americans should continue to use less gasoline because of the possibility of a shortage [152], but nonwhites, in a later survey, were slightly more inclined to rate a severe shortage in the next year "very likely" [150]. These findings lend themselves to no clear pattern of racial differences perceived regarding future near- and long-term energy shortages. 
A 1973 national survey found no racial differences in ascribing responsibility for the energy crisis [213], but a 1974 Los Angeles study found that blacks were less likely to blame oil companies and that blaming the President was related to black ethnicity [207]. A 1977 national survey found the following differences in attributing major blame for the energy crisis: blacks were more likely to blame the Administration, Congress, electric power companies, Arabs, and Israel; whites were more likely to blame the American consumer; there was no difference regarding oil company blame [151]. Again, no clear pattern is evident in the data.

Although, in the abstract, there were no apparent differences by race in belief in the energy crisis or its seriousness, nonwhites appeared to be more personally affected by the crisis or to report greater financial impacts. Three national surveys in 1974 [137, 139 , 308] found that somewhat more nonwhites reported that food prices had risen as a result of the energy crisis. The last survey also found that more nonwhites reported that "everything" had gone up in price. Nonwhites were also slightly more likely than whites to report that the price of gasoline had risen "a great deal" and that gasoline prices had had "a great deal of impact on inflation" [308]. A 1974 Washington, D.C., survey found more nonwhites reporting that someone in the family had been laid off or had their overtime or regular workweek cut because of the energy crisis [121]. These findings suggest that nonwhites, most likely because they tend to have lower incomes, are more severely impacted by energy shortages in a personal financial sense than are whites.

This is supported by the relative weighting given to various national problems by racial groups. A 1975 national survey found nonwhites to be slightly more concerned with unemployment, whites with inflation, and no difference in concern with the energy erisis (which ranked last for both groups) [134]. A 1976 national survey found substantially more whites expressing a desire for their Congressman or Senator to pay attention to developing a national energy policy, while nonwhites were somewhat more in favor of hiring the unemployed in government jobs or stricter food labeling [168]. This suggests that nonwhites, who in general are of lower income, tend to be more concerned with issues that affect them immediately than with abstract goals like developing an energy policy, even though they tend to be more severely affected by present policies.

A 1974 survey found no racial differences in belief in the possibility of the United States being completely self-sufficient in energy [308]; when this question was repeated in 1975 , however, somewhat more whites believed this was possible, while nearly one-fifth of nonwhites reported they did not know [133]. A 1976 survey in five states revealed that somewhat more nonwhites preferred a policy of "producing the maximum, limiting usage," while "producing maximum, importing rest," or "rationing, importing none" showed no racial difference in support [303]. A 1977 national survey revealed that somewhat more whites believed that major government effort should be placed on developing new energy sources and on conservation [151]. A 1975 national survey revealed that somewhat more whites believed the United States should try to reduce oil imports [214].

A 1974 national survey showed whites somewhat more inclined to believe that sufficient steps had been taken to deal with the energy crisis [174]. A 1975 national survey showed no racial difference in approval of "the way Carter is dealing with the energy situation"; slightly more whites disapproved [309]. The same question in February of 1977 revealed no racial differences [217]. In the spring of that year, slightly more nonwhites reported an unfavorable reaction to the President's energy plan, although there were no differences of opinion on whether or not the program called for too many sacrifices [218]. Another 1977 survey, however, found that nonwhites tended to term the plan 
"more drastic then necessary," while whites showed a slightly greater tendency to say it "didn't go far enough," and about 40 percent of each group felt it was "in line" [147]. For these findings, once again, it is difficult to discover a consistent pattern of racial differences.

\section{Energy and the Environment}

When a 1977 survey asked respondents if "environmental regulations have gone too far or not," som ewhat more whites felt they had gone too far (22 to 10 percent for nonwhites), while somewhat more nonwhites were unsure. About 40 percent of both groups found them "about right" [147]. Another 1977 survey found no difference by race in those favoring the environment as opposed to increased energy production [148]. Nonwhites were found in a 1974 national survey to be slightly more likely to associate a great deal of environmental damage with increased energy production [308]. A 1974-75 survey also revealed that slightly more nonwhites believed that power plants and oil refineries cause air pollution [131], although the earlier survey revealed no racial difference on this question [308]. This last survey revealed that slightly more nonwhites saw strip mining as the most serious problem associated with a policy of energy self-sufficiency. Although there is not compelling support, it appears that nonwhites are slightly more concerned about environmental quality than are whites. Newman and Day (1975) found that the negative effects of energy production and use (e.g., pollution) are inordinately borne by those of lower socioeconomic status.

This concern must be placed in context, however. A 1977 national survey revealed that slightly more whites cited air and water pollution and somewhat more cited the fuel and energy crisis as among their two or three major concerns; somewhat more nonwhites cited money to pay bills and recession and unemployment as concerns [154]. While nonwhites may tend to support environmental concerns, their greatest concern is likely to be personal financial problems. This is consistent with their greater report of financial impacts reported in the earlier section.

Further support for this conclusion came from the finding of a 1977 national survey that somewhat more whites favored relaxing air pollution standards in order to convert industry to the use of coal [218]. However, when a 1975 survey posed the importance of strip-mining regulations versus lower electricity prices, somewhat more whites preferred the regulations while somewhat more nonwhites favored lower prices [128]. Nonwhites were somewhat more likely, as revealed in a 1974 national survey, to support the building of power plants and refineries in unpolluted areas [308].

\section{Knowledgeability and Information Sources}

A clear pattern of greater reported objective knowledge by whites concerning energy issues is revealed in several surveys. Somewhat more whites reported in a 1977 national survey that they believed the United States must import oil, although there were no racial differences in estimates of what percentage was imported [218]. Somewhat more whites reported having seen or read articles or advertisements about gasoline mileage for new cars [308]. Substantially more whites reported following discussions on nuclear energy development in the media (Gallup, 1976). In a 1976 five-state survey, significantly more whites reported having heard of solar and wind energy [303]. A 1973 national survey found nonwhites notably more likely not to have heard or read about the energy crisis [211]. 
A 1975 survey that inquired about credibility of information sources revealed that the only differences among a variety of sources were that nonwhites were somewhat less inclined to believe Ralph Nader, and whites were markedly more likely to report they were least inclined to believe major oil companies [170]. A 1974 national survey showed that nonwhites were somewhat more likely to believe auto companies on gasoline mileage [308].

\section{Solar Energy}

A 1975 survey in Chicago revealed significantly greater support among whites for using solar energy and wind energy to produce electricity [303]. When this survey asked respondents to name the one of a variety of sources that "should be used most," more whites named solar energy (42 to 20 percent), hydroelectricity ( 22 to 11 percent), and nuclear energy (14 to four percent), while nonwhites revealed a marked preference (49 to nine percent) for oil and natural gas. Similarly, a 1977 survey found slightly more whites preferring nuclear energy, and notably more preferring solar energy as the "best longterm source," while somewhat more nonwhites preferred offshore oil, and notably more, coal [152]. One might hypothesize that nonwhites, who tend to feel the adverse effects of energy shortages more severely than whites, were expressing their concern for increased energy supplies through their preference for more conventional sources. These groups may tend to consider solar energy and other unconventional sources as capable of providing little relief to their immediate problems. Such a position was cited by the NAACP in their 1977 stance supporting deregulation of oil and gas prices and increased production of fossil fuels.*

\section{Nuclear Energy}

One survey in 1974 found nonwhites somewhat more likely to be "very favorable" toward nuclear power plants in general, but there were no differences by race in combined ratings of very and fairly favorable (70 percent of whites, 64 percent of nonwhites). In this survey, slightly more nonwhites were either very or fairly unfavorable [308]. A 1976 survey revealed somewhat more whites considering it extremely or somewhat important to have more nuclear plants, while somewhat more nonwhites had no opinion (Gallup, 1976). A 1975-76 national survey also showed more support in both years among whites for building more nuclear power plants; in both cases, one-fourth or more of nonwhites were not sure of how they felt [141]. A 1978 national survey showed no significant difference by race in support for the Hartsville reactor [145]. These findings suggest that whites have a greater tendency to express general support for nuclear power.

Further support for the conclusion that whites are more favorable toward nuclear power than nonwhites comes from several surveys that inquired about support for nuclear power in the vicinity and about nuclear safety. A 1975 national survey found somewhat more whites (56 to 39 percent for nonwhites) favoring nuclear power "as a main source of energy for electric power in your community" [141]. In 1976 the same pattern held, but fewer of both groups expressed support (50 and 41 percent). In both years, nonwhites tended to be unsure (35 and 27 percent) [14l]. A 1974 national survey also found greater support among whites (54 to 39 percent who were very or fairly favorable to "having a

*NAACP Statement of Policy on National Energy Plan, NAACP Newsletter, vol. 1, no. 9, (May 1978) pp. 3-4. 
nuclear power plant within 20 miles of where you live") [308]. Black ethnicity was found to correlate negatively with support for building nuclear power plants in Los Angeles County [207]. A 1976 survey similarly showed that somewhat fewer nonwhites would not oppose the construction of a nuclear power plant "within five miles of here" (Gallup, 1976). This survey found that somewhat more whites felt that nuclear power plants are "safe enough" (36 to 19 percent), while somewhat more nonwhites had no opinion (42 to 25 percent). A 1977 study also revealed that whites tended to see atomic plants as somewhat safer [148]. A 1974 survey revealed no racial difference in rating of a variety of potential nuclear problems, with the exception that somewhat more whites cited nuclear accidents as a cause of concern [308].

Perhaps because of the greater tendency of nonwhites to respond that they had no opinion or to be unsure about nuclear issues, fewer of this group supported the idea of the voting public making decisions about atomic waste disposal and nuclear power plant siting [152].

In summary, there is a great deal of evidence that support for nuclear power is stronger among whites than nonwhites.

\section{Conservation}

"Energy conservation" can mean many things, ranging from more efficient use of energy to accomplish the same end use to reduced consumption of energy through curtailment of various energy-consuming behaviors. Newman and Day (1975), in their survey of energy consumption patterns, found that blacks of all income groups consumed less energy than did whites.

A 1975 study in Kentucky revealed that living in a small house or apartment was one of the few energy-saving "devices" that was strongly supported by blacks; the authors hypothesized that this may reflect their present poor housing conditions [221]. This study also showed somewhat less support among blacks for turning down heat in winter. To speculate, this may have reflected already minimal levels of home heating by this group due to financial considerations. Similarly, somewhat fewer nonwhites "thought it was really worth the effort to use fewer lights to save energy," again possibly reflecting already curtailed usage [139]. This survey found slightly more nonwhites saying they felt more comfortable with one or two, as opposed to many, lights on, while whites were somewhat more likely to say it made no difference. A 1973-74 national survey found greater support among whites for year-round daylight savings time [142]. A 1977 national survey found that substantially fewer nonwhites reported they would feel good about a more austere life caused by energy shortages ( 33 percent versus 62 percent) [150]. A 1973 survey showed that whites were markedly more likely to favor more strict controls on the use of energy [212]. Taken together, most of these findings can be interpreted as evidence that nonwhites tend to associate conservation with further reductions in energy consumption. Such policies receive less support from this group, possibly because their energy use is already minimal.

In a 1974 national survey, whites were somewhat more likely to believe that the public has the most responsiblity to see to it that we "do not use up our supplies of natural resources" [137]. In this same survey, whites were notably more likely than nonwhites to rate both the federal government and the business community as doing a "poor" job in meeting their responsibilities. The next month, however, somewhat more nonwhites rated the public's performance as "poor," while notably more whites rated it "average" [139]. 
A 1974 Los Angeles study found that race was unrelated to energy use reduction [207]. In contrast, a 1977 national survey found that somewhat more whites reported turning down the thermostat and making minimum use of air conditioners, while somewhat more nonwhites reported "not doing anything" to reduce energy use; on 10 other items there were no differences in reported conservation behavior by race [220]. A 1975 survey revealed that notably more whites reported living in insulated houses [256].

A 1974 national survey revealed that there were no racial differences in concern over gasoline mileage of one's car [308], while nonwhites were slightly more likely to have a full-size car. There were no differences by race in car-buying plans, according to a 1977 national survey [147]. A 1973 national survey showed that whites were notably more supportive of a 55-mph speed limit [211]. A 1977 national survey showed only slightly more whites supporting the new speed limit, and this group was somewhat more likely to report reduced driving speeds. This survey showed, however, that slighty more nonwhites favored a lower speed limit for trucks, while whites were somewhat more in favor of keeping the limit at 55-mph hour for trucks [217]. A 1975 Kentucky study showed that more nonwhites opposed the idea of taking a vacation close to home than did whites [221]. A 1977 national survey indicated that slightly more whites would find it very difficult to reduce the number of miles they drove by one-fourth; there were no racial differences in those who considered it very or fairly important to do so [310].

Findings by race on gasoline policy are mixed. A 1974-75 national survey revealed that nonwhites were slightly more in favor of a policy of increasing gasoline taxes and reducing income taxes, while slightly more whites opposed this plan [131]. A 1974 survey revealed that somewhat more whites preferred keeping gasoline taxes the same, while nonwhites were somewhat more in favor of lower taxes; few of either group favored increasing taxes to promote conservation [137].

A 1975 national survey showed that nonwhites were somewhat more likely to favor raising the price of gasoline "a lot" as opposed to raising the price of many things "a little" [128]. A 1974 survey, which asked if Americans should conserve gasoline or pay higher prices and use all they want, revealed that slightly more nonwhites preferred higher prices [308]. This survey also showed slightly more of this group favoring substantially higher prices but unlimited availability. When asked in a 1977 national survey to choose between rationing and higher prices, however, no racial differences were revealed, except that slightly more nonwhites had no opinion [220]. A 1974 survey showed no difference in opinion on whether those who drove over 200 miles per week should pay higher gasoline prices [308]. However, when this question was repeated a few months later, nonwhites were somewhat more likely to favor this policy, whites to oppose it [131]. The former survey showed somewhat greater preference among whites for a policy of higher gasoline prices for those with cars that get less than $15 \mathrm{mpg}$, while nonwhites were slightly more likely to have no opinion [308]. When this survey asked respondents to choose between a tax on gasoline or on large cars, nonwhites were somewhat more in favor of the former, and whites were slightly more in favor of the latter and also slightly more likely to give no answer.

A 1975 national survey asked several questions about public transportation [129]. Nonwhites were notably more likely to perceive a great need for public transportation in the 50-mile area within which they lived and worked; whites were slightly more likely to report no need at all. Nonwhites had a somewhat greater tendency to perceive public transportation as costing more than driving one's own car; the reverse held for whites. Nonwhites were notably more likely to report that they would use public transportation if it ran twice as of ten. In a 1974 national survey whites had a slightly greater tendency to 
report that they were "not too likely" to use a "park and ride" system [308]. Nonwhites were slightly more likely to report that they would carpool if their company reduced its parking by 25 percent; whites were somewhat more likely to report they would carpool "not at all," as revealed in a 1974 national survey [137].

\section{Summary}

There were no revealed patterns of race-related differences in perception of the energy situation, but few surveys contained data on this issue analyzed by race. There were also no apparent race-related differences in attribution of responsibility for the energy situation, and there were no differences by race on option regarding future energy shortages.

The perceived salience of the energy situation appeared to be greater for whites, particularly when this was measured in comparison with economic problems (which were perceived as more serious by nonwhites).

There appeared to be a pattern of greater reported energy-related impacts among nonwhites than whites, probably as a function of the generally lower incomes of the former racial group.

No clear pattern of preferred policy options by race was evident.

Nonwhites tended to show stronger support than whites for environmental concerns, except where environmental quality issues were posed as competitive with low consumer costs. This pattern of nonwhite support is the same as that revealed in the data for low income groups.

There was a strong, consistent pattern of greater reported objective knowledge among whites than nonwhites on energy-related issues. This pattern for nonwhites is the same as that reported for low income groups.

Solar energy received greater support among whites than nonwhites, while the latter tended to support development of conventional energy sources.

Support for nuclear energy appeared to be consistently greater among whites than nonwhites; the latter group revealed a consistent pattern of doubt or indecision on this issue.

There was no pattern of racial differences discernible in data on attitudes or behavior concerning energy conservation.

\section{POLITICAL ORIENTATION}

Political theorists have noted the decline in relevance of partisan affiliation to political issues and a concomitant increase in the importance of membership in special interest groups. With the diversity of value systems and stakeholder group interests in energy, an increased politicization of energy decision making is to be expected. Analyses of survey data reflect this political reality through measurement of partisan differences in opinion, and through use of political philosophy dichotomies, although these are by no means the only important political differences concerning energy in society today. The differences 
by political affiliation and liberalism/conservatism reflected by survey data touch only the tip of the iceberg of sociopolitical realities of energy.

The partisan categories used in survey data analysis were Democrats, Republicans, and Independents. The political philosophy categories used were conservative (very or moderately so), moderate (middle-of-the-road), and liberal (very or moderately so), based on how people regarded their own political/social outlooks. The discussion in this section is organized into two parts, the first on partisan affiliation and the second on political philosophy.

\section{Partisan Affiliation}

Twelve studies (10 percent of the surveys included in this review) specifically analyzed differences in attitudes, opinion, and knowledge for 37 variables, finding differences by partisan affiliation in all but seven of these.

The discussion concerning the direction of these findings is organized by (1) how the energy crisis is viewed, (2) knowledge and information sources, and (3) attitudes toward various solutions (conservation, coal, and nuclear power).

Perceptions of the Energy Situation. In May 1977 Democrats were more likely than Republicans or Independents to identify the energy crisis as "very serious" [218], but by November 1977 there was little difference by party in a "very serious" assessment of the situation [175]. Republicans, however, were more likely to define it as "fairly serious" (51 percent) than Democrats (4l percent). In a study comparing the relative salience of national issues, Democrats gave energy a higher average ranking than Republicans or Independents [120]. The data suggest that Democrats, perhaps in support of the Carter administration, are somewhat inclined to view the energy situation more seriously than Republicans, although a majority of both parties see it as serious.

One survey reported that in 1973 Republicans (27 percent) were more likely than Democrats (19 percent) to blame "the federal government" for the energy crisis. Following party lines, Democrats saw "the Nixon Administration" as blameworthy more of ten than Republicans ( 27 percent to 11 percent). There was no difference by party affiliation in parceling out responsibility to "big business" and other response categories [213].

Three surveys reported that Democrats were more likely to approve President Carter's handling of the energy situation than were Republicans, suggesting partisan support for the President on this issue [217, 218, 310]. From 12 to 18 percent more Democrats supported Carter, but even Republicans tended to approve (45 to 54 percent Republican approval).

When asked whether we as a nation should try to reduce our oil imports (a firm element of the Carter position) all partisan affiliations were in favor, but Democrats, other than Southern Democrats, were most adamantly in favor (82 percent compared to 68 percent of Southern Democrats). Republicans were 73 percent in favor.

In early 1975 partisans were divided on the issue of President Ford's proposal to increase the oil import tax to reduce the nation's dependence on foreign oil. Following party lines, 51 percent of Democrats opposed the proposal, compared to 42 percent of 
Republicans, while about a third of Democrats and half of Republicans favored it [134]. At that time, almost a third of the oil consumed in the United States was imported (Lange, 1978).

Knowledgeability and Information Sources. Four variables falling into this category were analyzed by political affiliation. In 1976 Republicans were slightly more likely than Democrats to report that they were following the discussion in the media on nuclear energy development (Gallup, 1976). A majority of those in all political parties stated they were following the issue: Republicans, 81 percent; Independents, 80 percent; and Democrats, 74 percent. Reasons for this apparent difference in subjectively reported exposure to information on nuclear energy are unclear.

A 1977 study in Denver, Colorado, undertook an analysis of the credibility of information sources by political affiliation. Findings showed that Democrats were more likely to believe President Carter than Republicans, with Independents falling between the two. Republicans were more likely to believe the utility company* than were Democrats or Independents. Finally, Republicans granted more credibility to John Love (former Republican Governor of Colorado) than did Democrats. These findings underscore the political nature of the credibility of partisan political figures, regardless of the issue involved. They suggest that the source of information rather than its content may often be the criterion for granting credence.

One study explored objective knowledge of the fact that the United States imports oil from foreign countries [218]. In the spring of 1977, Republicans were slightly more likely than Democrats ( 56 to 49 percent) to indicate that the nation must import oil (which is objectively the case). The same study found that, of those who knew the nation imports oil, there was no difference by party affiliation on knowledge of what proportion of the needed supplies were actually imported. The finding on objective knowledge, coupled with the finding on subjectively reported exposure to media sources of information, suggests a very slight tendency for Republicans to be more well-informed on energy issues than Democrats. Other correlates of political affiliation, notably higher socioeconomic status-a variable related to educational attainment-probably explain this slight difference.

Attitudes Toward Various Solutions to the Energy Problem. President Carter recommended heavy reliance on coal as an energy source to decrease the nation's dependence on imported oil; yet, this recommendation came at a time when the nation was somewhat hopeful that its efforts to clean up the environment were meeting with some success through a variety of environmental programs. In the spring of 1977, respondents were asked whether air pollution standards should be relaxed to permit use of coal as an energy source. Republicans ( 50 percent) were somewhat more likely to indicate approval of this idea than were Democrats (43 percent) or Independents ( 39 percent). The reasons for this difference are not readily apparent, especially since the finding does not support the general tendency for opinion on energy issues by political affiliation to vary somewhat by party line. In this case, however, the item phraseology did not include reference to a well-known political incumbent by name.

*Public Service Company of Colorado. 
The findings concerning opinion on nuclear energy by party affiliation are complex and interesting. As reported in the section on knowledgeability, more Republicans than Democrats tended to say they were following the media discussions on nuclear energy development. In this context of at least subjectively reported exposure to information, during the same year Republicans were more likely to view nuclear power plants as safe enough (44 percent compared to 30 percent of Democrats), while Democrats tended to think nuclear plants should be "cut back" (Gallup, 1976). Republicans were also more likely than Democrats to say it is "extremely important" to have more nuclear power plants (40 percent compared to the Democrats' 31 percent) (Gallup, 1976). While in 1974 Republicans were more favorable than Democrats to living near a nuclear power plant [211], two years later, Republicans were more likely than Democrats to oppose construction of a nuclear power plant within five miles of their homes (48 percent opposed compared to 38 percent of Democrats opposed) (Gallup, 1976).

This apparent inconsistency in Republican partisan opinion may have occurred for several reasons. There may have been an error in data or reporting, or there may have actually been a change in Republican opinion between 1974 and 1976. However, the 1976 data are internally inconsistent, leaving the impression that while Republicans tended to feel there should be more nuclear power plants, they themselves would not want to live near one. Conversely, Democrats who were inclined to feel nuclear plants are not particularly safe, would tend to be somewhat tolerant of one in their vicinity.

Several variables related to conservation have been cross-tabulated by political affiliation. In a 1973 study, respondents were asked whether controls on the use of energy should be made more strict, less strict, or kept about the same. Republicans tended to prefer stricter controls (45 percent) more often than did Democrats (35 percent), while more than half of Democrats thought they should stay about the same [212]. Four years later, a related item queried respondents on whether President Carter's energy program called for "too many sacrifices" on the part of the public, or not enough. This time, more Republicans than Democrats were inclined to say the Carter program went too far in calling for public sacrifices (Republicans, 44 percent; Democrats, 32 percent) [218]. Democrats tended to think the Carter plan was "about right" somewhat more of ten than Republicans (34 to 25 percent, respectively), while there was no difference by party on the proportion saying the plan did not call for enough public discipline. This apparent inconsistency in Republican viewpoint between 1973 and 1977 may reflect a genuine change in opinion during the intervening four years. An alternative explanation is that the affiliation of the plan with a Democratic president elicited more negative Republican response. In fact, a 1977 study found no difference by political affiliation in reported respondent reduction in energy use [220].

Partisans did not differ on how important they felt it was to reduce their amount of driving by one-fourth [310]. Republicans, however, were slightly more likely than Democrats to oppose a gasoline rationing law requiring people to drive one-fourth less (58 to 51 percent) [310]. They were also somewhat more likely than Democrats to say that reducing their driving by one-fourth would be "very difficult" for them (40 percent compared to 32 percent).

Partisans did not differentially favor or oppose the 55-mph speed limit [220]. Republicans were more likely to say that the speed limit had reduced the speed at which they drove (70 percent compared to 59 percent Democrats). Republicans (62 percent) were more likely than Independents (55 percent) to favor the $55-\mathrm{mph}$ speed limit for trucks, with Democrats falling between them (59 percent) [217]. Two studies [220, 310] reported no difference by political affiliation in preferred methods of reducing gasoline consumption. 
These studies together suggest a slight tendency for Republicans to favor stricter controls in the abstract and for others. Although they tend to state they are law-abiding and favor the 55-mph speed limit, they tend to oppose any further restriction for energy conservation.

In 1975 a national sample was asked whether they favored or opposed President Ford's proposal to grant the automobile industry a five-year delay on stricter auto pollution control requirements to improve gas mileage [134]. The results were as follows:

Democrats $\quad$ Republicans

Favor $\quad 59 \%$

Oppose $\quad 32 \quad 23$

This finding may be more reflective of partisan support for and opposition to President Ford than a result of greater Republican commitment to energy conservation policy.

A recent Colorado sample [210] was quizzed on its level of interest in membership in energy conservation-oriented organizations. About 28 percent of Democrats indicated they would be willing to pay to belong to such an organization, with 18 percent of Republicans and 19 percent of Independents responding similarly. Expressing no interest were 64 percent of Republicans, and 50 percent of Democrats.

Roper (1979) reported that one percent of Republicans reported owning solar systems in January, compared to less than 0.5 percent of Democrats and Independents. There were no notable differences by partisan affiliation among those with possible solar buying plans; 19 percent of Republicans, 17 percent of Independents, and 14 percent of Democrats were considering a solar purchase.

In summary, variance in opinion by political affiliation along party lines tends to be elicited by items mentioning political personalities (Nixon, Ford, Carter). In general, the survey findings show Democrats to be slightly less knowledgeable about energy issues, somewhat more likely to view the energy crisis as quite serious, less favorable to nuclear and coal development, and more favorable toward energy conservation than Republicans. Republicans are slightly more concerned about maintaining conventional energy sources and not having their own lives affectec, which may translate into a desire to maintain what has become the traditional American lifestyle and its energy use patterns. Republicans' slightly greater knowledge of issues has apparently not resulted in a willingness on their part to act. To speculate, the in plication of these findings, taken as a whole, is that traditional centralized energy systerns may be somewhat preferred by Republicans and innovative decentralized systems by Democrats.

\section{Political Philosophy}

The only survey data using political philosophy in cross-tabulations with energy items were produced by the Roper Organization. Results from analyses included here were generated from national samples between 1975 and 1977. In general, results for moderates fell between those for conservatives and liberals.

Belief in the Energy Crisis. No cross-tabulation by political philosophy was run by belief in the seriousness or reality of the energy crisis. Three items pertaining to the salience 
of the energy crisis were cross-tabulated by political philosophy. No difference by political philosophy was found in salience as measured by the "two or three things people were most concerned about" (with the "fuel and energy crisis" one response category in a list of national problems) [154]; nor was difference found by political philosophy on salience as measured by things people wanted their Congressman and Senator to give major attention to [168]. Difference by political philosophy was also not found for salience as measured by assessment of "how much government effort should be put on various problems today," with energy sources and conservation as one of the response categories in a list [151].

Conservatives (17 percent) were more likely than liberals ( 10 percent) to blame environmentalists for the energy crisis; liberals (34 percent) were more likely than conservatives (25 percent) to say that environmentalists bore "no blame at all" for the energy crisis [151]. No difference was found by political philosophy in attribution of responsibility for the energy crisis to other groups.

No difference by political philosophy was found on perception of the likelihood in the next year of "another severe energy shortage" [150]. Also, no difference was found for feelings about the possibility of a more austere life caused by shortages being a good or bad thing (the majority of both groups thought it would be a good thing) [150] .

Knowledge and Information Sources. One item falling into this category was crosstabulated with political philosophy. This item pertained to the perceived credibility of information sources about the energy crisis: respondents were asked which group or organization they would be most likely to believe if different statements were issued as to the reason for the price increase of gas and oil. A list of information sources followed. No difference by political philosophy was found except that liberals (42 percent) indicated more frequently than conservatives ( 27 percent) that they would be most likely to believe "Ralph Nader's office" [170]. When asked who they would be least likely to believe, liberals ( 62 percent) were more likely than conservatives ( 53 percent) to indicate "major oil companies" [170]. Intuitively, these differences seem to make sense, suggesting that liberals are more likely than conservatives to find a consumer advocate organization a credible source of energy information, and that conservatives are more likely than liberals to believe major corporations.

Attitudes Toward Various Solutions to the Problem. In an energy-environment tradeoff, conservatives ( 49 percent) indicated they were more likely than liberals ( 36 percent) to favor "adequate energy" [148]. Liberals (43 percent) favored the environment more than conservatives (33 percent) [148]. Similarly, conservatives (25 percent) were more likely than liberals (15 percent) to think that environmental regulations have "gone too far"; liberals (35 percent) were more likely than conservatives (24 percent) to think such regulations had not gone "far enough" [148].

When asked what additional energy-conserving measures they were likely to take in the next two years if a tax credit were given, conservatives ( 34 percent) were more likely than liberals ( 21 percent) to indicate that they would not take additional measures [164]. Conservatives ( 50 percent) were found to be more likely than liberals ( 40 percent) to own a full-sized car; liberals (20 percent) were more likely than conservatives (10 percent) to own a subcompact [150]. However, no difference by political philosophy was found in car buying plans relative to the size of automobile to be purchased [150] . 
With respect to energy policy, liberals (15 percent) were slightly less likely than conservatives (22 percent) to see the steps called for in President Carter's national energy plan as more drastic than necessary, and the liberals were more likely to see them as "about in line" with what was needed [147].

Regarding nuclear energy, conservatives (43 percent) were more likely to think that a nearby atomic energy plant would be "safe" than liberals (35 percent); conversely, 52 percent of liberals thought such a plant "would present dangers" compared to 45 percent of conservatives [148]. Liberals (46 percent) were slightly more likely than conservatives (37 percent) to think the voting public should make decisions on where atomic plants should be built; conservatives ( 54 percent) were more likely than liberals ( 44 percent) to indicate that an expert group should decide [152].

Although no notable differences occurred in preferences for "best long term sources of energy," a very slight difference was found by political philosophy on preferences for nuclear and solar energy. Conservatives (37 percent) tended to favor nuclear energy slightly more frequently than did liberals (31 percent); liberals (73 percent) tended to favor solar energy slightly more frequently than conservatives (67 percent) [152].

Roper reported that one percent of liberals reported solar ownership in January, 1979 compared to less than 0.5 percent of conservatives and moderates (Roper, 1979). Considering solar purchase in the near future were 17 percent of liberals and conservatives and 13 percent of moderates.

In sum, though these findings can hardly be viewed as conclusive proof of important differences on energy attitudes by political philosophy, an interesting pattern emerges. This pattern fits with everyday observation of domestic political values and action: liberals tend to be more favorable to the environment and to solutions to the energy problem involving energy conservation and solar energy (although this latter difference is not marked). Conservatives tend to find major corporations credible sources of information, to blame environmentalists for the energy crisis (more than liberals), and to favor nuclear energy more than liberals. These findings lend further support to the findings on energy attitude differences by political partisan affiliation.

\section{RELIGIOUS AFFHIATION}

Religious affiliation (Protestant and Catholic*) was examined in eight studies (or seven percent of the surveys included in this review). Cross-tabulations using religious affiliation were performed on only 16 items. This paucity of attention to religious affiliation is probably due to the fact that there is little theoretical or empirical support for predicting religious affiliation as an important explanatory variable in energy-related issues.** The studies using this variable did so as a part of an analytical convention the

*Data on religious affiliation were not further broken down in any of the studies reporting on this variable.

**Though the traditional Protestant ethic would suggest a waste-not/want-not motivation toward energy conservation (for example, see Max Weber, The Protestant Ethic and the Spirit of Capitalism, London: Allen and Unwin, Ltd., 1930), the trend toward secularization of the major religions in American society probably mitigates this practice. 
researchers use with all of their poll data. That is, all findings are consistently crosstabulated with a given set of sociodemographic variables of which religious affiliation is one.

In general, religious affiliation did not result in a pattern of statistically significant differences of response on energy items. No significant differences in response between the two groups were found on the following variables:

- $\quad$ seriousness of the energy crisis [175, 218]; who/what is to blame for the energy crisis [213];

- overall favorable or unfavorable reaction to President Carter's energy plan [218];

- whether Carter's plan calls for too many sacrifices on the part of the public or not enough [218];

- knowledge of whether we import oil and what proportion of the oil we use is imported [218];

- whether environmental standards concerning air pollution should be relaxed to permit the use of coal [218];

- whether gasoline rationing should be required in order to reduce driving by 25 percent, how important it is to reduce driving, and what would be the best ways to conserve gasoline $[310]$.

Significant differences were found between Protestants and Catholies on the following items.

- Concerning credibility of information sources on energy, respondents were asked which groups or organizations they were most inclined to believe. Of the set of possible responses Catholics and Protestants differed on only one. Catholies were more likely to believe Ralph Nader (38 percent) than Protestants (26 percent) [170]. To speculate, this result may be due to more widespread liberalism among Catholics than among Protestants, rather than to religious belief, although the two may be correlated.

- Protestants were slightly more likely than Catholics to see nearby nuclear energy plants as safe (42 to 34 percent) [148]. There is no known reason why this should be so, and the results of demographic analyses of other studies on attitudes toward nuclear energy should be further explored to determine if this a consistent finding.

- Responsibility for the energy crisis is slightly more likely to be laid at the oil companies' doorstep by Catholics than by Protestants ( 59 to 52 percent) [15l]. This finding may be the result of greater political conservatism and sympathy for big business on the part of Protestants as opposed to Catholics.*

- One survey asked respondents to look toward the year 2000 and identify the best sources of energy. Results are reported in Chapter 6, and there was no

\footnotetext{
*The correlation between religious affiliation and social class, also a correlate of political preference, is reported in Mercer, Blaine E. and Jules J. Wanderer, The Study of Society, Wadsworth, Belmont (1970), pp. 285-286.
} 
variation in response by religious affiliation except for one source, coal [152]. Protestants were slightly more likely to indicate a preference for coal than Catholics ( 21 percent to 13 percent).

- Finally, Protestants were slightly more likely to oppose gasoline rationing than Catholics (by seven percentage points) [310]. This finding is inconsistent with the pattern of no differences in opinion concerning gasoline rationing by religious affiliation found in the same study, and is probably a statistical artif act.

In general, as would be expected, religious affiliation is most likely not an important predictive variable in accounting for public response to energy issues or public preferences among energy policy options. What differences are found by religion are probably attributable to other correlates of the variable, such as so :ioeconomic status.

\section{LIFESTYLE CHARACTERISTICS}

Some of the surveys in our universe analyzed energy attitudes and behaviors by characteristics of lifestyle. In particular, these include marital status, housing characteristics and housing ownership, and transportation patterns.

The discussions of these variables has been grouped together because few studies analyzed any single variable and because the variables are closely related in describing lifestyle of the respondents.

\section{Marital Status}

There might be some reason to expect that people would vary in their willingness or ability to engage in conservation behavior according to marital status and their lifestyles, but there is little reason to predict that marital status alone would affect other opinions about the energy crisis and energy alternatives. Marital status is primarily used as a sociodemographic variable in studies where cross-tabulations are done in accordance with convention. This variable was used in seven surveys (six percent of the surveys included in this review) and was cross-tabulated with 11 variables.

Differences in opinion by marital status clustered around items having to do with conservation. For example, unmarried individuals tended more than those married to see themselves as unable to "do a better job of saving energy by cutting back a little on many things" (68 to 58 percent) [128]. This finding is probably a function of unmarried lifestyle which is less likely than married living to result in prolific household energy use through cooking, laundry, and the like.

Gasoline conservation appears to be more acceptable to married than unmarried respondents. For example, those married were more willing to take a vacation closer to home to save gasoline than those unmarried [221]. Married persons (10 percent) were slightly less likely to oppose using the car less of ten than singles (20 percent), although most people opposed this measure [221]. The widowed specifically were less likely than others to want to walk or ride a bicycle, but this is likely a function of age rather than marital status [221]. There was no difference by marital status on willingness to cut back on trips in the car if gasoline were rationed [262]. Singles were slightly more likely to own a subcompact car than the total population (31 to 21 percent, respectively), and 
were less likely to have a full-size car (31 to 46 percent, respectively) [150]. However, this finding is probably the result of several factors: (1) the greater economic power of the married couple relative to young or old unmarried persons, (2) the greater need of the married couple with children for larger automobiles, and (3) the greater conservation ethic among the young (single) adults than among older adults. In general, then, married couples are slightly more likely to tolerate minimal infringements on their mobility than are unmarried persons. To speculate, unmarrieds may depend on mobility more for their social life, or married couples may be more likely to own multiple cars, and thus be able to cut down their gasoline consumption more conveniently.

With respect to domestic energy conservation, married persons are much more likely to disapprove of living in a small residence (40 percent) compared to unmarried (17 percent) [221]. This, again, may well be a function of need, especially for married couples with children. Interestingly, the married between 45 and 60 years of age were most supportive of turning down the thermostat in winter. These couples in the postparental phase of the family life cycle have neither concern about young children nor loneliness to interfere with lowering household temperatures. These findings suggest that existential living situations are rather potent variables in peoples' ability and willingness to conserve in various ways. What would be trivial to one group could be a rather difficult sacrifice for another.

Not surprisingly, no significant difference was found by marital status on whether to permit construction of a nearby nuclear power plant [143]. Singles in one survey, however, were more likely than the sample as a whole to feel that environmental regulations have not gone far enough [148]; this finding may be more a function of age than marital status by itself, since singles are more prevalent at both ends of the age scale.

Single persons were more likely than a total sample to feel that there never was a real oil shortage-that the shortage was contrived (68 percent of unmarried respondents compared to 53 percent of the total sample) [172].

Taken together, these findings suggest that unmarried persons are somewhat more likely to find infringement of their personal mobility a hardship than married persons. Singles are more likely than those married to be able to function domestically with less energy use by living in smaller residences, but not via adopting domestic energy-conserving practices.

\section{Housing Characteristics/Stage in Family Life Cycle}

The type, size, and value of the living unit as well as the stage in the family life cycle is related to attitudes about energy use. In a national survey, 65 percent of the sample said they would be willing to live in a small house or apartment in order to cut fuel consumption; 86 percent believed in turning down the heat in winter [221].

Concern about the amount of electricity being used increases with the size of the house (as measured by number of rooms) [253]. While acceptance of "time-of-day" pricing was low for those in all house sizes, those in larger houses were more accepting of the measure than were those in smaller houses [253]. Those in larger homes also viewed future conservation as more difficult than did those in smaller homes (Curtin, 1974). A Michigan study found that physical housing factors explained more of the variance than family socioeconomic factors in energy consumption in single family detached units 
[106]. Residents of homes valued at $\$ 60,000$ or more were less concerned about "making sure that there's enough energy to go around" than were those in homes valued at less than $\$ 35,000[120]$.

When asked about their willingness to buy a solar-heated house, persons in multifamily housing and those in single-family homes showed no difference [209]. No significant relationship was found between the value of the home owned and the expectation of when solar energy would be in general use [302]. However, respondents' home value was found to have a significant positive relationship ( $\angle .05$ ) to support for tax incentives for solar energy [302]. No significant relationship was found between value of home and willingness to buy a solar water heater if it cost the same as other units, feelings about the attractiveness of solar energy, or belief in the reality of the energy crisis. The data indicate that these latter attitudes were not tied to a person's relative monetary worth (as measured by value of home).

In one national survey, one percent of families with children 13-18 years of age reported solar system ownership compared to less than 0.5 percent by families with younger children (Roper, 1979). No differences in solar buying plans occurred by family composition.

In a New York study, families with children had increased their conservation efforts (as measured by an index of domestic conservation habits) more than couples without children and singles had [1011. In a national survey, families with children were more likely to blame power companies for the energy crisis than were singles (52 percent to 43 percent) [151].

A New Hampshire study reported that those with families of five or more were more likely to say that they were "very concerned" about the amount of electricity used in the home (71 percent) than were those with one to two persons in the household ( 62 percent) [253]. The same large households (71 percent) were also more likely to read utility pamphlets than were the small households (63 percent). In a national survey, those in large families of five or more were more likely to own and plan on owning a full-size car than were those in families of one to four [150]. A Chicago study reported that individuals in households of one to two persons were more likely than those in households of three or more to agree that many people would switch to public transportation if gasoline availability continued to be a problem (75 percent compared to 62 percent). Households of three or more were more likely to disagree on this issue ( 36 percent compared to 22 percent for one-to-two-person households) [150]. The larger households were less likely to agree that they would switch to public transportation if gasoline availability continued to be a problem (49 percent compared to 65 percent for one-totwo-person households) [150]. In another study, one- and two-person households (71 percent negative response) were less likely to intend to retrofit their homes with a solar system than were families of three or more (54 percent negative).

Concern about conservation increased with house size and family size. Support for tax incentives for solar energy was positively related to home value but willingness to buy solar systems was not. The lack of analytical data on housing characteristies and living situations in relation to energy use patterns and attitudes toward energy conservation and solar energy, in particular, reveals a gap in existing research. 


\section{Home Ownership}

Four studies explicitly examined differences in attitude between homeowners and renters. Three of the surveys were conducted at the regional level (New Hampshire [253] and Colorado Springs, Colorado [104, 105]); another used a sample drawn from six different "rural and small urban" parts of the United States [303]. The survey findings can be categorized into (1) knowledge and information sources, (2) concerns related to energy use and associated costs and lifestyle changes, and (3) attitudes toward ownership of a solar energy system.

Knowledge and Information Sources. In a Colorado sample, owners (71 percent) were more likely than renters (52 percent) to read utility bill pamphlets [104]. No notable difference existed between owners and renters in their subjective knowledge of solar energy [104]. In a national sample, home ownership and having heard about solar energy were positively related $(p \leqslant .05)$ [303]. In Colorado, owners and renters agreed $(42$ percent owner, 41 percent renter) that of several alternative fuel sources (solar, wood, coal, nuclear, wind, geothermal) solar energy offered the best possibility for home heating if conventional fuels were to become unavailable [104].

Concerns Related to Energy Use. Since owners are more likely than renters to be responsible for their utility bills, they would be expected to have characteristics which reflect a desire to reduce utility costs. Results from two studies supported this. In a New Hampshire sample, owners (68 percent) were slightly more likely than renters (56 percent) to express concern about the amount of electricity being used in the home [253]. In a Houston study, owners also tended to conserve more than renters taken as a group, although house renters conserved more than apartment renters (Warkov, 1976). This latter finding was probably due to the fact that house renters, unlike many apartment renters, were responsible for their own utility bills.

Concern with the cost of energy was reflected in the finding that homeowners were less likely than renters to prefer pollution-free energy at a cost increase of 25 percent (p .01) [303]. When questioned regarding "time-of-day pricing," (a system of charging different rates for electricity depending upon the time of its use) both owners and renters demonstrated a low index of acceptance [253]. The measure of acceptance was an index of the combined answers to questions regarding how likely respondents would be to change the timing of certain domestic activities (i.e., cooking meals, doing laundry, taking showers, etc):

$\frac{\text { Index of Acceptance of Time of Day Pricing }}{\text { High }}$

$\begin{array}{llll}\text { Owners } & 21 \% & 30 & 49 \\ \text { Renters } & 11 & 28 & 60\end{array}$

The overall low acceptance index suggests that although owners and renters may have wanted to reduce costs, they did not want to do so if it entailed a change in lifestyle (i.e., changing the timing of their activities). A conflict existed between the desire to reduce costs and the acceptable means for achieving such reductions.

The desire to achieve long-term cost reductions and to build investment equity may account for the finding that homeowners (66 percent) were more willing to accept the 
additional cost to install solar systems to supplement their present heating system than were renters (52 percent) [104]. Although this result seems to contradict the previously cited finding that owners were less willing to accept pollution-free energy at a cost increase of 25 percent, the foci of the questions differed. The latter question addressed solar systems specificially and had positive investment implications which offset the increased cost factor; the former question included solar systems as one alternative among many for producing pollution-free energy and asked only if respondents were willing to pay more for energy exclusive of other potential benefits.

Attitudes toward Ownership of a Solar Energy System. One study addressed attitudes among owners and renters toward ownership of a solar energy system [104]. More homeowners (65 percent) than renters (47 percent) preferred individual ownership of a solar heating system to utility company ownership. About half of renters felt the system should be owned and operated by some type of private or public company while only a third of homeowners felt similarly. Two-thirds of owners and almost half of renters preferred having an individual unit on the roof or in the yard to having a central community collector. Owners and renters did not differ in their belief that the law should protect solar homeowners from shading by neighbor's trees and houses.

In a four-city survey, 84 percent of those who were planning to buy a home within two years said they were willing to buy a solar home, while 62 percent of those not planning to buy a home at any time answered similarly [209]. Intention to buy a solar home was not found to be related to the type of fuel presently being used in the home.

In sum, the data are too sparse to permit conclusions, but they suggest that homeowners demonstrated more of a desire to reduce energy consumption and costs than did renters. They also were better informed about energy alternatives than were renters. This is not surprising given the fact that owners more frequently than renters assume their own utility costs, and seek ways to reduce them. Owners also preferred individual-oriented solutions to energy generation; a preference which accords with their homeownership status. However, the desire to reduce costs was tempered by a reluctance among both owners and renters to accept changes in the timing of their domestic activities.

\section{Transportation Characteristics}

Energy usage is the backbone of the transportation system. Not surprisingly, car and noncar households have experienced the impacts of the energy crisis differently due to the relative difference in their gasoline consumption. The data show, however, that both car and noncar households want gasoline to be available.

This analysis is divided into four sections:

- perceptions of the energy crisis and its effects

- concern with energy consumption and lifestyle change

- preferred solutions to the energy problem; and

- perceptions of environmental problems.

Perceptions of Car and Noncar Households of the Energy Crisis and Its Effects. During January and February of 1974, increasing percentages of nationally sampled licensed drivers reported trouble obtaining gasoline. Over half of those with one licensed driver 
in the household reported such trouble. More than 50 percent of those with cars in the household reported trouble. By May these percentages had declined to 23 percent for four-car households and 10 percent for one-car households [142].

When questioned about energy cost increases other than gas and heating oil, car-owning households and noncar households did not differ markedly. All respondents felt that "everything" had gone up in price (noncar, 44 percent; one-car, 51 percent; and two-car, 49 percent), although more noncar households answered "don't know" than did car-owning households (noncar, 19 percent; one-car, eight percent; and two-car, nine percent) [308]. The one-car and two-car households (around 60 percent) were in virtual agreement that the price of gasoline had gone up "a great deal" [308].

The effects of gasoline price increases were noted by both car and noncar households. More than 60 percent of all groups perceived the price increases as having had "a great deal" of impact on the rate of inflation, although more two-car households ( 30 percent) than noncar households (15 percent) felt the impact was only a "fair amount" [308].

Perceptions of the U.S. oil and gas reserves differed among car and noncar households. Ten percent of those in noncar households thought it was not very likely that natural gas supplies would run out in 50 years, as compared to 22 percent of one-car households and 35 percent of two-car households [137]. Fif ty percent of those in noncar households felt it was very likely that natural gas supplies would run out in 50 years while 37 percent of those in one-car and two-car households thought it would be very likely [137].

When questioned regarding oil supplies, 43 percent of two-car households answered that it was not very likely that the United States would run out in the next 50 years, while 33 percent of noncar households and 34 percent of one-car households answered similarly [139]. Car-owning households also tended to be more optimistic than noncar households about the United States' ability to be self-sufficient in energy supplies. About two-thirds of those in both one-car and two-car households, and half of those in noncar households, felt that energy self-sufficiency was possible [308]. These results taken together suggest that some correlation may exist between perception of energy supply and car ownership. This may be due to the fact that car owners depend on an adequate supply of energy in order to maintain their more energy-consumptive lif estyle. They have more at stake if supplies decrease.

In a Chicago metropolitan sample, 86 percent of automobile commuters agreed that drivers would pay $\$ 1.00$ a gallon for gasoline if necessary (compared to 77 percent of public-transportation commuters) [127]. About 75 percent of all respondents in the survey, however, agreed that many people would switch to public transportation if there were to be a continuing problem with gasoline supplies. (These apparently contradictory results may have been due to the different conceptual foci of the two questions: the "\$1.00 a gallon" question assumed gasoline availability, the other questioned gasoline availability.)

Generally, car and noncar households felt that the federal government and the business community were doing an "average" job in meeting their responsibilities to conserve national resource supplies $[137,139]$. However, a discrepancy existed among those who reported poor ratings. About one-third of noncar households reported poor ratings for the business community and the federal government, compared with poor ratings by 45 percent and 48 percent of the two-car households [139, 137]. The larger number of impacts of the energy crisis felt by car-owning households due to higher relative energy consumption may account for this discrepancy. 
Concern with Energy Consumption and Lifestyle Changes. Given the recognition of rising energy and living costs registered by those in car-owning households, it is not surprising to find a moderate positive correlation $(\mathrm{r}=0.45, \mathrm{p}<.001)$ between car ownership and energy conservation practices (e.g., driving $55 \mathrm{mph}$, adding storm windows, and turning off TV and lights when not in use) [101]. Car ownership was also found to be positively correlated $(\mathrm{r}=0.15, \mathrm{p} \leq .001)$ with knowledge about certain domestic energyconserving behaviors (i.e., cleaning air conditioning filters, using a pressure cooker instead of a frying pan, and washing clothes in cold rather than hot water) [101].

When car owners were asked about present and anticipated conservation actions, 84 percent responded that they planned their shopping trips to make several stops on one trip (14 percent did not plan, two percent did not know) [144]. In the same survey, the majority of car owners said that they usually had their car tuned at least every six months (one-car household, 53 percent; two-car household, 63 percent).

Owners of two or more cars (45 percent) were less likely than owners of one or no cars (66 percent) to say they would depend on public transportation if gasoline supplies continued to be a problem [127]. This is not surprising, given the increased investment in and reliance upon cars implicit in ownership of more than one car.

The availability of public transportation did not largely affect respondent decisions "to make that trip" even if gasoline were rationed to 10 gallons per week or the waiting lines for gasoline were an hour long [262].

As would be expected, those in car-owning households tended to be more informed about car fuel economy. Sixty-eight percent of owners of two or more cars reported having seen or heard information about the gas mileage of new cars, compared with 48 percent of noncar households [308]. Both noncar ( 40 percent) and two-car ( 54 percent) households agreed that government agencies provide more reliable information on gasoline mileage than do the auto companies (noncar, 33 percent; two-car, 23 percent) [308].

Three other variables were related to attitudes about energy use: car gasoline mileage, miles driven per week, and driving speed. When asked in 1974 how concerned they were with their gas mileage, over half of the respondents were "very concerned," regardless of the gas mileage of their car (see Table B-33) [308].

When asked again in 1975, most respondents were still "very concerned," while the number of those who were "fairly concerned" and drove cars with mileage ratings of 16 to $19 \mathrm{mpg}$ and 20 or more mpg increased markedly (up to 30 percent and 28 percent, respectively) [144]. Those who drove cars which got under $15 \mathrm{mpg}$ (27 percent) were less likely than those who drove 20 -or-more-mpg cars (4l percent) to say that they were making a great deal of effort to save energy [308]. Drivers of $15 \mathrm{mpg}$ cars (79 percent) and 20 -or-more-mpg cars (70 percent) answered that they would cut down on pleasure driving rather than nonpleasure driving (e.g., to work, school, shopping) [308] .

As would be expected, a higher percentage of those who were "very concerned" about gasoline mileage drove 100 or more miles per week (60 percent) [308]. These same drivers (29 percent) were less likely than those who drove 30 miles per week or less (45 percent) to say that they were making a great deal of eff ort to save energy [308].

Those who drove $56 \mathrm{mph}$ or more tended to be less concerned about gas mileage than those who drove $55 \mathrm{mph}$ or less, although all groups were predominantly "very concerned" (see Table B-34) [144]. 
TABLE $\quad B-33$

CONCERN ABOUT GAS MILEAGE BY MILEAGE ACHIEVED

Gas Mileage

Under $15 \mathrm{mpg}$ mileage

15 to $19 \mathrm{mpg}$

20 or more mpg

\begin{tabular}{|c|c|c|}
\hline & rtion Res & \\
\hline $\begin{array}{c}\text { Very } \\
\text { Concerned }\end{array}$ & $\begin{array}{l}\text { Fairly } \\
\text { Concerned }\end{array}$ & $\begin{array}{l}\text { Not Too } \\
\text { Concerned }\end{array}$ \\
\hline
\end{tabular}

$51 \%$

61

54
31

19

17
17

20

26

[308] 


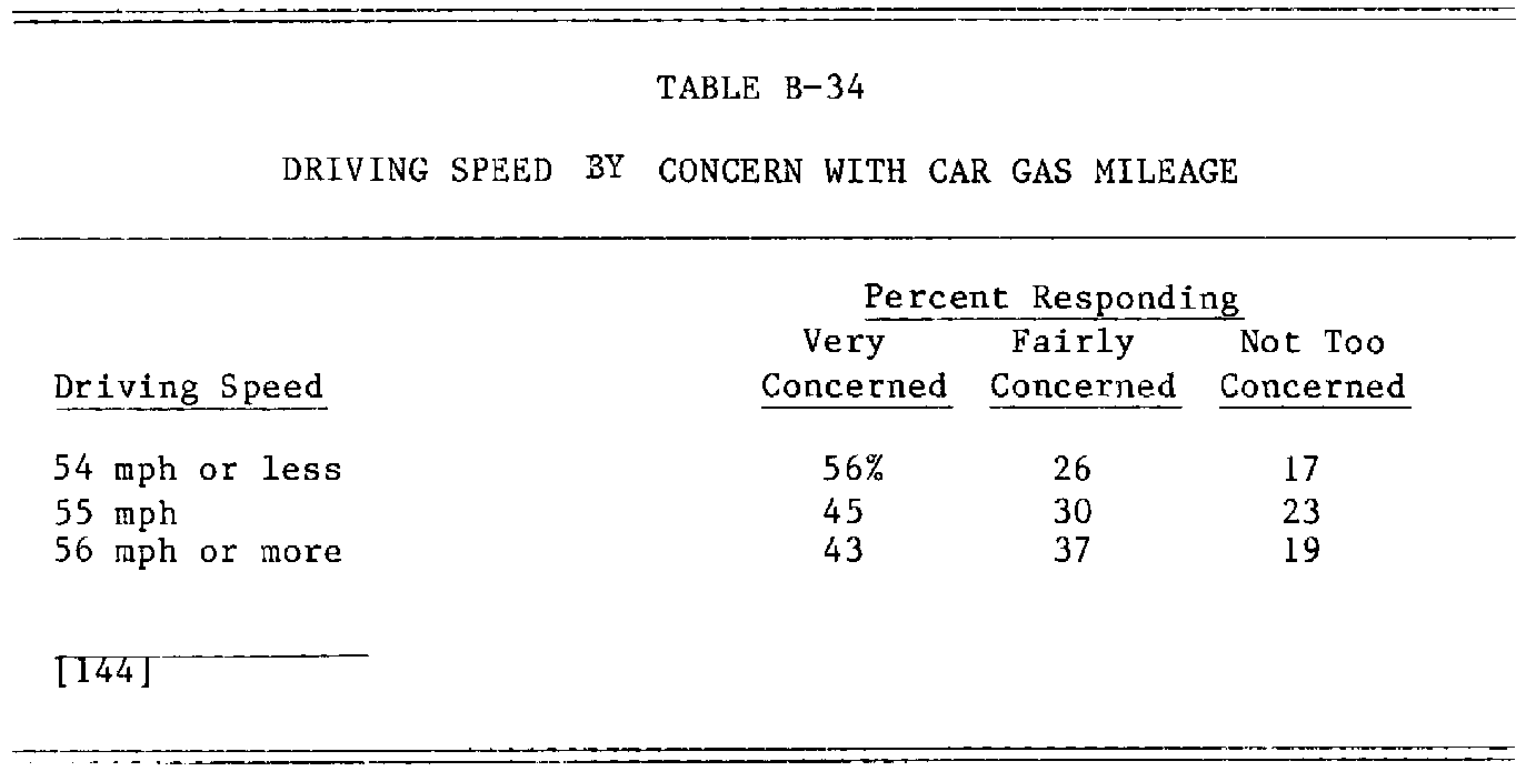


Those who drove faster and who owned more gas-consumptive cars may have done so either because they had more pressing concerns (e.g., getting to work on time) or because they were less concerned with or aware of the energy problem.

High-speed drivers ( $56 \mathrm{mph}$ or more) were as likely as low-speed drivers (54 $\mathrm{mph}$ or slower) to think that their personal conservation habits had an effect upon total energy consumption (74 percent and 72 percent, respectively) [258]. The same high-speed drivers were also as likely as the low-speed drivers to express their willingness to drive a small car to save gasoline (provided everyone in their neighborhood drove small cars). In the same study, those who drove at high speeds (over $60 \mathrm{mph}$ ) attached less importance to energy conservation than did those who drove at $50 \mathrm{mph}$ or less (35 percent as compared to 65 percent). The over -60 -mph drivers ( 53 percent) were also less likely than the under-50-mph drivers ( 79 percent) to be willing to save energy by turning down their hot water heater control from "hot" to "warm." The majority of respondents in both high- and low-speed driving groups (67 and 54 percent, respectively) felt that it was not too likely that other people would drive at $50 \mathrm{mph}$ or less in order to save gasoline. About one-third (34 percent) of those who normally drove $55 \mathrm{mph}$ expressed some willingness to reduce their average driving speed while two-fifths (42 percent) of those who normally drove $60 \mathrm{mph}$ or more said they would be unwilling to drive more slowly.

Preferred Solutions to the Energy Problem. Several questions addressed possible solutions to the energy problem. Some required personal appraisals of the merits of particular and alternative solutions, others asked for rejection or support of specific solutions.

The majority of those in both car-owning and noncar households agreed that they could do a better job personally and would prefer saving energy by cutting back a little on many things rather than cutting back a lot on gasoline [128]. This general reluctance to decrease car use is also reflected in the finding that nearly one-half of both one- and two-car households were not likely to use a park-and-ride system (in which people drive to a central location and take the bus) if such a system were instituted [308].

Most car owners preferred present prices and rationing to higher prices and limited supply, or to very high prices and unlimited supply [308]. Two-thirds preferred a tax on gas guzzlers at time of purchase rather than a higher tax on gasoline [308], but did not feel that those who drive over 200 miles a week or who own cars that get less than 15 mpg should pay higher prices for gasoline [131, 308]. In 1974 over half of two-car households opposed institution of a tax structure under which car drivers would pay higher taxes than nondrivers. Those in noncar households were nearly evenly split between favoring (38 percent) and opposing (36 percent) the issue $[131,139]$. When asked the same question again a year later, the number opposed in noncar households had increased to 50 percent and those favoring had declined to 29 percent [133].

Forty-seven percent of those in one-car households and 45 percent of those in two-car households felt that the United States should not export food in order to pay for oil imports, as compared with only 28 percent of noncar households [137].

There were no differences between those in car and noncar households in feeling that public transportation should be subsidized by taxes [127]; and that fares paid by users of public transportation should reflect the full cost of service [127]. This contradiction between wanting to subsidize mass transit (an action which would reduce fares) and wanting to have fares which reflect full costs may be an indicator of conflicting values 
of wanting to practice conservation by promoting mass transit, but of not wanting to pay higher taxes.

Environmental Problems. Those in noncar households were more likely to say that increased energy production in the United States would cause "a great deal" of environmental harm, although more than a third of both noncar and car households agreed that "a fair amount" of damage would be done [131, 308]; There were no differences between noncar and car households on the most serious environmental consequence of U.S. energy self-sufficiency efforts [308]; whether to have strip-mining regulations and consequently higher electricity prices or the reverse [128]; knowledge that power plants and oil refineries cause air pollution [131, 308]. and desire that new power plants and refineries be built in already polluted places [308].

When asked about nuclear power plants, the owners of two or more cars responded more favorably and felt more comfortable about having a plant within 20 miles of home than did one-car and noncar households [308]. Car and noncar households agreed that disposal of wastes, rather than thermal pollution, radiation discharge, or nuclear accident, was the most serious problem associated with nuclear power [308].

Overall, as would be expected given their higher energy consumption, the effects of the energy crisis have been felt more by those who drive and own cars than by those who do not. This effect inereased proportionally with the number of cars owned. Consequently, more car owners have made an attempt to conserve on gasoline and to keep themselves informed on mileage standards for cars. Respondents in both car and noncar households were concerned about keeping prices down via conservation practices, but did not want to pay higher taxes in order to promote mass transit. In all cases, proposals for taxes on gasoline were rejected in favor of taxes on specific users of large amounts of gasoline. Car owners were more optimistic about the future of energy supplies than were noncar owners, a finding which suggests that optimism about future supplies may be partially influenced by relative need for those supplies. Overall, Americans want gasoline and appear to be ready to pay for it no matter how reluctantly.

\section{URBAN/RURAL RESIDENCE}

Summarizing the overall picture presented by studies analyzing data by place of residence is made difficult by the different ways in which the urban/rural dimension is measured. Three different sets of categories are used by Roper, Gallup, and the Opinion Research Corporation (ORC). Roper surveys use the four categories of market size developed by A. C. Nielson for marketing purposes: "A"-counties comprising the 25 largest metropolitan areas; "B"-all other counties that have a population of 150,000 or form part of a metropolitan area with an aggregate population of 150,000 or more; "C"counties which have a population of 35,000 or form part of a metropolitan area with an aggregate population of 35,000 or more; and " $D "$-all remaining counties in the country. While this gives an indication of the general level of urbanization for the area, it does not tell us whether the individual lives in the city, the suburbs, a small town, or on a farm. Respondents to Gallup surveys are categorized by their place of residence rather than by county characteristics. Categories are community populations of: $1,000,000$ and over; 500,000 to 999,$999 ; 50,000$ to 499,$999 ; 2,500$ to 49,999 ; and under 2,500 to rural. ORC uses word categories of city, suburb, small town, and rural area. 


\section{Perception of the Energy Situation}

Studies by Blakely in three California areas [202] and by Gottlieb in Texas [116] found little or no difference by place of residence on belief in the energy crisis. Blakely also found little difference on opinion about the cause and duration of the energy crisis, the capacity of public officials and institutions to respond to the crisis, and preferred alternatives to resolve the crisis.

Surveys by Morrison in Lansing, Michigan, in 1974 and 1976 found a change in rural respondents in the level of belief in the energy crisis (38 percent in 1974 to 47 percent in 1976) [106]. There was no change for urban residents, with about half in both years believing in the energy crisis. An additional statement was added to the survey in 1976: "The 'energy crisis' was a 'put on' in order to raise the price of fuels." Fifty-five percent of urban respondents and 72 percent of rural respondents agreed or strongiy agreed with the statement.

A Gallup survey in April to May 1977, found no urban-rural difference on whether the U.S. energy situation was seen as very or fairly serious [218]. People in cities of 500,000 to 999,999 were slightly more likely to see the situation as very serious. Other groups were fairly evenly divided in their responses as very or fairly serious. The results of this survey are presented in Table B-35.

Only three sizable changes were reflected in another Gallup poll in November 1977 [175]. The residents of cities from 500,000 to 999,999 dropped from 50 to 41 percent in the "very serious" responses and increased from seven to 16 in the "not at all serious" responses. Residents of the largest cities also increased in the "not at all serious" responses from 13 to 20 percent.

A Roper survey in January 1977 found one-fourth to one-third of the respondents in each group concerned about the fuel and energy crisis [154]. The individuals in counties with populations of less than 35,000 were the least concerned ( 25 percent).

Exploring anticipated natural fuel shortages for the winter of 1975-76, ORC found that persons from small towns and rural areas were more likely to say that such a shortage was "very likely" [129] (see Table B-36).

A Roper survey in May 1974 found that the rural area respondents were the most likely group to feel that the gasoline shortage would continue over the summer [172]. When asked their opinion about future oil shortages, one-half or more of all the groups said there was never a real shortage. The rural residents were most negative ( 63 percent). A Roper survey in July 1977 found no difference by place of residence (urban or rural) in estimating chances in the next year of another severe energy shortage (over two-thirds of each group felt a shortage was somewhat or very likely) [150]. A Roper survey in April to May 1978 found that 41 to 51 percent of all groups thought that the gas and oil shortage was contrived (Roper, 1978c).

The 1976 wave of the Morrison survey in Lansing, Michigan [106] tested attitudes or perceptions on particular issues that are part of the overall energy situation. Differences between the urban and rural respondents were found on the following four items: 


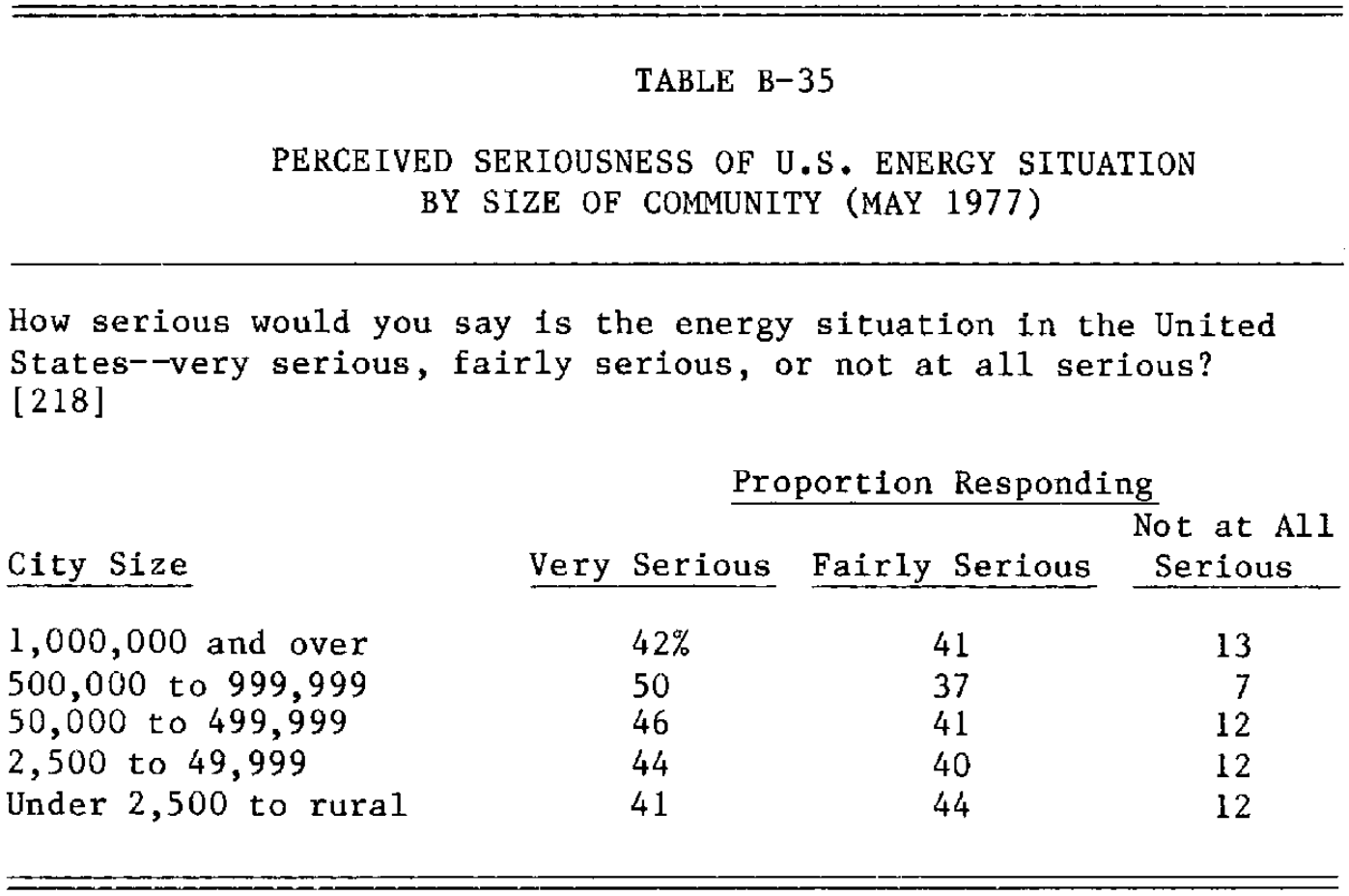




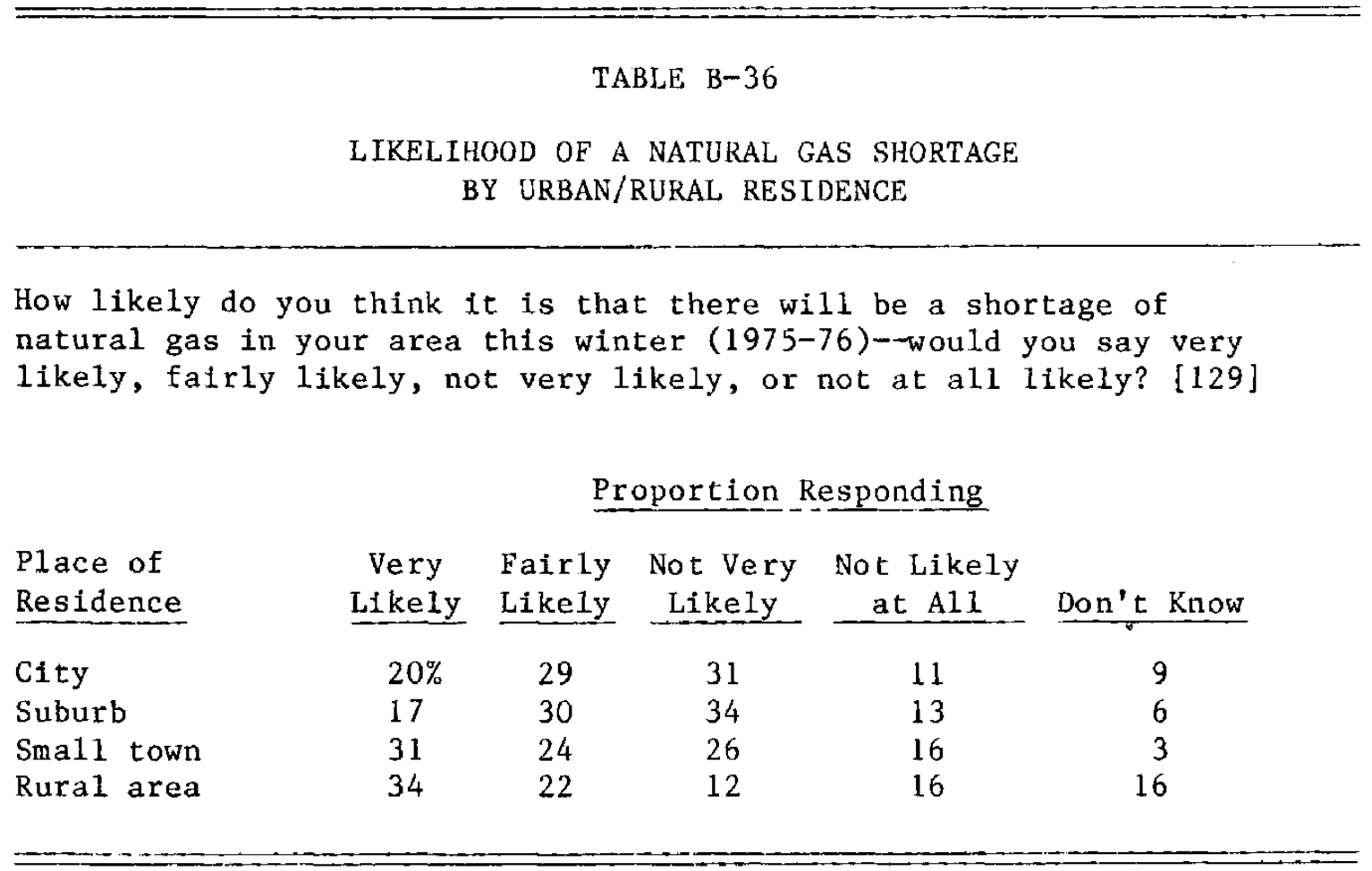


- The price of energy is too low, considering that most energy sources cannot be replaced.

- If we continue our high levels of energy use, future generations will not have a level of living like ours.

- Our family is entitled to as many material goods as we can afford, regardless of the energy required to produce them.

- The only way to get families to conserve energy is by imposing government controls.

No difference between rural and urban residents was found on the following items:

- Government officials are not providing any clear directions to help families make decisions on energy use.

- The citizens of the United States are entitled to use as much energy as they can aff ord.

- My family can maintain a satisfying way of living even though we buy fewer material goods.

- The natural environment should be preserved even if I must change my way of living.

- If most Americans continue their present high levels of living, they will deprive people in poorer parts of the world of basic necessities.

In addition, Morrison asked the respondents whether they perceived energy price increases as a great problem. The rural residents were more likely to perceive gasoline and electricity price rises as serious (67 percent versus 54 percent urban, and 68 percent versus 55 percent urban), but heating fuel was equally perceived as a great problem by both groups ( 62 to 63 percent).

Three studies explored citizen perceptions of price changes due to the energy shortage. An ORC survey in November and December 1974 found no differences between urban and rural respondents on perceived price changes due to the energy shortage for electricity, food, and plastics [308]. There were only small differences as to the perceived increase in the price of gasoline, with 56 to 63 percent indicating that the price had gone up a great deal (city, 56 percent; suburbs, 62 percent; small towns, 63 percent). Small town respondents were less likely to feel that price increases for oil and gasoline had had a great deal of impact on the rate of inflation (54 percent versus 64 to 68 percent for other groups). When asked whether Americans should conserve gasoline or pay the higher price

\footnotetext{
*Percentage agreeing or strongly agreeing.
} 
and use all they want, three-quarters or more of each group said "conserve." The suburban respondents were the most conservation-minded ( 86 percent).

ORC surveys in November and December 1974 [308] and in January 1975 [133] reminded respondents that President Ford had urged that the United States be self-sufficient so it would not have to import oil from other countries, and asked respondents whether they felt the United States could be completely self-sufficient in energy supplies. Only small differences were found in the earlier wave, with the proportion of respondents in each group saying yes ranging from 61 to 67 percent. Larger differences were found in the second wave, with the cities and small towns ( 51 and 56 percent) being less likely than suburbs and rural areas (69 and 75 percent) to say yes.

A Gallup survey in December 1973 found no difference by city size on perceived responsibility for the energy crisis [213]. A Roper survey in June 1977 found no difference by city size in tendency to blame the oil companies for the crisis (the most likely actors to be blamed by all groups) [151]. Those living in rural areas placed less blame on the environmentalists and Israel than did the urban groups. Those in smaller towns and rural areas tended somewhat more than did other groups to blame the American consumer; and residents of the largest urban areas were slightly more likely to blame the Arabs.

A survey in three California areas in September 1975 found that all groups felt the overall effect of the energy crisis on the nation's morale was negative [202]. Urban respondents were more likely than suburban or rural residents to feel this way $(46,40$, and 36 percent, respectively). All groups, however, were less negative on the long-run effects if the energy crisis were to continue for years (urban, 31 percent; suburban, 31 percent; and rural, 28 percent).

Surveys have explored not only perceptions of responsibility for the crisis, but also perceived or desired responsibility for handling the energy situation. An ORC survey in August to September 1974 asked individuals who they felt had responsibility for seeing that the United States does not use up its supplies of natural resources [137]. Persons in cities, small towns, and rural areas gave the American public much more responsibility than either the federal government or the business community. Suburban residents were split fairly evenly between the public and the federal government. Table B-37 summ arizes the results.

When asked who should make decisions on various energy-related issues-the voting public or expert groups-respondents to a March 1977 Roper survey differed according to place of residence (see Table B-38) [152]. The rural residents preferred the voting public in all cases more than did the urban residents. Residents of counties with populations of 35,000 to 150,000 were the most favorable toward expert groups.

As Table B-39 shows, an ORC survey in August to September 1974 found that in general the business community was seen as average or poor in meeting its responsibilities with regard to energy [137]. The rural people were most favorable, while the suburban residents were most negative. A second ORC survey only a few weeks later found an increase for all groups in favorable appraisals of the business community [139].

As presented in Table B-40, the Blakely survey in California in September 1975 [202] asked respondents to rate the capacity of public officials and institutions to respond to the energy crisis. Public utilities were rated the highest of the choices, with about a quarter of the urban and suburban residents rating their performance as good or excellent, and 38 percent of the rural residents doing so. 


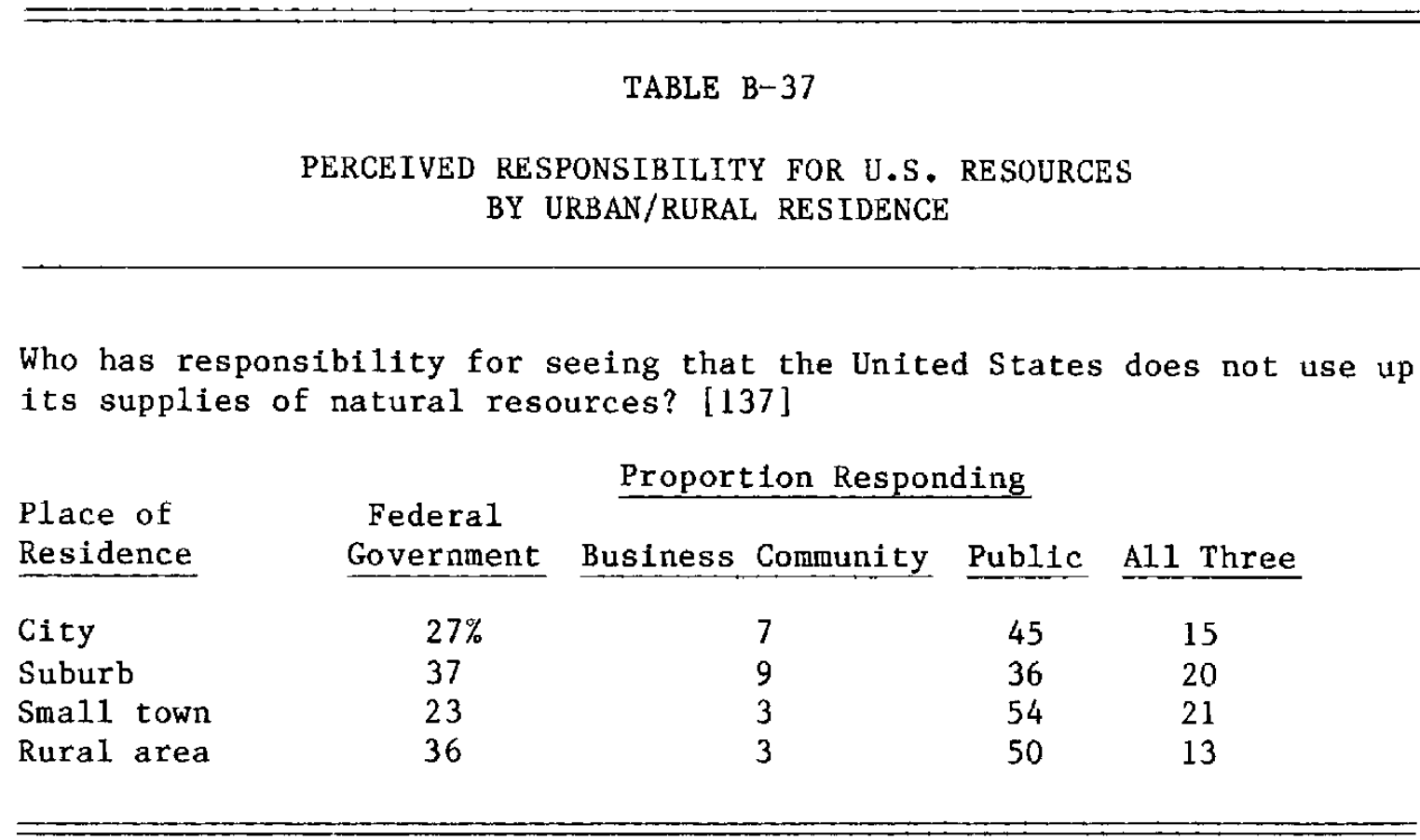


TABLE $\quad B-38$

DECISION-MAKING RESPONSIBILITY BY URBAN/RURAL RESIDENCE

Who should make decisions on various energy-related issues: the voting public or expert groups? [152]

Decisions

Where atomic plants showld be built:

Voting public

Some other group

Don't know/no answer

How atomic wastes should be disposed of: Voting public

Some other group

Don't know/no answer

Speed limits on highways:

Voting public

Some other group

Don't know/no answer

\section{Proportion Responding}

Total A B B C D

$40 \% \quad 41 \quad 44 \quad 32 \quad 50$

$\begin{array}{lllll}49 & 48 & 48 & 55 & 34\end{array}$

$\begin{array}{lllll}11 & 11 & 8 & 13 & 16\end{array}$

$\begin{array}{lllll}24 & 28 & 25 & 15 & 41\end{array}$

$\begin{array}{lllll}64 & 61 & 66 & 70 & 45\end{array}$

$\begin{array}{lllll}12 & 11 & 9 & 15 & 14\end{array}$

$\begin{array}{lllll}36 & 38 & 35 & 31 & 50\end{array}$

$\begin{array}{lllll}58 & 56 & 60 & 63 & 43\end{array}$

$\begin{array}{rrrrr}6 & 6 & 4 & 5 & 7\end{array}$

*See the beginning of this section for a description of the market size categories. 


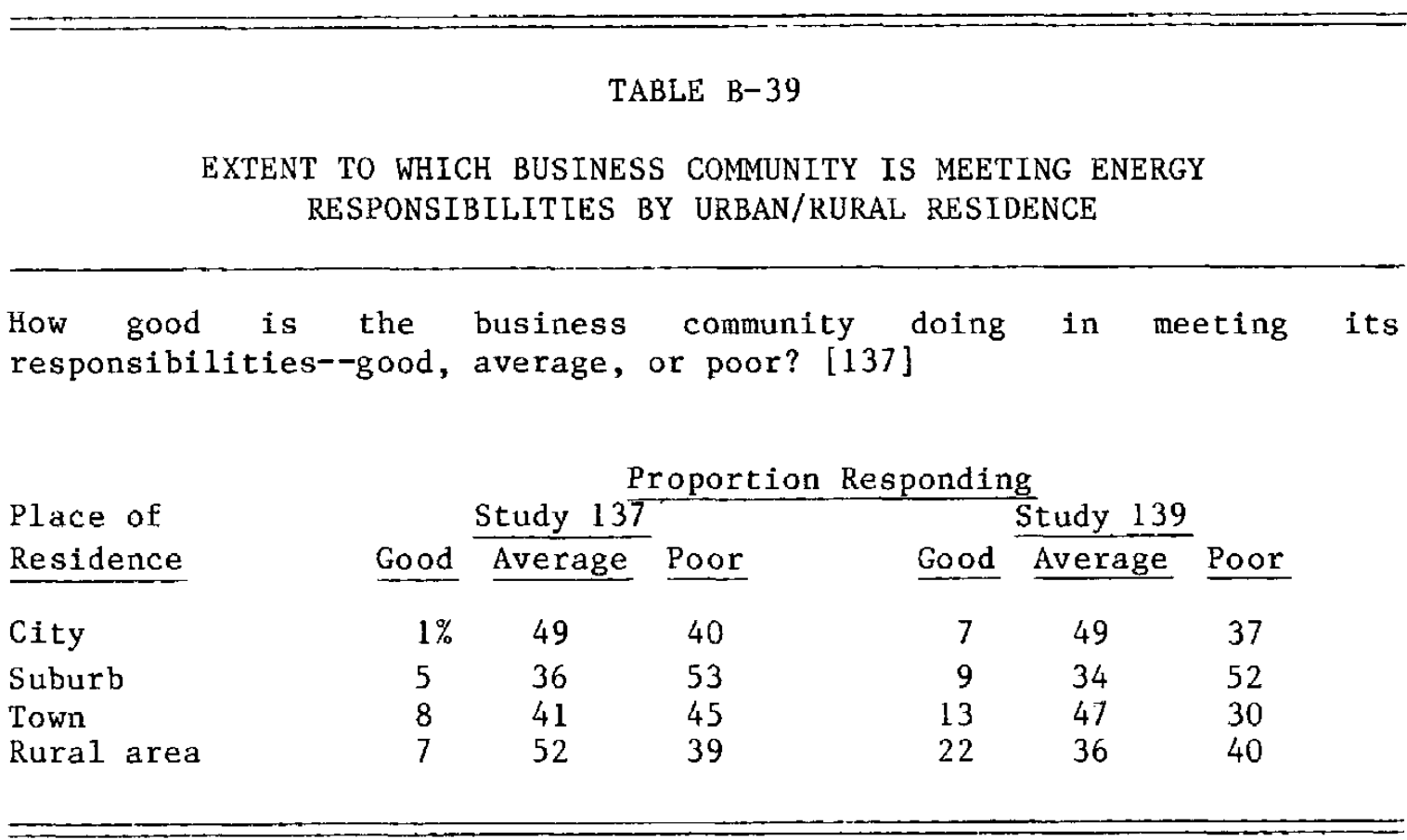




\begin{tabular}{|c|c|c|c|}
\hline \multicolumn{4}{|c|}{$\begin{array}{l}\text { HIGH PERFORMANCE RATING OF PUBLIC OFFICIALS } \\
\text { AND INSTITUTIONS BY URBAN/RURAL RESIDENCE* }\end{array}$} \\
\hline & \multicolumn{3}{|c|}{ Proportion Responding } \\
\hline Public official/Institution & Urbañ & Suburban & Rura 1 \\
\hline $\begin{array}{l}\text { Federal administration } \\
\text { Congress } \\
\text { Oil companies } \\
\text { Public utilities }\end{array}$ & $\begin{array}{l}13 \% \\
9 \\
8 \\
25\end{array}$ & $\begin{array}{l}12 \\
12 \\
10 \\
23\end{array}$ & $\begin{array}{l}17 \\
12 \\
12 \\
38\end{array}$ \\
\hline *Study 202 & & & \\
\hline
\end{tabular}


The Blakely study also explored attitudes toward government intervention as a means to ease or resolve energy shortages (see Table B-41). Urban residents were more likely than suburban or rural groups to favor nationalizing the energy industry. Rural residents were more likely than the other groups to favor rationing.

A number of studies have identified a desire to have a stronger handling of the energy situation. A Roper survey in May 1977 found that 70 to 77 percent of the individuals in each group wanted their Congressman or Senator to give major attention to the development of a national energy policy [168]. In May 1974, a Roper survey found that all groups were slightly more in favor of more drastic steps to deal with the energy crisis [174]. The 25 largest metropolitan areas were more likely than other residence categories to feel that more drastic measures were $r$ : ?ded and that present measures were not sufficient. A Roper survey in June 1977 found only slight differences by residence in the feeling that major effort should be devoted to developing new energy sources and conservation methods [151]. The groups ranged from 83 to 92 percent.

The April-May 1978 Roper survey found the respondents split between a perceived need for more controls, especially price controls, and a feeling that controls were adequate (Roper, 1978c). Residents of counties with populations of 150,000 or more felt the least need for price controls and were most likely to feel controls were adequate. The Gallup survey in November to December 1973 asked whether controls on the use of energy should be stricter, about the same, or less strict [212]. Less than 10 percent of any group felt that the controls ought to be relaxed. Residents of cities of $1,000,000$ and over were most likely to say the controls ought to be stricter.

The Roper survey in March 1978 found the larger urban areas more likely to believe the United States could not get along without foreign oil during the next five years [180].

A January 1975 Gallup survey found that the majority of individuals in each group favored the reduction of oil purchased from foreign nations, with a tendency for the urban areas to be more concerned ( $1,000,000$ and over, 77 percent; 500,000 to $999,999,82$ percent; 50,000 to $499,999,78$ percent; 2,500 to 49,999 , 73 percent; and under 2,500 to rural, 65 percent) [214].

Gallup polls in February and August 1977 found only slight differences between residence groups in the approval of the way Carter was dealing with the energy situation [217, $309]$. In the February survey, residents of cities of 1,000,000 and over approved less (56 percent); 50,000 to 499,999 approved most (64 percent); and the other two groups approved by over 62 percent. By August the level of approval had dropped below 50 percent for all groups (41 to 48 percent), and those approving were almost balanced by those disapproving.

In November 1977, a Roper survey found that all groups tended to think that the steps called for in Carter's national energy plan were about in line [147]. The rural areas were more likely to feel that way, and they were less likely than urban areas to think that the steps were too drastic. A Roper survey in March 1978 again found the rural areas more likely than more populated areas to approve of Carter's handling of the energy crisis [180].

The Gallup survey in April to May 1977 asked individuals for their overall reaction to President Carter's energy plan [218]. For all groups, one-half or more of the people were favorable and one-fourth to one-third were unfavorable. The survey also asked whether the President's energy program called for too many sacrifices on the part of the public. 


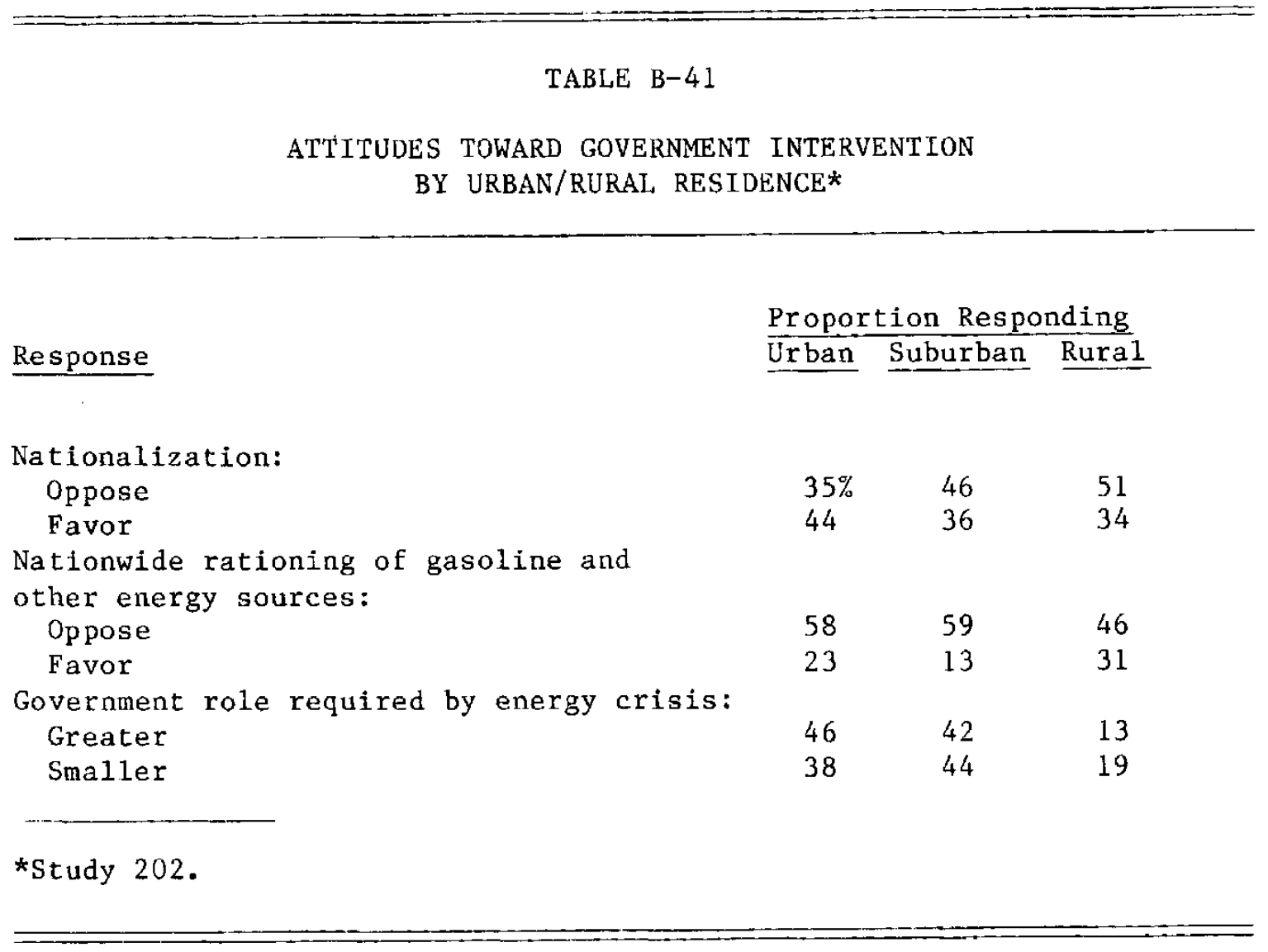


In general, residents of smaller communities were more likely to think that the sacrifices were too many.

A national survey by Murray in 1973-74 found the influence of daylight saving time (DST) to be greater in urban areas, since the urban respondents reported greater change in driving patterns [142]. However, all groups tended to drive more with DST. The liking for DST was greatest in rural nonfarm areas and suburbs. It was least liked on farms and in small towns. Support for year-round DST was less on farms than elsewhere. ORC fielded surveys in August to September and September to October 1974 asking a question on whether gasoline taxes should be increased to cut usage [137, 139]. Less than 12 percent in any group in both surveys said taxes should be increased. Of the balance, about half said they should stay the same and half said they should be lowered.

An ORC survey later that same fall (November to December 1974) found rural areas favoring an energy policy of higher prices for gasoline and unlimited availability [308]. About half of the individuals in the urban groups preferred maintaining price levels and rationing. Suburban residents preferred taxes on large cars, while city and rural areas slightly preferred increased gasoline taxes.

Lopreato and Meriweather (1976) cited a study by Morrison and Gladhart in 1976 which found a difference between urban and rural residents in acceptance of various possible energy policies.* Urban women were most favorable toward all policies suggested, followed by urban men, rural women, and rural men. The rural residents were less accepting of tax deductions for apartment dwellers and small-car owners, gas rationing, deductions for owning only one car, and free mass transit.

In general, the surveys showed no differences between urban and rural groups in perception of the energy situation and responsibility for the situation.

\section{Energy and Environment}

A Roper survey in September 1977 found rural residents more in favor of adequate energy as opposed to protection of the environment than urban residents [148]. Rural residents were also more likely to feel that environmental regulations had gone too far, although a larger proportion in all groups thought that the right balance had been struck.

A Gallup survey in April to May 1977 asked individuals if they thought air standards should be relaxed to permit greater use of coal [218]. Rural residents were somewhat more likely to permit relaxation of the rules.

ORC found in December 1974 to January 1975 that perception of air pollution caused by power plants and oil refineries was lowest for rural workers and highest for small towns [131]. In a Kentucky study in August to October 1975, Burdge found that to a small extent more urban dwellers favored banning of strip mining [221].

*The study by Bonnie Mass Morrison and Peter M. Gladhart is abstracted in the Lopreato and Meriweather volume. The original article is "Energy and Families: The Crisis and the Response," Journal of Home Economics, (January 1976), pp. 15-18. 
An ORC survey in November to December 1974 found that one-half or more of all groups said that U.S. production of more energy will cause a fair amount or a great deal of environmental damage [308]. Those from rural areas were somewhat less strong in their estimates, but three-fourths of all groups felt there would be some environmental damage. Those who felt damage would occur were asked which environmental problems were most serious. No differences were found among groups, with the most votes for strip mining and air pollution. About 10 percent in each group were concerned about nuclear wastes.

In general, rural groups were more likely than urban groups to favor adequate energy over environmental protection.

\section{Knowled:ability and Credibility of Information Sources}

A survey by Morrison in the Lansing, Michigan, area in 1976 found that rural people were more aware of and responded more accurately to the following items: transportation requires the most energy for families; the hot water heater uses the most household energy; microwave ovens use the least energy for cooking [106]. Urban residents were more accurate in their answers concerning these following items: aluminum containers waste the most energy of beverage containers; beef is the protein that requires the most energy to produce; apartments use less energy than other types of housing; the amount of imported oil has risen since 1973-74; natural gas is the fuel in shortest supply. No differences were found on awareness that most heat loss is through the ceiling and that buses are the cross-country transportation mode using the least energy.

A Roper survey in January 1975 [170] asked who people would believe if different statements were given for a price rise in gasoline. The only clear differences were that the more rural areas were more likely to believe the Department of Commerce, and urban areas were more likely to believe Ralph Nader. All groups were least likely to believe the major oil companies. In contrast, Gottlieb found no differences between rural and urban groups with respect to confidence placed in information sources [116].

The Gallup survey in April to May 1977 found that cities of 500,000 to 999,999 and areas of under 2,500 or rural were most likely to answer that we must import oil to meet our present energy needs [218]. About one-third of all groups did not know or would not guess what percentage of the oil used in this country is imported. No differences were found in the patterns of estimates for the groups.

Only five studies analyzed energy-related knowledge by urban-rural residence, and no patterns emerged.

\section{Attitudes Toward Solar Energy}

Only three of the surveys covered allowed analysis of solar energy attitudes by place of residence (urban versus rural). A survey in five regions in the spring and summer of 1976 found no relationship between size of community and having heard of solar energy. A Michigan study found urban residents more likely than rural to agree to pay for more costly solar energy in order to decrease the demand for new sources of petroleum (52 to 37 percent) [106]. 
A Roper study in March 1977 found that all residence groups felt solar energy offered the best long-term source of energy in looking to the year 2000 (58 percent to 71 percent) [152]. The second choice for all groups was nuclear energy (29 to 37 percent).

\section{Attitudes Towand Nuelear Energy}

A Gallup survey in June 1976 (Gallup, 1976), found no difference by area of residence in following the media discussions on nuclear energy development. The urban areas were in the 78 to 82 percent range. Rural residents were slightly lower with 72 percent. Respondents were asked how important they felt it was to have more nuclear plants. About a third of respondents in medium-size cities $(50,000$ to 500,000$)$ were slightly more likely to think that more nuclear plants were extremely important and another third somewhat important.

When asked whether or not they felt present plants were operating safely enough with existing safety regulations, the larger the community of residence, the more likely the respondent was to say that operations should be cut back until stricter regulations can be put into practice. A Harris poll in 1975 and 1976 asked what problems with nuclear power plants people perceived as major [141]. The problems identified in 1976 ranged from disposal of radioactive wastes to chances of explosion and sabotage. For all but atmospheric radioactivity (rural, 53 percent; towns, 57 percent) and chance of an explosion in case of an accident ( 49 percent for both rural and towns), rural residents were less concerned about the problems with nuclear plants than were urban residents. When asked whether they favored or opposed the building of more nuclear power plants in the United States, residents of larger cities were less favorable. This difference had increased since the 1975 survey, with urban areas becoming less favorable and rural areas more favorable. About half of the people in each group said they personally favored having nuclear power as the main source of energy for electric power in their community, with cities the least favorable ( 45 percent) and towns the most favorable ( 54 percent). Fifty-one percent of those in suburbs and rural areas were favorable. This represents a drop in favorability for cities and suburbs from the 1975 study, where the percentages were 53 and 60 percent, respectively.

In 1974 Becker Research Corporation asked whether individuals would oppose the building of a nuclear plant by the electric company in their general area [311]. Those in central city areas of metropolitan areas larger than 1,000,000 were most likely to oppose the plant and least likely to think it would be alright. Metropolitan areas under 1,000,000 were most likely to say that construetion of the plant would be alright.

Persons were asked if there was a nuclear power plant within 100 miles of where they lived. Suburban residents were more likely than other groups to correctly state that there was a planned or operating plant in this radius; however, they were correct only 21 percent of the time. In January 1975, a national survey found that residents of cities of 500,000 to 999,999 were most likely to be against construction of a nuclear power plant within a five-mile radius (Gallup, 1976). Rural residents were less likely to be against construction than were residents of major urban areas. These differences were not confirmed in a study of the TVA power plant near Hartsville, however, where fewer rural residents than urban residents said they would permit construction of the plant [143].

A November to December 1977 survey by ORC found that all groups favored nuclear plants, with residents of cities being slightly less favorable than other groups [308]. 
Those living in suburbs were more favorable than other groups toward having a plant within 20 miles. When asked what were the serious problems associated with nuclear power plants, approximately half of all groups said nuclear wastes (rural areas, 59 percent; small towns, 45 percent). A Roper survey in September 1977 found major urban areas least likely to feel that nearby nuclear plants were safe [148].

Only one survey asked about the sale of nuclear power plants to foreign countries. A Roper survey in March 1978 found rural areas least favorable toward sales of nuclear plants to other countries [180]. They were also less likely than urban groups to volunteer that they based their judgment on which countries purchased the plant.

Based on 11 national probability samples which asked general questions and questions about nearby plants, Melber et al. (1977) concluded that differences according to residence in urban, suburban, or rural areas are less consistent than those for other demographic variables and that size of the community is not an important or primary determinant of nuclear power attitudes (p. 97).

While there are some contradictory findings, the general pattern which emerged from the data is that urban residents are less favorable than rural groups toward nuclear energy in general. They are also less favorable toward building more nuclear plants, both in general and in their immediate area. They are more pessimistic about the safety of nuclear plants.

\section{Attitudes Toward Conservation}

Morrison found no differences in energy consumption reductions between urban and rural residents of the Lansing, Michigan area [106]. A Roper survey in July 1977 found that between one-half and two-thirds of the people in each urban/rural category felt that a more austere life-style caused by shortages would be a good thing [150]. The percentages for the four market categories were: A, 52 percent; B, 65 percent; C, 59 percent; and D, 67 percent.

In California in September 1975 Blakely found that the rural lifestyle was already more frugal than that of urban or suburban residents [202]. In particular, rural residents kept the temperature of the house lower, used air conditioning less, did less pleasure driving, and went to movies and restaurants less.

A Gallup survey in April to August 1977 asked people what things they were doing to conserve electricity, gas, or gasoline [220]. Residents of communities under 50,000 were less likely to turn off lights in their homes (17 and 18 percent as compared to 26 to 29 percent for larger communities), but were more likely to say they were conserving in general ways ( 23 and 26 percent versus 14 to 18 percent for larger communities). Rural residents were less likely to conserve on air conditioners (but were probably less likely to have or use one anyway) and were more likely to use wood for heat (11 percent versus one or two percent for urban groups). In March 1976 Roper asked homeowners what they would do in the next two years if a tax credit were given [164]. Rural residents (D) were the most likely group to install new storm doors and windows and the urban (B) group was most likely to install insulation. However, the highest percentage of respondents doing anything was 20 percent.

In April to August 1977 a Gallup survey asked people whether they preferred rationing or a price increase to reduce the consumption of gasoline [220]. All groups preferred the 
price increase, with cities of 500,000 to 999,999 slightly more likely to favor it.

A study in 1976 in the Lansing, Michigan, area explored attitudes toward conservationrelated energy policies [106]. Table B-42, shows those for which there was an urban/rural difference.

No difference was found for year-round daylight savings time or for direct government help to the poor and elderly in paying utility bills. The survey also asked about changes in energy-use behavior and asked what difficulties were encountered in the behavior change. The only differences between urban and rural groups were that rural residents were more likely to share equipment with friends and relatives (34 percent versus 21 percent for urban), and were more likely to report an increase in drying clothes on a clothesline rather than in a dryer (42 percent versus 29 percent for urban). Rural people were more likely to indicate great difficulty in reducing the number of miles driven, the amount of electricity used, and the material goods purchased. They were more likely than urban residents to plan local trips to include more than one errand (70 percent versus 60 percent) and less likely to walk or ride a bicycle for short trips (24 percent versus 37 percent). Rural people were also more likely not to heat some rooms in the winter (55 percent versus 44 percent). No differences were found for transportation behaviors except that more urban residents preferred recreation requiring physical activity (hiking, swimming) rather than motor vehicles (47 percent urban versus 30 percent rural).

Fifty-four percent of the rural residents and 41 percent of the urban residents agreed that the amount of energy all families could save is unimportant compared to the amount of energy government and industry could save. A survey in Kentucky in August to October 1975 found people in farm areas less likely to say they would walk, ride a bike, or carpool because of where they live and work [221]. Farmers were much more likely than urban dwellers to say that they would not use air conditioning (64 percent versus 40 percent).

The conservation issue receiving the most attention in the surveys was the transportation use of energy. An ORC survey in November to December 1974 found no difference in use of carpools by place of residence [144]. However, use of public transportation was higher in cities and use of one's own car was highest in small towns. In September to October 1974, ORC asked individuals what they thought of a policy to increase gasoline taxes and cut income taxes such that people who drove a lot would pay more in total taxes [308]. One-half or more in each group was opposed, with a general tendency for the more urban areas to be slightly more favorable. No difference was found between groups on whether drivers of cars getting less than $15 \mathrm{mph}$ should pay higher prices for gasoline. A Gallup survey in June 1973 found about half of all groups favorable toward the proposal that the highway speed limit be dropped by $10 \mathrm{mph}[21 \mathrm{ll}$. Residents of large cities $(1,000,000$ and over) were slightly less favorable than other groups (46 percent versus 50 to 57 percent for others).

A Gallup survey in November 1977 asked people whether they would favor or oppose a gasoline rationing law that would require people to drive one-fourth less [310]. Residents of cities of 50,000 to 499,999 were most favorable at 42 percent. Other respondents were 32 to 36 percent favorable. Slightly more than half in each category were opposed. Individuals were then asked what would be the best way to get people to reduce their use of gasoline. No alternative scored higher than 21 percent. Respondents in 


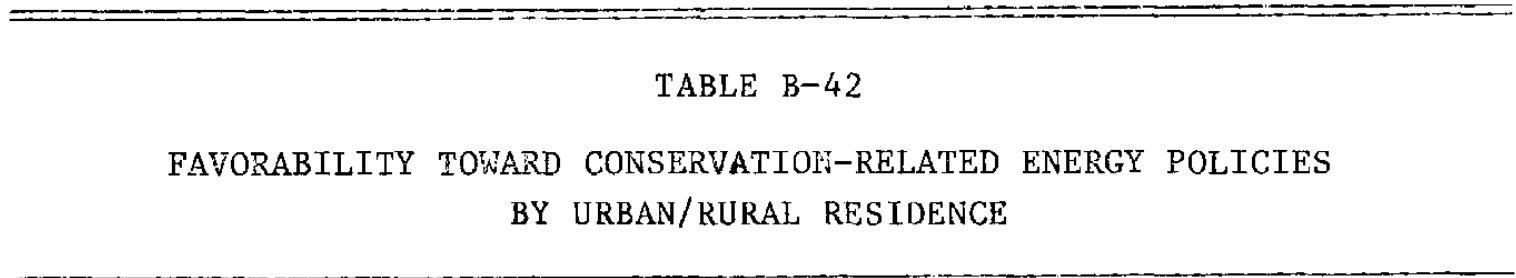

Proportion Responding

Policy

Rural Urban

Gasoline rationing

$17 \% \quad 35$

Tax deduction for families with only one car

$47 \quad 66$

Tax deduction for insulating older homes

$75 \quad 85$

Tax deduction for families with only two children $38 \quad 54$

Tax deduction for driving small cars

$35 \quad 51$

Increased taxes for families with more than two children

$11 \quad 22$

Tax deduction for apartment living

Increased taxes for driving large cars

$17 \quad 33$

Required energy labeling for appliances

$20 \quad 36$

Added federal tax on gasoline

$75 \quad 85$

Peak load pricing

$3 \quad 15$

Inverted rate structure

$15 \quad 36$

Tax supported mass transportation

$22 \quad 43$

$40 \quad 60$

*Study 106. 
small towns and rural areas favored building gas-saving cars and those from middle-size cities favored cutting down unnecessary driving and improving public transit.

In November to December 1974 persons were asked whether people who drive more than 200 miles per week should pay more for gasoline than those who drive less [308]. Those in small towns were slightly less likely than other groups to disagree with this proposal. Small town residents were slightly less concerned than other groups about the mileage their cars got. Over half of all groups had seen or heard articles about gas mileage, with the urban areas more informed (city, 64 percent; suburb, 70 percent; small town, 59 percent; and rural, 51 percent). When asked who provides the more reliable information on gas mileage, less than one-third of any group indicated the auto companies (residents of small towns were the most favorable with 32 percent). Respondents from suburban areas more frequently reviewed government agencies as credible information sources (54 percent versus 43 to 47 percent for other areas). "Park and ride" systems were described and the people were asked whether they would use one if it were nearby. Rural residents were somewhat more favorable than other groups. A Gallup survey in February 1977 asked people whether they favored the same $55-\mathrm{mph}$ speed limit for trucks as for automobiles [217]. Those in large cities were more in favor of lower speed limits than were other groups. The survey also found that over half of the people in each group felt that the 55-mph speed limit had reduced the speed at which they drove. Rural and small town residents were least likely to have reduced their driving speed (58 percent), and respondents from cities of 500,000 to 999,999 were most likely ( 71 percent).

An ORC survey in August 1975 asked, "If gas were rationed so you were allowed only 10 gallons per week, would you still have made that trip?" [262]. Rural residents were slightly more likely than other groups to say yes (64 percent), and suburban residents were least likely (53 percent) (other groups, 56 to 57 percent). Another question asked by this survey was: "If you had to wait in line one hour for gas, would you still have made that trip?" The rural residents were again somewhat more likely to say yes (61 percent) than those in cities, ( 49 percent), suburbs, (52 percent), or small towns, ( 56 percent).

A Gallup survey in November 1977 asked people how important they felt it was to reduce their driving by one-fourth [310]. About one-quarter of all groups but those from cities of 500,000 to 999,999 (16 percent) felt it was very important. They then asked, "How difficult would it be to do this?" Residents of cities of 2,500 to 49,999 said it would be less difficult than did other groups (26 versus 33 to 39 percent for other groups for "very difficult;" 45 percent versus 26 to 34 percent for "not at all difficult").

An ORC survey in 1975 asked people whether it was more important to spend money on highways or on mass transit [129]. Over half of all groups preferred mass transit, with rural less favorable than urban respondents (53 percent versus 60 to 66 percent). Residents of cities and suburbs were more likely than those of small towns and rural areas to perceive a need for mass transit within a $50-$ mile radius. They were also more likely than other groups to think that the United States as a whole would profit from improved mass transit. Families whose head worked away from home and drove or carpooled but had public transportation available were asked whether they would use it if it got them to work 15 minutes faster. Small town residents were more likely to say yes; rural residents were somewhat more likely to say no. They were then asked whether they would use public transportation if it ran twice as of ten. City residents were most likely to say yes (see Table B-43).

An ORC survey in April to May 1975 found that, of those who did not presently have public transportation close to where they lived, the suburban residents were more likely 
TABLE B-43

POTENTIAL USE OF PUBLIC TRANSPORTATION

BY URBAN/RURAL RESIDENCE

Would you use public transportation if it got you to work 15 minutes faster? [129]

$\begin{array}{lll}\text { Place of } & \text { Proportion Respond } \\ \text { Residence } & \text { Yes } & \text { No } \\ & & \\ \text { City } & 59 \% & 38 \\ \text { Suburb } & 50 & 46 \\ \text { Small town } & 64 & 36 \\ \text { Rural area } & 40 & 60\end{array}$

Would you use public transportation if it ran twice as often? [129]

Place of

Residence

City

Suburb

Sma11 town

Rural area
Proportion Responding Yes No Dont Know

$53 \% \quad 44 \quad 3$

$\begin{array}{lll}31 & 64 & 5\end{array}$

$29 \quad 28 \quad 43$

$\begin{array}{lll}25 & 75 & 0\end{array}$ 
than other groups to say that they would definitely or probably use it for shopping if it were available (53 percent versus 35 to 41 percent for other groups) [255]. When the same question was asked with regard to getting to work, rural residents were most likely to say they would use it, with suburbanites next (city, 39 percent; suburbs, 49 percent; small towns, 36 percent; and rural, 62 percent).

A study in the Chicago metropolitan area in 1977 asked people to assess others' attitudes and behaviors [127]. About two-thirds of the suburban residents and three-quarters of the city residents agreed that many people would switch to public transportation if problems with the gasoline supply continued. When asked if they themselves would depend more on public transit in such a situation, 71 percent of the city residents and 50 percent of the suburban dwellers said yes. Both eity and suburban dwellers felt that public transit is a public service and should be subsidized by taxes, although more city dwellers than others felt that way (city, 62 percent; suburban, 54 percent).

An ORC survey in April to May 1975 asked how great was the need for public transit within the 50-mile area in which the surveyed individual lived and worked [255]. In general, the residents of urban areas expressed a greater need for mass transit than did those living in small towns and rural areas. Sixty-four percent of the city residents and 71 percent of the suburbanites responded that there was a great need or some need, versus 54 percent for the small town residents and 45 percent for the rural residents.

\section{Summary}

There appears to be only a minor difference by place of residence (urban versus rural) on perception of the energy situation or its seriousness $[106,116,154,175,202,218]$. This may in large part be due to the way in which some surveys categorized individuals. Rural people were more likely to be pessimistic about energy shortages [129, 172], but they were also more likely to feel that the energy crisis was a "put-on" and that there was never a real shortage [106, 172]. However, this disbelief was found for all groups [172; Roper, $1978 \mathrm{c}$.

Little or no difference was found between groups on perceived responsibility for the crisis $[151,213]$. In one study, rural residents were found more likely than other groups to feel that the voting public should make the decisions on various energy-related issues [152].

All residential groups wanted more attention devoted to the energy situation and a stronger handling of the problems $[151,168,174]$. There were minor differences in approval of Carter's handling of the energy crisis, with rural areas slightly more favorable [147, 217, 309].

Rural residents were more concerned than urban residents about the availability of energy than about environmental protection $[131,148,218,221,308]$.

Attitudes toward energy conservation were fairly similar across groups, but specific conservation behavi ors differed $[106,150,164,202,220]$.

Urban residents were more favorable toward mass transit, more likely to perceive a need for mass transit in their area, and more likely to think the United States as a whole would profit from mass transit $[129,255]$. 
No difference was found by community size in knowledge about solar energy, but urban residents were more likely to consider paying more for costly solar systems [106, 303] .

Urban residents were less likely than other groups to think nuclear plants are safe and were more likely to be against construction of new plants in general or in the local area [141; 148; Gallup, 1976; 308]. 


\section{INDEX}

Age, 208-16, 253, B-20 special rates for elderly, B-50, B-141

Air pollution standards, 127, 173, B-90, B-103, B-114, B-137

Air quality, concern about, 81,152 , $168,173,177,197,204,229,235$, B-26, B-54, B-103, B-125, B-137

Alaska pipeline, $169, \mathrm{~B}-47$

Appliance labeling, 138, 246

A rabs (OPEC countries), perception of, $67,74,95,167,227$, B-22, B-45.

See also Oil importation

Attitudes, discussion of concept, 13 policy relevance of, $20,222,249$

Bicycling, 119, 231 , B-37,B-98, B-115, B-141

Business, per ception of, $67,74, \mathrm{~B}-45$, B-108, B-120, B-130. See also Oil companies; Utility companies

Carpooling, 119, B-36, B-70, B-85, B-98, B-141

Climate, $140,142,145,148,165$. See also Regional differences

Coal, 100, 172, 197, 25 l, B-79, B-1 04, B-109, B-115, B-137 and environment, 235

Conservation, 115 attitudes about, $76,85,215,227$, $241, \mathrm{~B}-13, \mathrm{~B}-34, \mathrm{~B}-68, \mathrm{~B}-81, \mathrm{~B}-96$, $\mathrm{B}-105, \mathrm{~B}-140$

effects of technical knowledge on, 237

incentives for, see Tax

perceived effectiveness of, 115 , 241,250

residential, 4, 130, B-34, $\mathrm{B}-82$,

B-116, B-140

resistance to, $\mathrm{B}-36$

regulation of, $117,138,240,250$,

B-34, B-105

transportation, $89,119, \mathrm{~B}-34, \mathrm{~B}-70$, B-83, B-96, B-106, B-115, B-119,

B-129, B-140

See also Transportaton

Consumer education. See Information

Daylight saving time, 137, 256, B-105, B-137

Deregulation, 171, 251
Education and energy attitudes, 208, $211,253, \mathrm{~B}-41$

Elec tricity, 61, 88, 90, 13 1, B-35

Emission controls, automobile, $125,127,246, \mathrm{~B}-111$

Energy vs. environment, $112,197,210$, $246, \mathrm{~B}-7, \mathrm{~B}-26, \mathrm{~B}-54, \mathrm{~B}-76, \mathrm{~B}-90$, B-103, B-112, B-123, B-137

Energy policy, national, 53, 73, 82, $101,105,111, \mathrm{~B}-47, \mathrm{~B}-135$

Energy policy, presidential, 53, 101 , $105,115,249, \mathrm{~B}-7, \mathrm{~B}-25$, B-50, B-53, B-86, B-89, B-102, B-108, B-114, B-130, B-135

Energy self-sufficiency, 112, 167, 198, $227, \mathrm{~B}-50, \mathrm{~B}-102, \mathrm{~B}-125, \mathrm{~B}-130$

Energy shortage, future expectations, $89, \mathrm{~B}-23, \mathrm{~B}-76, \mathrm{~B}-102$

impact of, $87,221,239, \mathrm{~B}-24, \mathrm{~B}-46$, B-102

perceived blame for, $55,67,221$, B-21, B-45, B-75, B-87, B-102, $\mathrm{B}-114, \mathrm{~B}-130$ perceived seriousness of, 2, 53, 207, $219,249, \mathrm{~B}-21, \mathrm{~B}-43, \mathrm{~B}-74, \mathrm{~B}-86$, B-101, B-108, B-111, B-114, B-116, B-1 26

Environmentalists, 223 perception of, $55,75,105, \mathrm{~B}-22$, B-112. See also Energy vs. environment

Environmental regulation, favorability toward, $246, \mathrm{~B}-7, \mathrm{~B}-26$

Environmental risk, 37, 155, 168, 173, $181,204,234,241$, B-1 25

Federal charter for oil companies, 171

Federal government perception of, 53 , $67,73,105, \mathrm{~B}-22, \mathrm{~B}-45, \mathrm{~B}-60, \mathrm{~B}-78$, B-120, B-130, B-141

regulation of energy, $111,138,205$, B-47, B-89, B-141. See also Information, sources of; preferred energy options

Gasoline mileage, 124, 228, B-10, B-12 1, B-1 43

Gender and energy attitudes, 207, 210, 252, B-2, B-137

Government ownership of oil, 171, 234, 251 , B-135 
Government ownership of utilities, B-135

Hydropower, 53, B-53, B-104

Incentives, financial. See Tax; Solar energy

Income and energy attitudes, 209, 211, $253, \mathrm{~B}-73$

special rates for poor, B-50, B-141

Industry profit-taking, $171, \mathrm{~B}-22$

Industry tax incentives. See Tax

Inf ormation, programs, 125, 237

sources of, $39,101,116,120,125$, $132,154,169,174,187,204,212$, $222,229,236, \mathrm{~B}-10, \mathrm{~B}-30, \mathrm{~B}-57$, B-77, B-9 1, B-109, B-112, B-118, B-138, B-143

Insulation. See Weatherization

Leasing schemes, solar energy, 154

Lif estyle and energy attitudes, 210 , $222,255, \mathrm{~B}-115$

Low-interest loans, 164

Marital status and energy attitudes, B-115

Mass transit. See Transportation, public

Nader, Ralph, 55, 105, 244, 188, B-30, B-62, B-78, B-9 1, B-114, B-138

Natural gas, 97, 234, 25 1, B-120, B-126. See also Conservation, residential

News media, 54, 101, 125, 223

and oil companies, 55

and nuclear power, 187, B-109

perceived credibility of, B-60

Natural resources, conservation of. See Conservation; depletion of, 85

Nuclear energy, 100, 175, 214, 234, $238,241,251, \mathrm{~B}-13$, B-32, B-64, B-79, B-94, B-104, B-113, B-125, B-1 39

knowledge about, $\mathrm{B}-30, \mathrm{~B}-62, \mathrm{~B}-9 \mathrm{l}$, B-103

opposition to, 188,244

regulation of, 186

safety concerns about, 18, 234, 24I,

B-110, B-114, B-125, B-I 39

sale of, $B-140$

wastes, $181,243, \mathrm{~B}-33$

Occupation and energy attitudes, 209, $211,254, \mathrm{~B}-86$

Offshore oil drilling, 168, 198, 234, B-28, B-47
Oil companies, perception of, 55,67 , $70,105,110,167,249, \mathrm{~B}-22, \mathrm{~B}-31$

Oil importation, $167,222,251$, B-50, B-57, B-89, B-91, B-102, B-108, B-114, B-124, B-130, B-135, B-I 38

Oil import tax, B-108

Park-and-ride, 124

Peak-load (time-of-day) pricing, 137, B-81, B-116, B-118

Political orientation and energy attitudes, 210, 255, B-107

Preferred energy options, 40, 110, $117,123,127,137,163,169,175$, 188,204

Price controls, B-89, B-135

Price increases, gasoline, 87, 97, 117, 228 , B-16, B-24, B-38, B-53, B-70, $\mathrm{B}-76, \mathrm{~B}-84, \mathrm{~B}-92, \mathrm{~B}-102, \mathrm{~B}-106$, B-120, B-129, B-137 other, 93, 131, 171, 222

Policy preferences. See Preferred energy options

Radioactivity, radioactive wastes. See Nuclear energy

Race and energy attitude, 210,254 , B-101

Rationing, 120, 128, 227, B-26, B-38, B-53, B-70, B-76, B-84, B-96, B-102, B-110, B-114-15, B-135

Religious affiliation and energy attitudes, 255, B-113

Reduced driving, 89, 117, 119, B-19, $\mathrm{B}-36, \mathrm{~B}-39, \mathrm{~B}-47, \mathrm{~B}-71, \mathrm{~B}-83$, B-96, B-106, B-110, B-114, B-12 1, B-141

Reduced parking, 123

Reducing demand vs. increasing supply, 111, 115

Regional differences, 100, 197, 252 conservation, 139 conventional energy, 197 nuclear energy, 197 shortages, 88 solar energy, 164

Sociodemographic character istics and energy attitudes, 207, 253, B-1

Solar energy, 141, 213, 235, 238, 250, B-11, B-31, B-62, B-78, B-94, B-104, B-113

and climate, 142,165

and energy shortages, 240

knowledge about, B-30, B-57, B-78, B-91, B-103 
as long-term energy source, 198 , $235, \mathrm{~B}-53$

ownership, B-111, B-113, B-117,

B-119, B-138

tax incentives for, $163,235, \mathrm{~B}-3 \mathrm{I}$, B-117

Speed limit, $55 \mathrm{mph}, 127,250, \mathrm{~B}-19$,

B-83, B-96, B-106, B-110, B-123, B-141

Strip mining, 173, 197, 246, B-28,

B-47, B-54, B-77, B-90, B-103,

B-125, B-1 37

Supply and demand. See Reducing demand vs. increasing supply

Survey methods, 12, 27

Tax, credits for solar energy, 163, $205,235, \mathrm{~B}-31, \mathrm{~B}-117$ gasoline, 228, B-106, B-125, B-137, B-14I

on "gas guzzlers," I 28, B-38, B-70, B-84, B-106, B-112, B-124, B-137, B-141

incentives for conservation, 137, $112, \mathrm{~B}-141$

industry incentives for increasing supply, 171

rebates, 228

Time-of-day pricing. See Peak-load

Transportation, conservation in, 2 , $119, \mathrm{~B}-38, \mathrm{~B}-40, \mathrm{~B}-96, \mathrm{~B}-106, \mathrm{~B}-119$ public, $119,228, \mathrm{~B}-18, \mathrm{~B}-70, \mathrm{~B}-84$, B-98, B-106, B-117, B-121, B-124, B-141

Trend analyses, $58,60,63,65,66,68$, $71,80,83,84,91,92,106,108,109$, $121,122,134,136,170,176,185$, $193,195,200,201,219,225,233$, $252, \mathrm{~B}-8, \mathrm{~B}-14, \mathrm{~B}-48, \mathrm{~B}-56, \mathrm{~B}-88$, B-92

Urban/rural residence and energy attitudes, B-1 25

Utility bills, $76,88,93131,144, \mathrm{~B}-16$, B-24, B-32, B-43, B-78, B-118

Utility companies, 105, 144, B-22, B-30, B-35, B-109, B-130

Walking, 120, 231, B-37, B-98, B-115

Water quality, B-54, B-77

Weatherization, $135,237, \mathrm{~B}-38, \mathrm{~B}-70$, B-100, B-106

Wind energy, B-31, B-57, B-78, B-91, B-103 


\section{SEPI}




\begin{tabular}{|c|c|c|c|}
\hline & $\begin{array}{l}\text { Document Control } \\
\text { Page }\end{array}$ & $\begin{array}{l}\text { 1. SERI Report No. } \\
\text { TR-53-155 }\end{array}$ & 3. Recipient's Accession No. \\
\hline \multirow{2}{*}{\multicolumn{3}{|c|}{$\begin{array}{l}\text { Public Opinion About Energy: } \\
\text { A Literature Review }\end{array}$}} & \multirow[t]{2}{*}{ June 1979} \\
\hline & & & \\
\hline 7. & $\begin{array}{l}\text { Barb } \\
\text { Char }\end{array}$ & $\begin{array}{l}\text { ra C. Farhar, Patricia Weis, } \\
\text { es T. Unseld, Barbara A. Burns }\end{array}$ & 8. Performing Organization Rept. No. \\
\hline \multirow{2}{*}{\multicolumn{3}{|c|}{ 9. Performing Organization Name and Address }} & $\begin{array}{l}\text { 10. Project/Task/Work Unit No. } \\
\text { Task nos. } 5124 ; 5328.30\end{array}$ \\
\hline & & & $\begin{array}{l}\text { 11. Contract (C) or Grant (G) No. } \\
\text { (C) EG-77-C-01-4042 } \\
\text { (G) }\end{array}$ \\
\hline \multirow{2}{*}{\multicolumn{3}{|c|}{ 12. Sponsoring Organization Name and Address }} & $\begin{array}{c}\text { 13. Type of Report \& Period Covered } \\
\text { Technical Report }\end{array}$ \\
\hline & & & 17. \\
\hline
\end{tabular}

15. Supplementary Notes

16. Abstract (Limit: 200 words)

This study analyzed over 115 surveys of the general public, including 82 national samples taken between 1973 and 1978. The analysis identified patterns of findings and research gaps across surveys; mixed or contradictory findings are described. Following a discussion of the strengths and limitations of survey data and their implications for energy policy, results are presented on the public's definition of the energy situation. Included are data on perception of the seriousness, reality, and importance of the energy situation; responsibility for it; the energy future; and experienced impacts of energy shortages. There are chapters on public opinion and knowledge concerning energy alternatives, including energy conservation (both domestic and transportation), solar energy, and conventional energy sources (nuclear energy, coal, oil, and natural gas). Two chapters present analytical findings from the surveys - one on sociodemographic analyses and the other on social-psychological variables. A lengthy appendix presents detailed energy survey findings by 10 major demographic categories (e.g., occupation, income). The report is indexed.

17. Document Analysis

a. Descriptors

b. Identifiers/Open-Ended Terms

c. UC Categories

18. Availability Statement

\begin{tabular}{|l|}
\hline 19. No. of Pages \\
450 \\
\hline 20. Price \\
\hline
\end{tabular}

